Ressources et construction : la transmission des savoirs sur les chantiers

François Blary, Jean-Pierre Gély (dir.) 


\section{Ressources et construction : la transmission des savoirs sur les chantiers}

\section{François Blary et Jean-Pierre Gély (dir.)}

DOI : $10.4000 /$ books.cths. 10387

Éditeur : Éditions du Comité des travaux historiques et scientifiques

Lieu d'édition : Paris

Année d'édition : 2020

Date de mise en ligne : 29 septembre 2020

Collection : Actes des congrès nationaux des sociétés historiques et scientifiques

EAN électronique : 9782735508990

\section{OpenEdition}

Books

https://books.openedition.org

Référence électronique

BLARY, François (dir.) ; GÉLY, Jean-Pierre (dir.). Ressources et construction : la transmission des savoirs sur les chantiers. Nouvelle édition [en ligne]. Paris : Éditions du Comité des travaux historiques et scientifiques, 2020 (généré le 28 juin 2022). Disponible sur Internet : <http://books.openedition.org/ cths/10387>. ISBN : 9782735508990 . DOI : https://doi.org/10.4000/books.cths.10387.

(C) Éditions du Comité des travaux historiques et scientifiques, 2020 Conditions d'utilisation :

http://www.openedition.org/6540 


\section{RÉSUMÉS}

Diffusées par le geste et la parole puis par l'écriture et le dessin, les connaissances sur les matériaux et la construction ont traversé des générations de bâtisseurs. Les contributions réunies dans cet ouvrage offrent des regards multiples sur l'élaboration, la transmission et l'évolution des savoirs et savoir-faire sur les chantiers, de l'Antiquité au $\mathrm{xx}^{\mathrm{e}}$ siècle.

Le Congrès national des sociétés historiques et scientifiques rassemble chaque année universitaires, membres de sociétés savantes et jeunes chercheurs. Ce recueil est issu de travaux présentés lors $\mathrm{du} 143^{\mathrm{e}}$ Congrès sur le thème « La transmission des savoirs ».

FRANÇOIS BLARY (DIR.)

Université libre de Bruxelles (ULB), CREA-Patrimoine

JEAN-PIERRE GÉLY (DIR.)

Université Paris I - Panthéon-Sorbonne, Laboratoire de médiévistique occidentale de Paris (LAMOP, UMR 8589 du CNRS)

\section{NOTE DE L'ÉDITEUR}

Les articles de cet ouvrage ont été validés par le comité de lecture des Éditions du Comité des travaux historiques et scientifiques dans le cadre de la publication des actes du $143^{\mathrm{e}}$ Congrès national des sociétés historiques et scientifiques tenu à Paris en 2018. 
Diffusées par le geste et la parole puis par l'écriture et le dessin, les connaissances sur les matériaux et la construction ont traversé des générations de bâtisseurs. Les contributions réunies dans cet ouvrage offrent des regards multiples sur l'élaboration, la transmission et l'évolution des savoirs et savoir-faire sur les chantiers, de l'Antiquité au xxe siècle.

Le Congrès national des sociétés historiques et scientifiques rassemble chaque année universitaires, membres de sociétés savantes et jeunes chercheurs. Ce recueil est issu de travaux présentés lors $\mathrm{du} 143^{\mathrm{e}}$ Congrès sur le thème « La transmission des savoirs ».

\section{FRANÇOIS BLARY}

Université libre de Bruxelles (ULB), CREA-Patrimoine

\section{JEAN-PIERRE GÉLY}

Université Paris I - Panthéon-Sorbonne, Laboratoire de médiévistique occidentale de Paris (LAMOP, UMR 8589 du CNRS) 
SOMMAIRE

Introduction

François Blary et Jean-Pierre Gély

\section{Construction des savoirs}

Les matériaux des constructions romaines de quelques sites du nord de la Gaule et la transmission des savoirs en maçonnerie Annie Blanc et Philippe Blanc

Les murs de moellons de l'époque romaine

Les constructions du Moyen Âge : continuité et inventions

Les constructions antérieures à 1945

Les constructions du $\mathrm{xx}^{\mathrm{e}}$ siècle

La construction des pêcheries en pierre appelées écluses sur l'île de Ré: des techniques de construction complexes et un savoir-faire ancestral

Jacques Boucard

L'origine des écluses sur Ré

L'autorisation de construction

Le secret de la construction : une bonne équipe

La construction : une technique complexe demandant un grand savoir-faire

Un savoir-faire qui disparaît lentement et de façon inéluctable

Les éléments de colonnes en pierre de l'oppidum de Bibracte (mont Beuvray, BourgogneFranche-Comté) : un savoir-faire local appliqué à un édifice romain du milieu du $\mathrm{I}^{e r}$ siècle avant J.-C.

Florent Delencre et Jean-Pierre Garcia

Des matériaux uniques : les éléments de colonnes en pierre de l'oppidum de Bibracte

Caractérisation pétrographique et morphométrique

Production des outils de mouture et éléments de colonnes : l'exaptation d'un savoir-faire

La construction en petit appareil modulaire des voûtes de caves à Bourges (Cher) entre le $\mathrm{XIII}^{e}$ et le milieu du XVI ${ }^{e}$ siècle

Lucie Gaugain, Marie Lafont et Laura Millat

Contexte: Bourges, foyer de la construction pendant trois siècles

Méthode de travail

Présentation du corpus de caves

Typologie des voûtes des caves

Mesures d'appareil et analyse statistique du petit appareil

Description du faciès géologique des roches

Conclusions

La citerne Basilique et l'approvisionnement en eau de Constantinople (actuelle Istanbul, Turquie) à l'époque tardo-antique: des ruptures économiques et constructives avec l'époque romaine

Anaïs Lamesa et Ferudun Özgümüş

Le système de conservation des eaux à Constantinople

La citerne Basilique ou Yerebatan Sarnicı

Colonnes et chapiteaux : des rebuts

Conclusions 
Ambrogio Attendolo (1505-1585) : la formation d'un architecte sur le chantier des fortifications de la ville de Capoue

Nicolas Moucheront

La construction de la mémoire d'un architecte

Un architecte à pied d'œuvre

Les roches décoratives antiques de Meaux (Seine-et-Marne) : apports des découvertes du XXI siècle à la connaissance de la parure décorative et des espaces de la ville de $\mathrm{Ia}(\mathrm{n})$ tinum Arnaud Prié, Annie Blanc et Philippe Blanc

Le contexte meldois : architecture romaine et décor

Fouilles et méthode d'étude

Variété des pierres : un aperçu du commerce et du monde antique

Matériaux et sites antiques du méandre ou plaine Saint-Faron

La transmission des savoirs : conclusion

La transmission des savoirs et des modèles liés à la construction chez les Cisterciens aux XII et XIII siècles

Benoît Rouzeau

Une place pour les manuscrits dans les modèles de l'architecture cistercienne?

Abbés, moines et convers bâtisseurs

Les vestiges et le plan de Morimond II, un modèle?

Les expérimentations de logements sociaux en terre crue au Maroc dans les années 1960 : modernisation et transmission des savoirs

Nadya Rouizem Labied

Le Maroc, un contexte favorable à l'expérimentation

Alain Masson : la rationalité d'un ingénieur

L'industrialisation de la brique de terre crue ou adobe

La modernisation du pisé

Construire des ponts : un voyage technique à Lyon en 1672 de François Cuenot, ingénieur du duc de Savoie

Patricia Subirade

Une mission technique à Lyon pour observer l'art de construire les ponts

Les espaces de diffusion lyonnais du savoir technique des ponts

Les chantiers lyonnais de construction des ponts, des trading zones?

\section{Évolution des savoirs sur le temps long}

Tradition et nouveauté dans la transmission de l'art de bâtir en pierres sèches

Ada Acovitsióti-Hameau et Louis Cagin

Contexte de la technique et contenu de l'étude

Enjeux de la technique

Études et transmission de l'art

Assembler, bloquer, appareiller

« Tradition » et « nouveauté » : face à face mais de concert

Provenance des matériaux de construction du site de la citadelle d'Amiens (Somme) de l'Antiquité à nos jours : un circuit court pour des matériaux oubliés

Pascal Barrier, Pauline Leconte et Maël Pacaud

Présentation du site et répartition des vestiges par secteurs

Les matériaux lithiques employés au cours des siècles

Les carrières de craie de la citadelle d'Amiens : exploitations antiques et médiévales

Les signes lapidaires : regard sur un chantier de construction de la seconde moitié du $\mathrm{Xv}^{\mathrm{e}}$ siècle 
Des pierres pour une ville disparue au XVI siècle: Thérouanne (Pas-de-Calais)

François Blary et Jean-Pierre Gély

Problématique

Les ressources lithiques disponibles

Les ressources lithiques sollicitées à l'Antiquité

Les ressources lithiques locales utilisées au Moyen Âge

Les ressources régionales et inter-régionales sollicitées à la période médiévale

L'évolution du schéma d'approvisionnement de Thérouanne

Le mortier de tuileau en France de l'Antiquité à l'époque moderne : héritage ou réinvention permanente?

Stéphane Büttner

Chaux hydraulique naturelle, chaux hydraulique artificielle et mortier de tuileau

L'usage des mortiers de tuileau à travers les âges

Conclusions

Les jardins et les parcs de l'île-de-France du XVI au XVIII ${ }^{e}$ siècle : données environnementales et mise en cuvre des matériaux (pierres et bois)

Jean-Claude Koeniguer

Généralités : remarques géobotaniques sur la végétation, la biomasse végétale et l'évolution du climat au cours des Temps modernes

Les premiers grands jardins historiques et le monde végétal

Les jardins historiques de la fin $d u \mathrm{XV}^{\mathrm{e}}$ siècle et des premières décennies $\mathrm{du} \mathrm{XVI}^{\mathrm{e}}$ siècle (première

École de Fontainebleau)

Les jardins et la seconde École de Fontainebleau

Les jardins du XVII ${ }^{\mathrm{e}}$ siècle

Les jardins du siècle des Lumières

Les jardins et les parcs romantiques ( $\mathrm{XIX}^{\mathrm{e}}$ siècle)

Conclusions

Les usages du plâtre dans la construction en Île-de-France de l'Antiquité à l'époque contemporaine

Ivan Lafarge

Petite mise au point : la géologie et la chimie

Le plâtre dans l'Antiquité

Le haut Moyen Âge

Le bas Moyen Âge

Le plâtre aux Temps modernes

L'époque contemporaine

Transmettre sur le temps long: pour une archéologie de papier du chantier de l'église SaintSulpice de Paris (1645-1836)

Léonore Losserand

La transmission des savoirs chez les compagnons tailleurs de pierre en France aux XVIII et XIX ${ }^{e}$ siècles

Jean-Michel Mathonière

Quel savoirs?

Le métier de tailleur de pierre

Les autres savoirs professionnels

Quels modes de transmission? 
De la conception médiévale à la restauration des $\mathrm{XIX}{ }^{e}$ et $\mathrm{XX}$ siècles : réception et traduction du décor sculpté gothique en vallée mosane (Belgique et Pays-Bas)

Aline Wilmet

Un critère de définition de l'architecture régionale sujet à débat : le chapiteau mosan

Les matériaux lithiques comme produits de terroir

Le chapiteau « mosan », un concept « préfabriqué »?

Perception du décor médiéval par les dessinateurs et architectes restaurateurs au XIX ${ }^{\mathrm{e}}$ et au XX

siècle

Conclusions et perspectives 


\section{NOTE DE L'ÉDITEUR}

Les articles de cet ouvrage ont été validés par le comité de lecture des Éditions du Comité des travaux historiques et scientifiques dans le cadre de la publication des actes du $143^{e}$ Congrès national des sociétés historiques et scientifiques tenu à Paris en 2018. 


\title{
Introduction
}

\author{
François Blary et Jean-Pierre Gély
}

1 La question de la transmission des savoirs dans le monde de la construction a, de tous temps, été une notion extrêmement importante de la structuration individuelle et sociale. Depuis qu'existent les sociétés humaines, cette transmission constitue un enjeu majeur alliant le geste et la parole dans un premier temps, pour ensuite développer la diffusion écrite et érudite de ces savoirs, comme l'illustrent les traités techniques issus d'une longue tradition depuis Vitruve, de l'Antiquité jusqu'à nos jours.

2 Si le compagnonnage est depuis 2010 inscrit au patrimoine mondial immatériel de l'Unesco, c'est en raison de l'originalité de son mode d'enseignement lié étroitement au voyage et de sa philosophie de vie. Cette reconnaissance marque tout l'intérêt porté à ce mode de transmission des savoirs et savoir-faire liés en particulier aux métiers de la pierre, du bois, du métal, du cuir et des textiles, mais également aux métiers de bouche. Le compagnonnage ne constitue pas le seul mode d'apprentissage dans les métiers du bâtiment, mais le grand public a souvent retenu son existence, lui associant une part importante de mystère, en relation supposée avec les bâtisseurs de cathédrales et avec leurs secrets jalousement gardés au sein des loges au Moyen Âge. C'est la synthèse de méthodes et de procédés de transmission des savoirs extrêmement variés qui lui confère son originalité. Le compagnonnage sait mettre à profit la force du voyage en instituant une période dite de "tour de France » - une itinérance éducative à l'échelle nationale, voire internationale, accompagnée de rituels d'initiation, d'enseignement scolaire, d'apprentissages coutumiers et techniques. Ce mode de transmission des savoirs n'est cependant pas - et de très loin - l'unique moyen.

3 Les contributions réunies dans le présent ouvrage offrent ainsi une vaste palette d'exemples couvrant la période qui va de l'Antiquité au $\mathrm{xx}^{\mathrm{e}}$ siècle. Elles résultent d'une rencontre de chercheurs effectuée dans le cadre du $143^{\mathrm{e}}$ Congrès national des sociétés historiques et scientifiques organisé par le CTHS en 2018 afin de leur permettre d'échanger sur le thème de la transmission des savoirs. Le colloque « Ressources et construction" au sein de ce congrès a considéré ainsi l'ensemble des matériaux architectoniques et leur mise en œuvre: pierre, plâtre, terres cuites architecturales, mortiers et enduits, roches décoratives et, dans une moindre mesure, métaux, verre et bois. De nombreuses avancées scientifiques récentes concernant ces différents 
éléments permettent d'envisager de manière renouvelée la notion de transmission des savoirs dans le domaine de la construction.

4 La transmission des savoirs en matière de ressources et de construction revêt deux aspects, celui de l'élaboration des savoirs, d'une part, et celui de l'évolution de ces savoirs sur le long terme, d'autre part. La transmission peut s'entendre de manière empirique, d'homme sachant à celui apprenant, et s'inscrire ainsi comme une chaîne rarement interrompue du geste et de la parole, passant de génération en génération. Ce mode d'apprentissage et de partage limité à quelques individus regroupés en corporations sachant extraire les meilleurs matériaux, appliquer les techniques les plus adaptées au travail de la pierre et maitriser l'assemblage des éléments constructifs contribue à former des chaînes de spécialisations par métiers comme carrier, tailleur de pierre, maçon... jusqu'à la maîtrise de l'ensemble des corps par l'entrepreneur et l'architecte. La transmission passe alors aussi par d'autres modes, où l'écrit et le dessin vont prendre une part de plus en plus importante. Cette dernière forme pourrait sembler plus rigide, moins propice à l'imagination et à l'invention, ancrée dans la conservation et la transmission des savoirs ancestraux.

Cette géométrie variable de la transmission au sein des différents corps de métiers de la construction et de l'approvisionnement des chantiers en matériaux est parfaitement illustrée dans ce recueil, qui offre des exemples choisis de diverses pratiques à différents temps de l'histoire de la construction. Les matériaux issus d'une transformation, comme par exemple les mortiers de chaux ou de plâtre, sont ici l'objet d'études approfondies dont le lecteur ne pourra que bénéficier. La notion d'itinérance et de formation spécialisée trouve aussi de beaux éclairages, entre compréhension des actes constructifs et assimilation des techniques propres. La transmission de savoir peut aussi être volontairement absente ou choisie pour ne conserver que les modes constructifs réellement employés. La pratique consistant à retrouver un savoir perdu est à mettre en relation avec la prise de conscience de la nécessité de conserver des témoignages de construction ancienne et d'en assurer la conservation, la restauration avec les techniques les plus proches possibles de celles utilisées à l'époque. Querelle des anciens et des modernes, sur la base permanente de l'absolue nécessité d'apprendre à ceux qui ne savent pas et d'assurer à ceux qui ont cette connaissance le fait d'en conserver la mémoire.

6 De cette mémoire du geste, du plus simple au plus élaboré, des lieux d'approvisionnement, des techniques d'outillage, de construction ou d'assemblage dépend ce savoir au long terme. Ce recueil d'exemples choisis fournit une belle étape de réflexion et contribue à l'enrichissement de nos connaissances, dans l'attente d'un travail de synthèse à venir. 


\section{AUTEURS}

FRANÇOIS BLARY

Université libre de Bruxelles (ULB), CREA-Patrimoine

\section{JEAN-PIERRE GÉLY}

Université Paris I - Panthéon-Sorbonne, Laboratoire de médiévistique occidentale de Paris (LAMOP, UMR 8589 du CNRS) 
Construction des savoirs 


\title{
Les matériaux des constructions
} romaines de quelques sites du nord de la Gaule et la transmission des savoirs en maçonnerie

\author{
Annie Blanc et Philippe Blanc
}

1 Les constructions romaines de la Gaule sont observables sur de nombreux sites étudiés par les archéologues, et les musées conservent les plus belles pièces comme les sculptures, les marbres, etc. Les murs de maçonnerie en divers matériaux qui restent sur place ont perdu leur décor de marbre ou d'enduit, et on peut ainsi observer les pierres de taille, les moellons et les mortiers ainsi que les techniques utilisées. Aussi, par quelques exemples pris depuis l'Antiquités jusqu'à nos jours, il est possible de suivre l'évolution des techniques de maçonnerie, en regardant les moellons et les mortiers, sous les enduits et les placages qui les cachaient quand le bâtiment était habité.

\section{Les murs de moellons de l'époque romaine}

En commençant par l'époque romaine, on ne peut qu'admirer la technique des maçons, qui a permis à de nombreux murs de parvenir jusqu'à nous. Plusieurs exemples peuvent alimenter la réflexion et montrer à quel point on a su utiliser les ressources locales : craies, calcaires divers, grès et meulières. La fabrication des mortiers était aussi remarquable, car la construction dépend de leur tenue dans le temps. Leur résistance à l'altération est telle qu'à certains endroits on peut encore observer la trace du fer qui a serré le mortier des joints.

3 À Paris, aux thermes de Cluny, le petit appareil de calcaire lutétien alternant avec des lits de briques est une technique qui a été appliquée avec rigueur et qui a défié les siècles. La connaissance des ressources en divers calcaires du Lutétien ${ }^{1}$ et de leurs propriétés physiques a été reprise et poursuivie au Moyen Âge. La voûte en béton du 
frigidarium a perdu son décor mais a résisté à tous les avatars qu'elle a subis au cours des temps. La recette de ce béton paraît aujourd'hui extraordinaire ; c'était pourtant un savoir-faire répandu au début de notre ère.

4 À Bavay (Nord), le forum semble construit avec la même technique, les moellons sont en divers matériaux : grès, pierre bleue ${ }^{2}$ (calcaire givétien), calcaires lutétiens (à milioles et à Ditrupa) et calcaires jurassiques de la Meuse (fig. 1). Ces deux dernières provenances sont éloignées d'environ deux cents kilomètres. À l'époque moderne, on n'utilisera plus que les pierres bleues et les grès des carrières locales. Les sources des pierres se sont réduites.

Fig. 1. - Bavay (Nord), vue du forum.

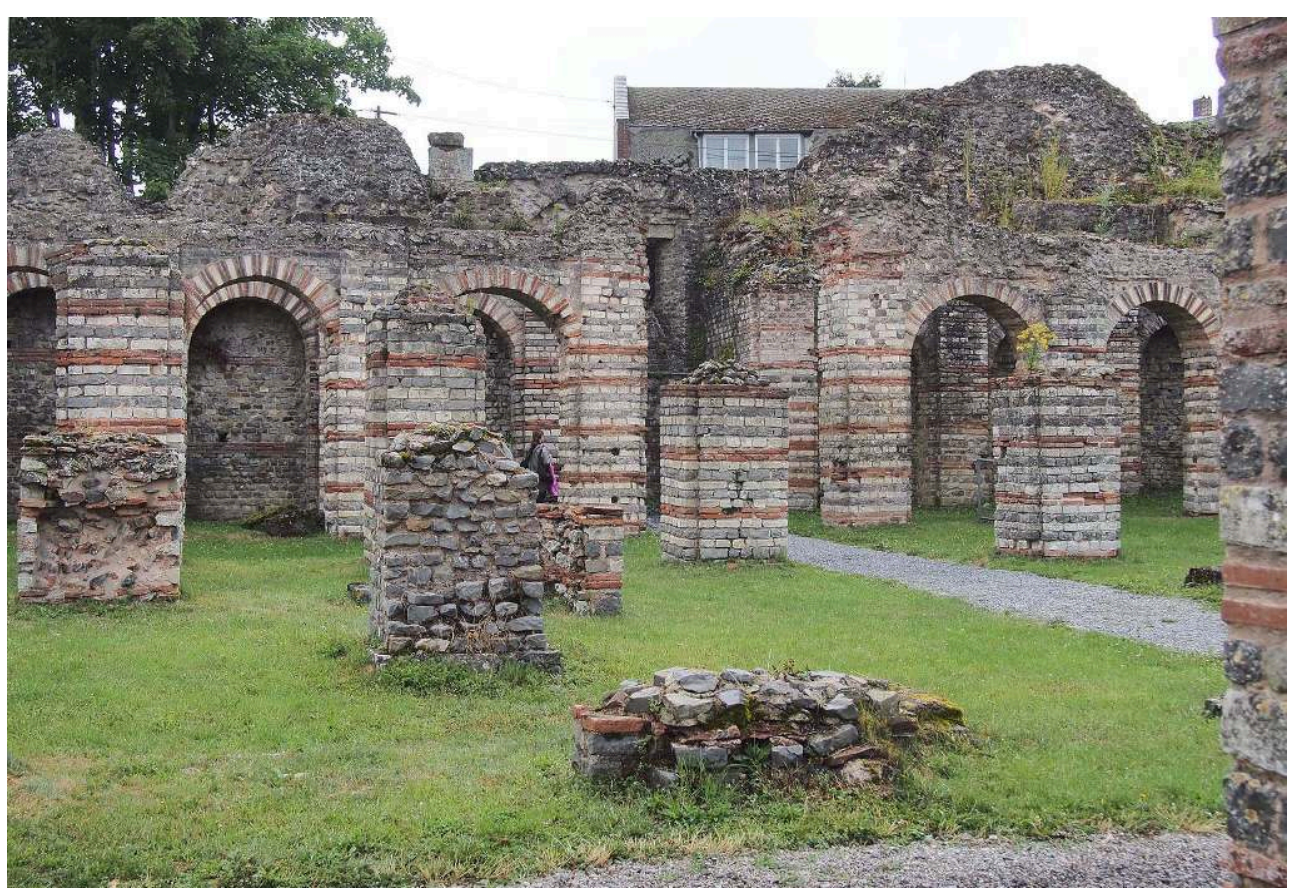

Les moellons sont en matériaux divers : grès, pierre bleue (calcaire givétien), calcaires lutétiens (à milioles et à Ditrupa) et calcaires jurassiques de la Meuse alternant avec des rangs de briques.

(c) Philippe Blanc.

5 À Autun, les moellons de granite, pour les portes, les grès divers (du Permien et du Trias) au temple de Janus, au théâtre ou dans les murs des remparts ${ }^{3}$, sont utilisés sans lits de briques. Le granite a été abandonné et les grès ont été exploités jusqu'au $\mathrm{xx}^{\mathrm{e}}$ siècle pour les monuments, les maisons et les restaurations. Les carrières ${ }^{4}$ qui ont fourni la pierre à la ville, du Moyen Âge au xIx ${ }^{e}$ siècle, étaient la continuité des carrières romaines. Dans la même région, à Cluny, les murs des remparts médiévaux et le mur ouest, à l'intérieur du grand transept de l'abbatiale, sont en petit appareil de belle qualité, dans la même lignée que les murs romains d'Autun. Cette construction du grand transept de Cluny a résisté depuis le XII siècle sur une hauteur d'environ 30 mètres, ce qui est tout à fait remarquable. On peut en déduire que l'observation des techniques antiques sur les nombreux monuments romains de la région a permis aux maçons du Moyen Âge de continuer à travailler avec soin.

6 Plus au sud, les murs du temple antique d'Eysses (Villeneuve-sur-Lot, Lot-et-Garonne) sont en moellons de grès et de calcaires locaux (fig. 2). Comme il n'y a pas d'autres 
ressources locales, les murs modernes (antérieurs au $\mathrm{xx}^{\mathrm{e}}$ siècle) sont de même composition dans les villages des environs.

Fig. 2. - Villeneuve-sur-Lot (Lot-et-Garonne), temple antique d'Eysses.

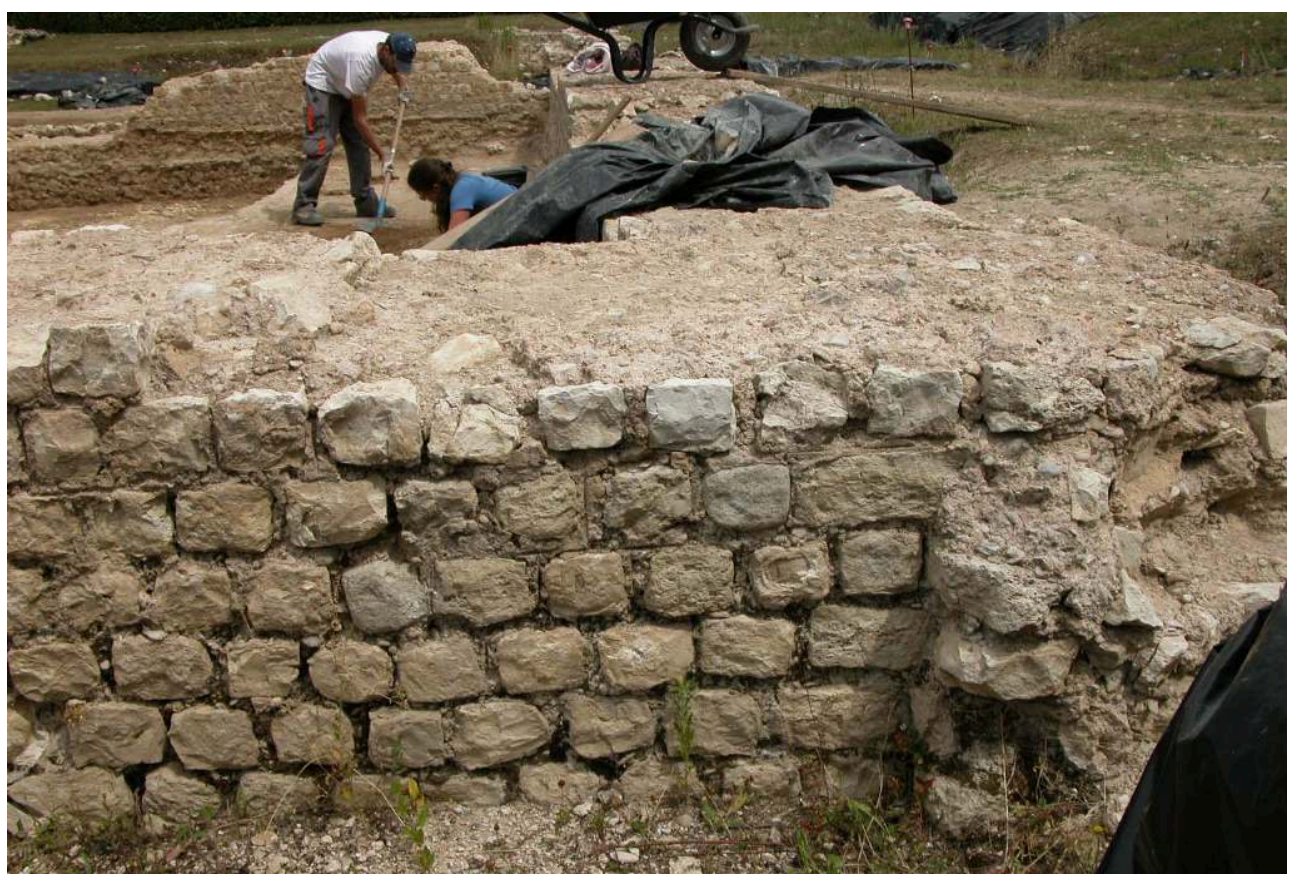

Les murs sont composés de moellons de grès et de calcaires locaux.

(c) Philippe Blanc.

7 En région parisienne, les sites de Genainville (Val-d'Oise) ou de Senlis (Oise) sont au milieu d'un bassin carrier de calcaire lutétien, et on observe dans ces régions la continuation des murs de moellons aussi bien pour les maisons et les églises que les clôtures.

8 Au Vieil-Évreux (Eure), site établi sur la craie, les murs sont plus complexes : calcaires lutétiens, craies et tuf calcaire voisinent, englobés dans un solide mortier. L'usage des tufs calcaires se poursuit au début du Moyen Âge et sera abandonné plus tard, peut-être à cause de l'épuisement des gisements.

9 Dans la Brie, à Meaux, en ville ou dans le site romain de La Bauve, les murs sont édifiés en divers calcaires du Bartonien, avec des angles bien taillés en calcaire lutétien; certaines bases de murs sont en moellons de meulière. À Châteaubleau (Seine-etMarne), le calcaire de Brie et le calcaire de Provins ont fourni la majorité de la construction des édifices entre le $\mathrm{II}^{\mathrm{e}}$ et le $\mathrm{IV}^{\mathrm{e}}$ siècle sous forme de gros blocs utilisés pour les soubassements, des dalles, des moellons et même des tesselles. Les calcaires lutétiens, de provenance plus lointaine (pays meldois et vallée de l'Oise), ont servi pour les colonnes, chapiteaux, sculptures et aussi pour le petit appareil des temples. Dans ces derniers, les moellons, faits de calcaire tendre lutétien, présentent des entailles pour accrocher les enduits; ils proviennent probablement de la vallée de l'Oise. Les propriétés de ces calcaires des diverses carrières régionales sont bien connues dans tout ce monde romain de la vallée de la Seine ${ }^{5}$. 


\section{Les constructions du Moyen Âge : continuité et inventions}

10 Les maçonneries romaines étant encore en place dans des nombreux sites, la question de la survivance des savoir-faire au début du Moyen Âge semble difficile à évaluer. Cette analyse sera poursuivie par région et par type de matériau.

\section{Les calcaires}

11 Les régions riches en carrières de calcaire ont continué à utiliser les mêmes sources pour les constructions médiévales, avec parfois de petites inventions pour l'appareillage décoratif. De rares exemples sont encore en place, comme à Jouarre (Seine-et-Marne), dans la crypte Saint-Paul de l'ancienne abbaye : un mur carolingien est en petit appareil hexagonal, de calcaire lutétien. Ce type d'appareil décoratif est encore visible sur le pignon de la façade de Notre-Dame-la-Grande de Poitiers (Vienne).

12 Les meulières et les calcaires silicifiés ont parfois été mis en place en opus spicatum, comme sur plusieurs églises des environs de Septeuil, dans les Yvelines (fig. 3) ; mais on peut constater que cette façon de faire des $\mathrm{x}^{\mathrm{e}}$ et $\mathrm{XI}^{\mathrm{e}}$ siècles a été oubliée au cours des âges pour les chantiers des agrandissements de ces églises.

Fig. 3. - Église de Mondreville (Yvelines) : mur méridional en calcaires silicifiés et en meulière disposés en opus spicatum.

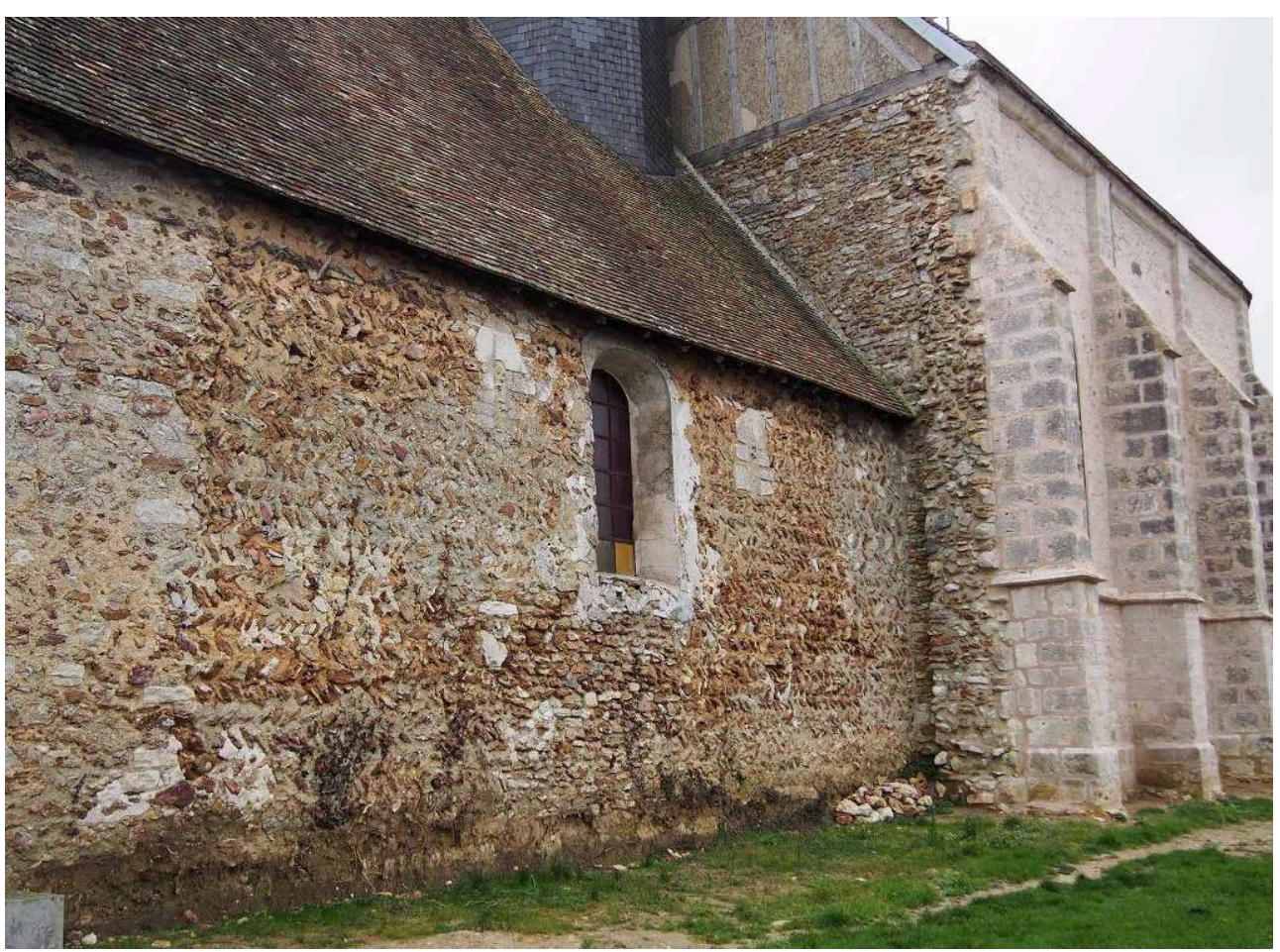

La partie plus récente du mur n'a pas été réalisée avec la même dextérité.

(c) Philippe Blanc. 


\section{Le gypse et le plâtre}

13 Le gypse saccharoïde a été utilisé pour des moellons depuis l'Antiquité en région parisienne, car il a été observé sur le site de La Bauve, à Meaux, dans une base de mur datée d'avant la conquête romaine. Ce matériau, réputé fragile, était le seul utilisé pour de nombreux monuments de Crète, de Syrie et de Perse. En Provence, autour de Mormoiron (Vaucluse), où les carrières de gypse ont été très actives, le gypse est utilisé en construction dans les maisons du village. Dans la région parisienne, le gypse est encore utilisé pour des moellons au début du Moyen Âge, dans les murs carolingiens de Saint-Pierre de Montmartre et à Saint-Martin-de-Champs (Paris) ${ }^{6}$, puis cet usage du gypse en construction a disparu, et il n'est plus employé que pour la fabrication du plâtre, aux multiples usages : enduits extérieurs et intérieurs, cloisons, etc.

\section{L'utilisation des grès en construction}

Depuis le Néolithique, les grès sont recherchés pour les dolmens en région parisienne, puis pour les meules et les moellons. Dès les premiers siècles, les grès du Bassin parisien sont utilisés pour le petit appareil. On peut remarquer que les plus durs sont réservés pour les meules. En Bourgogne et dans le Massif central, les constructeurs choisissent plutôt des arkoses (comme à Autun, en Saône-et-Loire, ou au Puy-en-Velay, dans la Haute-Loire), qui permettent une taille plus précise que les grès durs de Fontainebleau. Mais certaines sculptures ont été réalisées en grès, par exemple un dieu à Javols (Lozère), des stèles à Strasbourg (Bas-Rhin), un chapiteau avec sa colonne à Andilly-enBassigny (Haute-Marne). En région parisienne, il faut attendre le $\mathrm{xv}^{\mathrm{e}}$ siècle pour que les tailleurs de pierre améliorent leur technique, comme le montre la tour de Montlhéry (Essonne), où les premiers niveaux sont beaucoup moins bien taillés que la partie supérieure, plus récente. Un autre exemple est l'église de Dourdan (Essonne), dont la partie $\mathrm{du} \mathrm{Xv}^{\mathrm{e}}$ siècle est entièrement en grès bien appareillé, alors que le château possède des murs de moellons plus frustes. Ces exemples sur les grès montrent que les savoirs plus avancés dans certaines régions, comme l'Alsace, ne parviennent que tardivement en Île-de-France. Les propriétés des grès sont peu à peu mieux comprises et utilisées, dans les soubassements comme barrière contre l'humidité, et pour les ponts (pont de Moret-sur-Loing, dans la Seine-et-Marne, par exemple). C'est au château de Fontainebleau (Seine-et-Marne), au XvII ${ }^{\mathrm{e}}$ siècle, que le grès sera le mieux mis en valeur, avec des colonnes monolithes pour la cour ovale et des sculptures pour les entourages de portes.

\section{Les constructions antérieures à 1945}

$\mathrm{Au}$ cours des Temps modernes, puis au xIX siècle et au début $\mathrm{du} \mathrm{xx}^{\mathrm{e}}$ siècle, on a poursuivi l'utilisation des matériaux locaux ou traditionnels : pierres, briques, plâtre, avec des mortiers à la chaux aérienne ou légèrement hydraulique. Les ressources locales permettent une continuation des techniques de construction, mais les pierres de provenance plus lointaine sont abandonnées. Les savoir-faire sont-ils transmis par tradition ou par nécessité ? Les exemples dans les bâtiments qui n'ont pas été détruits suffisent-ils à transmettre le savoir-faire? L'invention du ciment hydraulique va complètement perturber les techniques et surtout les apprentissages. Pour les grands 
ouvrages, ponts, barrages, ports, phares, le ciment hydraulique issu d'un mélange de calcaire et argile, chauffé au-dessus de 1300 degrés, révolutionne la construction depuis le milieu du XIX ${ }^{e}$ siècle, et le béton apparaît pour les grands bâtiments à partir de 1900 à Paris : garage Perret, théâtre des Champs-Élysées.

Jusqu'en 1900, les architectes ont une formation traditionnelle, comme on peut le constater aux Grand et Petit Palais, édifiés pour l'exposition universelle de 1900. Ils ont une parfaite connaissance des qualités des pierres, ce qui leur est enseigné en de nombreux cours à l'école d'architecture. Leurs connaissances s'étendent aux marbres pour les décors, aux matériaux de couverture (tuiles, ardoises, zinc, plomb), à la ferronnerie (rampes, balcons) et à la charpente ; enfin, aussi bien pour le gros œuvre que pour le second œuvre, la formation est complète. Ceux qui choisissent le béton, comme les frères Perret, le font avec grand soin. Ils surveillent la fabrication des mélanges avec des granulats bien sélectionnés, et leurs œuvres sont conservées et admirées.

\section{Les constructions du $x^{e}$ siècle}

Pour la construction courante après 1945 , la pierre est abandonnée au profit du béton et des parpaings de ciment. Dès cette période, les architectes doivent se fier aux compétences des entreprises et des bureaux d'études, ils n'ont plus besoin d'enseignement sur les matériaux. Avec le béton, à la fin $\mathrm{du} \mathrm{xx}^{\mathrm{e}}$ siècle, la pénurie de granulat et de sable se fait sentir. La ponction de granulat dans les rivières étant la cause de l'écroulement des ponts, on doit chercher une solution en concassant des roches dures : granites et calcaires durs. Les carrières sont exploitées à l'explosif, la masse est fissurée et les granulats n'ont pas la qualité des graviers de rivière, si bien que la qualité et la durabilité des bétons en sont affectées. La conséquence de ce changement de mode de construction est aussi la pénurie de sables, ce qui entraîne la destruction des plages, des côtes et des paysages.

Issues de cette évolution, des normes utilisées pour les constructions contemporaines vont s'appliquer à des bâtiments anciens. Il a fallu argumenter pendant des années, au ministère de la Culture, pour que les DTU (documents techniques unifiés) ne soient applicables qu'aux bâtiments construits après 1945 - sinon les quartiers anciens étaient voués à la ruine progressive. Le problème réside dans la formation des maçons, à qui les normes modernes sont enseignées et qui ont perdu le savoir-faire pour le bâti ancien. Après avoir dressé un court inventaire des savoirs en maçonnerie, après l'abandon de la construction traditionnelle, il est possible de dresser une liste non exhaustive de la perte des savoirs.

\section{La perte des savoirs en maçonnerie}

Les mortiers à base de chaux aérienne ou hydraulique pour les joints et les enduits ont été abandonnés peu à peu au cours du $\mathrm{xx}^{\mathrm{e}}$ siècle, car le ciment à prise rapide permet de travailler vite, par tous les temps, sans se préoccuper de la pluie ni de la chaleur. Devant les dégâts causés aux pierres par les joints en mortier à base de ciment hydraulique, certains artisans ont pris conscience de la situation et ont recherché une solution adaptée aux maisons anciennes. Les fabricants ont mis sur le marché des mortiers et enduits de mélanges «tout prêts ». Ces recettes ont parfois produit des 
surprises au bout de quelques années, comme par exemple un enduit contenant des éléments qui favorisent des points de rouille engendrant des " dégoulinures " rouge sombre sur le mur blanc, après quelques années d'exposition (fig. 4).

Fig. 4. - Exemple d'enduit mis en œuvre il y a environ dix ans et qui montre des traînées rouges (d'algues?) très inesthétiques.

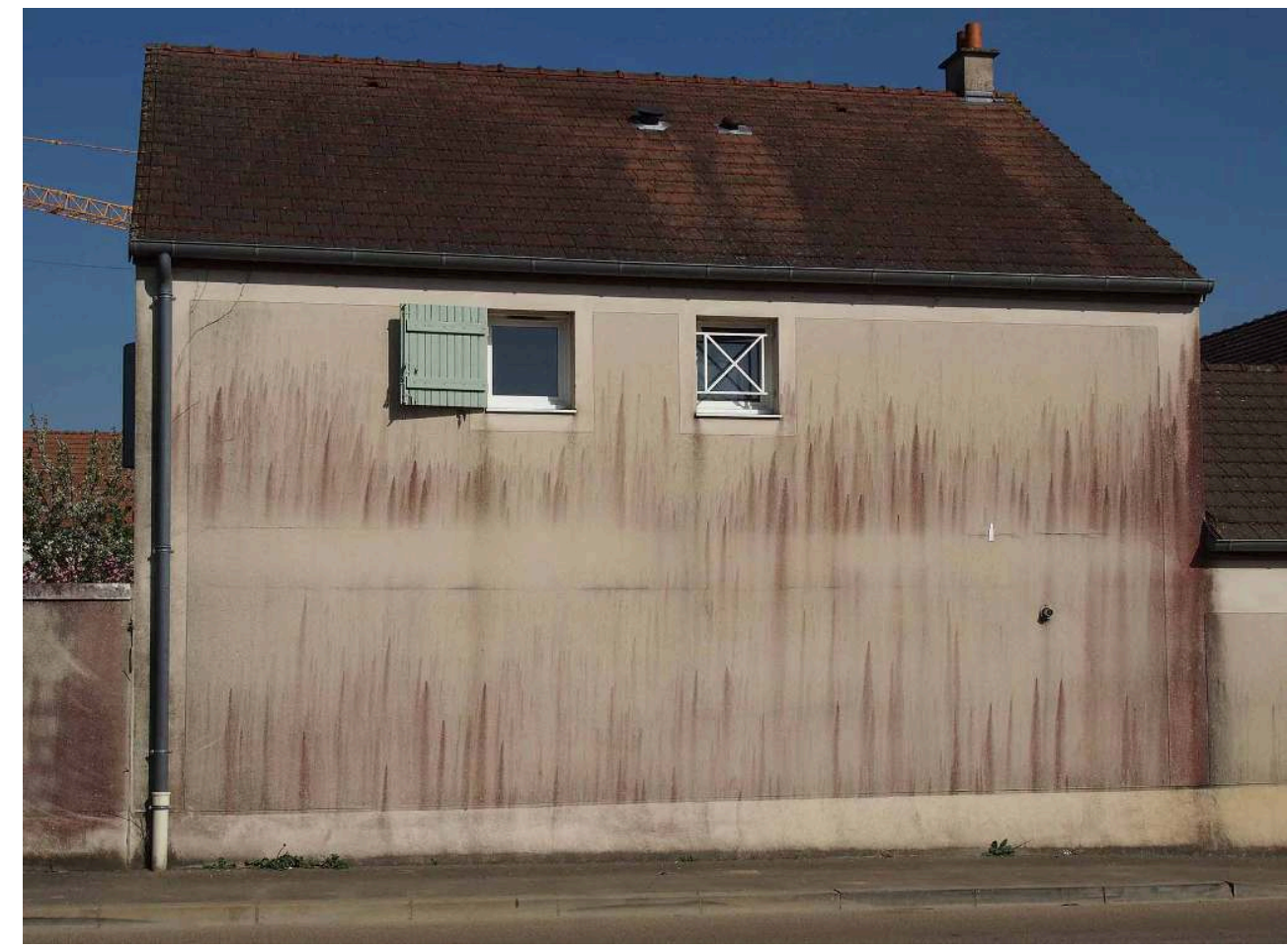

(C) Philippe Blanc.

\section{Les incompatibilités entre matériaux}

20 Une des conséquences les plus graves de l'oubli des savoir-faire est la méconnaissance des incompatibilités entre matériaux. La première, évoquée plus haut, est l'utilisation des joints en mortier à base de ciment sur les anciens bâtiments en pierre de taille ou en moellons. Une autre incompatibilité est celle qui existe entre plâtre et ciment : la superposition des deux matériaux provoque de petites explosions, il se forme des cratères dans les enduits. Un troisième exemple est l'incompatibilité fer/plâtre, connue de chacun il y a moins d'un siècle. Le plâtre fait rouiller le fer, et aucun scellement ne doit être fait au plâtre.

21 La liste est incomplète et malgré le grand nombre d'ouvrages écrits et de cours de maçonnerie publiés au cours du XIX ${ }^{e}$ siècle, les recettes et les tours de main des maçons ne peuvent être transmis que de personne à personne.

\section{Le plâtre des façades}

Entretenir et restaurer les enduits au plâtre de Paris, des façades des immeubles dans la capitale et en Île-de-France, doit être confié à quelques rares entreprises que la plupart des propriétaires ignorent. Les savoir-faire ne sont plus enseignés, mais ces techniques 
sont encore connues par des passionnés qui savent accomplir ces travaux et transmettent leurs savoirs. Mais de nombreux immeubles ont perdu leurs belles façades avec les décors, le plâtre a été remplacé par des enduits imperméables qui enferment l'humidité à l'intérieur du bâtiment.

\section{Les toitures en laves de Bourgogne}

Les toitures en laves de Bourgogne représentent un cas particulier : une grande partie des maisons et églises des villages de l'Yonne, de la Côte-d'Or et de la Saône-et-Loire étaient couvertes de dalles calcaires appelées « laves» (fig. 5). La technique de pose a été abandonnée au cours du $x^{\mathrm{e}}$ siècle et les laves furent remplacées peu à peu par des tuiles ou de la tôle ondulée. En 1980, il ne restait qu'un « lavier » à Clessé, qui travaillait dans le Mâconnais et qui a réussi à former de jeunes couvreurs, lesquels ont acquis le savoir-faire. Les toits en laves de Bourgogne peuvent de nouveau être entretenus ou refaits; mais ces toitures, qui étaient celles des maisons pauvres, sont maintenant plutôt celles des privilégiés.

Fig. 5. - Clessé (Saône-et-Loire) : toiture en laves calcaires dans un village du Mâconnais.

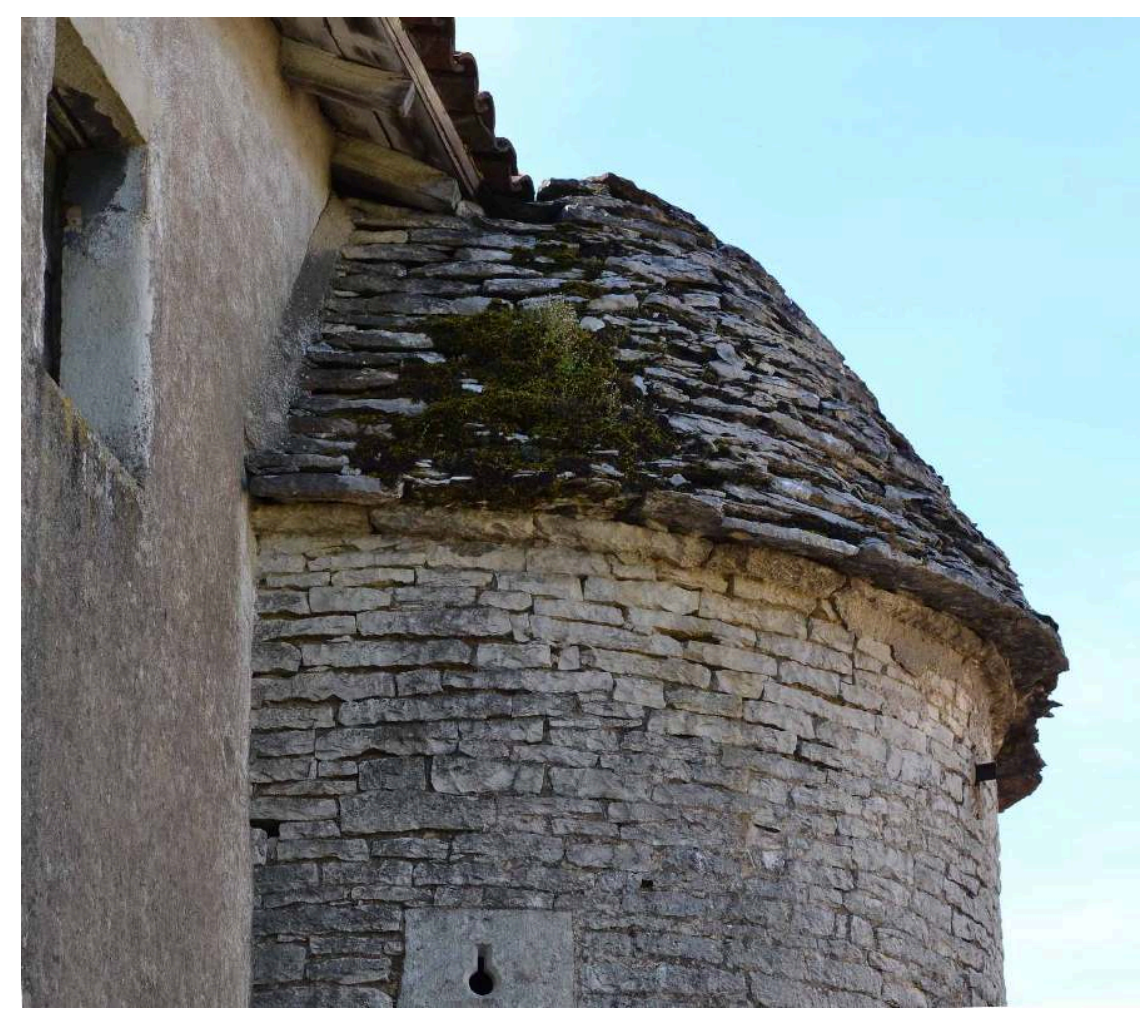

(C) Philippe Blanc.

24 À toutes les époques, on peut constater des abandons de techniques anciennes; par exemple, certains calcaires comme le tuf sont oubliés au cours du Moyen Âge. Mais la grande césure se situe autour de 1950, au moment de l'oubli de la fabrication et de l'utilisation des mortiers de chaux. La construction courante se faisant en parpaings de ciment ou en béton, l'enseignement des maçonneries en pierre est abandonné. 
Malgré tous ces exemples négatifs, il reste quelques espoirs de reprise des techniques anciennes pour les restaurations du patrimoine bâti ancien, mais ces espoirs reposent sur de bonnes volontés, sur des entreprises spécialisées, rares et souvent plus chères, réservées aux secteurs sauvegardés qui peuvent obtenir des subventions pour les travaux d'entretien.

\section{BIBLIOGRAPHIE}

BLANC A., BLANC P., LA COMBLE J. de, LORENZ C., LORENZ J., 1985, « Caractérisation et origine des matériaux utilisés dans les monuments gallo-romains d'Autun (Saône-et-Loire) », Bulletin de la Société d'histoire naturelle d'Autun, $\mathrm{n}^{\circ} 113$, p. 3-28.

BLANC A., 2014, « Augustodunum, Autun : du granite au béton », dans Lorenz J., Blary F., Gély J.-P. (dir.), Construire la ville : histoire urbaine de la pierre à bâtir, Paris, Éditions du CTHS (CTHS sciences, 14), p. 209-219.

BLANC A., BLANC P., GÉLY J.-P., 2016, « Les pierres dans la construction monumentale galloromaine ", dans À la romaine ! Résidence privée, construction publique en Gaule du Nord, cat. exp. (Guiry-en-Vexin, Musée archéologique du Val-d'Oise, 2016), Roissy-en-France, Archéa, p. 136-139. GÉLY J.-P., VIRÉ M., BUSSON D., ROBIN S., 2008, « L’approvisionnement en pierre de Lutèce », dans Blary F., Gély J.-P., Lorenz J. (dir.), Pierres du patrimoine européen : économie de la pierre de l'Antiquité à la fin des Temps modernes, Paris, Éditions du CTHS / Château-Thierry, Patrimoine vivant, p. 256-266.

GROESSENS E., 2016, « La ou les pierres bleues ? La géologie du calcaire noir », dans S. Cormier et B. Beirnaert-Mary (dir.), La pierre bleue de l'Avesnois entre paysage et architecture : les collections du forum antique de Bavay, Milan, Silvana, p. 14-20.

\section{NOTES}

1. Gély et al. 2008.

2. Groessens 2016.

3. Blanc et al. 1985.

4. Blanc 2014.

5. Blanc et al. 2016.

6. Fouilles de Catherine Brut, Commission du vieux Paris. 


\section{RÉSUMÉS}

Dans le nord de la Gaule, les calcaires du Lutétien sont utilisés pour les parements des bâtiments d'époque romaine. Pierres de taille et moellons bien équarris ont été soigneusement conservés dans les musées et les réserves archéologiques à l'instar des sculptures, des fûts de colonnes et des chapiteaux. Diverses roches ont été utilisées : du gypse, des meulières, des grès, des tufs calcaires, de la craie, des silex et plusieurs calcaires du Bassin parisien. Ces roches représentent la plus grande partie de la construction et sont issues des terrains proches des chantiers. Le choix et l'association de ces matériaux dans les murs peuvent varier suivant les périodes de construction des bâtiments. Des exemples pris à Meaux (site de La Bauve), Châteaubleau (Seineet-Marne), Paris, Genainville (Val-d'Oise), Le Vieil-Évreux (Eure) et Bavay (Nord) illustrent cette diversité. L'observation du comportement des roches utilisées dans ces murs antiques permet de connaître la résistance de ces matériaux à l'érosion. Les maçons des époques successives ont-ils profité de ces leçons, ou ont-ils refait leurs propres expériences, comme c'est le cas pour les constructions en béton $\mathrm{du} \mathrm{xx}^{\mathrm{e}}$ siècle?

\section{INDEX}

Mots-clés : maçonnerie, moellon, mortier, plâtre, incompatibilité

\section{AUTEURS}

\section{ANNIE BLANC}

Chercheur associé au Laboratoire de médiévistique occidentale de Paris (LAMOP, université Paris I - Panthéon-Sorbonne, UMR 8589 du CNRS), membre de l'Association des géologues du bassin de Paris

\section{PHILIPPE BLANC}

Chercheur bénévole à Sorbonne université, membre de l'Association des géologues du bassin de Paris 
La construction des pêcheries en pierre appelées écluses sur l'île de Ré : des techniques de construction complexes et un savoir-faire ancestral

Jacques Boucard

$\mathrm{Au}$ début $\mathrm{du} \mathrm{xx}^{\mathrm{e}}$ siècle, les nouveaux venus sur l'île de Ré étaient intrigués par la présence d'un nombre considérable d'épais murs bâtis sur les parties rocheuses de l'estran; il s'agissait des pêcheries en pierre appelées localement écluses. L'origine de ces ouvrages gigantesques remonte au lointain Moyen Âge. De forme irrégulière, mais souvent proche de celle d'un fer à cheval, elles atteignent plusieurs centaines de mètres. Elles sont submersibles à marée haute et le poisson y reste prisonnier lorsque la mer se retire (fig. 1). 
Fig. 1. - Saint-Clément-des-Baleines (Charente-Maritime), écluse de Mouffet, 2010.

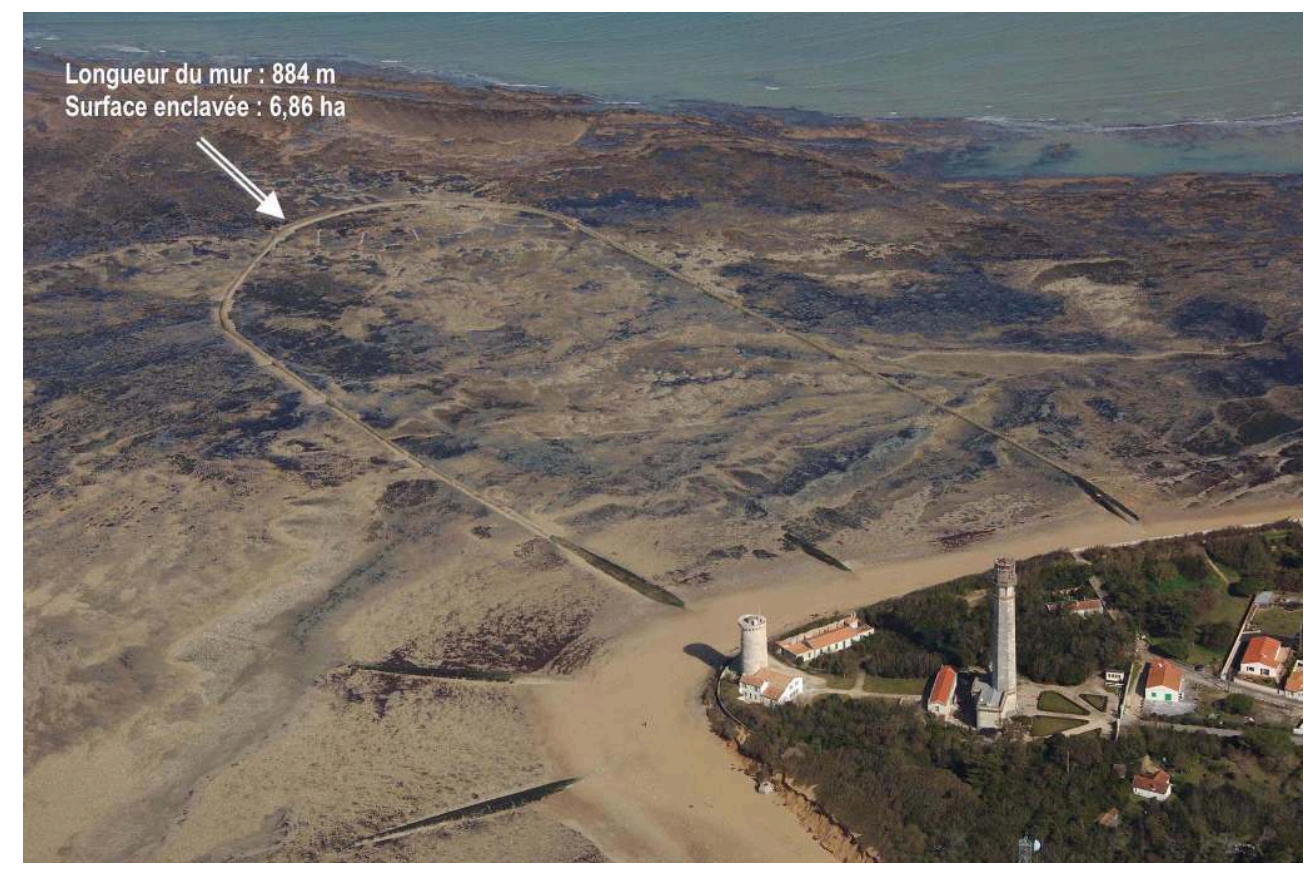

(c) ECAV Aviation / Michel Bernard.

2 Aujourd'hui, la plupart de ces ouvrages sont ruinés, parfois à peine discernables des rochers environnants. Alors qu'il n'en reste plus que quatorze en exploitation sur Ré, au XIX ${ }^{e}$ siècle ce n'était pas moins de 140 ouvrages qui se répartissaient sur les estrans rocheux rétais, emprisonnant plus de 500 hectares. De nombreux documents datant de l'Ancien Régime montrent que ce type de construction s'est largement diffusé dans tout le Centre-Ouest, sur toutes les côtes propices à l'édification de tels ouvrages, c'est-àdire des estrans calcaires, et quoique beaucoup plus rarement - comme en Bretagne et Normandie - des espaces rocheux granitiques.

\section{L'origine des écluses sur Ré}

3 Le terme écluse, du latin exclusa, encore en usage aujourd'hui sur les îles de Ré et d'oléron, désigne les pêcheries en pierres sèches édifiées sur les parties rocheuses de l'estran. Ce terme apparaît très tôt, puisqu'il est attesté dès le $\mathrm{IX}^{\mathrm{e}}$ siècle pour la construction de pêcheries sur le littoral guérandais ${ }^{1}$.

4 Les écluses sur Ré sont-elles aussi anciennes? Probablement pas, car l'île semble avoir été quasi déserte au haut Moyen Âge. Le repeuplement datant $\mathrm{du} \mathrm{xI}^{\mathrm{e}}$ siècle, il est possible que les premiers ouvrages datent de cette période. Toutefois, les fonds documentaires médiévaux ne subsistent qu'à l'état d'épaves et rendent difficile toute recherche documentaire dans les sources anciennes. En effet, pendant les guerres de Religion, d'une particulière intensité dans toute la région, ont disparu des fonds de toute première importance. La destruction totale des archives de la vieille abbaye bénédictine de Saint-Michel-en-l'Herm (Vendée) est une perte irrémédiable, qui nous prive d'une couverture documentaire pour les îles d'Ars, les Portes et de Loix en l'île de Ré qui relevaient de la seigneurie monastique. De même, dans l'incendie de la Chambre des comptes à Paris en 1737, ont brûlé les archives de La Rochelle et des régions 
circonvoisines, sans oublier l'incendie de la mairie de Saint-Martin-de-Ré en 1901, qui a détruit un fonds d'archives médiévales et de l'Ancien Régime. Quant aux comptes seigneuriaux de l'abondant chartrier de Thouars, ils n'existent qu'à l'état lacunaire.

5 L'absence de documentation ne permet pas de trancher, mais nous pensons que les premières écluses à poissons sont apparues sur les îles de Ré et d'oléron pendant la guerre dite de Cent Ans, mais qui, pour notre région, dura pratiquement de 1242 à 1462. La charte de Guy de Thouars, en $1289^{2}$, particulièrement précise et détaillée, ne mentionne pas les pêcheries, alors que des précisions sont apportées dans de nombreux domaines, ce qui laisse supposer qu'il n'en existait pas encore d'édifiées sur Ré. La première mention d'écluses n'apparaît dans le chartrier de Thouars qu'en $1408^{3}: 36-$ chiffre très élevé - sont alors répertoriées dans la «seigneurie " (l'ancien canton de Saint-Martin-de-Ré, la partie sud-est de l'île), 5 écluses au Bois, 8 à La Flotte, 2 à SaintMartin, 18 à Sainte-Marie (comprenant Rivedoux), dont une sur le rocher de Chauveau, et 3 dans un lieu non précisé. S'agit-il de nouvelles pêcheries ou de reconstructions pendant une période un peu plus calme? Une enquête diligentée sur l'île d'oléron, voisine, en 1737 par l'intendant Barentin, nous apporte quelques éléments qu'il est tentant d'utiliser pour Ré. Dans ce dossier, sur 17 contrats de construction d'écluses, présentés comme pièces justificatives d'une requête, 14 sont datés de la période 1420-15304. Pour les actes les plus anciens, notamment celui daté de 1418, les documents utilisent l'expression de "place déserte", ce qui laisse suggérer une création. Par contre, comme le suggère Thierry Sauzeau, pour les deux suivants (1436, «Rachou » - sans doute le rocher de Rouchoux - et « conche d'Availhes ») évoquent des places «en ruyne » pour lesquelles on ajoute même que la "place est demourée en ruyne par sy longc temps qu'il n'est de mémoire de homme au contraire et auxy a été et encores est de nul prouffit à Mondit Seigneur». Ces documents attestent incontestablement d'écluses existant avant 1436, probablement à la fin du XIII ${ }^{\mathrm{e}}$ siècle ou au tout début du XIV siècle. Il devait en être de même sur Ré, trop proche pour ne pas bénéficier de ce type de pêcheries très adaptées aux estrans rocheux qui ourlent ces deux îles.

6 En 1727, lors de son inspection ${ }^{5}$, l'inspecteur des pêches Le Masson du Parc dénombre 114 écluses sur l'île de Ré, dont 42 sur le territoire couvert par le compte seigneurial de 1408. L'ensemble de ses rapports couvrant les côtes françaises (Manche, Atlantique et Méditerranée) permet de constater qu'il existe alors 393 pêcheries en pierre sur les côtes de l'Atlantique et de la Manche; Ré et Oléron avec, respectivement, 114 et 115 écluses représentent, chacune, $29 \%$ du total ${ }^{6}$.

7 La dernière période de grande construction date des années 1945 (année durant laquelle les vignes ont été complètement détruites par des gelées tardives les trois premiers jours de mai) à 1950 .

8 Ces ouvrages imposants sont tout à fait représentatifs de la culture maritime qui s'est progressivement mise en place à partir du Moyen Âge et qui va profondément modeler le mode de vie des insulaires et des populations littorales, ces " paysans de la mer » qui vivaient avec l'océan et en tiraient une partie importante de leur subsistance, tant pour la nourriture que pour engraisser leurs maigres terrains avec le varech utilisé en fumure. Depuis dix siècles, ces paysans et/ou sauniers ont pris l'habitude de vivre avec et de la mer, mettant en place une société complexe s'appuyant sur une forte solidarité. Ces magayant $(e) s^{7}$ ont su acquérir et transmettre les éléments d'une connaissance 
intime du milieu maritime proche, qu'ils ont exploité comme leurs terres, avec une conscience aiguë des grands équilibres écologiques.

9 L'étendue de ces pêcheries, qui nécessitent de bâtir entre $2000 \mathrm{~m}^{3}$ de mur (pour les plus petites) et $6000 \mathrm{~m}^{3}$ (pour les plus grandes), concrétise le fruit d'un travail communautaire et s'appuie sur une expérience séculaire et une connaissance intime du milieu maritime difficilement imaginable aujourd'hui. L'ordonnance de Colbert de 1681, qui reprend probablement des usages plus anciens, précise :

«Les parcs de pierre seront construits de pierres rangées en forme de demi-cercle, et élevés à la hauteur de quatre pieds au plus, sans chaux, ciment, ni maçonnerie ; et ils auront dans le fond, du côté de la mer, une ouverture de deux pieds de largeur, qui ne sera fermée que d'une grille de bois ayant des trous en forme de maille d'un pouce au moins en quarré, depuis la Saint Remy jusqu'à Pâques, et de deux pouces au carré, depuis Pâques jusqu’à la Saint Remy ${ }^{8}$.»

10 Si la construction des écluses est largement documentée à l'époque moderne, il n'en est pas de même avant le $\mathrm{XIX}^{\mathrm{e}}$ siècle. Aussi est-il très délicat de répondre à une question importante: les pêcheries médiévales étaient-elles identiques à celles que nous connaissons aujourd'hui ? Rien n'est moins sûr; l'analyse de certains textes laisse au contraire supposer que les établissements auraient pu être plus petits. Nous n'étudierons donc, dans cet article, que les techniques de construction existant aux XIX et $\mathrm{Xx}^{\mathrm{e}}$ siècles.

\section{L'autorisation de construction}

11 Dans les seigneuries (Ars, Les Portes et Loix) la requête est présentée auprès du sénéchal :

«Vu la requête à nous présentée par Paul Dubois, Pierre Tardy, Louis Regreny Esmon et Mathieu Tardy Dubois tous fariniers demeurants au village de la rivière tendant à ce qu'il nous plaise leur permettre de construire une écluse sur la côte du lizais au lieu appellé vulgairement le chef des noues, en deçà des rochers qui bordent la côte, laquelle écluse construite contiendra cent trente cinq toises dont une branche sera à terre à commencer du côté de l'écluse du lisais et à cinquante toises de distance entre l'ancienne écluse, vu le certificat de Denis Raitou, arpenteur et autres gens experts qui ont visité le terrain et affirmé que lad. écluse ne pourra nuire ni préjudicier à la navigation attendu la quantité de Rochers qui s'étendent bien au-delà de l'écluse prétendue et qui rendent la côte impraticable ${ }^{9}[. .$.$] »$

12 Bien qu'en vertu de l'ordonnance de la Marine de 1681, le sénéchal n'ait aucun pouvoir pour accorder l'autorisation d'une construction sur l'estran, il n'hésite pas à le faire en tenant compte des spécifications de l'ordonnance!

13 Dans la baronnie (la partie sud-est de l'île), le régime est identique. Soumis à la législation définie par Colbert, le baron de Ré ne peut concéder d'autorisations de construction ni bailler l'estran, mais il ne s'en prive pas, comme le constate une note du 13 août 1720 : « Le Seigneur de l'Isle de Rhé qui est un marchand donne des baillettes à tous ceux qui en veulent et bâtissent des écluses ${ }^{10}$. »

14 À partir de la Révolution, les amirautés ayant disparu, toutes les demandes de construction d'écluses concernant l'ensemble de l'île de Ré transitent par le commissaire aux Classes, puis de l'Inscription maritime, à Saint-Martin-de-Ré.

15 Aujourd'hui, l'application de l'arrêté de 1967 interdit la construction de nouvelles pêcheries; seules sont acceptées les restaurations et les reconstructions. 


\section{Le secret de la construction : une bonne équipe} dans le voisinage, rarement dans la famille : «C'est trop compliqué !». Pour Anthony Guilbeau $^{11}$, il fallait avant tout que l'équipe soit d'accord et que tous possèdent «le même tempérament, la même générosité, la même volonté d'arriver jusqu'au bout, et disposent de temps libre. Si l'équipe n'est pas bonne, le résultat sera mauvais. » Chaque membre de l'équipe doit s'engager dans le projet commun et disposer de temps libre, car ces chantiers particulièrement importants nécessitent entre 10000 et 15000 heures de travail. L'équipe de construction deviendra l'équipe de pêche et restera immuable. De ce fait, le monde paysan - laboureurs ou sauniers - est très majoritairement représenté, alors que les marins le sont très peu, même lorsqu'ils ne naviguent plus, ce que confirme le dépouillement de l'« État des parcs et pêcheries de l'isle de Ré » dressé par les officiers de l'amirauté de La Rochelle en 1752. Le préambule de ce document mentionne :

« Comme ces écluses sont sujettes à un grand entretien, elles n'appartiennent qu'à des sauniers et à des journaliers qui réparent eux-mêmes les fréquents dommages que la mer y cause ${ }^{12}$.» villages sauniers, la très grande majorité des détenteurs d'Ars et Loix sont sauniers ou laboureurs; seul le village des Portes dénote. Dans ce dernier, marchands et notaires possèdent des parts très significatives dans plusieurs pêcheries. Cet état de fait peut s'expliquer par la grande pauvreté des sauniers, payés seulement sur la vente du sel (décidée par le propriétaire de la saline), qui pouvaient être amenés à céder des parts d' écluse pour payer une dette. De même, dans la baronnie, c'est-à-dire la partie sud-est de l'île, où l'on cultive la vigne, la majorité des pêcheries appartient à des laboureurs.

L'« État des écluses autorisées pour le quartier de l'île de Ré13 " dressé un siècle plus tard, en 1855, qui précise le nom de tous les détenteurs avec leur profession, permet de constater que, tous villages confondus, sur Ré les cultivateurs (y compris les sauniers mentionnés comme cultivateurs) représentent 95,2\% des détenteurs, les meuniers $1,9 \%$, les marins $0,5 \%$ et l'ensemble des autres professions $2,4 \%$.

19 L'équipe se compose exclusivement d'hommes, car la construction et les réparations nécessitent des travaux très physiques et pénibles. À l'intérieur du groupe constitué, on choisit un chef d'écluse, expérimenté et respecté de tous, pour diriger les travaux et animer l'équipe. Pour ces travaux longs et difficiles, l'ambiance de travail est fondamentale et le chef d'écluse doit y veiller en privilégiant le consensus plutôt que les choix autoritaires. Aussi, les solutions techniques, surtout si elles ne sont pas évidentes, font l'objet de discussions, mais en dernier ressort c'est chef d'écluse qui prend la décision; elle ne sera plus ensuite discutée. Dans les éléments techniques, c'est lui aussi qui valide l'horizontalité du mur - un élément important pour avoir un piège pêchant en prenant un niveau sur l'horizon de la mer. En dernier lieu, le chef d'écluse tient à jour un état du temps passé par chaque détenteur, à la fois pour la construction et, ensuite, pour les réparations, afin que chacun fasse le même temps de présence (calculé en marées). 
Dans l'équipe de construction, trois fonctions doivent être assurées, aussi retrouve-ton:

- Les bâtisseurs : ils construisent le parement extérieur du mur et effectuent son remplissage intérieur. Ce sont eux qui vont choisir la «bonne pierre » et la poser en l'emboîtant pour former la voute externe. Les pierres doivent « se marier », c'est-à-dire s'ajuster parfaitement entre elles sans être retaillées, pour ne pas créer de zones de faiblesse (microfractures...). Pour ce faire, au sud-est de lîle, où les strates calcaires sont épaisses, il faut trouver le point d'équilibre : on fait tourner la pierre dans la main pour déterminer le centre de gravité, qui doit se trouver vers le bas et « entraîner » naturellement la pierre vers l'emplacement qui lui est dévolu par le bâtisseur. Cette technique, très efficace, permet un parfait ajustement de la voûte, mais demande une grande expérience. On dit qu'« un bon maçon n'a jamais fait un bon bâtisseur [d'écluse] », car les techniques de construction sont différentes. Dans la partie nord-ouest, où les strates calcaires sont beaucoup moins épaisses, on utilise des pierres qui sont toutes d'épaisseur proche, les galettes. Un peu plus faciles à emboîter, elles nécessitent des blocages plus fins, à l'aide de pierres intercalées que l'on enfonce en frappant avec une autre pierre ou un maillet en bois, jamais en fer. Certaines galettes apparaissent friables et de doivent pas être utilisées dans la construction, car elles pourraient s'effriter à tout moment et générer des brèches; elles sont appelées galettes en bois. Les ouvertures, indispensables au bon écoulement des eaux, sont un élément de fragilité majeur et nécessitent une construction très particulière pour arrêter le mur par un front de lourdes pierres placées horizontalement et, ensuite, protéger la grille qui permet l'écoulement des eaux et empêche les poissons de ressortir. Seuls les très bons bâtisseurs s'attaquent à la construction des ouvertures.

- Les porteurs de pierres : ils ramassent les bonnes pierres, trient celles qui vont être utilisées pour la construction du parement extérieur, les passent aux bâtisseurs et préparent les pierres restantes, qui vont être utilisées pour le remplissage intérieur du mur. Si les pierres sont bien triées pour la construction, le travail des bâtisseurs en est facilité. Lorsque les pierres à transporter sont trop lourdes, on utilise une sorte de brancard en bois, le boyard ${ }^{14}$, porté par deux ou quatre hommes (fig. 2). 


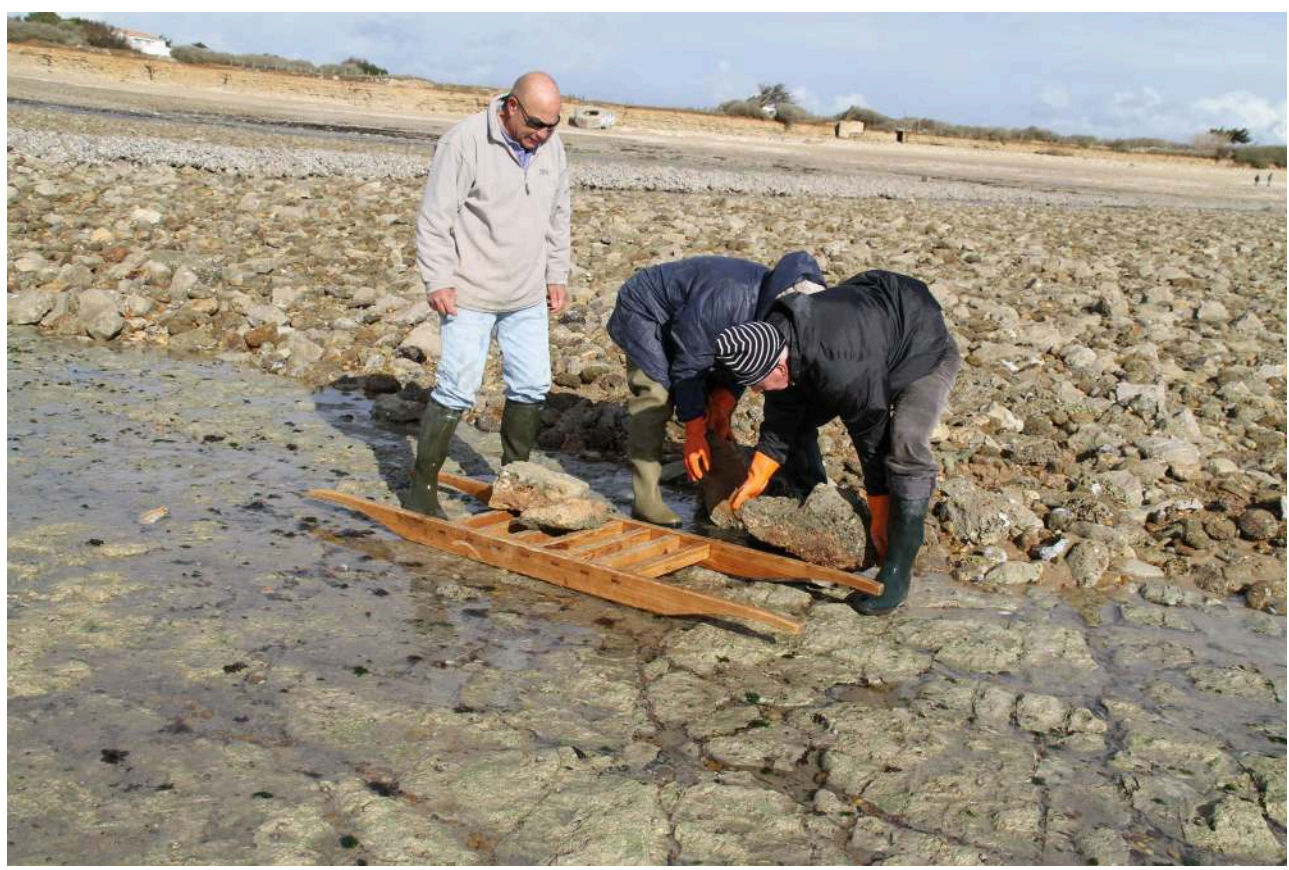

(C) Jacques Boucard.

- Les ramasseurs de pierres : autrefois, ils cassaient la première strate de banche pour avoir des pierres bien rugueuses utilisées dans la construction du parement ou des ouvertures. Outre l'approvisionnement en pierres de bonne qualité, cette méthode permettait de découvrir la couche argileuse séparant les strates calcaires et mettait à jour la faune marine vivant dans ce substrat, ce qui allait attirer les poissons lorsque l'écluse serait mise en pêche. Aujourd'hui, l'interdiction de débancher oblige à l'utilisation de pierres roulantes, moins rugueuses, rendant l'ouvrage d'autant plus fragile, surtout les deux ou trois premières années avant que les balanes ${ }^{15}$ s'y soient fixées et développées. Les ramasseurs rassemblent au pied du mur les pierres utilisables pour la construction et pour le remplissage du mur, sans faire aucun tri. Ils assurent ensuite la fonction de colmatage du haut du mur en incorporant de petites pierres enfoncées à force pour assurer un meilleur blocage (le clabounage, au sud-est de l'île), voire en terminant par des jets de gravier pour pénétrer dans les plus petits espaces (le p'tin au nord-ouest de l'île).

Pour construire la Belle-Vanne, raconte Albert Guilbon,

«Nous étions dix, mais pendant un moment nous avons travaillé à vingt. Nous étions en équipes, chacun avait son travail. Moi, j'étais assez jeune, alors on m'avait mis avec Albert Charpentier et Gilbert Henry. On débanchait. D'autres transportaient les pierres dans des charrettes, on faisait la navette. Les anciens, qui connaissaient bien bâtir, y'avait Charpentier, Anthony Giraudeau, Henry Chaigne, Alexis Bouyer, eux bâtissaient. On choisissait les pierres. On ne prenait pas n'importe lesquelles. Dans les banches, en général, elles étaient assez plates et on avait des banches épaisses. Les pierres roulantes, on s'en servait pour le remplissage, le gabu ${ }^{16}$. »

La construction d'une pêcherie, mais surtout les réparations plus ou moins importantes, permettaient d'acquérir une expérience de plus en plus pointue et de passer, pour les meilleurs, de ramasseurs de pierres à bâtisseurs. De plus, la transmission d'une part - ou d'un fragment de part - dans le cadre familial, puis dans le cadre marital, conduisait à détenir plusieurs participations, parfois jusqu'à cinq ou six. 
Ces participations multiples permettaient de côtoyer plusieurs équipes pouvant avoir des techniques ou des savoir-faire légèrement différents, surtout si les écluses n'étaient pas dans le même village. Ainsi, au fil du temps, s'acquéraient des tours de main, des innovations techniques et un savoir-faire beaucoup plus complexe qu'il n'y parait de prime abord.

Depuis le XII ${ }^{\mathrm{e}}$ siècle, les pêcheries de l'île de Ré sont, à de rares exceptions près, des propriétés collectives, divisées en parts; chaque membre de l'équipe de construction a droit à une part. Néanmoins, lors de la construction, on peut utiliser une main-d'œuvre extérieure afin d'accélérer l'avancement des travaux. Ainsi, lors de la reconstruction de la Belle-Vanne (Sainte-Marie), en 1945, pendant plusieurs marées, l'équipe a été doublée, chaque détenteur amenant une personne pour bâtir, mais sans qu'elle eût droit de pêche.

La part d'écluse comprend, d'une manière indissociable, part de pêche et part de réparations, car, une fois bâti, l'ouvrage nécessite un entretien continu et permanent. Le nombre de participants à l'équipe de construction détermine, de façon immuable, le nombre de parts d'écluse, en général 8 à 10, jamais 7, car les marées de pêche seraient en phase avec le cycle lunaire et, de ce fait, toujours semblables (même coefficient de marée). Les parts se transmettent entre vifs (échange, ventes...), mais le plus souvent lors d'une succession ; la part est alors divisée entre le nombre d'enfants intéressés, le repreneur étant dans l'obligation d'assumer son «devoir» d'entretien. Lors d'une transmission, le nouveau détenteur doit être accepté par la communauté, ce qui est en général le cas, sauf si le nouveau venu n'est pas en capacité d'assurer sa part de réparations, par exemple, car n'habitant plus dans le village, ou pour les filles célibataires, l'incapacité d'assurer des travaux souvent très pénibles et nécessitant une certaine force physique. En revanche, pour les femmes mariées, le mari « hérite » des droits - et des devoirs - de pêche de sa femme. Il n'est alors pas rare qu'un détenteur détienne des participations dans plusieurs pêcheries: par exemple, $1 / 8^{\mathrm{e}}$ dans l'une, $1 / 24^{\mathrm{e}}$ dans une autre et $1 / 16^{\mathrm{e}}$ dans une troisième. La participation à plusieurs équipes et aux travaux d'entretien et de réparation qui en découlent permet une meilleure intégration. Ces participations diverses sont un facteur fort de renforcement de la cohésion sociale de la communauté des "paysans de la mer» au niveau de chaque village, un peu moins au niveau de l'île, car jusqu'aux années 1920/1930, les déplacements se faisant à pied ou en charrette, on ne pêchait donc que dans les écluses proches du domicile, tout au plus à quelques kilomètres.

Le constat sur la distance entre l'écluse et le domicile peut, également, s'appliquer à la diffusion du savoir-faire et notamment des innovations. En effet, si la multiplication des participations favorisait les transferts, la diffusion ne s'étendait que sur quelques kilomètres, soit l'échelle du village ou, plus rarement, du village le plus proche. Ainsi, le système de ralentissement de la propagation des brèches appelé clé, que l'on retrouve sur les ouvrages de Sainte-Marie-de-Ré et de Rivedoux, n'existe pas sur celles d'Ars et de Saint-Clément-des-Baleines, pourtant soumises à des houles du large pouvant être très violentes.

Dans la première moitié du xxe siècle, l'utilisation de la bicyclette a élargi le périmètre de pêche. Par exemple, Marcel Cordon, de Sainte-Marie-de-Ré, avait deux écluses à Rivedoux, près du rocher de Chauveau, la Danseuse et le Petit-Fossé, à quatre kilomètres de son domicile ${ }^{17}$. Aujourd'hui, l'utilisation d'un véhicule automobile offre une diffusion encore plus large. Lors de la réparation en 2017 de l'écluse de Mouffet, à 
Saint-Clément-des-Baleines, l'aide apportée par l'association l'ADEPIR (Association de défense des écluses à poissons de l'île de Ré), sous forme de main-d'œuvre, a permis de transférer des savoirs venant de Sainte-Marie-de-Ré, village situé à plus de vingt-cinq kilomètres.

\section{La construction : une technique complexe demandant un grand savoir-faire}

Pour le profane, l'estran rocheux qui borde l'île semble, à marée basse, très plat. En réalité, les strates calcaires - les banches - qui le composent, de 20 à 50 centimètres d'épaisseur, sont parcourues par de nombreux courants, les vannes, qui permettent l'assèchement du rocher à marée basse. Les différentes strates sont séparées par une couche d'argile en décomposition, de faible épaisseur, colonisée par de petits vers et une faune marine très riche. À marée haute, les poissons viennent y chercher de la nourriture, les courants de marée érodant régulièrement cet espace.

Pour être pêchante, l'écluse doit être implantée sur le lieu de passage des poissons et comporter une ou plusieurs ouvertures. Lorsque les meilleurs emplacements ont été occupés, il a bien fallu construire là où il restait une place vide, qui risquait d'être moins pêchante, mais avait le mérite d'être disponible. Aujourd'hui encore, les écluses disparues - ou non - gardent leur réputation. Certaines pêchaient été comme hiver, d'autres plutôt au printemps et l'été. Roche-Nue, à Sainte-Marie, était réputée pour ses meuilles (mulets) attrapés en grande quantité, au contraire de la Paillarde, très proche, dont on appréciait la variété des poissons pêchés. Certaines étaient considérées comme pêchantes, d'autres non. Les noms, ou surnoms, conservent encore trace de ces différences : la Petite-Chavêche ou Non-Prenante, à Sainte-Marie ; la Misère ou GrandePierre, à Saint-Clément; Foirouze (soit Foireuse), à Ars et Loix; au contraire de la Jalousie, à Sainte-Marie.

$\mathrm{Au} \mathrm{xx}^{\mathrm{e}}$ siècle, toutes les écluses ont été rebâties sur l'assiette de pêcheries plus anciennes. Pour bâtir, ou plus exactement rebâtir, on utilisait les pierres provenant de l'ancienne écluse, mais peu, car la plupart sont enfouies ou disparues, emportées par les tempêtes. On utilisait très peu de pierres roulantes, car lorsqu'une pierre a roulé pendant des années, ses arêtes s'arrondissent et elle n'accroche plus. On préférait débancher (tirer la pierre de la banche, l'estran calcaire); les arêtes sont alors plus vives et le bloc reste rugueux. Aujourd'hui, cette pratique est interdite par l'État, ce qui rend les écluses reconstruites plus fragiles, les pierres accrochant moins.

Pour construire, on commence en même temps la construction des deux bras. Albert Guilbon ${ }^{18}$ raconte :

« Pour la Belle-Vanne, on est parti du bord du rivage. Puis on a commencé le deuxième bras, car par faible coefficient on pouvait travailler sur les bras, mais pas sur le fond. Elle était très large et haute. On y allait tous les jours, que le coefficient soit faible ou fort. On faisait de grandes marées, on y allait quand la mer descendait et l'on revenait quand elle montait. Il y avait plus de quatre heures de travail à chaque marée. On a fini dans le fond, les dernières marées il restait encore pas mal à faire, je me souviens, on avait mis un filet pour arrêter le poisson et on avait pêché! » 
murs parallèles à la base, formant un passage, le gouyau, que l'on remplit de petites pierres et de pierres roulantes, le gabu. Les pierres de base constituant les deux murs parallèles sont des pierres triangulaires appelées des pierres trois coins. On réunit ensuite ces deux murs parallèles, pour former une véritable voûte ; à chaque nouvelle rangée de pierres correspond un remplissage de l'intérieur par du gabu (fig. 3).

Fig. 3. - Section théorique d'un mur d'écluse.

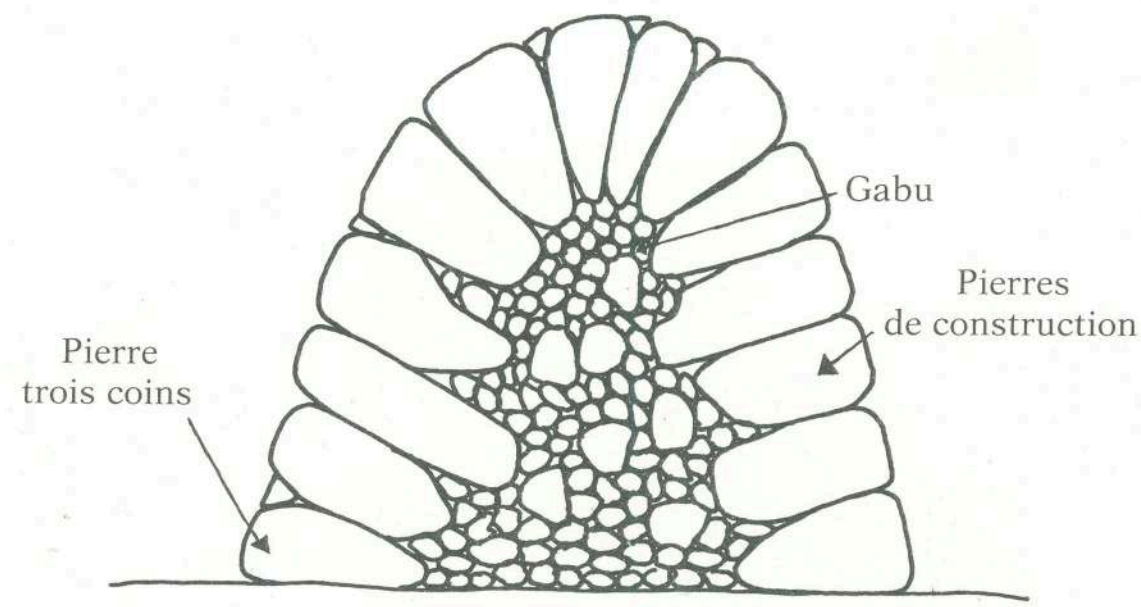

(c) Jacques Boucard.

La surface du parement extérieur (côté océan) est particulièrement soignée pour éviter l'ébranlement de la structure par la houle. En effet, la vague éclatant au pied du mur remonte vers le haut du mur et, en percutant une pierre dépassant, va la faire basculer et l'arracher, provoquant une amorce de brèche.

Extérieurement, le mur présente une forme relativement arrondie, proche de celle d'une voûte, système autobloquant sans utilisation d'un liant (chaux, ciment). La structure reste donc relativement "souple", ce qui lui permet de mieux encaisser le choc de la houle, car lors de fortes tempêtes, l'énergie dissipée par le flot s'écrasant sur le mur atteint facilement 20 tonnes par mètre carré.

De plus, pour éviter la propagation de brèches, on inclut de place en place un système de chaînage, très efficace, appelé clé. Une clé est constituée de pierres plates formant l'arrondi du mur d'écluse, placées perpendiculairement aux pierres posées directement sur la banche, et élevées à partir de la seconde rangée. Pour reconstruire la BelleVanne, aussitôt après la Seconde Guerre mondiale, « On prenait des pierres, il fallait se mettre à quatre pour les soulever, alors pour bien les mettre en place, c'était pas facile ${ }^{19}$ !» On bâtit une clé tous les dix mètres environ, moins s'il s'agit d'un endroit très exposé à la mer. La partie renforcée de l'écluse de la Jalousie (Sainte-Marie), par exemple, très exposée aux vents d'ouest/sud-ouest, comporte des clés espacées de moins d'un mètre cinquante (fig. 4). 
Fig. 4. - Sainte-Marie-de-Ré (Charente-Maritime), écluse de la Belle-Pointe : détail d'une clé, 2017.
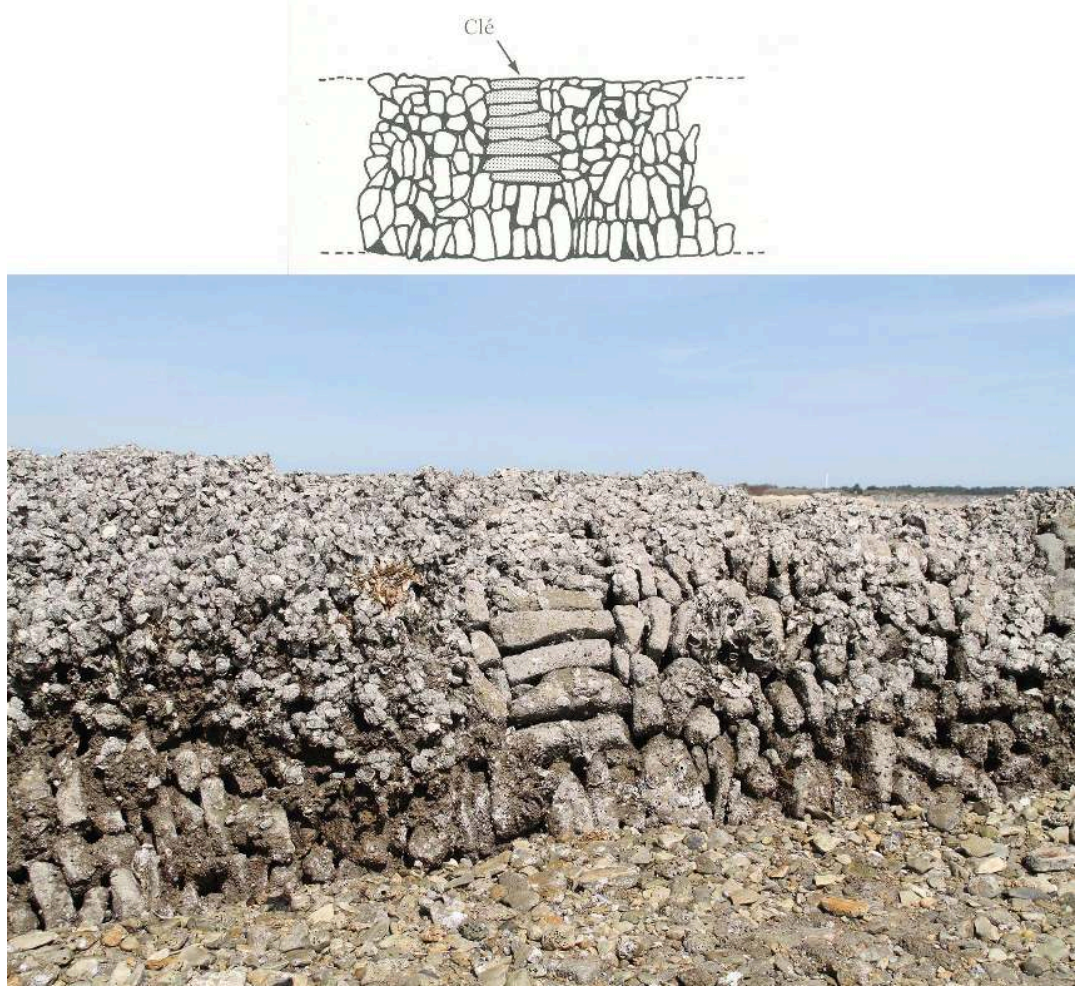

(c) Jacques Boucard.

Les ouvertures sont également des points de fragilité et nécessitent un savoir-faire particulier. En effet, pour permettre à l'ouvrage de se vider (de s'égoutter), on procède dans le mur à des ouvertures. L'ordonnance de Colbert n'en autorise qu'une seule, dans le fond de la pêcherie, ce qui est très insuffisant pour assécher l'écluse. Dans la pratique, les ouvertures ne sont que rarement disposées au fond. Leur position dépend essentiellement de la configuration de l'estran, car elles sont toujours implantées à l'emplacement des courants d'eau naturels, les vannes. Il faut que la pêcherie puisse s'égoutter complètement, mais aussi très vite, pour que les poissons ne passent pas pardessus le mur. Le nombre d'ouvertures est variable, suivant leur largeur et leur hauteur, mais il atteint communément six à huit à Sainte-Marie, et dix à douze à Ars et aux Portes.

Suivant les époques et les paroisses, les ouvertures portent un nom différent et ne possèdent pas une forme identique. Sur les côtes rarement soumises aux fortes tempêtes, les ouvertures font toute la hauteur du mur, et une largeur de soixante centimètres environ ; on les appelle bouchots. Pour fermer le passage aux poissons, on y installe une grille montée sur des traverses, dépassant au-dessus du mur (fig. 5). Sur les côtes plus exposées, on ne peut utiliser cette technique ; il faut protéger la grille contre l'action de la mer. Le passage, appelé claie à Rivedoux et Sainte-Marie, cia aux Portes et coui (ou coi) à Ars et Saint-Clément, se présente donc différemment (fig. 6). 
Fig. 5. - Loix (Charente-Maritime), écluse de La Verdonnais : détail d'un bouchot, 2017.

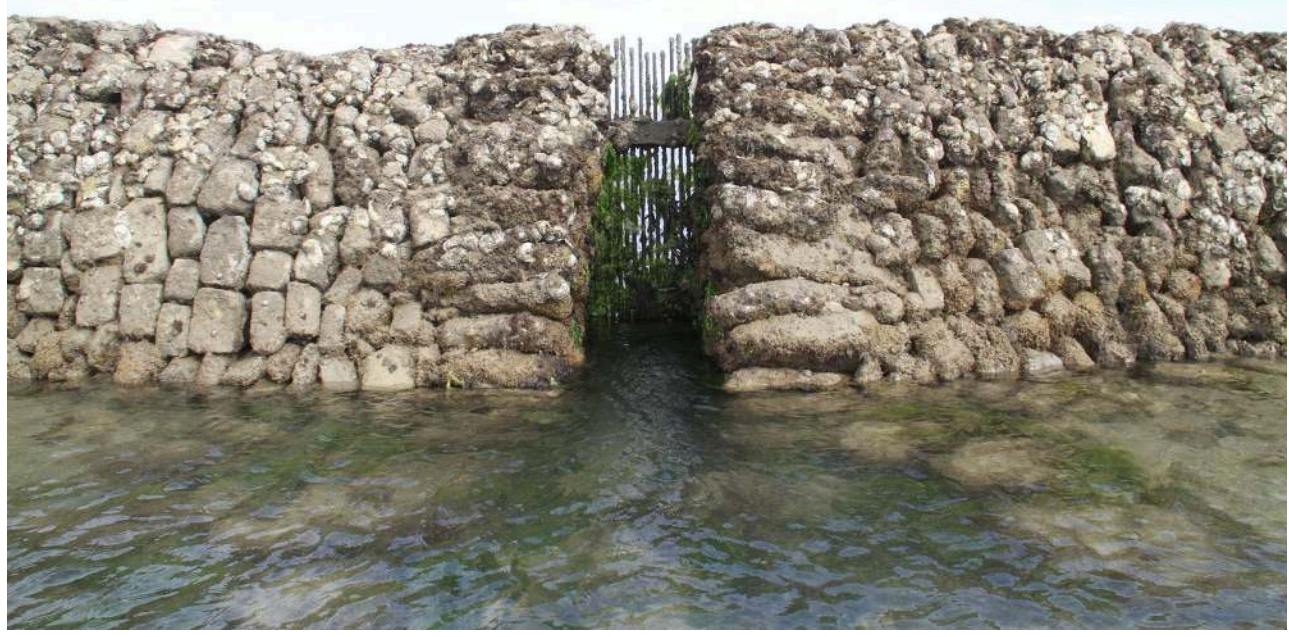

En zone calme, non soumise à la houle du large, la grille en arrière-plan n'a pas besoin d'être protégée. (c) Jacques Boucard.

Fig. 6. - Sainte-Marie-de-Ré (Charente-Maritime), écluse de La Belle-Pointe : détail d'une ouverture, 2017.

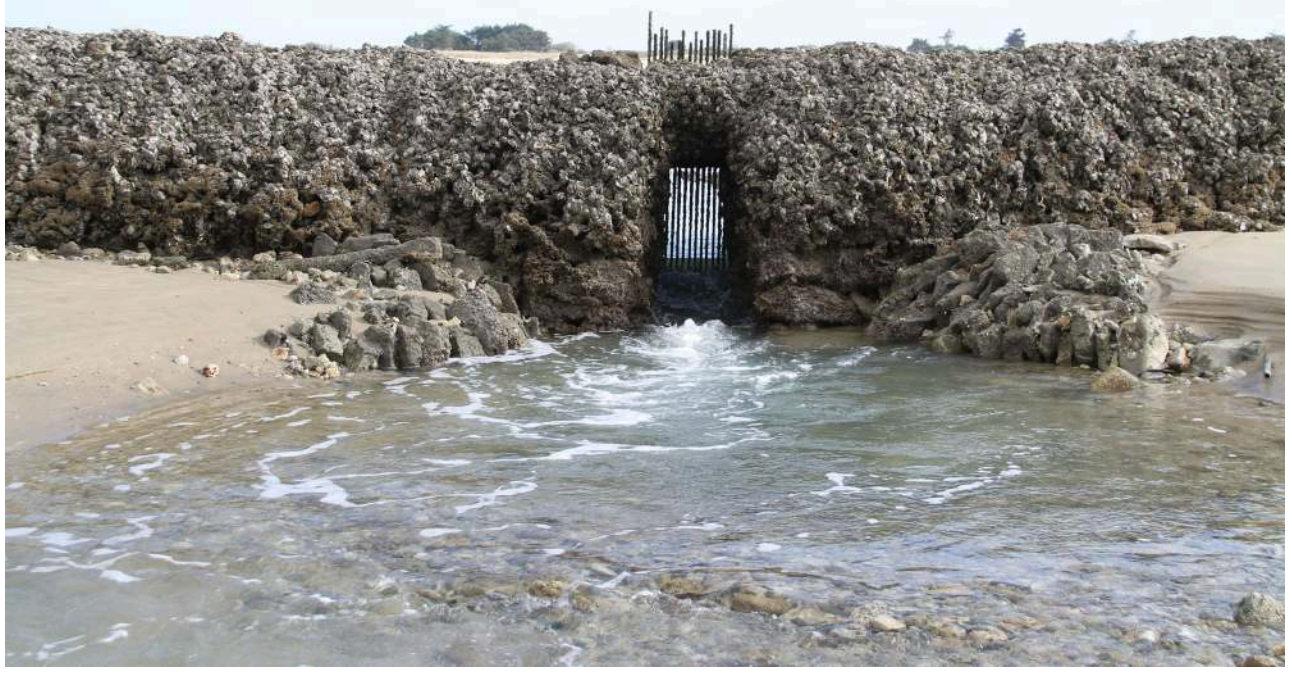

On notera la grille placée en arrière-plan pour ne pas être soumise à la houle.

(c) Jacques Boucard.

Passages et grilles sont des points fragiles qu'il faut particulièrement protéger. On doit, tout d'abord, arrêter le mur, formé d'une voûte, par un mur perpendiculaire formé de larges pierres plates que l'on place horizontalement et qu'il faut soigneusement 
raccorder au mur existant. Si l'ouverture est exposée aux houles d'ouest, on élargit le mur (jusqu'à dix mètres à la base) et on forme un véritable tunnel, peu élevé, avec une grille placée en retrait à l'intérieur.

La construction d'une pêcherie demande de transporter, puis de bâtir, un volume de pierres considérable. Pour en donner une idée, nous pouvons estimer le volume de quelques murs pour lesquels nous avons des données précises:

- Le Grand-Nouron (Ars) : section du mur : dans la fonte, 2,60 m de haut, $9 \mathrm{~m}$ de large ; bras : on revient à 3-4 $\mathrm{m}$ de large pour l'un et 4-5 $\mathrm{m}$ de large pour l'autre; longueur du mur: environ $700 \mathrm{~m}$; volume du mur : environ $4400 \mathrm{~m}^{3}$.

- La Fontaine (Le Bois) : section de la fonte : 2,20 m de haut, entre 3,50 et $4 \mathrm{~m}$ à la base ; $1 \mathrm{~km}$ de tour, pour $500 \mathrm{~m}$ d'ouverture; volume du mur : environ $3300 \mathrm{~m}^{3}$.

- La Belle-Vanne (Sainte-Marie): longueur du mur: environ $600 \mathrm{~m}$; section de la fonte: 2,80 $\mathrm{m}$ de haut, 3 à 3,50 $\mathrm{m}$ à la base ; volume du mur : environ $2100 \mathrm{~m}^{3}$.

La période de construction, ou d'importantes réparations, allait de la mi-mars, fin des labours d'hiver, à la mi-juin, début des travaux d'été, plus rarement d'octobre (fin des vendanges) à l'hiver. Le carnet de construction du Pas-des-Bœufs (Le Bois) - le seul retrouvé -, en 1869, permet de connaître exactement la durée de la construction. Les travaux ont commencé mi-septembre pour se terminer mi-février, soit 101 jours. En général, on n'a pas travaillé pendant les marées de mort d'eaux (les plus faibles coefficients de marée). La construction a demandé : 1605 marées-homme, 890 maréesfemme, 842 marées-charrette et 2 marées-bateau, ce qui correspond à environ 13000 heures.

Élevés sans chaux ni ciment, seulement à pierres jointives, les murs nécessitent une surveillance et un entretien constant. Aussi chacun, lorsqu'il a terminé sa pêche, doit faire le tour de l'ouvrage, une fois à l'intérieur, une fois à l'extérieur, consolider immédiatement les pierres qui bougent et remettre la - ou les - pierre(s) partie(s), amorce d'une plus grande brèche qui peut se former très vite si le temps est mauvais.

"Quand le temps est calme, il ne se passe rien - ou il ne devrait rien se passer mais le jour où il fait mauvais, c'est autre chose ! [...] Les grandes brèches, c'est rare, c'est que l'on n'a pas fait la réparation à temps. L'hiver il y a toujours des brèches, mais des petites que l'on répare en une ou deux marées. Si les réparations sont plus importantes, c'est la communauté entière qui décide des réparations ${ }^{20}$. »

41 Dans ce cas, le chef d'écluse convoque toute la communauté, valide les travaux à réaliser, les suit et note les temps de présence de chaque détenteur (en marées) pour avoir une contribution parfaitement égalitaire.

La menace d'une brèche est très grave pour les écluses neuves et les écluses basses (loin en mer). Pour une pêcherie fraîchement bâtie, les pierres ne sont pas encore parfaitement stabilisées par la houle, et balanes et petites huîtres n'ont pas encore lié les pierres ; une brèche importante peut se produire très vite, en une marée ou deux. Il faut donc la réparer le plus rapidement possible. Pour les écluses basses, le problème concerne les brèches qui se forment pendant les marées de faible coefficient, au moment du mort d'eau, quand les murs ne découvrent pas, ou peu. Mais, heureusement, à ce moment-là, il y a souvent beaucoup d'eau au-dessus du mur et la houle heurte moins la structure (fig. 7). 
Fig. 7. - Travaux de réparation d'une brèche sur la Paillarde (Sainte-Marie-de-Ré, CharenteMaritime), janvier 2014.

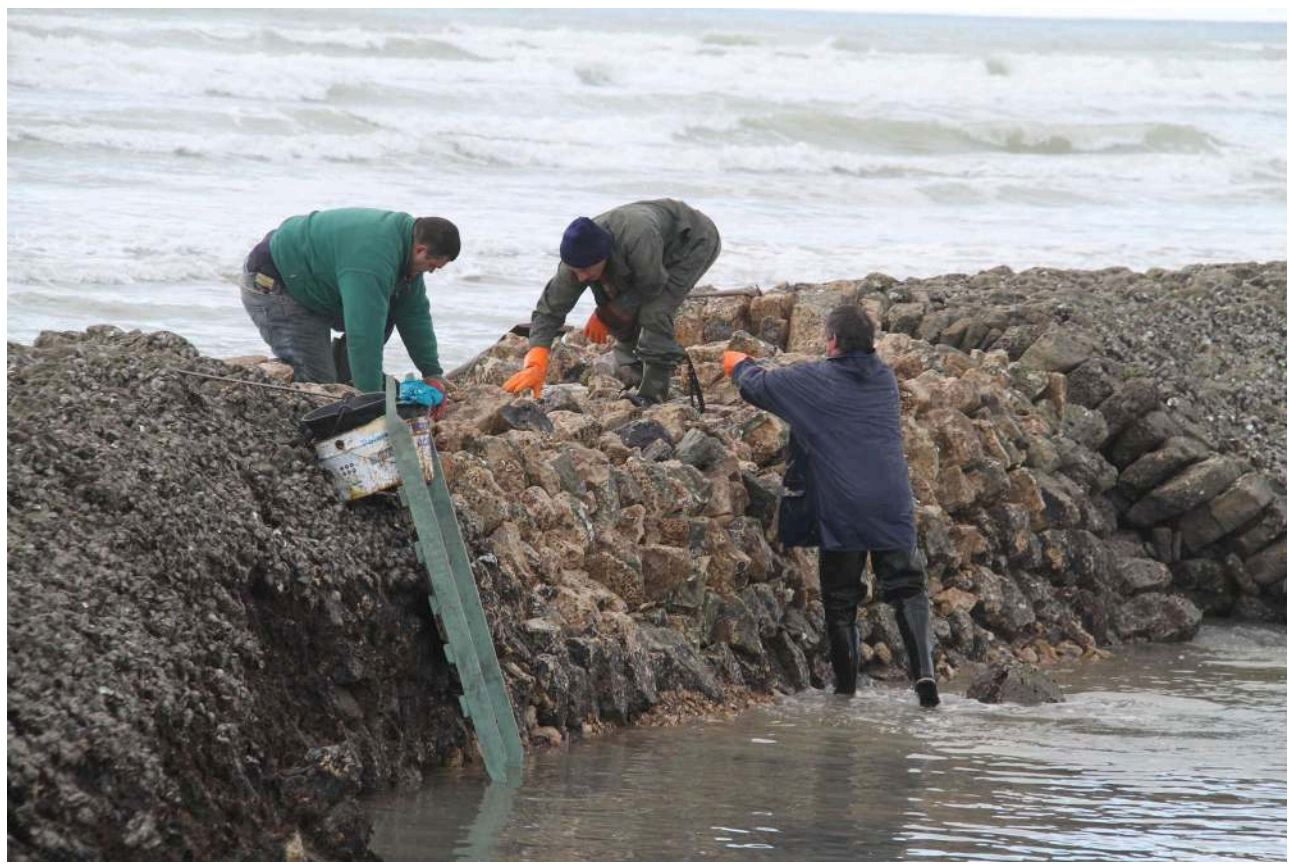

(c) Jacques Boucard.

\section{Un savoir-faire qui disparaît lentement et de façon inéluctable}

Pendant plusieurs siècles, les écluses ont permis de nourrir une partie importante de la population insulaire, plus de la moitié de son village, estime le maire d'Ars en 1853. Aujourd'hui, les dernières sont en voie de disparition: il n'en reste plus que 14 à l'échelle de l'île, contre 68 recensées en 1968 et plus de 140 dans les années 1870.

En 1992, quelques passionnés se sont regroupés en association ${ }^{21}$ pour sensibiliser le public et les élus à l'intérêt patrimonial de ces ouvrages et participer à leur maintien en apportant une aide lors des réparations. Une première pêcherie a été reconstruite à Sainte-Marie-de-Ré, la Belle-Pointe, une autre à Loix, la Verdonnais, et d'importants chantiers ont été engagés avec des résultats contrastés. En effet, si les interventions ont été efficaces pour réparer des brèches de taille moyenne, la perte d'une partie du savoir-faire qu'il faut essayer de réapprendre peut entraîner de lourdes déconvenues. Ainsi, l'écluse de Mouffet, qui a subi d'énormes brèches en décembre 1999 (250 mètres pour un mur de 884 mètres enclosant 6,86 hectares) a demandé 4000 heures de travail et, en 2015, après les tempêtes de janvier 2014, qui avaient ébranlé la structure, ce ne sont pas moins de 400 mètres de murs qui se sont écroulés début 2015. En juillet 2018, malgré 6000 heures d'intervention, le chantier n'est pas terminé et les bonnes volontés sont un peu découragées.

Ces ouvrages séculaires, témoins d'une société de paysans de la mer, étaient parfaitement adaptés à la vie insulaire. Pendant des siècles, ils ont permis de nourrir une population très nombreuse, vivant sur un petit territoire. Mais ils ne correspondent plus aux besoins de la vie actuelle. De nouveaux modes de vie, des 
contraintes qui paraissent aujourd'hui trop lourdes pour une maigre pêche et une pression touristique accrue, peu respectueuse de ces ouvrages qu'ils ne connaissent pas, ont incité les derniers détenteurs à abandonner peu à peu les écluses qu'ils exploitaient. Chaque tempête occasionne des brèches dans les dernières pêcheries; certaines ne seront pas réparées. Ainsi, au fil des ans, une à une, les dernières écluses disparaissent, entraînant la perte irrémédiable d'une culture maritime parfaitement adaptée au monde insulaire, mais encore très mal connue.

\section{BIBLIOGRAPHIE}

BORDEREAUX L., DEBANDE B., DESSE-BERSET N., SAUZEAU T., 2009, Les écluses à poissons d'Oléron, mémoire de pierre, La Crêche, Geste éditions.

BOUCARD J., 1984, Les écluses à poissons dans l'île de Ré, La Rochelle, Éditions Rupella.

BOUCARD J., 2017, «Le Moyen Âge : les fondements d'une société insulaire », dans Augeron M., Boucard J., Even P. (dir.), Histoire de l'île de Ré des origines à nos jours, Saintes, Le Croît Vif, p. 31-111. BURON G., 1992, « Sur quelques toponymes nautiques de Piriac (IV) », Pen Piriak, n 55, $2^{\mathrm{e}}$ trimestre, p. 20-25.

LIEPPE D. (éd.), 2009, Pêches et pêcheurs du domaine maritime et des îles adjacentes de Saintonge, d'Aunis et du Poitou au XVIII siècle : procès verbaux des visites faites concernant la pesche dans le ressort des amirautés de Marennes, de La Rochelle et des Sables d'Olonne en 1727 et en 1728 par François Le Masson Du Parc, Rochefort-sur-Mer, Observatoire européen de l'Estran / Saint-Quentin-de-Baron, Éd. de l'Entre-deux-mers.

VALIN R.-J., 1766, Nouveau commentaire sur l'ordonnance de la Marine du mois d'août 1681, La Rochelle, chez Jérôme Leguier, imprimeur du Roi, au canton des Flamands, 2 vol.

\section{NOTES}

1. Buron $1992: 20-25$.

2. Arch. nat., carton P 2145, $2^{\mathrm{e}}$ liasse, cité par Boucard 2017 : 63-73.

3. Arch. nat., 1 AP 1999, Chartrier de Thouars, comptes du receveur de la seigneurie de l'île de Ré pour les années 1408 à 1410.

4. Arch. dép. Charente-Maritime, Intendance C 39-16, « Procès-verbal de présentation des titres de propriété des écluses, suite aux arrêts du conseil de 1737 » cité par Bordereaux et al. $2009: 23$, n. 25.

5. Lieppe 2009 : 93-106.

6. Boucard 1984 :123. 
7. Magayant / magayante: terme sur Ré désignant, au XIX siècle, un paysan pêchant beaucoup sur l'estran, mais plus généralement un aussi bon paysan(ne) que pêcheur (à pied).

8. Valin 1766, vol. 2, liv. V, titre III, «Des Parcs \& pêcheries ", art. V : 727. Remi est l'un des patrons catholiques de l'archidiocèse de Reims; dans ce diocèse, il est fêté le $1^{\text {er }}$ octobre, conformément à une tradition remontant au $\mathrm{VI}^{\mathrm{e}}$ siècle. Ailleurs en France, il est fêté le 15 janvier et est inscrit le 13 janvier au martyrologe romain. Le commentaire de R.-J. Valin sur cet article s'appuie sur la date du $1^{\mathrm{er}}$ octobre.

9. Arch. dép. Charente-Maritime, B 2153, Justice seigneuriale d'Ars, «Registre des audiences extraordinaires 1784-1787 », audience du 24 octobre 1785.

10. Arch. dép. Charente-Maritime, B 5634, note du 13 août 1720.

11. Enquête de l'auteur auprès d'Anthony Guilbeau, l'un des derniers grands bâtisseurs d'écluses, Sainte-Marie-de-Ré, 1980.

12. Arch. dép. Charente-Maritime, B 5635, «État des parcs et pêcheries de l'isle de Ré », 1752.

13. L'" État des écluses autorisées pour le quartier de l'île de Ré », 1855, existait dans les archives de la direction départementale de l'Équipement, subdivision de l'île de Ré, Ars, en 1980 où nous l'avons consulté. Lors de la suppression de cette subdivision, en 2005, l'ensemble des archives a été détruit.

14. Le boyard : à rapprocher du bayart en usage dans les ports au $\mathrm{XVI}^{\mathrm{e}}$ siècle : P.-É. Littré, Dictionnaire de la langue française, Chicago, Encyclopaedia Britannica Inc., 1978, vol. 1 : 476.

15. Balane commune (Balanus perforatus) : petit crustacé se fixant sur les pierres, très fréquent sur les zones côtières des régions tempérées chaudes de l'océan Atlantique, appelé rougne dans le langage vernaculaire de l'île de Ré.

16. Boucard $1984: 166$.

17. Enquête de l'auteur auprès de Jeanne Cordon, épouse de Marcel Cordon, SainteMarie-de-Ré, 2017.

18. Boucard $1984: 166$.

19. Ibid. : 172 .

20. Ibid. : 200.

21. ADEPIR, Association de défense des écluses à poissons de l'île de Ré.

\section{RÉSUMÉS}

À partir du XIVe siècle, le littoral rétais se couvre de grandes pêcheries collectives, en pierre, appelées localement écluses. À la fin du XIX ${ }^{e}$ siècle, ce ne sont pas moins de 140 ouvrages emprisonnant plus de 500 hectares qui assurent entre le tiers et la moitié de la consommation insulaire. D'une longueur variant de cinq cents mètres à un kilomètre, les murs construits sans aucun liant, seulement en pierres sèches, sont capables de résister aux tempêtes d'hiver. Leur 
construction particulièrement complexe nécessite un savoir-faire très pointu, qui était transmis de génération en génération, et un long apprentissage pour devenir un bon bâtisseur. La disparition des écluses témoigne de la perte irrémédiable d'une culture maritime parfaitement adaptée au monde insulaire, mais cependant très mal connue.

INDEX

Mots-clés : pêcherie en pierre, pêcherie collective, écluse, technique, construction, île, pêche, population littorale, insulaire

Index géographique : île de Ré

\section{AUTEUR}

JACQUES BOUCARD

Docteur en histoire moderne, membre du Groupement d'études rétaises 


\title{
Les éléments de colonnes en pierre de l'oppidum de Bibracte (mont Beuvray, Bourgogne-Franche- Comté) : un savoir-faire local appliqué à un édifice romain $d u$ milieu du $\mathrm{I}^{\mathrm{er}}$ siècle avant J.-C.
}

\author{
Florent Delencre et Jean-Pierre Garcia
}

1 Le thème "transmission des savoirs " peut particulièrement bien s'appliquer aux matériaux de construction, qui appartiennent pleinement au discours de caractérisation des sites archéologiques, ainsi qu'en témoignent les nombreuses études menées sur le sujet depuis plusieurs décennies. Ainsi, ces matériaux sont souvent évoqués à travers la recherche des provenances géologiques, la mise en évidence des circuits d'approvisionnements nécessaires au chantier de construction, ou encore la définition des propriétés intrinsèques des roches pour leur mise en forme et en œuvre.

2 Ces questions se posent notamment avec l'apparition et la diffusion des matériaux de construction romains dans le nord-est de la Gaule, pour lesquels il est également nécessaire de développer leur place en tant que marqueurs culturels et identitaires ${ }^{1}$. En effet, ces matériaux produits à partir de ressources naturelles se posent également comme témoins des relations interculturelles entre le monde méditerranéen et les divers peuples gaulois, avant et après la conquête romaine.

Il apparaît clairement que la monumentalisation et la pétrification des villes, principalement dans les premières décennies $d u \mathrm{I}^{\mathrm{er}}$ siècle après $\mathrm{J} . \mathrm{C}$., mais également avant, sont liées sans conteste à des changements dans la conception des bâtiments. Les modes de construction considérés comme gaulois, employant des ressources périssables tels que le bois, le chaume ou encore la terre crue, sont progressivement remplacés par, ou parfois mis en œuvre conjointement avec de nouvelles formes 
architecturales où les matériaux font notamment appel à la pierre et à la terre cuite. Ainsi, l'espace exploité pour les chantiers de construction est mobilisé différemment, avec l'ouverture de carrières d'extraction pour la pierre et l'argile nécessaires à la production des matériaux.

4 De fait, l'oppidum de Bibracte s'avère particulièrement important, puisque son occupation à un moment charnière de l'histoire des Gaules permet d'observer la « romanisation» des matériaux de construction à partir des stratigraphies et des vestiges immobiliers conservés sur le site.

\section{Des matériaux uniques : les éléments de colonnes en pierre de l'oppidum de Bibracte}

5 Cet oppidum, implanté sur le mont Beuvray, est le chef-lieu du territoire des Éduens durant la période gauloise, avant d'être abandonné progressivement au début de notre ère suite au transfert du statut de capitale à Autun / Augustodunum, comme en témoignent les phases d'occupation les plus récentes du site ${ }^{2}$. Le territoire de ce peuple gaulois, vaste et centré sur le Morvan, se trouve donc géographiquement à un carrefour stratégique pour les routes commerciales (fig. 1), en raison notamment de la présence de trois bassins versants d'importance (la Loire au sud, la Seine et l'Yonne au nord et la Saône à l'est), qui ont été parcourus par les marchands romains pour transporter leurs produits vers le nord de la Gaule. De ce fait, les Éduens sont un peuple riche et puissant, et ils ont su lier des contacts privilégiés avec le monde romain. Cette proximité se traduit notamment par le titre fratres consanguineique (frères de même sang) attribué par le Sénat romain dès le milieu du $\mathrm{II}^{\mathrm{e}}$ siècle avant $\mathrm{J}$.-C. et la rencontre, peu avant la Guerre des Gaules, entre un vergobret ${ }^{3}$ et le sénateur romain Cicéron ${ }^{4}$. 
Fig. 1. - Oppidum de Bibracte (mont Beuvray, Bourgogne-Franche-Comté) : localisation des matériaux de l'étude.

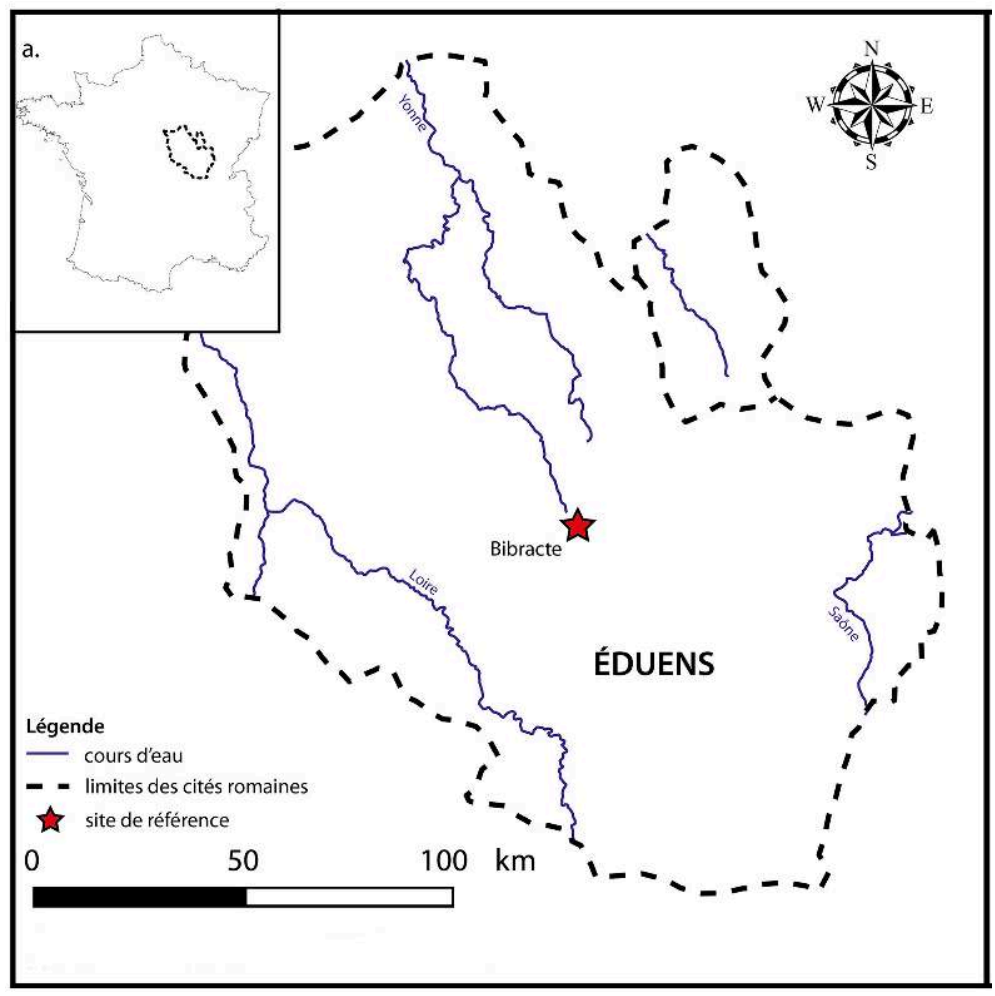

(c) Florent Delencre. Sources : BDCarto, BDCarthage, IGN Paris, MSH Dijon.

6 Le site, établi en hauteur, est entouré de deux remparts monumentaux de type murus gallicus, qui ceinturent une surface de près de 200 hectares pour son extension maximale $^{5}$. À l'intérieur de cette zone délimitée par les fortifications, de très nombreuses structures liées à l'occupation de la ville ont été découvertes (fig. 2). 
Fig. 2. - Oppidum de Bibracte (mont Beuvray, Bourgogne-Franche-Comté) : plan de l'oppidum et localisation des vestiges découverts.

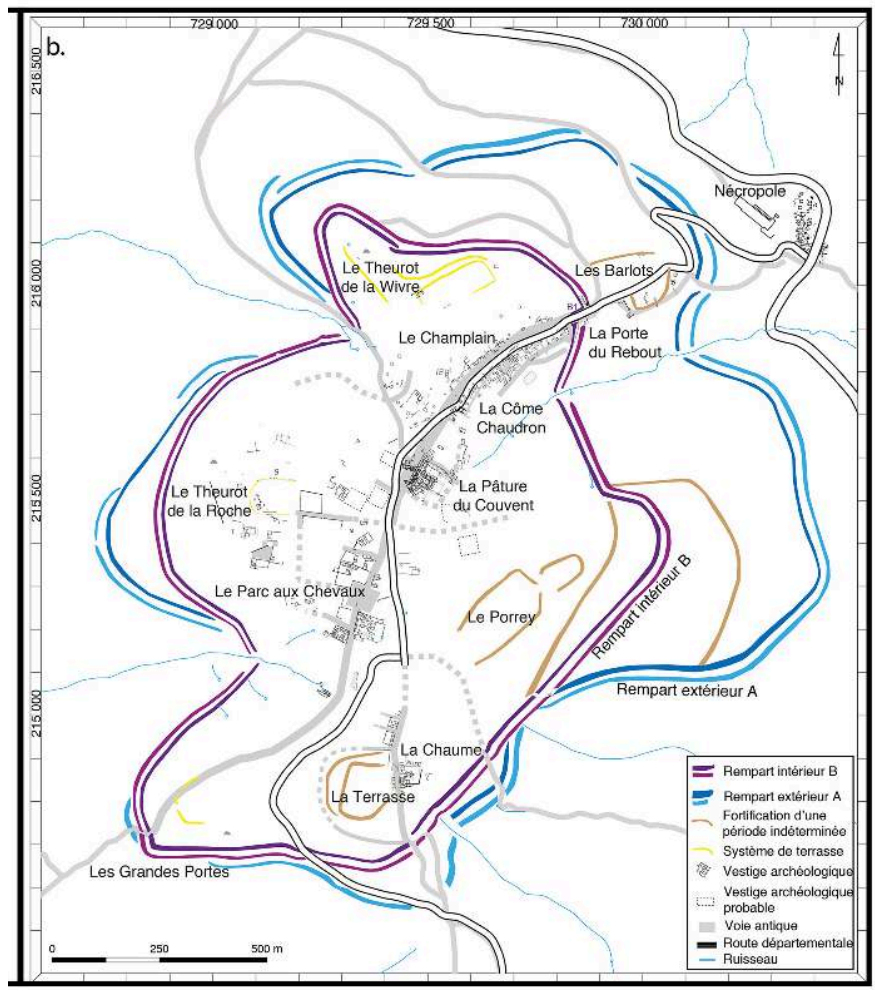

(c) Arnaud Meunier / Bibracte EPCC et Florent Delencre.

7 Les pratiques collectives religieuses, politiques et économiques sont ainsi bien représentées à l'intérieur du site, en différents points de l'oppidum, ainsi que l'artisanat métallurgique et l'habitat privé. Tous ces édifices présentent des modes de construction très variés; les bâtiments concernés peuvent être édifiés en terre et bois, quand certaines maisons mettent en œuvre les matériaux classiques du monde méditerranéen. Pour ces dernières, les plans des structures ainsi que le soin et les innovations apportées à la construction permettent même de les cataloguer comme de véritables domus de type italique ${ }^{6}$.

La fouille des vestiges de l'oppidum a ainsi permis la mise en évidence de l'emploi de matériaux de construction et de couverture romains sur de nombreux bâtiments, parmi lesquels les éléments de colonnes en pierre. La quasi-totalité des éléments découverts dès 1989 sur les différents chantiers de fouilles au lieu-dit La Pâture du Couvent ${ }^{7}$ est trouvée autour du lieu principal de mise en œuvre, un édifice à plan basilical (fig. 3). L'interprétation première de ce bâtiment en tant que basilique civile ${ }^{8}$, bien que très discutée ${ }^{9}$, repose principalement sur le plan des vestiges immobiliers, la monumentalité incontestable du bâtiment et la précocité des modes de construction méditerranéens. En l'absence de corpus épigraphiques et des bâtiments caractéristiques confirmant la présence d'un forum tripartite sur cet oppidum, la question de l'intégration des modèles romains dans les institutions politiques éduennes reste posée. 
Fig. 3. - Oppidum de Bibracte (mont Beuvray, Bourgogne-Franche-Comté), édifice à plan basilical de La Pâture du Couvent : éléments de colonnes en pierre découverts à proximité de leur lieu de mise en œuvre.

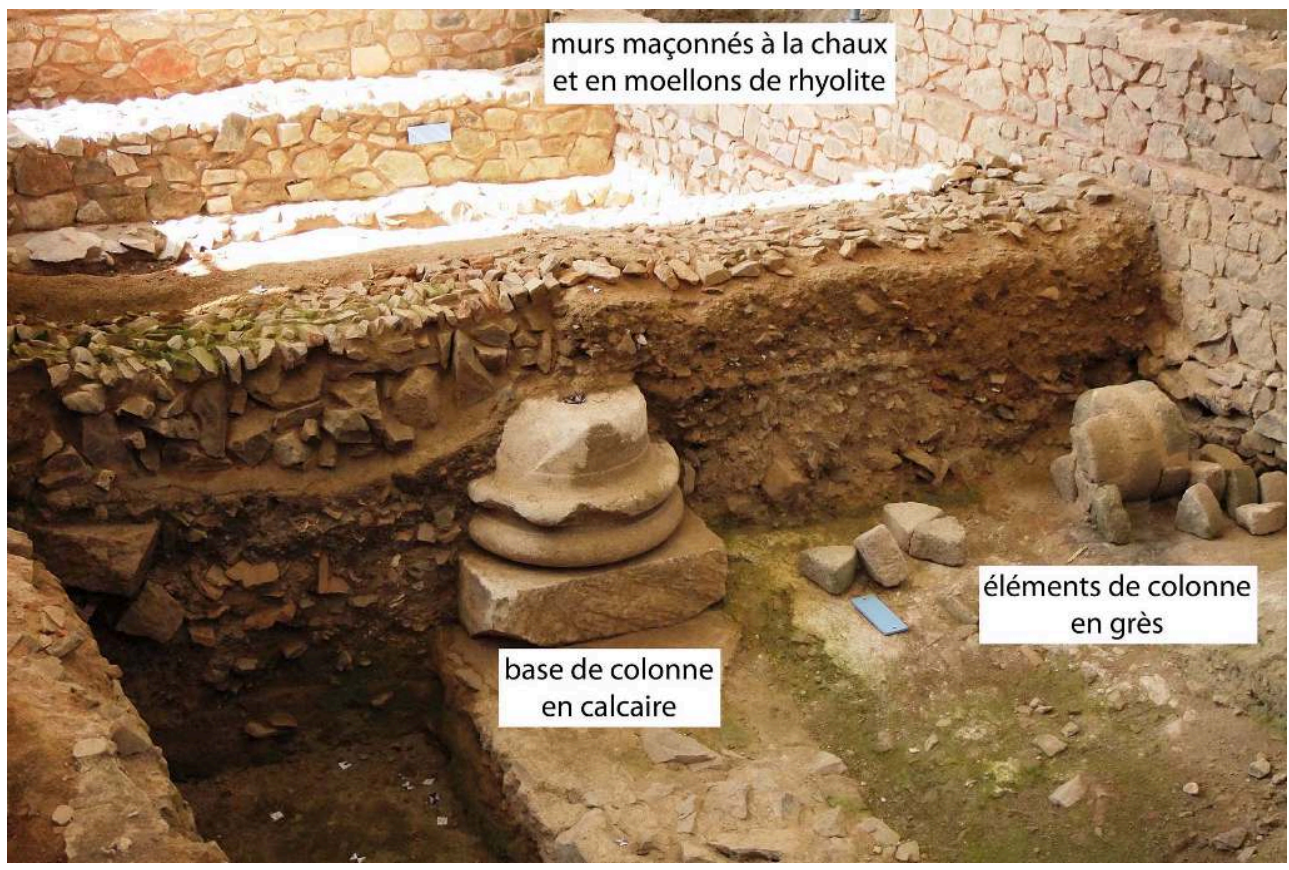

(c) Florent Delencre 2011.

9 Les fouilles archéologiques ont permis de dater la construction de ce bâtiment précoce entre 50 et 30 avant $\mathrm{J}$.-C., un édifice qui est très rapidement détruit et remplacé par une domus dès le début de la période augustéenne ${ }^{10}$. Une grande diversité de mise en œuvre des matériaux existe pour ce premier bâtiment aux maçonneries de pierres liées à la chaux, couvert de tuiles, faisant appel notamment à des normes romaines pour sa conception. Ainsi, ce bâtiment possède une parure monumentale qui est clairement restituable à partir des éléments architecturaux découverts, dont des colonnes de hauteur variable.

Les éléments en pierre constituant les fûts de ces colonnes ont différentes formes, puisqu'il s'agit en effet soit de quarts, soit, pour le cas le plus majoritaire, de sixièmes de disques en pierre de diverses natures lithologiques. Plusieurs éléments sont associés pour former une assise de 15 à 20 centimètres d'épaisseur, pour une colonne d'une hauteur maximale restituable de 5,40 mètres en incluant base et chapiteau. Tous ces éléments sont liés entre eux et en quinconce avec un mortier de chaux, et des traces sur les parties externes montrent la présence d'un enduit à la chaux.

\section{Caractérisation pétrographique et morphométrique}

11 La constitution d'un corpus important de 1331 objets, accompagné de la conservation quasi exhaustive de ces éléments en contexte ou non, permet donc ainsi de comprendre leur mise en œuvre, mais nécessite aussi de caractériser finement leur nature lithologique et leur forme à partir de déterminations et de mesures fiables.

12 L'étude de ces éléments s'est effectuée en deux temps. Tout d'abord, la reconnaissance macroscopique des roches permet de les classer en deux catégories: les roches 
magmatiques plutoniques (les granites) et les roches sédimentaires détritiques silicoclastiques (les grès). Ensuite, tout un ensemble de mesures ont été prises sur ces objets pour caractériser leur forme : hauteur de l'assise, côtés, détermination du rayon à partir de l'arc de courbure externe, etc.

\section{Détermination pétrographique des éléments de colonnes}

13 En ce qui concerne les granites (fig. $4 \mathrm{a}$ à $4 \mathrm{~d}$ ), quatre faciès se déclinent en fonction de la texture et/ou de la composition minéralogique des pierres. Ils ont été nommés selon leur aspect général, principalement leur couleur ${ }^{11}$, mais cette dernière ne constitue pas un critère déterminant pour différencier ces pierres; il s'agit tout au plus d'une commodité de langage $\mathrm{e}^{12}$.

Fig. 4. - Oppidum de Bibracte (mont Beuvray, Bourgogne-Franche-Comté), référentiel pétrographique des éléments de colonnes.

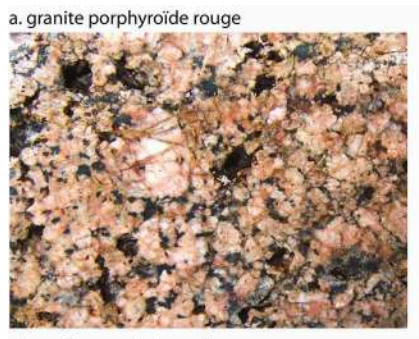

d. granite rose à deux micas

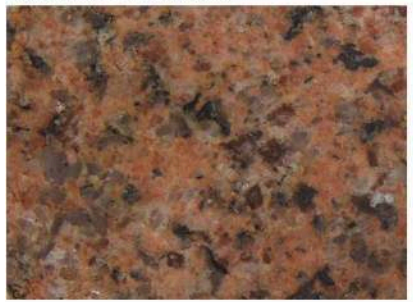

g. grès feldspathique à grains hétérométriques

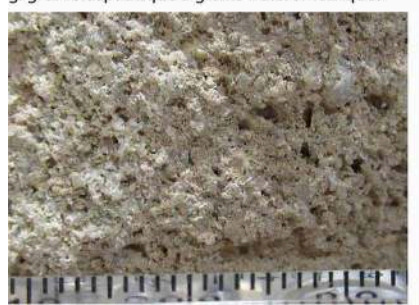

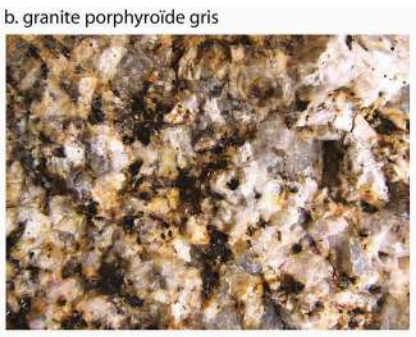

e. grès feldspathique à grains moyens

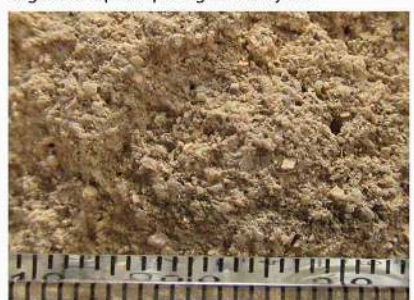

h. grès vacuolaire à grains grossiers

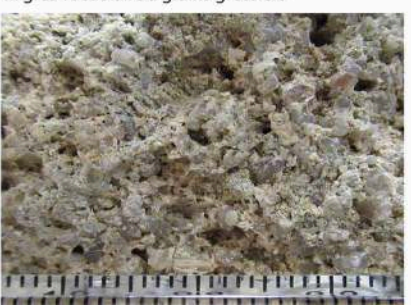

c. granite blanc

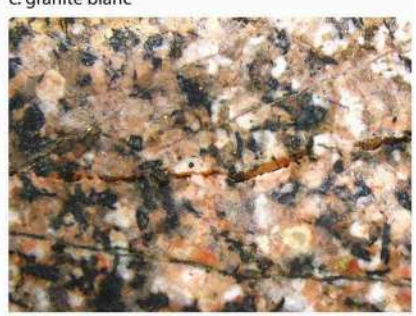

f. grès feldspathique à grains grossiers

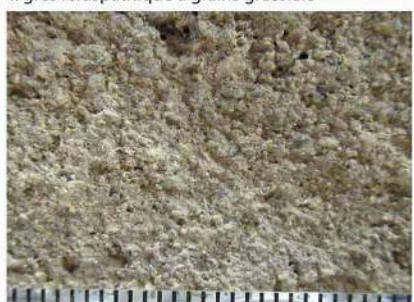

i. grès à muscovite

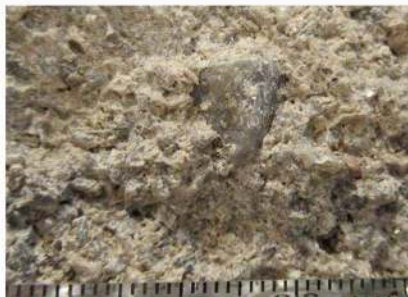

A : granite porphyroïde rouge. $\mathbf{B}$ : granite porphyroïde gris. $\mathbf{C}$ : granite blanc. $\mathbf{D}$ : granite rose à deux micas. $\mathbf{E}$ : grès feldspathique à grains moyens. $\mathbf{F}$ : grès feldspathique à grains grossiers. $\mathbf{g}$ : grès feldspathique à grains hétérométriques. $\mathbf{H}$ : grès vacuolaire à grains grossiers. $\mathbf{I}$ : grès à muscovite.

(c) Florent Delencre 2017, 2018.

Parmi les éléments en granite constituant les fûts des colonnes de l'édifice à plan basilical, il est possible de caractériser le "granite rose à deux micas» associant des grains de quartz, de feldspath, de biotite et de muscovite. Le deuxième faciès, appelé "granite porphyroïde gris ", se définit par une texture porphyroïde en raison de la présence de phénocristaux de feldspaths pluri-centimétriques. Le "granite porphyroïde rouge » est tout à fait semblable au précédent et ne s'en distingue que par la couleur. Enfin, le dernier faciès correspond au "granite blanc » se caractérisant par sa forte proportion en micas et par des minéraux de taille relativement homogène. 
Tous les éléments en grès sont issus d'affleurements d'âge triasique liés à l'altération des roches granitiques et métamorphiques du socle varisque (fig. 4e à 4i). Là encore, plusieurs faciès peuvent être distingués, qui sont fonction notamment de la granulométrie des constituants et de leur nature pétrographique.

Les premiers faciès définis appartiennent à la catégorie des grès feldspathiques à grains homométriques, se caractérisant par des grains majoritairement de quartz et de feldspath de taille identique. Les faciès constituant cette catégorie sont ainsi nommés en fonction de la taille principale des constituants (grès feldspathique à grains moyens, grès feldspathique à grains grossiers, grès feldspathique conglomératique).

17 Les grès feldspathiques à grains hétérométriques correspondent à des roches à matrice de grains de sable moyen, dans laquelle des quartz plurimillimétriques (sables grossiers à graviers) sont présents en abondance.

18 La catégorie des grès vacuolaires regroupe les roches dont les éléments sont liés par un ciment primaire blanc qui se caractérise par la présence de barytine, en cristallisations secondaires dans la porosité intragranulaire. Les nombreuses vacuoles semblent être dues à la dissolution postérieure de ce minéral.

19 Enfin, la dernière catégorie concerne les grès à muscovite, sans autres minéraux particuliers et quelle que soit la taille des constituants.

20 Sur l'ensemble du corpus des 1331 individus (fig. 5), les différents faciès des grès sont mieux représentés $(78 \%)$ que ceux des granites (22 \%).

Fig. 5. - Oppidum de Bibracte (mont Beuvray, Bourgogne-Franche-Comté) : représentativité des faciès lithologiques déterminés pour les éléments de colonnes.

\begin{tabular}{|c|c|c|}
\hline \multirow{4}{*}{ granite $(\mathbf{2 2} \%)$} & granite rose à deux micas $(\mathbf{2 1} \%)$ & \\
\hline & granite blanc (<1\%) & \\
\hline & granite porphyroïde rouge $(<1 \%)$ & \\
\hline & granite porphyroïde gris $(<1 \%)$ & \\
\hline \multirow{9}{*}{ grès $(78 \%)$} & \multirow{5}{*}{ grès feldspathiques à grains homogènes ( 39 \%) } & grès feldspathiques à grains fins (< $1 \%)$ \\
\hline & & grès feldspathiques à grains moyens $(19 \%)$ \\
\hline & & grès feldspathiques à grains grossiers (17\%) \\
\hline & & grès feldspathiques à grains grossiers et à éléments conglomératiques (2 \%) \\
\hline & & grès feldspathiques conglomératiques $(<1 \%)$ \\
\hline & grès feldspathiques à grains hétérométriques (13\%) & \\
\hline & \multirow{2}{*}{ grès vacuolaires ( $14 \%$ ) } & grès vacuolaires à grains grossiers $(\mathbf{1 2} \%)$ \\
\hline & & grès vaculaires à grains hétérométriques $(2 \%)$ \\
\hline & grès à muscovite $(12 \%)$ & \\
\hline
\end{tabular}

(c) Florent Delencre.

21 À l'intérieur de la population des éléments en granite, la grande majorité des blocs est en granite rose à deux micas, soit $21 \%$. Les autres faciès de granite sont très largement minoritaires et représentent respectivement chacun moins de $1 \%$ de l'ensemble des éléments de colonnes en pierre.

22 En ce qui concerne les grès, la catégorie des grès feldspathiques à grains homométriques regroupe le plus grand nombre d'individus ( $39 \%$ du corpus total), parmi lesquels ressortent en particulier les grès feldspathiques à grains moyens (19\%) et les grès feldspathiques à grains grossiers (17\%). Les autres faciès de cette catégorie restent, quant à eux, très minoritaires. La catégorie des grès vacuolaires correspond à $14 \%$ de l'ensemble du corpus (le faciès à grains grossiers étant majoritaire), celle des 
grès feldspathiques à grains hétérométriques rassemble $13 \%$ et, pour finir, les grès à muscovite concernent $12 \%$ des éléments de colonnes.

Trois ensembles se dessinent par la mobilisation du corpus total de ces différents faciès utilisés pour façonner ces matériaux de construction. Le premier ensemble correspond aux faciès privilégiés pour le façonnage des éléments de colonnes, c'est-à-dire ceux qui individuellement constituent plus de $15 \%$ du corpus, à savoir le granite rose à deux micas, le grès feldspathique à grains moyens et le grès feldspathique à grains grossiers. Les trois faciès concernés représentent d'ailleurs plus de $50 \%$ des éléments totaux. Le second ensemble s'identifie aux faciès communs qui concernent chacun entre 10 et $15 \%$ des individus. Le dernier ensemble concerne les faciès ponctuels, très minoritaires.

\section{Caractérisation des colonnes par la mesure des éléments}

Le but ici n'est pas de faire la restitution architecturale complète des colonnes de l'édifice à plan basilical, travail mené par ailleurs en prenant en compte les vestiges immobiliers, les charpentes, etc. ${ }^{13}$. Il est significatif de s'intéresser plus particulièrement aux diamètres de ces éléments architectoniques à partir du rayon estimé depuis l'arc de courbure externe de chaque objet, quand ce dernier possède évidemment une taille suffisante pour permettre cette mesure.

Ainsi, sur les 1331 individus constituant le corpus, seuls 603 ont pu être considérés dans l'analyse menée (fig. 6a). Le plus petit diamètre mesuré est de $20,6 \mathrm{~cm}$ et les résultats obtenus sont compris dans l'intervalle défini avec le diamètre le plus grand, qui est de $99,2 \mathrm{~cm}$. Le diamètre moyen est de $45,9 \mathrm{~cm}$, avec une dispersion de $8,5 \mathrm{~cm}$ autour de cette valeur.

Les fragments de bases et de chapiteaux de colonnes découverts lors des fouilles archéologiques, notamment une base entière encore en place dans son contexte stratigraphique, permettent de restituer un diamètre compris entre 40 et $60 \mathrm{~cm}$ pour les fûts ${ }^{14}$. Les deux intervalles définis à partir des éléments de colonnes en pierre et des éléments d'architecture se recoupent donc bien, permettant de donner une première estimation du diamètre moyen de ces colonnes.

27 La représentation graphique par un histogramme de fréquence de la distribution des diamètres de ces éléments de colonnes (fig. 6a) permet d'identifier des modes qui apparaissent distinctement. Il est d'ailleurs intéressant que l'intervalle le plus marqué, qui comptabilise le plus grand nombre d'individus, entre 45 et $45,9 \mathrm{~cm}$, est aussi celui dans lequel se trouve la moyenne des diamètres des éléments de colonnes.

Par ailleurs, il est possible de remarquer que la répartition des diamètres en fonction de la nature pétrographique, granite ou grès, est relativement similaire dans les deux cas, avec des moyennes et des dispersions très proches de celles du corpus total (fig. 6b). Ceci a une implication importante, puisque des éléments de colonnes en granite et en grès peuvent avoir été utilisés de manière indifférenciée dans une même assise. 
Fig. 6. - Oppidum de Bibracte (mont Beuvray, Bourgogne-Franche-Comté) : distribution des diamètres mesurés sur les éléments de colonnes.
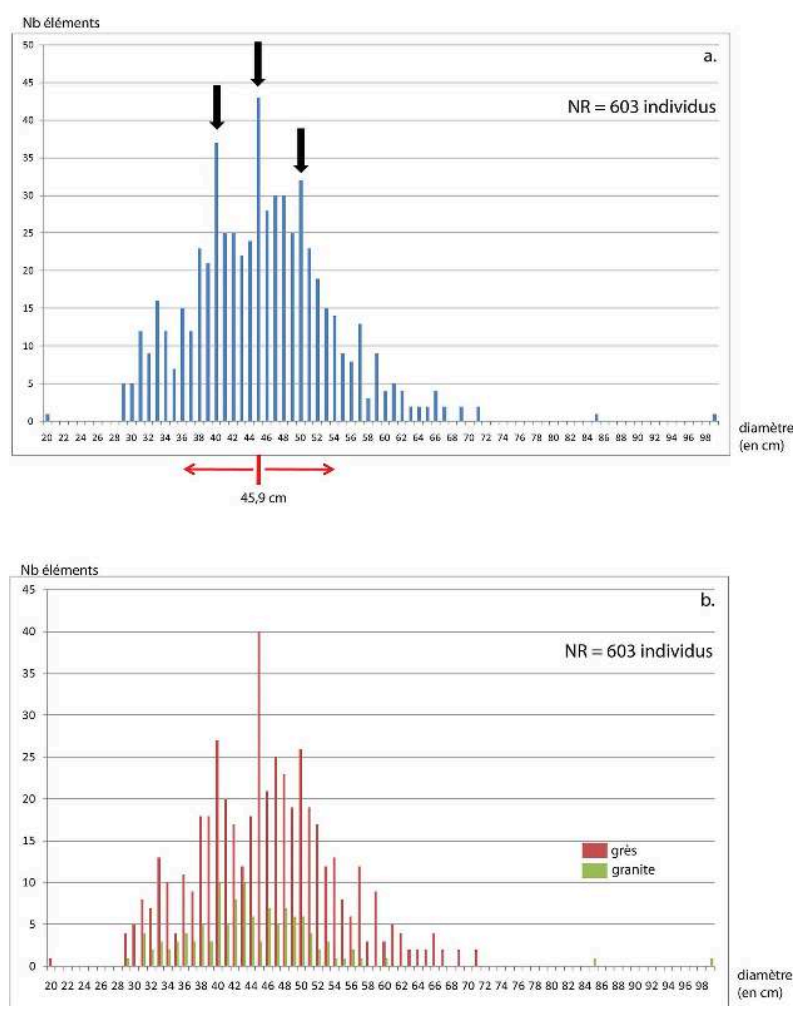

A : corpus total. B : selon la nature lithologique.

(C) Florent Delencre.

\section{Quelques traces observées sur les éléments de colonnes}

De nombreuses traces peuvent être relevées sur la surface des éléments de colonnes. La plupart correspondent au devenir de ces objets au moment de la destruction de l'édifice à plan basilical, avec des marques de chauffe qui sont les traces d'un incendie, mais aussi bien plus tard avec le remploi de ces éléments. Ainsi, le matériau abrasif (peu habituel pour un matériau de construction), avec l'emploi majoritaire du grès, a pu faciliter son remploi en tant qu'aiguisoir pour des outils métalliques.

Par ailleurs, les traces les plus remarquables correspondent à celles liées aux outils qui ont servi à la mise en forme et à la finition de ces objets, dont les empreintes spécifiques permettent de réattribuer les gestes des artisans aux différents moments des chaînes opératoires ${ }^{15}$. Ainsi, certaines empreintes en forme de chevrons se révèlent caractéristiques des pics qui ont permis l'extraction des pièces à l'origine des éléments de colonnes. Toutefois, si les surfaces de chaque élément sont brutes, les parois ont tout de même subi une régularisation assez grossière, qui permet de faire un parallèle avec ce qui peut être habituellement observé pour les outils de mouture ${ }^{16}$. C'est ce que montrent des impacts circulaires, qui peuvent être rapprochés des traces laissées par une broche, tandis que des incisions linéaires ne sont pas sans rappeler l'emploi du ciseau (fig. 7). 
Fig. 7. - Oppidum de Bibracte (mont Beuvray, Bourgogne-Franche-Comté) : traces d'outils observées sur les faces de pose et d'attente des colonnes.

\section{Traces de ciseau}

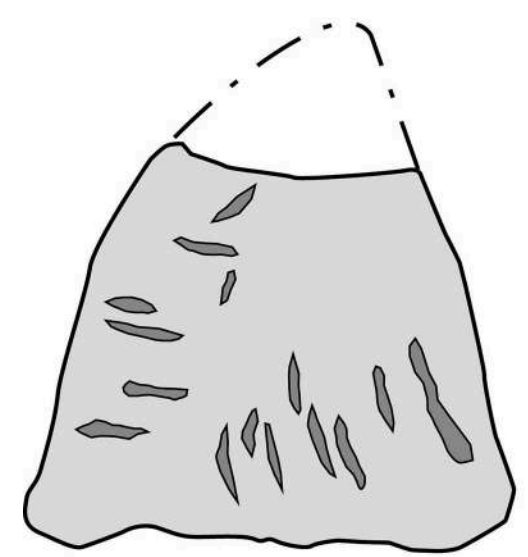

$10 \mathrm{~cm}$

\section{Traces de broche}

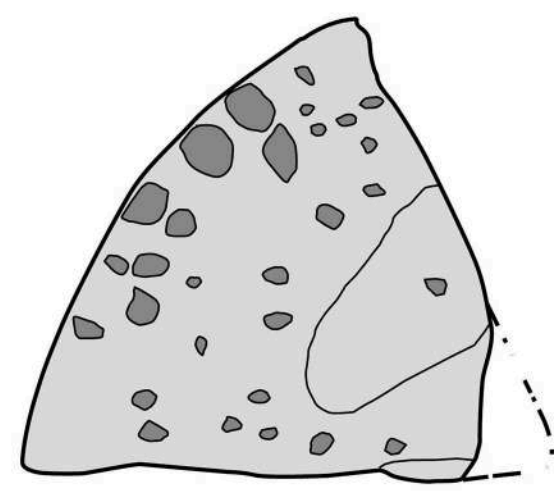

$10 \mathrm{~cm}$

Extrait de Duda 2014 (D.R.).

\section{Production des outils de mouture et éléments de colonnes : l'exaptation d'un savoir-faire}

L'ensemble des analyses présentées montre de prime abord que des liens peuvent être établis entre les éléments de colonnes en pierre et les outils de mouture à Bibracte.

Pour ce qui concerne la production des éléments de colonnes, les ressources lithiques exploitées sont tout à fait distinctes du substrat local du mont Beuvray, constitué principalement par des épanchements volcaniques parsemés d'intrusions filoniennes microgranitiques et microdioritiques qui ont largement été mobilisés pour l'édification des maçonneries de l'oppidum ${ }^{17}$.

Les quatre faciès de granite mobilisés dans la production des éléments de colonnes sont également employés pour les blocs architectoniques de grande dimension (comme les emmarchements et les chaînages d'angle), ou encore pour les blocs de moyen appareil d'un bassin monumental. Ces différents faciès de granites se succèdent à l'affleurement sur près de 5 kilomètres (fig. 8), à l'est du mont Beuvray ${ }^{18}$. 
Fig. 8. - Oppidum de Bibracte (mont Beuvray, Bourgogne-Franche-Comté), provenance des natures pétrographiques mobilisées pour les colonnes.

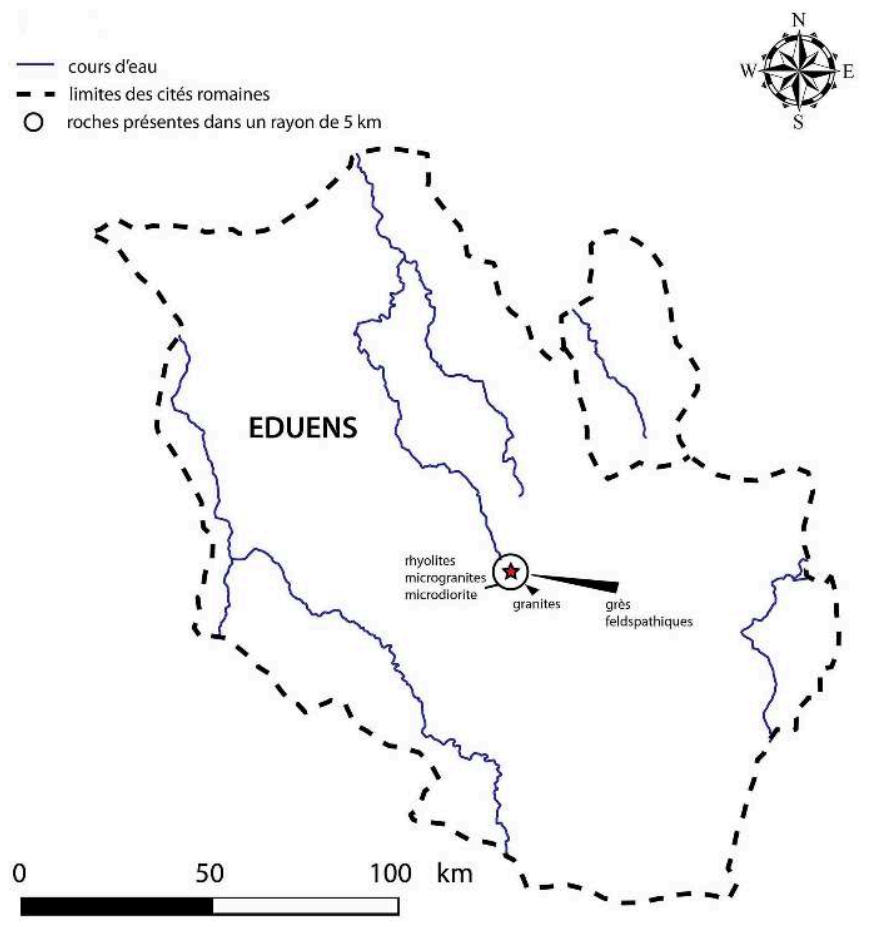

(C) Florent Delencre. Sources BDCarto, BDCarthage, IGN, MSH Dijon.

ce qui concerne les grès triasiques, les différents faciès semblent avoir une provenance unique, localisable sur le plateau d'Antully-Planoise, près d'Autun, soit à une distance maximale d'une quarantaine de kilomètres du mont Beuvray ${ }^{19}$. Cette matière lithique, qui est aussi employée pour les outils de mouture, a été l'objet d'investigations importantes en relation avec les recherches sur les meules gauloises et romaines autour de Bibracte et d'Autun. La recherche des carrières d'extraction pour ce matériel domestique a de ce fait permis de localiser certains des faciès observés spécifiquement en emploi à Bibracte ${ }^{20}$.

En raison de natures lithologiques similaires, un rapprochement entre les meules et les éléments de colonnes peut paraître pertinent. Toutefois, l'analyse fine montre que certains faciès déterminés pour les éléments de colonnes ne sont pas du tout mobilisés pour les meules, comme c'est le cas des grès feldspathiques à grains moyens, ceux à grains grossiers et des grès à muscovite. De plus, pour les faciès communs aux deux catégories de mobilier, il est très rapidement observable que les proportions diffèrent nettement (fig. 9). Ainsi, les faciès les plus représentés pour les éléments de colonnes sont ceux les moins exploités pour les meules, et inversement ${ }^{21}$. 
Fig. 9. - Oppidum de Bibracte (mont Beuvray, Bourgogne-Franche-Comté) : comparaison des faciès lithologiques entre les éléments de colonnes et les meules.

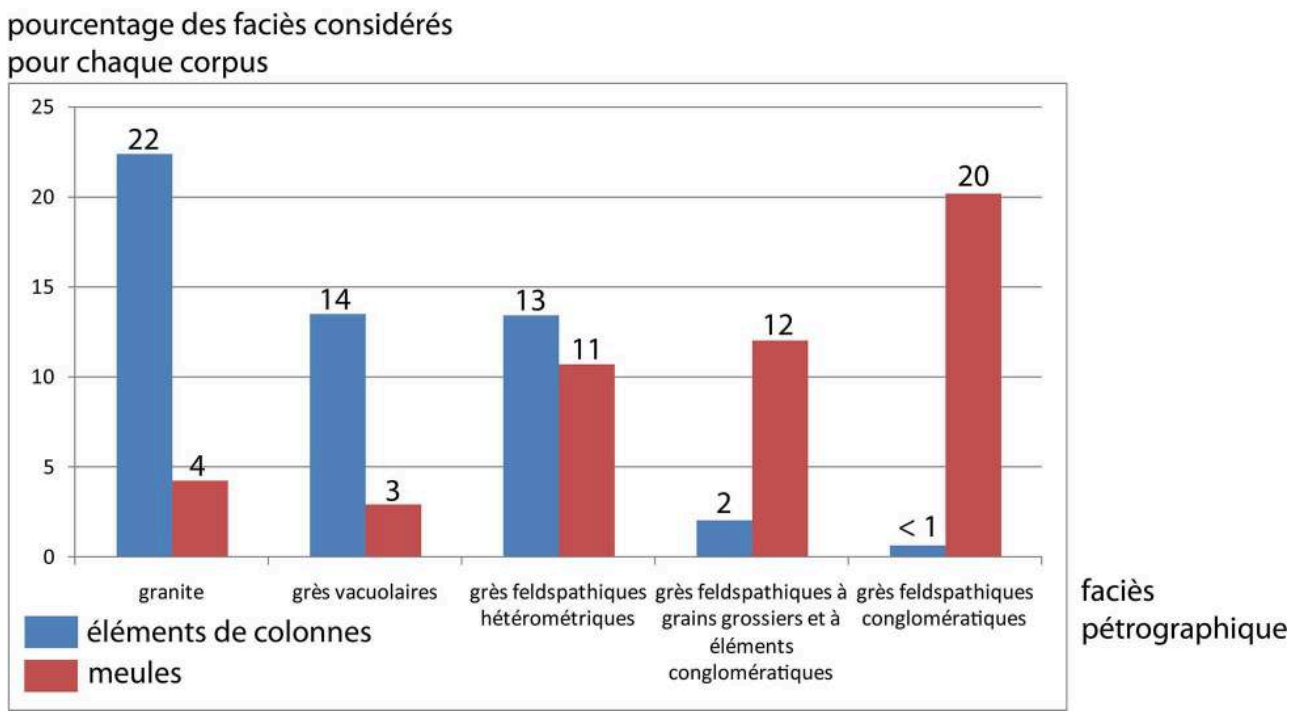

D’après Duda 2014.

De plus, si nous nous référons aux diamètres des meules pour la période de La Tène D2b en Bourgogne, soit entre 50 et 25 avant J.-C., ceux-ci sont principalement compris autour d'une moyenne de $39 \mathrm{~cm}^{22}$ : les meules ont donc des tailles nettement inférieures à celles des éléments de colonnes. Cependant, cet ensemble de valeurs correspond à des diamètres pour des meules finies. Ainsi, pour les plus petits diamètres estimés pour les éléments de colonnes, proches des valeurs mesurées pour les outils de mouture, une récupération opportuniste à partir d'éléments cassés peut être inférée, pratique qui semble toutefois rester ponctuelle.

Pour ce qui concerne les ébauches de meules, les diamètres sont très variables en fonction de l'étape de la chaîne opératoire où la mise en forme s'est arrêtée. Ainsi, pour une carrière de meules gauloises attestée à plusieurs dizaines de kilomètres de Bibracte (à Saint-Émiland, Saône-et-Loire), les diamètres des ébauches sont compris entre 37 et $80 \mathrm{~cm}$, pour une moyenne de $54,1 \mathrm{~cm}$. Ces différences n'impliquent toutefois pas pour autant qu'il n'existe aucun lien entre ces catégories de mobilier ${ }^{23}$.

En effet, nous avons déjà mis en évidence que les traces d'outils caractéristiques de la régularisation des parois pour les éléments de colonnes et les meules sont très similaires.

Il apparaît donc assez clairement que la mise en forme des éléments de colonnes est liée aux connaissances techniques d'artisans habitués au travail de la pierre abrasive, et plus particulièrement à celui des outils de mouture. Les roches employées pour ces matériaux font l'objet d'un choix réfléchi et adapté à leur utilisation, à un moment charnière où la mise en œuvre des colonnes n'est pas fréquente sur le territoire gaulois. La distinction des faciès de grès entre les meules et les éléments de colonnes pourrait ainsi s'expliquer par le degré de cimentation de ces roches, dont les propriétés intrinsèques sont nécessairement différentes selon leur usage pour la construction ou pour la mouture ${ }^{24}$. Les éléments de colonnes en pierre sont donc des objets uniques, dont aucun autre exemple n'est connu dans le monde romain. 
cation du concept biologique d'exaptation de Stephen Gould et d'Elisabeth (1982) semble particulièrement pertinente ici pour décrire un savoir-faire dérivé pour une production unique. En effet, il peut être considéré que l'usage d'un caractère biologique n'est pas forcément celui de son origine. Ainsi, ce concept se définit comme l'assimilation pour une nouvelle fonction d'un caractère formé à l'origine pour une autre fonction ou d'un caractère sans utilité apparente immédiate. Ceci expliquant pour la biologie, par exemple, que les proto-ailes ont été utilisées pour le vol quand leur fonction première est celle de la thermorégulation ${ }^{25}$.

41 Tout un faisceau d'indices tend donc à montrer que le savoir-faire nécessaire à la production des éléments de colonnes à partir de matériaux abrasifs est dérivé de celui des artisans meuliers (fig. 10). De fait, cette production par les Éduens de Bibracte n'est pas une adaptation de l'artisanat meulier, mais semble bien être le détournement d'un savoir-faire à l'intérieur d'un ensemble de pratiques déjà maîtrisées.

Fig. 10. - Schéma synthétique de l'exaptation du savoir-faire meulier.

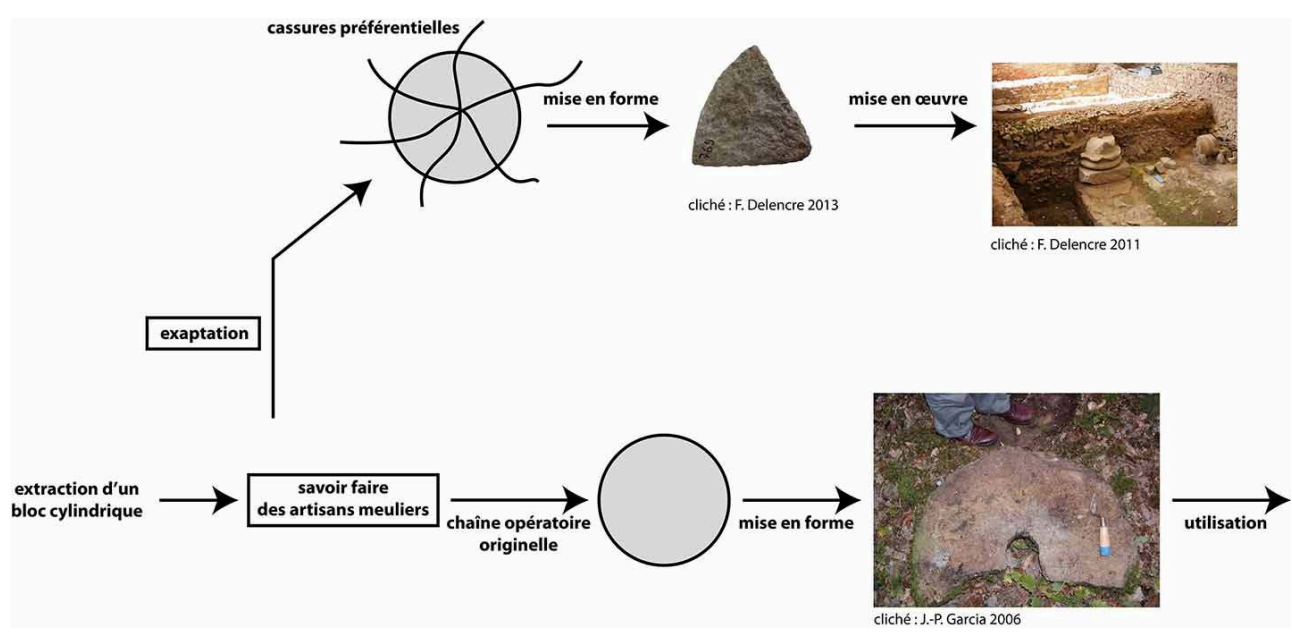

DAO Florent Delencre, clichés Florent Delencre et Jean-Pierre Garcia

42

Pour terminer, nous avons essayé de démontrer ici que l'emploi des éléments de colonnes pour un édifice précoce de l'oppidum de Bibracte manifeste l'adoption de techniques de construction nouvelles et l'appropriation - ici par exaptation - de savoirfaire nécessaires à sa réalisation. Si l'utilisation de la pierre semble bien répondre à des canons architecturaux romains, comme en témoignent les bases et les chapiteaux en calcaire, les Éduens de Bibracte mobilisent les ressources disponibles sur le mont Beuvray et dans son environnement proche. Cette recherche induit parfois un transport des ressources lithiques sur de longues distances pour répondre à des besoins spécifiques de la construction, lors de la toute première expression architecturale romaine d'ampleur en environnement laténien.

43

Ainsi, derrière cette analyse se pose la question de l'origine des artisans qui produisent et mettent en œuvre ces matériaux très précocement pour l'édifice à plan basilical tardo-républicain. Si les éléments de colonnes semblent ainsi être l'œuvre des artisans locaux, ceci n'est pas corroboré par la mise en forme des chapiteaux et des bases de colonnes, qui répondent aux canons architecturaux romains. Il est fort probable que les 
artisans ayant façonné le calcaire, roche allochtone au mont Beuvray, soient plutôt originaires d'Italie, de Rome même, ou tout au moins de territoires plus proches, bien intégrés dans la sphère romaine, comme la Gaule du sud. La pluralité des acteurs et le caractère hybride de leurs réalisations doivent donc être invoqués pour des bâtiments aussi monumentaux et tranchant nettement avec les réalisations architecturales habituelles de l'oppidum de Bibracte.

\section{BIBLIOGRAPHIE}

BESSAC J.-C., 1987, L'outillage traditionnel du tailleur de pierre de l'Antiquité à nos jours, Paris, CNRS éditions (Revue archéologique de Narbonnaise, $14^{\mathrm{e}}$ supplément).

BONENFANT P.-P., 1989, «Fouilles dans la Pâture du Couvent », dans Rapport annuel d'activité scientifique 1989 de Bibracte, centre archéologique européen, Glux-en-Glenne, Centre archéologique européen du mont Beuvray, p. 49-60.

BOYER F., 1998, «Les matériaux lithiques de la construction et de l'outillage », dans Gruel K. et Vitali D. (dir.), L'oppidum de Bibracte : un bilan de onze années de recherche (1984-1995), Paris, CNRS éditions (Gallia, $\left.\mathrm{n}^{\circ} 55\right)$, p. 60-63.

BOYER F. et FRONTEAU G., 2011, « Les géomatériaux meuliers : de l'identification des sources géologiques à la définition de catégories de gisements ", dans Buchsenschutz O., Jaccottey L., Jodry F., Blanchard J.-L. (dir.), Évolution typologique et technique des meules du Néolithique à l'an mille: actes des III Rencontres archéologiques de l'archéosite gaulois, Bordeaux, Fédération Aquitania (Aquitania, 23 ${ }^{\mathrm{e}}$ supplément), p. 121-135.

BUCHSENSCHUTZ O., GUILLAUMET J.-P., RALSTON I. (dir.), 1999, Les remparts de Bibracte, Glux-en-Glenne, Centre archéologique européen du mont Beuvray (Bibracte, 3).

DELENCRE F., 2017, « Terres et pierres pour matières de cultures : l'apparition et la diffusion de nouveaux matériaux et modes de construction dans le nord-est de la Gaule romaine (II ${ }^{\mathrm{e}}$ siècle avant J.-C.-II siècle après J.-C.) ", thèse de doctorat en archéologie, Dijon, université de Bourgogne, 2 vol.

DELENCRE F. et GARCIA J.-P., 2012, « Méthodologie et enjeux de l'analyse des matériaux de construction et de couverture romains de Bibracte. Un cas d'étude : les matériaux de construction en terre cuite de PC1 ", dans Rapport annuel d'activité scientifique 2012 de Bibracte, centre archéologique européen, Glux-en-Glenne, Centre archéologique européen du mont Beuvray, p. 365-378.

DUDA T., 2014, « Les meulières gauloises et antiques sur le site du "Bois des Mouilles" à SaintÉmiland : étude des ébauches, des carrières et des matières premières au sein du territoire éduen ", mémoire de master 2 en archéo-géosciences, Dijon, université de Bourgogne.

GOUDINEAU C et PEYRE C., 1993, Bibracte et les Éduens : à la découverte d'un peuple gaulois, Paris, Errance / Glux-en-Glenne, Centre archéologique européen du mont Beuvray (Hauts lieux de l'histoire). 
GOULD S. J., 1991 « Exaptation: a crucial tool for an evolutionary psychology », Journal of Social Issues, $\mathrm{n}^{\circ} 47$, p. 43-65.

GOULD S. J. et VRBA E. S., 1982, « Exaptation : a missing term in the science of form », Paleobiology, $\mathrm{n}^{\circ} 8$, p. $4-15$.

GRADELER M., 2018, « Approvisionnement en ressources lithiques des constructions de l'oppidum de Bibracte (mont Beuvray, Bourgogne) : approche géologique, (micro)géomorphologique et cartographique ", mémoire de master 2 en archéologie et sciences pour l'archéologie, Dijon, université de Bourgogne.

JACCOTTEY L., JODRY F., LONGEPIERRE S., ROBIN B., 2011, « Chronologie et diamètres des meules à bras à la fin de La Tène et à l'époque antique ", dans Buchsenschutz O., Jaccottey L., Jodry F., Blanchard J.-L. (dir.), Évolution typologique et technique des meules du Néolithique à l'an mille: actes des III Rencontres archéologiques de l'archéosite gaulois, Bordeaux, Aquitania, $23^{\mathrm{e}}$ supplément, p. 291-298.

LUGINBÜHL T., MEYLAN F., GUICHARD V., BARRIER S., CLÉMENT B., DELENCRE F., FOCHESATO A., MARTINI C., TIMÁR L., 2019, «Les maisons de tradition méditerranéenne de Bibracte : techniques et matériaux, types architecturaux, organisation spatiale et fonctions », dans Guichard V. et Vaginay M. (dir.), Les modèles italiques dans l'architecture des II et $I^{e r}$ siècles avant notre ère en Gaule et dans les régions voisines, actes du colloque de Toulouse (2013), Glux-en-Glenne, Centre archéologique européen du mont Beuvray (Bibracte, 30), p. 421-440.

MARC J.-Y., 2011, « Un excès de la romanisation ? L'identification dans les villes gauloises de monuments civiques romains ", dans Reddé M., Barral P., Favory F, Guillaume J.-P., Joly M., Marc J.-Y., Nouvel P., Nuninger L., Petit C. (dir.), Aspects de la romanisation dans l'est de la Gaule, Glux-en-Glenne, Centre archéologique européen du mont Beuvray, vol. 1 (Bibracte, 21), p. 309-317.

PAUNIER D. et LUGINBÜHL T., 2004, Bibracte : le site de la maison 1 du Parc aux Chevaux (PC 1) des origines de l'oppidum au règne de Tibère, Glux-en-Glenne, Centre archéologique européen du mont Beuvray (Bibracte, 8).

SZABÓ M. et TIMÁR L., 2008, « Édifices et lieux publics », Acta Archaeologica Academiae Scientiarum Hungaricae, t. 59, $\mathrm{n}^{\circ} 1$, p. 55-68.

SZABÓ M., TIMÁR L., SZABÓ D., 2007, « La basilique de Bibracte : un témoignage précoce de l'architecture romaine en Gaule centrale », Archäologisches Korrespondenzblatt, t. 37, nº 3, p. 389-408.

TIMÁR L., SZABÓ M., CZAJLIK Z., 2005, « La domus du dernier état de l'îlot des Grandes Forges », dans Guillaumet J.-P. et Szabó M. (dir.), Études sur Bibracte 1, Glux-en-Glenne, Centre archéologique européen du mont Beuvray (Bibracte, 10), p. 13-46.

\section{NOTES}

1. Delencre 2017.

2. Paunier et Luginbühl 2004, Timár et al. 2005.

3. Personnage d'importance dans les cités gauloises, occupant une fonction de magistrature.

4. Goudineau et Peyre $1993: 171$. 
5. Buchsenschutz et al. 1999 : 59.

6. Voir Paunier et Luginbühl 2004 concernant la domus PC1 en particulier et Luginbühl et al. 2019 pour les domus de Bibracte en général.

7. Bonenfant 1989.

8. Szabó et al. 2007 : 392, Szabó et Timár 2008.

9. Marc 2011.

10. Szabó et al. $2007: 390$, Timár et al. $2005: 14$.

11. Boyer $1998: 62-63$.

12. Delencre et Garcia 2012 : 366.

13. Szabó et al. $2007: 395-400$.

14. Ibid. : 395.

15. Bessac 1987.

16. Duda 2014 : 82-83.

17. Delencre $2017: 129$, Gradeler 2018.

18. Delencre et Garcia $2012: 366$, Delencre $2017: 129$.

19. Delencre et Garcia $2012: 366$, Delencre $2017: 130$.

20. Boyer et Fronteau $2011: 128$.

21. Duda 2014 : 79.

22. Jaccottey et al. $2011: 293$.

23. Duda 2014 : 84.

24. Boyer et Fronteau 2011.

25. Gould $1991: 47$.

\section{RÉSUMÉS}

Découverts dès 1989 sur l'oppidum de Bibracte, des blocs en pierre de forme triangulaire ont été identifiés comme des éléments de construction de colonnes appartenant à un édifice à plan basilical du milieu du $\mathrm{I}^{\mathrm{er}}$ siècle avant J.-C. La constitution d'un corpus important (1 331 éléments) a permis de mieux les caractériser pour comprendre leur forme, leur mise en œuvre et leur signification. Les faciès lithologiques (majoritairement en grès et en granite), la forme des objets, les traces d'outils et le matériau abrasif (peu habituel pour un matériau de construction) posent la question de l'origine d'un tel choix et celle du possible lien avec le mobilier de mouture. Les éléments de colonnes mis en œuvre à Bibracte sont donc des objets uniques, et tout un faisceau d'indices tend à montrer que le savoir-faire nécessaire à leur production est dérivé (exapté) de celui des artisans meuliers, lors de la toute première expression architecturale romaine d'ampleur en environnement laténien. 
INDEX

Mots-clés : matériaux de construction, oppidum, détermination pétrographique, détermination morphométrique, savoir-faire, exaptation

Index géographique : Bibracte

\section{AUTEURS \\ FLORENT DELENCRE}

ATER à l'université de Tours, membre associé au laboratoire Archéologie, terre, histoire, sociétés (ARTEHIS, université de Bourgogne, UMR 6298 du CNRS)

JEAN-PIERRE GARCIA

Professeur à l'université de Bourgogne, laboratoire Archéologie, terre, histoire, sociétés (ARTEHIS, UMR $6298 \mathrm{du}$ CNRS) 


\title{
La construction en petit appareil modulaire des voûtes de caves à Bourges (Cher) entre le XIII ${ }^{\mathrm{e}}$ et le milieu du XVI ${ }^{\mathrm{e}}$ siècle
}

\author{
Lucie Gaugain, Marie Lafont et Laura Millat
}

1 L'étude du petit appareil de pierre des caves de Bourges est née d'observations menées dans le cadre, d'une part, d'une thèse de doctorat conduite par Marie Lafont ${ }^{1}$ et, d'autre part, dans celui du projet Sicavor ${ }^{2}$ sur les caves en région Centre-val de Loire, qui amena à étudier les caves de l'hôtel Jacques Cœur ${ }^{3}$. Si l'étude des caves de Bourges mériterait d'être poursuivie, elle ne pourrait trouver son aboutissement que dans un travail commandé par la municipalité ou les instances archéologiques, pour faciliter l'accès chez les particuliers. Notre prospection a trouvé un accueil favorable auprès d'un certain nombre d'habitants - que nous remercions sincèrement -, mais bien d'autres ne semblent pas sensibles à la valeur patrimoniale des caves. Il s'est même avéré qu'au-delà du fait de pouvoir visiter ces caves, un nombre important d'entre elles n'étaient plus même accessibles, leur trappe, ouvrant à l'origine directement derrière la porte d'entrée du rez-de-chaussée, ayant été supprimée et bétonnée pour faciliter l'aménagement d'une boutique ${ }^{4}$.

2 L'enquête a révélé la présence de voûtes construites avec un petit appareil de pierre de taille présentant des modules de hauteur inscrits au charbon de bois. Les modules ont été mis en évidence tant dans les beaux hôtels de la ville (palais Jacques Cœur ou hôtel Lallemant) que dans des caves prenant place sous de petites maisons en pan de bois. Le postulat de départ était de supposer que la reconstruction de la ville après le grand incendie de 1487 avait pu induire un appel de main-d'œuvre, un brassage de gens de métier et un renouvellement des techniques de construction. Ce que nous souhaiterions démontrer est que l'emploi de ce petit appareil de pierre dans les caves - connu par ailleurs en Normandie ou en Anjou jusqu'au XIII ${ }^{\mathrm{e}}$ siècle - reste lié à Bourges à une période de grande construction (début du XIII ${ }^{\mathrm{e}}-1^{\mathrm{re}}$ moitié $\mathrm{du} \mathrm{XVI}$ siècle) et semble traduire la mise en place d'une économie de la pierre liée à la qualité et au 
nombre des chantiers. Il dépasse donc le strict cadre de la reconstruction postincendie.

\section{Contexte : Bourges, foyer de la construction pendant trois siècles}

3 La ville haute de Bourges est protégée par une enceinte gallo-romaine. La cathédrale ${ }^{5}$, située au point culminant, s'étend sur $6000 \mathrm{~m}^{2}$, son chevet étant construit à l'emplacement de l'ancien fossé de l'enceinte gallo-romaine. Les fortifications deviennent obsolètes dans la seconde moitié $d u$ XII ${ }^{e}$ siècle. À cette époque, la démographie croît rapidement, engendrant la naissance de nouveaux quartiers, puis la construction entre 1140 et 1189 d'une extension de l'enceinte pour les enclore. Les murs de la ville enfermaient alors 110 hectares, soit plus de quatre fois la superficie protégée par l'enceinte gallo-romaine. La fin $\mathrm{du}_{\mathrm{XII}}{ }^{\mathrm{e}}$ siècle et le début du suivant connaissent une période de construction particulièrement intense, marquée par l'édification de la Grosse Tour en $1189^{6}$ et l'ouverture de l'important chantier de la cathédrale, qui se déroule entre 1195 et $1250^{7}$.

$4 \quad$ Au XIII ${ }^{\text {e }}$ siècle, l'essor économique - dû à celui des foires et de la draperie - et l'essor religieux sont soutenus : reconstruction d'églises et mise en place du réseau paroissial une quinzaine d'églises paroissiales sont construites dans la ville entre le $\mathrm{xII}^{\mathrm{e}}$ et le $\mathrm{xIII}^{\mathrm{e}}$ siècle -, implantation des ordres mendiants, développement des moulins, des commerces et de l'artisanat ${ }^{8}$.

5 À la fin du XIV siècle, le mécénat de Jean de Berry érige Bourges au rang de centre artistique et culturel incontournable : à partir de 1370, les Dammartin conduisent les travaux du palais ducal et de la Sainte-Chapelleq. De très nombreux artistes sont attirés par ces chantiers, parmi lesquels il faut retenir l'édification du château de Mehun-surYèvre, la réalisation sur place de certains des plus beaux manuscrits peints du Moyen Âge - les Très Riches Heures, mais aussi les Belles Heures, les Grandes Heures, etc. -, les vitraux et les sculptures de la Sainte-Chapelle ainsi que le gisant du duc et ses pleurants, qui constituent l'un des sommets de l'art gothique international. André Beauneveu, Jean de Cambrai et les trois frères de Limbourg demeuraient à Bourges, qui peut dès lors être considérée comme un foyer des arts et de l'architecture gothique. À partir de 1418, Charles VII (1421-1463) s'installe à Bourges, au palais ducal, et en fait sa capitale. Jacques Cœur, argentier du roi, se fait construire un immense hôtel entre 1444 et $1445^{10}$. Encore faut-il considérer le grand incendie de 1487, qui nécessita la reconstruction d'une part non négligeable de la ville et qui alla de pair avec l'édification de l'hôtel des Échevins, entre 1489 et $1495^{11}$. La reconstruction de l'enceinte urbaine est presque totale. Enfin, on se lance dans la rénovation, voire la reconstruction de plusieurs églises (notamment Notre-Dame et Saint-Bonnet). De nombreux hôtels particuliers et des maisons plus modestes sont également reconstruits ${ }^{12}$.

6 Le $\mathrm{xvI}^{\mathrm{e}}$ siècle voit l'ouverture des chantiers de la construction du couvent de l'Annonciade sous l'impulsion de Jeanne de France (à partir de 1500), des hôtels Lallemant ${ }^{13}$ (1497 et 1506) et Cujas ${ }^{14}$ (1508-1515), de l'édification d'un nouvel hôtel-Dieu $(1508-1520)^{15}$, de la reconstruction de la tour nord de la cathédrale (1507-1537) (fig. 1). 
Fig. 1. - Bourges (Cher) : carte de localisation des caves étudiées, présentant la répartition des différents types de voûtement.

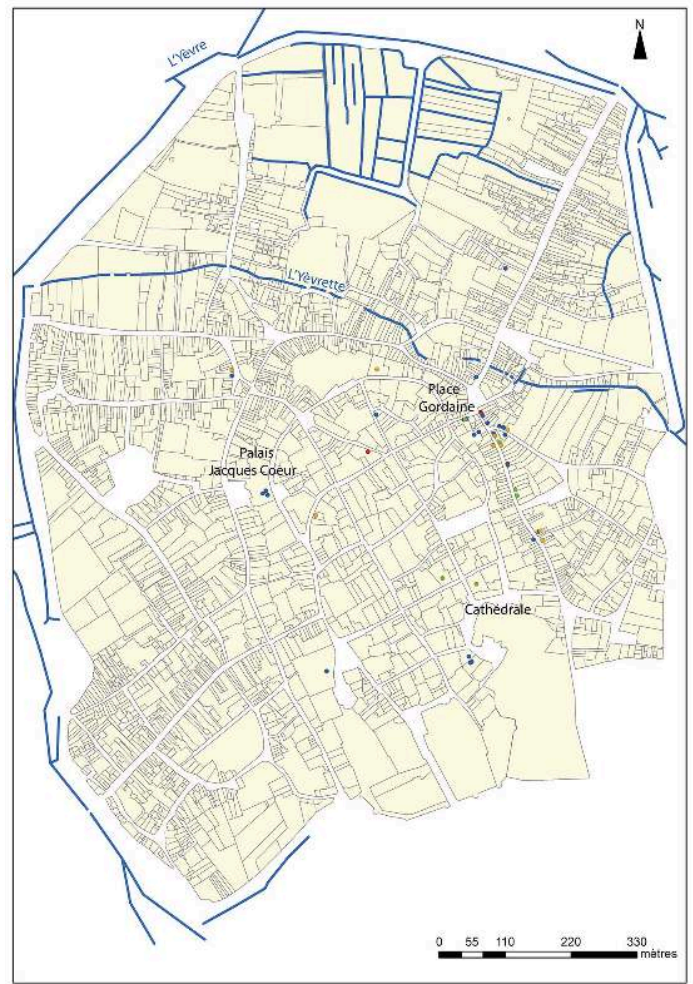

EN ROUgE : les voûtes d'ogives. EN VERT : les voûtes en berceau en moellons ou dont l'appareil est enduit. EN BLEU : les voûtes en berceau petit appareil. EN ORANgÉ : les voûtes en berceau en moellons. (c) Marie Lafont.

7 Bourges, qui abrita donc pendant un temps Charles VII et son administration, est à la fois le siège d'un immense archevêché, descendant jusqu'au sud d'Albi dès le XIII ${ }^{e}$ siècle, et la capitale du baillage de Berry ${ }^{16}$. Ce chantier considérable qu'est la ville de Bourges a ainsi nécessité la présence d'une main-d'œuvre très nombreuse jusqu'au milieu du $\mathrm{XvI}^{\mathrm{e}}$ siècle. Autant d'éléments qui font de Bourges un milieu de la construction privilégié du second Moyen Âge, où les plus grands maîtres et les meilleurs ouvriers se côtoient durant plus de trois siècles.

\section{Méthode de travail}

Notre étude a été menée selon une approche pluridisciplinaire : analyse des sources textuelles (comptabilités et délibérations municipales ${ }^{17}$ ), enquête de prospection pour répertorier les types de mises en œuvre des caves, mesures d'appareils et analyse statistique des mesures, analyses de mortier pour connaître la granulométrie de l'agrégat et quantifier la chaux, et enfin étude macroscopique des pierres mises en œuvre dans les caves et de celles présentes dans les carrières ${ }^{18}$ citées par les archives. Les échantillons prélevés dans les caves ont ainsi été confrontés aux deux principales sources d'approvisionnement en pierre que citent les comptes de la ville et de la cathédrale : les carrières des Averdines et de Charly, dans le Cher, qui présentent des faciès similaires, mais non identiques. Un troisième faciès s'en est clairement distingué, celui du substrat rocheux sur lequel la ville est construite. 


\section{Présentation du corpus de caves}

Les 43 adresses de caves ${ }^{19}$ que nous avons étudiées sont majoritairement situées dans la ville basse, dans les quartiers artisans et commerçants. Il conviendrait à l'avenir de poursuivre l'étude et de l'étendre à la totalité de la ville ${ }^{20}$, ce qui resterait cependant conditionné, d'une part, par la coopération des habitants à bien vouloir ouvrir leurs portes et, d'autre part, par la conservation des accès aux caves ${ }^{21}$. Dans la ville basse, la rivière de l'Yévrette constituait le principal axe économique: les artisans du drap travaillaient et habitaient le long de ses berges. La place Gordaine accueillait la plupart des boucheries et poissonneries. Ce quartier fut le premier touché par le grand incendie de $1487^{22}$.

10 Comme à Orléan ${ }^{23}$, les caves étudiées disposent en général d'un plan simple, avec un volume unique couvert dans la majorité des cas par une voûte en berceau. La disposition des parcelles, étendues en longueur selon un parcellaire laniéré, correspond à celle des vaisseaux quadrangulaires placés perpendiculairement à la rue. C'est notamment le cas des caves des numéros $5,9,12,13$ ou encore 35 de la rue Bourbonnoux; mais aussi du 3 bis rue Joyeuse ou du 3 rue du Chevreau. Dans le cas de caves sur plusieurs niveaux (douze caves repérées actuellement), il est courant que les niveaux bas, ayant servi à extraire du calcaire, montrent des plans plus complexes avec une série de galeries et de cellules latérales. Le fond de ces cellules présente couramment un front de taille dépourvu de tout appareillage. Les caves de l'hôtel Jacques Cœur en sont un bel exemple, mais cela se rencontre également aux BonnetsRouges ( 3 rue de la Thaumassière), dans les caves de l'ancien archevêché (sous l'actuel hôtel de ville ; 11 rue Jacques-Rimbaud), qui dispose d'un réseau de caves très étendu passant sous la place Étienne-Dolet, et à l'hôtel Lallemand (6 rue Bourbonnoux ; 5 rue de l'Hôtel-Lallemant).

11 Les voûtes, d'ogives et en berceau, sont majoritairement construites en petit appareil de pierre de taille. Il est relativement rare de trouver des voûtes en moellon (moins d'un tiers des cas). Il conviendra de revenir plus en détails sur le petit appareil.

12 Le lien entre la rue et la cave est manifeste, sans pour autant être direct. S'il est rare qu'elles s'ouvrent directement sur la rue, il est très fréquent que l'accès à la cave se fasse depuis un couloir latéral, par une trappe couvrant un escalier droit placé juste derrière la porte d'entrée (4 rue Joyeuse, 13 rue Bourbonnoux). L'accès à la cave se trouve par conséquent à proximité immédiate de la pièce du rez-de-chaussée donnant sur la rue, qui a pu servir de boutique, comme cela est bien souvent le cas en milieu urbain $^{24}$. La possibilité de décharger dans les caves - notamment des tonneaux de vin influe donc sur la distribution générale de la maison. Lorsque l'escalier est en vis (37 rue Bourbonnoux), la vocation domestique s'impose face à la vocation commerciale. L'escalier est alors rejeté sur la façade arrière, côté cour. Les dispositions de la cave restent à ceci près semblables.

Des soupiraux sont systématiquement ouverts dans au moins un mur de la cave, parfois dans les deux, côté rue et côté cour. Niches et placards muraux sont systématiquement ménagés dans les murs. Le plus souvent, une niche est disposée dans la descente d'escalier et une série de niches est placée sous le soupirail côté rue. La présence de puits qui sont accessibles depuis les niveaux de caves reste occasionnelle (5 rue Jean- 
Girard). Leur fonction n'a pas réellement pu être associée à un usage particulier de la cave.

\section{Typologie des voûtes des caves}

Sur 43 adresses de caves visitées dans la ville, 23 sont voûtées avec un petit appareil de pierre (fig. 2), soit la moitié des cas. Notre corpus de caves présentant un petit appareil de pierre de taille correspond principalement à des maisons en pan de bois de la fin du Moyen Âge. Sont également concernés quatre hôtels, dont l'immense demeure de Jacques Cœur. Dans ces caves, trois types de voûtes se distinguent.

Fig. 2. - Bourges (Cher) : les différents types de voûtes couvrant les caves.

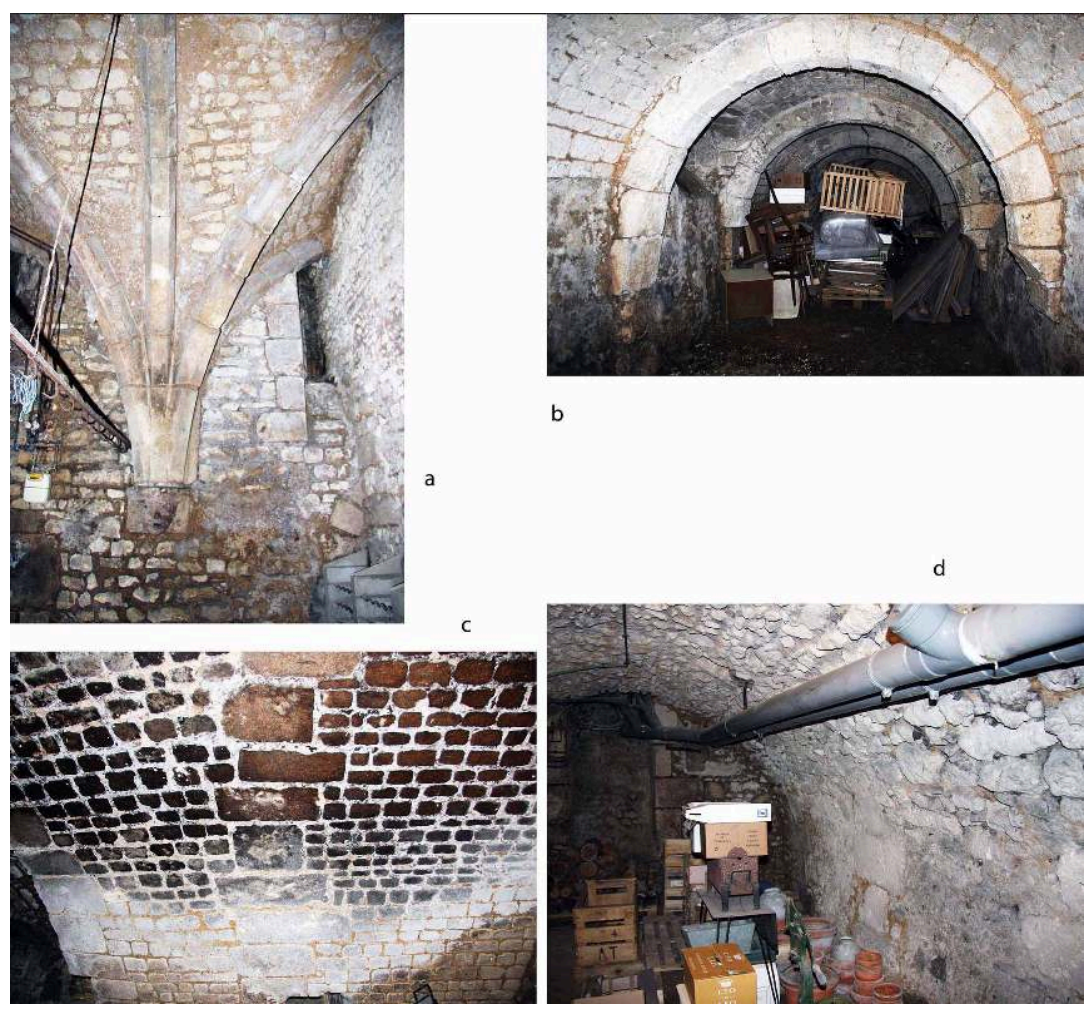

A : type 1, 3 rue Bourbonnoux, cave couverte de croisées d'ogives dont les voûtains montrent un petit appareil. B : type 2, 55 rue Édouard-Vaillant, cave couverte de berceaux, épaulée de doubleaux. c : type 2, 4 rue Joyeuse, cave renforcée par des harpes. D : type 3, 12 rue Bourbonnoux, cave voûtée en berceau coffrée en moellons.

(c) Lucie Gaugain.

\section{Type 1}

Trois adresses de caves sont couvertes de croisées d'ogives dont les voûtains montrent un petit appareil (fig. 2a) ${ }^{25}$, correspondant aux « pierres pendent » que les archives de la fin du Moyen Âge citent couramment ${ }^{26}$. Aucun signe lapidaire n'a pu y être relevé. Les traces d'outils correspondent à l'usage de la bretture. Il s'agit manifestement de caves des $\mathrm{XIII}^{\mathrm{e}}-\mathrm{XIV}^{\mathrm{e}}$ siècles, si l'on en croit le profil des nervures chanfreinées, les bases octogonales des colonnes et les quelques chapiteaux ( 3 rue Bourbonnoux par exemple) ou colonnes engagées (10 rue des Beaux-Arts) d'où naissent les ogives. En dehors de 
Bourges, ce type de construction est courant à Amboise ${ }^{27}$ et Tours ${ }^{28}$ (Indre-et-Loire), Douai $^{29}$ et Lille ${ }^{30}$ (Nord), Orléans ${ }^{31}$ (Loiret), Bonneval ${ }^{32}$ (Eure-et-Loir), Château-Thierry ${ }^{33}$ (Aisne), Paris $^{34}$, mais également à Riom ${ }^{35}$ (Puy-de-Dôme) et dans bien d'autres villes.

\section{Type 2}

Vingt-deux adresses de caves sont couvertes de berceaux et présentent trois variantes : épaulés de doubleaux (fig. 2b), dépourvues de doubleaux ou renforcées par des harpes (fig. 2c). À sept adresses de caves ${ }^{36}$, les voûtes en berceau sont construites en petit appareil, montées en assises réglées, avec des doubleaux chanfreinés, ou sans doubleau dans quinze cas $^{37}$, dont trois qui présentent des harpes (fig. 2c) ${ }^{38}$. Les pierres sont également dressées à la bretture. Sur les voûtes de neuf d'entre elles ${ }^{39}$, nous avons observé des signes lapidaires. L'analyse de 2500 mesures d'appareil permet d'affirmer qu'il s'agit bien de modules de hauteur.

La datation de ces caves à petit appareil, qui s'avèrent donc les plus nombreuses, reste cependant peu aisée car il est très fréquent de trouver des voûtes en berceau surbaissé de la fin du Moyen Âge au début de l'époque contemporaine ${ }^{40}$. Aussi nous interrogeonsnous sur la possibilité que les doubleaux puissent être des éléments de datation, car ils apparaissent également comme des organes stabilisateurs. Aux 13 rue Bourbonnoux, 3 rue Joyeuse et 3 rue de la Thaumassière, les arcs doubleaux sont remplacés par des harpes, ce qui tendrait à placer ces constructions après le premier quart du $\mathrm{XVI}^{\mathrm{e}}$ siècle, si l'on en croit l'usage des harpes dans l'architecture.

\section{Type 3}

Onze adresses de caves présentent des voûtes en berceau coffrées en moellons (fig. $2 \mathrm{~d})^{41}$. Aucun élément de datation n'apparait, sinon le fait qu'elles sont en substructure d'édifices datant de la fin du XVII ${ }^{\mathrm{e}}$ ou du XVIII ${ }^{\mathrm{e}}$ siècle.

Enfin, trois caves ne peuvent être classées, car les berceaux ont été enduits, empêchant toute lecture de leur appareil ${ }^{42}$; deux caves présentent une voûte en berceau construite en petit appareil, puis reprise en moellon ${ }^{43}$.

\section{Mesures d'appareil et analyse statistique du petit appareil}

Un peu plus de 2500 mesures d'appareil ont été effectuées à cinq adresses montrant chacune plusieurs niveaux de caves qui relèvent de phases d'aménagement successives $^{44}$. Ont ainsi été étudiées celles de l'hôtel Jacques Cœur, de l'hôtel Lallemant, de la maison des Trois Flûtes, du 5 rue Bourbonnoux et du 4 rue Joyeuse. Ces mesures ont permis de mettre en évidence l'évolution modulaire des appareils (fig.3). Les longueurs et les hauteurs des blocs sont faibles, ce qui autorise bien à parler de petit appareil. Aucune pierre ne mesure plus de $16 \mathrm{~cm}$ de haut. Les pierres sont calibrées selon des modules allant de 0 à VII, avec un faible intervalle entre chaque valeur : 15 à $20 \mathrm{~mm}$, soit un peu moins de 1 pouce $(=2,54 \mathrm{~cm})$. 
Fig. 3. - Bourges (Cher) : graphiques présentant les hauteurs de modules.

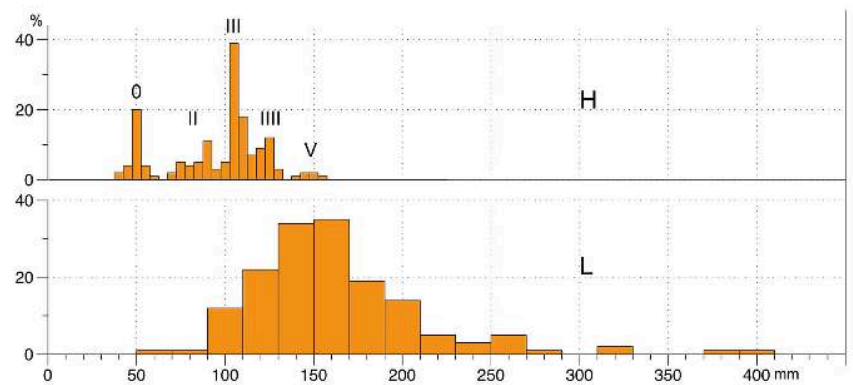

b
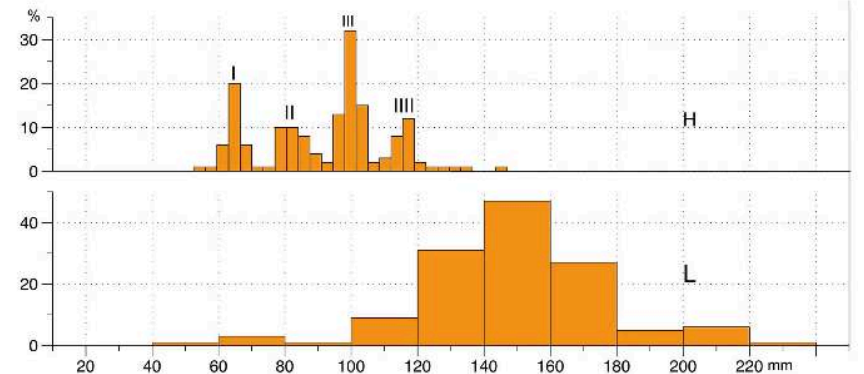

A : hôtel Jacques Cœur. B : maison des Trois Flûtes, 13 rue Bourbonnoux.

(c) Daniel Prigent.

21 Les marques de calibrages sont tracées au charbon et répondent à une numérotation dérivée des chiffres romains (fig. 4) ${ }^{45}$.

Fig. 4. - Bourges (Cher), hôtel Jacques Cœur : vue du petit appareil de pierre numéroté au charbon.

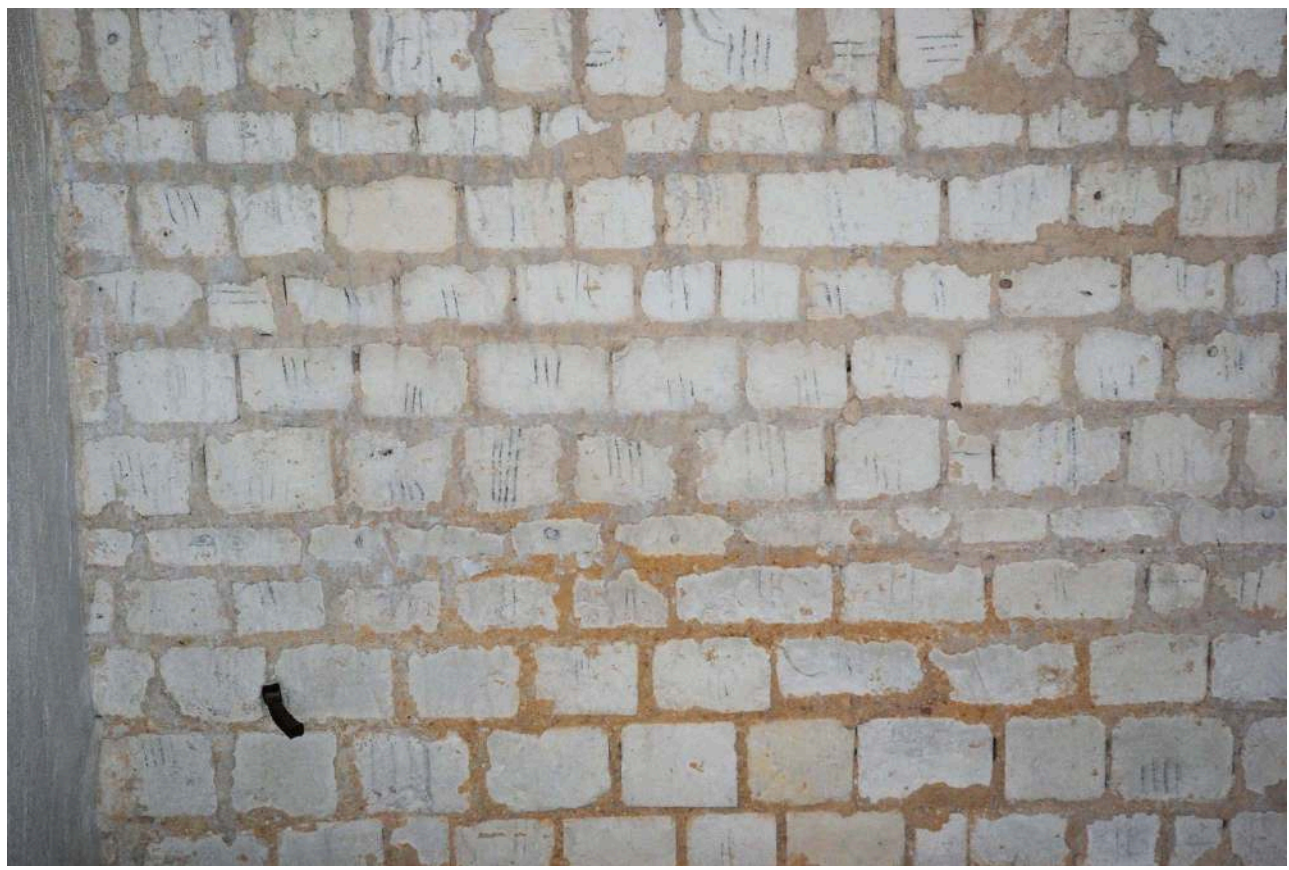

(c) Lucie Gaugain. 
Quelques rares modules incisés ont cependant été repérés au 3 rue de la Thaumassière. Les marques sont disposées sur la face de parement et ne sont pas masquées. Parfois, elles ne se trouvent pas dans le sens de la lecture depuis le sol ce qui, de fait, prouve qu'elles ont été inscrites après l'extraction et la taille des pierres afin de faciliter ensuite la pose en assises réglées lors de la construction. Les modules II, III et IV sont les plus employés. Aussi, près de $75 \%$ des pierres présentent une hauteur variant entre 6 et $12 \mathrm{~cm}$, pour une longueur comprise entre 13 et $16 \mathrm{~cm}$.

Toutes les caves dont l'appareil a été mesuré ne répondaient pas strictement à la même évolution modulaire, les écarts types variant de manière notable (fig. 3). Les modules très petits, le 0 et le $\mathrm{I}$, sont rares et mesurent en moyenne $4 \mathrm{~cm}$ et $5,5 \mathrm{~cm}$ de haut. Les modules les plus grands, tels que le VI et VII, sont tout aussi rares et mesurent en moyenne 13,5 à $15 \mathrm{~cm}$. Le module VII $(=15,3 \mathrm{~cm})$ n'a été rencontré qu'à l'hôtel Jacques Cœur. Ces différences de modules de hauteurs résultent très certainement de variations dans le temps, mais puisque la datation des voûtes en berceau surbaissé en petit appareil, sans harpe, court entre la fin du XIV siècle et le milieu du XVI ${ }^{e}$, elles restent difficiles à préciser. Elles résultent aussi très certainement de variations dans l'espace, car l'extraction a pu se dérouler dans différentes carrières; c'est ce que nous allons tenter de montrer.

\section{Description du faciès géologique des roches}

Dans les caves, trois types de pierre ont été observés. Le premier est un calcaire de couleur blanchâtre, qui présente de nombreuses oolithes ${ }^{46}$, des pisolithes ${ }^{47}$ et des fragments bivalves ${ }^{48}:$ il correspond au calcaire de Bourges ${ }^{49}$. Issue d'un sable très fin et de boues calcaires, cette pierre est tirée de l'étage Oxfordien supérieur et provient manifestement des carrières des Averdines, situées au sud-est de Bourges (fig. 5), à $2 \mathrm{~km}$ du centre, et exploitées jusqu'au début du $\mathrm{xx}^{\mathrm{e}}$ siècle $^{50}$. Le deuxième correspond à la pierre des carrières de Charly, situées à $44 \mathrm{~km}$ au sud-est de Bourges et aménagées dans l'étage Jurassique moyen (Bathonien), et qui présente quant à elle un faciès moins homogène (fig. 6) $)^{51}$. Elle est issue d'une boue calcaire riche en éléments biogéniques ${ }^{52}$ et se trouve couramment employée pour la réalisation des éléments sculptés de qualité ${ }^{53}$. 
Fig. 5. - Vue de la pierre dans les carrières des Averdines (Bourges, Cher).

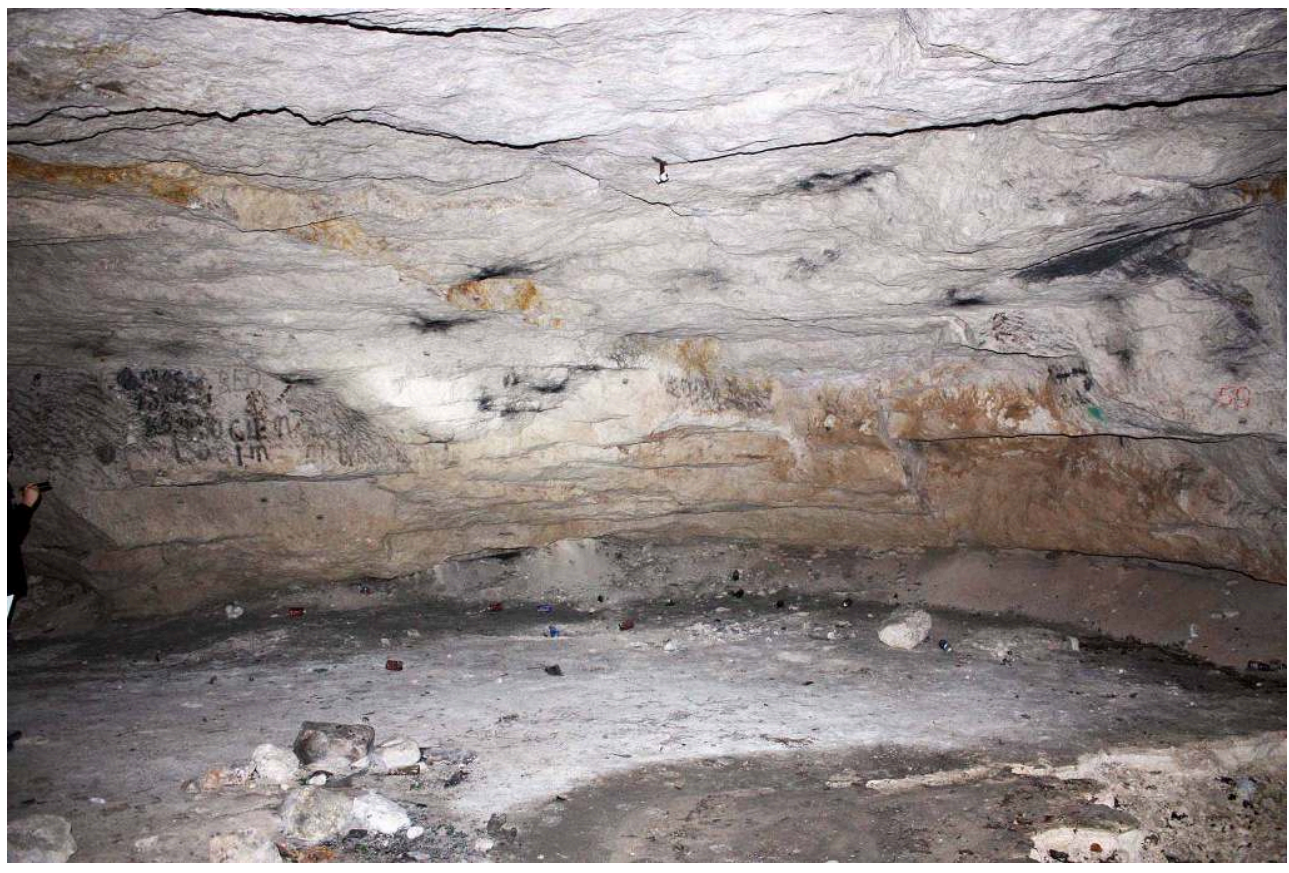

(c) Lucie Gaugain

Fig. 6. - Vue de la pierre dans les carrières de pierre de Charly (Cher).

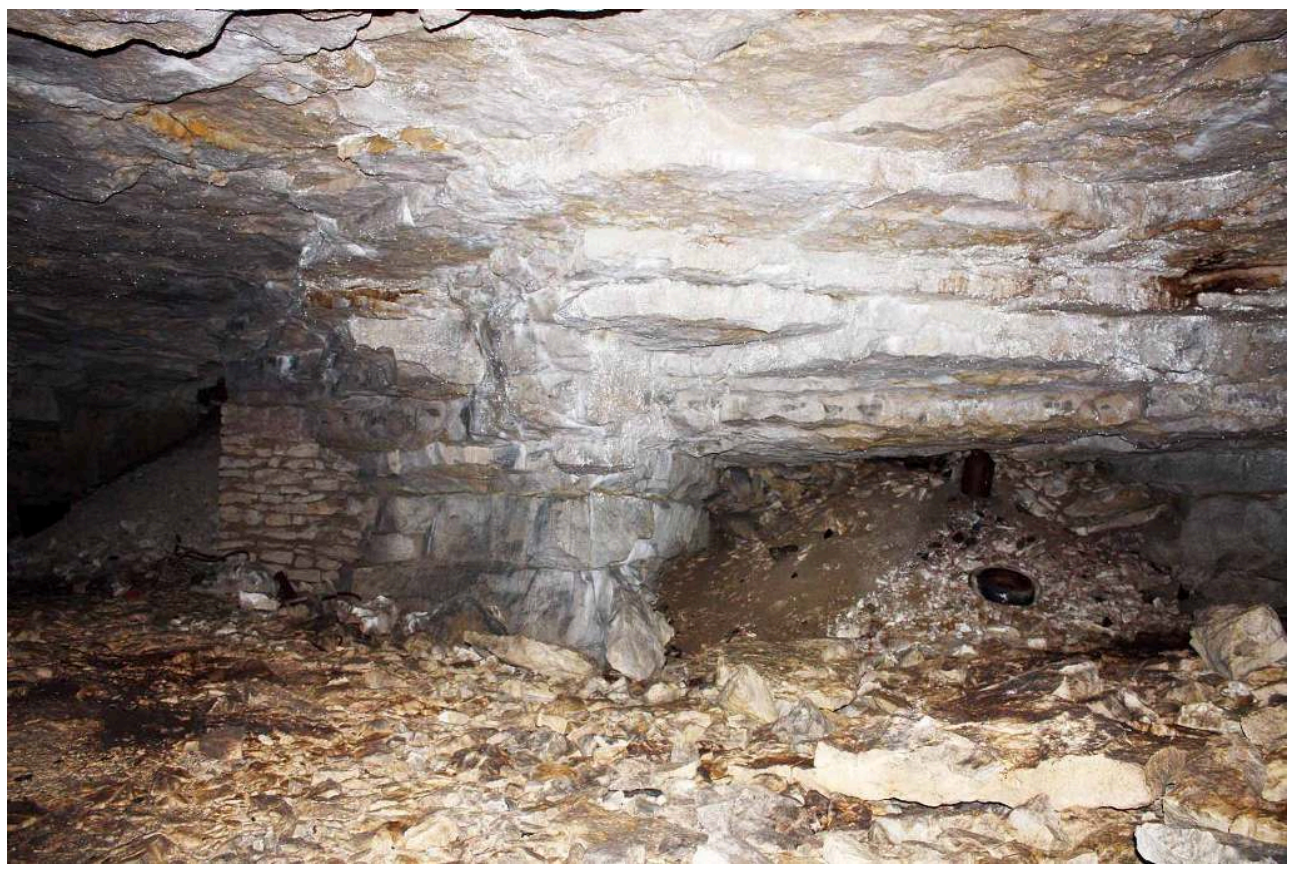

(c) Lucie Gaugain.

Les carrières dites du Château, ou des Averdines, existent encore aujourd'hui. Elles sont mentionnées dès le XIII ${ }^{\mathrm{e}}$ siècle ${ }^{54}$, et encore en usage $\mathrm{au} \mathrm{XVI}{ }^{\mathrm{e}}$ siècle ${ }^{55}$. Elles présentent des bancs de pierre de qualité, propre au moyen voire au grand appareil (fig. 5). Par conséquent, il semble bien improbable que l'on en ait débité de petites pierres, plus 
longues à mettre en œuvre. Force est donc d'admettre que certains bancs étaient de qualité nettement inférieure.

À Charly, les bancs actuels sont nettement plus maigres et se délitent naturellement en plaques de 5 à $15 \mathrm{~cm}$ (fig. 6). Soulignons d'ailleurs que le ciel de la carrière est par endroits soutenu par des piliers maçonnés en petit appareil très semblable à celui mis en œuvre dans les caves de Bourges. Il est manifeste que les beaux bancs ont été exploités notamment pour la pierre sculptée de la cathédrale ${ }^{56}$. Les carrières de Charly sont situées à $44 \mathrm{~km}$ de Bourges, ce qui est relativement éloigné. Rappelons combien le transport par voie terrestre est coûteux jusqu'à l'époque contemporaine, à plus forte raison pour les matériaux volumineux mais de peu de valeur ${ }^{57}$. À l'aune de plusieurs chantiers de la fin $d u x^{e}$ siècle, Denis Cailleaux évalue le coût du transport du chargement d'un chariot à 5 deniers tournois le kilomètre, à raison de $40 \mathrm{~km}$ parcourus dans la journée. Si l'on rapporte ce coût au prix de revient de la pierre de seconde qualité, il représente un surcoût important. Cependant, Bourges étant une véritable ville-chantier pendant plus de trois siècles, il paraît vraisemblable qu'un commerce du petit appareil s'était mis en place, parallèlement à celui des quartiers ou des beaux blocs de pierre de taille attestés par les comptes ${ }^{58}$. L'exploitation de ces bancs impropres au beau parement ou à la sculpture pouvait même permettre d'amortir les coûts de transport en les répartissant sur une clientèle variée.

Le troisième faciès est un calcaire oolithique du Jurassique supérieur, de couleur grise à très blanche (fig. 7). Issu d'une boue calcaire, c'est une roche très tendre, facile à tailler et mal stratigraphié ${ }^{59}$, qui présente un grain très fin, presque crayeux, et de très rares fragments de coquilles bivalves. Il est strictement identique à la pierre présente dans les nombreux fronts de taille des caves de la ville ${ }^{60}$. 
Fig. 7. - Bourges (Cher), hôtel Jacques Cœur : vue de la pierre du substrat de la ville dans les cellules latérales du niveau R-3 des caves.

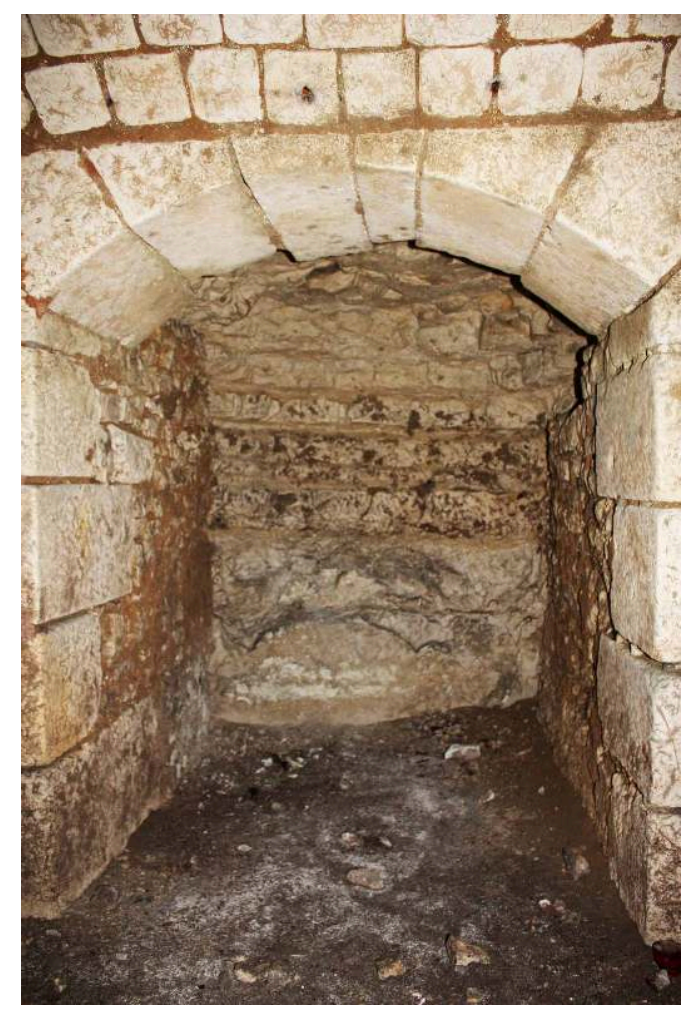

(c) Lucie Gaugain

Il est donc manifeste que les cavités ont servi de lieu d'approvisionnement d'appoint intra muros; c'est un mode d'extraction bien connu dans les villes, qui a été étudié à Orléans notamment ${ }^{61}$, mais aussi à Laon (Aisne), Provins (Seine-et-Marne), Crépy-enValois (Oise) ou Pontoise (Val-d'Oise) ${ }^{62}$. Si l'usage des caves dépasse notre présente étude, il semble néanmoins justifié de s'interroger sur les motivations qui ont pu présider à leur creusement. Les caves de l'ancien évêché présentent, au niveau le plus bas (R-2), une galerie appareillée en petit appareil avec le calcaire à grain fin du substrat rocheux affleurant in situ. Épaulée de deux doubleaux et d'une croisée d'ogives épaisse et simplement chanfreinée, elle ouvre sur un puits d'extraction creusé dans la roche. Sans pouvoir proposer une fourchette de datation plus précise que $\mathrm{XIII}^{\mathrm{e}}-\mathrm{XV}^{\mathrm{e}}$ siècle, cet exemple montre que le savoir-faire du petit appareil s'exprimait même dans la construction sans vocation commerciale.

Le choix d'un petit appareil de pierre réglé témoigne certes d'une volonté de rationalisation de l'extraction des ressources lithiques, mais sans pour autant perdre en qualité constructive. Il s'est agi d'exploiter des bancs de pierre qui n'auraient pu l'être que pour le moellon - ce qui aurait entaché le rendu esthétique des voûtes des caves tout en limitant la production de déchets. Il a d'ailleurs été observé dans certaines caves $^{63}$ que le mortier contenait de la pierre pilée, en remplacement partiel de l'agrégat ${ }^{64}$. À l'hôtel Jacques Cœur, où des analyses de mortiers ont été menées (granulométrie et quantification de la chaux), on a ainsi pu quantifier jusqu'à $20 \%$ de pierre pilée dans l'agrégat ${ }^{65}$ (fig. 8 et fig. 9). 
Fig. 8. - Bourges (Cher), hôtel Jacques Cœur : analyse granulométrique de mortier prélevé dans les voûtes du niveau R-1.

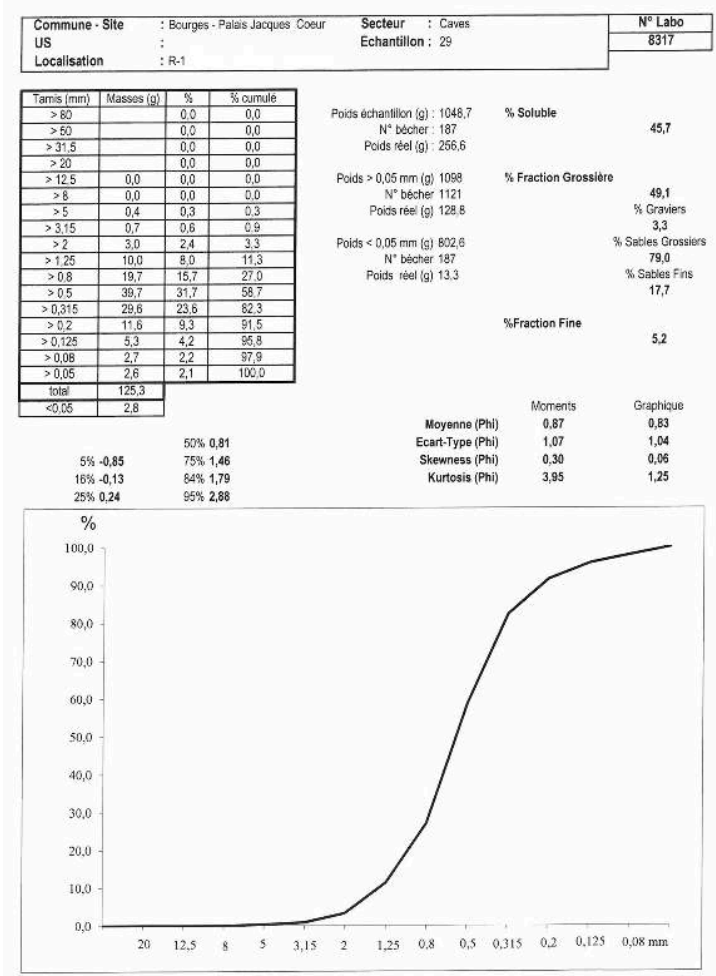

(c) Laura Millat et Daniel Prigent.

Fig. 9. - Bourges (Cher), 3 rue de La Thaumassière (Les Bonnets-Rouges, R-2) : vue de détail des voûtes dont le mortier contient de la pierre pilée en quantité.

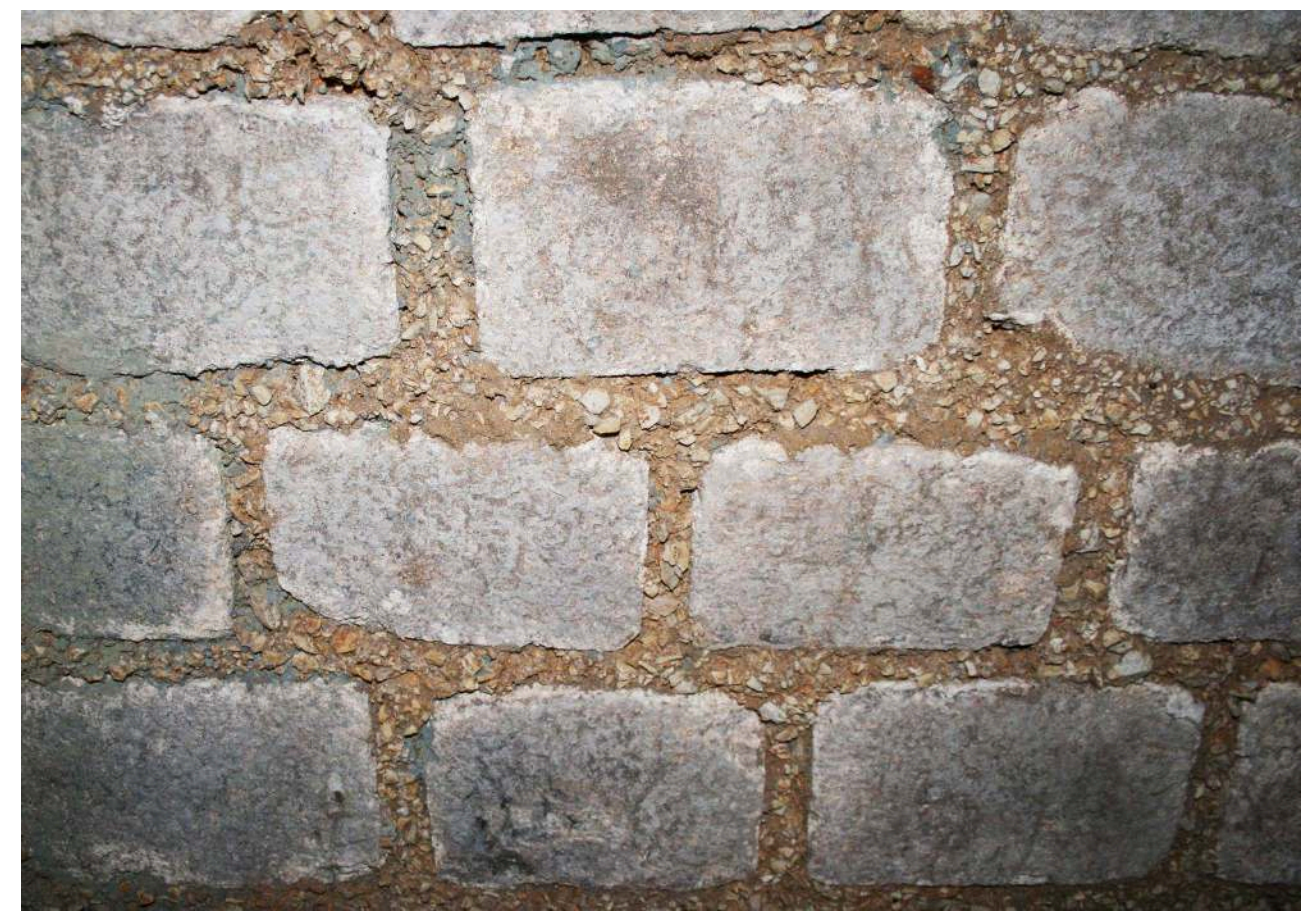

(c) Lucie Gaugain. 


\section{Conclusions}

30 grandit à mesure que l'on avance dans le Moyen Âge et l'époque moderne, si bien que le petit appareil tend à disparaître au XII siècle, au profit du moyen appareili6. En Normandie aussi, l'emploi du petit appareil de pierre de taille dans les caves est courant jusqu'au XIII ${ }^{e}$ siècle $^{67}$. La mise en œuvre du petit appareil présente un avantage non négligeable: les pierres peuvent être portées par un seul homme. Mais elle est plus longue, et consomme plus de mortier qu'un moyen appareil.

31 À Bourges, la particularité du petit appareil tient au fait qu'il est usité durant plus de trois siècles sans réelle évolution. Alors que les modules de hauteur et de longueur vont en s'agrandissant tout au long de l'époque médiévale et moderne, à Bourges, les constructeurs restent fidèles à l'emploi du petit appareil. Il résulte des possibilités techniques qu'offraient les ressources lithiques locales et du savoir-faire berruyer, mis en place dès les chantiers du XIII ${ }^{\mathrm{e}}$ siècle - notamment celui de la cathédrale, où certains voûtains des croisées d'ogives ${ }^{68}$ présentent cette même mise en œuvre - et qui se transmit ensuite avec constance. Le petit appareil tend à disparaître à la fin du $\mathrm{XVI}^{\mathrm{e}}$ ou au début du XVII ${ }^{\mathrm{e}}$ siècle, non pour un appareil plus grand mais pour une mise en œuvre moins soignée, en moellon et simplement coffrée. Notons encore sa diffusion dans des contextes très diversifiés, caves de modestes demeures urbaines ou de somptueux édifices civils ou religieux. S'il n'a pas été possible de montrer la corrélation entre la reconstruction de la ville après l'incendie de 1487 et l'usage de certaines techniques de construction, il semble en revanche permis de dire qu'à Bourges les savoir-faire se sont transmis grâce à la qualité et à la perméabilité des chantiers. Aussi faut-il s'interroger sur la mise en place d'une économie de la pierre liée au nombre des chantiers, qui permettait d'extraire des bancs de pierre pourtant peu propres à la construction en pierre de taille pour la mettre en œuvre sous forme de petit appareil.

\section{BIBLIOGRAPHIE}

ALCAYDÉ G., BROSSÉ R., LORENZ C., LORENZ J., RASPLUS L., 1989, Val-de-Loire, Anjou, Touraine, Orléanais, Berry, Paris, Masson (Guides géologiques régionaux), p. 159-178.

ALIX C., 2008, «L'habitat d'Orléans du $12^{\mathrm{e}}$ au début du $15^{\mathrm{e}}$ siècle ; état de la recherche : étude des élévations et apports de l'observation des caves ", Revue archéologique du Loiret et de l'axe ligérien, p. 123-147.

ALIX C. et MORLEGHEM D., 2019, « Les caves d'Orléans : apports de la recherche Sicavor », dans Salamagne A., Alix C., Gaugain L. (dir.), Caves et celliers dans l'Europe médiévale et moderne, Tours, Presses universitaires François Rabelais, p. 57-85.

ALIX C., JOSSET D., MASSAT T., 2014, « Activités d'extraction de matériaux calcaires au cœur de la ville d'Orléans entre la fin du $\mathrm{X}^{\mathrm{e}}$ et le $\mathrm{Xv}^{\mathrm{e}}$ siècle », dans Lorenz J., Blary F., Gély J.-P. (dir.), 
Construire la ville : histoire urbaine de la pierre à bâtir, actes du $137^{\mathrm{e}}$ Congrès national des sociétés historiques et scientifiques « Composition(s) urbaine(s) » tenu à Tours du 23 au 28 avril 2012, Paris, Éditions du CTHS, p. 11-26.

BERNON A. et TROTIGNON P., 1991, « Bourges : les carrières des Averdines ou du Château », Cahiers d'archéologie et d'histoire du Berry, $\mathrm{n}^{\circ}$ 106, p. 1-46.

BLANC A., LEBOUTEUX P., LORENZ J., DEBRAND-PASSARD S., 1982, « Les pierres de la cathédrale de Bourges ", Archéologia, n 17, p. 22-35.

BLARY F., 2013, " Archéologie du bâti : inventaire des caves et salles basses de Château-Thierry », dans Blary F. (dir.), Origines et développements d'une cité médiévale : Château-Thierry, Senlis, Revue archéologique de Picardie (numéro spécial 29), p. 86-111.

BRGM, 2004, « Piercentre : système d'information sur les pierres et monuments de la région Centre, rapport final », BRGM/RP-52645-FR, Orléans, BRGM (Bureau des recherches géologiques et minières).

CAILLEAUX D., 1999, La cathédrale en chantier : la construction du transept de Saint-Étienne de Sens d'après les comptes de la fabrique, 1490-1517, Paris, Éditions du CTHS.

CHAUMET G., 2012, « La maison d'Ourscamp : 44-48, rue François Miron », dans Hamon E. et Weiss V. (dir.), La demeure médiévale à Paris, Paris, Somogy, p. 91-92.

CHAZELLE A., 1997, Les maisons en pan de bois de Bourges (Cher), Paris, L'Inventaire.

CLABAUt J.-D., 2001, Les caves médiévales de Lille, Villeneuve d'Ascq, Presses universitaires du Septentrion.

CLABAUT J.-D., 2007, Les caves de Douai : la construction civile au Moyen Âge, Villeneuve d'Ascq, Presses universitaires du Septentrion.

COUTELAS A. (dir.), 2009, Le mortier de chaux, Paris, Errance.

DEFORGE O., 2003, «La maison urbaine au temps des foires de Champagne : l'exemple de Provins ", dans Garrigou Grandchamp P. (dir.), La maison au Moyen Âge, actes de la session de l'université d'été 2003 organisée par Via Patrimoine, Angoulême, Société archéologique et historique de la Charente ( ${ }^{\circ}$ spécial du Bulletin de la Société archéologique et historique de la Charente), p. 191-206.

DESHAYES G., 2019, « Les caves de l'abbaye de Conches-en-Ouche (Eure, Normandie) », dans Salamagne A., Alix C., Gaugain L. (dir.), Caves et celliers dans l'Europe médiévale et moderne, Tours, Presses universitaires François Rabelais, p. 225-240.

ESQUIEU Y. et HARTMANN-VIRNICH A. (dir.), 2007, « Les signes lapidaires dans la construction médiévales : études de cas et problèmes de méthode », Bulletin monumental, vol. 165, $\mathrm{n}^{\circ} 4$, p. 331-358.

FASSE-MOREAU A., 2014, « Deux petites exploitations de calcaire lutétien en contexte urbain à la fin du Moyen Âge : les carrières de la place des Moineaux à Pontoise (Val d'Oise) », dans Lorenz J., Blary F., Gély J.-P. (dir.), Construire la ville : histoire urbaine de la pierre à bâtir, actes du $137^{e}$ Congrès national des sociétés historiques et scientifiques « Composition(s) urbaine(s) » tenu à Tours du 23 au 28 avril 2012, Paris, Éditions du CTHS, p. 51-60.

GARRIGOU GRANCHAMP P., 2008, Demeures médiévales : cœur de la cité, Paris, Rempart.

GAUCHERY R., 1937-1938, « Matériaux employés dans les anciens édifices du Cher », Mémoires de la société littéraire et scientifique du Cher, $4^{\mathrm{e}}$ série, $43^{\mathrm{e}}$ vol., p. 85-97.

GAUGAIN L., 2014, Amboise : un château dans la ville, Tours, Presses universitaires François Rabelais. 
GAUGAIN L., 2019, « Le château de Pocé en Anjou (Distré, Maine-et-Loire), vers 1200-vers 1400 » Bulletin monumental, vol. 77, $\mathrm{n}^{\circ}$ 1, p. 15-37.

GAUGAIN L. et LAFONT M., à paraître, «L'hôtel des Échevins », dans Actes du 176 Congrès archéologique de France, «Bourges et le Berry» (Bourges, 2017), Société française d'archéologie.

GAUGAIN L., BRÉHERET J.-G., PRIGENT D., MECHLING J.-M., 2017, « Pierres, mortiers et parements de la tour des Minimes au regard du compte de construction de 1495-1496: des investigations archéologiques et des analyses pétrographiques ", ArchéoSciences, revue d'archéométrie, p. 45-63.

GAUGAin L., MILLAT L., SALAMAGNE A., BRÉHERET J.-G., 2019, « Les caves d'un hôtel marchand : le palais Jacques Cœur à Bourges ", dans Salamagne A., Alix C., Gaugain L. (dir.), Caves et celliers dans l'Europe médiévale et moderne, Tours, Presses universitaires François Rabelais, p. 390-402.

GRATIAS C. et STIEVENARD-BILLÈRE B., 1995, Bourges, la mémoire d'une ville, Bourges, service du Patrimoine.

GUillaume J. et Toulier B., 1983, « Tissu urbain et types de demeures : le cas de Tours », dans Guillaume J., Boudon F., Babelon J.-P. (dir.), La maison de ville à la Renaissance : recherches sur l'habitat urbain en Europe aux XVe et XV siècles, actes du colloque tenu à Tours du 10 au 14 mai 1977, [organisé par le] Centre d'études supérieures de la Renaissance, Paris, Picard, p. 9-23.

HAMON É., 2002, « La cathédrale de Bourges : bâtir un portail sculpté à l'époque flamboyante », Revue de l'art, vol. 138, $\mathrm{n}^{\circ}$ 4, p. 19-30.

HAMON É., 2003, « Les débuts du chantier de l'hôtel-Dieu de Bourges d'après les sources comptables ", Bibliothèque de l'École des chartes, vol. 161, nº 1, p. 9-32.

JOURD'HEUIL I., MARCHANT S., PRIET M.-H. (dir.), 2017, Cathédrale de Bourges, Tours, Presses universitaires François Rabelais.

MAROT É., à paraître, « Les maisons-tours, résidences de bourgeois au XII siècle à Châteauneuf (Tours) ", dans Hamon É. (dir.), Actes du colloque Formes de la maison au Moyen Âge et à la Renaissance entre Loire et Meuse (Amiens, 26- 27 mai 2016), Amiens, université de Picardie - Jules-Verne.

MiLlAT L., 2017a, « Les caves du palais Jacques Cœur », mémoire de master 1, Tours, université François-Rabelais, 3 vol.

MiLLAT L., 2017b, « Palais Jacques Cœur (caves) : étude des mortiers », rapport de stage de master 1, Tours, université François-Rabelais.

MINISTÈRE DES TRAVAUX PUBLICS, Répertoire des carriers de pierre de taille exploitées en 1889 : recherches statistiques et expériences sur les matériaux de construction, Paris, 1890.

MONTAGNE D., 1995, « Observations dans les anciennes carrières Lutétien de Laon (Aisne) », dans Lorenz J., Benoit P., Obert D. (dir.), Pierres et carrières : géologie, archéologie, histoire, actes des journées Claude Lorenz, Paris, Association des géologues du bassin de Paris / Association pour l'édition et la diffusion des études historiques, p. 225-228.

PRIGENT D., 1997, « Méthodes d'investigations archéologiques utilisées à l'abbaye de Fontevraud », Fontevraud histoire-archéologie, $\mathrm{n}^{\circ}$ 4, p. 17-37.

PRIGENT D., 2000, « La pierre de construction et sa mise en œuvre : l'exemple de l'Anjou », dans Utilis est lapis in structura : mélanges offert en hommage à Léon Pressouyre, Paris, Éditions du CTHS, p. 461-474. 
RAPIN T., 2010, «Les chantiers de Jean de France, duc de Berry : maîtrise d'ouvrage et architecture à la fin du Moyen Âge », thèse de doctorat sous la direction de Claude Andrault-Schmitt, Poitiers, université de Poitiers.

RENAUD B., 2016, «Les caves médiévales de la ville de Riom (Puy-de-Dôme) », dans Goer M., de Vries D. J., Furrer B., Klein U., Stiewe H., Weidlich A. (dir.), West-und mitteleuropäischer hausbau im wandel, 1150-1350, Marburg, Jonas (Jahrbuch für Hausforschung, 56), p. 227-242.

RISSELIN-NIN C., 1989, Le rempart de Philippe-Auguste et la grosse tour de Bourges, Bourges, Université populaire du Berry.

SABIN M., 2002, «L'approvisionnement et l'organisation des chantiers médiévaux des enceintes urbaines de Bourges », mémoire de DEA, Tours, université François-Rabelais.

SAILLAND F., 2017, L'hôtel Renaissance des Lallemant dévoilé par leurs manuscrits enluminés, Bourges, F. Saillant.

SALAMAGNE A., à paraître a, « Le palais Jacques Cœur », dans Actes du $176^{e}$ Congrès archéologique de France, « Bourges et le Berry» (Bourges, 2017), Société française d'archéologie.

SALAMAGNE A., à paraître b, «L'hôtel Cujas ", dans Actes du $176^{e}$ Congrès archéologique de France, «Bourges et le Berry» (Bourges, 2017), Société française d'archéologie.

SANDRON D., 2012, «Les caves médiévales », dans Hamon E. et Weiss V. (dir.), La demeure médiévale à Paris, Paris, Somogy, p. 87-90.

\section{NOTES}

1. Thèse en cours sous la direction d'A. Salamagne au Centre d'études supérieures de la Renaissance (CESR), portant sur la reconstruction de la ville de Bourges après le grand incendie de 1487.

2. Projet porté par A. Salamagne (CESR, UMR 7323 du CNRS), réalisé entre 2014 et 2018.

3. Millat 2017a, Gaugain et al. 2019.

4. C'est notamment le cas de la rue Mirebeau.

5. Jourd'heuil et al. 2017.

6. Risselin-Nin 1989.

7. Jourd'heuil et al. 2017.

8. Gratias et Stievenard-Billère 1995.

9. Rapin 2010.

10. Salamagne à paraître $a$.

11. Gaugain et Lafont à paraître.

12. Chazelle 1997.

13. Sailland 2017.

14. Salamagne à paraître $b$.

15. Hamon 2003.

16. Jourd'heuil et al. 2017. 
17. Les archives municipales ne renseignent pas directement la construction de l'architecture civile privée, mais comme les sources textuelles documentant le chantier de la cathédrale, elles livrent le nom des carrières approvisionnant la ville en pierre.

18. Nous adressons nos profonds remerciements à Jean-Gabriel Bréheret (université de Tours, laboratoire GéHCO) qui a réalisé les observations macroscopiques des pierres.

19. Ces 43 adresses correspondent à quelques 65 vaisseaux de caves, car dans bon nombre de cas les demeures disposent d'un réseau relativement étendu. Les caves de l'hôtel Jacques Cœur, les plus grandes, se déploient sur $600 \mathrm{~m}^{2}$, 3 niveaux et 12 vaisseaux.

20. La présence de caves est bien attestée dans la totalité de l'emprise de l'enceinte, comme en témoignent les très nombreux soupiraux ouvrant sur les rues.

21. Les caves de la rue Bourbonnoux, et vers la place Gordaine, sont bien étudiées car les habitants ont ouvert leurs portes. Rue Mirebeau par exemple, où nous avons observé un porte-à-porte systématique, aucune cave n'a pu être visitée, en dépit des très nombreux soupiraux ouvrant sur la rue.

22. Ceci est bien renseigné par les minutes notariales qui ont été dépouillées. Voir notamment: Arch. dép. Cher, E 1212 à 1215, 1223, 1224, 17210, «Minutes de Pierre Baujard, notaire à Tours ", 1487-1500.

23. Alix et Morleghem 2019.

24. Chazelle 1997, Guillaume et Toulier 1983, Alix 2008, Garrigou Granchamp 2008.

25. 3 rue Bourbonnoux, 25 rue Bourbonnoux, 10 bis rue des Beaux-Arts.

26. Gaugain et al. 2017. Ce terme n'a pas été retrouvé dans les archives municipales de Bourges, mais les « menues » pierres pourraient les désigner.

27. Gaugain 2014.

28. Marot à paraître.

29. Clabaut 2007.

30. Clabaut 2001.

31. Alix et Morleghem 2019.

32. Nous faisons là référence aux observations d'Alain Lelong, qui nous a gentiment fait visiter la cave Alcyde Hayer.

33. Blary 2013.

34. Chaumet 2012, Sandron 2012.

35. Renaud 2016.

36. Hôtel Lallemant (niveau -1), palais Jacques Cœur (niveaux -1 et -2), palais du duc de Berry, 15 rue Bourbonnoux (niveau-1), 54 rue Coursarlon (niveau-1, cavité 2 ), 3 rue Joyeuse, 3 rue du Chevreau.

37. Hôtel Lallemant (niveau -2), hôtel Jacques Cœur (niveau -3), 5, 9, 13, 25 et 68 rue Bourbonnoux, 54 rue Coursarlon (niveau-1, cavité 1), 5 rue Jean Girard, 1 bis rue Joyeuse, 17 place Planchat, 3 rue Michel-Servet, 1 rue Victor-Hugo (niveaux -1 et -2), Service culturel de la ville de Bourges (place Étienne-Dolet), 3 rue de la Thaumassière (niveaux -1 et -2).

38. 13 rue Bourbonnoux, 3 rue Joyeuse, 3 rue de la Thaumassière. 
39. Hôtel Lallemant (niveaux -1 et -2), palais Jacques Cœur (niveaux -1 et -3), 5, 13 et 68 rue Bourbonnoux, 4 rue Joyeuse, 21 rue Victor Hugo (niveaux -1 et -2 ), Service culture de la ville de Bourges (place Étienne-Dolet), 3 rue de la Thaumassière (niveau -2).

40. Alix et Morleghem 2019.

41. 12, 72, 13 (niveau -2), 15 (niveau -2) rue Bourbonnoux, 3 bis rue Joyeuse, 13 rue Édouard-Branly, 1-3 rue du Docteur-Témoin, 3 rue de la Thaumassière (niveau -1)

42. 25 et 35 rue Bourbonnoux, 54 rue Coursarlon (niveau -2).

43. 13 rue Bourbonnoux, 3 rue Joyeuse.

44. Nous témoignons nos plus sincères remerciements à Daniel Prigent, qui a accepté d'analyser statistiquement ces mesures d'appareil.

45. Dans l'état actuel des connaissances, il semble que le marquage des modules fasse son apparition $\mathrm{au} \mathrm{XIII}{ }^{\mathrm{e}}$ siècle. C'est en tout cas ce que l'on constate dans les régions où cet aspect de la construction est bien étudié, comme l'Anjou-Touraine (Esquieu et Hartmann-Virnich 2007, Gaugain 2019).

46. Oolithe: «petit grain sphérique calcaire ou ferrugineux, composé d'un corps central entouré de fines couches concentriques superposées et ressemblant à un œuf de poisson ", définition du Centre national de ressources textuelles et lexicales (CNRTL).

47. Pisolithe : « concrétion calcaire sphérique à structure concentrique, d'un diamètre supérieur à celui d'une oolithe », définition du CNRTL.

48. Bivalve : "coquille composée de deux valves réunies par un ligament ", définition du CNRTL.

49. Bernon et Trotignon 1991, BRGM $2004: 15-17$ et 32 .

50. Ministère des Travaux publics 1890 .

51. Alcaydé et al. 1989.

52. Gauchery 1937-1938, Blanc et al. 1982.

53. Hamon 2002, Sabin 2002.

54. Bernon et Trotignon 1991.

55. Autour de 1495, dans les comptabilités de la ville (Arch. mun. Bourges, CC 265, «Compte du receveur de la ville pour l'année 1494-1495»), le moyen appareil coûte entre $2 \mathrm{~s} .1 \mathrm{~d}$. et $3 \mathrm{~s}$. le quartier de pierre, ce qui est relativement élevé. Le prix de revient des pierres du petit appareil n'a pas été rencontré dans les comptes, car l'organisation des chantiers est gérée par des entrepreneurs (par prix fait et non en régie) et que le détail des achats n'apparaît pas. Il pourrait cependant être rapproché des mentions de pierres "menues", qui sont opposées aux "cartiers ». Arch. mun. Bourges, CC 152, «Compte des dépenses de l'octroi sur le sel accordé par Charles VIII, 1487-1492 » : «A prudent homme Bernard Villain payé la somme de deux mil huit cens livres tournoy pour la maçonnerie qu'il a faicte faire ou aupres de la maison de la ville de Bourges fourny de cartiers de Charly, Saint Crapaix, les Avardines, pierre menue, chau, sable et guallement toutes autres choses adce necessaires pour ce icy ".

56. Hamon 2002.

57. Cailleaux 1999 : 290-293. Gaugain 2014 :181-182.

58. Arch. mun. Bourges, série CC. Les registres de compte sont conservés quasiment intégralement à partir de 1487. 
59. Blanc et al. 1982.

60. Hôtel Jacques Cœur, 4 rue Joyeuse, 3 rue de la Thaumassière, 11 rue Jacques Rimbault.

61. Alix et al. 2014, Alix et Morleghem 2019.

62. Montagne 1995, Deforge 2003, Fasse-Moreau 2014.

63. Hôtel Jacques Cœur et 3 rue de la Thaumassière.

64. Il s'agit là d'un mode de fabrication du mortier peu usité, ou tout du moins peu étudié. Coutelas 2009.

65. Millat 2017a et 2017b.

66. Prigent 2000 et 1997.

67. Deshayes 2019.

68. Sur les voûtains des travées du bas-côtés sud, l'enduit portant un faux-appareil peint est tombé par endroit, laissant ainsi apparaître les pierres «pendants » dont les modules sont proches du petit appareil des voûtes des caves.

\section{RÉSUMÉS}

L'étude récente des caves de l'hôtel Jacques Cœur de Bourges a mis en évidence la construction de voûtes en berceau construites en petit appareil numéroté selon des modules de hauteur d'assises (0 à VII et 0 barré), de 3,9 à 15,3 cm de haut. Ce type de construction a été retrouvé dans les caves de la ville dans des contextes très diversifiés allant de l'hôtel particulier à la petite unité d'habitation en pan de bois, entre le $\mathrm{XIII}^{\mathrm{e}}$ et le milieu du $\mathrm{XVI}^{\mathrm{e}}$ siècle. L'étude macroscopique des pierres mises en œuvre et de celles citées par les archives, croisée avec les mesures d'appareil et les analyses de mortiers, autorisent à avancer certaines hypothèses sur les origines de cette technique. Foyer artistique de la création architecturale du second Moyen Âge jusqu'au début de la Renaissance, Bourges mit ainsi en place, en réponse à la nature de ses ressources lithiques, une économie de la pierre qui transparaît dans la permanence de ce savoir-faire.

\section{INDEX}

Mots-clés : petit appareil, cave, économie de la pierre, technique de construction, fabrique de la ville, identité urbaine, Moyen Âge

Index géographique : Bourges

\section{AUTEURS}

\section{LUCIE GAUGAIN}

Chercheuse associée à l'université de Tours, Centre d'études supérieures de la Renaissance (UMR $7323 \mathrm{du}$ CNRS) 


\section{MARIE LAFONT}

Doctorante contractuelle à l'université de Tours, Centre d'études supérieures de la Renaissance (UMR $7323 \mathrm{du}$ CNRS)

LAURA MILLAT

Titulaire d'un master à l'université de Tours 


\title{
La citerne Basilique et
} l'approvisionnement en eau de Constantinople (actuelle Istanbul, Turquie) à l'époque tardo-antique : des ruptures économiques et constructives avec l'époque romaine

\author{
Anaïs Lamesa et Ferudun Özgümüş
}

1 L'étude de l'approvisionnement en eau de Constantinople a connu ces dernières années un développement sans précédent, notamment grâce au programme de recherche " Engineering the Byzantine water supply : procurement, construction and operation » mené par le professeur J. Crow de l'université d'Edimbourg. Son équipe a pu mettre en exergue plusieurs ruptures entre les époques romaine et tardo-antique dans les stratégies d'approvisionnement et de conservation de l'eau à Constantinople ${ }^{1}$.

Outre ces quelques points, nous souhaitons également nous arrêter sur la citerne Basilique ou Yerebatan Sarnıcı. Elle est actuellement l'une des attractions touristiques de la ville d'Istanbul. Depuis les premiers témoignages de voyageurs au XVI siècle, elle a toujours étonné par sa structure et son esthétique ${ }^{2}$. Une de ses particularités est l'emploi de chapiteaux et de colonnes pour l'édifier ${ }^{3}$. L'origine de ces éléments architecturaux n'a pas semblé poser question, la plupart des chercheurs les voyant comme des remplois ou des produits semi-finis provenant directement des carrières de Proconnèse (île de Marmara, Turquie). Le but principal de cet article est de questionner ces hypothèses à la lumière d'observations de terrain et de mettre en lumière la possible existence d'une économie basée sur les rebuts de carrières et de chantiers, mise en place à Constantinople durant la période des $\mathrm{V}^{\mathrm{e}}$ et $\mathrm{VI}^{\mathrm{e}}$ siècles, très active d'un point de vue de la construction et de la restauration de monuments publics et privés ${ }^{4}$. 


\section{Le système de conservation des eaux à Constantinople}

3 Dans une récente étude, K. Ward, J. Crow et M. Crapper rappellent les enjeux de l'approvisionnement en eau de Constantinople ${ }^{5}$. La ville, déjà importante à l'époque romaine, se développe véritablement lorsque Constantin décide d'en faire la capitale de son nouvel Empire. À l'image d'une nouvelle Rome, Constantinople s'étend symboliquement sur sept collines. Lieu stratégique, à mi-chemin entre les frontières occidentales et orientales de l'Empire, Constantinople possède un système de défenses naturelles, puisque trois de ses côtés donnent sur la mer.

4 Toutefois, un problème majeur semble se poser à la ville dès l'époque romaine, son manque d'eau douce ${ }^{6}$. Pour le résoudre, plusieurs réseaux d'adduction d'eau prenant la forme de conduites souterraines et d'aqueducs sont progressivement construits, principalement durant le règne de Valens ${ }^{7}$. Aucune trace du réseau construit par Hadrien n'a été retrouvée pour le moment, contrairement à celui de Valens, dont plusieurs canalisations ont pu être authentifiées ${ }^{8}$.

5 C'est à partir de cette seconde période que la stratégie d'approvisionnement en eau semble évoluer et forme la principale et première rupture avec l'époque romaine : en effet, l'apport en eau répondait au besoin des citoyens, on augmentait le volume si nécessaire. Le $\mathrm{IV}^{\mathrm{e}}$ siècle marque un tournant, dans la mesure où prime progressivement le stockage de l'eau dans des citernes et des réservoirs au gabarit varié9. Cette nouvelle politique expliquerait le développement significatif de ce type d'infrastructures à Constantinople durant la période tardo-antique ${ }^{10}$. On dénombre actuellement 211 citernes et réservoirs à Istanbul, construits entre le $\mathrm{IV}^{\mathrm{e}}$ et le $\mathrm{XV}^{\mathrm{e}}$ siècle, chiffre remarquable pour une ville méditerranéenne ${ }^{11} ; 33,8 \%$ d'entre eux ont pu être datés entre le $\mathrm{IV}^{\mathrm{e}}$ et le $\mathrm{VII}^{\mathrm{e}}$ siècle $^{12}$. La contenance de certaines citernes - la citerne Basilique et la citerne Binbirdirek - les distingue des plus grandes citernes du monde méditerranéen ${ }^{13}$. Elles pourraient illustrer cette politique impériale de conserver les eaux affluant vers la capitale. La raison de ce changement de stratégie à l'époque tardoantique n'est pas établie avec certitude et pourrait résulter de plusieurs facteurs ${ }^{14}:$ la présence de karsts rendant le flot des eaux discontinu, ou encore, en se basant principalement sur des témoignages textuels, la rigueur de l'été et la menace d'une interruption de l'approvisionnement en eau lors de sièges ou d'une conquête ont été avancées ${ }^{15}$.

6 La deuxième rupture réside dans la forme même que prennent les citernes constantinopolitaines ${ }^{16}$. Ainsi, on rencontre une variété de modes de couvrements (voûtes, coupoles) contrastant avec la traditionnelle voûte en berceau dans la plupart des citernes romaines et tardo-antiques du monde méditerranéen ${ }^{17}$. Si l'on s'attarde sur la citerne Basilique, celle-ci est couverte de voûtes d'arêtes ${ }^{18}$. Ce mode de couvrement, associé à des tirants en bois placé entre chaque colonne, pourrait avoir un rôle parasismique $^{19}$. De même, l'emploi de la brique prime sur la pierre dans la plupart des citernes de la ville; cela serait également dû au risque de tremblement de terre ${ }^{20}$.

7 La troisième particularité est l'utilisation de colonnes en marbre ou en granit et de chapiteaux en marbre comme structures portantes ${ }^{21}$. Dans le cadre des citernes édifiées après le milieu du $\mathrm{VI}^{\mathrm{e}}$ siècle, il semble que la plupart de ces éléments architectoniques soient des remplois de l'époque tardo-antique ${ }^{22}$. Pour les chercheurs, les types de 
chapiteaux mis en œuvre dans ces infrastructures sont des indices pour déterminer leur terminus post quem ${ }^{23}$. Le réemploi de matériaux issus de bâtiments plus anciens durant les périodes médiévale et moderne à Constantinople n'est plus à démontrer ${ }^{24}$. Dans le cas des citernes construites à l'époque tardo-antique, l'identification de ces éléments porteurs pose davantage question. C'est sur ce dernier point que nous souhaiterions à présent nous attarder en nous intéressant plus particulièrement à la citerne Basilique, Yerebatan Sarnıcı.

\section{La citerne Basilique ou Yerebatan Sarnıcı}

La citerne Basilique se situe entre la première et la deuxième colline d'Istanbul, non loin de l'église Sainte-Sophie et du palais impérial, et alimentait les jardins de palais ottomans ${ }^{25}$. Elle s'étend sous l'actuelle Yerebatan Caddesi (fig. 1a). Elle a été construite ou agrandie par Justinien (527-565) sous la cour d'un ancien bâtiment public, la Basilique comme en témoigne Procope, historien contemporain de Justinien, qui relate sa construction dans son ouvrage Les Édifices ${ }^{26}$. La date exacte du chantier n'est pas connue, mais J. Crow propose de le placer entre 527 et 561, date où le préfet de la ville Longinus aurait pavé à nouveau la cour de la Basilique et construit une colonnade ${ }^{27}$.

Fig. 1. - Plan du quartier fortifié d'Istanbul, de Galata et de Péra (a) et de la citerne Basilique (b)

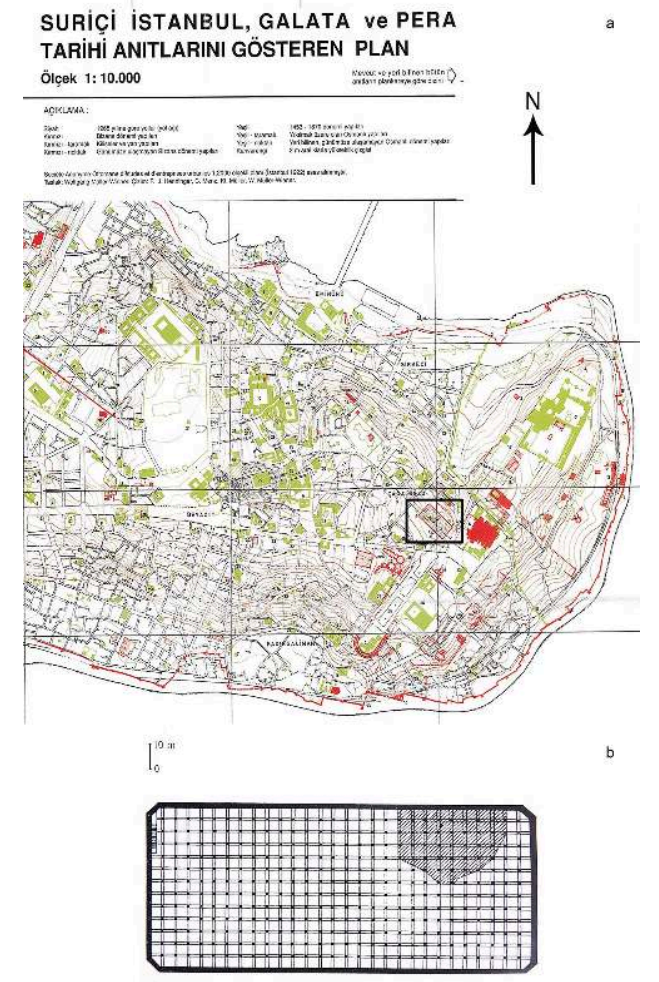

A : en rouge, les structures de l'époque byzantine ; en rouge rayé, les églises et les structures secondaires; ; en pointillés rouges, les structures byzantines détruites à l'heure actuelle. Échelle 1:10 000. B : la partie grise du plan de la citerne Basilique est une zone inaccessible, délimitée par un mur réalisé pour une restauration sous Abdulhamid II, à la fin du xıx ${ }^{\mathrm{e}}$ siècle.

Extrait de W. Müller-Wiener et al., Bildlexikon zur Topographie Istanbuls, avec l'aimable autorisation de $M^{\text {me }}$ Müller-Wiener. 
La citerne Basilique mesure $138 \times 64,6$ mètres et est divisée en 12 travées formées de 28 supports chacune; elle compte donc 336 colonnes (fig. 1 b) ${ }^{28}$. Sa capacité a été estimée 80230 mètres cubes ${ }^{29}$. Elle a subi plusieurs remaniements et restaurations aux époques moderne et contemporaine. Une partie au sud-ouest de la structure a été détruite, semble-t-il à l'époque du sultan Adbülhamid II (1876-1909) ${ }^{30}$. Identifiée de manière certaine, la citerne Basilique a fait l'objet de nombreuses publications ${ }^{31}$.

Les éléments architectoniques qui la composent ont également fait couler beaucoup d'encre, plusieurs ayant été assimilés à des spolia ${ }^{32}$ : les plus remarquables sont les deux têtes de Méduse utilisées comme bases ; leur datation est discutée, elles pourraient être datées de l'époque de Septime Sévère (193-211) ou appartenir à un des monuments construits par Constantin (310-337) ${ }^{33}$ (fig. 2).

Fig. 2. - Istanbul (Turquie), citerne Basilique de Constantinople : une des deux têtes de Méduse servant de base dans la zone nord-ouest.

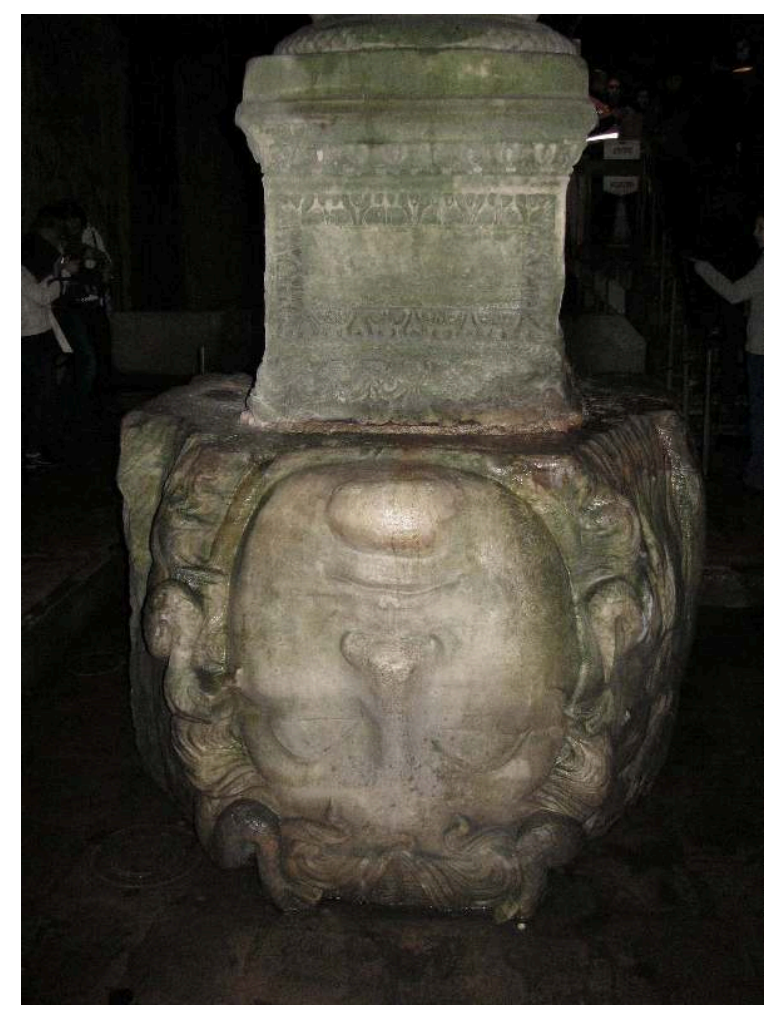

(c) Anaïs Lamesa.

11 Une architrave inscrite, à proximité du mur de l'époque ottomane, proviendrait du forum de Constantin ${ }^{34}$.

Les chapiteaux sont les artefacts les plus étudiés. Un seul a été identifié de manière certaine à l'époque sévérienne ${ }^{35}$; deux autres pourraient avoir été sculptés, selon les auteurs, soit autour de 200 après J.-C., soit à l'époque de Constantin ${ }^{36}$. L'origine d'un lot homogène de 98 chapiteaux corinthiens complètement achevés est également discutée. C. Mango propose d'y voir l'utilisation d'un vieux stock du ve siècle conservé à Constantinople ${ }^{37}$. A contrario, W. E. Betsch, suivi par la majorité des chercheurs, propose de les placer au $\mathrm{VI}^{\mathrm{e}}$ siècle, à l'époque du chantier de la citerne ${ }^{38}$. Enfin, la grande majorité des chapiteaux et impostes sont des produits semi-finis ou en cours 
d'épannelage; ils dateraient donc $\mathrm{du} \mathrm{VI}^{\mathrm{e}}$ siècle et proviendraient directement des carrières de marbre de Proconnèse ${ }^{39}$.

13 L'unique colonne ayant attiré l'attention des chercheurs est située quasiment au centre de la citerne, elle est ornée d'un motif reprenant la forme d'ocelles de paon. Elle a été datée $\mathrm{du} \mathrm{IV}^{\mathrm{e}}$ siècle, car ses motifs correspondent à ceux des colonnes de l'arc de Théodose ${ }^{40}$ (fig. 3).

Fig. 3. - Istanbul (Turquie), citerne Basilique de Constantinople : colonne à décor d'ocelles de paon datée de l'époque théodosienne.

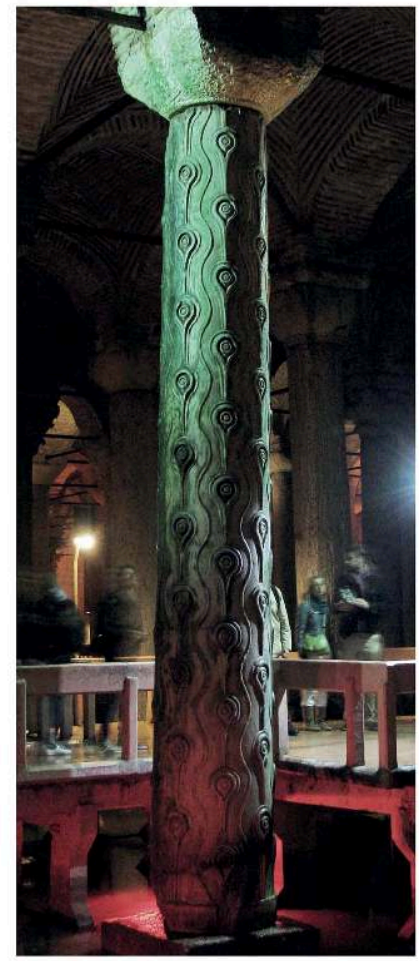

\section{Colonnes et chapiteaux : des rebuts}

14 Si nous résumons les hypothèses précédemment évoquées, les chapiteaux de la citerne Basilique seraient donc en grande majorité des produits semi-finis provenant des carrières, d'autres des remplois de bâtiments des époques romaine ou tardo-antique, et enfin un groupe homogène de produits finis, datables $\mathrm{du} \mathrm{VI}^{\mathrm{e}}$ siècle, provenant directement des carrières.

Seul W. Müller-Wiener, dans une légende d'illustration, identifie ces éléments architectoniques à des rebuts de carrières. Il justifie cette hypothèse en mentionnant le grand nombre de pièces défectueuses observables dans la citerne et le fait qu'elles ont pu être préfabriquées dans les carrières de Proconnèse ${ }^{41}$. Cette proposition nous paraît très intéressante et demande à être approfondie, dans la mesure où elle permet de mieux cerner l'origine des colonnes, élément architectonique complètement délaissé par les recherches sur la citerne. 
Si nous poussons plus loin le raisonnement W. Müller-Wiener, ces éléments, abîmés lors de leur façonnement, seraient tout de même acheminés avec le reste des pièces intactes à Constantinople. Il est certain que l'époque justinienne a été propice à l'importation de ce type d'artefacts, pour la plupart issus des carrières de Proconnèse, situées sur l'île de Marmara, très actives entre le $\mathrm{V}^{\mathrm{e}}$ et le $\mathrm{VI}^{\mathrm{e}}$ siècle $^{42}$. N. Asgari développe le modus operandi des carrières: une fois le bloc extrait, il était équarri directement dans la zone d'extraction. Il pouvait ensuite être envoyé soit directement par bateau vers sa destination finale, soit acheminé dans le port de Saraylar (principal port au nord-est de l'île de Marmara), où plusieurs ateliers étaient installés ${ }^{43}$. Elle précise également que seule la phase de polissage était réalisée lors de la réception de ce produit préfabriqué, à pied d'œuvre ${ }^{44}$. Elle remarque toutefois un changement à l'époque tardo-antique, qui serait dû au vaste programme de constructions à Constantinople : certains éléments luxueux pouvaient être achevés dans les ateliers du port, mais d'une part, il ne s'agit pas de la majorité de la production des carrières de Proconnèse et d'autre part, $\mathrm{N}$. Asgari semble encline à dater cette pratique de l'époque théodosienne ${ }^{45}$. Dans son article sur le port de Saraylar, elle recense 50 colonnes abandonnées qui pourraient être datées entre le $\mathrm{II}^{\mathrm{e}}$ et le $\mathrm{VI}^{\mathrm{e}}$ siècle, ce qui paraît peu par rapport au nombre de colonnes exportées vers Constantinople ${ }^{46}$. Bien que les carrières soient encore exploitées, ce constat pourrait être un indice pour étayer la proposition de W. MüllerWiener. Ainsi une économie autour des rebuts, au même titre que des produits bien exécutés et conformes aux commandes, existerait. Elle concernerait Constantinople, où semblaient être acheminés l'ensemble des produits semi-finis ou finis à l'époque tardoantique ${ }^{47}$. Cette hypothèse incite à penser également qu'un lieu de dépôt équivalent à la Marmorata romaine devait exister nécessairement à Constantinople ${ }^{48}$.

Si nous nous intéressons maintenant aux colonnes mises en œuvre dans la citerne, deux catégories principales apparaissent: les produits semi-finis et les colonnes complètement achevées. Dans les deux cas toutefois, on observe des imperfections qui pourraient justifier la qualité de rebuts de ces colonnes.

Pour les produits semi-finis :

- forme oblongue, voire quasiment carrée, alors que la phase d'épannelage est très avancée (fig. 4a) ;

- imperfections dans la pierre ayant entraîné une épaufrure durant la phase d'épannelage (fig. 4b) ;

- imperfections dans la pierre ayant compromis la phase de finition (fig. 4c). 
Fig. 4. - Istanbul (Turquie), citerne Basilique de Constantinople : produits semi-finis comportant des imperfections.

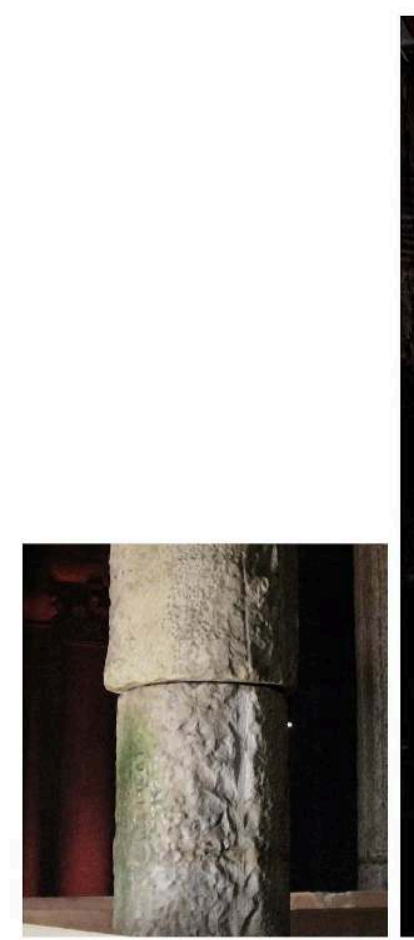

a

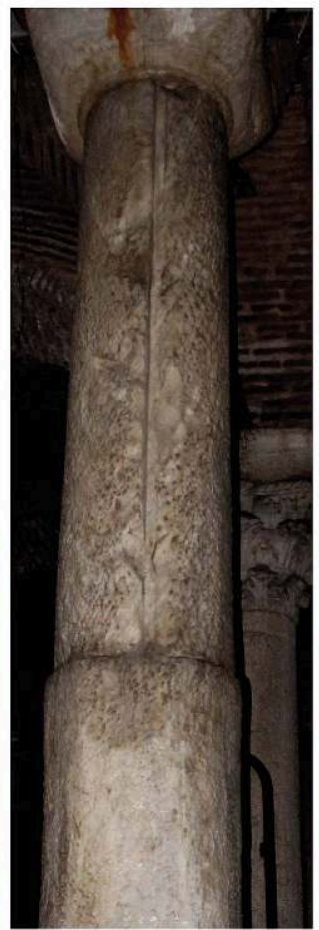

b

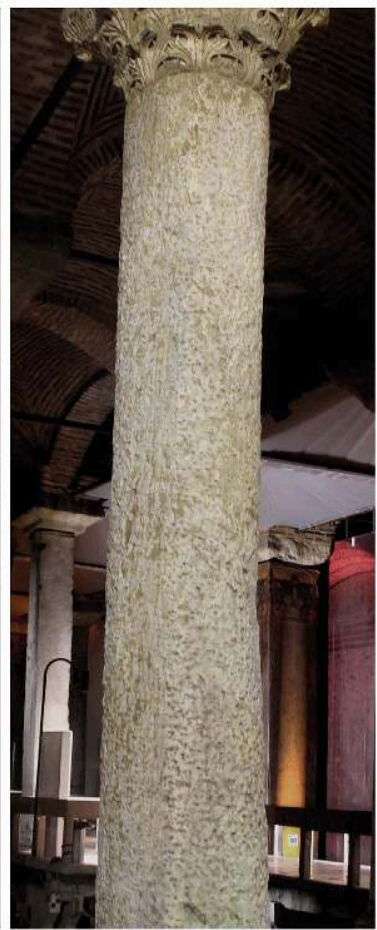

C

A : colonne de forme oblongue alors qu'elle est en cours d'épannelage (partie du bas). B : colonne brisée durant la phase d'épannelage ; c : imperfections dans la pierre, ayant compromis la phase de finition.

(c) Anaïs Lamesa.

D'autres causes pourraient avoir engendré le rebut de la colonne, comme un problème de dimensions. Cette dernière hypothèse ne peut pas être observée directement dans la citerne, mais les éléments porteurs comme les colonnes faisaient partie de commandes précises: leur aspect et surtout leurs proportions dépendaient des spécificités des ouvrages concernés. Un problème de ce type devait entraîner nécessairement leur mise au rebut ${ }^{49}$. Une autre hypothèse pourrait être un refus lors du débarquement à Constantinople. Le transport de colonnes par bateau est bien attesté, et il est évident que des dommages pouvaient être causés durant la traversée $e^{50}$. Les contrats entre la carrière et le commanditaire pouvaient prendre en compte ce genre d'accident ${ }^{51}$. Bien que les carrières de Proconnèse fussent impériales et donc ne devaient pas posséder ce genre de contrats restrictifs, les colonnes endommagées auraient pu être mises de côté, dans cette Marmorata constantinopolitaine, puis récupérées afin de bâtir des ouvrages comme les citernes. N. Asgari rappelle que la plupart des colonnes étaient envoyées sous l'aspect de produits semi-finis ${ }^{52}$. Il est donc possible que certaines d'entre celles qui ont été mises en œuvre dans la citerne aient été écartées à l'arrivée de la livraison (fig. 5a). Cela pourrait être le cas de la colonne décorée d'ocelles, dont les extrémités sont brisées, N. Asgari ayant bien montré que ce décor avait été réalisé en carrière ${ }^{53}$ (fig. 5b). Ces éclats pourraient également venir de la destruction du monument théodosien, mais l'absence d'autres colonnes avec ce décor dans la citerne ou dans tout autre monument de ce type à Istanbul incite à penser que la colonne était déjà au rebut et n'a jamais été mise en œuvre ailleurs. 
Fig. 5. - Istanbul (Turquie), citerne Basilique de Constantinople : colonnes qui auraient pu être écartées à l'arrivée de la livraison.

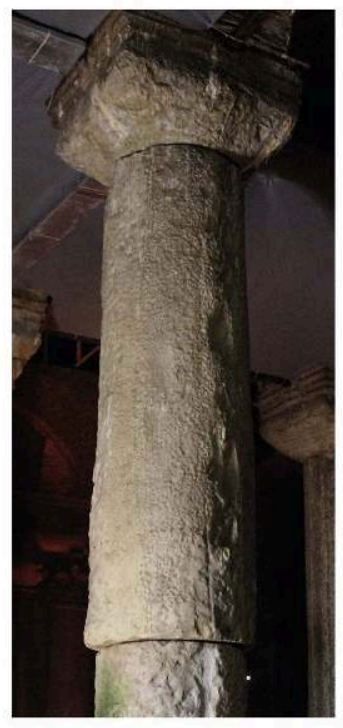

a

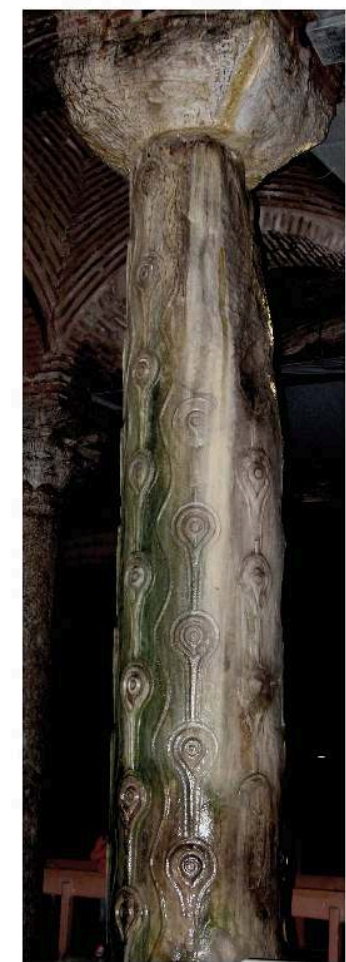

A : colonne possiblement abîmée durant le transport (partie du haut). B : colonne à décor d'ocelles de paon à l'extrémité brisée.

(c) Anaïs Lamesa.

Pour certaines colonnes finies, on observe à leur extrémité la présence d'épaufrures (fig. 6a). Cette dernière catégorie serait alors des rebuts de chantiers. Cette idée correspond à la chaîne opératoire proposée par N. Asgari. L'hypothèse semble confirmée par la présence, au bas d'une colonne achevée, d'une marque en grec de tâcheron ou de pose « $\Theta E$ » qui prouve que la pièce n'était pas abîmée en carrière, mais qu'elle a bien été achevée sur le chantier et abandonnée par la suite (fig. 6b). Les raisons de l'abandon de ces colonnes pourraient être multiples: accident durant la phase de finition, dommage lié aux convois arrivant sur le chantier, etc ${ }^{54}$. 
Fig. 6. - Istanbul (Turquie), citerne Basilique de Constantinople : colonnes qui correspondraient à des rebuts de chantiers.

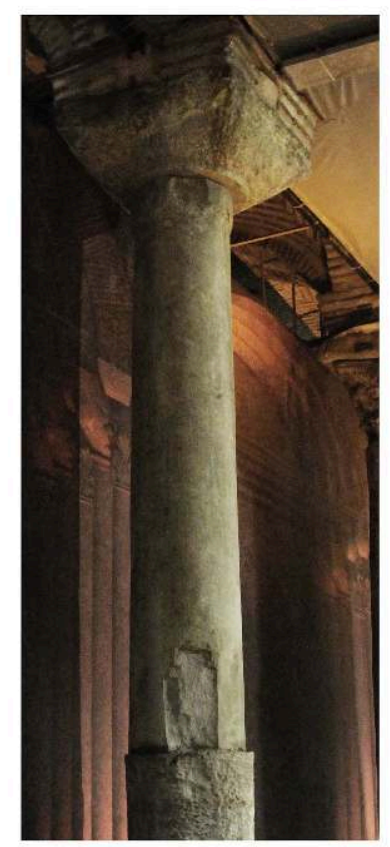

a

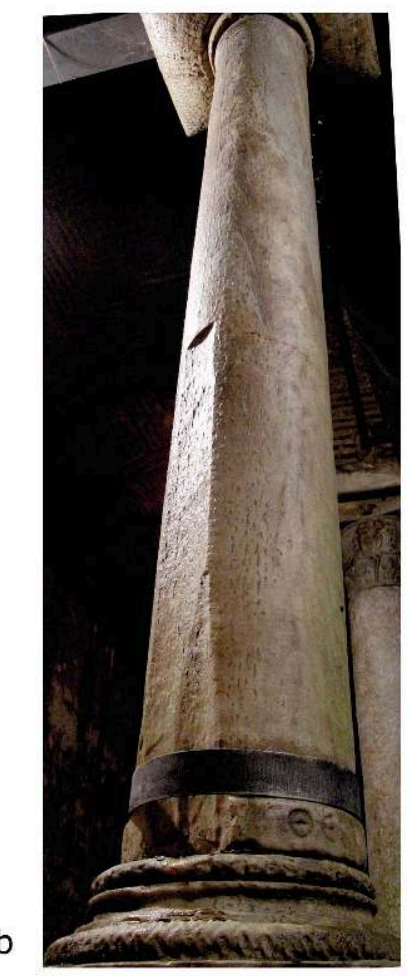

A : éclats sur une colonne finie. B : colonne achevée, inscrite, avec éclats.

(C) Anaïs Lamesa.

Cette dernière hypothèse pourrait apporter une explication cohérente au groupe homogène de chapiteaux. Ne pourraient-ils pas être, eux aussi, des rebuts de chantiers qui par leurs dimensions ne correspondaient pas à la commande, et donc après la taille auraient été refusés par le maître d'œuvre ? En effet, N. Asgari tend à penser que les chapiteaux corinthiens de la période tardo-antique, à l'instar des colonnes, étaient tous réalisés à Constantinople et donc importés sous la forme de produits semi-finis de l'île de Proconnèse ${ }^{55}$.

\section{Conclusions}

L'étude des systèmes d'adduction d'eau à Constantinople a permis de mettre en exergue quatre ruptures entre la période romaine et la période tardo-antique et plus spécifiquement à partir du Iv ${ }^{\mathrm{e}}$ siècle, à partir duquel la conservation de l'eau dans des citernes et des réservoirs semble privilégiée. L'aspect que prennent les citernes à Constantinople dénote par rapport aux autres structures de ce genre conservées dans d'autres villes méditerranéennes. L'emploi de la brique ainsi que la variété des systèmes de voûtement pourraient s'expliquer par les risques importants de tremblements de terre. Enfin, la mise en œuvre d'éléments architecturaux comme des colonnes et des chapiteaux rend ces citernes remarquables par rapport au bassin Méditerranéen.

Dans le cas de la citerne Basilique, nous avons montré que ces éléments ne sont pas uniquement des remplois ou des éléments semi-finis, mais pour une grande majorité 
des rebuts, hypothèse évoquée déjà par W. Müller-Wiener. Ceux-ci pourraient être directement issus des carrières de Proconnèse, refusés après destruction lors de leur transport, ou encore écartés après la phase de finition à pied d'œuvre. Ces hypothèses incitent à penser qu'un entrepôt équivalent à la Marmorata romaine devait exister à Constantinople. Enfin l'étude des ces éléments a permis de mettre en exergue l'existence d'une économie basée sur les rebuts mise en place à Constantinople pour la période tardo-antique, cette hypothèse constituant la quatrième rupture avec l'époque romaine.

\section{BIBLIOGRAPHIE}

ALTUĞ Kerim, « Istanbul'da Bizans Dönemi Sarnıçlarının Mimari ve Özellikleri ve Kentin Tarihsel Topografyasındaki Dağılımı », thèse de doctorat en histoire de l'architecture, Istanbul, Istanbul Teknik Üniversitesi, 2013.

ALTUĞ Kerim, «Planlama İlkeleri ve Yapım Teknikleri Açısından Tarihi Yarımada'daki Bizans Dönemi Sarnıçları », Restorasyon Konservasyon Çalışmaları, 2012, nº 15, p. 3-22.

ALTUĞ Kerim, « Reconsidering the use of spolia in Byzantine Constantinople », dans Pedone Silvia et Paribeni Andrea (dir.), Di Bisanzio dirai ciò che è passato, ciò che passa e che sarà : scritti in onore di Alessandra Guiglia, Rome, Bardi, vol. 1, p. 3-16.

ALTUĞ Kerim, « Tarihi Yarımada'da Bizans Dönemi Sarnıçları Envanteri Işığında Topografik Gözlemler », İstanbul Araştırmaları Yıllığı, 2014, nº 3, p. 23-38.

ALTUĞ Kerim, « Tarihi yarımada'nın sütunlu mirası : sarnıçlar », Toplumsal Tarih Dergisi, 2016, nº 271 , p. $16-21$.

ASGARI Nuşin, « Objets de marbre finis, semi-finis et inachevés du Proconnèse », dans Waelken Marc (dir.), Pierre éternelle, du Nil au Rhin : carrières et préfabrication, cat. exp. (Bruxelles, 12 octobre-2 décembre 1990), Bruxelles, Crédit communal, 1990, p. 107-126.

ASGARI Nuşin, «The Proconnesian production of architectural elements in late Antiquity, based on evidence from the marble quarries ", dans Mango Cyril, Dagron Gilbert, Greatex Geoffrey (dir.), Constantinople and its hinterland. Papers from the twenty-seventh spring Symposium of byzantine studies, Oxford, April 1993, Aldershot, Varorium, 1995, p. 263-288.

ASGARI Nuşin, « Roman and early Byzantine marble quarries of Proconnesus », dans Akurgal Ekrem (dir.), The Proceedings of the $X^{\text {th }}$ international Congress of classical archaeology I, Ankara-Izmir 23-30/IX/1973, Ankara, Türk Tarih Kurumu Basimevi, 1978, p. 467-480.

ASGARI NuŞin, « Zwei Werkstücke für Konstantinopel aus dem prokonnesischen Steinbrüchen », Istanbuler Mitteilungen, 1989, 39, p. 49-65.

AVNAMAK Bülent, ÇILI Feridun, ÖZGÜMÜș Feridun, ERSEN Ahmet, Yerebatan Sarnıcı : rölöve restitüsyon, restorasyon projesi, Istanbul, Tarihi çevre koruma müdürlüğü projeleri (Etüd ve projeler daire başkanlığı), 2011. 
BARDILL Jonathan, «A bibliographical concordance of cisterns in Istanbul », dans Crow Jim, Bardill Jonathan, Bayliss Richard (dir.), The water supply of Byzantine Constantinople, Londres, Society of the promotion of Roman studies (Journal of Roman Studies monographs, 11), 2008, p. 143-155. BARDILL Jonathan et KRAUSMÜLLER Dirk, « Translation of major texts and inscriptions relating to water supply, storage, and use in byzantine Constantinople ", dans Crow Jim, Bardill Jonathan, Bayliss Richard (dir.), The water supply of Byzantine Constantinople, Londres, Society of the promotion of Roman studies (Journal of Roman Studies monographs, 11), 2008, p. 222-247.

BARSANTI Claudia, «Le cisterne bizantine di Istanbul: nuovi dati sulla scultura dal V al VII secolo. La cisterna n 9 (la c.d. Cisterna della Scuola) », dans Brandt Olof, Cresci Silvia, López Quiroga Jorge, Pappalardo Carmelo (dir.), Acta XV congressus internationalis archaeologiae christianae, Toleti, 8-12.9.2008 : episcopus, civitas, territorium, Città del Vaticano, Pontificio Istituto di Archeologia cristiana, 2013, vol. 2, p. 1481-1496.

BARSANTI Claudia, « Note archeologiche su bisanzio romana », dans De'Maffei Fernanda, Barsanti Claudia, Guidobaldi Alessandra Guigli (dir.), Costantinopoli e l'arte delle province orientali, Rome, Edizionie Rari Nantes (Million. Studi e ricerche d'arte bizantina), 1990, p. 11-72.

BETSCH Willian Earl, « The history, production and distribution of the late antique capital in Constantinople », Ph. D. Fine Arts, Ann Abor, University of Pennsylvania, 1977.

CROW Jim, « Water and the creation of a new capital », dans Magdalino Paul et Ergin Nina (dir.), Istanbul and water, Leuven, Peeters (Ancient near eastern studies, suppl. 47), 2015, p. 115-128. CROW Jim, BARDILL Jonathan, BAYLISS Richard (dir.), The water supply of Byzantine Constantinople, Londres, Society of the promotion of Roman studies (Journal of Roman Studies monographs, 11), 2008.

ERTUĞRUL Özkan, «Istanbul'da Bizans Devri Su Mimarisi », thèse (Sanat Tarihi Doktora Tezi), Université d'Istanbul, 1989.

FANT J. Clayton, « Contracts and cost for shipping marble in the Roman Empire », dans Guttiérrez Garcia-M. Anna, Lapuente Pilar, Rodà Isabel (dir.), Interdisciplinary studies on ancient stone: proceedings of the IX Association for the Study of Marbles and Other Stones in Antiquity (ASMOSIA) Conference, Tarragona, 2009, Tarragone, Institut Català d'Arqueologia Clàssica, 2012, p. 528-532. FORCHHEIMER Philipp et STRZYGOWSKI Josef, Die Byzantinischen Wasserbehälter von Konstantinopel, Vienne, Mechitharisten-Congregation in Wien (Byzantinische Denkmäler, 2), 1893.

HELLMANN Marie-Christine, L'architecture grecque : les principes de la construction, Paris, Picard (Manuels d'art et d'archéologie antiques), 1998.

JANIN Raymond, Constantinople byzantine : développement urbain et répertoire topographique, Paris, Institut français d'études byzantines, 1950.

KINNEY Dale, «The concept of spolia », dans Rudolph Conrad (dir.), A Companion to medieval art : romanesque and gothic in northern Europe, Malden, Blackwell, 2006, p. 233-252.

MAMBOURY Ernest, Constantinople : guide touristique, Constantinople, Rizzo, 1925.

MAMBOURY Ernest et WIEGAND Theodor, Die Kaiserpaläste von Konstantinopel zwischen Hippodrom und Marmara-meer, Berlin, De Gruyter, 1934.

MANGO Cyril, The brazen house : a study of the vestibule of the imperial palace of Constantinople, Copenhague, I kommission hos Ejnar Munksgaard, 1959.

MANGO Cyril, Byzantine architecture, Milan, Electa, 1978. 
MANGO Cyril, « The development of Constantinople as an urban center », dans MacMullen Ramsay (dir.), The seventeenth international byzantine congress, main papers, New York, Aristide D. Caratzas, 1986, p. 117-136.

MANGO Cyril, Le développement urbain de Constantinople (IVe-VII siècle), Paris, De Boccard (Travaux et mémoires du Centre de recherche d'histoire et civilisation de Byzance, monographie 2), 1985.

MANGO Cyril, « Water supply of Constantinople », dans Mango Cyril, Dagron Gilbert, Greatex Geoffrey (dir.), Constantinople and its hinterland. Papers from the twenty-seventh spring Symposium of byzantine studies, Oxford, April 1993, Aldershot, Varorium, 1995, p. 9-18.

MAYS Larry, ANTONIOU George P., ANGELAKIS Andreas N., « History of water cisterns : legacies and lessons », Water, 2013, nº 5, p. 1916-1940.

MÜLLER-WIENER Wolgang, SCHIELE Wolf, SCHIELE Renata, Bildlexikon zur Topographie Istanbuls :

Byzantion, Konstantinupolis, Istanbul bis zum Beginn des 17. Jahrhunderts, Tübingen, Wasmuth, 1977.

OUSTERHOUT Robert G., Eastern medieval architecture: the building traditions of Byzantium and neighboring lands, New York, Oxford University Press (Onassis Series in Hellenic Culture), 2019.

PRALONG Annie, « Recherches sur les chapiteaux corinthiens tardifs en marbre de Proconnèse », thèse de doctorat en archéologie, Paris, université Paris I - Panthéon-Sorbonne, 1997.

PENSABENE Patrizio, « Architectural spolia between Late-antiquity and the Middle Ages ", dans Russo Valentina (dir.), Landscape as architecture: identity and conservation of Crapolla cultural site, Florence, Nardini, 2016, p. 223-232.

PENSABENE Patrizio, Le vie del marmo: $i$ blochi di cava di Roma e di Ostia, il fenomeno del marmo nella Roma antica, Rome, Ministerio per i Beni Culturali e Ambientali / Soprintendenza Archeologica de Ostia (Itinerari ostiensi, 7), 1995.

RUSSELL Ben, « Shipwrecks and stone cargoes: some observations », dans Guttiérrez Garcia-M. Anna, Lapuente Pilar, Rodà Isabel (dir.), Interdisciplinary studies on ancient stone: proceedings of the IX Association for the Study of Marbles and Other Stones in Antiquity (ASMOSIA) Conference, Tarragona, 2009, Tarragone, Institut Català d'Arqueologia Clàssica, 2012, p. 533-539.

SCHNEIDER Alfons Maria et KARNAPP Walter, Byzanz: Vorarbeiten zur Topographie und Archäologie der Stadt, Berlin, Mann, 1936.

STRIKER Cecil L. et KUBAN Doğan (dir.), Kalenderhane in Istanbul: final reports on the archaeological exploration and restoration at Kalenderhane Camii, 1966-1978, vol. 1 : The buildings, their history, architecture, and decoration, Mainz am Rhein, P. von Zabern, 1997.

WARD Kate, CRAPPER Martin, ALTUĞ Kerim, CROW Jim, « The byzantine cisterns of Constantinople », Water Science and Technology: Water Supply, 2017, vol. XVII, n 6, p. 1499-1506.

WARD Kate, CROW Jim, CRAPPER Martin, « Water-supply infrastructure of Byzantine Constantinople », Journal of Roman Archaeology, 2017, vol. XXX n 1, p. 175-195.

WULZINGER Karl, « Byzantinische Substruktionsbauten Kontaninopels », Jahrbuch des Kaiserlich Deutschen Archäologischen Instituts, 1913, vol. 28, p. 370-395.

\section{NOTES}

1. J. Crow et al., The water supply of Byzantine Constantinople, et plus récemment «Water and the creation of a new capital »; K. Ward et al., "Water-supply infrastructure of 
Byzantine Constantinople» reconstituent les réseaux hydrauliques de la ville de Constantinople. Voir également pour des études récentes des citernes et réservoirs les travaux de K. Altuğ: «Planlama İlkeleri ve Yapım Teknikleri Açısından Tarihi Yarımada'daki Bizans Dönemi Sarnıçları », « Istanbul'da Bizans Dönemi Sarnıçlarının Mimari ve Özellikleri ve Kentin Tarihsel Topografyasındaki Dağılım», "Tarihi yarımada'nın sütunlu mirası: sarnıçlar » et K. Ward et al., "The Byzantine cisterns of Constantinople ». La première étude systématique sur les infrastructures hydrauliques à Constantinople a été réalisée par P. Forchheimer et J. Strzygowski, Die Byzantinischen Wasserbehälter von Konstantinopel. Enfin, une thèse de doctorat sous la direction de Semavi Eyice en 1989 recense l'ensemble des structures connues à cette époque: Ö. Ertuğrul, « Istanbul'da Bizans Devri Su Mimarisi ».

2. W. Müller-Wiener etal., Bildlexikon zur Topographie Istanbuls: Byzantion, Konstantinupolis, Istanbul bis zum Beginn des 17. Jahrhunderts, p. 284.

3. J. Crow, "Water and the creation of a new capital », p. 124, propose d'y voir un " modèle constantinopolitain ».

4. L'idée de cet article m'a été suggérée par J.-C. Bessac lors d'une visite de la citerne. Je le remercie chaleureusement de l'aide qu'il m'a apportée durant ce travail. Mes remerciements vont également à Kerim Altuğ pour m'avoir transmis des documents non publiés ou difficile d'accès. Toutes les erreurs sont de l'auteur.

5. K. Ward et al., "Water-supply infrastructure of Byzantine Constantinople », p. 191.

6. C. Mango, "Water supply of Constantinople », p. 9 ; J. Crow et al., The water supply of Byzantine Constantinople, p. 9 ; K. Ward et al., « Water-supply infrastructure of Byzantine Constantinople », p. 191.

7. Grégoire de Nazianze témoigne de ces réseaux à la fois souterrains et à ciel ouvert : C. Mango, Le développement urbain de Constantinople (IV-VII esiècle), p. 41; J. Bardill et D. Krausmüller, «Translation of major texts and inscriptions relating to water supply, storage, and use in Byzantine Constantinople ", p. 226 ont réalisé la compilation des sources médiévales et modernes mentionnant les infrastructures hydrauliques à Constantinople.

8. La construction d'un premier réseau, attribué à Hadrien, est actuellement discutée. Il se pourrait que le réseau d'Hadrien n'ait jamais existé ; voir C. Mango, «Water supply of Constantinople», p. 20 ; L. Striker et D. Kuban, Kalenderhane in Istanbul..., vol. 1, p. 30-31 contra J. Crow et al., The water supply of Byzantine Constantinople, p. 13-14 en dernier lieu.

9. J. Crow, «Water and the creation of a new capital», p. 123.

10. J. Crow et al., The water supply of Byzantine Constantinople, p. 214 ; K. Ward et al., "Water-supply infrastructure of Byzantine Constantinople», p. 191; K. Ward et al., "The Byzantine cisterns of Constantinople ", p. 1501.

11. J. Bardill, «A bibliographical concordance of cisterns in Istanbul» a recencé 161 citernes et K. Altuğ, « Istanbul'da Bizans Dönemi Sarnıçlarının Mimari ve Özellikleri ve Kentin Tarihsel Topografyasındaki Dağılımı» en a recensé 158; K. Ward et al., "Water-supply infrastructure of Byzantine Constantinople », p. 191.

12. K. Ward et al., «The Byzantine cisterns of Constantinople », p. 1504-1505.

13. J. Crow, «Water and the creation of a new capital », p. 123. 
14. C. Mango, Le développement urbain de Constantinople (IVe-VII siècle), p. 42 ; "Water supply of Constantinople», p.14-15; J. Crow et al., The water supply of Byzantine Constantinople, p. 214.

15. C. Mango, "Water supply of Constantinople», p.14-15; J. Crow et al., The water supply of Byzantine Constantinople, p. 214 ; J. Crow, "Water and the creation of a new capital », p. 122.

16. Sur les techniques de construction et les éléments architectoniques des citernes constantinopolitaines: K. Altuğ, "Planlama İlkeleri ve Yapım Teknikleri Açısından Tarihi Yarımada'daki Bizans Dönemi Sarnıçları », p. 8-15; « Istanbul'da Bizans Dönemi Sarnıçlarının Mimari ve Özellikleri ve Kentin Tarihsel Topografyasındaki Dağılım », p. 55-78.

17. Sur la structure des citernes romaines et tardo-antiques, voir B. Mays et al, " History of water cisterns: legacies and lessons »; K. Altuğ, " Planlama İlkeleri... », p. 13-14 ; «Istanbul'da Bizans Dönemi Sarnıçlarının Mimari... », p. 75-78, sur la variété des modes de couvertures dans les citernes constantinopolitaines.

18. K. Altuğ, « Istanbul'da Bizans Dönemi Sarnıçlarının Mimari... », p. 77.

19. J. Crow et al., The water supply of Byzantine Constantinople, p.137; R. Ousterhout, Eastern medieval architecture, p. 92.

20. J. Crow et al., The water supply of Byzantine Constantinople, p. 137, 217-218.

21. Ibid., p.137-138 ; K. Altuğ, "Istanbul'da Bizans Dönemi Sarnıçlarının Mimari... », p.59. La citerne à l'ouest de la mosquée de Zeyrek n'est pas dotée de ce type d'aménagement.

22. J. Crow et al., The water supply of Byzantine Constantinople, p. 137-139 ; C. Barsanti, « Le cisterne bizantine di Istanbul... », p. 1487 ; K. Altuğ, « Reconsidering the use of spolia in Byzantine Constantinople ».

23. W. E. Betsch, The history, production and distribution of the late antique capital in Constantinople, p. 270-277; J. Crow et al., The water supply of Byzantine Constantinople, p. 138.

24. Pour un état des lieux de la recherche sur les spolia: P. Pensabene, «Architectural spolia between late Antiquity and the Middle Ages ».

25. K. Ward et al., «Water-supply infrastructure of Byzantine Constantinople », p. 183.

26. C. Mango, "Water supply of Constantinople», p. 16 ; J. Bardill et D. Krausmüller, "Translation of major texts... », p. 232. Les patriographes attribuent sa construction à Constantin: E. Mamboury, Constantinople: guide touristique, p. 42 et 195; R. Janin, Constantinople byzantine: développement urbain et répertoire topographique, p. 202, note 2 ; J. Bardill et D. Krausmüller, "Translation of major texts... », p. 223. Cette incertitude quant à l'origine de son commanditaire est reprise par C. Barsanti, «Le cisterne bizantine di Istanbul... », p. 1485. A. M. Schneider et W. Karnapp, Byzanz: Vorarbeiten zur Topographie und Archäologie der Stadt, p. 24-25, considèrent que la citerne aurait été creusée non pas sous, mais à côté de la basilique.

27. C. Mango, The Brazen House: a study of the vestibule of the imperial palace of Constantinople, p. 49-50 ; J. Crow et al., The water supply of Byzantine Constantinople, p. 17. Cette proposition s'appuie sur les témoignages de l'historien Malalas, 18.91 ; J. Bardill et D. Krausmüller, «Translation of major texts... », p. 233.

28. W. Müller-Wiener et al., Bildlexikon zur Topographie Istanbuls.., p. 285. 
29. K. Ward et al., « The Byzantine cisterns of Constantinople », p. 192.

30. W. Müller-Wiener et al., Bildlexikon zur Topographie Istanbuls.., p. 284 ; B. Avnamak et al., Yerebatan Sarnicl: rölöve Restitüsyon, Restorasyon projesi, p. 20.

31. Nous sommes partis de J. Bardill, «A bibliographical concordance of cisterns in Istanbul », p. 154-155.

32. Nous entendons par le terme spolia la définition que donne D. Kinney, «The concept of spolia... ", p. 233.

33. C. Mango, Le développement urbain de Constantinople (IVe-VII siècle), p. 69, les date de l'époque de Constantin. C. Barsanti, « Note archeologiche su bisanzio romana », p. 36-39 et J. Crow et al., The water supply of Byzantine Constantinople, p. 138, les placent à l'époque de Septime Sévère.

34. C. Mango, Le développement urbain de Constantinople ( $V^{e}-\mathrm{VII}{ }^{e}$ siècle), p. 69. Un fragment de statue de l'époque sévérienne, plusieurs piédestaux et une grande architrave inscrite sont évoqués. Toutefois, ils ne sont pas relevés dans l'étude technique de B. Avnamak et al., Yerebatan Sarnıcl: rölöve Restitüsyon, Restorasyon projesi.

35. W. E. Betsch, The history, production and distribution..., p. 251 ; J. Crow et al., The water supply of Byzantine Constantinople, p. 138 ; B. Avnamak et al., Yerebatan Sarnicl..., p. 25.

36. W. E. Betsch, The history, production and distribution..., p. 183-184 ; B. Avnamak et al., Yerebatan Sarnici..., p. 25, contra J. Crow et al., The water supply of Byzantine Constantinople, p. 138 ; J. Crow, "Water and the creation of a new capital », p. 124.

37. C. Mango, Byzantine architecture, p. 123 ; B. Avnamak et al., Yerebatan Sarnici..., p. 27.

38. W. E. Betsch, The history, production and distribution..., p.134; B. Avnamak et al., Yerebatan Sarnici..., p. 25.

39. P. Forchheimer et J. Strzygowski, Die Byzantinischen Wasserbehälter von Konstantinopel, p. 55, identifie une imposte mise en œuvre en cours d'épannelage; repris dans K. Wulzinger, «Byzantinische Substruktionsbauten Kontaninopels», p. 383; W. E. Betsch, The history, production and distribution..., p. 123. C. Barsanti, «Le cisterne bizantine di Istanbul... », p. 1485 ; J. Crow, "Water and the creation of a new capital ", p. 12 (suggestion d'Annie Pralong). La préfabrication des colonnes et chapiteaux au sein des carrières de marbre a été bien démontrée par N. Asgari, "Roman and early Byzantine marble quarries of Proconnessus », p.479. Une revue des publications de N. Asgari jusqu'en 1997 a été proposée par A. Pralong, « Recherches sur les chapiteaux corinthiens tardifs en marbre de Proconnèse », p. 284.

40. E. Mamboury et T. Wiegand, Die Kaiserpaläste von Konstantinopel zwischen Hippodrom und Marmara-meer, p. 57 ; K. Altuğ, « Istanbul'da Bizans Dönemi Sarnıçlarının Mimari ve Özellikleri ve Kentin Tarihsel Topografyasındaki Dağılım », p. 61. Une colonne similaire, abandonnée dans les carrières de Proconnèse à cause d'une imperfection, a également été recensée par N.Asgari, "Objets de marbre finis, semi-finis et inachevés du Proconnèse ", p. 123; voir aussi A. Pralong, «Recherches sur les chapiteaux corinthiens... », p. 287-288, 292.

41. W. Müller-Wiener et al., Bildlexikon zur Topographie Istanbuls..., p. 284, Abb. 322 : « Die in der Zisterne verwendeten Bauglieder sind wohl weitgehend verworfene Stücke aus der fabrikmässig organisierten Produktion der Prokonnesos-Brüche, wie die zahlreichen fehlerhaften Stücke beweisen ». 
42. W. E. Betsch, The history, production and distribution..., p. 164-166; N. Asgari, «The Proconnesian production...», p. 267 ; C. Mango, "The development of Constantinople as an urban center », p. 124-127.

43. N. Asgari, "The Proconnesian production of architectural elements in late Antiquity... », p. 267.

44. N. Asgari, «Roman and Early Byzantine Marble Quarries of Proconnesus », p. 475.

45. N. Asgari, "Zwei Werkstücke für Konstantinopel aus dem prokonnesischen Steinbrüchen », p. 50-53; «The Proconnesian production... », p. 267. L'ensemble des données a également été observé par W.E. Bestch pour les chapiteaux: The history, production and distribution..., p. 161-162.

46. N. Asgari, « The Proconnesian production... », p. 266.

47. N. Asgari, «Objets de marbre... », p. 121.

48. Ce lieu n'a toujours pas été retrouvé néanmoins. W. E. Betsch, The history, production and distribution..., p. 160-162. Sur la Marmorata romaine, P. Pensabene, Le vie del marmo.

49. N. Asgari, «Objets de marbre... », p. 117.

50. J. C. Fant, «Contracts and cost for shipping marble in the Roman Empire » pour la bibliographie ; B. Russell, « Shipwrecks and stone cargoes: some observations » pour la remise en question des naves lapidariae.

51. Des contrats d'époque grecque classique mentionnent l'obligation de livrer par chargement des pierres "saines et sans épaufrure »: M.-C. Hellmann, L'architecture grecque. Les principes de la construction, p. 24-25.

52. N. Asgari, « Objets de marbre... », p. 124.

53. Ibid., p. 123.

54. M.-C. Hellmann, L'architecture grecque : les principes de la construction, p. 72.

55. N. Asgari, « Objets de marbre... », p. 121.

\section{RÉSUMÉS}

Cet article est l'occasion de nous pencher sur l'approvisionnement en eau de Constantinople (actuelle Istanbul, Turquie) entre l'époque antique et tardo-antique et de nous intéresser principalement aux éléments portants de la citerne Basilique (Yerebatan Sarnıcı). L'étude de l'approvisionnement en eau de Constantinople s'est particulièrement développée ces dernières années et a mis en exergue trois ruptures entre les époques romaine et tardo-antique. L'une d'entre elles est l'utilisation de colonnes et de chapiteaux en marbre dans les citernes de l'ancienne capitale impériale. Ces supports ont été identifiés à des spolia, remplois de structures plus anciennes. Nous proposons une autre interprétation dans le cadre de la citerne Basilique, suivant en cela l'intuition de W. Müller-Wiener: les colonnes seraient des rebuts issus des carrières de Proconnèse (île de Marmara, Turquie). Cet aspect révèle la mise en place d'une économie de rebut dans la Constantinople tardo-antique. 
INDEX

Index géographique : Turquie, Constantinople

Mots-clés : Antiquité tardive, carrières de Proconnèse, architecture, citerne Basilique

\section{AUTEURS}

\section{ANAIIS LAMESA}

Chercheuse postdoctorante, domaine d'intérêt majeur " Matériaux anciens et patrimoniaux "; laboratoire Orient et Méditerranée (UMR 8167 du CNRS), équipe Mondes sémitiques ; membre associée à l'Institut français d'études anatoliennes (Istanbul, Turquie)

\section{FERUDUN ÖZGÜMÜŞ}

Ass. Prof. Dr., Istanbul University 


\title{
Ambrogio Attendolo (1505-1585) : la formation d'un architecte sur le chantier des fortifications de la ville de Capoue
}

\author{
Nicolas Moucheront
}

1 Comment se forme-t-on à l'architecture dans le royaume de Naples au XvI siècle ? S'il n'est pas possible d'apporter une réponse générale à une telle question, le parcours personnel d'Ambrogio Attendolo permet de formuler quelques hypothèses sur la double transmission nécessaire à l'identification d'une figure d'architecte.

En l'absence de confrérie de métier ou d'école institutionnalisée, il est rare que des documents précisent les modalités de la transmission des savoirs au cours des années de formation d'un architecte à la Renaissance. On peut supposer qu'il reçoit une formation initiale sur des chantiers conduits par des maitres d'œuvre expérimentés, exactement comme un artiste, qui passe par l'atelier d'un ou de plusieurs maîtres avant de développer une production autonome. Les plus célèbres architectes de la Renaissance italienne sont d'ailleurs, au départ, souvent peintres ou sculpteurs. D'autres sont issus des milieux du bâtiment et se forment aux aspects théoriques du métier au contact de commanditaires privés ou d'administrations publiques ${ }^{1}$.

Des techniciens de plus en plus spécialisés reçoivent ainsi une formation au sein des magistratures de la Toscane médicéenne et de la République de Venise. Ils s'occupent de fortifications et de ponts et chaussées, mais aussi d'architecture civile ${ }^{2}$. Dans l'Empire espagnol, dont fait alors partie le royaume de Naples, des corps d'ingénieurs militaires se constituent dès le $\mathrm{XVI}^{\mathrm{e}}$ siècle. Ces derniers préfèrent souvent porter le titre d'architecte, si bien que la confusion entre les termes «ingénieur " et "architecte » perdure dans la langue italienne jusqu'à la fin du $\mathrm{xvII}^{\mathrm{e}}$ siècle $^{3}$. Ce problème terminologique dépasse la définition de disciplines distinctes.

4 En effet, les cadres théoriques tracés dans les traités d'architecture, d'hydraulique ou de poliorcétique ne correspondent pas encore à des professions structurées. Sur les 
chantiers, les compétences des différents acteurs se recoupent, et il est souvent impossible d'attribuer le projet à un auteur unique. Néanmoins, quels que soient ses compétences et son rôle effectif à pied d'œuvre, celui des bâtisseurs auquel on dédie une épigraphe ou dont le nom est cité dans un livre passe à la postérité en tant qu'architecte. Les Vies de Vasari ${ }^{4}$ et leurs rééditions successives sont en Italie l'expression la plus illustre d'une transmission de savoirs qui concourt à la formation de figures d'architectes par l'attribution d'une liste d'œuvres 5 . La production de traités d'architecture favorise également la transmission d'images d'édifices antiques et contemporains. Leurs auteurs, souvent architectes eux-mêmes, contribuent à la formation d'une clientèle pétrie de culture classique et à celle de leur propre postérité.

5 Aucun traité d'architecture n'est publié à Capoue au XVI ${ }^{\mathrm{e}}$ siècle, mais des érudits locaux participent à la redécouverte des vestiges de la cité romaine. Les réalisations architecturales d'Ambrogio Attendolo concourent également, en dialoguant avec les monuments de l'Antiquité, à la construction d'une identité locale. Nous verrons dans une première partie comment son œuvre est célébrée dans la production littéraire de son fils, Giovanni Battista Attendolo. Ce portrait rétrospectif d'un notable érudit sera dans une seconde partie confronté aux écrits de la pratique, qui donnent une tout autre image du personnage. Les sources comptables napolitaines et les registres de délibérations capouans permettent d'observer les origines modestes de ce fonctionnaire zélé.

6 Bien que les quarante premières années de ce profil biographique n'aient pas pu être reconstituées faute de documents, on peut suivre l'insertion progressive d'Ambrogio Attendolo au sein de l'appareil d'État espagnol et son rapprochement avec les milieux humanistes capouans. C'est probablement dans ces deux milieux qu'il s'est formé à l'architecture classique. Il transmet à son tour son savoir par les expertises qu'il réalise et les projets qu'il met en œuvre. Ceux-ci démontrent en effet une connaissance approfondie des techniques de construction et une sensibilité aiguë pour les antiquités.

\section{La construction de la mémoire d'un architecte}

7 Ambrogio Attendolo a exercé l'essentiel de ses activités dans la ville de Capoue, en Campanie. Dans l'Antiquité, c'est une ville prospère où les troupes d'Hannibal découvrent, en 215 avant J.-C., les « délices de Capoue », avant d'être écrasées par les Romains. Capoue est également le foyer de la révolte des gladiateurs menés par Spartacus en 73 avant J.-C., suite à laquelle est reconstruit un amphithéâtre presque aussi vaste que le Colisée. Au cours du haut Moyen Âge, la ville est abandonnée et les Lombards s'installent sur un site plus facile à défendre, situé dans une anse du fleuve Volturno. La Capoue moderne correspond à ce second emplacement, mais depuis le XIX siècle une seconde commune s'est reconstituée sur le site de la Capoue antique, sous le nom de Santa Maria Capua Vetere.

$8 \mathrm{Au} \mathrm{XVI}{ }^{\mathrm{e}}$ siècle, la région fait partie du royaume de Naples, placé sous la tutelle de l'Espagne de Charles Quint puis de Philippe II. Capoue souffre de la proximité de la métropole napolitaine, vers laquelle le vice-roi don Pedro de Tolède concentre les richesses, la population, la noblesse et l'administration. Cependant, la ville conserve une forte identité. Ses institutions municipales héritées du Moyen Âge ${ }^{6}$ permettent aux Capouans de négocier l'assiette des impôts avec le vice-roi espagnol. Ils interviennent en particulier dans les travaux de fortification de ce site, considéré depuis les guerres 
d'Italie à la fin $d u x^{e}$ siècle comme la clé du royaume de Naples. La ville contrôle en effet le pont romain par lequel la voie Appia franchit le fleuve Volturno. Ces travaux de fortification engendrent d'un côté la démolition de la porta delle Torri, monument emblématique de la ville, et de l'autre la construction de la porta Napoli, inspirée de la porta Capuana de Naples. Ces deux chantiers permettent à Ambrogio Attendolo de s'illustrer comme intermédiaire entre les citoyens de Capoue et les autorités espagnoles.

Capoue est $\mathrm{au} \mathrm{XVI}^{\mathrm{e}}$ siècle un centre culturel régional particulièrement fécond. Humanistes laïques et ecclésiastiques redécouvrent la splendeur du passé de la ville, et les vestiges de la Capoue antique sont mis en scène par les familles patriciennes ${ }^{7}$. Comme cela se pratique à Naples ou à $\mathrm{Nola}^{8}$, des collections de sculptures antiques se constituent, et l'on dispose de part et d'autre des portails des palais des blocs de calcaire provenant de la Capoue antique. Ce phénomène de réemploi des matériaux s'observe dès la fondation de la ville nouvelle par les Lombards; mais à partir du Xvi ${ }^{e}$ siècle, les registres municipaux témoignent d'une gestion consciente de cette ressource, qui commence à se raréfier. L'amphithéâtre antique, devenu château du Berelais au moment de l'occupation par les Sarrasins, commodément situé le long de la via Appia, à la sortie de la Capoue antique, à 5 kilomètres de la Capoue actuelle, servait de dépôt de matériaux. $\mathrm{Au} \mathrm{XvI} \mathrm{e}^{\mathrm{e}}$ siècle, on commence à s'attaquer aux éléments de décor qui ornent la façade de l'édifice, et les élus de la ville passent des décrets interdisant de toucher aux deux arcades qui sont encore debout et dont les matériaux sont réservés aux bâtiments publics. L'amphithéâtre est entouré d'un mur de protection, et seuls les blocs tombés à terre peuvent être prélevés par les maçons.

Ambrogio Attendolo, qui occupe diverses charges municipales liées notamment à l'entretien des égouts et de l'aqueduc de la ville, est également chargé de suivre les principaux chantiers municipaux, comme la construction de l'église de l'Annunziata et le palais des Tribunaux ${ }^{10}$. On y observe en façade des figures de grandes dimensions, qui ornaient les clés des arcades de l'amphithéâtre. Ambrogio Attendolo procède également à des travaux réguliers d'entretien de la voie Appia pour faciliter le transport de gros blocs vers la Capoue moderne. Le calcaire qu'il emploie dans les édifices de la ville provient des environs de Caserte ; il doit suivre le même itinéraire que les blocs de réemployés de la Capoue antique. Les carrières de Garzano ou Sarzano ${ }^{11}$, dont la pierre était exportée jusqu'à Naples, existent encore de nos jours. Elles ont en particulier été utilisées au XvIII ${ }^{\mathrm{e}}$ siècle pour construire l'immense palais royal de Caserte et son aqueduc.

11 Un intérêt particulier pour les vestiges de l'Antiquité est cultivé par le fils de l'architecte, Giovan Battista, ecclésiastique dont le nom est entré dans le dictionnaire biographique des Italiens ${ }^{12} \mathrm{du}$ fait de sa production littéraire. Il rédige un poème sur l'amphithéâtre capouan, qui évoque les relevés de l'édifice que son père a réalisés. À la mort d'Ambrogio en 1585, c'est Giovan Battista qui rédige l'épitaphe en latin et fait passer son père à la postérité en tant qu'architecte.

12 Cette inscription se trouve toujours dans l'église Santa Caterina de Capoue, conformément aux dernières volontés d'Attendolo. Il avait en effet spécifié dans son testament, conservé à l'Archivio di Stato de Caserte : «Je désire que mon corps soit enseveli dans ma chapelle, en l'église Santa Caterina des Franciscains, sans pompe et de nuit $^{13}$.» 
13 La chapelle en question n'existe plus et la plaque a été déplacée au niveau de la contrefaçade de l'église. Elle se trouve aujourd'hui accrochée à gauche de l'entrée principale en entrant, avec les pierres tombales d'autres membres de la famille Attendolo. La première partie de cette inscription est dédiée à la mémoire du père d'Ambrogio Attendolo, Giovan Battista Attendolo père, condottiere originaire de Cotignola, en Émilie, qui suite à l'effondrement de la dynastie des Sforza de Milan s'est installé en 1499 dans le sud de l'Italie, à Capoue. Giovan Battista Attendolo fils, auteur de ces inscriptions, précise ensuite les trois activités principales d'Ambrogio Attendolo :

«Ambrogio Attendolo, ayant acquis la fidélité du clairvoyant Philippe II roi d'Espagne, devint le grand architecte du royaume de Naples (NEAPOLIS SUMMUS ARCHITECTUS), ordonna par la mathématique Capoue, Crotone et Gaëte (MATEMATICA RATIONE), dota les routes de Naples à Rome de revêtements de pierre. »

Cette inscription a été rédigée en 1585 , et son auteur connaissait probablement les Vies de Vasari, publiées en 1550 et en $1568^{14}$. Il ne faut donc pas prendre pour argent comptant cette interprétation très vasarienne de la carrière d'Ambrogio Attendolo. Ce personnage aux compétences multiples n'était pas un architecte de cour. Au XVIII ${ }^{\mathrm{e}}$ siècle, lorsque l'ouvrage de Vasari connaît à Venise, à Sienne et à Naples de multiples rééditions afin d'ajouter au bataillon des grands artistes les protagonistes des différentes écoles régionales, des érudits de Capoue retranscrivent cette inscription de façon erronée. Ils font à dessein d'Ambrogio Attendolo «l'architetto maggiore del regno di Napoli $^{15}$ » : le plus grand architecte du royaume de Naples serait né dans la petite cité de Capoue. À la dimension apologétique de l'inscription rédigée par le fils s'ajoute l'exaltation chauviniste d'une figure locale.

15 Toutes ces considérations, qui peuvent être faites à partir d'un personnage de second plan comme Ambrogio Attendolo, sont également valables pour des figures bien plus renommées. Par exemple, la construction historiographique qui a conduit à attribuer à Fra Giocondo le pont parisien de Notre-Dame a suivi exactement le même parcours : des lettrés auxquels ce moine, mort en 1514, est personnellement lié, en l'occurrence Guillaume Budé et Jacques Sannazare, le qualifient d'architecte dans leurs publications et dans des inscriptions commémoratives ; Vasari reprend l'information dans ses Vies; à l'occasion d'une réédition, ce texte fait l'objet au XviII ${ }^{\mathrm{e}}$ siècle de polémiques entre érudits locaux. Seul un retour aux sources, c'est-à-dire vers les documents témoignant de la gestion quotidienne du chantier, permet de sortir d'une vision idéalisée de l'architecte construite par des humanistes et que les historiens de l'art ont pendant longtemps reprise à bon compte ${ }^{16}$.

\section{Un architecte à pied d'œuvre}

16 Le plus ancien document signé de la main d'Ambrogio Attendolo conservé parmi les papiers de la chambre des comptes napolitaine remonte à $1542^{17}$. Alors âgé de trentesept ans, il signe un reçu pour 4 ducats qui ne lui sont pas destinés. En tant qu'intendant du chantier, il a en effet avancé cette somme à un certain Francesco de Lecce, venu assister l'ingénieur militaire Gian Giacomo d'Acaya. Ce dernier a séjourné pendant six jours à Capoue pour projeter le nouveau circuit de fortifications de la ville et s'en est ensuite allé à L'Aquila, dans les Abruzzes ${ }^{18}$. 
17 L'exécution des travaux est confiée à des intendants locaux, que l'on appelle en italien provveditori. C'est un terme qu'on retrouve également très fréquemment dans la documentation vénitienne: certains se voient confier un chantier de construction limité dans le temps, d'autres assurent un mandat au sein d'une magistrature permanente. Leur responsabilité est engagée en cas de malfaçon, mais ils ne sont pas forcément des spécialistes d'art militaire, ni même des professionnels du bâtiment. On fait confiance à leur honorabilité, qui leur confère autorité. Ces deux idées sont liées en italien dans un seul terme : autorevolezza. Il s'agit de l'autorité octroyée par l'estime dont on jouit et les faveurs dont on bénéficie. En Toscane, Daniela Lamberini a étudié le profil professionnel de nombreux provveditori aux forteresses ${ }^{19}$.

«Généralement d'humbles origines, l'intendant devait savoir lire, écrire et tenir des comptes - on lui confiait les registres des entrées et des sorties de la fabrique - mais surtout, il devait avoir l'habitude des hommes et du matériel, car sa mission était de les administrer. C'était une sorte d'homme à tout faire aux mille astuces et aux mille ressources. Conciliant et servile vis-à-vis de ses supérieurs, ambigu et parfois prévaricateur avec l'architecte, dur et inflexible à l'égard des subalternes ${ }^{20}$. "

La direction du chantier de Capoue (fig. 1) ne revient pas encore en 1542 à Ambrogio Attendolo. De nombreux autres noms figurent dans les documents de la chambre des comptes espagnole. Le capitaine Bernardino Cervellone est depuis 1536 soprastante, c'est-à-dire qu'il procède au recrutement dans toute la province des paysans de corvée sur le chantier ${ }^{21}$. En dessous de lui, plusieurs chefs d'équipe, comme Tartaglione, conduisent des équipes de 25 guastatori, paysans corvéables chargés de réaliser les ouvrages de terrassement ${ }^{22}$. Ces ouvriers non spécialisés représentent la majeure partie des effectifs sur les chantiers de fortifications en terre, mais pour réaliser une chemise maçonnée, on fait également appel à une main-d'œuvre spécialisée. La construction des parements est ainsi confiée à un entrepreneur en bâtiment nommé Gismundo Saputo ${ }^{23}$. Le prêtre Braczillo de Santo Andrea est chef d'une équipe de 25 compagnons qui creusent le terrain et probablement en extraient le tuf utilisé pour construire la chemise des bastions ${ }^{24}$. 
Fig. 1. - Plan de la ville de Capoue dans le royaume de Naples fait par Vervier, du $1^{\text {er }}$ régiment du génie le 4 brumaire an III de la République, 1794.

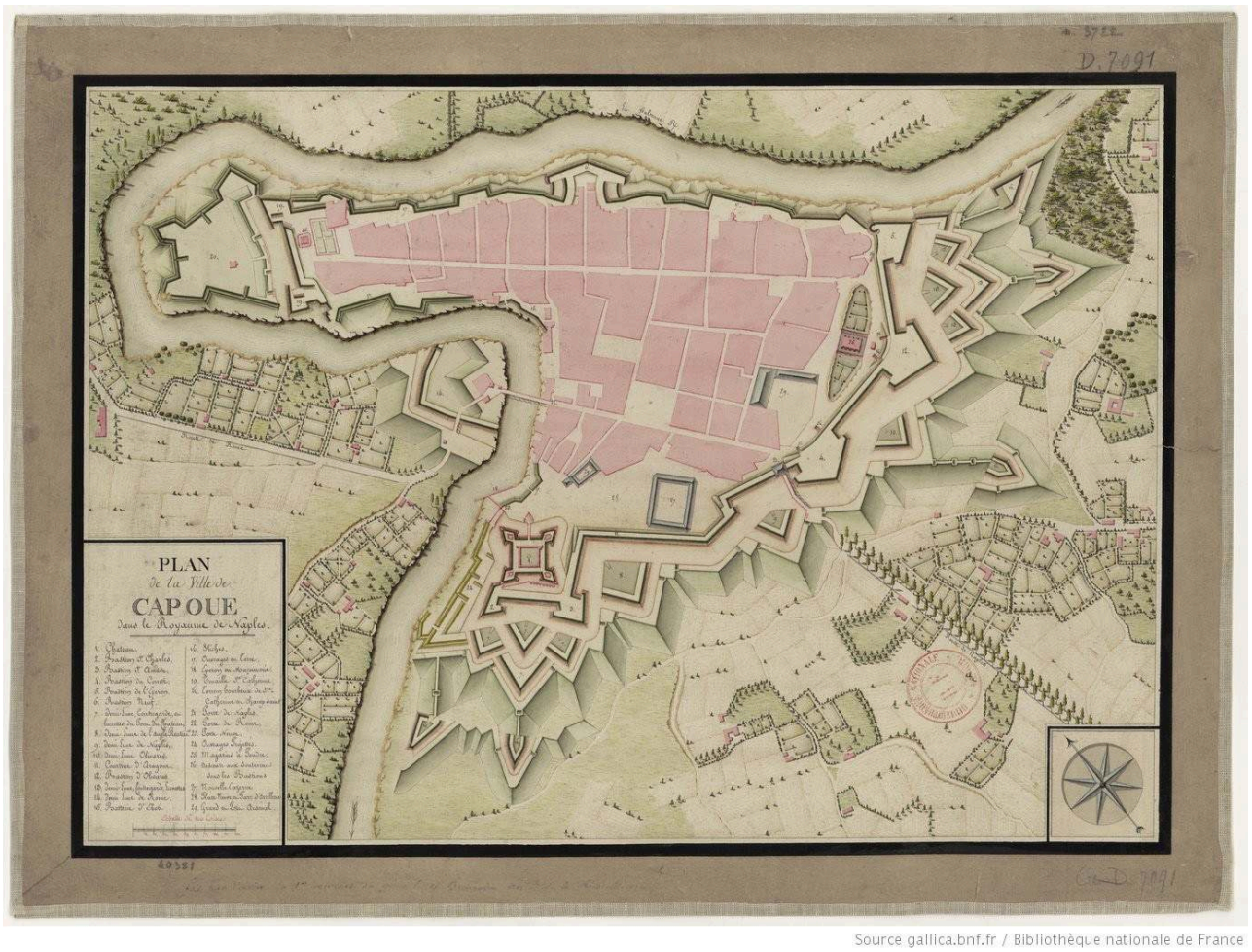

(c) Bibliothèque nationale de France, ark:/12148/btv1b8445984h. peu de pierre. La pierre de taille est mise en œuvre seulement aux angles des bastions ${ }^{25}$, tandis que le reste du parement est réalisé en tuf, probablement directement extrait des fossés creusés aux pieds des murs. Vingt ans plus tard, on continue en effet à cavar la pezzolana, c'est-à-dire à extraire la pouzzolane de ces mêmes fossés ${ }^{26}$. Le terme " pouzzolane » désigne également à Rome un moellon produit à partir d'une pierre de site, et non le précieux agrégat permettant de rendre un mortier hydraulique.

est Baldassare d'Aquino, qui reçoit deux ducats en tant que responsable du dépôt de matériaux ${ }^{27}$. Il a peut-être des liens de parenté avec Girolamo d'Aquino, précepteur de Giovan Battista Attendolo, le fils écrivain, qui n'est encore qu'un enfant.

21 La charge d'Ambrogio Attendolo est celle de deputato a tirar il dissegno : il est chargé de " tirer » le dessin de la fortification, expression ambiguë dont Isabella De Resta a déduit qu'il était le concepteur de ces fortifications ${ }^{28}$. En réalité, c'est sous la supervision de Gian Giacomo d'Acaya que du 27 au 30 mars 1543 l'entrepreneur Girolamo Gismundo et huit autres ouvriers plantent les piquets et tendent les cordes pour tracer sur le terrain, à l'échelle 1 , le dessin des nouveaux bastions approuvé à Naples.

« Pour le maitre Gismundo Saputo de Capoue, entrepreneur, cinq ducats [...] pour les causes ici indiquées et pour ce qu'il a rendu comme service en faisant travailler six maîtres qui avec lui font sept et deux manœuvres pendant quatre jours commencés le lundi 27 et pendant tout le jeudi 30 du mois passé de mars afin d'assister le marquis baron d'Acaya, envoyé par Son Excellence pour dessiner la dite fortification et pour tirer les lances et mesurer tout le plan de cette fortification ${ }^{29}$. » 
La mission d'Ambrogio Attendolo relative à ces dessins est de contrôler la correspondance entre les œuvres exécutées et le projet. Son toisé permet de définir les paiements adressés aux fournisseurs de matériaux et aux artisans. Il consigne ses observations dans un livre des mesures auquel se réfèrent les ordres de paiement ${ }^{30}$. Cette activité tout à fait modeste de métreur à laquelle s'adonne Ambrogio Attendolo dans les années 1540 contraste avec le titre d'architecte que lui confère son fils, mais aussi avec les importantes missions qu'il se voit confier à la fin de sa vie, et qui lui donnent plutôt un profil d'ingénieur.

23 En 1566, il est en effet engagé dans le service des Routes royales de Rome et des Abbruzzes. Il reçoit à partir de cette date dix ducats de salaire par mois pour seconder l'ingénieur Franco Alghiera ${ }^{31}$. Ensemble, ils réparent la route menant à Chiaia, et il semble qu'Attendolo est promu ingénieur en chef en 1573, lorsque son salaire est porté à vingt ducats mensuels. En tant qu'ingénieur, il témoigne lors d'un procès intenté par l'entrepreneur d'un pont construit sur le fleuve Garigliano en 1575, procès au cours duquel il démontre posséder des compétences techniques:

«Comme l'on voulait faire un pont royal sur le fleuve Garigliano di Regno, il a été conclu, le sol de ce fleuve étant pierreux, plein d'éclats et dur, qu'il faudrait mettre des pointes de fer à tous les pieux que l'on plantait pour l'ancrage de ce pont. Mais étant donné qu'il s'agissait d'un fleuve très puissant, et comme on l'a dit, qu'il s'agissait d'un sol fort gaillard, on s'est résolu de faire ces pointes plus grosses et plus longues que celles que l'on avait mises en œuvre au pont de Patria, lequel est un lac au sol boueux et non pas tant gaillard. Et afin que l'on ne se trompe pas, d'après mon dessin on réalisa un modèle en bois de l'une de ces pointes et l'on ordonna à maître Gioan Domeneceo dello Mastro, qui avait remporté le marché, de les réaliser en métal $^{32}$.»

Ces observations relatives à la consistance différente des sols ainsi qu'à l'utilisation d'un modèle à l'échelle 1 sont significatives de l'empirisme du travail des ingénieurs du $\mathrm{xvI}^{\mathrm{e}}$ siècle. On ne découvre la nature du sol qu'en creusant les fouilles pour les fondations, d'où les justes réclamations de l'entrepreneur. Grâce au témoignage de l'architecte, il se verra accorder l'augmentation qu'il demandait par rapport au prix fixé dans le marché initial.

Un autre chantier attribué à Attendolo, documenté là aussi du fait d'un procès intenté par un entrepreneur, est celui de la scagliuta del Posilippo, une rampe qui gravit l'escarpement du Posillipe, à proximité de la tombe de Virgile, et du tunnel antique conduisant de Naples à Pozzuoli. Difficile cependant de savoir si le projet de cet ouvrage d'art encore en service aujourd'hui est l'œuvre d'Attendolo ${ }^{33}$.

Ce dernier est également consulté en 1577 pour la réalisation d'un aqueduc. Avec l'hydraulicien Benvenuto Tortelli, il se rend à Benevento pour examiner la faisabilité de cet ouvrage d'adduction de la ville de Naples ${ }^{34}$. À la mort d'Ambrogio Attendolo en 1585, c'est Benvenuto Tortelli qui lui succède en tant qu'inspecteur des fontaines de la ville de Capoue ${ }^{35}$.

Comment Ambrogio Attendolo, modeste métreur et contrôleur de chantier, a-t-il acquis d'une part des compétences techniques et d'autre part une culture humaniste? D'un côté, son statut de citoyen de Capoue lui permet d'assurer des charges municipales et de s'insérer parmi les familles patriciennes de la ville. Son épouse, Gea Manna, 
appartient ainsi à la famille du greffier qui tient les registres municipaux ${ }^{36}$. De l'autre, la confiance que lui accordent les ingénieurs militaires espagnols qui lui confient en leur absence le chantier des fortifications de la ville ${ }^{37}$ permet à Ambrogio de développer une culture technique par l'expérience du chantier.

Acquisition d'un statut social et compétences techniques reconnues vont de pair. Elles confèrent à Ambrogio Attendolo autorevolezza, c'est-à-dire honorabilité et autorité. Citoyen de la ville de Capoue et homme de confiance de l'administration espagnole, sa position d'intermédiaire lui permet en 1557 de désamorcer un conflit relatif aux travaux de fortifications. Alors que la guerre du sel avec les États pontificaux voisins menace la ville, le gouverneur espagnol décide d'abattre la porta delle Torri pour l'englober dans un bastion moderne. Un nouvel ingénieur militaire, Anton il Grieco, est

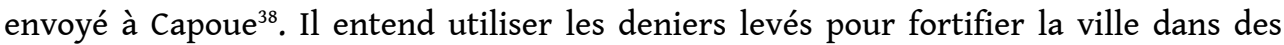
travaux relatifs à la citadelle hors du contrôle du trésorier municipal. Les Capouans ont accepté une augmentation de la gabelle pour protéger leur ville et la doter d'une enceinte moderne, mais refusent la construction d'une citadelle autonome ${ }^{39}$. Ils élisent Ambrogio Attendolo au conseil municipal ${ }^{40}$. Ses liens de parenté avec le gouverneur espagnol, le comte de Santa Fiora, et ses compétences techniques en font l'homme de la situation pour éviter une scission du chantier. Le chantier des fortifications de la ville reste sous la houlette de la municipalité ${ }^{41}$, et l'année suivante, le vice-roi espagnol don Pedro da Toledo se rend à Capoue et renouvelle sa confiance à l'ingegnere della ciudad Ambrogio Attendolo ${ }^{42}$.

Jusqu'à sa mort en 1585, et alors que se multiplient ses missions officielles partout dans le royaume, c'est Ambrogio Attendolo qui conduit tous les grands chantiers municipaux. Il fait notamment partie du conseil qui décide de restaurer la statue de Federico II, abattue en 1557 avec la porta delle Torri, et dont les débris sont restés depuis lors à même le sol. L'effigie du grand roi souabe, qui régna au xIII ${ }^{\mathrm{e}}$ siècle sur une Italie du sud indépendante et unifiée, est installée en 1584 dans une niche de marbre attenante au corps de garde ${ }^{43}$.

Une inscription en latin retranscrite dans les registres des délibérations de la ville rattache ce modeste monument à l'œuvre littéraire des humanistes locaux tels que Giovan Battista Attendolo. Sur un ton élégiaque, proche des poèmes de Joachim Du Bellay, ils déplorent la ruine des monuments de l'Antiquité. Leurs manuscrits sont cependant longtemps restés confidentiels, alors que l'opération spatiale imaginée par Ambrogio Attendolo est d'une grande force politique. Jeté à bas de son arc triomphal, le vieux roi ne regarde plus vers les confins du royaume, mais dans l'axe du pont, vers la ville de Capoue. Comme les statues antiques ou les vierges miraculeuses, cette figure tutélaire est placée au niveau des citadins, qui la saluant se remémorent la glorieuse époque où l'Italie méridionale n'était pas encore espagnole. 


\section{BIBLIOGRAPHIE}

CANGEMI Lidia, « Il castello dell'Aquila: la storia, la costruzione », dans Marino Angela (dir.), Fortezze d'Europa: forme, professioni e mestieri dell'architettura difensiva in Europa e nel Mediterraneo spagnolo, Rome, Gangemi Ed., 2003, p. 243-250.

CARVAIS Robert et BARBOT Michela, « Les livres sur le toisé et l'estimation en France et en Italie ( $\mathrm{XVI}^{\mathrm{e}}-\mathrm{XIX}^{\mathrm{e}}$ siècle) : circulation, continuité, ruptures ", dans Hilaire-Pérez Liliane, Nègre Valérie, Spicq Delphine, Vermeir Koen (dir.), Le livre technique avant le $\mathrm{XX}^{e}$ siècle : à l'échelle du monde, Paris, CNRS éditions, 2017, p. 243-270.

DE DIVITIIS Bianca, « Architecture, Poetry and Law: The amphitheatre of Capua and the new works sponsored by the local élite », dans Enekel Karl A. E. et Ottenheim Koen A. (dir.), The Quest for an Appropriate Past in Literature, Art and Architecture, Leyde, Brill, 2018.

DE DIVITIIS Bianca, « Rinascimento meridionale: la Nola di Orso Orsini tra ricerca dell'antico e nuove committenze », Annali di architettura, 2016, $n^{\circ} 28$, p. 27-48.

DE DOMINICI Bernardo (SANTORO FIORELLA S. et ZEZZA Andrea éd.), Vite de' pittori ed architetti napoletani, Naples, Paparo, 2003.

DI RESTA Isabella, Capua, Rome, Laterza, 1985

DUBOURG GLATignY Pascal, « Artifex, architecte, ingénieur : les conditions d'émergence d'un vocable à la Renaissance », Le Journal de la Renaissance, 2005, vol. 3, p. 95-110.

GIORGI Lucia, « L'intervento di Benvenuto Tortelli nel monastero benedettino di Santa Maria delle Dame Monache a Capua », Atti della Accademia Pontaniana, 1990, nº 39, p. 91-108.

GIORGI Lucia, « Maestranze forestiere a Capua e Caserta dalla seconda metà del 1500 agli inizi del $1600 »$, Rivista di Terra di Lavoro, 2007, vol. 2, n 2, p. 5-13.

HAMON Étienne, Une capitale flamboyante : la création monumentale à Paris à la fin du XVe siècle, Paris, Picard, 2011.

JESTAZ Bertrand, Monuments vénitiens de la première Renaissance à la lumière des documents, Venise, Istituto veneto di scienze, lettere ed arti / Paris, Picard, 2017.

LAMBERINI Daniela, « Il cantiere di fortificazioni nella Toscana del Cinquecento », dans Guillaume Jean (dir.), Les chantiers de la Renaissance, Paris, Picard (De Architectura - colloques), 1991, p. 227-235.

MANNA Antonio, Prima parte della cancelleria di tutti i privilegj, capitoli, lettere regie, et altre firitture della Città di Capua dall' anno 1109. infine al .1570, Naples, 1588.

MERRILL Elizabeth, "The "Professione di Architetto" in Renaissance Italy », Journal of the Society of Architectural Historians, 2017, vol. 76, nº 1, p. 13-35.

MIGNOT Claude, « La monographie d'architecte à l'époque moderne en France et en Italie : esquisse d'historiographie comparée ", Perspective, 2006, vol. 1, n 4, p. 629-636.

MILETTI Lorenzo, «L'anfiteatro e il criptoportico di Capua nell'antiquaria del Cinquecento: due sonetti inediti di Giovan Battista Attendolo ", La parola del passato, 2012, vol. 2, n 6, p. 134-148.

MILETTI Lorenzo, « Sulla fortuna di Livio nel Cinquecento: le domus dei nobili capuani nella veduta di Capua vetus di Cesare Costa », Bollettino di Studi Latini, 2014, vol. 44, n 1, p. 107-126. 
MUTTINI Claudio, « Attendolo, Giovan Battista », dans Dizionario Biografico degli Italiani, Rome, Istituto dell'Enciclopedia italiana, 1962.

NÈGRE Valérie, « Les figures de l'architecte "savant" ( $\mathrm{XV}^{\mathrm{e}}-\mathrm{XVIII}{ }^{\mathrm{e}}$ siècle) ", dans Hilaire-Pérez Liliane, Simon Fabien, Thébaud-Sorger Marie (dir.), L'Europe des sciences et des techniques : un dialogue des savoirs (XVe-XVIII siècle), Rennes, Presses universitaires de Rennes, 2017, p. 133-139.

SENATORE Francesco, Una città, il Regno: istituzioni e società a Capua nel XV seccolo, Rome, Istituto Storico per il Medioevo, 2018.

STRAZZULLo Franco, Architetti e ingegneri Napoletani dal ‘500 al ‘700, Naples, G. e M. Benincasa, 1969.

STRAZZULLO Franco, Edilizia e urbanistica a Napoli dal ‘500 al ‘700, Naples, Arte Tipografica, 1995.

VASARI Giorgio, Le Vite de' più eccellenti pittori, scultori e architettori, $2^{\mathrm{e}}$ éd., Florence, Giunti, 1568, 3 vol.

\section{NOTES}

1. E. Merrill, « The "Professione di Architetto" in Renaissance Italy ".

2. V. Nègre, «Les figures de l'architecte "savant" $\left(\mathrm{XV}^{\mathrm{e}}-\mathrm{XVIII}{ }^{\mathrm{e}}\right.$ siècle) ".

3. P. Dubourg Glatigny, «Artifex, architecte, ingénieur : les conditions d'émergence d'un vocable à la Renaissance ».

4. G. Vasari, Le Vite de' più eccellenti pittori, scultori e architettori.

5. C. Mignot, « La monographie d'architecte à l'époque moderne en France et en Italie : esquisse d'historiographie comparée ».

6. F. Senatore, Una città, il Regno: istituzioni e società a Capua nel XV secolo.

7. L. Miletti, «Sulla fortuna di Livio nel Cinquecento: le domus dei nobili capuani nella veduta di Capua vetus di Cesare Costa ».

8. B. De Divitiis, «Rinascimento meridionale: la Nola di Orso Orsini tra ricerca dell'antico e nuove committenze ».

9. B. De Divitiis, "Architecture, Poetry and Law: The amphitheatre of Capua and the new works sponsored by the local élite ».

10. I. Di Resta, Capua, p. 63 et 67.

11. L. Giorgi, « Maestranze forestiere a Capua e Caserta dalla seconda metà del 1500 agli inizi del $1600 »$, p. 11-13.

12. C. Muttini, « Attendolo, Giovan Battista », dans Dizionario Biografico degli Italiani.

13. Archivio di Stato di Caserta (désormais ASCa), Notai Bertone, corda 772, anni 1567-1588, fol. 114 et 117. Je remercie Lucia Giorgi de m'avoir transmis les photographies de ce testament.

14. G. Vasari, Le Vite de' più eccellenti pittori, scultori e architettori.

15. B. De Dominici, « Notizie di alcuni pittori, scultori, ed architetti Capuani ed altri professi del regno », p. 714.

16. É. Hamon, Une capitale flamboyante: la création monumentale à Paris à la fin du XV siècle; B. Jestaz, Monuments vénitiens de la première Renaissance à la lumière des documents. Ces deux ouvrages accordent une place plus que modeste à Fra Giocondo y compris 
dans des chapitres consacrés à des édifices qui lui étaient traditionnellement attribués, comme le pont Notre-Dame ou l'église San Salvador.

17. Archivio di Stato di Napoli (désormais ASN), Dipendenze della Sommaria I, F. 178, fasc. IV, fol. 145, 12/06/1542 : «Ambrosio Attendolo di Capua, ducati quattro et tari dui correnti, quali selli dando per tanti ne ha pagati per ordine del Magnifico Innocentio Pellegrino et li altri eletti soi compagni a maestro Francesco de Leczia, in dono, a causa che molto have faticato appresso lo magnifico Signore barone de Acaya, circa el disegno per la fortificatione de decta cita questa ultima volta al ritorno de esso signore barone da l'Aquila, dove considerato se per decti Signori electi decta fatica hanno ordinato li siano donati decti quattro scuti. Pigliando dal decto Maestro Ambrosio debita apocha per receptione accio nel vedere questi conti in sua voltura et per nostra cautella havimo facto fare lo presente subscipto." $\mathrm{Au}$ dos du mandement, le reçu est signé par Ambrogio Attendolo et ses garants, Paolo Vigniaruolo et don Joanne Valla.

18. L. Cangemi, « Il castello dell'Aquila: la storia, la costruzione».

19. D. Lamberini, « Il cantiere di fortificazioni nella Toscana del Cinquecento ».

20. Ibid., p. 232.

21. ASN, Dipendenze della Sommaria I, F. 178, fasc. II, fol. 298 ; A. Manna, Prima parte della cancelleria, p. $108 \mathrm{r}^{\circ}, \mathrm{n}^{\circ} 25$.

22. Ibid., fol. 52 : «A Santo Tartaglione de Marcianise capo de squadra guastatori ducati uno tari uno e grano dieci correnti quali selli dando per haver faticato epso con 25 altri guastatori. »

23. Ibid., fol. 33 : « A mastro Gismundo Saputo de Capua fabricatore ducati cinque et grano uno a carlini dieci per ducato quali selli dando per queste cause inserite in questo nostro et per tanti ne ha servitij epso con opere de mastro sei et cum epso sept et opere doi de manipali per quattro giorni incominciato lunedi a 27 et per tutto iovedi a 30 del passato mese de marzo in assistere appresso al marchese baron de Acaya inviato per sua Excellentia a designar decta fortification a tirar le lenze et misurar tutta la pianta de decta fortification. "

24. Ibid., fol. 50: «A prete Braczillo de Santo Andrea capo de squadra de 25 compagni che hanno pigliato a cavar la partita de cane 50 del novo torrion de porta Santo Angelo designato per lo baron de Acaja a ragione di carlini cinque per cana."

25. A. Manna, Prima parte della cancelleria, p. $108 \mathrm{v}^{\circ}, \mathrm{n}^{\circ} 35-36$.

26. Museo Campano a Capua (désormais MC), Archivio 19, fol. $210\left(=220 \mathrm{v}^{\circ}\right)$ : « Giontati nella solita udienza l'Eccelenti Signori Antonio di Maio Girolamo San Tutto, Piro Pellegrino e Camillo Oliva quttro degli Eletti presenti, è comparso avante di loro mastro Stefano Saputo, asserendo come egli e Mastro Gismondo suo padre have tenuto il partito di cavar la pezzolana nelli fossi della mura di questa città a ragione di grana due il carretton e sempre l'hanno fatto diligentemente e fedelmente per servizio de la patria e perche have sentito che alcuni per farli dipiaccere voleno incantarli della pezzolana, per tanto have supplicato detti signori que non pemettano che li sia tolto detto patito, per esser povero e non haver altro mestiere da alimentarsi con detto suo padre decrepito et altra fameglia, e poi che è stato lasciato detto partito a grana uno e mezzo il carretto, egli s'offre di tenerlo per detto prezzo accio che non perda la città cosi li detti Eletti considerando la povertà di detto mastro Stefano e del suo padre vecchio e mal sano e che non hanno altro modo da sostenere la loro vità e la città avanza un tornese per carretton in detta offerta, hanno confirmato il detto partito al presente Mastro Stefano a tre tornesi il carreton. »

27. ASN, Dipendenze della Sommaria I, F.178, fasc. IV, fol. 35, 126, 130 et 219: « Baldaxarre d'Aquino di Capua, soprastante et monitionero della ditta fabrica ». 
28. Ibid., fol. 32 : «A mastro Ambrosio Attendolo di Capua deputato a tirar il dissegno della ditta Reggia fabrica per lo Magnifico Signore barone de Actiaia per ordine di sua Maestà, ducati quindece e carlini diece per ducati quali selli dando per tre mesi, gennaro, febraro et marzo prossimi elassi 1543, c'have servito adetta reggia fabrica all'effetto predetto a ragione di ducati cinque per ciascuno mese. » Voir I. Di Resta, Capua, p. 53.

29. Ibid., fol. 33 : « A mastro Gismundo Saputo de Capua fabricatore ducati cinque et tari uno a carlini dieci per ducato quali selli dando per queste cause inserite in questo nostro et per tanti ne ha servitij epso con opere de mastro sei et cum epso sept et opere doi de manipali per quattro giorni incominciato lunedi a 27 et per tutto iovedi a 30 del passato mese de marzo in assistere appresso al marchese baron de Acaya inviato per sua Excellentia a designar decta fortification a tirar le lenze et misurar tutta la pianta de decta fortification a tari uno l'opera de mastro et grana dieci de manipulo ducati uno et tari tre [...] et per tanti ne ha pagati in comparar la lenza di canne 103. "

30. Ibid., fol. 129 : " Tereno cavato per esso per li fondamenti del sinistro fianco del torrione di porta di San' Angel et della cortina che nasce dal detto fianco verso il fiume, mesurate per Ambrosio Attendolo accio depunto si come par' nel suo libro delle misure. » Voir R. Carvais et M. Barbot, «Les livres sur le toisé et l'estimation en France et en Italie $\left(\mathrm{XVI}^{\mathrm{e}}-\mathrm{XIX}^{\mathrm{e}}\right.$ siècle) : circulation, continuité, ruptures ».

31. ASN, Sommaria, Notamentorum, vol. 41, fol. 76, dans F. Strazzullo, Architetti e ingegneri Napoletani dal '500 al '700, p. 23, n' 3 : «Idem [dominus Stinca] retulit acta nobilis Albrosii Attendolo Incignerii petentis salarium pro mensibus 17 quibus vacavit in platea Aprutii et aliis locis. Provisum quod fiat consolatio cum voto quod dittum salarium solvatur ad rationem ducatrum decem pro mense pro tempore quo vacavit. »

32. ASN, Processi antichi, Pandetta nuovissima, F. 2375, fasc. 56 668, dans F. Strazzullo, Architetti e ingegneri Napoletani dal ' 500 al '700, p. 26, doc. II.

33. ASN, Processi antichi, Pandetta nuovissima, F. 1797, fasc. 50 285, dans F. Strazzullo, Edilizia e urbanistica a Napoli dal '500 al '700, p. 132, note 4.

34. ASN, Sommaria, Mandatorum Curiae, vol. 17 bis, fol. 190, dans F. Strazzullo, Architetti e ingegneri Napoletani dal '500 al '700, p. 326, doc. VI.

35. L. Giorgi, «L'intervento di Benvenuto Tortelli nel monastero benedettino di Santa Maria delle Dame Monache a Capua ».

36. ASCa, notai Bertone, corda 772, 1567-1588, fol. 114-115.

37. ASN, Collaterale, Curiae, vol.12, fol. 271 : «Et perché intendemo che per lo passato so sono dispesi certi danari e la dicta fabrica con intervento de Ambrosio Actendolo, quale dicto Barone lasso in loco suo quando partito, pero vi ordiniamo che havendo le cauthele necessarie de dicte spese con la interventione del dicto Ambosio li admictate et faziate bone al cunto del dicto regio pagatore.» Dans F. Strazzullo, Architetti e ingegneri Napoletani dal '500 al '700, p. 26, doc. I.

38. MC, Archivio 23, fol. $77 \mathrm{v}^{\circ}$. Voir A. Manna, Prima parte della cancelleria, p. 120, $\mathrm{n}^{\circ} 61$ : "Si concluse in consiglio che si tenessero li soprastanti della città con la solita provisione de 2 ducati il mese, e non lo spagnolo mandato dal Sig. Aldana con la provisione 6 il mese, e stantia strame e letto: e che s'investissero altri bastioni de la Città, intertenendo la fabrica di quei del castello e di non prendere ivi le denari de le mura de la Città come ha cominciato lo magnifico Anton Grieco ingegniero mandato dal Sig. Mastro de campo Aldana andando da esso Sig. Mastro di campo che ci proveda, e non provedendoci da li superiori. » 
39. Le cas de L'Aquila, où la forteresse est construite en représailles de la révolte de la ville, est très différent. Voir L.Cangemi, «Il castello dell'Aquila: la storia, la costruzione ».

40. MC, Archivio 23, fol. $75 \mathrm{v}^{\circ}, 19 / 11 / 1557$. Le trésorier des fortifications Ottaviano della Ratta est également élu ce jour.

41. MC, Archivio 23, fol. 85 et $150 \mathrm{v}^{\circ}, 16 / 08 / 1558$ : "Trattandosi in consigli delle lettere Reggie continenti che lo danaro de la fortificatione si spendesse in detta fortificatione e massime nel torrione che stà verso del fiume conforme al ordine del signor Aldana, e del peso che havevano havuto lo Sig. Eletti di provedere alle cose di detta fortificatione fù concluso che si obedisse ci calo spendere il danaro de la fortificatione nel torrione predetto si replicasse appresso de li superiori e del Rè nostro Signore. E che per compiaccere al Sig. Aldana si pagassero al soprastante spagnuolo 18 ducati per tre mesate che haveva servito. E che l'offitio di scrivania de ratione restasse al Sig. Ottaviano de la Ratta con provisione de ducati 36 l'anno per essere contentato de la provisione de onze 12 del magnifico Ambrosio Attendolo come deputato a tirare il disegno de la fortificatione se ne diminuissero onze due per essersene contentato. »

42. MC, Archivio 23, fol. $120 \mathrm{v}^{\circ}, 28 / 05 / 1558$. Voir A. Manna, Prima parte della cancelleria, p. $110, \mathrm{n}^{\circ} 62$.

43. MC, Archivio 24, fol. $97 \mathrm{v}^{\circ}, 3 / 01 / 1584$.

\section{RÉSUMÉS}

L'inscription gravée sur la pierre tombale d'Ambrogio Attendolo (1505-1580) le qualifie d'architecte et dresse la liste des ouvrages d'ingénierie qu'il a réalisés : fortifications de Capoue, Crotone et Gaëte, routes reliant Naples à Pozzuoli et à Rome. Dès 1542, son nom apparaît dans les paiements enregistrés par la cour des comptes espagnole. Il contrôle alors en tant que métreur l'exécution des bastions projetés dans sa ville natale de Capoue par l'ingénieur militaire Gian Giacomo d'Acaya. Tant au sein de l'administration communale que du corps des ingénieurs militaires espagnols, Ambrogio Attendolo acquiert peu à peu, grâce à sa probité, une autonomie qui lui permet de passer du statut de contrôleur de chantier à celui d'architecte. Les opérations de relevé documentées à l'occasion des visites des ingénieurs espagnols et les lettres qu'échangent le vice-roi et les élus capouans à propos du contrôle financier des travaux permettent de reconstituer le contexte technique, politique et culturel de cette formation au quotidien sur le chantier.

\section{INDEX}

Mots-clés : architecture militaire, ingénieur, Philippe II, Charles V, guerre du sel Index géographique : Naples, Volturno 
AUTEUR

NICOLAS MOUCHERONT

Doctorant en histoire de l'architecture, École des hautes études en sciences sociales, Centre Alexandre-Koyré / Università Iuav di Venezia 
Les roches décoratives antiques de Meaux (Seine-et-Marne) : apports des découvertes du XXI siècle à la connaissance de la parure décorative et des espaces de la ville de Ia(n)tinum

\author{
Arnaud Prié, Annie Blanc et Philippe Blanc
}

\title{
NOTE DE L'AUTEUR
}

Avec la collaboration de Marc Viré (INRAP, LAMOP, GESCAS), Lise Leroux (LRMH, LAMOP, GESCAS) et David Couturier (INRAP).

Nous tenons à remercier sincèrement nos collaborateurs pour leurs contributions respectives dans ces quinze ans d'études; ainsi que les responsables d'opérations archéologiques qui ont eu recours à nos services, principalement David Couturier.

\section{Le contexte meldois : architecture romaine et décor}

1 Ia(n)tinum était la capitale de la cité gauloise des Meldes avant Meaux (fig.1). L'occupation antique y était principalement installée dans la plaine alluviale dite plaine Saint-Faron, où ont été retrouvées des traces d'occupation de La Tène finale, puis une urbanisation entre le $\mathrm{I}^{\mathrm{er}}$ siècle av. J.-C. et le milieu du $\mathrm{IV}^{\mathrm{e}}$ siècle $^{1}$. Un vaste sanctuaire aux origines gauloises domine la ville à l'est (site de La Bauve ${ }^{2}$ ). Elle était également équipée a minima de deux théâtres (rue Camille-Guérin, La Bauve), d'un amphithéâtre (lieu-dit La Croix-Saint-Faron), d'un temple à Janus et d'un établissement thermal (rue Georges- 
Lugol). On lui connaît aussi 8 tronçons viaires ${ }^{3}$. À partir du milieu du III $^{\mathrm{e}}$ siècle, la vie de la ville semble se replier sur son castrum, dont une partie du rempart est conservée. Le reste de l'agglomération, monuments et domaines privés, semble en voie d'abandon et de démolition progressive. Le paysage urbain du Moyen Âge se met en place dès les IV $\mathrm{e}_{-}$ $\mathrm{v}^{\mathrm{e}}$ siècles ${ }^{4}$.

Fig. 1. - Carte du Meaux gallo-romain, la(n)tinum (Seine-et-Marne).

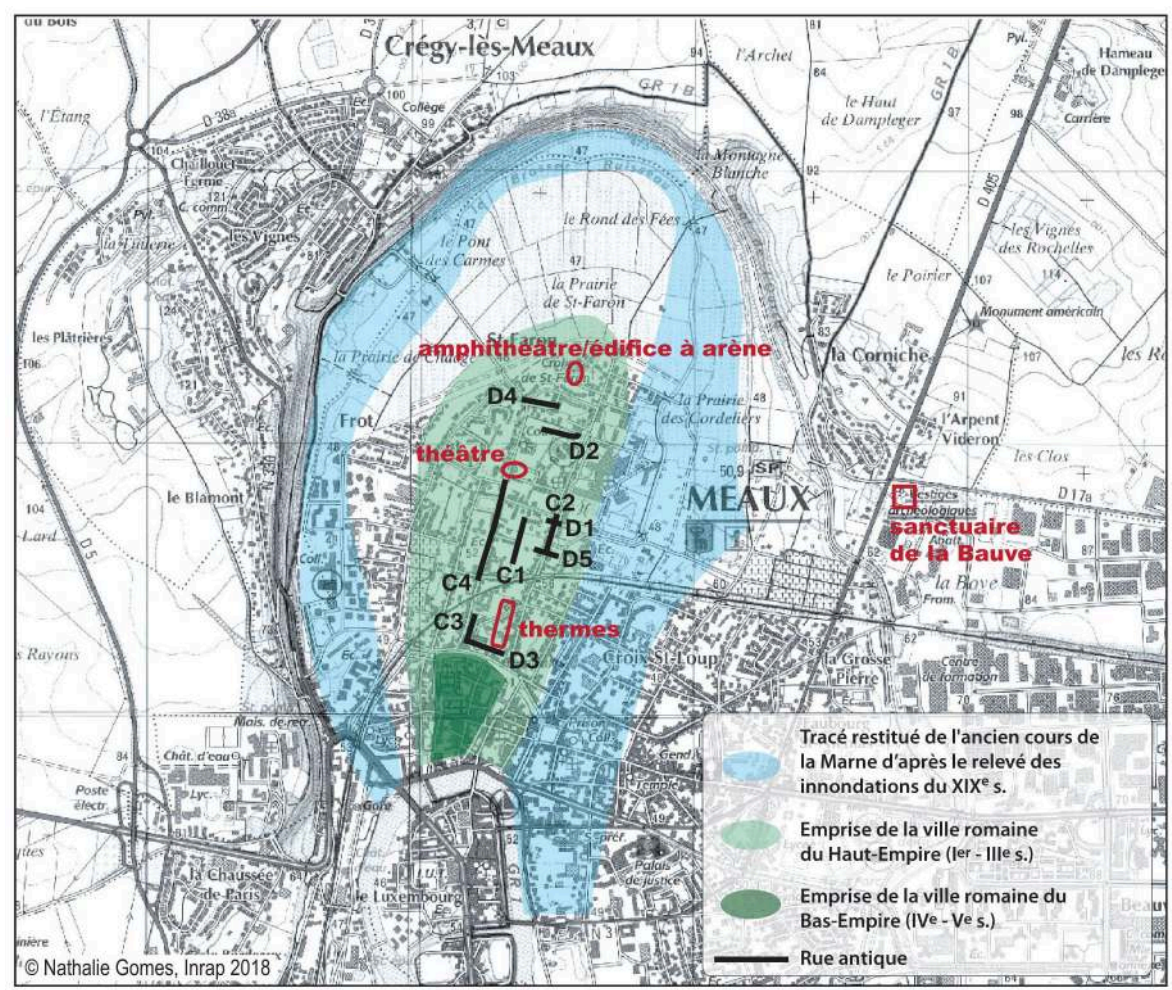

(c) Nathalie Gomes. () Fond de carte IGN 2018, extrait du scan 25® de l'IGN, autorisation n 80-1810.

2 L'image d'une cité étant liée, aujourd'hui comme autrefois, à sa parure monumentale, les édifices publics illustrent bien l'importance de ce chef-lieu de cité ${ }^{5}$ ainsi que la politique romaine d'équipement par des infrastructures et ensembles nécessaires à la vie communautaire urbaine, avec l'introduction de modèles et formes d'architecture publique et privée d'origine méditerranéenne.

3 L'environnement géologique de Meaux ${ }^{6}$ permettait de disposer facilement de pierres calcaires locales, pour le premier comme le second œuvre. Le décor est une composante significative de l'architecture romaine, et dans les provinces un élément d'identification culturelle et sociale, par son caractère attractif et prestigieux, tout comme la présence des parties typiques de la domus à partir du milieu du $\mathrm{I}^{\mathrm{er}}$ siècle $^{7}$. Le décor constitue principalement la peau de la construction et son ameublement. Il associe des techniques et matériaux diversifiés dans un jeu de formes et de polychromie : enduits, stucs et peintures murales, plaquages muraux ${ }^{8}$ et équipements au sol ${ }^{9}$, mobilier sculpté. Il peut être considéré comme un des indicateurs de l'avancement de la romanisation dans une région ${ }^{10}$. Le choix de décorer en marbre est associé à une possibilité et une volonté d'importation de roches décoratives nobles. Il témoigne d'une volonté du commanditaire d'afficher un état d'esprit romain et des moyens conséquents. Ces roches sont très diversifiées, pouvant donc satisfaire 
différents types de cadres décoratifs (monuments, habitats, commerces, ateliers) et d'utilités.

4 La mémoire de découvertes de marbres antiques à Meaux remonte principalement au $\mathrm{xx}^{\mathrm{e}}$ siècle (fig. 2). Elle concerne la zone des thermes dits « de la rue Georges-Lugol » (revêtements de calcaire et de marbres gris et bleutés, gris et blanc veinés ou blancs, attestés en au moins sept endroits ${ }^{11}$; un opus sectile en place (un dallage polychrome de pièce d'apparat d'habitat aisé $\left.{ }^{12}\right)$; et bien entendu, les fragments recueillis lors des fouilles programmées du site de La Bauve.

Fig. 2. - Meaux (Seine-et-Marne) : carte des opérations de 1982 à 2016, sites et vestiges antiques dans la plaine Saint-Faron. Échelle 1:5000.

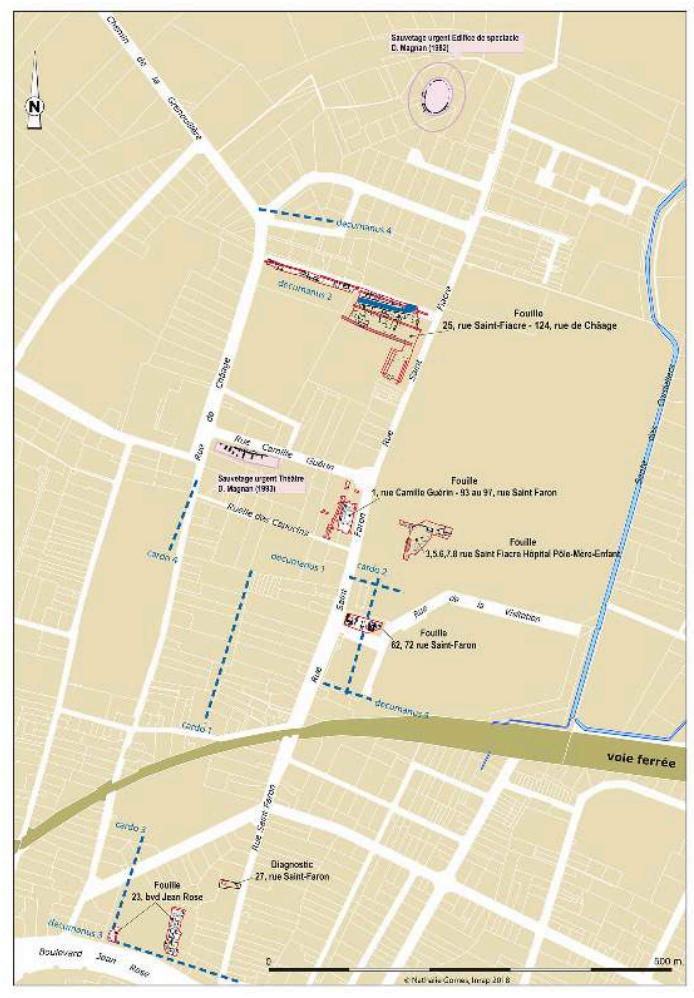

(c) Nathalie Gomes.

\section{Fouilles et méthode d'étude}

Depuis le début du xxI ${ }^{e}$ siècle, six études principales ont été associées à des fouilles archéologiques dans la plaine Saint-Faron afin de mieux appréhender des sites, leurs fonctions économiques ou celles de leur environnement proche, à l'échelle de l'agglomération antique. Nous utilisons les poids pour visualiser les proportions de chaque variété de roche dans un ensemble et apprécier l'importance d'un site (tabl. 1 et fig. 3). Mais comme la probabilité qu'un contexte soit proche d'une utilisation initiale augmente souvent avec le nombre de fragments, le dénombrement peut être plus adapté pour localiser les contextes les plus significatifs. 
Tabl. 1. - Meaux (Seine-et-Marne) : corpus des roches décoratives gallo-romaines de la(n)tinum (2005-2017).

\begin{tabular}{|l|l|l|}
\hline Sites & Nombre & Poids $\mathbf{( k g})$ \\
\hline 3-8, rue Saint-Fiacre, fragments & 67 & 9,3 \\
\hline 3-8, rue Saint-Fiacre, tesselles & 126 & 0,53 \\
\hline 25, rue Saint-Fiacre, fragments & 59 & 15 \\
\hline 25, rue Saint-Fiacre, tesselles & 11 & 0,052 \\
\hline 88, rue de Châage, fragments & 10 & 3 \\
\hline 88, rue de Châage, tesselles & 0 & 0 \\
\hline 27, rue Saint-Faron, fragments & 656 & 150,2 \\
\hline 27, rue Saint-Faron, tesselles & 0 & 0 \\
\hline 62-72, rue Saint-Faron, fragments & 62 & 32,8 \\
\hline $62-72$, r rue Saint-Faron, tesselles & 0 & 0 \\
\hline 1, rue Camille-Guérin (93-97 rue Saint-Faron), fragments & 437 & 98,2 \\
\hline 1, rue Camille-Guérin (93-97 rue Saint-Faron), tesselles & 328 & 1,3 \\
\hline 23, boulevard Jean-Rose, fragments & 135 & 43,4 \\
\hline 23, boulevard Jean-Rose, tesselles & 1022 & 4,9 \\
\hline La Bauve, fragments & 110 & 0 \\
\hline La Bauve, tesselles & 16 & 0 \\
\hline TOTAL & 3039 & 358,682 \\
\hline Total sans tesselles & 1552 & \\
\hline
\end{tabular}


Fig. 3. - Meaux (Seine-et-Marne) : corpus des roches décoratives gallo-romaines de la(n)tinum, 2005-2017.

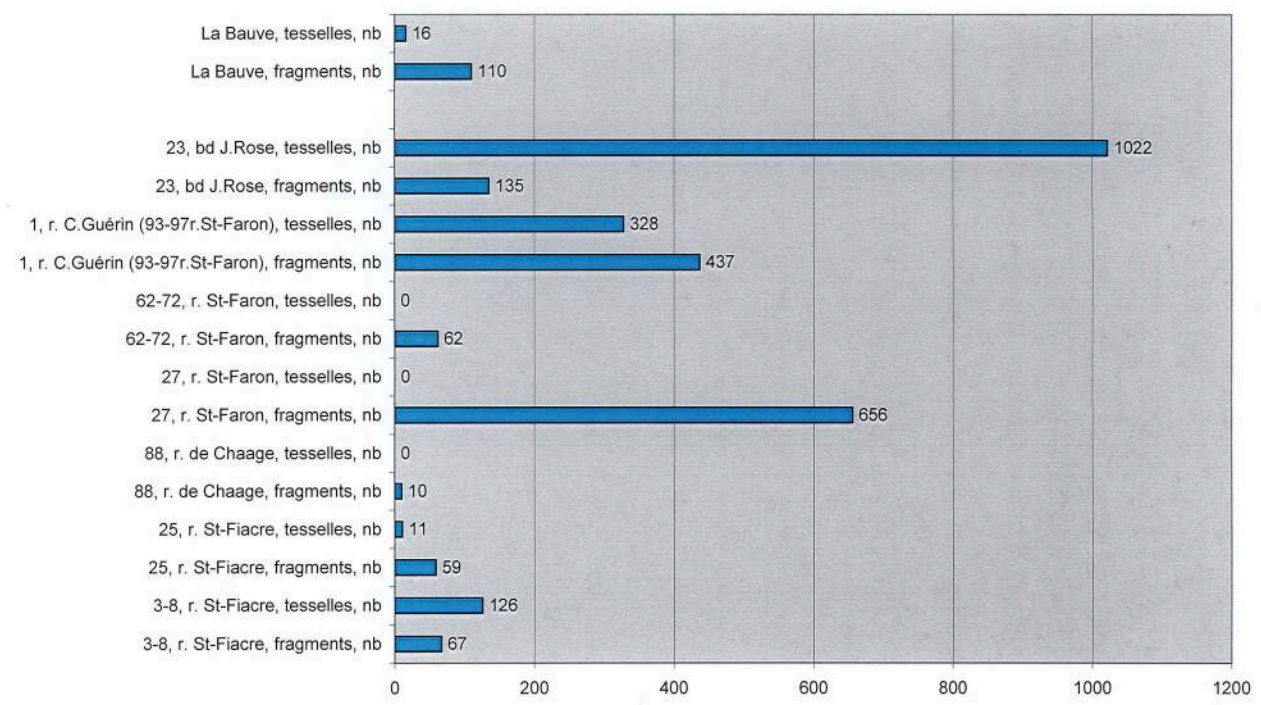

(c) Arnaud Prié.

(c) Arnaud Prié

6 Chaque fragment de roche est l'objet d'observations macroscopiques de structure, de minéralogie, de fossiles et souvent de teintes, et souvent de tests élémentaires (réactions chimiques, dureté...). Ces observations sont complétées si nécessaire par des examens au microscope (lame mince, MEB), qui facilitent la description des particularités et de la granulométrie, ainsi que l'identification des minéraux accessoires caractéristiques. Ces approches permettent de mesurer et de décrire les roches, souvent de les identifier, de les situer dans une classification et d'en proposer une origine.

7 Mais des limites méthodologiques sont imposées par la technique et la taille des restes. Lorsque l'identification pétrologique est bien assurée, le manque d'un référentiel chimique ou minéralogique peut limiter la possibilité d'une localisation de provenance. Et il est difficile d'identifier avec certitude à partir de petits fragments des roches dont la structure est bréchique (hétérogène et discontinue). Les connaissances disponibles sur les calcaires métamorphisés (paléozoïques) provenant de la périphérie des grands bassins sédimentaires au contact des socles anciens semblent permettre de reconnaître (sans lames minces), le plus souvent avec certitude, une provenance des Ardennes, de Mayenne ou des Pyrénées centrales, mais pas encore systématiquement.

Les marbres blancs étant par définition constitués uniquement de calcite (ou de dolomite), donc difficilement différenciables, leur « identification » et la détermination de leur origine nécessitent plusieurs approches. Le croisement de différentes mesures permet de déboucher sur une hypothèse ${ }^{13}$.

9 Les observations pétrographiques sont une première étape de l'étude en classant les grains par leurs caractéristiques : taille (maximum grain size), forme, contours, clivages, sutures intergranulaires et présence de rares minéraux accessoires ${ }^{14}$.

Il est très souhaitable d'y associer des analyses complémentaires (tabl. 2) :

-L'étude de cathodoluminescence. «La cathodoluminescence résulte des interactions entre une impureté $\left(\mathrm{Mn}^{2+}\right)$ et son environnement atomique $\left(\mathrm{CO}_{3} \mathrm{Ca}\right)$ au sein du cristal, lors d'une 
excitation par un bombardement électronique. La luminescence est alors caractéristique du minéral excité et de l'ion activateur ${ }^{15}$. » Cette analyse se pratique sur lame mince en donnant un faciès typique, ou sur poudre comprimée lorsque l'on ne dispose pas d'une quantité suffisante et que la quantification est utilisable.

- L'analyse des isotopes stables du carbone et de l'oxygène fournit les rapports des isotopes ${ }^{18} \mathrm{O} /{ }^{16} \mathrm{O}$ et ${ }^{13} \mathrm{C} /{ }^{12} \mathrm{C}$.

Tabl. 2. - Meaux (Seine-et-Marne), 25, rue Saint-Fiacre : analyse des marbres blancs (étude Philippe Blanc).

\begin{tabular}{|c|c|c|c|c|c|c|c|c|c|c|c|c|}
\hline Numéro & \begin{tabular}{|l|} 
Unité \\
stratigraphique
\end{tabular} & $\begin{array}{l}\text { épaisseur } \\
\text { en } \mathrm{cm}\end{array}$ & Caractères & \begin{tabular}{|l} 
maximum \\
grain size \\
en $\mathrm{mm}$ \\
\end{tabular} & $\begin{array}{l}\text { Cathodo- } \\
\text { luminescence }\end{array}$ & Aspect & Inclusions & Hypothèse 1 & Similaire & Isotope 0 & Isotope C & $\begin{array}{l}\text { Hypothèse } 2 \\
\text { finale }\end{array}$ \\
\hline M1 & 70075 & 1,5 & gros grain & 4 & forte & porcelané & & Châtelperron & & $-13,02$ & $-1,25$ & $\begin{array}{l}\text { Châtelperron } \\
\text { ? }\end{array}$ \\
\hline M2 & 7041 & & grain fin & & orange & gris & & Carrare & & $-5,82$ & 3,03 & Châtelperron \\
\hline M3 & 8002 & 3,5 & \begin{tabular}{|l|} 
grain \\
moyen
\end{tabular} & 0,6 & faible & porcelané & & Pyrénées & & $-2,05$ & 2,95 & Pyrénées \\
\hline M4 & 70592 & 1,6 & grain fin & & très faible & & & Carrare & & & & Carrare \\
\hline M5 & 8547 & 2,1 & grain fin & 0,8 & faible & & & Carrare & & $-1,44$ & 2,20 & Carrare \\
\hline M6 & 7595 & 2 & grain fin & 0,4 & faible & & & Carrare & $=\mathrm{M} 4$ ? & & & Carrare \\
\hline M7 & 70592 & 1,7 & gros grain & 3,5 & & \begin{tabular}{|l}
$\begin{array}{l}\text { laiteux } \\
\text { clivé }\end{array}$ \\
\end{tabular} & & Châtelperron & & & & Châtelperron \\
\hline M8 & 70209 & 1,7 & gros grain & 3 & faible & \begin{tabular}{|l} 
laiteux \\
clivé
\end{tabular} & & Châtelperron & & & & Châtelperron \\
\hline M9 & 70209 & 1,7 & gros grain & 3 & faible & \begin{tabular}{|l} 
laiteux \\
clivé
\end{tabular} & & Châtelperron & & & & Châtelperron \\
\hline M10 & 7595 & 2,5 & $\begin{array}{l}\text { gros grain } \\
\text { gras }\end{array}$ & 2,7 & bleu faible & & & Pyrénées & & $-2,59$ & 2,65 & Marmara \\
\hline M11 & 7595 & 1,7 & \begin{tabular}{|l} 
gros grain \\
gras
\end{tabular} & 5 & faible & \begin{tabular}{|l} 
clivage \\
simple
\end{tabular} & & Châtelperron & & & & \\
\hline M12 & 7376 & $3,2-2,4$ & $\begin{array}{l}\text { gros grain } \\
\text { gras }\end{array}$ & 5 & faible & clivé & & Pyrénées & & $-7,16$ & 0,80 & Châtelperron \\
\hline M13 & 7595 & 3,2 & & & faible & \begin{tabular}{|l} 
clivé + \\
simple
\end{tabular} & graphite & Pyrénées & & $-6,67$ & 1,87 & Pyrénées \\
\hline M14 & 7343 & 2,4 & $\begin{array}{l}\text { gros grain } \\
\text { gras }\end{array}$ & 3 & faible & clivé & & ??? & & $-6,86$ & $-0,43$ & Châtelperron \\
\hline M15 & 7594 & 2,9 & gris & 2,6 & faible & & pyrite & ??? Pyrénées & & $-1,95$ & 3,40 & Pyrénées \\
\hline M16 & 70592 & 4,5 & $\begin{array}{l}\text { marbre } \\
\text { bleu }\end{array}$ & $>4$ & faible & clivé & & Châtelperron & & $-8,62$ & 1,44 & Châtelperron \\
\hline M17 & 8587 & 3 & $\begin{array}{l}\text { laiteux } \\
\text { fissures } \\
\text { rouges }\end{array}$ & 20 & faible & clivé & & Châtelperron & & $-8,39$ & 0,82 & Châtelperron \\
\hline M18 & 7594 & 2,5 & $\begin{array}{l}\text { gros grain } \\
\text { gras }\end{array}$ & 2 & faible polluée & & & Pyrénées & & & & \\
\hline M19 & 7594 & 1,8 & & & faible & & & Châtelperron & $=\mathrm{M} 7$ & & & Châtelperron \\
\hline M20 & 7343 & 3-4 & $\begin{array}{l}\text { gros grain } \\
\text { gras }\end{array}$ & 1 & faible & macle & & \begin{tabular}{|l|}
$\begin{array}{l}\text { Pyrénées ou } \\
\text { Châtelperron }\end{array}$ \\
\end{tabular} & & $-6,84$ & 0,73 & Châtelperron \\
\hline M21 & 70592 & 24 & $\begin{array}{l}\text { marbre } \\
\text { gros grain }\end{array}$ & 2 & faible & \begin{tabular}{|l} 
clivage \\
porcelané \\
simple
\end{tabular} & & & & & & Châtelperron \\
\hline M22 & 7343 & 14 & blanc rosé & & $\begin{array}{l}\text { faible fissure } \\
\text { forte }\end{array}$ & porcelané & & Châtelperron & & & & Châtelperron \\
\hline M23 & 5 fragments & 40 & & & faible & porcelané & & $\begin{array}{l}\text { ?? Pyrénées } \\
\text { ou } \\
\text { Châtelperron }\end{array}$ & & & & \\
\hline
\end{tabular}


11 Ces analyses, réalisées par un ensemble de chercheurs à partir de nombreux échantillons, ont abouti à la représentation de l'espace des marbres classiques du monde méditerranéen et des marbres gaulois. Les superpositions des ellipses représentatives sont traitées par les autres propriétés appréhendées comme on l'a décrit précédemment (fig. 4).

Fig. 4. - Meaux (Seine-et-Marne), 3-8, rue Saint-Faron : graphique des isotopes du carbone et de l'oxygène.

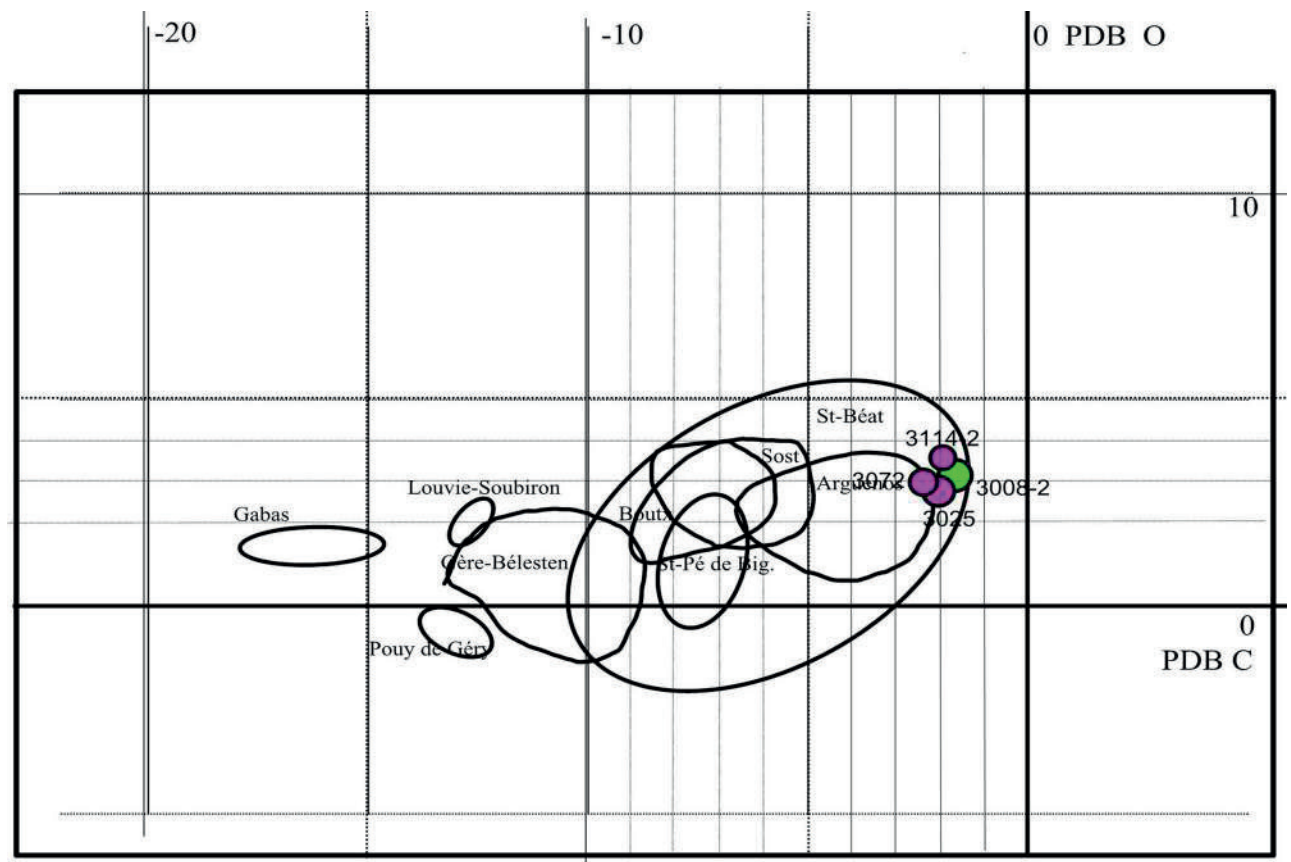

(c) Philippe Blanc, 2005.

12 Certains gisements de marbre n'ont pas été pris en compte par ces études internationales, mais peuvent être ajoutés, comme ceux des marbres pyrénéens, ceux du centre de la France, ou ceux d'Espagne. Les échantillons restant indéterminés sont devenus très peu nombreux grâce à une meilleure connaissance des gisements gaulois. 


\section{Variété des pierres : un aperçu du commerce et du monde antique}

Les calcaires du gros œuvre ou premier œuvre ${ }^{16}$ proviennent le plus souvent des districts carriers de Varreddes et d'Isles-les-Meldeuses (Seine-et-Marne), aux abords de la Marne, à quelques kilomètres en amont de Meaux, donc d'un périmètre local ${ }^{17}$.

Les autres vestiges courants en pierre retrouvés lors d'une fouille archéologique et principalement présentés ici sont les revêtements de sols (pavements), de parois (plaquages), et quelques fragments architectoniques secondaires (fig. 5). Lorsque des roches (plus dures) sont souhaitées pour ce second œuvre, elles sont importées d'un périmètre régional - bassins carriers de la vallée de l'Ourcq, de Paris et Charenton, de l'ouest ou nord parisien (Carrières-sur-Seine ou Le Pecq, dans les Yvelines; vallée de l'Oise) -, ou extrarégional pour les marbres ${ }^{18}$.

Fig. 5. - Meaux (Seine-et-Marne), 1, rue Camille-Guérin : restitution de principe d'une piscine à partir des revêtements calcaires retrouvés.

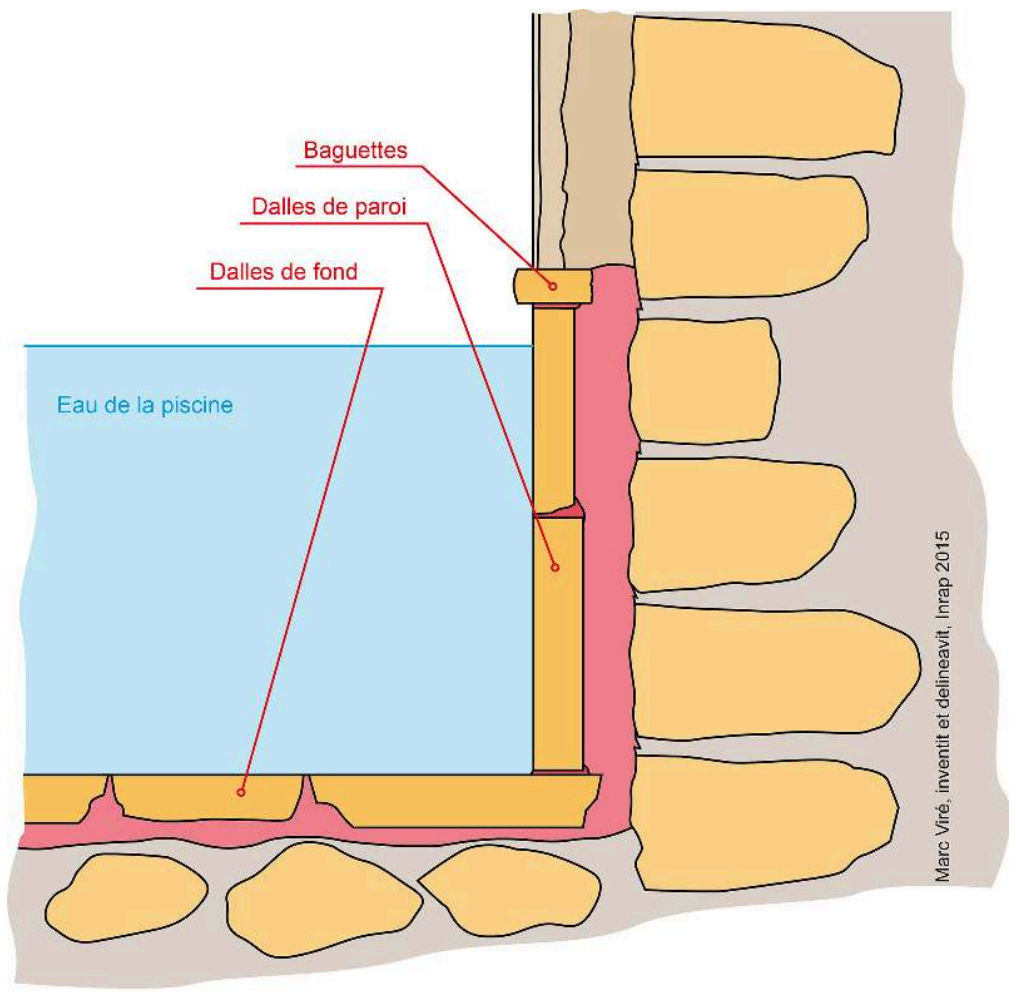

(c) Marc Viré, 2015.

Les marbres blancs proviennent le plus souvent de la Gaule et de ses abords, une grande majorité venant du centre de la France (3-8 et 25, rue Saint-Fiacre ; 23, boulevard JeanRose ; 1, rue Camille-Guérin) : nord du Massif central (Châtelperron, Allier), Pyrénées (Saint-Béat, Haute-Garonne), et accessoirement Carrare (Italie). Leurs provenances sont donc presque régionales, par souci de limitation rationnelle des frais de transport ${ }^{19}$. La présence des marbres blancs méditerranéens, assez semblables en apparence mais plus onéreux, doit s'expliquer par des mises en œuvre ou des opportunités différentes, ou par une différence d'usage ${ }^{20}$. Selon l'époque, ils pourraient avoir été achetés davantage 
sous forme de produits sculptés (statuaire, supports de table, autels...) que comme matériau ${ }^{21}$.

Les marbres monochromes, de provenances peu lointaines et peu prestigieuses pour l'île-de-France, sont parfaitement adaptés à un usage en habitat simple, en commerce ou atelier. Par rapport à d'autres marbres plus réputés, onéreux et prestigieux, ils peuvent être considérés comme des marbres d'usage courant ou "de remplacement ", «de substitution ${ }^{22}$ ». Les marbres blancs pyrénéens sont considérés précisément comme des marbres de remplacement de ceux de Méditerranée orientale ${ }^{23}$.

De nombreuses roches décoratives retrouvées à Meaux proviennent des Ardennes, de Mayenne ou du Morvan. Le sud-est du Bassin parisien semblait fournir couramment cinq types principaux : les marbres blancs à nuances de Châtelperron, le calcaire à gris variés de Gilly-Diou (Allier), le marbre blanc veiné de gris de Ferrières-sur-Sichon (Allier), le schiste d'Autun (Saône-et-Loire) et enfin les calcaires sublithographiques du jurassique supérieur (par exemple, au plus près, Molay ou Bailly, dans l'Yonne) pour les tesselles de mosaïque. Leur transport vers le centre du Bassin parisien se faisait assez facilement, par voie fluviale comme terrestre.

18 Mais la région la moins éloignée d'où provient une large variété de marbres renommés dans tout l'Empire romain reste indubitablement le versant septentrional des Pyrénées centrales. Le transport vers le centre du Bassin parisien était alors réalisé plutôt par voie d'eau, fluviale et maritime ${ }^{24}$. On retrouve très fréquemment à Meaux les calcaires amygdalaires ou griottes (jusqu'à sept variétés distinctes, du vert au rouge) provenant des hautes vallées du Salat, de la Garonne et de l'Adour (fig. 6a, 6b) ; souvent le marbre blanc à bleuté de Saint-Béat, et occasionnellement les brèches (Lez, Haute-Garonne, et autres). Les autres marbres réputés des Pyrénées, les brèches noir et blanc et jaune et blanc (celle de la carrière de La Pène Saint-Martin, à Saint-Béat), le marbre noir de la carrière d'Aubert (Moulis, Ariège) se trouvent plutôt à La Bauve. Au Bas-Empire, les marbres des Pyrénées ont bénéficié du ralentissement des importations depuis les provinces orientales, et cette activité est devenue une composante essentielle de la vie économique de la région ${ }^{25}$. 
Fig. 6. - Meaux (Seine-et-Marne), marbres remarquables.

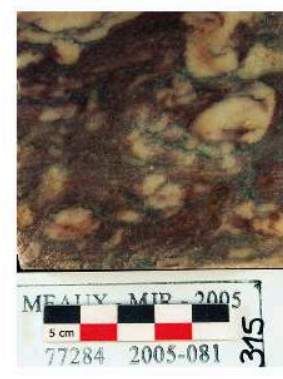

a

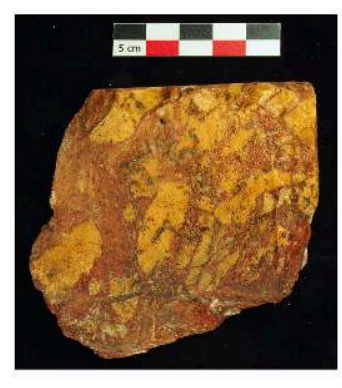

c
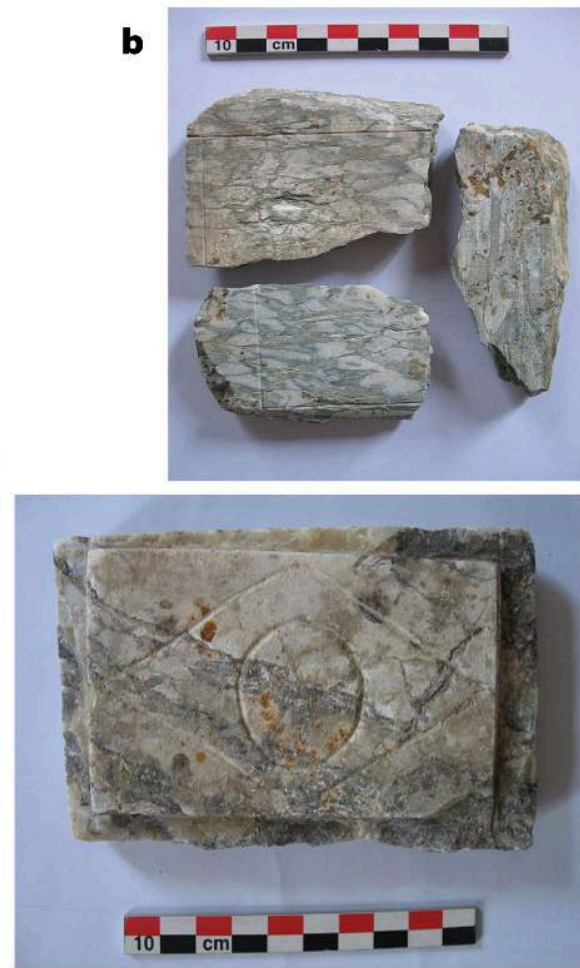

A : calcaire amygdalaire rouge des Pyrénées, opus sectile, 23, boulevard Jean-Rose. B : calcaire amygdalaire vert des Pyrénées, pavement, 25, rue Saint-Fiacre. $\mathbf{c}$ : brèche rouge et jaune de Chemtou, pavement, 23, boulevard Jean-Rose. D : marbre de Skyros, tableau, 25, rue Saint-Fiacre.

(c) Christelle Seng (A et $\mathbf{C})$, David Couturier (B et $\mathbf{D})$.

Les marbres du bassin carrier de Carrare-Luni (marmor lunense, blanc, ou luna, veiné de gris ou gris turquin) sont fréquents à Meaux, en petites quantités. L'usage de ces marbres unis ou atones était moins réglementé que celui des marbres aux couleurs chatoyantes $^{26}$.

Les marbres d'origine méditerranéenne lointaine, d'Afrique du Nord ou du bassin Méditerranéen oriental, sont très coûteux à amener jusqu'en Gaule du nord. Le coût du transport favorise des provenances en bord de côtes (ou de fleuve permettant de les rejoindre ${ }^{27}$ ), et les itinéraires concernés ont été longuement étudiés (itinéraire de l'Atlantique $\left.{ }^{28} . ..\right)$. Ces marbres colorés sont choisis pour leurs qualités esthétiques exceptionnelles, pour une notoriété et le prestige lié à leur usage, à Rome et sur d'autres grands sites antiques. Pour un importateur du bassin Méditerranéen occidental ou de Gaule, ces qualités peuvent alors avoir été le critère déterminant, plus que le prix. Ils peuvent être présents sur les sites meldois d'habitat et d'activités fouillés ces dernières années; ils sont ou ont été sans doute bien davantage présents sur les sites publics et monumentaux comme La Bauve, mais leur présence est au moins attestée dans les sites privés. Les marbres d'Afrique - Chemtou, en Tunisie (fig. 6c), mons porphyrites d'Égypte - ne sont présents qu'à l'état de traces.

21 Les marbres du monde grec égéen sont en revanche assez fréquents, même s'ils sont présents en très petite quantité. On retrouve assez régulièrement le marbre blanc du Proconnèse, la brèche de Skyros (fig. 6d), le cipolin de l'île d'Eubée (Grèce), et enfin le greco scritto d'Izmir (Turquie) ${ }^{29}$. Les marbres de Phrygie (brèche blanc-violet dite 
pavonazzetto et marbre blanc d'Afyon / Dokiméion, en Turquie) sont récurrents malgré leur provenance de l'intérieur des terres d'Asie Mineure. Le porphyre vert de Laconie (Grèce) et la brèche de Téos (Turquie) sont exceptionnels.

\section{Matériaux et sites antiques du méandre ou plaine Saint-Faron}

Le détail des quantités et proportions des types de roches de décoration pour chaque site contribue à en donner l'image la plus proche de ce qu'il a pu être.

\section{Le site du 25, rue Saint-Fiacre / 124, rue de Châage}

Ce site se trouve au nord de la plaine, à environ 200 mètres au sud de l'amphithéâtre, autour du decumanus $2^{30}$. Il comporte des vestiges d'habitat groupé dès La Tène D2b ; un urbanisme de front de rue avec artisanat du fer au $\mathrm{I}^{\mathrm{er}}$ siècle ; une densification urbaine, avec artisanat potier et verrier aux II $^{e}$ siècle et premier quart du ${ }_{\text {III }}{ }^{e}$ siècle. Les marbres ont été retrouvés en contexte de périphérie d'habitat, d'artisanat verrier, dans des rejets de four et des comblements de fosses, dès la fin du $\mathrm{II}^{\mathrm{e}}$-premier quart du $\mathrm{III}^{\mathrm{e}}$ siècle. Le nombre de fragments est de $59(15 \mathrm{~kg})$, plus 11 tesselles $(0,052 \mathrm{~kg})$. On y distingue 22 roches différentes.

Les variétés et proportions sont :

- Marbres du Morvan (Châtelperron, Ferrières-sur-Sichon) : 56 \% ;

- Schiste d'Autun : 0,1\% ;

- Marbres blancs (Pyrénées, Carrare, Proconnèse) : 37 \% ;

- Calcaires : 7,4 \% ;

- Calcaires amygdalaires et brèches (Pyrénées, Skyros) : 7 \% ;

- Provenances méditerranéennes : 17 \% (Carrare 11,5 \% + autres - Skyros, greco scritto - 5,5\%). Les particularités remarquables du corpus sont : la quantité de marbres blancs (37\%) ou blanc et blanc nuancé $(67,5 \%$, tabl. 2$)$, les dalles conséquentes de marbre de Ferrières-sur-Sichon (friable, donc taillé épais), les encroûtements hydriques.

Ce site a donc livré des pierres de provenance peu diversifiée, évoquant un décoratif sobre.

\section{Le site du 3-8, rue Saint-Fiacre / Hôpital pôle mère-enfant}

Ce site se trouve au centre-est de la plaine, à l'est du 93-97, rue Saint-Faron / 1, rue Camille- Guérin ${ }^{31}$.

Il comporte des vestiges d'occupations du dernier quart du $\mathrm{I}^{\mathrm{er}}$ siècle av. J.-C., d'activités artisanales (forge et extraction) et d'habitat des $\mathrm{I}^{\mathrm{er}}-\mathrm{II}^{\mathrm{e}}$ siècles, et d'extraction de sable au III ${ }^{\mathrm{e}}$ siècle. Les marbres ont été retrouvés en contexte d'habitat dans des comblements, démolitions, fosses, tranchées de récupération de la fin du $\mathrm{I}^{\mathrm{er}}$ et du $\mathrm{II}^{\mathrm{e}}$ siècle. Le nombre de fragments est de 67 (poids 9,3 kg) plus 126 tesselles (poids $0,53 \mathrm{~kg}$ ). On y distingue 23 roches différentes (tabl. 3 ). 
Tabl. 3. - Meaux (Seine-et-Marne), 3-8, rue Saint-Faron : quantification unitaire et pondérale.

\begin{tabular}{|c|c|c|c|c|c|c|c|c|c|}
\hline \multirow{2}{*}{\begin{tabular}{|l} 
ROCHES \\
Appellations \\
(provenance \\
probable ou \\
certaine)
\end{tabular}} & \multirow[b]{2}{*}{$\begin{array}{l}\text { Provenance: } \\
\text { pays } \\
\text { département }\end{array}$} & \multicolumn{4}{|c|}{ Catégories d'épaisseur en $\mathrm{cm}$} & & \multicolumn{2}{|c|}{ Total / catégorie } & \multirow{2}{*}{$\begin{array}{l}\text { Total } \\
\mathrm{g}\end{array}$} \\
\hline & & $0,3-0,8$ & $0,9-1,3$ & $1,4-1,9$ & $2-2,7$ & $2,8-4,5$ & $\begin{array}{l}\text { Poids en } \\
\text { grammes }\end{array}$ & Nombre & \\
\hline $\begin{array}{l}\text { Marbre blanc } \\
\text { Proconnèse, dit } \\
\text { marmor } \\
\text { proconnesium }\end{array}$ & AM & & & 1 & & & 9 & 1 & 0,09 \\
\hline $\begin{array}{l}\text { Marbre blanc } \\
\text { (Saint-Béat), } \\
\text { Pyrénées }\end{array}$ & F - 31 & & & & & 3 & 652 & 3 & 6,62 \\
\hline $\begin{array}{l}\text { Marbre blanc } \\
\text { veiné } \quad \text { rouge, } \\
\text { Mayenne (?) }\end{array}$ & $F-53 ?$ & & 2 & & & & 314 & 2 & 3,19 \\
\hline $\begin{array}{lr}\text { Marbre } & \text { blanc } \\
\text { veiné } & \text { gris, } \\
\text { Carrare? } & \end{array}$ & I ? & & & & 1 & & 191 & 1 & 1,94 \\
\hline $\begin{array}{l}\text { Marbre gris bleuté } \\
\text { à blanc, Carrare ou } \\
\text { Luni? (palette) }\end{array}$ & I $?$ & 1 & & & & & 25 & 1 & 0,25 \\
\hline $\begin{array}{l}\text { Marbre dit greco } \\
\text { scritto (Izmir) }\end{array}$ & $\mathrm{AM}$ & 1 & & 1 & & & 250 & 2 & 2,54 \\
\hline $\begin{array}{lr}\text { Marbre } & \text { gris } \\
\text { blanc } & \text { (très) } \\
\text { friable, } & \text { Ferrières } \\
\text { / Sichon } & \end{array}$ & F - 03 & & 1 & 7 & 1 & & 660 & 9 & 6,70 \\
\hline $\begin{array}{lr}\text { Cipolin } & \text { vert } \\
\text { d'Eubée, } & \text { dit } \\
\text { marmor caristium }\end{array}$ & G & & 2 & & & & 40 & 2 & 0,41 \\
\hline $\begin{array}{ll}\text { Brèche } & \text { dite } \\
\text { pavonazzetto } & \\
\text { (Iscehisar } & \text { ou } \\
\text { Skyros) } & \end{array}$ & $\mathrm{AM} / \mathrm{G}$ & 1 & 2 & & & & 50 & 3 & 0,51 \\
\hline $\begin{array}{l}\text { Brèche rosée de } \\
\text { Lez (?), Pyrénées }\end{array}$ & F- $31 ?$ & & 1 & 2 & & & 553 & 3 & 5,61 \\
\hline $\begin{array}{l}\text { Brèche de Téos ? - } \\
\text { marmor luculleum } \\
\text { (Izmir, Sigacik) }\end{array}$ & AM? & & 1 & & & & 31 & 1 & 0,31 \\
\hline $\begin{array}{l}\text { Brèche } \\
\text { (a)semesanto } \\
\text { (Skyros) o cenerina }\end{array}$ & G & & & & 1 & & 94 & 1 & 0,95 \\
\hline
\end{tabular}




\begin{tabular}{|c|c|c|c|c|c|c|c|c|c|}
\hline $\begin{array}{l}\text { Calcaire } \\
\text { amygdalaire } \\
\text { pélitique vert } \\
\text { (Couflens), } \\
\text { Pyrénées }\end{array}$ & F - 09 & & & & 1 & & 100 & 1 & 1,01 \\
\hline $\begin{array}{l}\text { Calcaire } \\
\text { amygdalaire } \\
\text { bréchique vert } \\
\text { (Seix), Pyrénées }\end{array}$ & F - 09 & & 1 & & & & 190 & 1 & 1,93 \\
\hline $\begin{array}{ll}\text { Calcaire } & \\
\text { amygdalaire vert } \\
\text { et rouge } \\
\text { (Campan), } \\
\text { Pyrénées }\end{array}$ & F - 65 & & & 2 & & & 315 & 2 & 3,20 \\
\hline $\begin{array}{l}\text { Calcaire frasnien } \\
\text { gris, Gilly-Diou }\end{array}$ & F - 03 & & 1 & & 1 & 1 & 704 & 3 & 7,14 \\
\hline $\begin{array}{l}\text { Calcaire lutétien } \\
\text { gris }\end{array}$ & $\mathrm{F}$ & & & & & & 314 & 2 & 3,19 \\
\hline $\begin{array}{l}\text { Calcaire } \\
\text { gris dinantien } \\
\text { (Mayenne, } \\
\text { Morvan...) }\end{array}$ & F ou B & & & 1 & 1 & 1 & 340 & 3 & 3,45 \\
\hline $\begin{array}{lr}\text { Schiste } & \text { ou } \\
\text { ampélite } & \text { d'Autun } \\
\text { (palette) } & \end{array}$ & F - 71 & 1 & & & & & 22 & 1 & 0,22 \\
\hline $\begin{array}{l}\text { Schiste ou } \\
\text { ampélite d'Autun }\end{array}$ & F - 71 & & & 11 & 10 & & 4208 & 21 & 42,70 \\
\hline $\begin{array}{l}\text { Micaschiste ou } \\
\text { quartzite } \\
\text { (polissoir) }\end{array}$ & F - 77 & & 1 & & & & 23 & 1 & 0,23 \\
\hline $\begin{array}{l}\text { Grès quartzite } \\
\text { stampien }\end{array}$ & F - 77 & & & & 2 & & 109 & 2 & 1,11 \\
\hline Microdiorite & E ou $F$ & & 1 & & & & 130 & 1 & 1,32 \\
\hline $\begin{array}{l}\text { Totaux } \quad \text { sans } \\
\text { tesselles }\end{array}$ & & 4 & 13 & 25 & 18 & 5 & 9324 & 67 & 94,62 \\
\hline Tesselles & & & & & & & & & \\
\hline $\begin{array}{l}\text { Porphyre vert } \\
\text { antique dit lapis } \\
\text { lacedaemonium }\end{array}$ & G & 1 & & & & & 3 & 1 & 0,03 \\
\hline $\begin{array}{l}\text { Schiste ou } \\
\text { ampélite d'Autun }\end{array}$ & F - 71 & 15 & & & & & 55 & 15 & 0,56 \\
\hline $\begin{array}{l}\text { Calcaire } \\
\text { Jurassique } \\
\text { supérieur Molay } \\
\text { ou Bailly }\end{array}$ & F - 89 & 107 & & & & & 462 & 107 & 4,69 \\
\hline
\end{tabular}




\begin{tabular}{|l|l|l|l|l|l|l|l|l|}
\hline $\begin{array}{l}\text { Tesselles en autres } \\
\text { matériaux }\end{array}$ & 3 & & & & & & & \\
\hline
\end{tabular}

AM : Asie Mineure. B : Belgique. É : Égypte. F : France. G : Grèce. I : Italie (Arnaud Prié, 2005).

Les variétés et proportions sont :

- Schiste d'Autun : $43 \%$;

- Marbres du Morvan (Diou, Ferrières-sur-Sichon) : $14 \%$;

- Marbres blancs : 15 \% (étude par P. Blanc) ;

- Marbres des Pyrénées (amygdalaire, blanc, brèche) : 18,3\% ;

- Calcaires : $8 \%$;

- Provenances méditerranéennes : 10 \% (Carrare 2,4\%, autres - asemesanto, Téos, pavonazzetto, cipolin d'Eubée, greco scritto, porphyre vert, microdiorite - 7,5\%).

Les particularités remarquables du corpus sont la quantité de schiste d'Autun et la diversité des roches.

Ce site a donc livré des pierres de provenances diversifiées évoquant un décoratif varié, mais résiduel ou occasionnel.

\section{Le site du 93-97, rue Saint-Faron / 1, rue Camille-Guérin}

Ce site se trouve au centre de la plaine, entre le théâtre et les 3-8, rue Saint-Fiacre ${ }^{32}$. Il comporte des vestiges d'aménagements hydrauliques des $\mathrm{I}^{\mathrm{er}}$ et $\mathrm{II}^{\mathrm{e}}$ siècles, en périphérie d'une construction importante hors emprise (théâtre), et ainsi que de domus du III siècle.

Les marbres ont été retrouvés en contexte d'habitat de la fin $\mathrm{du} \mathrm{I}^{\mathrm{er}}$ siècle (période $1 \mathrm{H} 2-3$ ) dans un aménagement de foyer (US 9422) et un comblement de caniveau (US 9480); de domus des $\mathrm{II}^{\mathrm{e}}$-III ${ }^{\mathrm{e}}$ siècles (période $1 \mathrm{H} 4$ ) dans un sol (US 9073), un comblement de caniveau (US 9259), un remblai ; et en contexte antique résiduel ( $\mathrm{xl}^{\mathrm{e}}$ XVII siècle, périodes 3-5) : remblai, tranchée de récupération, démolition. Le nombre de fragments est de 437 (poids 98,2 kg) plus 328 tesselles (poids $1,3 \mathrm{~kg}$ ). On y distingue 20 roches différentes.

37 Les variétés et proportions sont :

- Calcaires : 64,3 \% (étude par M. Viré) ; 
- Marbres du Morvan (Diou, Châtelperron, Ferrières-sur-Sichon) : 15,4 \% ;

- Schiste d'Autun : 2,47 \% ;

- Marbres des Pyrénées (blanc) : 14,7\% ;

- Provenances méditerranéennes 1,2\% (Carrare $1 \%$, autres - Eubée, Lesbos, pavonazzetto, portasanta - 0,3\%).

Les particularités remarquables du corpus sont: la quantité de plaquages de calcaire, les dalles conséquentes de marbre de Ferrières-sur-Sichon (friable, donc taillé épais), les encroûtements hydriques.

Ce site a donc livré des pierres de provenance peu diversifiée, évoquant un décoratif sobre.

\section{Le site du 23, boulevard Jean-Rose}

Ce site se trouve au sud de la plaine, immédiatement au nord du castrum, associé au cardo 3 et decumanus $3^{33}$. Il comporte des vestiges d'habitat et d'occupations cultuelles de la fin du $\mathrm{I}^{\mathrm{er}}$ siècle avant J.-C.; d'espace artisanal (forge) et d'habitat (murs en terre sur solins), de dallage de rue et portique de la seconde moitié du $\mathrm{I}^{\mathrm{er}}$ et du $\mathrm{II}^{\mathrm{e}}$ siècle; de domus du $\mathrm{III}^{\mathrm{e}}$ siècle. La domus nord était décorée d'éléments sculptés, la domus centrale comportait un réseau d'eau alimentant pièce d'agrément et hypocauste. De grands remaniements ont eu lieu en seconde moitié de siècle.

41 Les marbres ont été retrouvés en contextes d'habitat et domus dans des comblements et remblais, en contexte de démolition et d'abandon, dans une cave et une tranchée de récupération des fin $\mathrm{I}^{\mathrm{er}}$, $\mathrm{II}^{\mathrm{e}}$ et $\mathrm{III}^{\mathrm{e}}$ siècles.

Le nombre de fragments est de 135 (poids 43,4 kg) plus 1022 tesselles (poids 4,9 kg). On y distingue 31 roches différentes.

43 Les variétés et proportions sont :

- Calcaires : $37 \%$;

- Schiste d'Autun : 26,6\%;

- Marbres du Morvan (Diou, Châtelperron, Ferrières-sur-Sichon) 9,4 \% ;

- Marbres des Pyrénées (amygdalaire, blanc) : 13,5\%;

- Marbres blancs (Carrare, Pyrénées, Châtelperron) : 13,5\% ;

- Provenances méditerranéennes : 7 \% (Carrare 5,6\%, autres - Serravezza, Afyon, Chemtou, pavonazzetto - 1,5\%).

Les particularités remarquables du corpus sont: la quantité de schiste d'Autun (et la diversité des formes: bloc de $8 \mathrm{~kg}$, baguette, tesselles), le nombre de tesselles, l'importance des plaquages calcaires.

Ce site a donc livré principalement des pierres utilitaires de cadre artisanal. Les roches décoratives y sont assez diversifiées, mais résiduelles.

\section{Le site du 27, rue Saint-Faron}

Ce site se trouve au sud de la plaine, près du 23 , boulevard Jean-Rose et de l'ensemble thermal de la rue Georges-Lugol ${ }^{34}$. Il comporte des vestiges partiels de thermes (chambre de chaleur à pilettes) datés entre le II et la première moitié du IV siècle. 
Les marbres ont été retrouvés en contexte de suspensura des $\mathrm{II}^{\mathrm{e}}-\mathrm{III}{ }^{\mathrm{e}}$ siècles (US 1010) et remblais de démolition dits « antique résiduel ».

Le nombre de fragments est de 656 (poids 150,2 kg), sans aucune tesselle. On y distingue 8 roches différentes.

Les variétés et proportions sont :

- Marbres blanc nuancé (Châtelperron-Morvan : 75,4 \%, Ferrières-sur-Sichon 0,1 \%) ;

- Calcaires : 23,6 \% ;

- Brèches colorées : 0,9\% (Chemtou, Pyrénées).

Les particularités remarquables du corpus sont: la quantité de marbres blanc nuancé du Morvan, l'importance des calcaires, les encroûtements hydriques.

Ce site a donc livré des pierres de provenance peu diversifiée, évoquant un décoratif conséquent mais sobre. Les marbres blancs sont similaires à ceux de La Bauve.

\section{Le site des 62-72, rue Saint-Faron}

Ce site se trouve au centre de la plaine, au sud du 3-8, rue Saint-Fiacre (cardo 2) ${ }^{35}$. Il comporte des vestiges de voirie et de bâti léger $\mathrm{du} \mathrm{I}^{\mathrm{er}}$ siècle, de constructions en dur et caves des II $^{\mathrm{e}}-\mathrm{III}^{\mathrm{e}}$ siècles, abandonnées et démolies dans le dernier quart du $\mathrm{III}^{\mathrm{e}}$ siècle.

Les marbres ont été retrouvés en contextes d'habitat des $\mathrm{I}^{\mathrm{er}}$ à $\mathrm{III}^{\mathrm{e}}$ siècles : occupation (US 1379), comblement, remblai, démolition.

54 Le nombre de fragments est de 62 (poids $32,8 \mathrm{~kg}$ ), sans aucune tesselle. On y distingue 8 roches différentes.

Les variétés et proportions sont :

- Calcaires : 75,5 \% (étude par Marc Viré) ;

- Marbres veinés gris et blanc (dinantien, Carrare) : $20 \%$;

- Marbres blancs : $3 \%$;

- Marbres des Pyrénées : $4 \%$.

6 Les particularités remarquables du corpus sont: la quantité de plaquages de calcaire, l'importance des marbres blanc nuancé.

Ce site a donc livré principalement des pierres utilitaires de cadre artisanal, et très peu de roches décoratives.

\section{Le site de La Bauve}

58 Il s'agit d'un sanctuaire ${ }^{36}$ localisé sur le coteau, à l'est de la plaine et au nord de la Marne (espace périurbain). Il comporte des vestiges datés de la fin du IV siècle avant J.C., et de la fin du $\mathrm{I}^{\mathrm{er}}$ au début du $\mathrm{V}^{\mathrm{e}}$ siècle après J.-C.

Les marbres semblent avoir été surtout retrouvés en remblais.

Le nombre de fragments est de 110, plus 16 tesselles. On y distingue 10 roches différentes.

L'ensemble des fragments de marbres (blancs + colorés) représente un peu plus d'un mètre carré, ce qui est insignifiant par rapport à la surface des bâtiments (A. Blanc). Il n'y aurait donc pas de vestiges de marbres utilisés en premier œuvre. 
62 Sauf exception, la communication de données a toujours été principalement en présence-absence. Le poids des fragments ne nous ayant pas été disponible, comparer une quantité avec les autres sites est aléatoire (pas de chiffre pour le Châtelperron, plus grand nombre de fragments pour la brèche de Skyros).

Les variétés ont été publiées de façon récurrente :

- Marbres blancs : Châtelperron-Saint-Léon (les plus fréquents), corniches et plaques; SaintBéat, un fragment de corniche ; Thassos dolomitique, plaques ; Penteli, 2 inscriptions ;

- Calcaires et marbres dinantiens: Mayenne (3); calcaire noir de provenance indéterminée (2?) ;

- Marbres des Pyrénées : brèche noir et blanc, jaune et blanc, griotte ;

- Roches méditerranéennes diverses: Chemtou, asemesanto de Skyros, cipolin d'Eubée, porphyre vert de Laconie. importante dans un corpus peu important) :

- Plaquages (et dallages) calcaires: 1 , rue Camille-Guérin $(64 \mathrm{~kg}) ; 27$, rue Saint-Faron $(34,3 \mathrm{~kg}) ; 62$, rue Saint-Faron $(24,8 \mathrm{~kg}) ; 23$, boulevard Jean-Rose $(14,7 \mathrm{~kg})$. Ils se trouvent en contextes d'ateliers et habitat ;

- Marbres friables de Ferrières-sur-Sichon : 1, rue Camille-Guérin $(4,4 \mathrm{~kg}) ; 23$, boulevard JeanRose (2,8 kg). Ils semblent se trouver en contexte d'atelier ;

-Ampélite d'Autun : 23, boulevard Jean-Rose (12,8 kg); 3-8, rue Saint-Faron $(4,2 \mathrm{~kg})$; 1, rue Camille-Guérin $(2,4 \mathrm{~kg})$. Elle a été trouvée principalement sous forme de tesselles, en contextes de mosaïques de domus ;

- Marbres Châtelperron-Saint-Léon : 27, rue Saint-Faron $(113,4 \mathrm{~kg}) ; 25$, rue Saint-Fiacre $(8,4 \mathrm{~kg}) ; 1$, rue Camille-Guérin $(4,4 \mathrm{~kg})$; La Bauve (blanc dominant). Ils semblent se trouver en contextes d'équipements conséquents ;

- Marbres des Pyrénées : 1, rue Camille-Guérin (14,8 kg) ; 23, boulevard Jean-Rose $(6,5 \mathrm{~kg}) ; 25$, rue Saint-Fiacre $(2,5 \mathrm{~kg})$; $3-8$, rue Saint-Faron $(1,8 \mathrm{~kg})$. Ils semblent se trouver principalement en contextes d'habitats.

\section{La transmission des savoirs : conclusion}

67 L'étude des fragments d'architecture et l'identification de la roche constituante permettent de mieux connaître un cadre de vie et des goûts décoratifs, mais aussi le commerce, le réseau de communications et les politiques d'approvisionnement sousjacents. Elles illustrent donc un aspect important de l'économie de la pierre à l'époque gallo-romaine, en donnant une idée des productions - géographie des extractions, façonnage, mise en œuvre (pose, rôle architectural) - et des transports à travers l'aperçu archéologique de cette consommation (fig. 7). 
Fig. 7. - Meaux (Seine-et-Marne) : provenance des roches décoratives antiques de la(n)tinum.

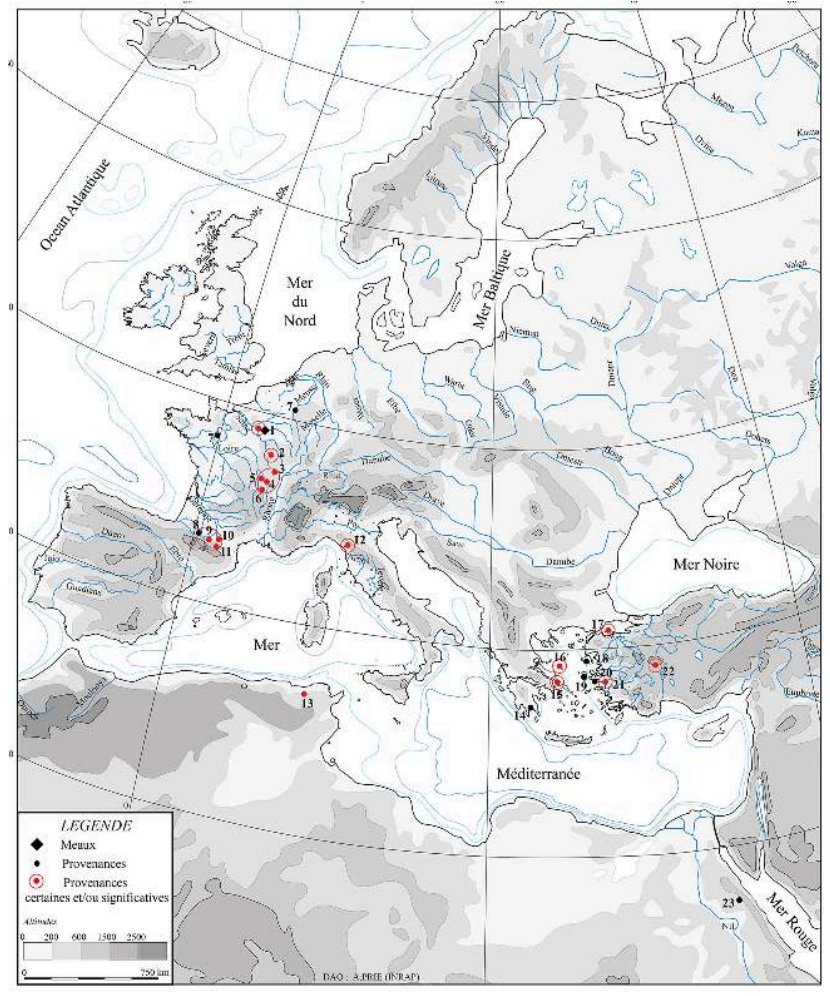

1 : Meaux et Île-de-France, calcaire lutétien, grès. $\mathbf{2}$ : Molay et Bailly (Yonne), calcaire jurassique. $\mathbf{3}$ : Autun (Saône-et-Loire), schiste. 4 : Diou (Allier), calcaire frasnien. 5 : Châtelperron (Allier), marbre blanc à rosé. $\mathbf{6}$ : Ferrières-sur-Sichon (Allier), marbre blanc veiné. 7 : Tournai (Belgique), Laval (Mayenne) et Sablé (Sarthe), calcaires dinantiens. 8 : brèche pyrénéenne. $\mathbf{9}$ : hautes vallées du Salat (Haute-Garonne), calcaire dévonien noduleux. 10 : Saint-Béat (Haute-Garonne), marbre blanc. 11 : Lez (Saint-Béat, Haute-Garonne), brèche. 12 : Carrare (Italie), marbre blanc, blanc veiné gris-bleu, gris-bleu. 13 : Chemtou (Tunisie), brèches. 14 : Laconie (Grèce), andésite-porphyre vert. 15 : Eubée (Grèce), cipolin. 16 : Skyros (Grèce), brèche, marbre. 17 : Proconnèse (Grèce), marbre blanc. 18 : Lesbos (Grèce), marbre. 19 : Chios (Grèce), brèche, portasanta. 20 : Téos (Turquie), brèche. 21 : Izmir (Turquie), marbre greco scritto. 22 : Dokimeion / Afyon (Turquie), brèche pavonazzetto. 23 : Égypte, mons porphyrites, microdiorite.

(c) Arnaud Prié.

Les fouilles dans la plaine Saint-Faron témoignent d'une omniprésence des marbres. Les vestiges de revêtement sont suffisamment conséquents pour pouvoir être liés au site dans un contexte d'atelier (25, rue Saint-Fiacre) et un autre de thermes (27, rue Saint-Faron). Ailleurs, les revêtements ont été le plus souvent retrouvés non scellés, en contextes de démolitions et remblais, avec une dispersion qui peut évoquer davantage un caractère résiduel (récupération, vestiges en bruit de fond) qu'un attachement à une construction conceptualisable. Ils renseignent sur un environnement large plus que sur un espace précis, dans l'espace comme dans le temps.

Leur diversité est typique du commerce général de matériaux connu dans l'Antiquité romaine. Les roches de Carrare-Luni et égéennes sont suffisamment récurrentes pour attester à Meaux de ce commerce de roches lointaines apportées par bateau. Mais les roches les plus représentées sont celles dites régionales, associées au Bassin parisien (les calcaires fins et durs, les marbres du Morvan au sud et les marbres dinantiens du nord ou de l'ouest), et à peine plus lointaines, provenant de la zone nord-pyrénéenne. Leur recherche, exploitation et diffusion correspondent à une transmission des modèles et des savoirs romains (repérage, exploitation, transport, utilisation). Mais 
l'usage de marbres de remplacement nous semble évoquer davantage un pragmatisme et des choix locaux qu'un savoir transmis de règles de substitution.

71 Le cas des roches de décoration antiques à Meaux rappelle que, comme la conquête romaine, la redécouverte du passé par l'archéologie de sauvetage permet bien une (re)transmission des savoirs.

\section{BIBLIOGRAPHIE}

ATTANASIO D., YAVUZ A. B., BRUNO M., HERRMANN J. J., TYKOT R. H., 2012, « On the Ephesian origin of Greco Scritto marble », dans Gutiérrez Garcia-M. A. (dir.), Interdisciplinary studies on ancient stone: proceedings of the IX ASMOSIA conference (Tarragona, 2009), Tarragona, Institut Català d'Arqueologia Clàssica (Documenta, 23), p. 245-254.

BALMELLE C., 2001, Les demeures aristocratiques d'Aquitaine : société et culture de l'Antiquité tardive dans le sud-ouest de la Gaule, Bordeaux, Ausonius (Mémoires, 5).

BALTY J.-C., 1992, « Une collection de marbres antiques », Dossiers d'archéologie, $\mathrm{n}^{\circ} 173$ (« Le marbre dans l'Antiquité »), p. 68-71.

BLANC P., 1993, « La détermination des pierres de construction : méthode générale. Adaptation d'une technique supplémentaire pour résoudre un cas particulier, celui des marbres blancs ", dans Lorenz J. (dir.), Carrières et constructions en France et dans les pays limitrophes, vol. II, Actes du $117^{e}$ Congrès national des sociétés savantes (Clermont-Ferrand, 1992), Paris, Éditions du CTHS, p. 31-42.

BLANC P., 1995, « La cathodoluminescence quantitative des marbres blancs », dans Lorenz J. (dir.), Carrières et constructions en France et dans les pays limitrophes, vol. III, Actes du $119^{e}$ congrès national des sociétés historiques et scientifiques (Amiens, 1994), Paris, Éditions du CTHS, p. 489-504.

BLANC P., 1999, «Quantification de la cathodoluminescence des marbres blancs et de leurs minéraux accessoires ", dans Schvoerer M. (dir.), Archéomatériaux, marbres et autres roches, actes de la Conférence internationale ASMOSIA IV (Bordeaux, 1995), Talence, Centre de recherches appliquées à l'archéologie / Presses universitaires de Bordeaux, p. 45-54.

BLANC A. et MAGNAN D., 1998, « Du marbre pour les dieux ? Les marbres et roches décoratives du sanctuaire de La Bauve et d'autres monuments gallo-romains du nord de la France », dans Delattre V., Magnan D., Blanc A., Le Cieux L. (dir.), Profane et sacré en pays meldois : protohistoire, gallo-romain, cat. exp. (Meaux, musée Bossuet, 1998-1999), Meaux, Association meldoise d'archéologie / musée Bossuet, p. 85-93.

BLANC P. et N'GUYEN H., 2004, « Démonstration de la cellule portable de cathodoluminescence sur une surface de marbre poli pour détermination de sa provenance », dans Sauron G., Lorenz J., Rat P., Chardron-Picault P. (dir.), Les roches décoratives dans l'architecture antique et du haut Moyen Âge, Paris, Éditions du CTHS (Archéologie et histoire de l'art, 16), p. 61-68.

BLANC P. et PRIÉ A., 2005, « Les roches décoratives du site de Meaux, 3-8, rue Saint-Fiacre, avec la collaboration de Blanc A., Leroux L. ", dans Couturier D. (dir.), Meaux (77), 3-8, rue Saint-Fiacre (Hôpital pôle mère-enfant), rapport de fouille archéologique, Pantin, INRAP, vol. 2, annexe 12, p. 291-319. 
BLANC P. et PRIÉ A., 2009, «Les matériaux décoratifs et utilitaires du site de Meaux, 25, rue SaintFiacre, avec la collaboration de Blanc A. », dans Couturier D. (dir.), Meaux (77), 25, rue SaintFiacre-124, rue de Châage, rapport de fouille archéologique, Pantin, INRAP, vol. 2, annexe 13, p. $413-430$.

BLANC A. et PRIÉ A. 2013, « Les matériaux décoratifs et utilitaires du site de Meaux, 23, boulevard Jean-Rose, avec la collaboration de Blanc P. », dans Couturier D. (dir.), Meaux (77), 23, boulevard Jean-Rose, rapport de fouille archéologique, Pantin, INRAP, vol. 2, annexe 7, p. 135-148.

BLANC A., LORENZ C., OBERT D., 1988, « Aperçu de géologie locale » et « Les matériaux de construction et de décoration de La Bauve », dans Magnan D. (dir.), Meaux gallo-romain et La Bauve, Meaux, Association meldoise d'archéologie, p. 12 et p. 81-83.

BLANC A., GUYARD L., MAGNAN D., PÉNISSON É., WYSS M., 2004, « Les roches ornementales de quelques sites gallo-romains et du premier millénaire à Paris, à Saint-Denis et à Meaux ", dans Sauron G., Lorenz J., Rat P., Chardron-Picault P. (dir.), Les roches décoratives dans l'architecture antique et du haut Moyen Âge, Paris, Éditions du CTHS (Archéologie et histoire de l'art, 16), p. 25-42.

BRAEMER F. 1992, «Les pierres ornementales du Haut-Empire romain », Dossiers d'archéologie, $\mathrm{n}^{\circ}$ 173 (« Le marbre dans l'Antiquité »), p. 8-15.

BRAEMER F. 2004, « Le rôle des pierres précieuses et nobles dans l'ornementation dans l'Antiquité et le haut Moyen Âge ", dans Sauron G., Lorenz J., Rat P., Chardron-Picault P. (dir.), Les roches décoratives dans l'architecture antique et du haut Moyen Âge, Paris, Éditions du CTHS (Archéologie et histoire de l'art, 16), p. 89-120.

BRUNET-GASTON V., 2003, « L'étude du lapidaire architectural gallo-romain : méthodologie et résultats ", Archéopages, $n^{\circ}$ 9, Paris, p. 12-19.

BRUNET-GASTON V., 2015, « Étude du lapidaire gallo-romain et des espaces de la domus », dans Couturier D., Meaux (77), 23, boulevard Jean-Rose, rapport final d'opération archéologique, INRAP, vol. 2, annexe 6, p. 99-134.

COUTURIER D. et MAGNAN D., 2013, « La capitale antique de la cité des Meldes », dans Förstel J., Meaux, patrimoine urbain, Paris, Somogy, p. 31-41.

FABRE J.-M. et SABLAYRolles R., 2002, « Carrières de marbre des Pyrénées centrales : le point sur la recherche », Gallia, n 59 , p. 61-81.

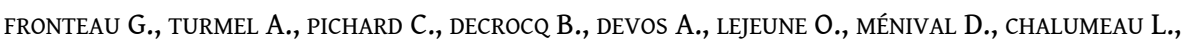
COMBAUD A., 2014, « Les approvisionnements en pierre de construction à Reims : des choix marqués par de fortes contraintes géologiques, géographiques et socio-économiques ", dans Lorenz J., Blary F., Gély J.-P. (dir.), Construire la ville : histoire urbaine de la pierre à bâtir, Paris, Éditions du CTHS, p. 235-250.

GÉLY J.-P., 2014, « Du centre carrier au centre urbain, stratégie d'approvisionnement en pierres d'appareil des chantiers de construction : l'exemple du bassin parisien », dans Lorenz J., Blary F., Gély J.-P. (dir.), Construire la ville : histoire urbaine de la pierre à bâtir, Paris, Éditions du CTHS, p. 61-82.

HERRMANN J. J., 1992, « Carrières et sculptures en marbre à l'époque romaine et tardive », Dossiers d'archéologie, $\mathrm{n}^{\circ} 173$ (« Le marbre dans l'Antiquité »), p. 30-39.

LAZARINI L., 1992, « Des pierres pour l'éternité : les granits utilisés dans l'Antiquité classique », Dossiers d'archéologie, $\mathrm{n}^{\circ} 173$ (« Le marbre dans l'Antiquité »), p. 58-67. 
LORENZ J. et LORENZ C., 1993, « De la roche à la construction : la localisation et la reconnaissance des carrières », dans Lorenz J. (dir.), Carrières et construction en France et dans les pays limitrophes, actes du $117^{\mathrm{e}}$ Congrès national des sociétés historiques et scientifiques (Clermont-Ferrand, 1992), Paris, Éditions du CTHS, p. 9-29.

MAGNAN D., 2008, « 284-Meaux », dans Griffisch J.-N., Magnan D., Mordant D. (dir.), Carte archéologique de la Gaule. 77/2 : la Seine-et-Marne, Paris, Académie des inscriptions et belles-lettres, ministère de l'Éducation nationale, p. 713-819.

PRIÉ A., 2016, « Les pierres de plaquage du site de Meaux, 27, rue Saint-Faron avec la collaboration de Blanc A. », dans Delozanne C. (dir.), Meaux (77), 27, rue Saint-Faron, rapport de fouille archéologique, Pantin, INRAP, annexe 3, p. 49-57.

PRIÉ A. et VIRÉ M., 2014, « Les roches décoratives et utilitaires du site de Meaux, 1, rue C. Guérin, avec la collaboration de Blanc A., Blanc P. ", dans Couturier D. (dir.), Meaux (77), 1, rue C. Guérin 93-97, rue Saint-Faron, rapport de fouille archéologique, Pantin, INRAP, annexe 4, p. 263-284.

PRIÉ A. et VIRÉ M., 2015, « Les pierres de plaquage du site de Meaux, 62-72, rue Saint-Faron, avec la collaboration de Blanc A., Blanc P. », dans Bergot E. (dir.), Meaux (77), 62-72, rue Saint-Faron, rapport de fouille archéologique, Pantin, INRAP, vol. 2, annexe 9, p. 343-352.

PENSABENE P., 1992, «Transport, diffusion et commerce des marbres », Dossiers d'archéologie, n 173 (« Le marbre dans l’Antiquité »), p. 86-92.

RAFÉLIS M., RENARD M., EMMANUEL L., DURLET C., 2000, « Apport de la cathodoluminescence à la connaissance de la spéciation du manganèse dans les carbonates pélagiques ", Comptes rendus de l'Académie des sciences, série IIA : Earth and planetary sciences, vol. 330, nº 4, p. 391-398.

WALKENS M., 1992, « Carrières et marbres de l'Asie mineure », Dossiers d'archéologie, n 173 (« Le marbre dans l'Antiquité »), p. 22-29.

\section{NOTES}

1. Magnan 2008, Couturier et Magnan 2013.

2. Magnan 2008 : 799-814, Blanc et Magnan 1998.

3. Couturier et Magnan $2013: 30,32$.

4. Magnan 2008 : 772-798.

5. Couturier et Magnan $2013: 31$.

6. Blanc et al. $1988: 12$.

7. Atrium, tablinum, triclinum, péristyle et hortus, fontaines et bains privés...

8. Plinthes, pilastres, chambranles, lambris, dont les sectilia parietali (Balty $1992: 70$, Balmelle 2001 : 198), frises, corniches, pièces en ronde-bosse, pavements (du dallage à la mosaïque), dont l'opus sectile non pariétal.

9. Seuil, bassin, caniveau, marches.

10. Brunet-Gaston $2003: 16,18$.

11. Magnan $2008: 740-743$.

12. Trouvé au 3, rue Camille-Guérin en 1963 ; Magnan 2008 : 765.

13. Blanc et Prié 2005. 
14. Blanc 1993 : 35, Blanc 1995 : 489, Blanc 1999, Blanc et N'Guyen 2004.

15. Rafélis et al. 2000 : 394, Blanc 1995.

16. Fondations, élévations (supports verticaux continus), supports verticaux discontinus (colonnes, entablements), couvrements (arcs, voûtes, couverture), ouvertures (fronton), aménagements intérieurs (escaliers, hydraulique, chauffage).

17. Brunet-Gaston 2015, Lorenz et Lorenz 1993 : 24-25.

18. Gély $2014: 62$, Fronteau et al. $2014: 242-244$.

19. Blanc et Prié 2009.

20. Blanc et Prié 2005.

21. Braemer $1992: 14$.

22. Ibid. : 10, 14 .

23. Pensabene 1992 : 92.

24. Fabre et Sablayrolles 2002.

25. Balmelle $2001: 64$.

26. Herrmann 1992 : 30.

27. Waelkens 1992 : 27, Lazarini 1992.

28. Braemer 1992 : 14, Braemer 2004.

29. Attanasio et al. 2012.

30. Blanc et Prié 2009.

31. Blanc et Prié 2005.

32. Prié et Viré 2014.

33. Blanc et Prié 2013.

34. Prié 2016, Magnan 2008 : 740-743, 765.

35. Prié et Viré 2015.

36. Blanc et Magnan 1998, Blanc et al. 2004.

\section{RÉSUMÉS}

À Meaux (Seine-et-Marne), les fouilles archéologiques menées au xxI ${ }^{\mathrm{e}}$ siècle dans la plaine SaintFaron poursuivent la redécouverte de la ville gallo-romaine, en livrant de nombreux restes de revêtements de pierre, qui complètent le petit corpus du site de La Bauve. La plupart des fragments proviennent de remblais : ils ne sont quasiment jamais conservés en place. Leur étude et leur identification, parfois avec analyses archéométriques, illustrent le goût romain pour les roches décoratives et nous informent sur les ressources, le commerce et le transport de ces matériaux d'origine plus ou moins lointaine. Les vestiges révèlent un usage dominant de calcaires et de marbres locaux, régionaux ou gaulois. Les marbres méditerranéens de référence sont omniprésents mais en petites quantités et n'ont peut-être jamais été abondants. 
INDEX

Mots-clés : commerce des pierres, marbre

Index géographique : Meaux antique

\section{AUTEURS}

\section{ARNAUD PRIÉ}

Institut national de recherche en archéologie préventive (INRAP) ; chercheur associé au Laboratoire de médiévistique occidentale de Paris (LAMOP, université Paris I - PanthéonSorbonne, UMR 8589 du CNRS), membre du Groupe d'étude scientifique des carrières et des applications du souterrain (GESCAS) ; membre de la Société amicale de géologie amateur (SAGA)

\section{ANNIE BLANC}

Chercheur associé au Laboratoire de médiévistique occidentale de Paris (LAMOP, université Paris I - Panthéon-Sorbonne, UMR 8589 du CNRS), membre de l'Association des géologues du bassin de Paris (AGBP)

\section{PHILIPPE BLANC}

Chercheur bénévole à Sorbonne université, membre de l'Association des géologues du bassin de Paris (AGBP) 


\title{
La transmission des savoirs et des modèles liés à la construction chez les Cisterciens aux XII ${ }^{\mathrm{e}}$ et XIII ${ }^{\mathrm{e}}$ siècles
}

\author{
Benoît Rouzeau
}

1 L'afflux des vocations et des aumônes chez les Cisterciens permet à cette congrégation d'atteindre plusieurs centaines de maisons à la fin du XIII ${ }^{\mathrm{e}}$ siècle. Cette dynamique des origines a permis à de nombreux auteurs d'y voir émerger une architecture et un art cistercien. Même si ces concepts font aujourd'hui débat, ils permettent de se poser la question de la transmission des formes et des modèles liés à l'architecture et à la construction dans l'ordre cistercien. Le premier élément de réponse est lié à la présence, dans certains manuscrits $\mathrm{du} \mathrm{xIII}^{\mathrm{e}}$ siècle, de représentations iconographiques qui ont pu servir de modèles dans l'ordre cistercien: le Reiner Musterbuch, réalisé à l'abbaye de Rein (Styrie, Autriche) entre 1208 et 1213 et le livre de comptes de l'abbaye de Beaulieu (Hampshire, Royaume-Uni), tenu entre 1269 et 1270. De même, l'architecte Villard de Honnecourt a dessiné dans son carnet deux plans d'église cistercienne. Le deuxième volet de la démonstration reprendra des informations issues des chartes, des chroniques et des vita, qui montrent le rôle très important qu'ont joué certains abbés, moines ou convers dans la transmission des plans aux débuts de l'ordre. Pour finir, si les édifices de Cîteaux (Saint-Nicolas-lès-Cîteaux, Côte-d'Or) et Clairvaux (Ville-sous-laFerté, Aube) ont pu servir de modèles amenant à la notion de plan bernardin, qu'en estil de l'abbaye de Morimond (Parnoy-en-Bassigny, Haute-Marne), dont le plan et les élévations de l'abbatiale sont révélés par les fouilles et l'archéologie du bâti réalisés depuis 2010 ?

Les Cisterciens, qui participent au renouvellement de la spiritualité du milieu du Moyen Âge, mais aussi parfaitement intégrés à l'économie, sont un bon terrain d'étude pour qui s'intéresse à la transmission des savoirs dans la société médiévale. En effet, l'afflux des vocations et des aumônes permet à cette congrégation d'atteindre plusieurs centaines de maisons, qui assurent un chantier permanent dans les monastères jusqu'à la fin du XIII ${ }^{e}$ siècle, voire le début du XIV ${ }^{e}$ siècle pour certaines. À l'heure ou l'histoire déconstruit et critique, il est bon de rappeler que cette dynamique des origines a 
permis à de nombreux auteurs d'y voir l'émergence d'une architecture cistercienne, comme Marcel Aubert, dans son article fondateur de 1958 dans les Cahiers de la civilisation médiévale où il indique: "Les traditions de l'architecture cistercienne commandent, à peine modifiées par les habitudes locales ${ }^{1}$ ». Il reprend les qualificatifs de dépouillement et d'austérité de la construction, entre autres. Les travaux du père Dimier en 1949, avec son recueil de plans d'églises cisterciennes, se placent dans la même lignée ${ }^{2}$. Cette universalité de la construction est aussi soulignée par Henri-Paul Eydoux, spécialiste de l'abbaye de Morimond, qui a cherché en ce lieu un modèle aux abbatiales allemandes qu'il a connues juste à la fin de la Seconde Guerre mondiale. C'est aussi lui qui précise, aux côtés de l'archéologue allemand Esser, qui fouille la première abbatiale d'Himmerod (Grosslittgen, Allemagne), sous celle reconstruite à l'âge baroque, la notion de plan "bernardin ${ }^{3}$ ». Ce plan de type dit bernardin a bien été défini au début des années 1990 par Benoît Chauvin ${ }^{4}$, qui insiste sur le chœur à chevet plat, l'alignement des chapelles latérales et le voûtement que l'on retrouve à Fontenay (modèle en place dans la plupart des abbatiales de la filiation de Clairvaux entreprises avant 1153, mort de saint Bernard). De nouvelles réflexions sur l'abbatiale de Fontenay font dire à Stuart Harrisson qu'il s'agit du second édifice, construit entre 1140 et $1165^{5}$.

3 C'est dans la même direction que la notion d'art cistercien se développe sous la plume de Georges Duby, dès 1976. Il y voit l'influence de Bernard de Clairvaux quand il indique : «[...] et dans les trois générations qui suivirent, des centaines de bâtiments s'élevèrent ici ou là, qui tous ressemblaient à Fontenay ${ }^{6}{ }^{\prime}$. Ce concept fait aujourd'hui débat. Il faut attendre les années 2010 pour que la déconstruction de cette notion d'art cistercien se fasse plus précise, dans les travaux de Thomas Coomans ${ }^{7}$. Une communication présentée par Sylvain Demarthe lors du colloque sur le temps long de Clairvaux se place dans la même lignée ${ }^{8}$. Il n'en reste pas moins intéressant de se poser la question de la transmission des formes et des savoirs liés à l'architecture et à la construction des édifices cisterciens. Plus récemment néanmoins, d'autres chercheurs mettent l'accent sur une certaine transmission : il s'agit des travaux réalisés par Sheila Bond et Clarck Mains sur l'abbatiale d'Ourscamp (Oise) et sur les oratoires primitifs des Cisterciens, principalement ceux issus de la filiation de Morimond. En 2018, Denise Borlée et Laurence Terrier-Aliferis remettent le modèle au centre de la réflexion de l'art et de l'architecture médiévale et posent par là même la question de leur transmission'.

4 Trois axes permettent d'illustrer ce thème. En premier lieu, dans un sens plus théorique, un certain nombre de manuscrits du XIII ${ }^{e}$ siècle montrent des représentations iconographiques qui ont pu servir d'inspiration de modèles à la mise en œuvre. Dans un deuxième temps, les sources écrites, chroniques, vita, tissent aussi un réseau de relations souvent lié à la filiation des abbayes, qui permet de voir émerger des liens assez forts entre monastères, du fait des artisans qui y ont œuvré, des Cisterciens, mais pas exclusivement. Pour finir sera développé l'exemple du plan de Morimond II, mieux connu aujourd'hui, après plusieurs campagnes de relevés d'archéologie du bâti dans les années 2010. 


\section{Une place pour les manuscrits dans les modèles de l'architecture cistercienne?}

5 Un moine copiste de l'abbaye de Rein a réalisé entre 1208 et 1213 un manuscrit rempli de dessins et de formes, le Reiner Musterbuch, conservé à la Bibliothèque nationale d'Autriche depuis le XIV siècle et actuellement enregistré sous la cote 507. L'artiste luimême, peut-être un certain "Henri ", est mal connu. Une version numérique du Reiner Musterbuch est disponible sur le site de la bibliothèque nationale autrichienne ${ }^{10}$. Le codex se compose de 149 folios, mais seule la première partie intéresse plus particulièrement ce sujet, à savoir quelques feuillets, 13 folios en tout. Il se compose d'alphabets graphiques ${ }^{11}$, de bestiaires ${ }^{12}$, de motifs, de formes ${ }^{13}$ et de scènes de la vie quotidienne ${ }^{14}$, dont certaines sont intégrées à des bâtiments et d'autres sont légendées. Une série de motifs sont déclinés en différentes versions inscrites dans des cercles, des rectangles ou des carrés. Des scènes historiées sont mises en avant dans des bâtiments à colonnes surmontées de chapiteaux avec des voûtes en plein cintre stylisées. Les historiens allemands pensent que ce document peut être l'un des premiers recueils de modèles cisterciens ${ }^{15}$.

6 La série de modèles est particulièrement intéressante, elle se retrouve quasiment à l'identique dans des motifs de vitraux, comme par exemple à Aubazine (Corrèze), Bonlieu (Peyrat-la-Nonière, Creuse) ou Pontigny (Yonne). On peut aussi voir des rapprochements dans les motifs des carreaux de pavement, ceux incisés et glaçurés du tournant des $\mathrm{XII}^{\mathrm{e}}$ et $\mathrm{XIII}^{\mathrm{e}}$ siècles, comme le propose Magali Orgeur dans sa contribution au colloque sur l'industrie cistercienne de $2015^{16}$.

7 Il convient de mettre ce manuscrit de Rein en rapport avec d'autres manuscrits cisterciens, dont le livre de comptes de l'abbaye de Beaulieu, un peu plus tardif $(1269 / 1270)^{17}$. Il s'agit d'un compte qui couvre une période d'un an. S. F. Hockey, qui l'a édité, considère qu'il a été conservé car il servait de modèle pour apprendre la comptabilité dans le monastère ${ }^{18}$. Ce manuscrit était richement illustré, mais le découpage n'a laissé que quatre illustrations, dont celle du ciseau du parcheminier qui coupe une bande de cuir. Des générations de moines ont eu ces images sous les yeux. Plusieurs d'entre elles représentaient sans doute des bâtiments en élévation, comme en témoigne le moulin à foulon de l'abbaye avec son système hydraulique, un des plus anciens connus à ce jour ${ }^{19}$.

8 Sans être un cistercien, l'architecte Villard de Honnecourt propose dans son carnet deux modèles d'églises cisterciennes qui posent la question de la transmission des formes de la construction chez les Cisterciens. Le manuscrit de Villard de Honnecourt est composé de feuilles de parchemin portant des dessins sur les deux faces et réunies en cahiers comportant un nombre de feuilles variable. Il se présente comme un carnet de format réduit, d'environ 14 sur 22 centimètres, relié et recouvert de cuir marron. Il est conservé à la Bibliothèque nationale de France. Entre un tiers et la moitié des feuilles du manuscrit, estimées au départ à une centaine, ont disparu, d'autres ont été modifiées ou grattées. 33 folios subsistent, soit 66 pages $^{20}$.

9 Mais en tout état de cause, ce qui frappe Villard de Honnecourt quand il dessine au verso du folio 14 de son carnet le plan d'une église cistercienne, mis en parallèle avec le chevet de l'église de Sainte Marie de Cambrai, il le laisse transparaitre dans la légende apposée sur le manuscrit: "Vescii une eglize desquarie ki fut esgardee a faire en 
l'ordene de Cistiaux », c'est qu'elle est " construite d'équerre, faite de carrés ${ }^{21}$ ». Le plan reprend les trois parties principales d'une abbatiale, nef, transept et chevet. Les piles y sont dessinées et le dessin laisse apparaître de manière très nette les arcs doubleaux séparant les travées mais aussi de manière plus fugace, les arcs des croisées d'ogives. Avec cinq travées pour la nef, l'espace semble dégager deux bas-côtés de taille équivalente. Le transept est découpé en trois travées irrégulières, mais dont le module est identique à ceux de la nef. Le chœur comporte trois travées, qui permettent de créer soit un déambulatoire, soit des chapelles rayonnantes. Où Villard de Honnecourt a-t-il trouvé le modèle de son dessin? Il est possible, alors qu'il se rendait en Hongrie en passant par Reims, qu'il soit passé par les abbayes de Cîteaux ou de Morimond, qui ont des abbatiales à chevet plat, mais ce fait n'est qu'une hypothèse ${ }^{22}$. Son activité professionnelle aurait pu aussi l'amener à voir le chantier de l'abbatiale de Vaucelles (Les Rues-des-Vignes, Nord). Le plan de cet édifice comporte un chevet construit entre 1216 et 1235 , doté de chapelles semi-circulaires et rectangulaires, et le voûtement fait nettement apparaître un déambulatoire venant circonscrire le chœur. Le transept est en partie confondu avec le chœur. La nef n'est représentée que par une travée ${ }^{23}$. Sans vouloir démesurément augmenter les liens entre Villard de Honnecourt et les Cisterciens, on peut observer que son carnet témoigne de la prise en compte de caractéristiques architecturales propres aux moines blancs au début du XIII ${ }^{\mathrm{e}}$ siècle.

\section{Abbés, moines et convers bâtisseurs}

10 Parmi les sources cisterciennes, les comptes, les chroniques, les hagiographiques et les textes règlementaires ou statutaires mentionnent tout particulièrement, plus que les chartes, le lien qui a pu s'établir par l'intermédiaire d'architectes ou de maîtres d'œuvre qui ont construit plusieurs monastères : on fait moins appel aux chartes en ce domaine. On voit ici se dessiner les réseaux de filiation propres à l'ordre cistercien, mais aussi celui du voisinage. L'obligation de fréquenter chaque année le chapitre général au mois de septembre à Cîteaux contraignit de nombreux abbés à passer par leur abbaye mère bourguignonne ou champenoise et à s'en inspirer (fig. 1). 
Fig. 1. - Cartes des déplacements des abbés moines et convers bâtisseurs cisterciens aux XII et $\mathrm{XIII}{ }^{\mathrm{e}}$ siècles.

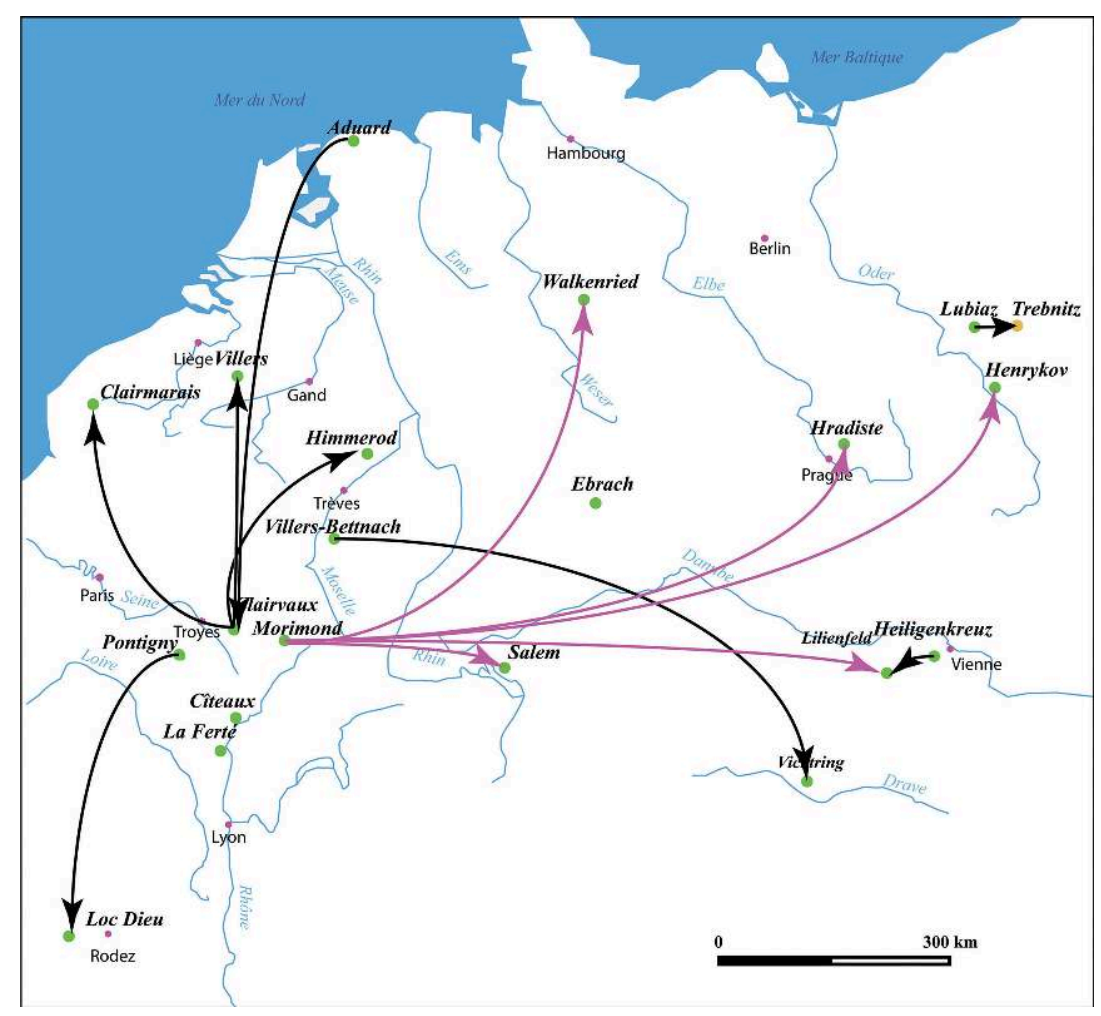

(C) Benoît Rouzeau.

11 Je ne citerai ici que quelques exemples : Clairvaux possédait au temps de saint Bernard deux architectes de grande réputation: Achard, maître des novices, qui dirigea la reconstruction de l'abbaye vers 1133, mais aussi la construction du couvent d'Himmenrod, dans l'Eifel, et celui du Cloître, près de Trèves (Allemagne), comme le précise une relation de l'Exordium magnum ${ }^{24}$. Geoffroy d'Ainay travailla aussi dans plusieurs abbayes ${ }^{25}$. Il est envoyé par Bernard de Clairvaux à Fountains (Ripon, Yorkshire, Royaume-Uni), où il débute le chantier en 1135. En Flandres, il aurait dessiné le plan de l'abbaye de Clairmarais (Pas-de-Calais) et débute les travaux vers 1140 avant de revenir mourir à Clairvaux. Toujours à l'époque de saint Bernard, l'abbé envoie 12 moines et 5 convers en 1147 construire Villers-en-Brabant (Villers-la-Ville, Belgique). La spécialité des convers n'est pas spécifiée, mais il y a fort à parier que certains d'entre eux avaient des compétences dans la construction. Toujours dans la filiation de Clairvaux, en ce qui concerne l'abbaye d'Ourscamp (Chiry-Ourscamp, Oise), fondée en 1129, les travaux de Clarck Mains et Sheila Bonde montrent aussi des liens avec l'abbaye de Clairvaux ${ }^{26}$. En effet, d'après les sondages réalisés, ils constatent que l'édifice primitif serait une construction en bois sur soubassement de pierres de $20 \times 25 \mathrm{~m}$, qui sera réutilisée longtemps après la construction de la seconde église et qui conservait selon toute vraisemblance le tombeau du fondateur, l'évêque de Noyon. Ce plan dans ses dimensions est assez similaire à ce que l'on voit du monasterium vetus sur le plan de dom Milley de 1708 ; les moines venant de cette abbaye se seraient contentés de reproduire le plan de Clairvaux. C'est la même conclusion à laquelle arrive Glyn Coppack pour les premiers édifices de Fountains ${ }^{27}$. 

et même, plus encore, fourni des plans et dirigé tous les travaux ou certaines campagnes de construction sont connus pour des monastères situés dans l'actuelle Allemagne. Ce sont les moines Jordan et Berthold qui dirigèrent la construction de Walkenried (Allemagne), aidé par 21 convers, tailleurs de pierre et maçons entre autres $^{29}$. L'abbé Marquard d'Heiligenkrutz envoie à Lilienfeld (Autriche) le frère Pokerus, très versé dans les traditions architecturales, le moine Gebhard et le convers Gerold $^{30}$. Des moines de Leubus/Lubiaz prirent une part importante à la construction du couvent de l'abbaye cistercienne de Trebnitz (Trzebnica, Pologne, travaux de 1203 à 1241, consacrée en 1219) et en montèrent notamment le toit et le clocher. La proximité a sans nul doute permis ici la transmission du savoir. Les convers qui accompagnèrent les moines fondateurs de Viktring (Klagenfurt, Autriche), en Carinthie, partis de Villers-Bettnach, en Lorraine, étaient habiles en divers arts "conversibarbati diversis artibus periti ${ }^{31} »$. En 1224, l'abbé Wigbold, d'Aduard en Frise (Pays-Bas), d'après la chronique de l'abbaye, envoya à Clairvaux un de ses convers accompagné de son fils pour relever les plans et la disposition du grand monastère afin de construire l'abbaye d'Aduard sur le modèle exact des bâtiments ${ }^{32}$. Le chantier fut si bien réussi que le convers fut enterré dans l'église abbatiale.

second lieu, de manière plus concrète, certaines abbatiales cisterciennes ont servi de modèles les unes aux autres. La circulation des abbés a pu être un relais de ces copies, un vecteur de la transmission, certains d'entre eux étant élevés à la dignité abbatiale dans plusieurs abbayes différentes à l'intérieur de leur filiation. Certains abbés ont été élus successivement dans trois ou quatre abbayes. Ainsi, Wicelon a d'abord été abbé de Parisis, puis de Lucelle en 1185, où il a participé à la troisième croisade. Ensuite il a été élu abbé de Bellevaux en 1194. Les chartes confirment qu'il est abbé de Morimond en 1197, mais peut-être un peu avant ${ }^{33}$. Si les édifices de Cîteaux et de Clairvaux ont servi de modèles pour que l'on parle de "plan bernardin ", qu'en est-il concrètement de l'abbaye de Morimond et de son église, qui se dévoilent après plusieurs campagnes d'archéologie du bâti?

\section{Les vestiges et le plan de Morimond II, un modèle?}

Diverses campagnes d'archéologie du bâti sur les vestiges encore en élévation de l'abbaye de Morimond, plusieurs travées du collatéral nord, ont permis de mieux situer chronologiquement le chantier de cette abbatiale et de voir comment le plan et les élévations de Morimond ont pu servir de modèles au début du XIII ${ }^{\mathrm{e}}$ siècle (fig. 2). 
Fig. 2. - Abbaye de Morimond (Parnoy-en-Bassigny, Haute-Marne) : plan de l'abbatiale avec les données des différentes campagnes de fouilles.

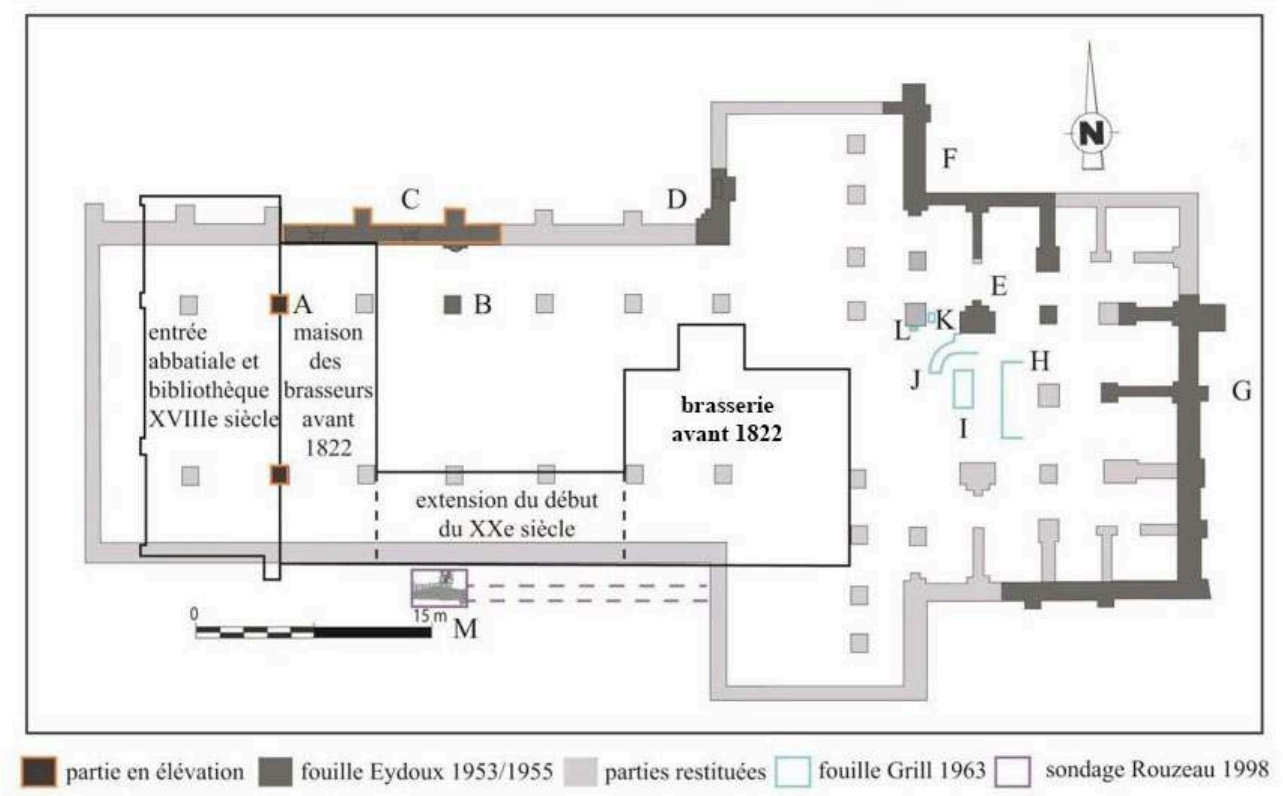

(c) Benoît Rouzeau.

Pour décrypter ces vestiges, il faut prendre en compte la reconstruction du $\mathrm{xvIII}^{\mathrm{e}}$ siècle. Elle donne à l'abbatiale une nouvelle entrée monumentale classique, avec sept portes assez hautes (fig. 3). 
Fig. 3. - Abbaye de Morimond (Parnoy-en-Bassigny, Haute-Marne) : entrée monumentale classique, dotée de sept portes, reconstruite au début du XVIII' siècle.

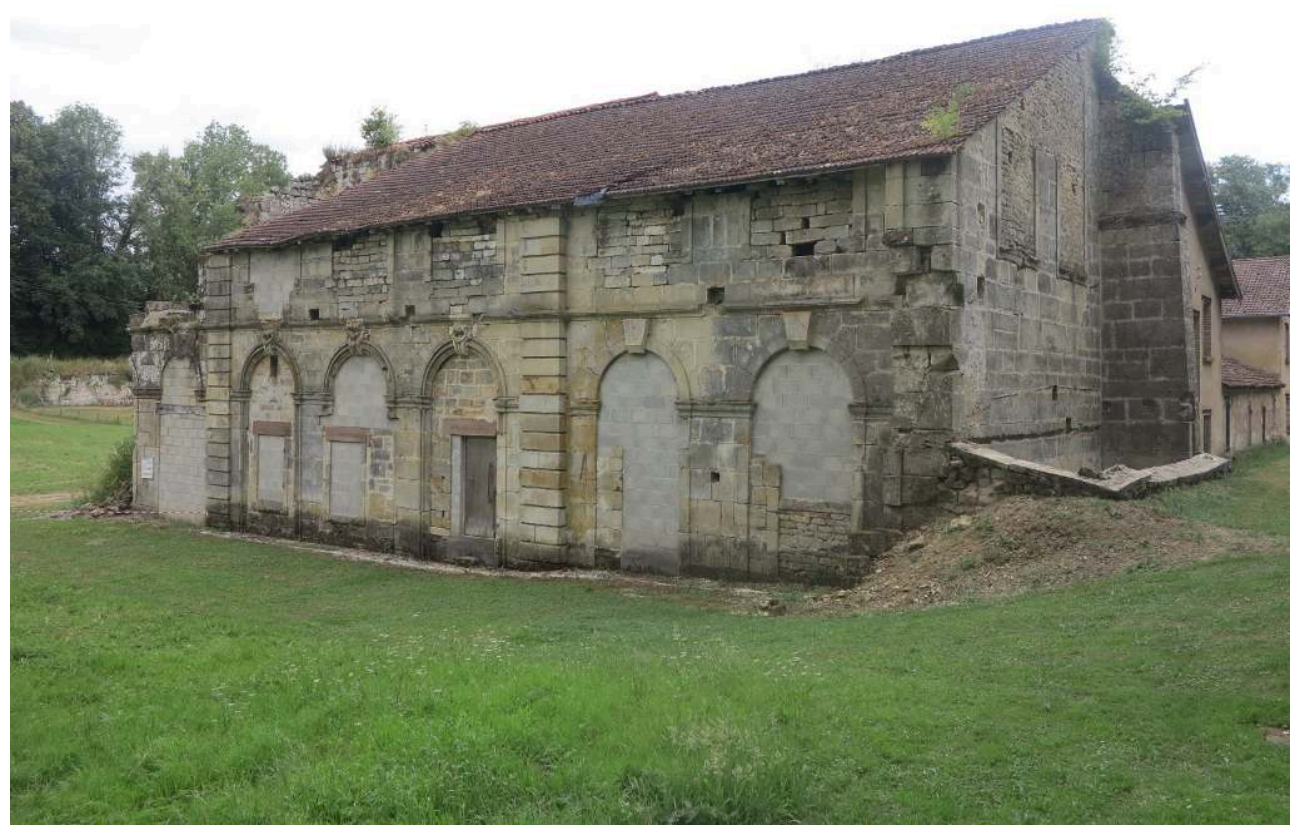

La porte la plus au nord s'est écroulée dans les années 1980.

(c) Benoît Rouzeau.

17 Cet espace est surmonté de la nouvelle bibliothèque de l'abbaye, dont les fenêtres sont aujourd'hui arasées à mi-hauteur. Pour compliquer encore un peu plus les choses, dans l'abbatiale démontée après la Révolution, une maison d'habitation prend appui sur une partie de la nef et des collatéraux, et sa façade est ponctuée de chapiteaux en remploi. Une brasserie est implantée au niveau du transept et collatéral sud (fig. 4). 
Fig. 4. - Abbaye de Morimond (Parnoy-en-Bassigny, Haute-Marne) : chapiteaux en remploi dans la façade de la maison des brasseurs, implantée après la Révolution au niveau de la nef et du collatéral nord.

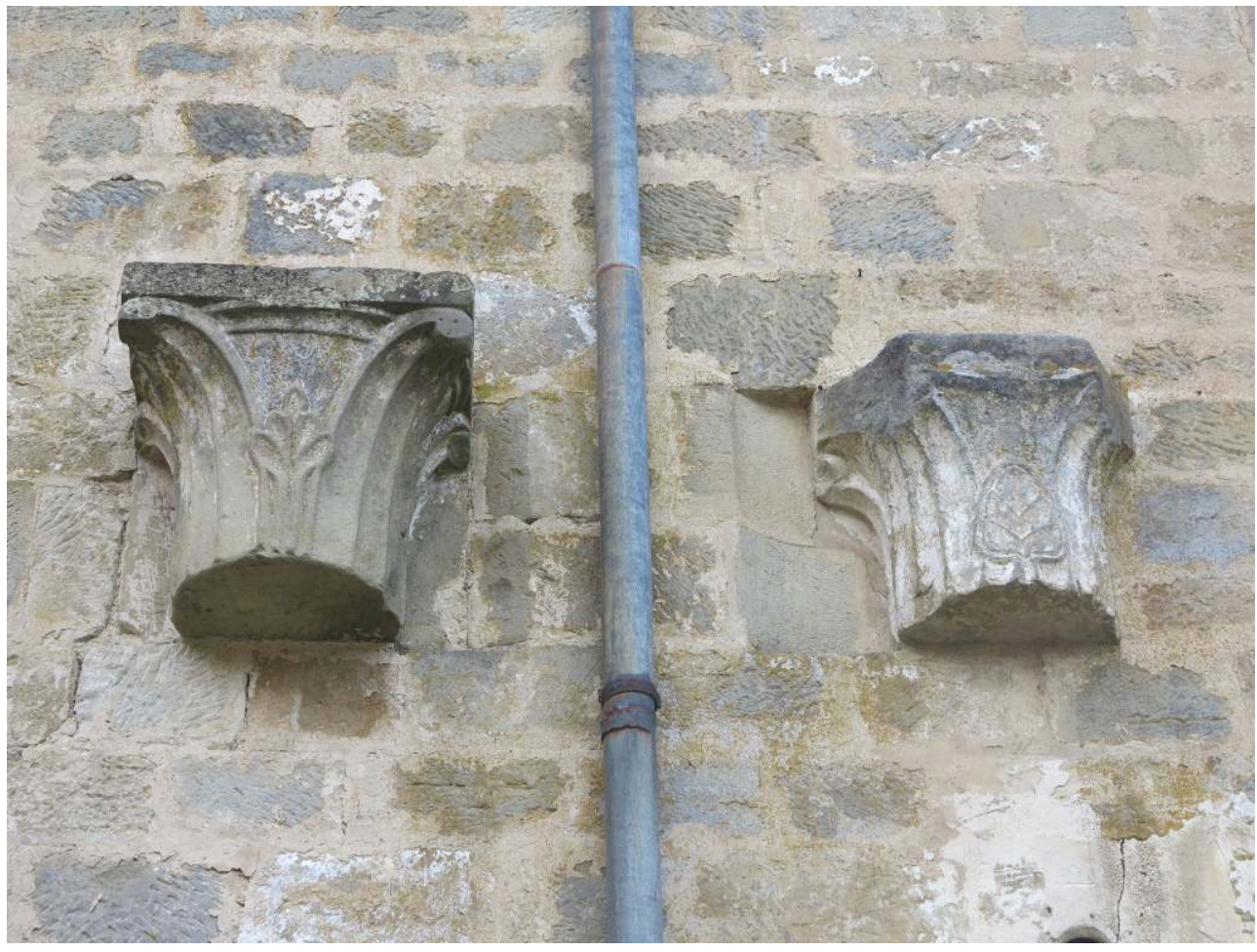

(c) Benoît Rouzeau.

Le collatéral nord, le seul conservé, laisse apparaître une structure liée au cloître et dont l'édification remonterait aux décennies 1170-1180. La mise en œuvre des maçonneries, très soignées, montre de nombreux points communs avec les édifices religieux du sud de la Lorraine à la même époque (fig. 5 et fig. 6). 
Fig. 5. - Abbaye de Morimond (Parnoy-en-Bassigny, Haute-Marne) : extérieur du collatéral nord.

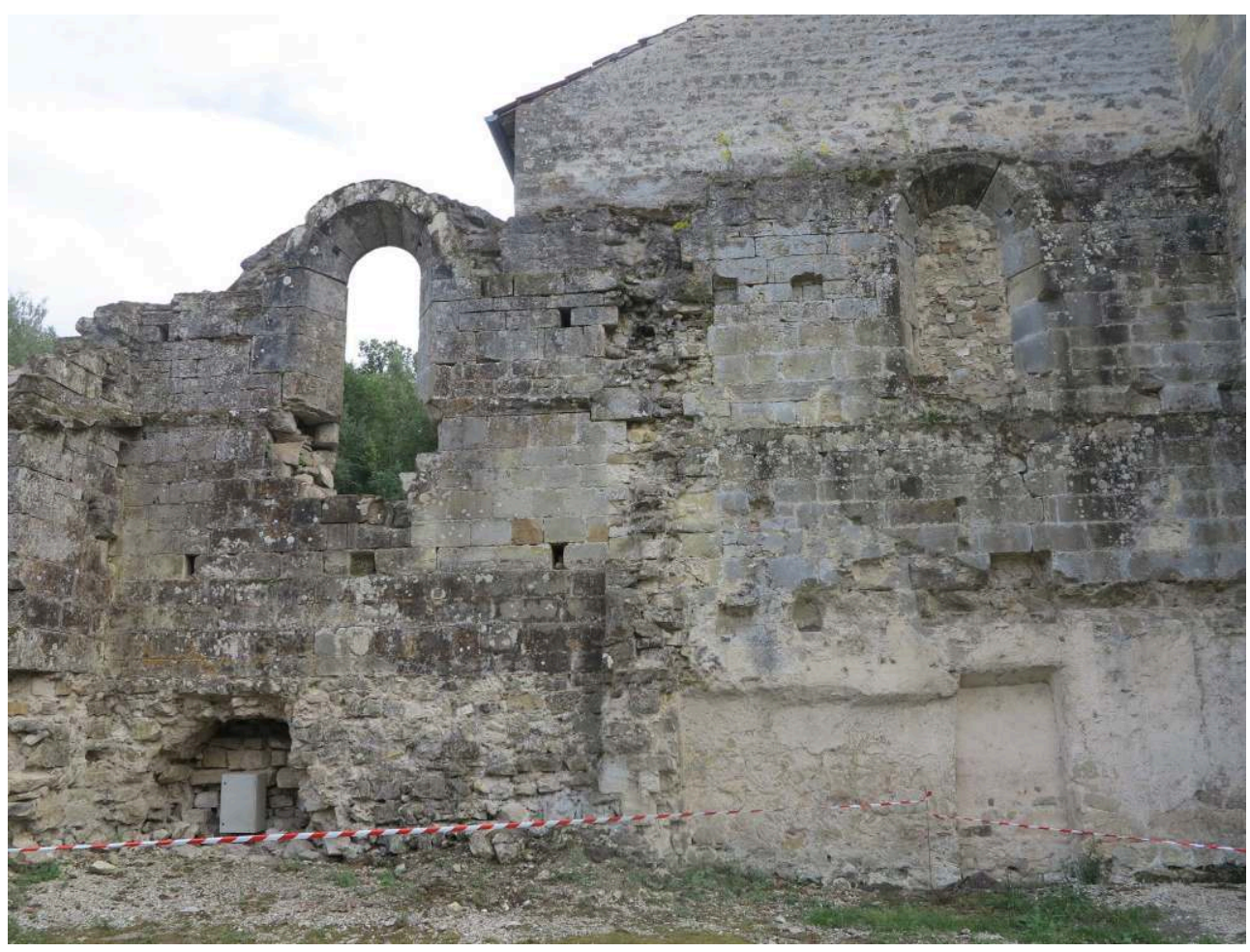

(c) Benoît Rouzeau.

Fig. 6. - Abbaye de Morimond (Parnoy-en-Bassigny, Haute-Marne) : relevé intérieur des travées 3, 4 et 5 du collatéral nord et restitution.

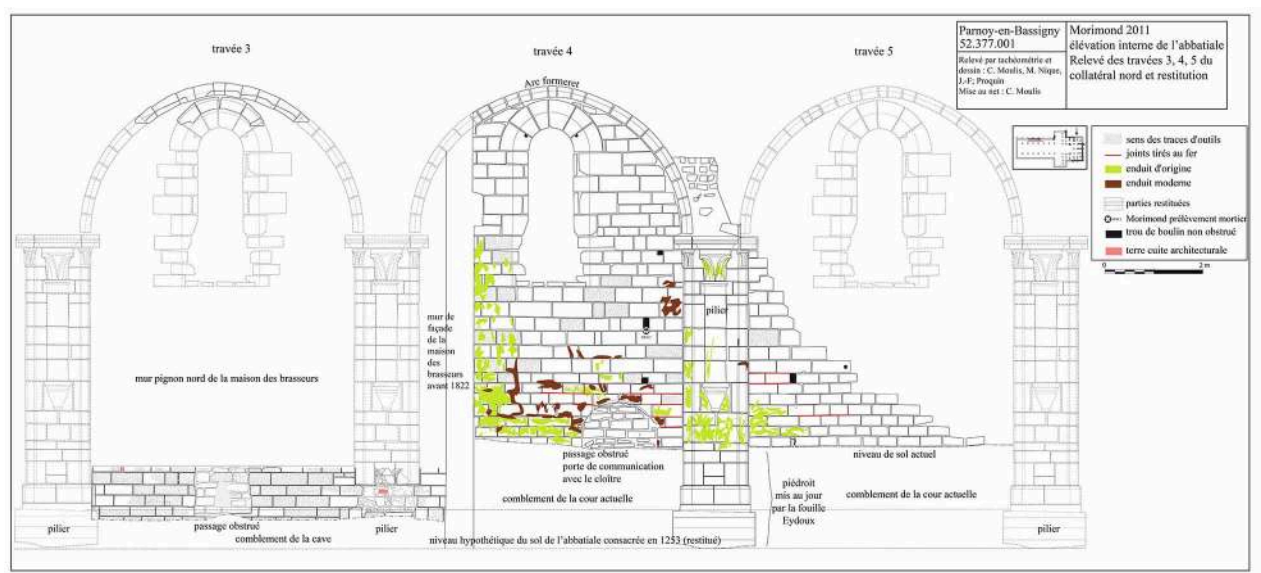

Relevé par tachéométrie et dessin Cédric Moulis, Marie Nique et Jean-François Proquin.

19 Un négatif du formeret du cloître, un contrefort et le solin du toit du collatéral, appuyé sur la pile cruciforme qui sépare la nef du même collatéral, sont conservés dans le grenier de cette maison (fig. 7). 
Fig. 7. - Abbaye de Morimond (Parnoy-en-Bassigny, Haute-Marne) : la pile cruciforme et le solin du toit du collatéral nord (partie gauche du cliché).

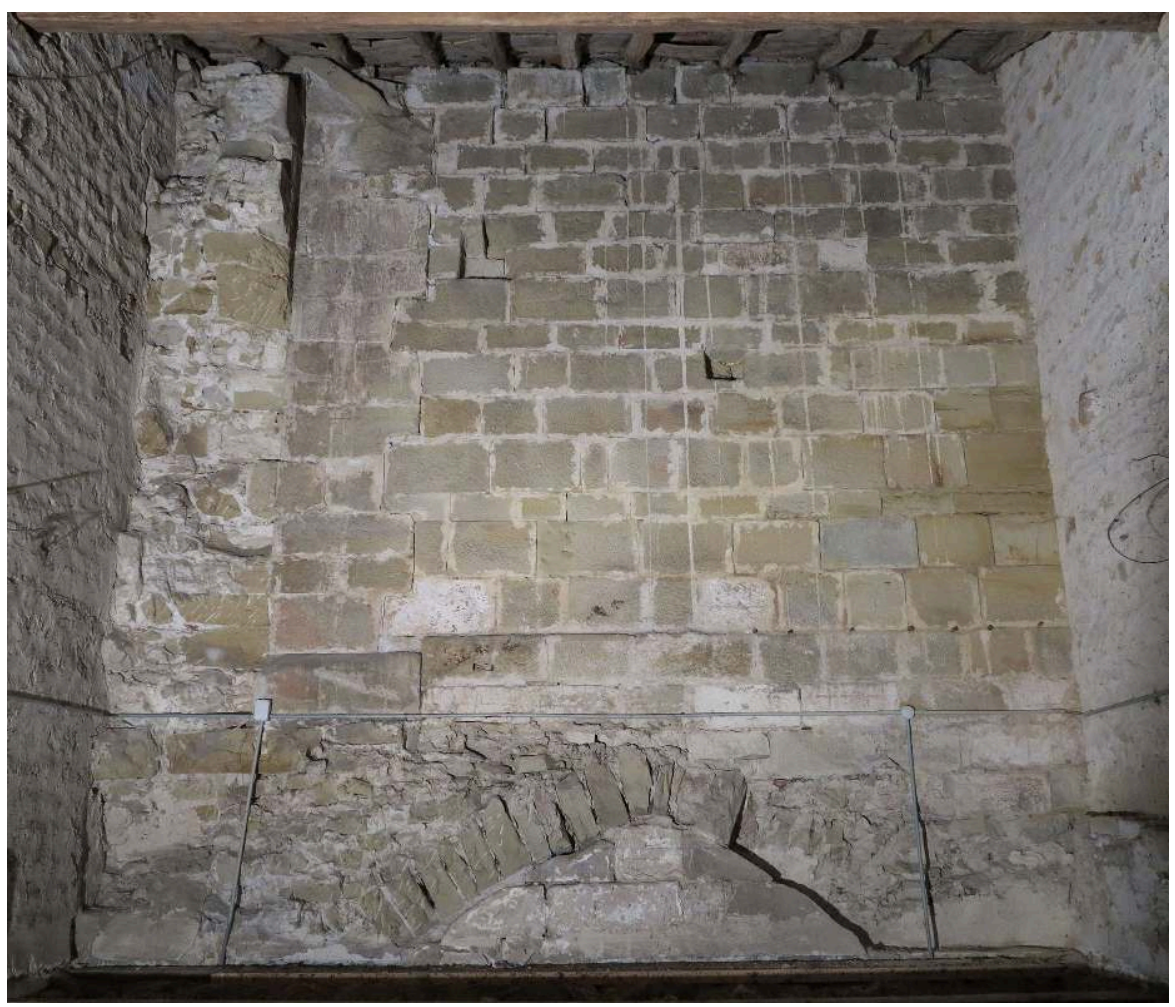

(c) Benoît Rouzeau.

Henri-Paul Eydoux fouille l'abbatiale en 1954-1955 dans des conditions rocambolesques. Il relève comme dimensions de l'église, $84 \mathrm{~m}$ de longueur pour $23 \mathrm{~m}$ de largeur (dont $12 \mathrm{~m}$ pour la nef et $3,8 \mathrm{~m}$ pour chaque bas-côté), avec un transept large de $13,6 \mathrm{~m}$ et long de $44 \mathrm{~m}$. Il n'a pas pu utiliser le plan de l'abbatiale relevé en 1789 par le neveu du dernier abbé, capitaine d'artillerie, dom Chautan de Vercly ${ }^{34}$ (fig. 8). Il laisse apparaître un chevet rectangulaire de même dimension que celui mis au jour durant la fouille. On remarquera que les toitures ne signalent aucune différence entre le déambulatoire et les chapelles rayonnantes. Ceci est confirmé par les inventaires révolutionnaires. Eydoux prendra d'ailleurs en compte ce plan dès qu'il en aura possession et amendera ses premières conclusions sur l'abbatiale dans les mélanges à la mémoire du père Anselme Dimier ${ }^{35}$. Qu'en est-il de ce plan du chevet rectangulaire, qui est celui de l'abbatiale Morimond II, consacrée en 1253 ? 
Fig. 8. - Abbaye de Morimond (Parnoy-en-Bassigny, Haute-Marne) : détail de l'abbatiale sur le plan de 1789 réalisé par le capitaine de Chautan, neveu du dernier abbé.

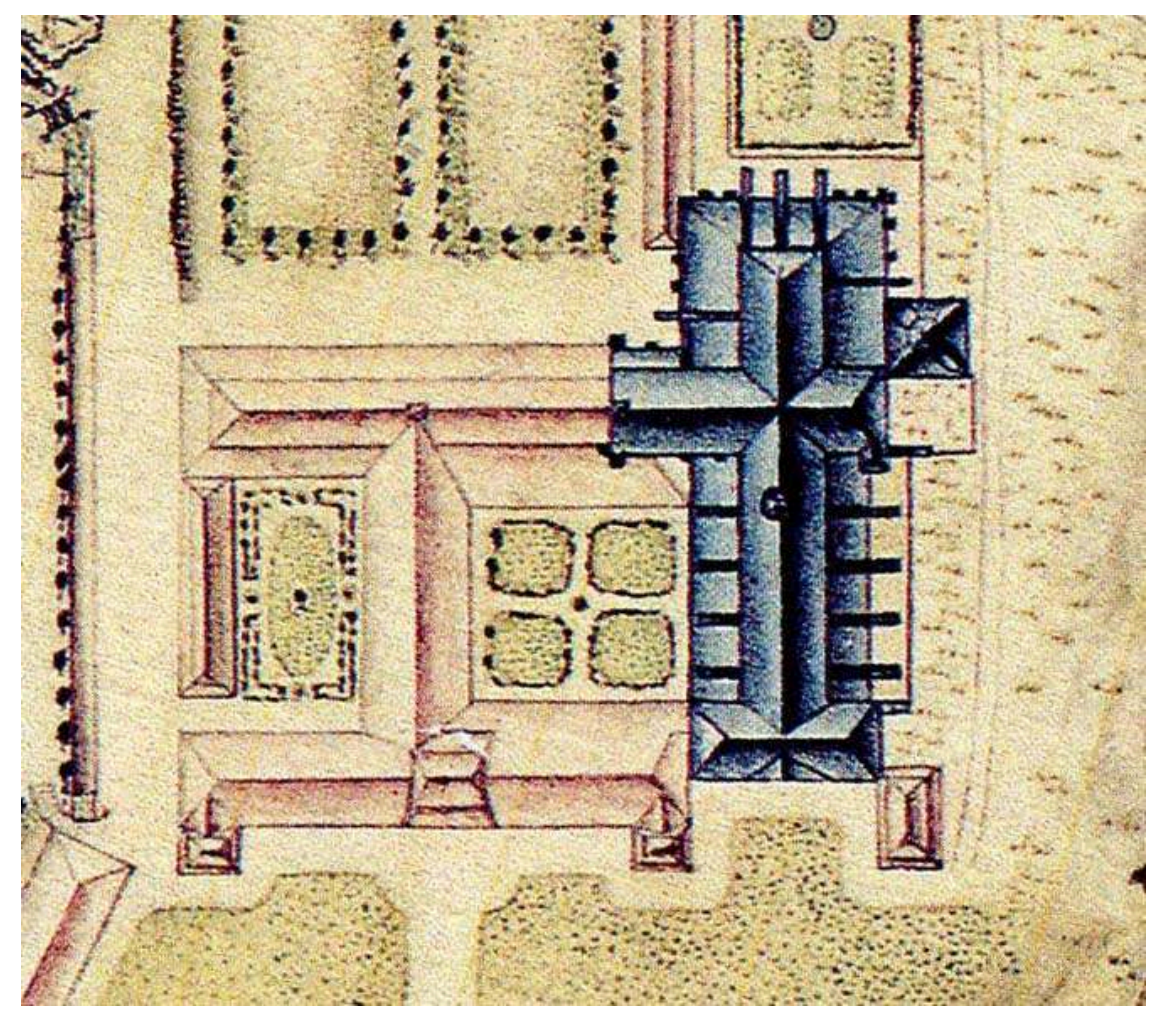

Société d'histoire et d'archéologie de Langres, musée de Langres.

Cliché Benoît Rouzeau (D.R.).

Il faut revenir brièvement sur la chronologie des grandes abbatiales cisterciennes pour comprendre le modèle de diffusion du plan de Morimond. Le chevet de Cîteaux II, construit entre 1170 et 1188 , est consacré en 1193 ; il reprend les évolutions du chevet de Clairvaux II (consacré en 1174), à savoir un chevet plus grand, avec un déambulatoire et des chapelles rayonnantes, mais sur un plan rectangulaire, à contrario de Clairvaux, qui possède un chevet circulaire d'après le plan de dom Millet en 1708 (fig. 9) ${ }^{36}$. 
Fig. 9. - Abbaye de de Clairvaux (Ville-sous-la-Ferté, Aube) : vue cavalière de l'abbatiale. Extrait du plan de dom Milley, 1708.

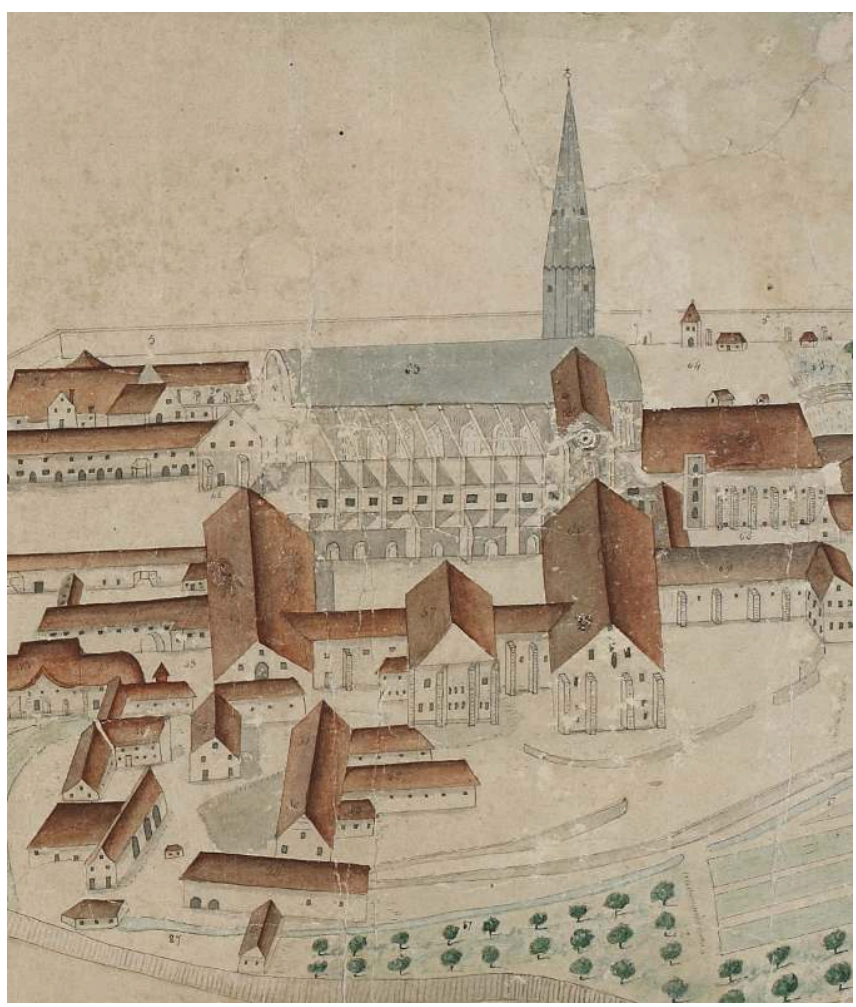

Médiathèque de Troyes Champagne métropole, Ms 3706.

(c) Médiathèque de Troyes Champagne métropole.

$\mathrm{Du}$ fait de leur poids dans l'ordre, Pontigny (Yonne) et Morimond adaptèrent et transformèrent ces modèles ${ }^{37}$. À Pontigny, entre 1180 et 1205, l'étagement du déambulatoire et des chapelles rayonnantes est presque entièrement nivelé. À Morimond, l'étagement a complètement disparu. Déambulatoire et chapelle rayonnante sont pour la première fois à la même hauteur. Cette disposition apparaît à Vézelay (Yonne) vers 1170. On voit ici comment les Cisterciens s'inspirent des évolutions architecturales des grands édifices religieux. Ce plan s'inspire de celui de Cîteaux II et a influencé différents édifices de la filiation de Morimond lors de leur reconstruction. On retrouve le chevet rectangulaire à Lilienfeld en 1206. C'est la même chose lors de la reconstruction de Walkenried (Allemagne) après 1209. À Walkenried et à Lilienfeld, les transepts sont plus courts, mais ils sont dotés comme à Morimond de chapelles collatérales de transepts. Pour Nicolaï Bernd, le plan de Lilienfield est transmis par l'intermédiaire du monastère d'Heilignekrutz, le margrave d'Autriche jouant sans aucun doute un rôle dans cette transmission ${ }^{38}$.

Ebrach entreprend sa reconstruction en 1200 ; le chantier de Morimond II ne semble pas encore achevé, donc le monastère s'inspire du plan de Cîteaux II, tout en conservant les sept travées, fidèle en cela au plan de Morimond II. Le rôle de l'abbé de Morimond Heidenrich (1205/1211), dont la carrière a été recomposée par Benoît Chauvin dans un article de la revue Francia ${ }^{39}$ est ici particulièrement éloquent. D'après des chroniques du monastère de Walkenried, d'époque moderne, cet ancien abbé de Walkenried et nouvel abbé de Morimond a décidé son successeur à Walkenried à partir de 1206 d'entreprendre la construction d'un nouveau monastère. Il doit le déplacer plus 
au sud et en le dotant d'une nouvelle abbatiale sur le modèle de ce qu'il avait entrepris à Morimond. Dans l'abbaye du Bassigny, le collatéral nord semble raisonnablement édifié entre 1170 et 1190 , sous les abbatiats de Henri (1170-1182) ou de Pierre I ${ }^{\text {er }}$ (1183-1193). Un second chantier s'effectue au tournant du XIII ${ }^{e}$ siècle, sans doute sous les abbatiats de Wicelon (1197-1204) et de Heindenrich (1205-1212), qui en est témoin. La fin des travaux interviendrait entre 1230 et 1253, durant l'abbatiat de Conon (1240-1263), juste avant la date de consécration officielle retenue par les moines blancs.

L'abbé Heindenrich séjourne souvent dans le royaume de Germanie ou en Italie, au service du pape et en négociation avec Otton IV. En 1209, il accueille ce dernier à Walkenried, en compagnie de 52 abbés cisterciens, pour la question de la régularisation de son mariage interdit par Innocent III. Puis dès 1210, Heindenrich fit cinq fois le déplacement Rome-Capoue pour des négociations entre Otton et Innocent III ${ }^{40}$. C'est dans la foulée de ses déplacements que les plans de type Morimond II se répandent; les grandes abbatiales prennent Morimond pour modèle et deviennent elles-mêmes ensuite des modèles pour les édifices de leurs régions. Ce sera plus tard la même chose à Hradischt (Klášter Hradiště nad Jizerou, République Tchèque) où les travaux de l'abbatiale se terminent après 1230 environ et à Salem (Allemagne) après $1299^{41}$. Les constructions de type Morimond et Cîteaux II n'ont été réalisées qu'au sein de la filiation de Morimond, en conservant un grand chevet rectangulaire dans deux types de cas. On les retrouve dans les grandes abbayes ayant un rôle prééminent dans l'ordre, principalement là où des donateurs de la haute noblesse voulaient installer des nécropoles et s'intéressaient aux cathédrales, mais aussi dans des monastères voisins de l'autorité souveraine ${ }^{42}$. Ces plans se diffuseront jusqu'en Silésie à Heinrichau (Henryków, Pologne) et en Bohème du nord à Hradischt.

Pour conclure, les réseaux de filiations et de voisinages ont pu jouer un rôle aux XII et $\mathrm{XIII}^{\mathrm{e}}$ siècles pour l'édification de nouveaux monastères et particulièrement des abbatiales. Quelques manuscrits témoignent que les Cisterciens ont pu représenter une norme, diffusant eux-mêmes des modèles, repris dans la construction de leurs carreaux de pavement et de leurs vitraux. Les déplacements fréquents des abbés en Bourgogne pour le chapitre général ont été le vecteur de la diffusion de techniques et de modèles de construction, les prélats passant souvent par les quatre abbayes filles avant l'arrivée à Cîteaux ou avant leur retour dans leur monastère d'origine. Il n'en demeure pas moins que certains abbés de premier plan, comme Heindenrich de Morimond, ont pu jouer un rôle déterminant dans la transmission des savoirs et des plans de construction. Cette contribution ne règle pas définitivement la question, mais elle invite à la fois à un retour salutaire aux sources, au travail sur les plans primitifs des établissements, et donc aux fouilles, mais encore à une étude des déplacements des principaux abbés de l'ordre pour montrer tous les liens paneuropéens de l'architecture cistercienne. 


\section{BIBLIOGRAPHIE}

AUBERT Marcel, L'architecture cistercienne en France, Paris, Éditions d'art et d'histoire, 1949.

AUBERT Marcel, « Existe-t-il une architecture cistercienne ? », Cahiers de civilisation médiévale, 1958, $\mathrm{n}^{\circ} 1-2, \mathrm{p} .153-158$.

AUMARD Sylvain, BEN AMARA Ayed, BÜTTNER Stéphane, 2011, « Analyses archéométriques des carreaux de l'église de Cudot et de l'abbaye des Écharlis ", Études villeneuviennes, $n^{\circ}$ 43, p. 57-64.

BARN Carl F., The Portfolio of Villard de Honnecourt (Paris, Bibliothèque nationale de France, MS Fr 19093): A New Critical Edition and Color Facsimile with a glossary by Stacey L. Hahn, Abingdon-on-Thames, Routledge, 2009.

BERNARD DE CLAIRVAUX, S. Bernardi abbatis primi Clarae-Vallensis Opera omnia, sex tomis in quadruplici volumine comprehensa, post Horstium denuo recognita... tertiis curis D. Joannis Mabillon,... Editio nova, accurante J.-P. Migne... (Patrologiae cursus completus : Series secunda, 185), Lutetiae Parisiorum : apud J.-P. Migne, 1854-1855.

BERND Nicolai, « Morimond et l'architecture cistercienne en Allemagne », Bulletin monumental, 1993, t. CLI, p. 181-197.

BONDE Sheila, KILLIAN Kyle, MAINES Clark, « The earliest church at Ourscamp and the long history of cistercian first churches in France ", Cîteaux - commentarii cisterciences, 2011, t. 62, nº 1-4, p. 5-34. BORLÉE Denise et TERRIER-ALIFERIS Laurence (dir.), Les modèles dans l'art du Moyen Âge (XII ${ }^{e}-\mathrm{XV}^{e}$ siècle), 2018, Turnhout, Brepols (Études du RILMA, 10).

CHAUVIN Benoît, « Les abbés de Morimond (1194-1213) : nomenclature critique, entre affaire locales et interventions européennes ", Francia, 2014, nº 41, p. 381-403.

CHAUvin Benoît, «Le plan bernardin : réalités et problèmes ", dans Histoire de Clairvaux, actes du colloque de Bar-sur-Aube, 22-23 juin 1990, Némont, association Renaissance de l'abbaye de Clairvaux, 1992, p. 243-244.

COOMANS Thomas, «Cistercian architecture or architecture of the Cistercian? », dans Bruun Mette Birkedal (dir.), The Cambridge companion to the Cistercian order, Cambridge, Cambridge University Press, 2012, p. 151-170.

COPPACK Glyn, Fountains abbey: the Cistercians in northern England, Stroud, Amberley, 2009.

DEMARTHE Sylvain, « Autour du concept d'“art cistercien" : construction, déconstruction, résistance », dans Baudin Arnaud et Grelois Alexis (dir.), Le temps long de Clairvaux, actes du colloque international (Troyes, 16-18 juin 2015), Paris, Somogy / Troyes, département de l'Aube, 2017, p. 281-296.

DEHIO Georg et BEZOLD Gustav von, Die kirchliche Baukunst des Abenlandes, Stuttgart, Cotta, 1892. DIMIER Marie-Anselme, Recueil de plans d'églises cisterciennes, Paris, Vincent-Fréal, 1949, 2 vol., 210 p., 336 f. de pl.

DUBY Georges, Saint Bernard : l'art cistercien, Paris, Flammarion, 1979.

EYDOUX Henri-Paul, « À propos des fouilles de Morimond », dans Chauvin Bernard (dir.), Mélanges à la mémoire du père Anselme Dimier, 3.5 : « Architecture cistercienne : ordre, fouilles ", Arbois, Pupillin, 1982, p. 353-355. 
EYDOUX Henri-Paul, « L'église abbatiale de Morimond », Analecta sacri ordinis cisterciensis, 1958, t. XIV, p. 3-116.

EYDoux Henri-Paul, « Les fouilles de l'abbatiale d'Himmerode et la notion de plan bernardin », Bulletin monumental, 1953, t. $111, \mathrm{n}^{\circ} 1, \mathrm{p} .29-36$.

HARRISON Stuart A., " Dating the abbey church of Fontenay: a reassessment of the evidence ", Cîteaux - Commentarii Cisterciences, 2010, t. 61, p. 99-124.

HIscock Nigel, « The two Cistercian plan of Villard de Honnecourt », dans Kinder Terryl N. (dir.) ; Perspective for an architecture of solitude essays on Cistercians, art and architecture in honour of Peter Ferguson, Turnhout, Brepols, 2004, p. 157-172.

HоскEY S. Frederick, The account-book of Beaulieu abbey, Londres, Royal Historical Society, 1975 (Camden Fourth series, 16).

LAFON Victor (abbé), Histoire de la fondation de l'abbaye de Loc-Dieu, Mémoires de la Société des lettres, sciences et arts de l'Aveyron, 1874-1878, t. 11, p. 339-395.

ORGEUR Magali, «Tuileries cisterciennes et carreaux de pavement en Bourgogne ", dans Baudin Arnaud, Benoit Paul, Rouillard Joséphine, Rouzeau Benoît (dir.), L'industrie cistercienne (XII $-\mathrm{XXI}^{e}$ siècle), actes du colloque international (Troyes-Clairvaux, septembre 2015), Paris, Somogy, 2019, p. 23-40.

SALAMAGNE Alain, " "Pour adviser et memorisier en eulx et par escript" : les modèles dans l'architecture de la fin du Moyen Âge », dans Borlée Denise et Terrier-Aliferis Laurence, Les modèles dans l'art du Moyen Âge (XII $-X V^{e}$ siècle), Turnhout, Brepols (Études du RILMA, 10), 2018.

SIMADER Friedrich, « Das so genannte "Reiner Musterbuch": Notizen zum Forschungsstand », dans Schwob et Kranich-Hofbauer Karin (dir.), Zisterziensisches Schreiben im Mittelalter: Das Skriptorium der Reiner Mönche, Beiträge der internationalen Tagung im Zisterzienserstift Rein, Mai 2003, Vienne, Peter Lang (Jahrbuch für internationale Germanistik, série A, vol. 71), 2005, p. 141-150.

TERRIER-ALIFERIS Laurence, « La datation du chœur de l'église de Vaucelles, reproduit en plan par Villard de Honnecourt », Zeitschrift für Kustgeschiste, 2018, vol. 81, n³ 3, p. 411-417.

\section{NOTES}

1. M. Aubert, « Existe-t-il une architecture cistercienne? », p. 158.

2. M.-A. Dimier, Recueil de plans d'églises cisterciennes.

3. H.-P. Eydoux, «Les fouilles de l'abbatiale d'Himmerode et la notion de plan bernardin ».

4. B. Chauvin, «Le plan bernardin, réalité et problèmes ».

5. S. Harrison, « Dating the abbey church of Fontenay: a reassessment of the evidence ».

6. G. Duby, Saint Bernard, l'art cistercien, p. 13.

7. T. Coomans, « Cistercian architecture or architecture of the Cistercian ».

8. S. Demarthe, « Autour du concept d'art cistercien ».

9. D. Borlée et L. Terrier-Aliferis, Les modèles dans l'art du Moyen Âge (XIII-XV siècle) ; A. Salamagne, " "Pour adviser et memorisier en eulx et par escript" : les modèles dans l'architecture de la fin du Moyen Âge ». 
10. Reiner Musterbuch, Österreichischen Nationalbibliothek, Cod. Vinob. 507, fol. $1 \mathrm{r}^{\mathrm{o}}-13 \mathrm{v}^{\mathrm{o}}$.

11. Ibid., fol. $1 \mathrm{r}^{\mathrm{o}}, 4 \mathrm{r}^{\circ}$ à $6 \mathrm{v}^{\circ}$.

12. Ibid., fol. $7 \mathrm{r}^{\circ}$ à $10 \mathrm{v}^{\circ}$.

13. Ibid., fol. $11 \mathrm{r}^{\circ}$ à $13 \mathrm{v}^{0}$.

14. Ibid., fol. $1 \mathrm{v}^{0}$ à $3 \mathrm{v}^{0}$.

15. F. Simader, « Das so genannte Reiner Musterbuch: Notizen zum Forschungsstand ».

16. M. Orgeur, "Tuileries cisterciennes et carreaux de pavement en Bourgogne", S. Aumard et al., "Analyses archéométriques des carreaux de l'église de Cudot et de l'abbaye des Écharlis ».

17. Londres, British Library, Add Ms 48978.

18. S. F. Hockey, The account-book of Beaulieu abbey.

19. Londres, British Library, Add Ms 48978 , fol. $39 \mathrm{v}^{\circ}$.

20. https://gallica.bnf.fr/ark:/12148/btv1b10509412z, consulté le 10 avril 2018.

21. N. Hiscock, « The two cistercian plan of Villard de Honnecourt », p. 157-172.

22. C.F. Barn, The portofolio of Villard de Honnecourt, a new critical edition and color facsimile, p. 106-107.

23. L. Terrier-Aliferis, «La datation du chœur de l'église de Vaucelles reproduit en plan par Villard de Honnecourt ».

24. M. Aubert, "Existe-t-il une architecture cistercienne?», p. 158 et L'architecture cistercienne en France, p.97; Bernard de Clairvaux, S. Bernardi abbatis..., Exordium magnum, livre 3, chap. 20, col. 1078-1079.

25. M. Aubert, « Existe-t-il une architecture cistercienne ?», p. 158.

26. S. Bonde et al., « The earliest church at Ourscamp and the long history of Cistercian first churches in France ».

27. G. Coppack, Fountains abbey: the Cistercians in Northern England, p. 21, 24-25.

28. V. Lafon, Histoire de la fondation de l'abbaye de Loc-Dieu, p. 339 et suiv.

29. M. Aubert, L'architecture cistercienne en France, p. 98.

30. Ibid., p. 99.

31. G. Dehio et G. von Bezold, Die kirchliche Baukunst des Abenlandes.

32. M. Aubert, L'architecture cistercienne en France.

33. B. Chauvin, «Les abbés de Morimond (1194-1213): nomenclature critique, entre affaire locales et interventions européennes ».

34. H.-P. Eydoux («L'église abbatiale de Morimond») est lors de la seconde campagne de fouille en Algérie et dirige la fouille à distance.

35. H.-P. Eydoux, «À propos des fouilles de Morimond », p. 353-355.

36. B. Chauvin, « Le plan bernardin, réalités et problèmes », p. 243-244.

37. N. Bernd, « Morimond et l'architecture cistercienne en Allemagne », p. 189.

38. Ibid.

39. B. Chauvin, « Les abbés de Morimond (1194-1213)... ».

40. Ibid. 
41. La chronologie de ces édifices serait bien évidemment encore à parfaire.

42. N. Bernd, « Morimond et l'architecture cistercienne en Allemagne », p. 190.

\section{RÉSUMÉS}

L'organisation en ordre des moines cisterciens depuis la rédaction de la charte de charité, qui impose à l'abbé père de visiter l'abbaye fille fondée chaque année, a fait de cet ordre, issu du renouveau religieux $\mathrm{du} \mathrm{XII}^{\mathrm{e}}$ siècle, une congrégation où l'on voyage beaucoup, et où les modèles d'architecture des bâtiments emblématiques comme l'abbatiale ont pu circuler. Cet article pose quelques jalons pour l'étude de la diffusion de l'architecture et de modèles, à partir de manuscrits $\mathrm{du} \mathrm{xIII}^{\mathrm{e}}$ siècle, de diverses sources écrites et des recherches sur l'abbatiale de Morimond (Parnoy-en-Bassigny, Haute-Marne), où se développent depuis plusieurs années des fouilles et des campagnes d'archéologie du bâti.

INDEX

Mots-clés : savoirs, construction, Cisterciens, $\mathrm{XII}^{\mathrm{e}}$ siècle, $\mathrm{XIII}^{\mathrm{e}}$ siècle

\section{AUTEUR}

\section{BENOÎT ROUZEAU}

Université Paris I - Panthéon-Sorbonne, Laboratoire de médiévistique occidentale de Paris (LAMOP, UMR $8589 \mathrm{du}$ CNRS) et Centre Malher 


\title{
Les expérimentations de logements sociaux en terre crue au Maroc dans les années 1960 : modernisation et transmission des savoirs
}

\author{
Nadya Rouizem Labied
}

1 Nous savons aujourd'hui que le choix des matériaux de construction et leur mode de production agissent durablement sur les ressources naturelles de la planète et sur le réchauffement climatique. Ces enjeux importants justifient l'étude et la valorisation de matériaux de construction naturels comme la terre crue.

En France, le mouvement de relance de la filière de construction en terre date de la fin des années 1970, suite à la crise pétrolière de 1973. En témoignent la création du Centre de recherche et d'application de la Terre (CRAterre ${ }^{1}$ ) et l'exposition « Des architectures de terre ou l'avenir d'une tradition millénaire » tenue au Centre Pompidou en 1981 sous la direction de Jean Dethier. Cet architecte belge est l'initiateur du Domaine de la terre, le premier quartier urbain d'habitat social bâti en terre en Europe. Composé de 64 logements, le Domaine de la Terre est inauguré à l'Isle d'Abeau, en 1985 ; Jean Dethier a été inspiré par l'architecture en terre du Maroc².

"C'est là que j'ai durablement pris conscience des atouts et enjeux de la construction en terre, qui allait devenir, durant un demi-siècle, l'une de mes passions ${ }^{3}$.»

$\mathrm{Au}$ Maroc, les premières actions en faveur de l'architecture de terre remontent à 1870 . Jean Dethier écrit à ce propos qu'il est temps que le Maroc soit intégré à l'histoire de " l'art moderne de construire en terre crue ${ }^{4}$ ». Notre recherche s'intéresse aux années 1960, une période très riche en projets expérimentaux en terre au Maroc. En 1962, Alain Masson, un ingénieur français, réalise à Marrakech un quartier de 2750 logements économiques en briques de terre stabilisée, qui restera pendant longtemps «le plus vaste ensemble urbain contemporain construit dans ce matériau ${ }^{5}$ ». Il réalise ensuite avec Jean Hensens, un architecte belge, 200 logements en pisé à Ouarzazate en 1967 et 400 logements en briques de terre en 1969 à Berkane. En 1968, un centre de recherche 
est créé au ministère de l'Habitat, à Rabat, le Centre d'expérimentation, de recherche et de formation (CERF), dirigé par Alain Masson ${ }^{6}$. Dans ce centre, il réunit une équipe pluridisciplinaire qui produira un grand nombre de projets et de recherches sur l'habitat social au Maroc, notamment l'habitat en terre crue, avec des procédés d'autoconstruction assistée. Ainsi la période des années 1960 était riche en expérimentations et en recherche sur la terre crue au Maroc, comme en témoigne le CRAterre :

«Les années 60 et 70 ont vu au Maroc un développement très significatif des

recherches et expérimentations sur la construction en terre ${ }^{7}$. »

Pourtant, dans l'historiographie de l'architecture en terre, les différents travaux ont étudié principalement le patrimoine vernaculaire; il y a très peu de publications sur l'histoire moderne ou «savante » de l'architecture en terre en Afrique. Les principaux ouvrages qui ont mentionné l'architecture moderne en terre au Maroc sont l'œuvre de Jean Dethier et du CRAterre.

5 Par exemple, dans un ouvrage du CRAterre qui dresse un bilan du savoir sur le pisé dans le monde, Jean Dethier écrit un chapitre intitulé «Le renouveau des expériences au Maroc ", dans lequel il décrit le projet de Ouarzazate ${ }^{8}$. Mais Jean Dethier est une figure militante de l'architecture en terre, et son but est de promouvoir ce matériau alternatif ; aussi décrit-il ces expérimentations dans des termes toujours élogieux : dans l'article « La terre et le roseau », il les qualifie de " succès technique et budgétaire ${ }^{9}$ ».

Puis en 1985, les travaux étrangers occupent la moitié de la bibliographie de l'ouvrage du CRAterre sur le pisé, car il y a une «absence presque totale en France de publications sur le sujet ${ }^{10} »$. Cependant, nos trois cas d'étude ne sont évoqués que très brièvement et ne sont pas replacés dans leur contexte. Nous avons également constaté que les ouvrages du CRAterre ont quelquefois un positionnement critique, mais uniquement du point de vue technique : par exemple, pour le projet de Ouarzazate, les coffrages sont selon eux trop coûteux, et l'épaisseur des murs insuffisante pour isoler thermiquement contre la chaleur ${ }^{11}$. Par ailleurs, le projet de Berkane n'a été évoqué dans aucun ouvrage, à notre connaissance.

7 Nous proposons d'étudier ces projets encore méconnus dans une approche critique qui interroge les modalités de la transmission des savoirs et leur transformation. Nous montrerons comment les techniques traditionnelles de construction ont été transformées par des coopérants européens, puis retransmises à la population qui les avait initiées. Notre recherche s'appuie sur un corpus varié : les archives de Jean Hensens, conservées à la faculté d'architecture La Cambre, à Bruxelles, les publications de Jean Dethier et du CRAterre, ainsi que des entretiens et photographies effectués sur place.

\section{Le Maroc, un contexte favorable à l'expérimentation}

8 L'architecture vernaculaire en terre crue est très présente au Maroc. Dans le sud du pays, la construction en pisé est la plus répandue, et c'est dans la province de Ouarzazate que se trouvent les forteresses, ou ksours, bâties en terre crue. Bâtiments de terre entourés de murailles, murs défensifs et tours d'angle, ces bâtiments regroupent des habitations, des commerces, une mosquée et deux cimetières.

Cette architecture monumentale a beaucoup inspiré Jean Hensens, dont de très nombreux croquis représentent les ksour et kasbahs du sud du Maroc ${ }^{12}$. À travers ses 
dessins, Jean Hensens s'est constitué une connaissance de la culture locale et semble montrer un grand intérêt pour l'architecture vernaculaire, avec laquelle il appelle à renouer dans les projets réalisés avec Alain Masson.

Par ailleurs, en 1987 le ksar d'Ait ben Haddou, bâti en pisé dans la région de Ouarzazate, est inscrit sur la liste du patrimoine mondial de l'Unesco, et c'est un croquis de Jean Hensens qui illustre un timbre édité à cette occasion.

11 En effet, l'intérêt pour l'architecture en terre ne va cesser de se développer à partir des années 1980, suite à la crise énergétique, comme évoqué précédemment. Mais l'essor actuel de ce matériau a été précédé par une époque d'expérimentation encore mal connue. Dans le premier ouvrage du CRAterre, publié en 1975, la bibliographie recense les différentes publications de l'époque sur des projets ou réalisations en terre ${ }^{13}$ : sur cent quarante-neuf titres, vingt-deux concernent le Maroc, avec une concentration des publications entre 1965 et 1969. Pendant cette même période, il y a une seule publication sur la terre en France (tabl. 1).

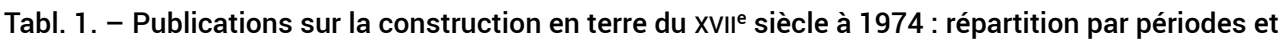
par pays des ouvrages, articles et rapports recensés dans la bibliographie du livre Construire en terre (École nationale supérieure d'architecture de Grenoble et Institut de l'environnement, 1975).

\begin{tabular}{|c|c|c|c|c|c|c|c|c|c|}
\hline $\begin{array}{l}\text { Périodes de } \\
\text { publication } \\
\text { Pays } \\
\text { concernés }\end{array}$ & $\mathrm{XVIII}^{\mathrm{e}}$-XIX ${ }^{\mathrm{e}}$ siècles & $1945-1949$ & $1950-1954$ & $1955-1959$ & 1960-1964 & 1965-1969 & $1970-1974$ & $\begin{array}{l}\text { sans } \\
\text { date }\end{array}$ & $\begin{array}{l}\text { TOTAL } \\
\text { par pays } \\
\text { concerné }\end{array}$ \\
\hline France & 3 & 2 & 3 & 1 & 1 & 1 & 10 & 8 & 29 \\
\hline Maroc & & & 2 & 2 & & 12 & 6 & & 22 \\
\hline Algérie & & & & & & & 16 & 1 & 17 \\
\hline Ghana & & & & 1 & 1 & 4 & 5 & & 11 \\
\hline Sénégal & & & 3 & 3 & 4 & 1 & & & 11 \\
\hline États-Unis & & & 1 & 2 & 2 & & & 1 & 6 \\
\hline $\begin{array}{l}\text { «Afrique de } \\
\text { l'Ouest» }\end{array}$ & & 1 & 2 & & 1 & & 1 & & 5 \\
\hline Inde & & & & & & 2 & 3 & & 5 \\
\hline Guinée & & & & 4 & & & & & 4 \\
\hline Égypte & & & & 1 & & 1 & 2 & & 4 \\
\hline ONU & & & & 1 & & 1 & 2 & & 4 \\
\hline Kenya & & & & 1 & 1 & & 1 & & 3 \\
\hline Madagascar & & & & & 1 & 1 & 1 & & 3 \\
\hline Zaïre & & & & 2 & & & & & 2 \\
\hline Congo & & & & & 1 & & 1 & & 2 \\
\hline Colombie & & & & 1 & 1 & & & & 2 \\
\hline Côte-d'Ivoire & & 1 & & 1 & & & & & 2 \\
\hline
\end{tabular}




\begin{tabular}{|c|c|c|c|c|c|c|c|c|c|}
\hline $\begin{array}{l}\text { Nouvelle- } \\
\text { Guinée }\end{array}$ & & & & & & 2 & & & 2 \\
\hline Australie & & & & 1 & & & 1 & & 2 \\
\hline Tunisie & & 1 & & & & & & & 1 \\
\hline Mauritanie & & & & & & & 1 & & 1 \\
\hline Cameroun & & & & & & & 1 & & 1 \\
\hline Haute-Volta & & & & & & & 1 & & 1 \\
\hline Dahomey & & & & & & 1 & & & 1 \\
\hline $\begin{array}{l}\text { République } \\
\text { Centrafricaine }\end{array}$ & & & & & & 1 & & & 1 \\
\hline Niger & & & & & 1 & & & & 1 \\
\hline $\begin{array}{l}\text { "Pays } \\
\text { musulmans » }\end{array}$ & & & & & & & 1 & & 1 \\
\hline Yemen & & & & & & & & 1 & 1 \\
\hline Venezuela & & & & & & 1 & & & 1 \\
\hline $\begin{array}{l}\text { Royaume- } \\
\text { Uni }\end{array}$ & & & & & & & 1 & & 1 \\
\hline Suède & & & & & & 1 & & & 1 \\
\hline Pologne & & & & & & & 1 & & 1 \\
\hline $\begin{array}{l}\text { TOTAL par } \\
\text { période } \\
\text { concernée }\end{array}$ & 3 & 5 & 11 & 21 & 14 & 29 & 55 & 11 & 149 \\
\hline
\end{tabular}

12 Ainsi, c'est surtout en Afrique qu'ont eu lieu les expérimentations d'architecture moderne en terre crue au milieu du $x^{e}$ siècle. Non seulement l'architecture vernaculaire en terre est très présente sur ce continent, mais nous savons aujourd'hui que les pays colonisés ont servi de laboratoire d'expérimentation aux architectes et urbanistes européens ${ }^{14}$.

13 C'est dans ce contexte qu'ont eu lieu les deux projets expérimentaux qui seront étudiés ici : l'un à Daoudiate, un quartier de Marrakech, en 1962, et l'autre à Ouarzazate en 1967.

\section{Alain Masson : la rationalité d'un ingénieur}

Ingénieur français, Alain Masson arrive à Marrakech en 1961, à l'âge de 34 ans, pour diriger l'arrondissement des Travaux publics de plusieurs provinces du sud du Maroc. Cette administration dirige l'habitat, les routes et les aménagements urbains à Marrakech et ses trois subdivisions, ainsi qu'à Ouarzazate. Dans un texte qu'il rédige entre 1981 et $2006^{15}$, il rapporte un témoignage de son expérience au Maroc. Ce poste représente pour lui une promotion, après dix ans en bureau d'études à Paris, puis à Marseille. Il insiste sur la liberté et la confiance dont il bénéficie de la part de ses 
supérieurs directs, européens pour la plupart. Masson décrit également la confiance que lui accorde le gouverneur de la province de Marrakech, qui est marocain.

Dans le domaine de l'habitat, le service réalise plusieurs grandes opérations de logement social, selon des plans établis par le pouvoir central. Pour le programme de résorption des bidonvilles à Marrakech, Masson présente en 1962 le projet Daoudiate à son supérieur, l'ingénieur en chef Gilbert Mailhebiau: un projet de logements en parpaings de terre améliorée au ciment, dans le respect de la trame de 6 mètres par 8 imposée par le ministère. Sans attendre que le prototype demandé au départ soit réalisé, la première tranche de 700 logements ${ }^{16}$ sera lancée.

16 Ainsi, il apparaît dans ce témoignage que les conditions de réalisation du projet de Daoudiate étaient particulières : d'une part, l'administration marocaine était dirigée par un Européen bénéficiant d'une certaine liberté et de la confiance de ses supérieurs, ce qui lui a permis de proposer des solutions expérimentales. D'autre part, l'insalubrité des bidonvilles présentait un contexte d'urgence qui imposait la rapidité de mise en œuvre de ces solutions. Par ailleurs, la population à reloger était insolvable: ces solutions devaient donc être très économiques.

Enfin, la région de Marrakech est connue pour la tradition constructive en terre crue en milieu rural. Alain Masson a donc eu la possibilité de proposer de nouvelles méthodes constructives, inspirées de la tradition locale, et de convaincre sa hiérarchie de les mettre en œuvre, pour la première fois, pour un nombre très important de logements. La réalisation des tranches suivantes montre le succès de l'opération, puisque 2750 logements en tout seront réalisés en briques de terre stabilisée.

\section{L'industrialisation de la brique de terre crue ou adobe}

Dans la tradition marocaine, il existe deux méthodes principales de construction en terre crue : l'adobe et le pisé. Dans la tradition employant la brique de terre crue, celleci est désignée par le mot adobe, qui vient du mot arabe toubia ou toub. La terre d'adobe peut être mélangée à de la chaux, de la paille ou de la cendre. Elle est mouillée, malaxée, puis coulée dans un cadre en bois, et les blocs obtenus sont séchés au soleil ${ }^{17}$. Toutes ces opérations sont réalisées à la main, ou avec les pieds pour le malaxage.

Le bloc de terre comprimée est une amélioration technique de l'adobe, permettant de pérenniser les constructions en diminuant leur entretien et de rationaliser le chantier.

Le rapport rédigé par la délégation régionale du ministère de l'Habitat à Marrakech décrit le chantier de l'unité 3 à Daoudiate comme un "chantier de construction industrie ${ }^{18} »$. Alain Masson a donc apporté dans ce projet son savoir-faire d'ingénieur, pour une rationalisation optimisée du chantier.

21 Dans les années 1950, époque de la reconstruction après la Deuxième Guerre mondiale, se développent en France l'industrialisation et la préfabrication dans le bâtiment afin de répondre à des besoins urgents et massifs de logements économiques. Comme l'a souligné Michel Ragon ${ }^{19}$, cette industrialisation est favorisée par les ingénieurs : Alain Masson apporte dans ce contexte au Maroc les compétences professionnelles acquises en France. Sur le chantier de Daoudiate, une entreprise privée a été sollicitée uniquement pour la plomberie, l'électricité, la menuiserie, les moules de préfabrication et une partie des 
approvisionnements des matériaux. Les autres postes du chantier ont été assurés par des ouvriers recrutés par le service de l'Habitat.

Cependant, l'industrialisation du chantier s'est adaptée aux conditions d'un pays en voie de développement. La zone de préfabrication a été aménagée dans le futur emplacement d'une place publique et couverte de roseaux. Le béton est vibré manuellement, sans bétonnière. La préfabrication se fait dans des moules métalliques. Plusieurs éléments sont ainsi préfabriqués en béton: parmi eux les sanitaires, les cadres des portes et fenêtres et les toitures.

La thèse d'Aleyda Resendiz-Vasque ${ }^{20}$ définit bien les paramètres de l'industrialisation de la construction, en se basant sur plusieurs ouvrages; nous relèverons les termes suivants : "série », "rationalisation ", «mécanisation », « organisation », "répétition». Alain Masson a également donné sa définition d'un chantier de construction industriel, dans laquelle il reprend les termes "rationalisation", "préfabrication ", et "programme d'exécution adapté ${ }^{21}$. Nous observons donc une volonté de faire participer le Maroc, un pays en voie de développement, à la dynamique d'industrialisation du bâtiment qui a lieu en Europe, mais avec un matériau et une main-d'œuvre locaux.

Les briques étaient composées d'un mélange de terre et de ciment. Des études en laboratoire ont permis de définir la granulométrie de la terre pour déterminer la quantité de ciment à utiliser pour le mélange : $100 \mathrm{~kg}$ par mètre cube de terre. Par ailleurs, le rapport indique également que la presse utilisée est la presse CINVA-RAM, mise au point "sous l'égide de l'ONU pour les pays en voie de développement ${ }^{22}$ ". Chaque presse avait un rendement moyen de 550 agglomérés par jour, et à Daoudiate le maximum de presses fonctionnant sur le chantier était de 20 . Selon le rapport ${ }^{23}$, il y a eu jusqu'à 17000 briques de terre fabriquées par jour.

La modernisation s'est donc faite à plusieurs niveaux : la préparation et l'organisation $\mathrm{du}$ chantier, la stabilisation avec le ciment, la réalisation mécanique de briques plus performantes, la rapidité de la mise en œuvre, etc. À Daoudiate, ainsi qu'à Berkane en 1969 , le chantier était donc très différent de la construction traditionnelle en terre. D'après Hubert Guillaud, «tendre à la rationalisation de la production de brique crue est une tentative de faire rentrer dans la normalité technique le matériau terre ${ }^{24} »$. Ainsi, pour ces deux projets expérimentaux, la brique de terre crue a été volontairement utilisée comme un matériau de construction moderne (fig. 1). 
Fig. 1. - Le site du projet de Daoudiate (Marrakech, Maroc) en juillet 2017.

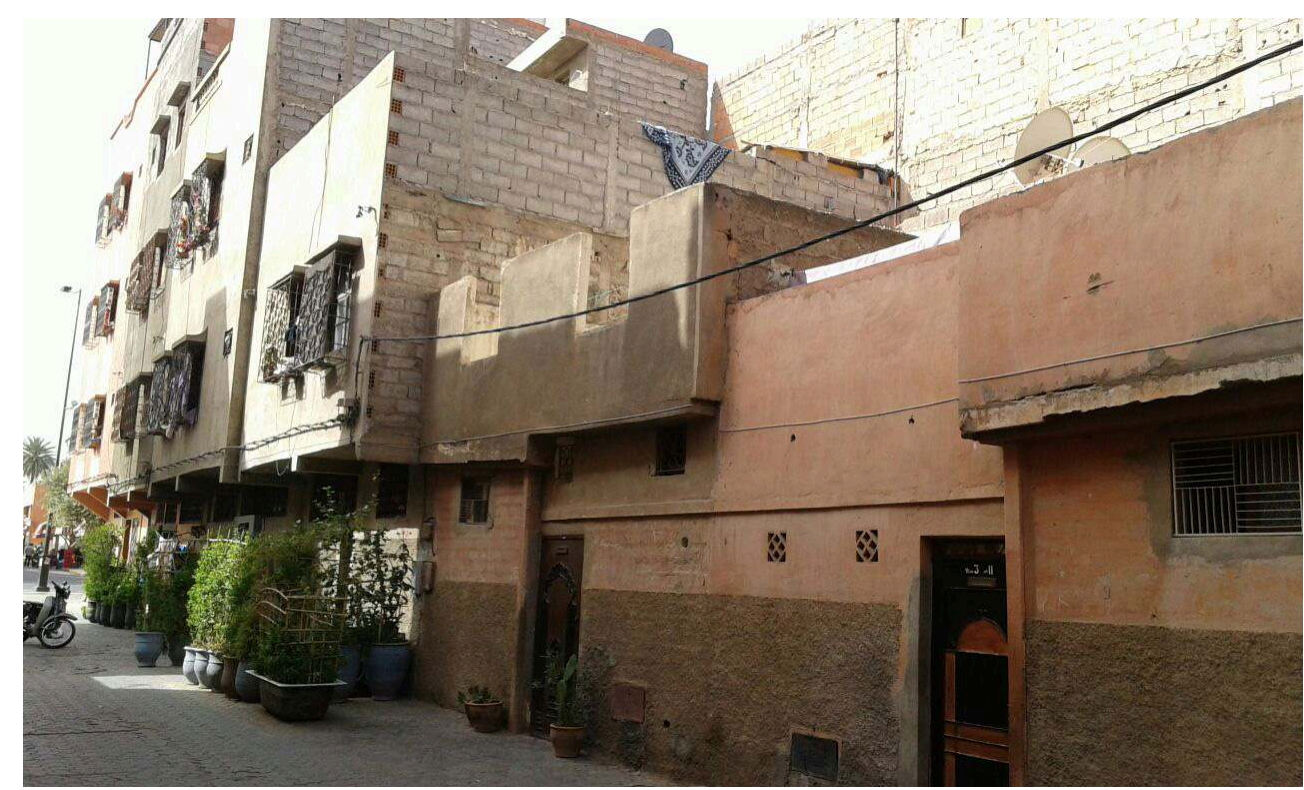

(c) Nadya Rouizem Labied.

\section{La modernisation du pisé}

Le deuxième projet que nous étudions, celui de Ouarzazate, a été réalisé en pisé, la technique de construction en terre crue la plus répandue au Maroc. C'est en piséé que sont réalisés les murs de fortification de la plupart des villes marocaines.

Le procédé constructif traditionnel se fait à l'aide de coffrages en bois appelés banches, constitués de deux panneaux mobiles tenus à l'aide d'entretoises et de tirants. Les ouvriers remplissent le coffrage et compactent la terre, puis se déplacent. "Trois ouvriers font le travail, un dame la terre (le maalem), pendant que les deux autres l'approvisionnent. Le remplissage et le compactage d'une banchée prendront $40 \mathrm{mn}$ environ $^{26}$. » Ainsi l'exécution d'un bâtiment demande plusieurs mois. Pour le projet de Ouarzazate, cette méthode traditionnelle a été modernisée grâce à la réalisation de coffrages métalliques : le montage des coffrages est réalisé le matin, le remplissage en terre et le compactage pneumatique prennent le reste de la journée, et le moule est démonté le lendemain ${ }^{27}$. Le gain de temps est donc considérable, une fois que les coffrages métalliques ont été réalisés. Mais cette méthode constructive n'est pas forcément la meilleure, selon certains spécialistes de la terre.

Dans Construire en terre ${ }^{28}$, l'équipe du CRAterre décrit en quelques lignes la méthode constructive du projet de Ouarzazate pour illustrer une partie du chapitre "Actualisation du pisé ». Le projet est décrit comme une " expérimentation du CERF », réalisée avec un coffrage complet en métal composé d'éléments assemblés manœuvrables à la main, qui a permis de réaliser des murs de faible épaisseur, $25 \mathrm{~cm}$, et une voûte surbaissée de $10 \mathrm{~cm}$ à la clé. Mais pour l'équipe du CRAterre, le coffrage métallique était trop coûteux, et la faible épaisseur des murs ne permettait pas suffisamment d'inertie thermique. Selon cet ouvrage, l'amortissement du coût du coffrage était calculé pour 3000 maisons: l'équipe de conception pensait donc renouveler l'opération de Ouarzazate un grand nombre de fois. Jean Hensens et Alain 
Masson étaient certains de pouvoir continuer à construire beaucoup de logements sociaux en terre, d'où l'investissement important dans les coffrages.

Nous savons également que pour d'autres acteurs de la construction en terre, ce dispositif a été considéré comme une amélioration du projet de Daoudiate, puisqu'il a permis de réduire la quantité de ciment dans la terre et le nombre d'ouvriers spécialisés. Ainsi dans l'article "La terre et le roseau », les auteurs décrivent cette expérimentation comme un succès technique, mais «suite à des circonstances politiques malencontreuses, la conception initiale de ce chantier a été profondément altérée et 8 maisons seulement sur 200 ont été édifiées telles que prévu ${ }^{29}$. "

Les notes contenues dans les archives de Jean Hensens indiquent que "la voûte fut abandonnée pour des raisons d'apparence et d'évolution ultérieure en étage, en cours de chantier. Elle fut remplacée par une dalle terrasse en ciment $\operatorname{armé}^{30}$. " Le style architectural proposé n’a donc pas été bien accueilli, le côté évolutif des logements étant déjà prévu par les autorités.

32 Nous nous sommes rendus en avril 2018 à Ouarzazate pour découvrir que la plupart des logements avaient été démolis par les habitants quelques années après leur réalisation, pour être remplacés par des petits immeubles de deux étages, réalisés en parpaings de ciment (fig. 2). Nous avons également réalisé des entretiens avec les habitants, qui nous ont appris qu'ils n'avaient pas apprécié la conception de leurs logements.

Fig. 2. - Le site du projet de Ouarzazate en avril 2018.

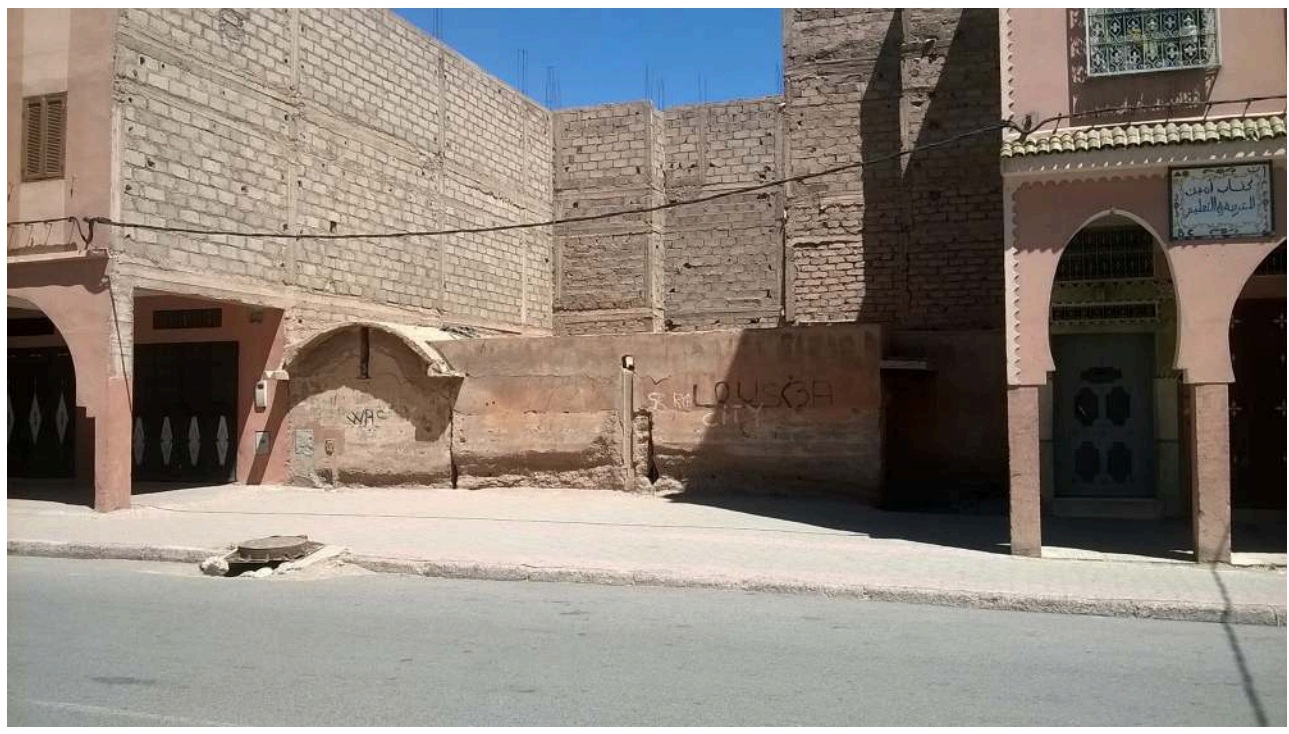

(c) Nadya Rouizem Labied.

Aujourd'hui, on s'intéresse à l'architecture en terre pour les enjeux importants de développement durable, on s'intéresse également à la démarche participative dans la conception de logements économiques suite aux crises sociales. Ces deux savoirs, celui de l'adobe et celui du pisé, issus de l'architecture vernaculaire, ont été réactualisés dans les années 1960 en Afrique par des concepteurs, européens pour la plupart, qui se sont approprié les savoir-faire anciens transmis par la tradition et les ont réinterprétés et adaptés au contexte de crise économique et de crise du logement dans les pays en voie de développement. 

réalité, en idéalisant la profession? Nous avons vu qu'en ce qui concerne le projet de Ouarzazate, les logements n'avaient pas été appréciés par les habitants. Ainsi l'architecte qui se positionne comme le transmetteur d'un savoir traditionnel n'a-t-il pas quelquefois une vision utopique? Notre recherche pourrait ainsi se poursuivre par un questionnement sur la place de l'architecte et les rapports qu'il entretient avec les autres acteurs du projet, en particulier dans un contexte post-colonial.

\section{BIBLIOGRAPHIE}

BAUER Gérard et DETHIER Jean, « La terre et le roseau, ou la réhabilitation et l'amélioration de techniques traditionnelles de construction au Maroc ", L'Architecture d'aujourd'hui, 1972, n 160, p. 104-111.

CHABARD Pierre, «Conversation avec Jean Dethier », Criticat, 2014, $\mathrm{n}^{\circ}$ 13, p. 16-31.

CRATERRE, Construire en terre, Paris, L'Harmattan, 1979.

DETHIER Jean, « 1789-1979, l'art moderne de bâtir en terre crue, une saga initiée en France », D’Architectures, 2017, $\mathrm{n}^{\circ}$ 255, p. 43-71.

DETHIER Jean, « 60 ans d'urbanisme au Maroc », Bulletin économique et social du Maroc, 1973, $\mathrm{n}^{\circ}$ 118-119, p. 13-18.

DETHIER Jean, Architectures de terre, Paris, Centre Pompidou, 1984.

DOAT Patrice, GUILLAUd Hubert, HoubEN Hugo, ROLLET Pascal, « Études raisonnées des architectures en pisé, état du savoir-faire français et étranger actuel ", rapport de recherche, Grenoble, Secrétariat de la recherche architecturale / École nationale supérieure d'architecture de Grenoble / CRAterre, 1985. 
ÉCOLE NATIONALE SUPÉRIEURE D’ARCHITECTURE (GRENOBLE) et INSTITUT DE L'ENVIRONNEMENT, Construction en terre, Paris, Institut de l'environnement, 1975.

ELEB Monique et COHEN Jean-Louis, Casablanca, mythes et figures d'une aventure urbaine, Paris, Hazan, 1998.

HASSAN Fathy, Construire avec le peuple, Paris, Martineau, 1970.

RAGON Michel, Histoire de l'architecture et de l'urbanisme modernes, de Brasilia au post-modernisme, 1940-1991, Paris, Le Seuil (Points. Essais, 233), 1991.

RESENDIZ-VAZQUEZ Aleyda, "L'industrialisation du bâtiment : le cas de la préfabrication dans la construction scolaire en France (1951-1973) », thèse sous la direction de Sabine Barles et André Guillerme, Paris, Conservatoire national des arts et métiers, 2010.

ZERHOUNI Selma, GUILLAUd Hubert, MOUYAL Élie, L'architecture de terre au Maroc, Paris, ACR, 2001.

\section{NOTES}

1. Laboratoire de recherche de l'École supérieure d'architecture de Grenoble, référence mondiale sur l'architecture en terre, créé en 1979.

2. J. Dethier, « 60 ans d'urbanisme au Maroc ».

3. P. Chabard, «Conversation avec Jean Dethier », p. 17.

4. J. Dethier, "1789-1979, l'art moderne de bâtir en terre crue, une saga initiée en France », p. 55.

5. J. Dethier, Architectures de terre, p. 52.

6. En 1973, le CERF est lauréat collectif du prix Abercrombie d'urbanisme, attribué par l'UIA.

7. P. Doat et al., Études raisonnées des architectures en pisé..., p. 293.

8. Ibid.

9. G. Bauer et J. Dethier, «La terre et le roseau, ou la réhabilitation et l'amélioration de techniques traditionnelles de construction au Maroc », p. 104-111.

10. P. Doat et al., Études raisonnées des architectures en pisé..., p. 313.

11. CRAterre, Construire en terre, p. 71.

12. Voir Jeanhensens.free.fr.

13. École d'architecture de Grenoble, Construire en terre, p. 83.

14. Cette hypothèse a été démontrée par de nombreux chercheurs sur l'histoire de l'architecture au Maghreb, dont M. Eleb et J.-L. Cohen dans Casablanca, mythes et figures d'une aventure urbaine.

15. A. Masson, «Mes années de coopération au Maroc: les plus formatrices de ma vie professionnelle ", texte de 6 pages publié sur le site jean.hensens.free.fr, non daté, mais postérieur à 1981, car cette date est mentionnée dans le texte, et antérieur à 2006, année de décès d'A. Masson.

16. Le texte d'A. Masson mentionne 800 logements, mais dans le rapport sur le projet se trouvant aux archives de Jean Hensens à la faculté d'architecture La Cambre de l'université libre de Bruxelles (désormais Arch. LC), la première tranche comprend 700 logements. 
17. S. Zerhouni et al., L'architecture de terre au Maroc.

18. Arch. LC, Jean Hensens, boîte $\mathrm{n}^{\circ} 1$, "Marrakech, résorption de bidonvilles, promotion nationale 1962-1965 ", fol. 1 .

19. M. Ragon, Histoire de l'architecture et de l'urbanisme modernes.

20. A. Resendiz-Vazquez, L'industrialisation du bâtiment : le cas de la préfabrication dans la construction scolaire en France (1951-1973).

21. Arch. LC, Jean Hensens, boîte $\mathrm{n}^{\circ} 1$, «Marrakech, résorption de bidonvilles, promotion nationale 1962-1965 », fol. 1 .

22. Ibid.

23. Ibid.

24. Ibid.

25. Alors que l'adobe est une brique de terre crue moulée dans des cadres, le pisé consiste à couler la terre crue dans des coffrages.

26. CRAterre, Construire en terre, p. 38.

27. G. Bauer et J. Dethier, « La terre et le roseau... », p. 107.

28. CRAterre, Construire en terre, p. 71.

29. G. Bauer et J. Dethier, « La terre et le roseau... », p. 107.

30. Arch. LC, Jean Hensens, boîte $\mathrm{n}^{\circ} 1$, «Marrakech, résorption de bidonvilles, promotion nationale 1962-1965", fol. 3 .

31. F. Hassan, Construire avec le peuple, p. 87.

\section{RÉSUMÉS}

La relance de la filière de construction en terre en France date de la fin des années 1970, mais elle a été précédée par une période encore mal connue, sans laquelle cet essor n'aurait pas eu lieu. $\mathrm{Au}$ Maroc, dès les années 1960, des milliers de logements sociaux en terre ont été réalisés par un ingénieur français et un architecte belge, qui ont modernisé le matériau, l'outillage et l'organisation des chantiers. Nous allons montrer par l'étude de deux sites (Daoudiate, Marrakech, 1962 ; Ouarzazate, 1967) comment les concepteurs européens se sont approprié les savoir-faire anciens transmis par la tradition vernaculaire, et comment ils les ont rationalisés grâce à de nouvelles techniques. Ainsi des coopérants européens ont révélé les savoirs locaux, tout en transmettant leur propre savoir d'industrialisation de la construction, dans le contexte particulier de la décolonisation et de l'émergence de mouvements de retour vers le vernaculaire.

\section{INDEX}

Index géographique : Maroc

Mots-clés : architecture en terre, transfert des techniques, modernisation, expérimentation, adobe, pisé 


\section{AUTEUR}

\section{NADYA ROUIZEM LABIED}

Architecte, doctorante à l'université Paris I - Panthéon-Sorbonne, laboratoire Architecture, urbanisme, société, savoirs, enseignement, recherches (AUSSER, UMR 3329 du CNRS) 


\section{Construire des ponts : un voyage technique à Lyon en 1672 de François Cuenot, ingénieur du duc de Savoie}

\section{Patricia Subirade}

Les ingénieurs jouent $\mathrm{au} \mathrm{XVII}^{\mathrm{e}}$ siècle un rôle majeur dans la transmission des techniques ${ }^{1}$. Le duc de Savoie envoie son ingénieur François Cuenot faire des missions techniques pour contribuer au développement économique de l'État, dans les salines européennes ainsi que, à plusieurs reprises, sur les chantiers urbains de construction de ponts à Paris et à Lyon, où François Cuenot va voir le pont du Rhône, c'est-à-dire le pont de La Guillotière, en $1670^{2}$ et $1672^{3}$ (fig. 1).

Fig. 1. - Le pont du Rhône à Lyon en 1644.

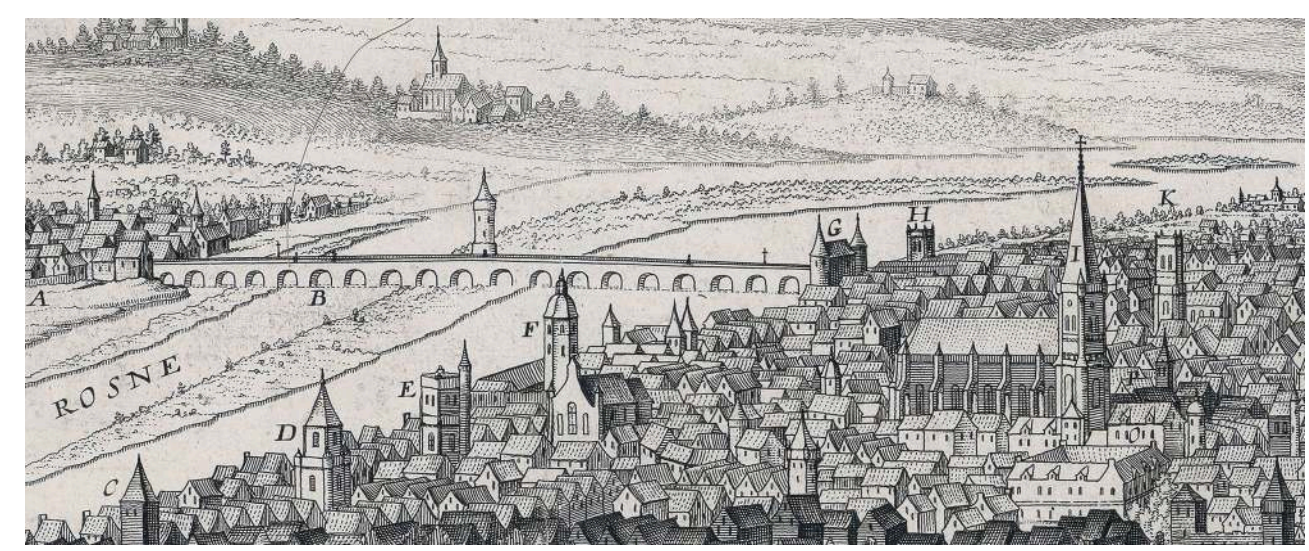

Extrait du plan «La puissante et importante ville de Lion archevesché et metropolitaine des Gaulles », Paris, Jean Boisseau, 1644, BNF, Cartes et plans, GE BB-246 (X, 71-72).

(c) Bibliothèque nationale de France. 
Cette période précède la professionnalisation des ingénieurs du $\mathrm{XVIII}^{\mathrm{e}}$ siècle, liée au corps des ingénieurs des ponts et chaussées français (1716), à l'École des ponts et chaussées $^{4}$ (1747) ou aux académies et sociétés savantes ${ }^{5}$. À l'époque moderne, la mobilité des ingénieurs, au service des princes et des États, reste un moyen essentiel de construction et de diffusion des savoirs techniques ${ }^{6}$. L'approche anthropologique des savoirs montre leur caractère d'entreprise partagée par des communautés de travail, par des groupes, par des acteurs constituant des réseaux ${ }^{7}$. À l'image de la géographie de la science ${ }^{8}$, il est possible d'établir une géographie des techniques inscrivant acteurs et pratiques dans l'espace, à différentes échelles. Pourquoi Cuenot va-t-il chercher dans l'État voisin de la Savoie, à Lyon, des solutions techniques aux problèmes rencontrés sur les chantiers savoyards? Quelle est la géographie des lieux de construction et de communication du savoir technique de l'art des ponts à l'échelle locale urbaine, et comment ce savoir circule-t-il d'un lieu à l'autre ? Les échelles de la ville et du lieu de savoir amènent la focale sur les détenteurs de ces savoirs et à s'interroger sur la pertinence de la notion de trading zone pour désigner ces lieux, ces espaces. Après une présentation de la mission technique dans un premier temps, le second moment sera consacré aux lieux du savoir technique lyonnais, avant l'étude des liens entre savoirs lettrés et savoirs pratiques.

\section{Une mission technique à Lyon pour observer l'art de construire les ponts}

3 Cuenot est envoyé à Lyon pour étudier le chantier du pont du Rhône, dont la construction a été un défi technique à cause des caprices du fleuve, des effets de l'érosion et des crues périodiques. L'étude historique et archéologique de ce pont montre une lacune sur le xvII ${ }^{e}$ siècle 9 , que les observations de Cuenot permettent partiellement de combler.

\section{Un ingénieur au service du duché de Savoie}

4 Le voyage technique est courant à l'époque moderne : les souverains envoient leurs ingénieurs à l'étranger pour acquérir un savoir. Après un démarrage économique raté à la fin du XVI ${ }^{e}$ siècle et au début du XVII ${ }^{e}$ siècle, la Savoie amorce une reprise économique à partir de Victor-Amédée I ${ }^{\text {er }}$ (1630-1637) et surtout sous Charles-Emmanuel II (1638-1675), promouvant une politique routière pour faciliter la circulation sur les axes économiques stratégiques : les routes de Maurienne et de Tarentaise, qui se prolongent vers Lyon à l'ouest et vers l'Italie à l'est, et l'axe nord-sud, du Dauphiné à Genève. Sollicité, Cuenot est envoyé à Lyon par la chambre des comptes de Savoie pour chercher des solutions techniques applicables aux chantiers savoyards et pour voir les «machines dont ils se servent à vider le bastardeau, la façon la plus prompte de les faire tourner, le moien d'establir un batardeau solide et pour battre les vieux, faire les paslées dans le bastardeau et hors d'iceluy le contre bastardeau pour la seureté de l'ouvrage; nous informer aussy de la fondation des empattements des piles ${ }^{10} »$. Le batardeau, ouvrage de protection en bois ou en terre, permet de travailler à l'abri de l'eau et il se vide avec des machines élévatoires. Le battage est l'enfoncement des pieux dans le sol, pour fonder une pile ou mettre en place un batardeau, la difficulté étant d'identifier la nature du sol au fond de la rivière. 
5 La formation de Cuenot dans l'art des ponts nous est totalement inconnue, à une époque où ce savoir, pas encore formalisé, est évoqué dans les grands traités d'architecture : Leon Battista Alberti, Sebastiano Serlio, Andrea Palladio et Vincenze Scamozzi ${ }^{11}$ abordent la fondation des ponts, sa mise au sec, les batardeaux et le battage des pieux. L'art des machines est diffusé par les théâtres de machines circulant dès le $\mathrm{xVI}^{\mathrm{e}}$ siècle, le livre d'Agostino Ramelli paru en $1588^{12}$, possédé par Cuenot, étant le premier manuel de machines imprimé à grande diffusion. Grues, sonnettes pour battre les pieux, machines d'exhaure, norias, sont déclinées dans ces ouvrages ${ }^{13}$. À partir du dernier quart $\mathrm{du} \mathrm{XvII}^{\mathrm{e}}$ siècle, la diffusion des connaissances techniques change, à cause du rôle de l'Académie d'architecture dans la formalisation des normes techniques et de celui de l'Académie des sciences, mais ce savoir n'est pas vraiment compris par les praticiens : le Traité des ponts d'Henri Gautier (1716), premier manuel pratique écrit par un inspecteur général des Ponts et chaussées, très en retard sur les recherches académiques en mécanique, a au contraire une utilité pratique ${ }^{14}$.

\section{La ville de Lyon, lieu d'innovation technique?}

6 La ville de Lyon est un pôle d'expertise et de formation du savoir technique sur les ponts. Avant la venue de Cuenot, la Savoie a déjà fait appel à des entrepreneurs lyonnais. Benoît Daurolles, maître juré de Lyon, entrepreneur en maçonnerie, connu pour son ouvrage de construction de l'hôtel de ville entre 1650 et $1654^{15}$, travaille au pont savoyard d'Étrembières, pour la fondation des piles et la construction de batardeaux, de 1666 à $1668^{16}$. Cuenot est mis en concurrence avec deux « architectes » lyonnais à Fréterive, en 1669 et 1671, Humbert Aynex et Jean-Pierre Cousin ${ }^{17}$, qu'il retrouve à Lyon en $1672^{18}$ (fig. 2). Attesté à Vienne dans la seconde moitié du XVI ${ }^{e}$ siècle et à Mâcon en $1610^{19}$, cet appel aux spécialistes lyonnais de la construction des ponts est ancien. 
Fig. 2. - Dessin des travaux à faire au pont de Fréterive par Humbert Aynex et Jean-Pierre Cousin, 1669.

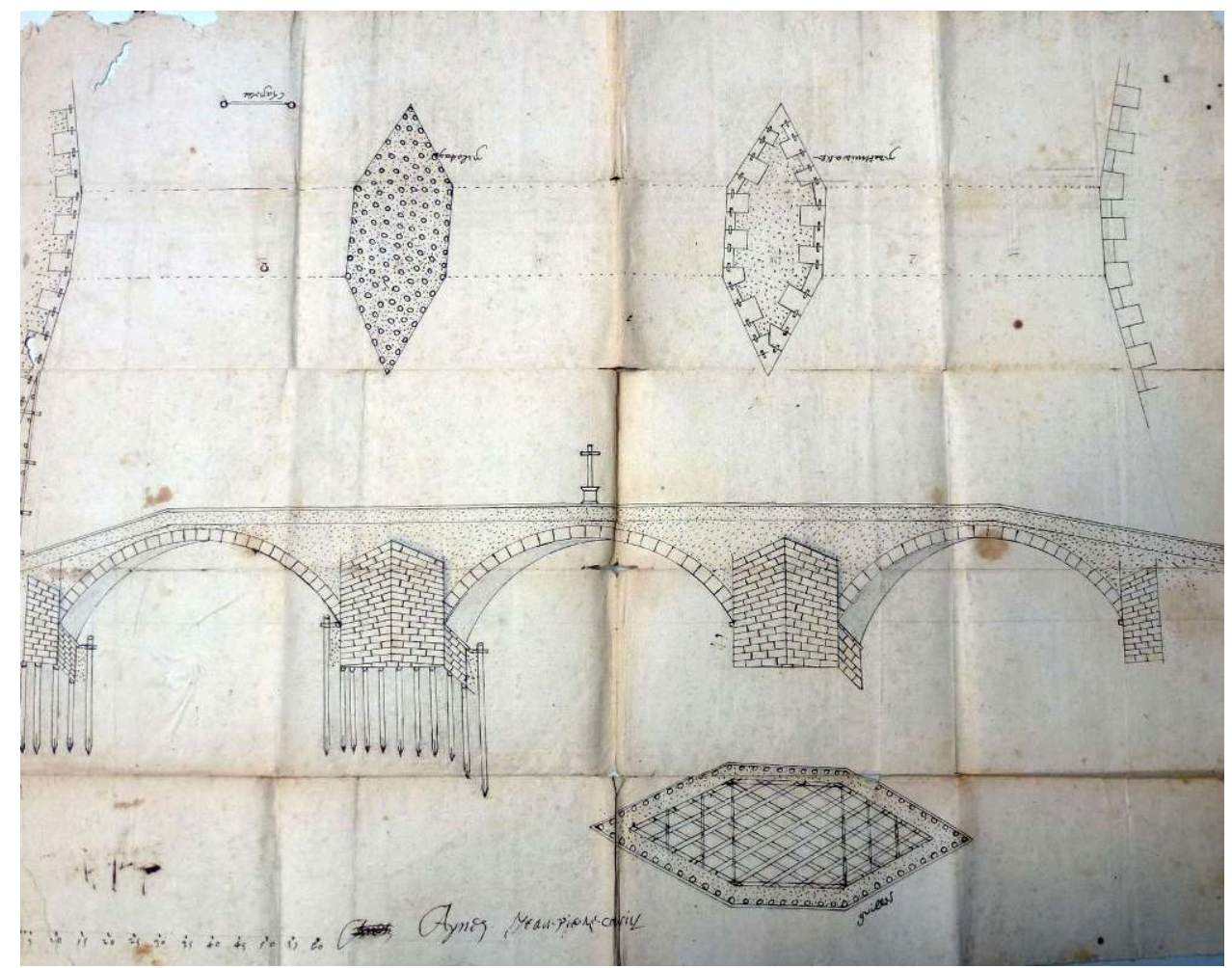

Arch. dép. Savoie, SA 5943.

Cliché Patricia Subirade (D.R.).

7 Ces Lyonnais sont des experts : Daurolles, « un des meilleurs maîtres qui ont travaillé au pont du Rhône ${ }^{20}$ ", possède «beaucoup de connaissances pour les travaux de cette sorte » et de pratique à Lyon, à Pont-Saint-Esprit et ailleurs ${ }^{21}$. L'entrepreneur Villette, dirigeant le chantier du pont du Rhône en 1572, a une "intelligence particulière [...] pour la fabrique des ponts ${ }^{22} »$ L'expert $^{23}$ possède un savoir pratique spécialisé, basé sur son expérience et la compréhension théorique de son activité. Il se distingue socialement des praticiens communs. Sa légitimité provient de l'autorité publique qui lui commande des travaux et de sa communauté de praticiens, maçons, architectes ou ingénieurs. Le lien entre la ville et l'expertise, mis en avant pour les capitales $^{24}$, se confirme pour des villes plus petites comme Lyon, néanmoins au second rang derrière Paris: le Parisien Christophe Marie, constructeur du pont Saint-Louis à Paris (1614-1635), est appelé en 1634 par le consulat lyonnais pour deux ponts de bois sur la Saône ${ }^{25}$.

\section{Les espaces de diffusion lyonnais du savoir technique des ponts}

8 Le voyage de Cuenot permet de dessiner les lieux matériels de savoir ${ }^{26}$, institutionnels ou non, où se déploient les connaissances techniques sur les ponts. 


\section{Le collège jésuite}

9 Cuenot visite en premier le collège jésuite de la Trinité, où il rencontre le jésuite mathématicien Claude-François Milliet de Challes (1621-1678). Lieu scientifique de première importance à Lyon aux XVII ${ }^{e}$ et XVIII ${ }^{e}$ siècles $^{27}$, lieu de sociabilité et de culture à l'échelle européenne de la République des lettres, le collège est l'étape obligée du voyageur érudit: "Une des plus belles singularités de la Ville de Lyon d'aujourd'hui, c'est sans contredit, le College de la Très-Sainte Trinité, où enseignent les RR. PP. Jésuites depuis $1566 "$ selon un voyageur ${ }^{28}$. Parmi les titulaires de la chaire de mathématiques, créée en $1604^{29}$, se comptent Claude Milliet de Challes ou le père de La Chaize (1624-1709) ${ }^{30}$.

10 Le père de Challes appartient à la grande noblesse savoyarde, qui sert l'État notamment dans les deux cours souveraines, le Sénat et la Chambre des comptes ${ }^{31}$. Dans la seconde moitié du XVII ${ }^{e}$ siècle, la gestion des travaux publics est aux mains de celle-ci ${ }^{32}$ et de ses maîtres auditeurs s'entourant d'experts et d'ingénieurs comme Cuenot ${ }^{33}$, qu'accompagne à Lyon l'auditeur César Sarde de Montagny. Ils remettent au jésuite une lettre de son frère François-Amédée (1623-1703), alors sénateur ${ }^{34}$, l'informant de la finalité du voyage. Le mathématicien les accompagne sur le chantier du pont du Rhône, les introduit auprès de Grollier de Servière. Il a enseigné sept ans les mathématiques à Lyon; cet enseignement jésuite des mathématiques englobe les mathématiques pures (arithmétique, géométrie ou algèbre) et les mathématiques appliquées (astronomie, optique, mécanique, hydraulique, art des fortifications et géométrie appliquée, c'est-àdire arpentage et topographie) ${ }^{35}$. Le traité XVI du deuxième tome de son Cursus mathematicus (1674) porte sur les machines hydrauliques ${ }^{36}$ (fig. 3). 
Fig. 3. - Deux méthodes pouvant servir à l'épuisement des batardeaux selon Claude-François Milliet de Challes.

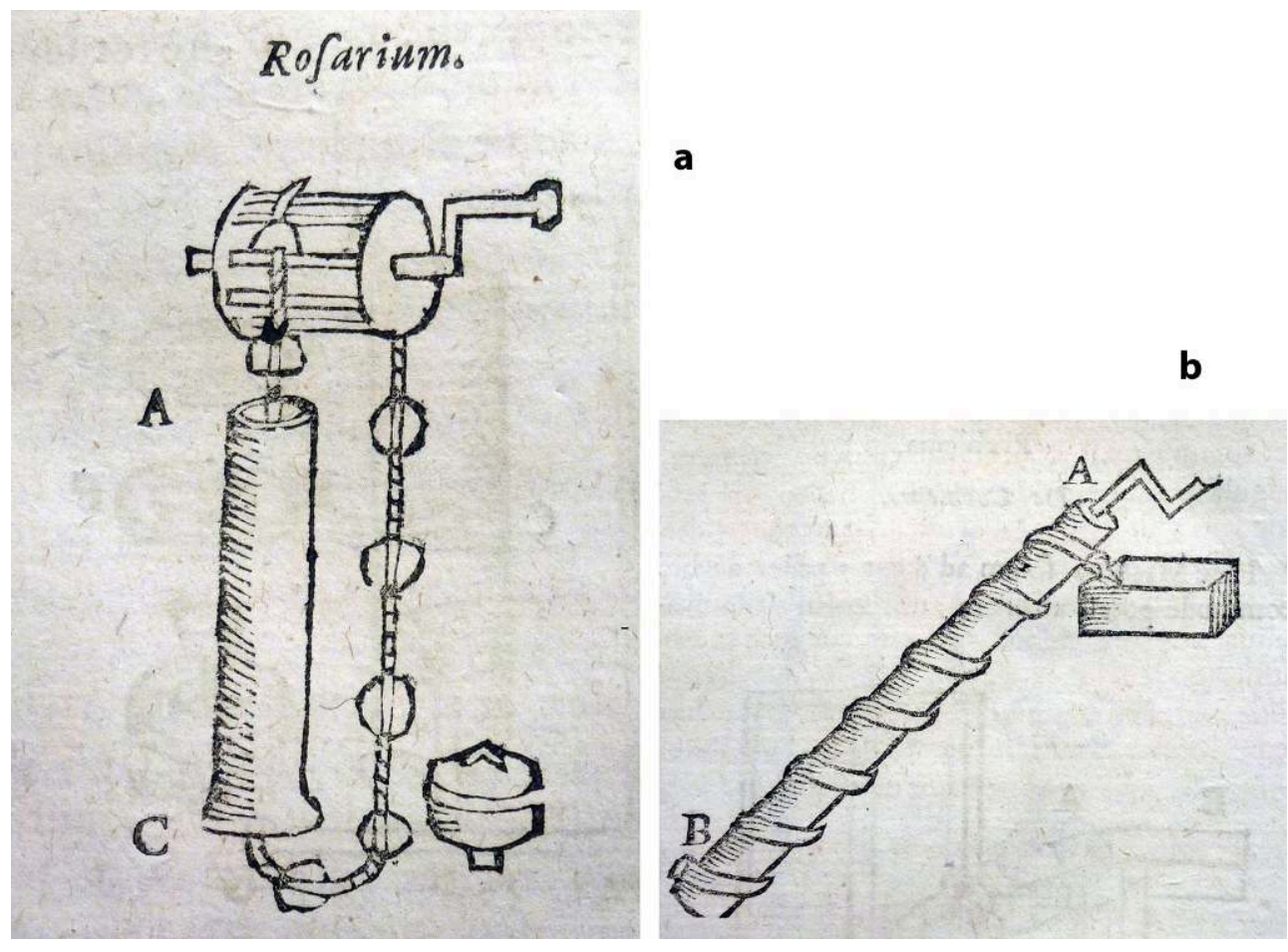

A : Le chapelet. B : La vis d'Archimède. Extraits de Cursus seu Mundus Mathematicus, Lyon, 1690, T. 3, p. 165, Bibliothèque centrale du Conservatoire national des arts et métiers, Pt Fol Py 12 Res. Cliché Patricia Subirade (D.R.).

Soucieux d'utilité pratique, de Challes a traduit en français certains de ses traités, comme l'Art de naviguer démontré par les principes (1677) pour les pilotes, matelots et ceux qui conduisent des bateaux ${ }^{37}$, mais il n'y a pas de traduction pour ses ouvrages théoriques utiles à la construction des ponts.

\section{Le cabinet de curiosités de Grollier de Servière}

Le cabinet de curiosités de Grollier de Servière (1599-1689), un des nombreux collectionneurs lyonnais, a un caractère technique original et constitue un autre lieu de savoir privé et non institutionnel. Les premières collections de la Renaissance ont une fonction cognitive. À partir des années 1540 apparaissent en Italie des jardins botaniques et les premières collections spécialisées dans les productions naturelles, puis dans les années 1560 les Wunderkammern, qui sont le fait des princes et des patriciens ${ }^{38}$. Jacob Spon (1647-1685), médecin et savant lyonnais, a répertorié les cabinets lyonnais remplis de tableaux, estampes, médailles antiques et modernes, curiosités des Indes et statues de bronze ${ }^{39}$. Celui de Nicolas Grollier se distingue par sa renommée et la place faite à la mécanique :

"Quand ie ne dirois mot du Cabinet de Mr de Servières, la renommée le fait assés apprendre aux Etrangers : \& l'empressement qu'ils témoignent tous à le voir, est une preuve de l'estime qu'ils en ont. On y void plusieurs sortes de Montres surprenants, des Ouvrages de Tour tres-delicats, \& des Machines de guerre fort singulières ; enfin presque tout ce que peut faire la Mathématique Mécanique ${ }^{40}$. » 

propriétaire ${ }^{41}$. Le cabinet Grollier est celui d'un ingénieur. Animé dès son jeune âge par « un génie naturel pour les mathématiques, une adresse merveilleuse et un goût décidé pour les armes $^{42}$ ", il mène une carrière militaire aux Provinces-Unies, visitant fortifications, digues, canaux et ports de mer, perfectionnant ses talents notamment en matière hydraulique, levant «les plans de touttes les machines qui lui parurent nouvelles ou singulières ${ }^{43}$ ». Il se retire à Lyon vers 1650 et «s'y occupa le reste de ses jours a inventer et a executer lui-même mes ouvrages de mechanique qui composent son cabinet » : machines de guerre, tours en ivoire et horloges ${ }^{44}$. Il conseille Colbert et Le Tellier sur les nouvelles machines et sur les travaux publics ${ }^{45}$. Colbert lui confie la direction des réparations du pont sur le Rhône à Lyon, en dessaisissant les entrepreneurs qui en étaient en charge ${ }^{46}$. Le ministre s'appuie sur des commis responsables d'une ou plusieurs généralités ou occasionnels, qui sont des techniciens éprouvés, ingénieurs et architectes ${ }^{47}$. Grollier, qui n'est pas ingénieur du roi, est un commis occasionnel atypique qui doit à « l'estime que l'on conserva [à la cour du roi de France] de ses vertus et de ses talens » d'être sollicité. Et il entreprend la construction d'un bardeau qui semble impossible à faire :

«Il ne falloit pas moins que des lumieres aussy supérieures que les siennes pour oser les entreprendre puisqu'il s'agissoit de faire un batardeau dans un endroit ou il paroissoit etre impraticable, et a la place deux arcades ruinées de n'en faire qu'une seule d'une grandeur qu'on trouvoit demesurée ${ }^{48}$. »

Cette connaissance technique des batardeaux rencontre l'objet de la mission lyonnaise de Cuenot ${ }^{49}$.

Les cabinets de curiosités ont une place essentielle dans l'économie des savoirs. Cuenot observe chez Grollier les « curiosités [...] et notemment les diverses machines qu'il avoit pour battre promptement les pieux [...] diverses autres machines pour enlever les eaux et fabriquer les batardeaux ${ }^{50}$ ». Selon un religieux augustin, le cabinet se divise en plusieurs pièces, le cabinet d'en haut avec des machines et le cabinet du dessous présentant des tours, comme la figure d'un mort sortant d'une porte, et contenant sept ou huit cabinets au sens de placards qui s'ouvrent par des mécanismes sur « quantité de jolies petites curiosités ${ }^{51}$ ». La description du cabinet de 1719 par le petit-fils de Nicolas, Gaspard II Grollier, même si elle ne reflète pas l'état de la collection à la mort de son propriétaire, car son fils Gaspard I l'a complétée ${ }^{52}$, présente dans sa troisième partie les machines de mécanique ${ }^{53}$, par exemple pour vider un batardeau avec des chapelets (fig. 3a) ou avec une vis d'Archimède (fig. 3b), pour battre le mouton. Ces planches seraient des reproductions des propres dessins de Nicolas, vus en 1665 par le naturaliste anglais Philip Skippon, selon qui le collectionneur « hath described [machines] with his pen, and bound them up together in a thick folio ${ }^{54} »$. Si les autres visiteurs se laissent séduire par les «magneticall tricks ${ }^{55}$ ", « un espece d'enchantement » et le "monde de Fées ${ }^{56}$ ", la présentation de ses enfants cachés derrière un rideau à Louis XIV en 1658, Cuenot, peu sensible à cette culture de la curiosité valorisant le merveilleux, se concentre sur les machines « qui peuvent servir aux fabriques des rivières ".

L'usage que fait François Cuenot du cabinet est professionnel: «nous avons faict le possible pour remarquer touttes les particularités des dites machines, pour pouvoir servir en temps et lieu ». Il décrit par exemple une machine à battre promptement grâce à une pompe et à une roue à eau ${ }^{57}$, très probablement la « Machine pour battre le mouton au moien du courant d'une rivière » du recueil de Gaspard ${ }^{58}$ (fig. 4). Il regrette 
de ne pouvoir prendre des notes, le manque de «raisonnement» avec Grollier, le manque de temps octroyé pour observer les machines.

Fig. 4. - « Machine pour battre le mouton au moien du courant d'une rivière ».

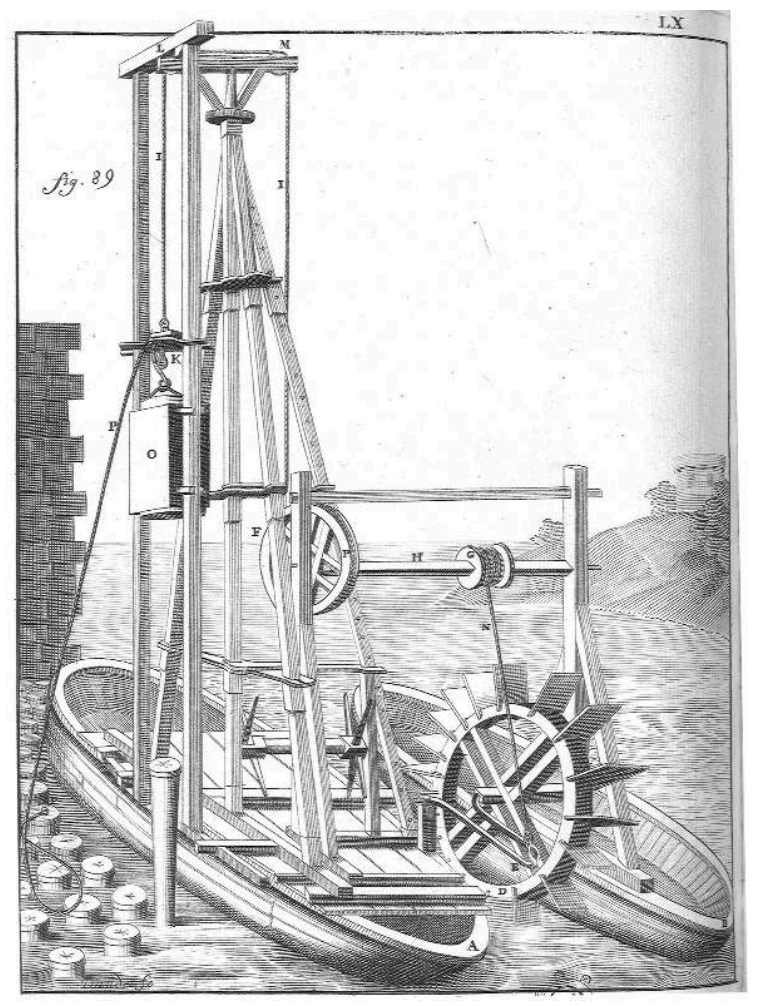

Extrait de M. Grollier de Servière, Recueil d'ouvrages curieux de mathématique et de mécanique, ou

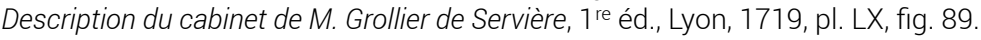

(C) CNUM - Conservatoire numérique des arts et métiers - http://cnum.cnam.fr.

17 François Cuenot réfléchit à l'utilisation pratique des machines et conclut en visitant le chantier du pont du Rhône qu' « elles estoient sans doute bien industrieuses mais qu'il n'y avait pas grande apparence qu'elles puissent servir utilement estant mises en grand volume ». Ce souci de l'utilité pratique se situe au tournant précurseur de la fin du XVII ${ }^{\mathrm{e}}$ siècle, annonciateur de la réflexion sur l'usage des arts mécaniques au $\mathrm{XvIII}^{\mathrm{e}}$ siècle et de la technologie, qui est un enseignement systématique des principes sous-tendant la pratique des arts et des activités artisanales ${ }^{59}$. Les racines de cette préoccupation sont déjà au cœur de l'expertise moderne de l'Angleterre du XVI siècle, où les experts en recherche de légitimité insistent sur la dimension pratique de leur travail ${ }^{60}$. Le savoir utile, qui selon Joël Mokyr a une application pour les vies humaines, les artefacts, l'énergie ${ }^{61}$, résulte au xvIII ${ }^{e}$ siècle de la diffusion d'une méthode scientifique, d'une mentalité scientifique et d'une culture scientifique ${ }^{62}$. Néanmoins, à la fin du XVII siècle, les collections mécaniques analogues à celles de Grollier sont encore rares ${ }^{63}$.

Le collectionneur lyonnais Balthazar de Moncony visite en 1663 à Cassel celle de Brostrup de Schort, juxtaposant aussi ouvrages de tour et machines, par exemple à élever les eaux ${ }^{64}$. L'exposition de machines parisienne de Jean-Baptiste $\operatorname{Picot}^{65}$ ou la commande d'un traité de mécanique décrivant les machines utiles aux arts et métiers faite par Colbert à l'Académie des sciences en $1675^{66}$, s'inscrivent aussi dans ce changement. 


\section{Les chantiers du Rhône}

19 L'essentiel de la visite de 1672 se déroule sur les chantiers du Rhône, en juin. Sur ce type de chantier, le travail s'effectue dans les mois chauds coïncidant avec les périodes de basses eaux. En raison de ces aléas techniques, il s'étale sur plusieurs années, chaque année étant consacrée par exemple à la construction ou la réparation d'une pile ${ }^{67}$. Le pont du Rhône, reconstruit une première fois en pierre en 1560, en partie emporté par une crue en décembre 1570, est réédifié entre 1579 et 1581. L'aggravation des conditions climatiques influant sur le régime du Rhône au XVII ${ }^{e}$ siècle, les réparations ponctuelles se multiplient sur les piles jusqu'à une campagne de travaux plus importants en 1718-1721 $1^{68}$ : c'est un de ces chantiers de réparation que visite Cuenot.

20 Après la visite de l'atelier de Bellecour pour voir "quelques machines inutiles, des platteaux, des testes de pilots et autres bois », il va sur le chantier du pont s'entretenir avec les entrepreneurs : la transmission du savoir technique est orale. Il se renseigne aussi sur les conditions juridiques et économiques du travail. Les quatre entrepreneurs reçoivent 40000 livres pour la construction des batardeaux, doivent fournir et faire tourner les machines. Ayant emprunté chacun 2000 à 3000 livres pour débuter le travail, ils «auront de la peyne de trouver leur compte quand la besogne sera parachevée ». Le terme d'" entrepreneur ", nouveau sous Colbert, désigne le titulaire du marché d'ouvrage qui est, maçon ou charpentier, issu de l'artisanat de la construction $^{69}$. La visite des fondations des remparts le long du Rhône complète la visite de Cuenot $^{70}$.

\section{Les chantiers lyonnais de construction des ponts, des trading zones?}

21 Le concept de trading zone appliqué aux lieux de production et de partage de savoirs entre artisans et praticiens ${ }^{71}$ est une clef de lecture des chantiers lyonnais de construction des ponts. L'humanisme a remis en cause la séparation médiévale entre lieux artisanaux et lieux lettrés, encourageant à rechercher le savoir à la fois dans l'étude et dans les ateliers: Juan Luis Vivens encourage les étudiants à résoudre des problèmes pratiques concernant le tissage, la navigation et l'agriculture; Thomas More, dans Utopia (1515), donne à chaque citoyen une responsabilité en matière d'agriculture et d'artisanat, quels que soient son statut social ou son éducation ${ }^{72}$. En Europe, aux $\mathrm{XVI}^{\mathrm{e}}$ et $\mathrm{XVII}^{\mathrm{e}}$ siècles, arsenaux et cours princières, ou magasins d'instruments à Londres au XVIII ${ }^{\mathrm{e}}$ siècle, permettent la rencontre entre praticiens et savants : ces lieux fonctionnent des trading zones selon les circonstances et des critères précis $^{73}$.

\section{Un investissement public}

Le premier critère est l'intérêt des élites et le fort investissement princier ou étatique. $\mathrm{Si}$, techniquement, la construction d'un pont sur le Rhône est difficile en raison des lônes (bras de rivière) à la confluence avec la Saône et d'îles instables ${ }^{74}$, la traversée du fleuve est stratégique : sa "conservation est importante non seulement pour la commodité des habitants de la dite ville, mais pour le commerce d'Italie, Allemagne, 
Suisse et des provinces de Languedoc, Provence ${ }^{75} »$. La construction des ponts est d'abord une affaire municipale : à partir de l'édit du roi Henri II de 1549, le Consulat nomme un voyer, qui assure avec les maîtres maçons et les charpentiers les visites d'expertise pour les travaux publics de la ville. Ces voyers manquent des connaissances techniques nécessaires, raison pour laquelle la ville fait appel à des architectes extérieurs ${ }^{76}$. Dès la fin du Xvi ${ }^{\mathrm{e}}$ siècle, le recours à l'ingénieur du roi devient courant, par exemple en 1579 pour le pont du Rhône ${ }^{77}$. En 1635-1636, le conseil du roi intervient pour le chantier du pont sur la Saône ${ }^{78}$. En 1672, le roi participe financièrement à la réparation du pont du Rhône, fournit les pilotis et la pierre de l'assisse d'une des piles, le chantier étant supervisé par un trésorier de France ${ }^{79}$. À partir de la fin du XVII siècle, l'administration royale contrôle entièrement les travaux du pont du Rhône ${ }^{80}$ : en 1687, l'ingénieur Mathieu travaille sous le contrôle du commissaire départi de la généralité de Lyon $^{81}$.

\section{De nouvelles technologies}

La trading zone est aussi le lieu d'innovations technologiques, par exemple l'invention de machines hydrauliques dans les mines ou sur les chantiers de ponts. Si les grands chantiers parisiens et lyonnais sont des lieux d'expérimentation technique à partir de 1665 avec Colbert, il faut attendre le xviII ${ }^{e}$ siècle pour voir de réelles avancées technologiques dans l'art de bâtir les ponts. Les modes de transmission des connaissances évoluent dans le dernier quart $\mathrm{du} \mathrm{xvII}^{\mathrm{e}}$ siècle, mais architectes et ingénieurs restent prisonniers de recettes de terrain et de formules empiriques.

\section{Des pratiques de mise en écriture et en dessin}

La trading zone est également liée à l'écrit et au dessin. Le procès-verbal de la visite détaillant les machines, leurs éléments, matériaux, rouages, fonctionnement, force motrice animale ou humaine, examinés "avec toutte l'exactitude possible», est accompagné de dessins de machines. La machine à décocher utilisée pour planter les pieux du pontet est actionnée par une roue tournée par quatre hommes. La « machine propre à enlever quantité d'eau ", mue par deux chevaux, est une signole, déjà vue en 1670 par Cuenot aux salines de Salins, en Franche-Comté ${ }^{82}$. L'hydraulique sert l'ingénieur dans diverses tâches : pour vider un batardeau ou exhaurer les mines, gérer les eaux salées et les eaux douces dans les salines. Le troisième dessin représente un treuil pour charger marchandises, pierres ou autres matières d'un bateau au bord de la rivière, et le plan de fondation du quai du Rhône, montrant les pilotis.

Le dessin technique, essentiel dans la pratique de l'ingénieur à l'époque moderne, est tracé par des techniciens dans un but professionnel. Né sur les chantiers des cathédrales gothiques, utilisé à partir du milieu du $\mathrm{Xv}^{\mathrm{e}}$ siècle pour les constructions civiles, il montre moulins, dispositifs de levage, pompes et machines à élever les eaux par exemple ${ }^{83}$. Ses usages sont multiples. Par le dessin, Cuenot fixe visuellement un savoir, le transmet et le fait appliquer :

«J'avertis l'ouvrier qui la [la machine à élever l'eau] fabriquera qu'il faut observer tant à celle-ci qu'à toute autre que les rouages des lanternes et fuseaux soient de grandeur proportionnée à l'élévation de l'eau et à la charge de la profondeur ${ }^{84}$. " 
Fig. 5. - « Dessin d'une machine propre à enlever quantité d'eau », Lyon, François Cuenot, 1672.

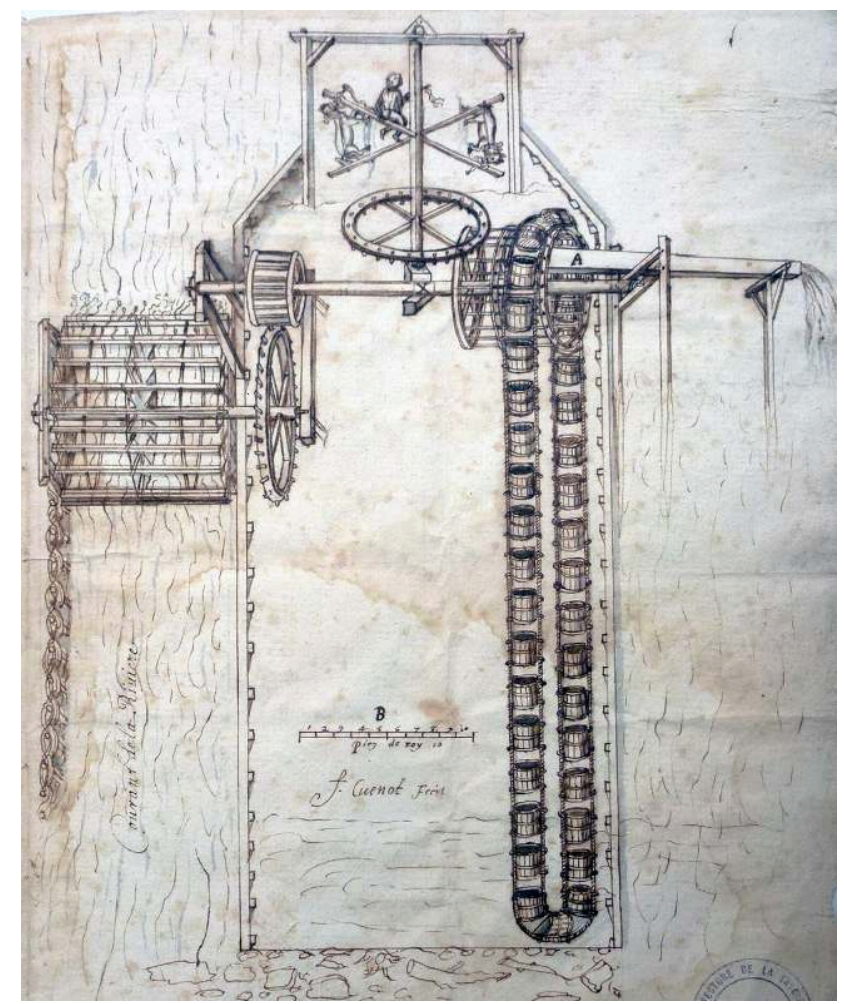

Arch. dép. Savoie, SA 6098.

Cliché Patricia Subirade (D.R.).

\section{Le contact entre savants et praticiens}

La trading zone est un lieu d'échanges entre artisans / praticiens et érudits passés par les universités, connaissant le latin, qui tous ont une véritable volonté de partage de leur savoir $^{85}$ par l'oral et par la discussion ${ }^{86}$. Le père de Challes, mathématicien, accompagne Cuenot dans ses visites, qui se terminent par un entretien : "Nous avons raisonné de tout ce qu'avons remarqué et qui pouvoir se mettre en pratique ${ }^{87}$ ». Plusieurs niveaux de savoir ${ }^{88}$ sont mis en relation : le savoir pratique; le savoir de l'entrepreneur et de l'ingénieur ; le savoir le plus abstrait, conceptuel et mathématique. Aux côtés du jésuite se côtoient à Lyon artisans et praticiens ${ }^{89}$, tels l'ingénieur Cuenot ou le commis et entrepreneur Villette, guidant les visiteurs sur le chantier du pont du Rhône : "Nous eusmes aussi conference avec le nommé Villette [...] en présence du Rd Père Dechalles ${ }^{90}$ ». Il y a aussi d'autres entrepreneurs de Lyon, Humbert Aisné et Jean-Pierre Cousin, ou de Seyssel, Renaud, dont nous ne savons pas s'ils sont des charpentiers ou des maçons. Grollier opère la même opération intellectuelle : mathématicien, dirigeant en 1658 les réparations du pont du Rhône, il effectue une codification d'un savoir pratique par la construction de ses machines: machines, instruments mathématiques, traités participent à la codification du savoir pratique ${ }^{91}$. 
L'approche anthropologique des savoirs, qui sont des entreprises partagées, permet de jouer sur les échelles. Elle met en lumière des réseaux où circulent les acteurs, comme les ingénieurs, et la position de centralité des villes qui concentrent les experts: les meilleurs spécialistes de la construction des ponts sont à Paris, Lyon arrivant en seconde position. À l'échelle de la ville, le savoir technique circule entre lieux institutionnels ou non, et certains de ces lieux peuvent fonctionner comme des trading zones selon les circonstances. Les pratiques associées à la circulation du savoir à une époque antérieure à la professionnalisation des ingénieurs sont la mission technique, ordonnée ici par le duc de Savoie dans le cadre d'une relation de patronage technique, permettant l'observation de terrain, mais aussi la production d'artefacts, textes écrits, dessins, qui pour l'ingénieur sont des vecteurs essentiels du savoir-faire.

\section{BIBLIOGRAPHIE}

ASH Eric, « Expertise and the Early Modern State », Osiris, 2010, vol. 25, nº 1, p. 1-24.

ASH Eric (éd.), Expertise: practical knowledge and the early modern state, Chicago, University of Chicago Press, 2010.

BERTUCCI Paola, Artisanal enlightenment: science and the mechanical arts in old regime France, New Haven, Yale University Press, 2017.

BIREMBAUT Arthur, «L'exposition de modèles de machines à Paris, en 1683 », Revue d'histoire des sciences, $1967, \mathrm{n}^{\circ} 2, \mathrm{p} .141-158$.

BLOND Stéphane, PÉREZ Liliane, VIROL Michèle (dir.), Mobilités d'ingénieurs en Europe, XVe-XVIII ${ }^{e}$ siècle : mélanges en l'honneur d'Hélène Vérin, Rennes, Presses universitaires de Rennes, 2017.

BURNOUF Joëlle, GUILHOT Jean-Olivier, MANDY Marie-Odile, ORCEL Christian, Le pont de La Guillotière : franchir le Rhône à Lyon, Lyon, Circonscription des antiquités historiques, 1991.

CHATELAIN Abel, « Les ponts du Rhône : étude de géographie humaine », Revue de géographie régionale, 1944, vol. 19, n³ 3-4, p. 109-139.

DAINVILLE François de, «L'enseignement des mathématiques dans les collèges jésuites de France du XVI ${ }^{\mathrm{e}}$ au XVIII ${ }^{\mathrm{e}}$ siècle ", Revue d'histoire des sciences, 1954, vol. 7, nº 1, p. 6-21 et nº 2, p. 109-123.

DELATTRE Pierre, Les établissements des Jésuites en France depuis quatre siècles, t. II : Danmartin-Lyon, Enghien, Institut supérieur de théologie, 1953.

GROLLIER DE SERVIÈRE Gaspard, Recueil d'ouvrages curieux de mathématique et de mécanique, ou Description du cabinet de M. Grollier de Servière, avec des figures en taille douce, Lyon, D. Forey, 1719. JACOB Christian, «Introduction : faire corps, faire lieu », dans Jacob Christian (dir.), Lieux de savoir : espaces et communautés, Paris, Albin Michel, 2007, p. 17-40.

JАСов Christian, Qu'est-ce qu'un lieu de savoir ?, Marseille, Open edition press, 2014.

LEFÈVRE Wolfgang, Picturing machines, 1400-1700, Cambridge / Londres, MIT Press, 2004. 
LEMONNIER Henry, Procès-verbaux de l'Académie royale d'architecture, 1671-1793, t. I : 1671-1681, Paris, J. Schemit, 1911.

LIGNEREUX Yann, « Franchir la Saône à Lyon au milieu du XVII ${ }^{\mathrm{e}}$ siècle : enjeux critiques d'un chantier urbain ", Revue historique, 2009, n 652, p. 805-829.

LIGNEREUX Yann, « L'éloquence des lieux : le pont de Saône à Lyon en 1635 », Histoire urbaine, 2001, $\mathrm{n}^{\circ}$ 3, p. 103-117.

LIVINGSTONE David, Putting science in its place: geographies of scientific knowledge, Chicago, University of Chicago Press, 2003.

LOCKE John, Locke's travels in France, 1675-1679: as related in his Journals, correspondence and other papers, Cambridge, Cambridge University Press, 1953.

LONG Pamela Olivia, Artisan, practitioners and the rise of the new sciences, 1400-1600, Corvallis, Oregon State University Press, 2011.

LONG Pamela Olivia, « Trading zones in early modern Europe », Isis, 2015, vol. 106, n 4, p. 840-847. MARTENS Pieter et VAN DE VIJVER Dirk, « Engineers and the circulation of knowledge in the Spanish Netherlands ", dans Dupré Sven, Werner Thomas, De Munck Bert, Vanpaemel Geert (dir.), Embattled Territory: the circulation of knowledge in the Spanish Netherlands, Gand, Academia Press, 2015, p. 73-106.

MESQUI Jean, Le pont en France avant le temps des ingénieurs, Paris, Picard, 1986.

MILLIET DE CHALLES Claude-François, L'art de naviguer demontré par principes, \& confirmé par plusieurs observations tirées de l'experience, Paris, Estienne Michallet, 1677.

MILLIET DE CHALLES Claude-François, Cursus seu mundus mathematicus, Lyon, Anisso, Joan Possuel et Claude Rigauc, 1690.

MOKYR Joel, The gifts of Athena: historical origins of the knowledge economy, Princeton / Oxford, Princeton University Press, 2002.

MONCONYS Balthasar de, Voyages de mr. de Monconys, conseiller du roi, \& lieutenant criminel au siege presidial de Lyon, Paris, Pierre Delaulne, 1695.

NICOLAS Jean, La Savoie au XVIII ${ }^{e}$ siècle : noblesse et bourgeoisie en Savoie au XVIII ${ }^{e}$ siècle. T. I : Situations au temps de Victor-Amédée II ; T. II : Inflexions au siècle des Lumières, Paris, Librairie de la nouvelle faculté, 1976.

OLMI Giuseppe, « Science-honour metaphor: Italian cabinets of the sixteenth and seventeenth centuries ", dans Impey Olivier et MacGregor Arthur (dir.), The origins of museums: the cabinet of curiosities in sixteenth and seventeenth-century Europe, Oxford, Clarendon Press, 1985, p. 5-16.

PAUTET Sébastien, « Les ingénieurs à l'époque moderne », dans Hilaire-Pérez Liliane, Simon Fabien, Thébaud-Sorger Marie (dir.), L'Europe des sciences et des techniques, XV'-XVIII ${ }^{e}$ siècle, Rennes, Presses universitaires de Rennes, 2016, p. 111-121.

PÉREZ Marie-Félicie et GUILLEMIN Jean, « Curieux et collectionneurs à Lyon d'après le texte de Spon (1673) », dans Roland Étienne et Mossière Jean-Claude (dir.), Jacob Spon : un humaniste lyonnais du XVII ${ }^{e}$ siècle, Lyon, Bibliothèque Salomon-Reinach, 1993, p. 39-50.

PERRILLAT Laurent, «L'administration des Ponts et chaussées en Savoie sous l'Ancien Régime ( $\mathrm{XVI}^{\mathrm{e}}$ XVIII ${ }^{e}$ siècles) ", dans Échanges et voyages en Savoie, actes du XL $L^{e}$ Congrès des sociétés savantes de Savoie 
(2004, Saint-Jean-de-Maurienne), Chambéry, Société savoisienne d'histoire et d'archéologie, $\mathrm{p}$. 191-216.

PICON Antoine, L'invention de l'ingénieur moderne : l'École des ponts et chaussées, 1747-1851, Paris, Presses de l'École nationale des ponts et chaussées, 1992.

PICOT Jean-Baptiste, Explication des modèles des machines et forces mouvantes que l'on expose à Paris dans la rue de la Harpe, vis-à-vis Saint Cosme, Paris, C. Guillery, 1683.

POMIAN Krzysztof, «La Wunderkammer entre trésor et collection particulière », dans Martin Pierre, Marrache-Gouraud Myriam, Moncond'huy Dominique, Garcia Géraldine (dir.), La licorne et le bézoard : histoire des cabinets de curiosités, Montreuil, Gourcuff Gradenigo, 2013, p. 17-27.

RABUT François, « Histoire généalogique de l'illustre maison Millet (de Chambéri) par M. Besson, curé de Chapeiri, avec une notice sur Besson ", Mémoires et documents publiés par la Société savoisienne d'histoire et d'archéologie, 1864, nº 8, p. 147-205.

ROBERT Etienne et MOSSIÈRE Jean-Claude (éd.), Jacob Spon : un humaniste lyonnais du XVII siècle, Lyon, Bibliothèque Salomon Reinach, p. 31-37 et 39-50.

ROUVIÈRE Henri de, Voyage du tour de la France, Paris, Ganeau, 1713.

SKIPPON Philip, « An account of a journey made thro' part of the Low-Countries, Germany, Italy and France ", dans Churchill Awnsham et John Churchill (éd.), A collection of voyages and travels: some now first printed from original manuscripts, Londres, 1732, p. 359-736.

SPON Jacob, Recherche des antiquités et curiosités de la ville de Lyon, ancienne colonie des Romains \& capitale de la Gaule celtique, Avec un Mémoire des principaux antiquaires \& curieux de l'Europe, Lyon, Jacques Faeton, 1673.

TURNER Anthony, « Grollier de Servière, the brothers Monconys: curiosity and collecting in seventeenth-century Lyon », Journal of the History of Collections, 2008, n 20, p. 205215.

VALLERIANI Matteo (dir.), The structures of practical knowledge, Cham, Springer, 2017.

VAN DAMME Stéphane, «Expertise in capital cities », dans Rabier Christelle (dir.), Fields of expertise: a comparative history of expert procedures in Paris and London, 1600 to present, Newcastle, Cambridge scholars publishing, 2007, p. XI-XVIII.

VAN DAMME Stéphane, "Sociabilité et culture urbaines : le rôle du collège de la Trinité à Lyon (1640-1730) », Histoire de l'éducation, 2001, n 90, p. 79-100.

VAN DAMME Stéphane, Le temple de la sagesse : savoirs, écriture et sociabilité urbaine, Lyon, XVII ${ }^{e}$-XVIII siècles, Paris, École des hautes études en sciences sociales, 2005.

VÉRIN Hélène, « La technologie : science autonome ou science intermédiaire ? ", Documents pour l'histoire des techniques, 2007, $\mathrm{n}^{\circ}$ 14, 2 ${ }^{\mathrm{e}}$ semestre, p. 134143.

VIAL Eugène, « Les voyers de la ville de Lyon », Revue d'histoire de Lyon, 1911, vol. 10, p. 180-197.

\section{NOTES}

1. S. Blond et al. (dir.), Mobilités d'ingénieurs en Europe, $X V^{e}-X V I I I^{e}$ siècle..., p. 11-25.

2. Arch. dép. Savoie, SA 6293, « Procès-verbal (désormais PV) de la visite à Paris ».

3. Arch. dép. Savoie, SA 6098.

4. A. Picon, L'invention de l'ingénieur moderne : l'École des ponts et chaussées, 1747-1851. 
5. S. Pautet, « Les ingénieurs à l'époque moderne ».

6. Ibid. ; P. Martens et D. Van de Vijver, « Engineers and the circulation of knowledge in the Spanish Netherlands », p. 455.

7. C. Jacob, «Introduction : faire corps, faire lieu ».

8. D. N. Livingstone, Putting science in its place: geographies of scientific knowledge.

9. J. Burnouf et al., Le Pont de La Guillotière: franchir le Rhône à Lyon.

10. Arch. dép. Savoie, SA 6098, fol. 1.

11. L. Battista Alberti, De re aedificatoria (1485); S. Serlio, Sette libri dell'architettura (1537); A. Palladio, I Quattro Libri dell'Architettura (1570); V.Scamozzi, L'idea della architettura universale (1615).

12. A. Ramelli, Le Diverse et artificiose machine del capitano Agostino Ramelli dal ponte della Tresia... Nelle quali si contengono varii et industriosi movimenti... composte in lingua italiana et francese (1588).

13. J. Mesqui, Le pont en France avant le temps des ingénieurs, p. 163.

14. Ibid., p. 162-165.

15. Arch. mun. Lyon, B 199, « Registre des actes consulaires », 1645, fol. 45.

16. Arch. dép. Savoie, SA 5949 à SA 5956, SA 5971, SA 5972 ; Arch. Ét. Turin, Lettres de particuliers, Milliet de Challes, 28 septembre 1666, 10, 22 et 30 décembre 1666, 11 mars 1667, 30 juillet 1667.

17. Arch. dép. Savoie, SA 5976, «PV de visite du pont d'Étrembières », 15 février 1669 ; SA 5977 « Mémoire plan des travaux du pont d'Étrembières », 16 février 1669.

18. Arch. dép. Savoie, SA 6098, «PV du voyage à Lyon », fol. 4.

19. J. Mesqui, Le pont en France avant le temps des ingénieurs, p. 130.

20. Arch. Ét. Turin, Lettres des particuliers, mazzo 53, «Lettre de Milliet de Challes », $1^{\text {er février } 1669 .}$

21. Ibid., 12 février 1669.

22. Arch. dép. Savoie, SA 6098, fol. 3.

23. E. H. Ash, « Expertise and the early modern state».

24. S. Van Damme, « Expertise in capital cities », p. XI-XVIII.

25. Y. Lignereux, «Franchir la Saône à Lyon au milieu du XVII ${ }^{e}$ siècle : enjeux critiques d'un chantier urbain ", p. 808.

26. C. Jacob, Qu'est-ce qu'un lieu de savoir?

27. S. Van Damme, Le temple de la sagesse: savoirs, écriture et sociabilité urbaine, Lyon, XVII XVIII siècle, p. 19, et «Sociabilité et culture urbaines : le rôle du collège de la Trinité à Lyon (1640-1730)».

28. H. de Rouvière, Voyage du tour de la France, p. 186.

29. F. de Dainville, «L'enseignement des mathématiques dans les collèges jésuites de France du XVI ${ }^{e}$ au XVIII ${ }^{e}$ siècle », p. 9.

30. P. Delattre (dir.), Les établissements des Jésuites en France depuis quatre siècles, p. 1550-1555.

31. J. Nicolas, La Savoie au XVIII siècle: noblesse et bourgeoisie en Savoie au XVIII siècle, t. I, p. 225-240. 
32. L. Perrillat, "L'administration des Ponts et chaussées en Savoie sous l'Ancien Régime (XVI ${ }^{\mathrm{e}}$-XVIII ${ }^{\mathrm{e}}$ siècles) », p. 10-11.

33. Ibid.

34. F. Rabut, «Histoire généalogique de l'illustre maison Millet (de Chambéri) par M. Besson, curé de Chapeiri, avec une notice sur Besson », p. 194.

35. F. de Dainville, «L'enseignement des mathématiques dans les collèges jésuites de France du XVI ${ }^{\mathrm{e}}$ au XVIII ${ }^{\mathrm{e}}$ siècle », p. 6 et 8.

36. C.-F. Milliet de Challes, De Machinis hydraulicis dans Cursus seu mundus mathematicus, vol. 2, p. 212-240.

37. C.-F. Milliet de Challes, L'art de naviguer demontré par principes, \& confirmé par plusieurs observations tirées de l'experience, avant-propos non paginé.

38. K. Pomian, «La Wunderkammer entre trésor et collection particulière », p. 19-23.

39. J. Spon, Recherche des antiquités et curiosités de la ville de Lyon, ancienne colonie des Romains \& capitale de la Gaule celtique... ; E. Robert et J.-C. Mossière (dir.), Jacob Spon : un humaniste lyonnais du XVII siècle, p. 31-37 et 39-50.

40. J. Spon, Recherche des antiquités et curiosités de la ville de Lyon, p. 205.

41. G. Olmi, "Science-honour metaphor: italian cabinets of the sixteenth and seventeenth centuries ", p. 5.

42. Académie des sciences, belles-lettres et arts de Lyon, « Éloge de Nicolas Grollier de Servières par son petit-fils », ms. 182-211, 6 mars 1742, fol. 215.

43. Ibid., fol. $215 \mathrm{r}^{\circ}$.

44. Ibid., fol. $224 \mathrm{v}^{\circ}$.

45. Ibid., fol. $225 \mathrm{r}^{\circ}$.

46. Académie des sciences, belles-lettres et arts de Lyon, «Éloge de Nicolas Grollier de Servières par son petit-fils », ms. 182-211, p. 140-141.

47. J. Mesqui, Le pont en France avant le temps des ingénieurs, p. 46.

48. Académie des sciences, belles-lettres et arts de Lyon, « Éloge de Nicolas Grollier de Servières par son petit-fils ", ms. 182-211, fol. $225 \mathrm{v}^{\circ}$.

49. Arch. dép. Savoie, SA 6098, fol. 1.

50. Arch. dép. Savoie, SA 6098, fol. 7.

51. BNF, Manuscrits, Fr. 24255, « Voyage en Provence fait par deux Augustins en 1671 », cité par M.-F. Pérez et J. Guillemin, « Curieux et collectionneurs à Lyon d'après le texte de Spon (1673)», p. 50.

52. A. Turner, «Grollier de Servière, the brothers Monconys: curiosity and collecting in seventeenth-century Lyon », p. 207.

53. G. Grollier de Servière, Recueil d'ouvrages curieux de mathématique et de mécanique..., préface, non paginé.

54. P. Skippon, "An account of a journey made thro' part of the Low-Countries, Germany, Italy and France », p. 708.

55. J. Locke, Locke's travels in France, 1675-1679: as related in his Journals, correspondence and other papers, p. 6.

56. H. de Rouvière, Voyage du tour de la France, p. 207.

57. Arch. dép. Savoie, SA 6098. 
58. G. Grollier de Servière, Recueil d'ouvrages curieux de mathématique et de mécanique..., pl. 89 et p. 59-61.

59. H. Vérin, « La technologie : science autonome ou science intermédiaire?».

60. E. H. Ash, Expertise: practical knowledge and the early modern State, p. 10-15.

61. J. Mokyr, The gifts of Athena: Historical origins of the knowledge economy, p. 36.

62. P. Bertucci, Artisanal enlightenment: science and the mechanical arts in old regime France, p. 21-23.

63. A. Turner., "Grollier de Servière, the brothers Monconys: curiosity and collecting in seventeenth-century Lyon », p. 214, n. 15.

64. B. de Monconys, Voyages de mr. de Monconys, p. 32-34.

65. J.-B.Picot, Explication des modèles des machines; A. Birembaut, "L'exposition de modèles de machines à Paris, en 1683 ».

66. H. Lemonnier, Procès-verbaux de l'Académie royale d'architecture, 1671-1793, t. I, p. 131.

67. J. Mesqui, Le pont en France avant le temps des ingénieurs, p. 149.

68. J. Burnouf et al., Le pont de La Guillotière : franchir le Rhône à Lyon, p. 106-116.

69. J. Mesqui, Le pont en France avant le temps des ingénieurs, p. 147.

70. Arch. Ét. Turin, Lettres des particuliers, mazzo 45, «Lettre de Sarde de Montagny », fol. 6, 25 juin 1672.

71. P. Long, « Trading zones in early modern Europe».

72. E. H. Ash (éd.), Expertise: practical knowledge and the early modern state, p.12-15; P. Long, Artisan, Practitioners and the Rise of the New Sciences, 1400-1600, p. 5.

73. P. Long, "Trading zones in early modern Europe », p. 842-846.

74. A. Chatelain, «Les ponts du Rhône : étude de géographie humaine», p. 112-113.

75. Arch. mun. Lyon, AA 9, «Arrêt du conseil d'État pour les réparations au pont du Rhône ».

76. E. Vial, « Les voyers de la ville de Lyon », p. 182 et 189-190.

77. J. Burnouf et al., Le pont de La Guillotière : franchir le Rhône à Lyon, p. 126.

78. Y. Lignereux, "L'éloquence des lieux : le pont de Saône à Lyon en 1635 ", p. 107-108.

79. Arch. dép. Savoie, SA 6098.

80. J. Burnouf et al., Le pont de La Guillotière : franchir le Rhône à Lyon, p. 126.

81. Arch. dép. Rhône, 1 C 159, « Extrait des registres du conseil d'État », 10 juin 1687.

82. Arch. dép. Savoie, SA 2275-2, "PV de visite des sources salées de Pontamafrey », 5 février 1670 , fol. 1.

83. W. Lefèvre, Picturing machines, 1400-1700, p. 2.

84. Arch. dép. Savoie, SA 6098.

85. P. Long, « Trading zones in early modern Europe».

86. P. Long, Artisan, practitioners and the rise of the new sciences, 1400-1600, p. 95.

87. Arch. dép. Savoie, SA 6098.

88. M. Valleriani, The structures of practical knowledge, p. 1-19.

89. P. Long, Artisan, practitioners and the pise of the new sciences, 1400-1600, p. 1 et 132, n. 1. 
90. Arch. Ét. Turin, Lettres des particuliers, mazzo 45, «Lettre de Sarde de Montagny », fol. 6, 25 juin 1672.

91. M. Valleriani, The structures of practical knowledge, p. 4.

\section{RÉSUMÉS}

Le voyage technique est un des modes d'acquisition du savoir pour les ingénieurs au XvII ${ }^{\mathrm{e}}$ siècle, qui précède la professionnalisation du siècle suivant. La mission de l'ingénieur du duc de Savoie François Cuenot, envoyé à Lyon observer la construction des ponts en 1672, s'inscrit dans une relation de patronage technique. L'approche anthropologique des connaissances techniques permet, par un jeu d'échelles, de dresser une géographie du savoir de la construction des ponts à l'échelle du royaume de France, voisin de la Savoie, les villes étant liées à l'expertise : Paris est suivie de Lyon, au second rang. À l'échelle urbaine, cette approche met en lumière le partage des connaissances entre différents acteurs praticiens ou lettrés dans des lieux de savoir, institutionnels ou non, qui pour certains, tels les chantiers du Rhône, fonctionnent à ce moment comme des trading zones.

\section{INDEX}

Mots-clés : construction de ponts, cabinet de curiosités, savoirs techniques, $\mathrm{XVII}^{\mathrm{e}}$ siècle Index géographique : Lyon

\section{AUTEUR}

\section{PATRICIA SUBIRADE}

Professeur agrégé, Institut d'histoire moderne et contemporaine (IHMC, UMR 8066 du CNRS /

École normale supérieure / université Paris I - Panthéon-Sorbonne) 
Évolution des savoirs sur le temps long 


\title{
Tradition et nouveauté dans la transmission de l'art de bâtir en pierres sèches
}

\author{
Ada Acovitsióti-Hameau et Louis Cagin
}

\section{Contexte de la technique et contenu de l'étude}

1 La pierre sèche fait partie des "maçonneries à sec", que l'on peut diviser en trois genres de pratiques se distinguant par le rapport de l'opérateur à la pierre et au geste technique :

- les maçonneries à pierres sèches, qui assemblent les pierres par des contacts ponctuels entre elles sans les retailler et sans se soucier de l'espace que cette pose pourrait générer entre les joints des blocs ;

- les maçonneries à joints vifs, qui interviennent systématiquement sur chaque pierre par une action de taille afin de les faire correspondre par des surfaces jointives en laissant le moins d'espace possible entre elles ;

- les appareillages mégalithiques (dits parfois cyclopéens) et les enrochements à sec, qui utilisent des blocs de pierres non transportables par l'homme et nécessitent des machines ou systèmes de levage perfectionnés. La mise en place des ouvrages mégalithiques et des enrochements peut se décliner selon les pratiques précédentes, l'une ou l'autre, ou les deux combinées.

2 Nous nous en tiendrons ici aux maçonneries à pierres sèches, sujet principal de notre propos. Ce procédé de bâtir met donc en œuvre des pierres brutes ou à peine travaillées, transportables et agencées manuellement, assemblées sans aucun mortier ou liant. Les ouvrages ainsi construits s'équilibrent et se stabilisent par l'agencement et l'ajustement des éléments assemblés. Souvent, cet $\operatorname{art}^{1}$ est qualifié d'intemporel et d'universel à cause de la nature de l'appareil qui, lié à la gravité, répond à des impératifs partout univoques, mais aussi à cause de son existence à toutes époques et en tous lieux. En effet, la mise en œuvre d'un matériau naturel disponible par la simple cueillette (pierres qui affleurent) ou par l'épierrement (pierres qui apparaissent après 
travail du sol) et utilisé avec le seul geste individuel d'assemblage constitue une action d'appareillage transversale et réalisable de tout temps et dans tous les contextes humains.

Liée au sol, à l'espace, au paysage et à leurs caractéristiques, « la " pierre sèche est une pratique qui se réalise selon deux axes techniques ${ }^{2}$ :

- le terrassement et la réorganisation du sol et de l'espace conformément aux besoins de leur/ s usage/s ;

- la mise en place des ouvrages en pierres sèches proprement dits, afin de structurer et de pérenniser cette réorganisation.

De fait, lors de cette pratique, il ne faut pas oublier que les ouvrages en pierres sèches ne sont que des moyens d'aménagement et qu'ils ne peuvent être abstraits des contextes pédologiques, géographiques et fonctionnels (agronomiques et autres) dont ils sont issus. Tant dans leurs caractéristiques que dans la possibilité même de leur construction, les ouvrages ne sont en fait, traditionnellement ${ }^{3}$, que la conséquence des contextes ainsi que l'adaptation à ces mêmes contextes dans un but d'aménagement de l'espace. La capacité à articuler et faire correspondre les deux axes techniques évoqués détermine la maîtrise du praticien ${ }^{4}$ à réaliser la totalité du processus. Fréquemment, l'observateur "non initié » dissocie les deux chaînes opératoires, considérant d'une part l'appareillage des pierres comme une activité de « haute technicité » et assimilant d'autre part le terrassement à un dur labeur physique de manœuvre. C'est pourtant bien dans la mise en œuvre, de concert, de ces deux activités, lors d'une même action/ conception de l'espace avec et par ses propres matières et potentialités, que se révèle le génie de la technique de la pierre sèche. La prise de conscience de cette articulation est la seule façon d'aborder cette technique sans la dénaturer et sans l'abstraire de ses dimensions historiques, humaines et écologiques. Les enjeux de la transmission moderne de cette pratique ancestrale en dépendent.

5 En effet, les connaissances et les compétences nécessaires à l'exercice de l'art de la pierre sèche sont traditionnellement acquises par transmission orale et gestuelle avec observation et pratique sur site. Cela entraîne une réelle prise en compte du lieu et de sa «culture ${ }^{5}$ " et induit une approche empirique de la technique adaptée aux ressources et aux particularités de chaque terrain. Cependant, ce processus d'apprentissage s'est étoffé et diversifié au cours du temps. Il est doublé aujourd'hui d'une filière d'enseignement issue de démarches et de recherches d'ingénieurs qui conceptualisent les appareillages en tant qu'objets en eux-mêmes ${ }^{6}$, abstraits du lieu. Le processus traditionnel s'appuie sur des savoirs et des connaissances transversales liées au lieu, il diffuse des savoirs et des perceptions élaborés par et déposés dans les mémoires individuelles et collectives, les habitudes de vie, les cultures locales. La filière "savante " travaille dans un cadre de formalisation de procédés techniques et d'établissement de règles précises pour la construction.

6 Les deux types de démarche coexistent et structurent aujourd'hui l'offre de transmission. Souvent, ils se retrouvent dans des mises en œuvre de l'art, comme le montre la reprise actuelle de terrasses oléicoles anciennes dans une campagne de Provence (fig. 1) : l'étagement suit les sinuosités du versant mais le chemin nouveau, droit, amène à l'édification d'angles de murs orthogonaux, constitués d'assises en gros blocs taillés et chaînés. Les couronnements des murs s'harmonisent avec la régularité des angles malgré un corps de mur au cœur irrégulier, en pierres brutes de petit module. 
Fig. 1. - Entrecasteaux (Var) : ensemble de terrasses anciennes reprises récemment.

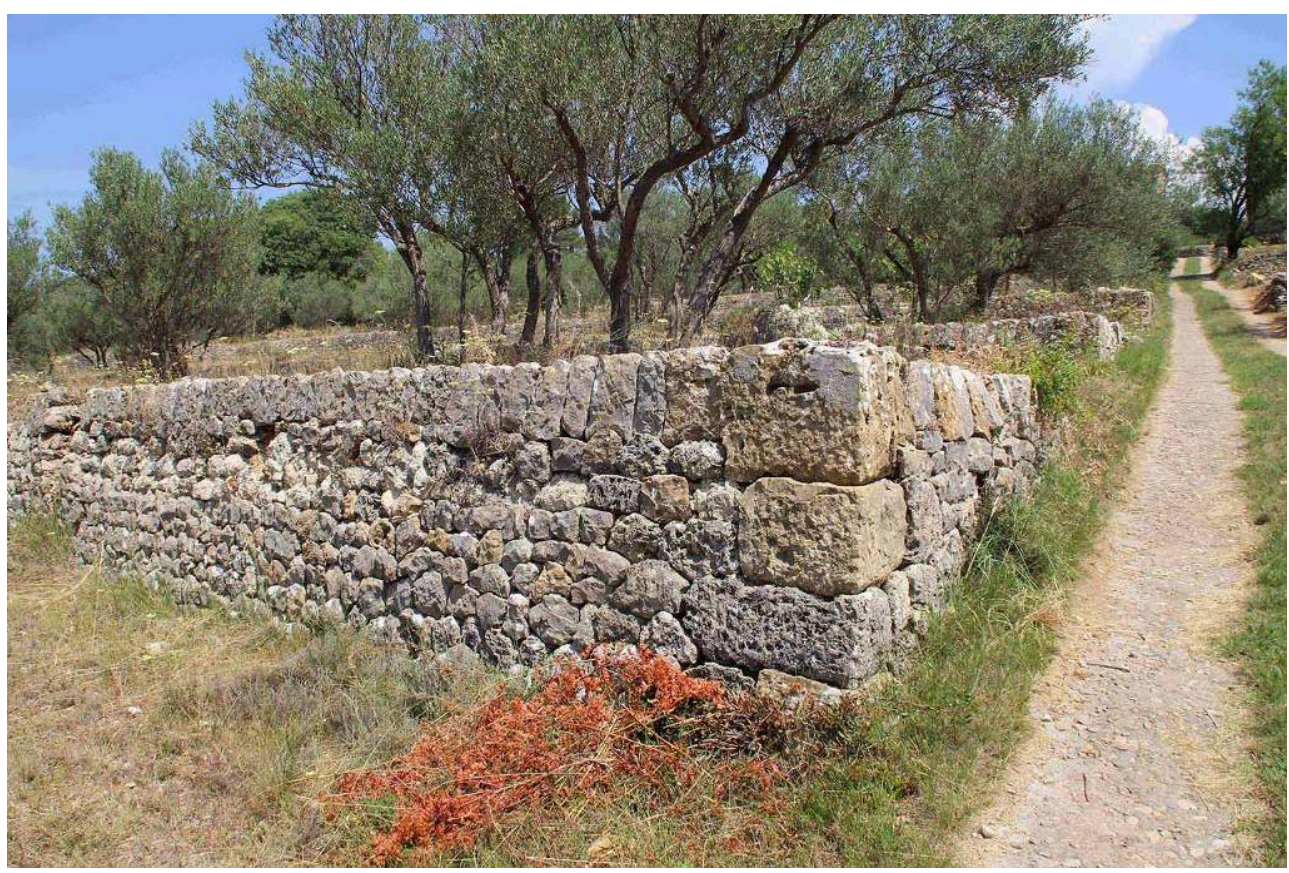

(c) Philippe Hameau

7 Ici se conjuguent techniques traditionnelles s'adaptant d'emblée aux données de terrain et techniques théorisées appliquant des schémas prémédités. Ailleurs, selon les lieux et/ou les moments, l'un de ces types de démarche peut dominer sans totalement occulter l'autre. Malgré une apparente opposition fondée sur des postures d'idéologie technique («statut» du bâtisseur et de l'œuvre), les deux approches peuvent être qualifiées de professionnelles et profiter mutuellement de leurs acquis.

8 Nous analyserons par la suite ces deux voies de la transmission des techniques de la pierre sèche et de leur gestuelle, sans perdre de vue la nécessaire convergence de chaque action dans la perspective de l'aménagement général des lieux. Pour ce faire, nous commencerons par aborder la transmission des seules techniques d'appareillage, puis nous développerons l'activité dans sa globalité en y articulant le rapport au sol, à l'usage et à l'aménagement, ceci afin de révéler l'aspect toujours singulier des solutions apportées par la pierre sèche à chaque contexte particulier. Au préalable, un exposé rapide des caractéristiques et des enjeux socio-économiques et environnementaux de la technique nous aidera à comprendre les processus cognitifs en œuvre pendant la transmission. Une récente publication collective ${ }^{7}$ sur la définition, les fondements et l'évolution de la construction en pierres sèches constituera la base de cette présentation.

\section{Enjeux de la technique}

9 Choix d'une société donnée à un moment précis de son histoire, les aménagements en pierres sèches affichent une grande homogénéité dans leurs rôles fonctionnels en même temps qu'une grande diversité dans leurs formes. Ainsi, dans des territoires géographiquement éloignés ou historiquement et sociologiquement différents, 
l'ordonnancement des espaces par la construction en pierres sèches peut être très similaire dans sa logique, qui apparie la pierre sèche à la valorisation des ressources locales, au travail en coopération et à la naturalité (fig. 2). Cela n'exclut pas les différences d'apparence dues à la visibilité (ostensible ou discrète) et à la densité (forte ou faible) des ouvrages. Ces derniers se combinent avec les éléments physiques et le couvert du sol pour produire les paysages. Selon les cas, l'aspect dominant perçu d'un territoire est plutôt minéral ou plutôt végétal.

Fig. 2. - Amorgos (Cyclades, Grèce) : la campagne agropastorale sur une île de la mer Égée.

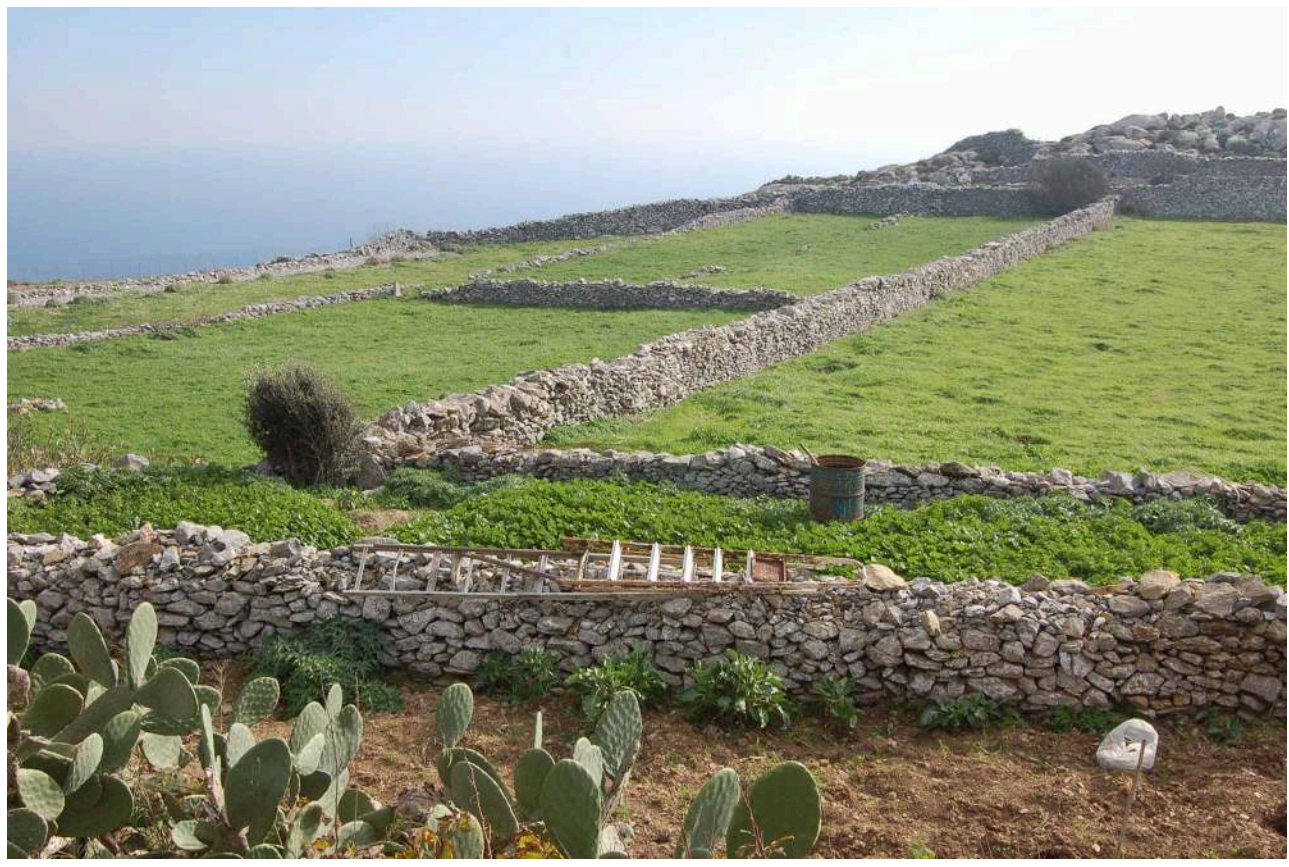

(c) Ioulia K. Papaeftychiou.

10 Traditionnellement, la technique est liée aux espaces ruraux et aux terroirs agrosylvopastoraux voués, de préférence, à un habitat saisonnier ou occasionnel. Elle aménage ces espaces de façon globale, " habillant ${ }^{8}$ » terres basses, hauteurs, forêts et littoraux. Elle est connue sur les cinq continents et montre des réalisations remarquables en Europe, en Asie, en Mésoamérique et, probablement, ailleurs 9 . Certains ouvrages remontent à l'Âge du Bronze et à l'Antiquité. Tous participent à la mise en place d'ensembles monumentaux témoins d'un mégalithisme ancien ${ }^{10} \mathrm{ou}$ contemporain ${ }^{11}$, mais se déclinant aussi sous forme de vastes ensembles d'ouvrages plus ordinaires, tels les territoires en terrasses, les réseaux de collecte et de distribution des eaux, les réseaux routiers, les édifices de stockage, de service, d'artisanat, de protection, d'habitat. Ces ensembles ordinaires sont autant d'aménagements paysans du quotidien connus de longue date.

11 Nombre d'entre eux gardent encore leur utilité et sont entretenus. Structurants, ces ouvrages retiennent les terres, régulent la circulation des eaux, des vents, de la lumière et de la chaleur, répartissent les activités de production et de cueillette, marquent les limites et rappellent la nécessaire existence de réseaux d'entraide et de sociabilité. Par le biais de ses utilités et des interactions qu'elle initie, la pierre sèche devient un élément unifiant pour les groupes humains qui la pratiquent. Ses mises en œuvre diverses en font aussi un élément identifiant, tant pour les usagers que pour les lieux 
qui l'accueillent. Ce rôle identitaire est principalement endossé par les architectures fermées (notamment les cabanes : fig. 3) et par plusieurs particularismes constructifs dus aux matériaux et/ou aux habitudes. Ainsi, partout, les aménagements en pierres sèches se trouvent étroitement liés à l'histoire agraire et aux variations des peuplements humains ${ }^{12}$.

Fig. 3. - Mane (Alpes-de-Haute-Provence) : cabanoun pounchu (cabanon pointu), cabane typique de la région de Forcalquier.

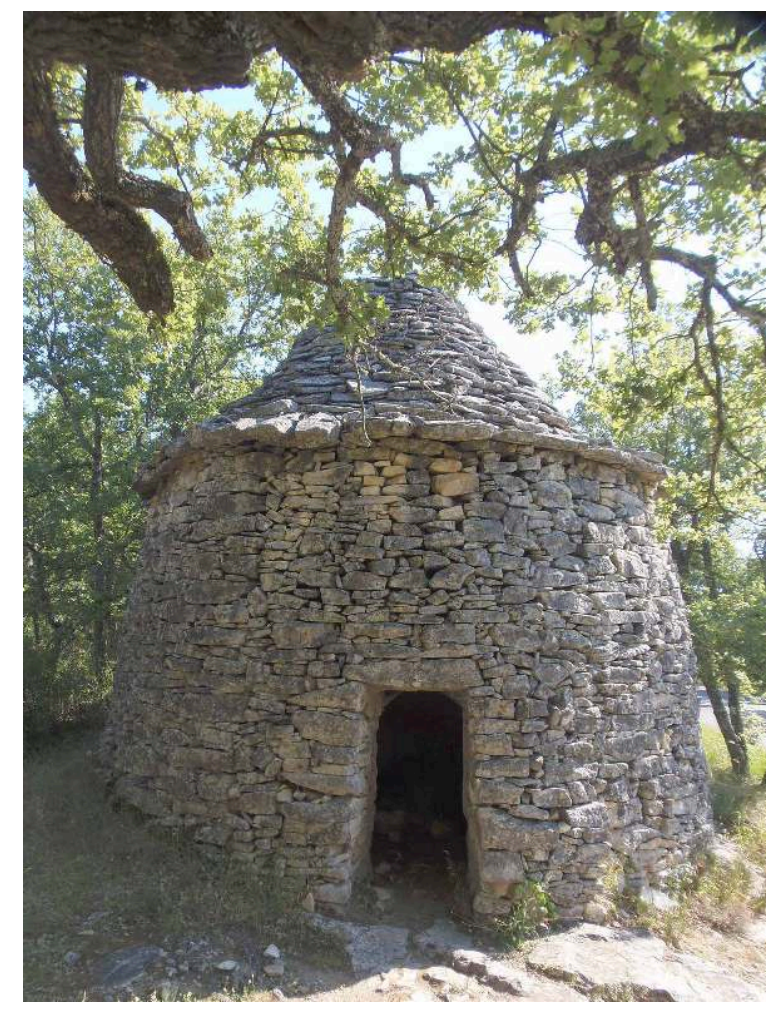

(c) Philippe Hameau.

12 En Europe et en Méditerranée, par exemple, les territoires de la pierre sèche vont de l'Espagne au Proche et Moyen-Orient, et des rivages nord-africains aux îles Britanniques et en Scandinavie. Il est difficile de dire si formes et fonctions s'inventent sur place ou se répandent de proche en proche: les deux schémas généralement se complètent. Il est toutefois difficile de documenter les cas de transfert technique ou d'acculturation dans le domaine de la pierre sèche. De tels cas sont signalés pour l'Afrique du Nord ou pour les campagnes des États-Unis et de l'Australie (apports des migrants et/ou des colons ${ }^{13}$ ) mais la marge de distinction entre savoirs et usages locaux et importés reste souvent ténue ou ambigüe. Les dernières proliférations des ouvrages ordinaires s'échelonnent entre le début du $\mathrm{XvII}^{\mathrm{e}}$ siècle et le milieu du $\mathrm{xx}^{\mathrm{e}}$ siècle. Leurs essors et abandons vont de pair avec des avancements et des régressions de l'occupation agricole associés aux reculs et progressions de la végétation forestière.

Par conséquent, les réseaux bâtis expriment les modes d'ordonnancement et de fairevaloir des terres suivant des règles élaborées et acceptées par les communautés. Cependant, l'individualisation de la propriété foncière mène à la multiplication et à la stabilité statutaire des aménagements. Or la stabilité du statut des terres empêche l'alternance de leurs fonctions : rotations des cultures, pâtures, boisements admettant 
ou interdisant certaines activités pour un certain temps, friches diversement accessibles, etc. L'utilisation différenciée des espaces communautaires/communaux par tous les groupes professionnels et sociaux est ainsi compromise. Les enclosures en pays de Galles, Écosse, Irlande, dès le $\mathrm{xvII}^{\mathrm{e}}$ siècle, des structures équivalentes (enregistrement officiel et imposition du foncier) en Italie, Sicile et Sardaigne, au XIX siècle, ou la législation consacrant la propriété privée après la Révolution en France, sont à la base de tels conflits. Dans les domaines britannique et irlandais, les études sur ces questions abondent dès les années 1930. Elles sont rappelées ou reprises régulièrement jusqu'à nos jours ${ }^{14}$. Pour le domaine français, on peut consulter à ces sujets le travail monumental de Maurice Agulhon sur la France postrévolutionnaire ${ }^{15}$ ainsi que celui de Philippe Blanchemanche sur les aménagements agraires ${ }^{16}$. Les questions de l'existence, du statut et de la gestion de ces terres considérées comme des «biens communs» occupent encore de nos jours historiens, juristes, écologues et ethnologues.

14 Ainsi, les clôtures départageant cultures/pâtures/propriétés ne trouvent leur pleine efficacité et signification qu'en incitant à " regarder des deux côtés des murs », car la collaboration entre insiders et outsiders est essentielle pour la bonne marche des systèmes ${ }^{17}$. En somme, ces aménagements ont tout autant divisé les communautés et l'opinion publique qu'ils ont généré des coopérations favorisant la cohésion sociale. De nos jours encore, ils accomplissent ce rôle à travers leurs fonctions environnementales et paysagères et à travers leur patrimonialisation.

\section{Études et transmission de l'art}

15 Jusqu'au milieu du $\mathrm{xx}^{\mathrm{e}}$ siècle et malgré les spécificités locales, l'étude de la pierre sèche intègre partout l'étude plus générale de l'architecture du quotidien dite "populaire " ou « vernaculaire ». Par la suite, elle devient un objet d'investigation en soi. Dès les années 1950, historiens et géographes l'intègrent dans les études sur la ruralité pour l'Europe, l'Afrique du Nord, l'Asie ou l'Amérique ${ }^{18}$. Ce faisant, ils mettent en avant le rôle important de certaines monocultures dites «de rapport » (vigne, olivier, caféier, etc.) pour expliquer le développement spectaculaire de certains ensembles en pierre sèche, ainsi que les conséquences des changements survenus dès le XIX ${ }^{e}$ siècle dans les rapports cultures/pâtures. Au nombre des signes de ce changement figurent l'abandon progressif des jachères et le développement des prairies artificielles ainsi qu'un épierrage accru à but pastoral, qui produit des murs (canalisation des bêtes) et des pierriers volumineux marquant durablement coteaux et plateaux. À la même époque, la pratique de la pierre sèche décline à cause de l'exode rural et de la mécanisation des cultures. Agitant le spectre de la technique "oubliée », ce déclin finit par raviver l'intérêt des usagers, des praticiens et des chercheurs et amène à l'intensification et à la diversification des études à partir des années 1970-1980. Cette activité finit par se formaliser avec la création en 1998, en France, de la Société scientifique internationale pour l'étude pluridisciplinaire de la pierre sèche (SPS), qui rassemble tous les types d'acteurs et perpétue les rencontres internationales bisannuelles sur le sujet. Dès le premier congrès, tenu en Italie (Bari) en 1987, les grandes lignes de similarités de l'art dépassant toutes frontières apparaissent clairement ${ }^{19}$. Peu à peu, cet intérêt se centre sur les moyens de transmission de l'art en tant que remède au risque de sa disparition. 
l'immersion dans les territoires à aménager et dans l'action de construction et d'entretien des ouvrages. Elle s'opère en même temps que les activités agricoles, pastorales et forestières auxquelles participent la plupart des membres de la communauté, jeunes et âgés. Se forment ainsi le geste et le regard par l'observation, l'imitation, l'essai guidé ou autodirigé ${ }^{20}$. L'apprentissage et l'usage de l'art renforcent le sentiment d'appartenance au lieu, via son aménagement et entretien et au groupe humain, via l'expression de la solidarité familiale et sociale. Il s'agit ici du rôle identitaire de l'art, que nous avons évoqué précédemment. Les savoir-faire ainsi transmis sont compris dans le lot des connaissances générales du paysan mais aussi du maître maçon, du tâcheron bâtisseur, du cantonnier et de différents spécialistes tels que les puisatiers et les miniers.

Des tâcherons spécialisés dans la construction en pierres sèches existent dans toutes les sociétés traditionnelles, mais rares sont ceux pour qui cet art est le métier principal, et plus rares encore ceux qui ont laissé une empreinte individuelle: détail technique spécifique ou signature de bâtisseur éponyme. C'est par exemple le cas de la famille Long, qui a déployé son activité constructive pendant plusieurs générations dans l'arrière-pays toulonnais entre le $\mathrm{xIX}^{\mathrm{e}}$ siècle et le $\mathrm{xx}^{\mathrm{e}}$ siècle (fig. 4).

Fig. 4. - Ollioules (Var) : signature datée (1874) d'un bâtisseur de la famille Long.

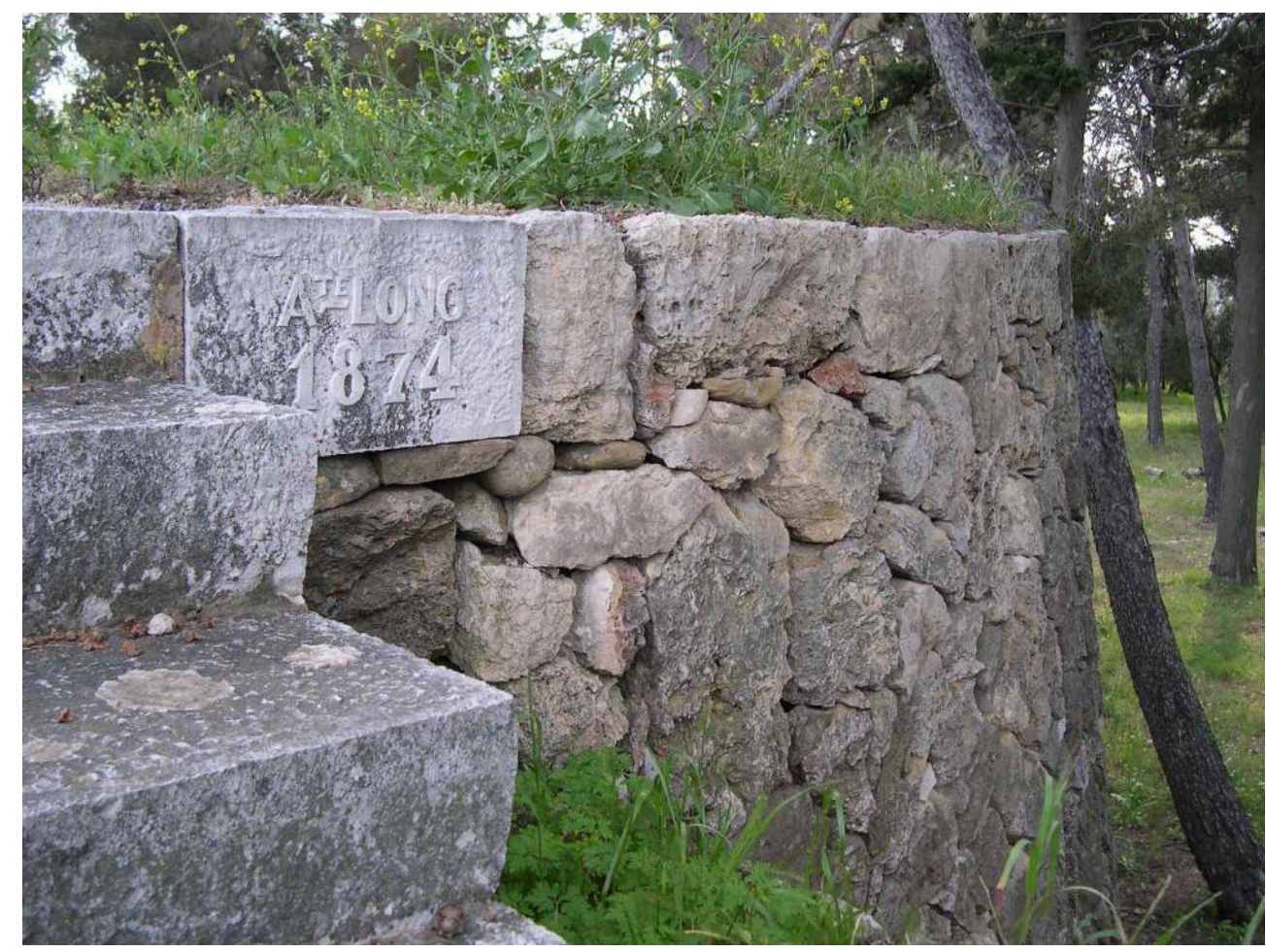

(c) Louis Cagin.

18 Les témoignages anciens écrits sur ces types d'ouvrages sont encore plus épars. L'organisation de la construction routière pendant l'Ancien Régime et l'essor du réseau ferroviaire au XIX ${ }^{e}$ siècle en France, mais aussi l'aménagement des terres de montagne et la prévention des avalanches (murs canalisant et déviant les flux) dans tous les pays 
de l'arc alpin, utilisent la technique et finissent par occasionner des théorisations écrites qui ont servi pour les études académiques actuelles ${ }^{21}$.

De nos jours, la transmission empirique par des aînés et des pairs côtoie celle, doctrinale, dispensée par des professionnels et des experts. Il s'agit là d'un enseignement théorique et pratique qui est en partie livresque (usage de «manuels ») et mène à des cursus diplômants diversement reconnus. Depuis les années 1990, nous assistons à la création d'organismes de formation comme l'école spécialisée de Majorque, aux Baléares, les « compagnies » des « pétradés » des Cyclades, en Grèce, ou un service spécifique de la Fondation pour l'environnement (FAFE) en Suisse. L'organisation de cette formation a un long passé au Royaume-Uni, où les bâtisseurs en pierres sèches sont réunis en une association nationale (Dry Stone Walling Association) organisée en sections régionales. Pour la France, l'organisation du métier est plus récente. Elle s'est affirmée en 2010 avec l'instauration du certificat de qualification à validité nationale (concours annuel) pour les artisans qui le souhaitent. Cette disposition vient à la suite de l'approbation de règles de bâtir avec abaques pour les dimensionnements, le tout édité en un manuel officiel en $2008^{22}$. La plupart des professionnels français sont regroupés en une fédération nationale, sans que cela exclue l'existence d'autres groupements et de bâtisseurs indépendants.

Cet enseignement met l'accent sur les matériaux et les règles de bâtir, et valorise l'ouvrage lui-même, sa technicité et son esthétique. Il traite la pierre sèche comme un métier en soi, tout à la fois artisanal et artistique, et contribue à quantifier et certifier l'efficacité des ouvrages dans des conditions prescrites, de préférence, en avance. Cette dimension « hors sol » introduit un approvisionnement extérieur en matériaux et crée ainsi une filière économique qui part de l'extraction des pierres en carrière à leur pose par les bâtisseurs selon des normes préétablies et des réseaux de distribution. Dans cette évolution, l'approche globale du lieu à aménager passe parfois en arrière-plan. Le bâtisseur se pose plus comme un technicien de la pierre et de la statique et résistance des matériaux que comme un visionnaire et un usager de l'espace. Pourtant, réorganiser un lieu exige une compréhension profonde de ses particularités physiques et humaines, et cela ne peut se faire sans un long travail d'études préalables centrées sur les sciences de l'homme, de la vie et de la terre. Ce travail doit précéder et accompagner transmissions et réalisations.

21 À ce titre, l'étude de la cabane du charbonnier contemporain en Provence est un exemple convaincant. La reconstitution de clairières de charbonnage arrive à la suite de plusieurs années de prospections, relevés, enquêtes orales et archivistiques, fouilles archéologiques et travaux dirigés de carbonisation expérimentale, et bénéficie de l'aide effective d'anciens artisans ${ }^{23}$. La restauration de sites agraires et pastoraux suit peu ou prou le même processus.

Le temps nécessaire manque souvent pour de telles approches. Pourtant, la conscience de l'importance des études préalables devrait toujours guider les projets de restauration et d'aménagement et empêcher les interventions rapides et radicales. Il est à espérer que l'interpénétration des deux démarches "techniques" finira par émerger et par résoudre cette opposition sans véritables fondements. Pour exemple allant dans ce sens, l'enseignement proposé par le ministère de l'Agriculture français, qui décerne le titre d'" agent technique patrimonial ", met l'accent sur les savoirs techniques spécifiques applicables au bâti et aux éléments du milieu naturel et vivant des opérations. En s'appropriant les outils proposés par les analyses modernes des 
appareillages, cet enseignement amène le praticien à comprendre les données issues des appareillages et des coupes des ouvrages anciens dans leurs particularités locales. Ceci permet de les reproduire en observant une correspondance aux lieux dans leurs ressources géologiques, pédologiques, écologiques et culturelles (fig. 5).

Fig. 5. - Alpes-de-Haute-Provence : cabane encorbellée en cours de restauration.

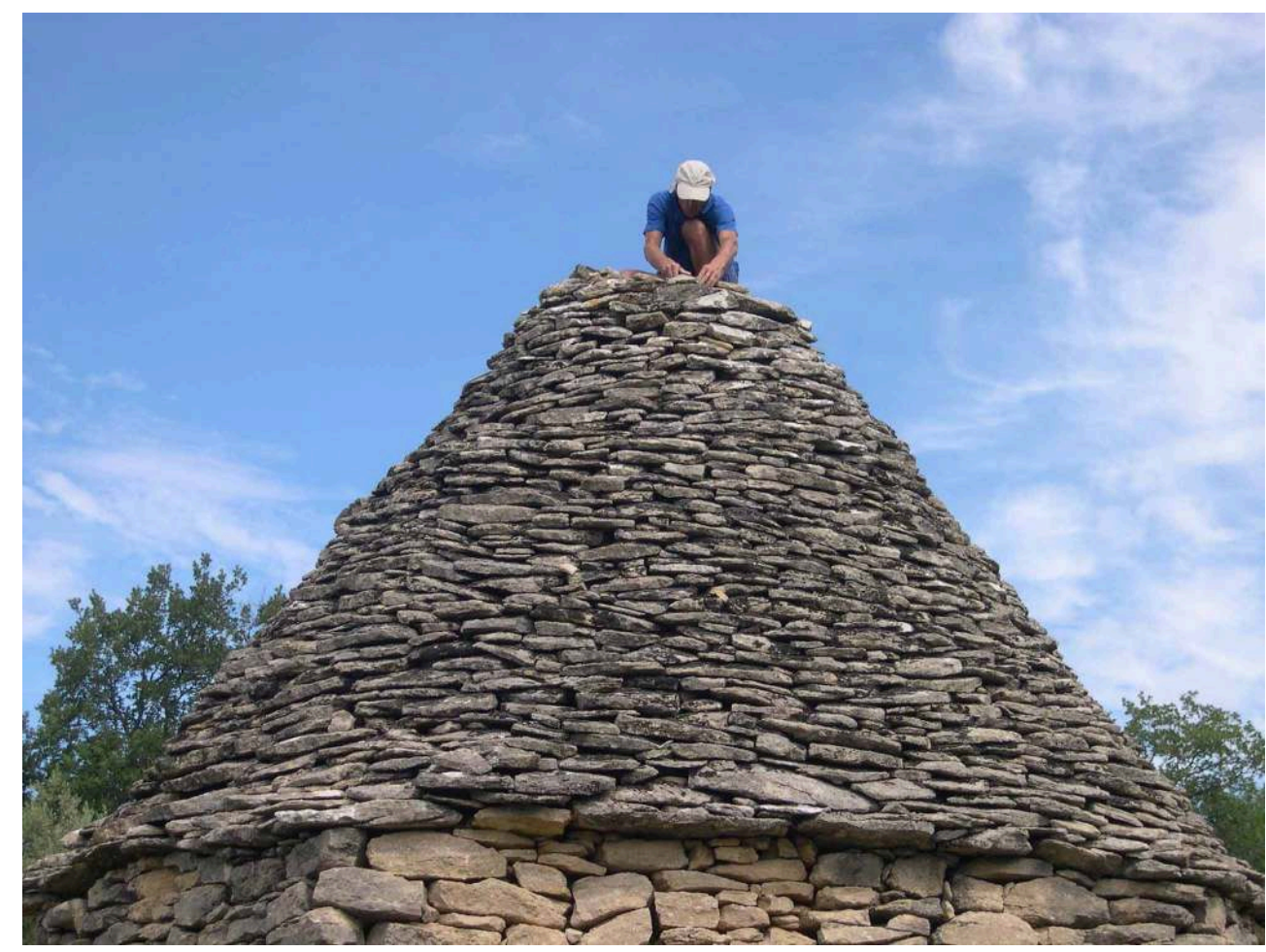

(c) Louis Cagin.

Par bonheur, empirique ou doctrinale, la transmission s'effectue simultanément dans les deux sens: vertical (intergénérationnel) et horizontal (inter-groupes et interespaces). Les interactions produites fondent tant la compréhension des réseaux territoriaux et humains que la philosophie des ateliers, chantiers et échanges actuellement en vogue. De même, empirique ou doctrinale, la transmission dépend de façon égale de la communication des perceptions sensorielles et de la maîtrise de la gestuelle. Elle se réalise principalement via l'appropriation du geste par l'apprenant et se travaille au niveau de sa sensibilité personnelle. Le sujet reste seul au cœur du geste. Le transmetteur se limite à suivre, verbaliser puis valider la réalisation de cette intériorité en jugeant de la justesse du résultat. Des deux côtés, les sens encadrent, anticipent, dirigent et confirment l'efficacité du geste. Plus qu'un enseignant, le transmetteur est l'accompagnant d'une «découverte de soi» qui va de pair, généralement, avec la "découverte du lieu»: c'est là que nous pouvons parler d'autochtonie de l'art.

\section{Assembler, bloquer, appareiller}

Pour l'appareillage des pierres, le constructeur «joue» avec leurs surfaces - leurs contacts et leurs appuis - jusqu'à obtenir le blocage de ces matériaux. La maittrise du 
geste se fonde sur l'adaptation à la matière ${ }^{24}$. Le travail de "pose " crée des «liens " entre tous les éléments du mur ou de l'ouvrage. La cohésion de ces éléments peut être comparée à la cohésion de la toile du tisserand : le fil (de la transmission des forces) renforce la trame (des points de contact des pierres) (fig. 6 et fig. 7). Cette métaphore plaide pour la dimension intemporelle de la technique, dimension à laquelle la modernité n'a pas grand-chose ni à apporter, ni à changer. Le fait que, de plus en plus, mécaniciens et ingénieurs représentent graphiquement ces trames et les modélisent, se résume souvent à des règles indicatives, difficiles à appliquer telles quelles hors du cas étudié. Les actions de pose sont donc peu nombreuses et restent simples: placer, assiser, bloquer, croiser pour répartir les charges, calculer les pendages des pierres et des corps bâtis, etc. Enfin, il faut soigner les parements, faces et couronnements, ce soin esthétique se combinant aussi, selon les cas, avec une fonction mécanique portée par les inclinaisons et les ancrages des blocs. Ces quelques règles permettent une infinie diversité de réalisations, due à la diversité des matériaux eux-mêmes (en structures minérales, formes, capacités d'assemblage) mais aussi à la variabilité des mises en œuvre d'un même matériau. Cette variabilité est due aux différences entre les groupes humains, les terroirs et leurs besoins, due aussi aux compétences et à la sensibilité des bâtisseurs ainsi qu'aux enjeux de leurs créations.

Fig. 6. - Tisser la toile de la gravité.
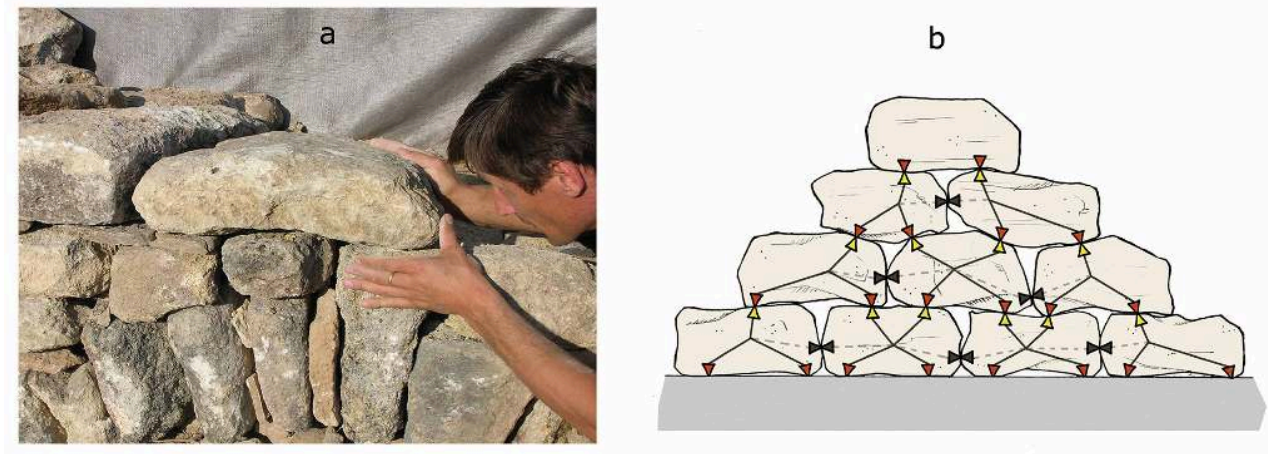

A : «jauger la bonne pose ». B : transmission des forces via les jointures des pierres.

Photo Louis Cagin, schéma Olivier Hérault. 
Fig. 7. - Mécanique et statique du mur : un équilibre qui évolue.

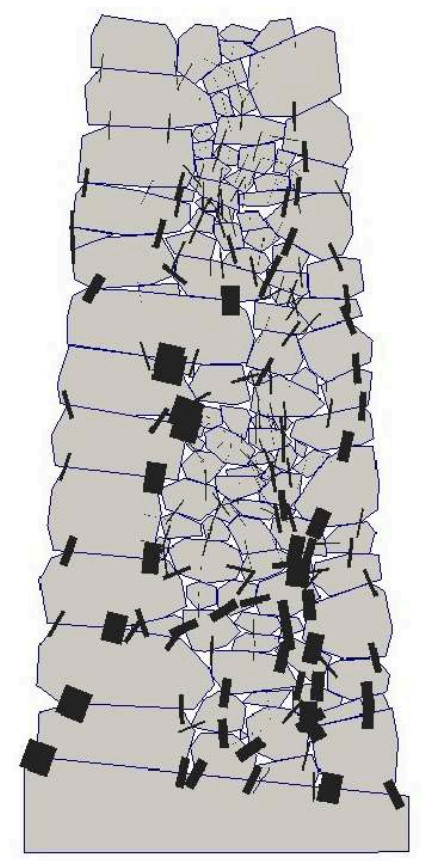

Schéma Michel Jean et Marine Bagneris, photo Louis Cagin.

L'activité est purement gestuelle, manuelle. Cependant, nous observons que la modernité transgresse les relations directes homme-matière et homme-milieu au niveau :

- du praticien qui utilise des machines et des interfaces entre la pierre et la main (disqueuses, tractopelles, etc.) et qui définit son métier par la seule activité d'appareillage, excluant le rapport au sol et la dimension terrassière de l'activité ;

- du lieu et de la ressource, par la délocalisation des approvisionnements et la normalisation de la qualité des pierres;

- de l'échelle dans le travail qui change, car elle se lie à l'utilisation d'engins de levage et de terrassement ;

- du caractère des ouvrages, via un mélange des «styles » où la pierre sèche devient un décor, un revêtement qui n'est plus dicté par les ressources micro-locales mais imaginé ou commandité de l'extérieur.

Malgré la réalité de ces évolutions, les artisans et usagers qui expliquent l'art lors du film tourné récemment (2017-2018) pour être présenté à l'UNESCO ${ }^{25}$ parlent de travail éminemment manuel, des "six faces" des pierres en quête de «liens", de «sensations» tactiles, visuelles, acoustiques d'appariement interne aux ouvrages et externe avec le lieu, de "beauté ». Actives au niveau de la personne, ces perceptions rallient la modernité ambiante aux prescriptions de bonnes pratiques héritées.

\section{« Tradition » et « nouveauté » : face à face mais de concert}

Aujourd'hui, la construction en pierres sèches se situe au carrefour des savoir-faire traditionnels, transmis empiriquement par des aînés et des pairs dans le respect des 
contextes "autochtones » et des techniques formellement structurées, enseignées en théorie et pratique à partir d'études d'ingénierie dans le cadre d'une filière économiquement organisée et globalisée. Assimilée à une passation et à une intériorisation des savoir-faire, la transmission traditionnelle révèle la gestuelle, la variabilité, la profondeur historique et les contextes territoriaux et sociaux de l'art de bâtir à sec. Tendant à la théorisation et procédant par exercices testant savoirs et compétences, la transmission nouvelle et actuelle suit ou encourage le suivi de règles issues d'études académiques. Toutefois, bien que semblant s'opposer, ces deux démarches partagent finalement les mises en écrit des connaissances sur les contextes des ouvrages, sur les règles et calculs régissant la construction, sur les retombées pour l'environnement, la biodiversité et le paysage, sur les perspectives artistiques, sur l'enrichissement du patrimoine matériel et immatériel. Enfin, par-dessus tout, si de nos jours tout change, l'homme n'a pas encore interféré sur le rapport gravitaire entre les pierres et, donc, dans l'acte de les appareiller sans liant. L'expérience empirique demeure valable. Pour les uns et pour les autres, le calage et le blocage des pierres à bâtir sur toutes les dimensions des ouvrages sont des actions essentielles. Cet assemblage, empreint de diversité, est à la base de constructions paysagères auxquelles praticiens, usagers des lieux et aménageurs prêtent une attention particulière et en font un indice de « qualité de vie».

Des divergences existent. En amont, la pratique de la pierre sèche induit invariablement une mise en ordre des éléments géo et hydro-morphologiques et une réorganisation des matériaux issus du sol. Dans le processus traditionnel, le praticien planifie et exécute ces travaux : il est donc terrassier autant que bâtisseur. Dans le processus moderne, ces deux étapes du travail sont le plus souvent dissociées et le terrassement entièrement mécanisé. Autre différence importante : nous nous trouvons actuellement face à une inversion de la perception de la technique. En effet, autrefois conçus comme des réalisations utilitaires du quotidien, les ouvrages en pierres sèches sont de plus en plus ressentis comme des œuvres techniquement et esthétiquement admirables. Leur rôle dans les domaines de l'écologie, de l'histoire locale, des relations humaines est explicité et valorisé. Dorénavant, devenue artisanat à part entière et flirtant ouvertement avec l'art tout court - le land art en est un courant éminent - la pratique intègre l'identité des territoires ruraux et contribue à son émergence et aux enjeux de développement qui lui sont affiliés. Cet élargissement de regard amène aussi à différencier la perception du bâtisseur lui-même, de l'artisan-artiste, qui, selon ses ancrages sociaux et professionnels et selon ses ambitions, adopte la posture de la singularité (acteur nominal d'œuvres spécifiques) ou la posture de la communauté (collectif partageant et appliquant des connaissances et modes d'action partagées). Cette différenciation ${ }^{26}$ est observable pour d'autres "métiers artistiques », tel par exemple celui des musiciens, où la virtuosité côtoie constamment la pratique ordinaire. Cette dernière se rapproche, actuellement et dans certains contextes, des postures des artisans du bâtiment qui, selon le corps auquel ils appartiennent, placent leur travail entre art et métier $^{27}$ (fig. 8 et fig. 9). 
Fig. 8. - Llanidryr (pays de Galles, Royaume-Uni) : enclos anciens et enclos nouveaux se mêlent en ensembles toujours fonctionnels.

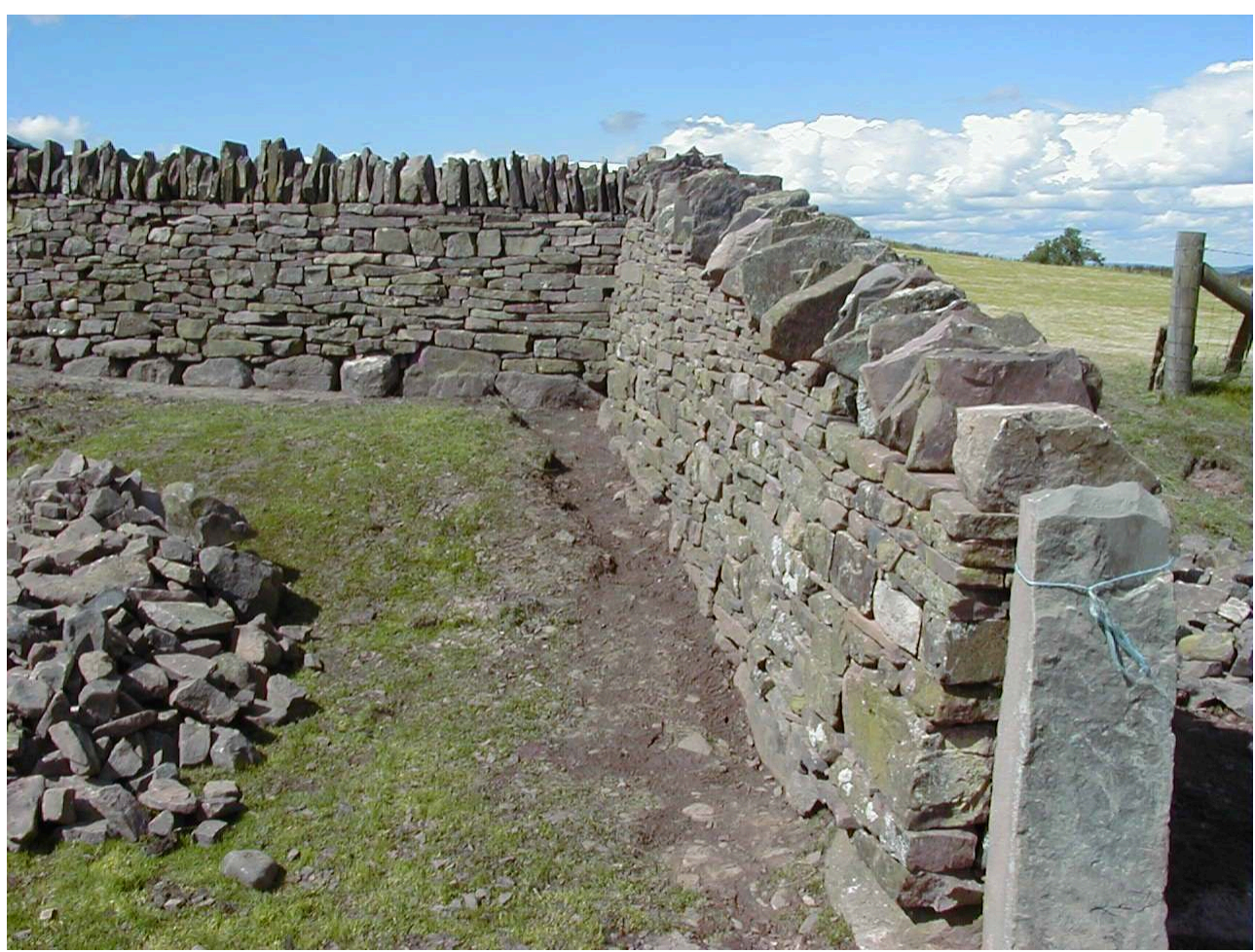

(c) Philip Clark, original déposé à la Société scientifique internationale pour l'étude pluridisciplinaire de la pierre sèche (SPS).

Fig. 9. - Haute-Saône : cadole (cabane) nouvelle dans le vignoble bourguignon : une extension heureuse de l'existant.

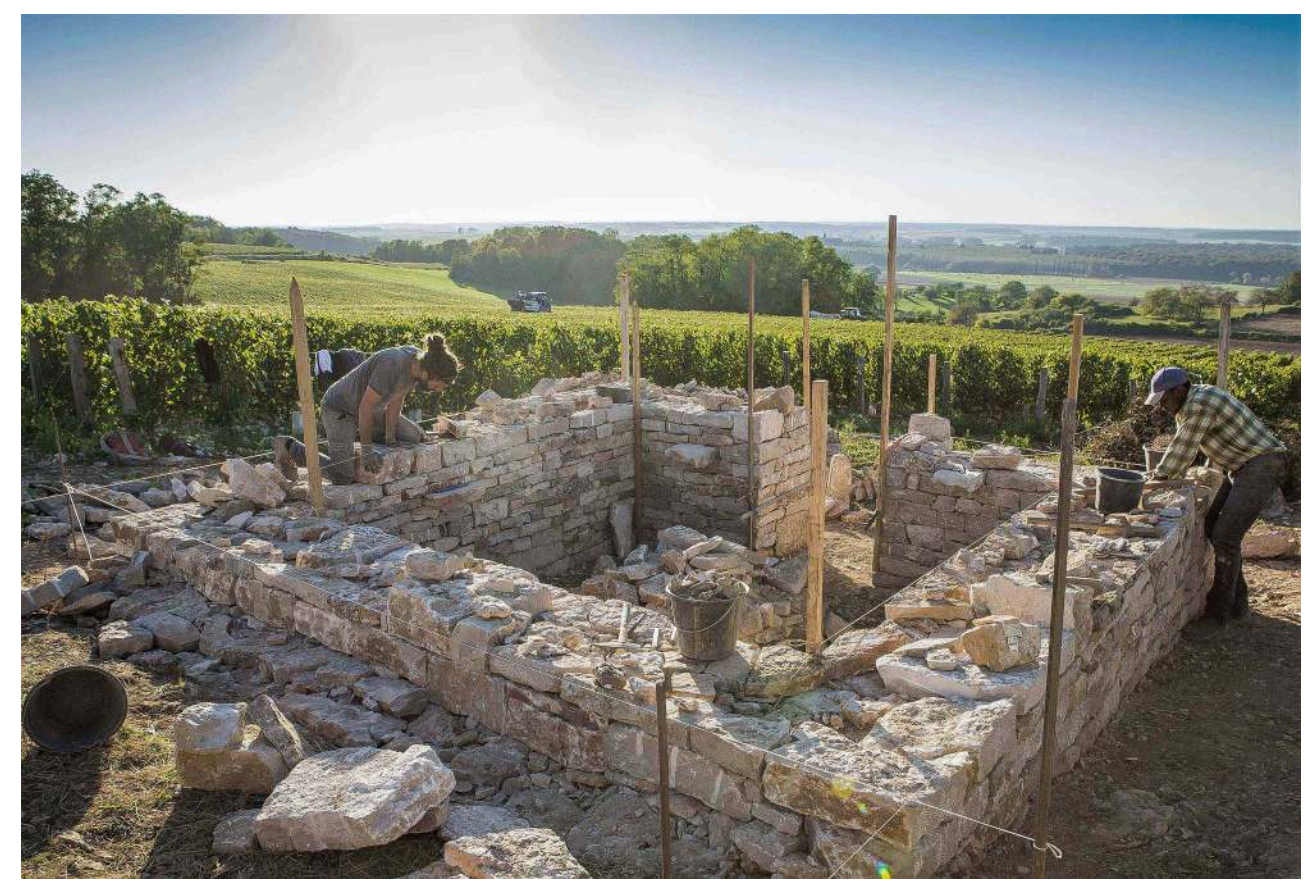

(c) Association Laviers et muraillers de Bourgogne, original déposé à la Société scientifique internationale pour l'étude pluridisciplinaire de la pierre sèche (SPS). 
Les conséquences de ces évolutions sont multiples. Ces réorientations reclassent la technique de la pierre sèche dans le monde actuel et en font un outil d'action pour les bons principes de l'habiter et pour l'environnement. Adaptée ainsi aux milieux urbains, la pratique participe à des aménagements nouveaux : réseaux routiers, parcs et jardins, théâtres de plein air, hangars et autres locaux professionnels. Cela ne diminue en rien la part de la pierre sèche dans les représentations identitaires rurales, son statut d'indicateur de qualité pour la terre, pour ses produits et pour l'art de vivre qui s'y déploie. Ainsi, la demande multinationale de certification des savoir-faire de la pierre sèche en tant que patrimoine culturel immatériel de l'humanité se place dans le faisceau des tendances exposées précédemment : l'universalité, la diversité inhérente, l'ancrage aux lieux et la flexibilité de la pratique et des praticiens. Pour toutes ces raisons, le va-et-vient passé-présent et les rôles des groupements d'aménageurs, bâtisseurs, chercheurs et usagers sont de valeur équivalente et restent essentiels pour l'avenir. L'enjeu final et primordial est le bon accord entre acteurs et la convergence de leurs agissements afin d'atteindre le moment de grâce où tradition résonne avec nouveauté et particularité locale avec concept global.

\section{BIBLIOGRAPHIE}

ACOVITSIÓTI-HAMEAU A., 2000, « Transformer et habiter la forêt : les sites de charbonnage dans le Var ", dans Brun B., Dufour A.-H., Picon B. et al. (dir.), Cabanes, cabanons et campements : formes sociales et rapports à la nature en habitat temporaire, $11^{\text {es }}$ Journées scientifiques de la Société d'écologie humaine (Perpignan, novembre 1999), Châteauneuf-de-Grasse, Éd. de Bergier, p. 109-121.

ACOVITSIÓTI-HAMEAU A., 2002, « Constructions en pierre sèche en Méditerranée : pour une reconversion en souplesse ", Bulletin de l'Association de géographes français, vol. 79, nº 3, p. 332-343. ACOVITSIÓTI-HAMEAU A., 2003, Le bois, la meule et la cabane, Méounes, ASER du Centre-Var (Cahiers de l'ASER, suppl. 10).

ACOVITSIÓTI-HAMEAU A., 2006, « La pierre sèche dans le domaine euro-méditerranéen : du savoirfaire à la manière d'être », dans Lassure C. (dir.), Actes du colloque Pierre sèche, Avallon-Yonne, Bourgogne, 24 septembre 2005, Paris, Centre d'étude et de recherche sur l'architecture vernaculaire (Bulletin du CERAV, 14), p. 48-63.

ACOVITSIÓTI-HAMEAU A., 2007, « Trois essais sur la pierre sèche : la forme et la fonction, apprendre et comprendre l'art de bâtir à sec, les paysages de terrasses ", Cahiers de l'ASER, nº 15, p. 103-130. ACOVITSIÓTI-HAMEAU A., 2010a, «À la frontière du durable : les cabanes en pierres sèches dans leurs contextes multiples ", dans Acovitsióti-Hameau A., Painaud A., Hameau P. (dir.), Savoirs, paysages, structures, actes du $10^{e}$ congrès de la SPS (Montalbán, Aragon, Espagne, septembre 2006), Méounes, ASER du Centre-Var (Cahiers de l'ASER, suppl. 13), p. 7-15.

ACOVITSIÓTI-HAMEAU A., 2010b, « Dry stone works and piles: breakings and partitions that carry social links », dans Dry stone walls as part of the cultural landscape, Proceedings of the 12th international 
congress of the SDS (Ambleside, UK, September 2010), Milnthorpe-Cumbria, Dry Stone Walling Association, p. 19-22.

AGUlHon M., 1970, La vie sociale en Provence intérieure au lendemain de la Révolution, Paris, Société des études robespierristes.

AITKEN N., 2010, « Drystone, the essential foundation for all stonework. Quoting ST Kilda and other international examples ", dans Dry stone walls as part of the cultural landscape, Proceedings of the 12th international congress of the SDS (Ambleside, UK, September 2010), Milnthorpe-Cumbria, Dry Stone Walling Association, p. 42-44.

AMBRosi A., 1990, «L'archittetura in pietra a secco: costruzione, progetto, tipologie », dans Ambrosi A., Degano C., Zaccaria D. A., (dir.), Architettura in pietra a secco, Actes du $1^{\text {er }}$ séminaire international sur la pierre sèche (Noci-Alberobello, septembre 1987), Brindisi, Schena, p. 17-84.

BAGNERIS M. et JEAN M., 2017, « La vision du mécanicien », dans Cagin L. (dir.), Pierre sèche : théorie et pratique d'un système traditionnel de construction, Paris, Eyrolles, p. 191-213.

BLANCHEMANCHE P., 1990, Bâtisseurs de paysages : terrassement, épierrement et petite hydraulique agricole en Europe (XVII ${ }^{e}$-XIX ${ }^{e}$ siècle), Paris, Maison des sciences de l'homme.

CAGIN L. (dir.), 2017, Pierre sèche : théorie et pratique d'un système traditionnel de construction, Paris, Eyrolles.

CAGIN L., 2019, « Murailleur-terrassier », Cahiers de l'ASER, n² 21, p. 113-116.

CAPEB, 2008, Pierre sèche : guide de bonnes pratiques de construction des murs de soutènement, Lyon, École nationale des travaux publics de l'État.

COLAS A.-S., 2009, « Mécanique des murs de soutènement en pierre sèche », thèse de doctorat, Lyon, École nationale des travaux publics de l'État.

COOMBEY N., 2010, « Galloway Dykes - from civil unrest to community cohesion », dans Dry stone walls as part of the cultural landscape, Proceedings of the 12th international congress of the SDS (Ambleside, UK, September 2010), Milnthorpe-Cumbria, Dry Stone Walling Association, p. 45-46. HARFOUCHE R., 2007, Histoire des paysages méditerranéens terrassés : aménagements et agriculture, Oxford, Archaeopress (BAR International Series, 1634).

HEINICH N., 2005, L'élite artiste, Paris, Gallimard.

HEINICH N., 2010, « La construction d'un regard collectif : le cas de l'inventaire du patrimoine », Gradhiva, $\mathrm{n}^{\circ} 11$, p. 162-180.

JONES B., 2010, « Dry stone in Great Britain », dans Dry stone walls as part of the cultural landscape, Proceedings of the 12th international congress of the SDS (Ambleside, UK, September 2010), MilnthorpeCumbria, Dry Stone Walling Association, p. 17-18.

MARSHALL R., 2010, « Dry stone art in the Australian landscape: from the artisan skills of the early settlers to the influence of Andy Goldsworthy on contemporary dry stone sculpture ", dans Dry stone walls as part of the cultural landscape, Proceedings of the 12th international congress of the SDS (Ambleside, UK, September 2010), Milnthorpe-Cumbria, Dry Stone Walling Association, p. 103-109. PAPALARDO M., 2002, « Il terrazzamento antropico in Liguria », Bolletino de la Societá Geografica Italiana, série XII, vol. VII, p. 267-306.

PERRENOUD M., 2008, « Les musicos au miroir des artisans du bâtiment : entre "art" et "métier" ", Ethnologie française, $\mathrm{n}^{\circ}$ 2008/1, p. 101-106. 
VAROTTO M. et LODATTI L., 2010, « Adopting terraces and maintaining cultural landscapes. Drystone works between inside and outside ", dans Dry stone walls as part of the cultural landscape, Proceedings of the 12th international congress of the SDS (Ambleside, UK, September 2010), Milnthorpe-Cumbria, Dry Stone Walling Association, p. 36-39.

VILLEMUS B., 2004, «Étude des murs de soutènement en maçonnerie de pierres sèches ", thèse de doctorat, Lyon, Institut national des sciences appliquées.

WEBLEY P., 2004, Dry stone walling: techniques and traditions, Milnthorpe, Dry Stone Walling Association of Great Britain.

\section{NOTES}

1. «Art» dans le sens d'un ensemble de savoirs et de compétences, dans le sens de la téchné grecque : intelligence cognitive, intuitive et inventive autour du fait technique.

2. Cette idée est plus amplement développée dans Cagin 2019.

3. Il faut entendre ici "traditionnel» comme sans apport notable de matériaux extérieurs, contrairement à ce qui arrive aujourd'hui avec les moyens de transport disponibles et la mécanisation généralisée.

4. Ce praticien est généralement nommé à partir du radical qui signifie «mur»: muraihaire et parfois murayeur ou (em)paredaïre dans les langues occitanes, waller ou dyker dans les langues anglo-saxonnes, etc. Le matériau, la pierre, sert aussi pour désigner l'artisan: dit petras dans les îles grecques ou lavier en Bourgogne. Reconnu comme artisan d'art (JORF du 31/01/2016), le bâtisseur en pierres sèches se dit en France murailler (dérivé de la forme vernaculaire provençale) ou murailleur (forme francisée).

5. À entendre dans ses deux sens.

6. Telles les thèses d'A.-S. Colas, 2009 ou de B. Villemus, 2004.

7. Cagin 2017.

8. Ce terme est usuel dans les baux à ferme et les contrats de construction du $\mathrm{XVII}^{\mathrm{e}}$ au XIX ${ }^{\mathrm{e}}$ siècle.

9. Des ensembles monumentaux, récemment classés aux sites du patrimoine mondial par l'UNESCO (juin 2018), se trouvent au Kenya, à Oman et en Arabie Saoudite.

10. Comprenant, généralement, des constructions publiques militaires et civiles (murailles, palais) et des constructions cultuelles et sépulcrales (temples, allées/ enceintes, tombeaux).

11. Nous pensons aux compositions artistiques mais aussi aux simples enrochements pour les soutènements et les clôtures tels qu'ils se multiplient actuellement.

12. Nous avons développé ces thèmes dans Acovitsióti-Hameau 2002, 2006 et 2010a.

13. Tels les cas signalés pour l'Australie par R. Marshall (2010).

14. Webley 2007, Jones 2010, Coombey 2010, Aitkens 2010.

15. Agulhon 1970.

16. Blanchemanche 1990.

17. Acovitsióti-Hameau 2010b, Varotto et Lodatti 2010. 
18. Il existe plusieurs recensements de ces études (Blanchemanche 1990, Papalardo 2002, Harfouche 2007, etc.). Généralement, tous les chercheurs se réfèrent aux travaux pionniers de J. Despois sur l'Europe et l'Afrique du Nord (1956 et 1961), de Niederer sur le Valais suisse (années 1950), de Donkin, Mitchell et plusieurs autres sur l'Amérique (années 1970-1980). Les travaux significatifs sur le golfe Persique (Yémen) et sur l'Asie du Sud-Est datent des mêmes décennies. Mentionnons encore le travail de J.-F. Blanc sur l'Ardèche (1984) et l'impulsion donnée à ces études par l'association CERAV et son fondateur C. Lassure depuis la fin des années 1970 jusqu'à aujourd'hui, mais dans un cadre plus large traitant d'architecture vernaculaire.

19. Ambrosi 1990.

20. Heinich 2010.

21. Bagnéris et Jean 2017.

22. CAPEB 2008.

23. Acovitsióti-Hameau 2000 et 2007.

24. À la différence de la maçonnerie à joints vifs qui adapte la matière à la pose en la reprenant par l'action de taille, ici c'est le geste du praticien qui s'adapte à la matière pour en réaliser la pose.

25. Dans le cadre de la demande d'inscription de «l'art de la construction en pierres sèches, savoir-faire et techniques " au patrimoine culturel immatériel de l'humanité, soutenue par Chypre, la Croatie, l'Espagne, la France, la Grèce, l'Italie, la Slovénie et la Suisse, demande agréée par l'UNESCO en novembre 2018.

26. Heinich 2005.

27. Perrenoud 2008.

\section{RÉSUMÉS}

Jusqu'au milieu du $\mathrm{xx}^{\mathrm{e}}$ siècle et malgré ses spécificités, la pierre sèche est comprise dans l'architecture dite "populaire» ou «vernaculaire». La transmission de l'art est orale et empirique. Les savoir-faire transmis font partie des connaissances générales du paysan, mais aussi du maître maçon ou du tâcheron bâtisseur et de spécialistes comme les puisatiers et les miniers. De nos jours, la transmission empirique par des aînés côtoie celle enseignée en théorie et en pratique par des experts. La première communique la gestuelle, la variabilité, la profondeur historique et les contextes territoriaux et sociaux de l'activité. La deuxième met l'accent sur les matériaux et les règles de bâtir sans éliminer les autres aspects, et notamment la gestuelle. Ce courant représente la pierre sèche vue et vécue comme un métier en soi, placé entre l'artisanat et l'art et dégage ses implications environnementales, stylistiques et émotionnelles.

\section{INDEX}

Mots-clés : pierre sèche, empirisme, théorisation, professionnalisation, identité territoriale, identité culturelle, approche diachronique 


\section{AUTEURS}

\section{ADA ACOVITSIÓTI-HAMEAU}

Anthropologue culturelle, administratrice de la Société scientifique internationale pour l'étude pluridisciplinaire de la pierre sèche et de l'Association de sauvegarde, d'étude et de recherche pour le patrimoine naturel et culturel du Centre-Var

\section{LOUIS CAGIN}

Murailleur terrassier, membre de la Société scientifique internationale pour l'étude pluridisciplinaire de la pierre sèche et du Centre d'études et de recherches sur l'architecture vernaculaire, fondateur de l'association Une pierre sur l'autre 


\title{
Provenance des matériaux de
} construction du site de la citadelle d'Amiens (Somme) de l'Antiquité à nos jours : un circuit court pour des matériaux oubliés

\author{
Pascal Barrier, Pauline Leconte et Maël Pacaud
}

\begin{abstract}
Le site de la citadelle d'Amiens (Somme) a été concerné par plusieurs opérations archéologiques ces dernières années, du fait de la construction de bâtiments voués à accueillir, dès septembre 2018, le département de lettres, langues et sciences humaines de l'université de Picardie - Jules-Verne. Faisant suite à un diagnostic réalisé par l'AFAN en $2000^{1}$, les fouilles préventives réalisées par le Service d'archéologie préventive d'Amiens métropole d'octobre 2011 à mai 2015 ont permis de mettre au jour de nombreux vestiges, notamment bâtis. Ils témoignent d'un certain nombre d'occupations successives, depuis le Haut-Empire jusqu'à l'édification de la citadelle d'Amiens, commanditée par Henri IV dans les premières années du XVII ${ }^{e}$ siècle $^{2}$.
\end{abstract}

\section{Présentation du site et répartition des vestiges par secteurs}

2 Implanté sur un plateau crayeux en rive droite du fleuve Somme, le site occupé par la citadelle présente une position stratégique, dominant la vallée, qui a, de toute évidence, retenu l'attention des populations anciennes. Sept zones distinctes, dont une à l'extérieur de l'enceinte moderne de la citadelle, ont été prescrites par le service de la recherche archéologique des Hauts-de-France (fig. 1). 
Fig. 1. - Citadelle d'Amiens (Somme), fouilles archéologiques 2011-2015 : répartition des secteurs 1 à 7 .

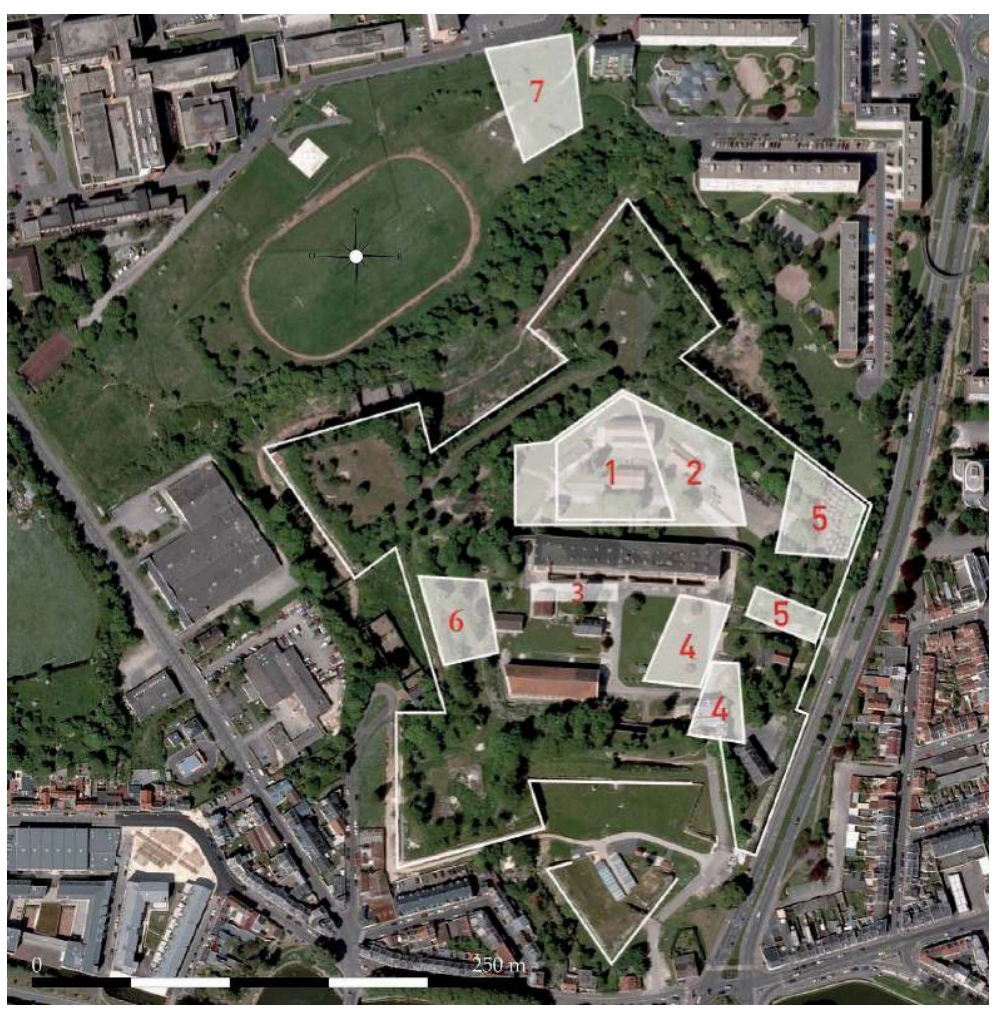

(c) Service d'archéologie préventive d'Amiens métropole.

Aux secteurs 1 et 2 correspond une occupation antique initiée dès le début du $\mathrm{I}^{\mathrm{er}}$ siècle de notre ère, et poursuivie jusqu'à la fin $\mathrm{du}_{\mathrm{IV}}^{\mathrm{e}}$ siècle. Ainsi, une première installation se met en place dès les années 15/20 ap. J.-C. et perdure jusqu'au début du II $^{\mathrm{e}}$ siècle. Un habitat est représenté dans la seconde moitié du i ${ }^{\mathrm{er}}$ siècle par des fossés parcellaires, des trous de poteau et sablières basses, ainsi que de nombreuses grandes fosses creusées directement dans le substrat crayeux. Cette zone est ensuite réinvestie par une importante nécropole durant les $\mathrm{III}^{\mathrm{e}}$ et $\mathrm{IV}^{\mathrm{e}}$ siècles, dont 160 tombes ont été fouillées ${ }^{3}$.

4 Le secteur 6, quant à lui, montre un habitat articulé autour d'un carrefour de voirie, avec entre autres les vestiges de fours et d'une cave maçonnée. Cette occupation, relativement courte, est datée de la fin du $\mathrm{I}^{\mathrm{er}}$ siècle jusqu'à la seconde moitié du $\mathrm{II}^{\mathrm{e}}$ siècle ${ }^{4}$.

5 Situé hors des murs de la citadelle actuelle, plus au nord, le secteur 7 révèle les vestiges d'une voirie s'installant au début $\mathrm{du} \mathrm{I}^{\mathrm{er}}$ siècle ainsi que deux puits livrant des restes humains, témoins d'activités funéraires dès le Haut-Empire dans cette zone. Pour les $\mathrm{II}^{\mathrm{e}}$ et $\mathrm{III}^{\mathrm{e}}$ siècles, on suppose la présence d'établissements routiers le long de la voie ${ }^{5}$.

L'occupation médiévale et moderne (secteurs 4 et 5) est caractérisée par un ensemble de vestiges bâtis témoignant de la mise en défense du site, de la fin du XII au début du $\mathrm{XVII}^{\mathrm{e}}$ siècle. D'une importance stratégique majeure, car représentant l'accès à la ville depuis Abbeville, Boulogne-sur-Mer, Arras et Saint-Pol ${ }^{6}$, la porte de ville Montrescu est probablement édifiée dès la fin du XII ${ }^{\mathrm{e}}$ siècle, avant d'être reconstruite à la fin du XIV ${ }^{\mathrm{e}}$ siècle en reprenant les normes de l'architecture philippienne, puis d'être surmontée, 
lors de l'édification de la citadelle d'Henri IV, par un corps de logis. Dès les années 1470, la défense de cette porte est renforcée par un premier boulevard d'artillerie de plan polygonal, puis à partir des années 1520 par un second boulevard plus imposant, intégrant sur son flanc oriental une deuxième porte voûtée monumentale, toujours visible de nos jours, dite porte de François $\mathrm{I}^{\mathrm{er}}$. La fouille des secteurs 4 et 5 a rendu possible la mise au jour et l'étude des fondations de ces deux ouvrages avancés successifs, le secteur 5 ayant livré un tronçon intact de la voie pavée menant d'Arras à Amiens depuis le nord-est ${ }^{7}$.

7 Signalons également ici les vestiges d'une carrière souterraine médiévale à l'ouest $d u$ secteur $6^{8}$. Bien d'autres galeries similaires sont présentes sur le site, puisque la citadelle d'Henri IV a été directement édifiée sur un important réseau de carrières souterraines antérieures ${ }^{9}$. La connaissance et la cartographie de ce très vaste réseau se déployant au moins jusqu'à l'ancien faubourg Saint-Maurice sont complétées pas à pas, depuis les explorations entreprises au xix ${ }^{e}$ siècle jusqu'aux nombreuses interventions réalisées de nos jours par le service de gestion des risques d'Amiens métropole ${ }^{10}$. Son étendue précise reste cependant impossible à estimer, la construction des fossés de la citadelle en ayant oblitéré une grande partie à la fin $\mathrm{du} \mathrm{xvI}^{\mathrm{e}}$ siècle. Des portions explorées à ce jour sur plus d'une centaine de mètres subsistent dans la partie nord de la citadelle, tandis qu'un réseau dépassant 200 mètres de longueur est connu dans le quartier voisin de Saint-Maurice. La largeur des galeries est très variable, mais peut parfois dépasser 5 mètres. Du point de vue de l'étagement vertical des galeries, les rares indices évoquent plutôt l'existence d'un seul niveau (altimétrie moyenne située autour de 31/34 mètres NGF), mais en vérité rien n'exclut que plusieurs niveaux à présent inaccessibles aient ici pu être exploités. Ainsi, la fouille du terre-plein du boulevard François- $\mathrm{I}^{\mathrm{er}}$ a mis au jour la base d'un pilier de carrière antérieur, situé à environ 31 mètres NGF et directement recoupé par les fondations de l'édifice ${ }^{11}$.

\section{Les matériaux lithiques employés au cours des siècles}

8 Au terme des fouilles de ces différents secteurs, un inventaire des roches ouvrées des éléments architecturaux antiques, médiévaux et modernes a été réalisé. Dans un premier temps, il a été macroscopique, à la loupe de terrain. Un classement des roches rencontrées en plusieurs groupes pétrographiques a été élaboré. Ensuite, chaque groupe de roches a fait l'objet d'une étude du microfaciès au microscope pétrographique polarisant, après fabrication de lames minces. La reconnaissance des microfaciès et leur positionnement précis dans la colonne stratigraphique régionale constituent un premier résultat. La lecture des cartes géologiques existantes ${ }^{12}$ et la connaissance géologique régionale des auteurs ont ensuite facilité la localisation des gîtes primaires potentiels et les propositions de lieux d'approvisionnement en matériaux de construction durant les périodes anciennes.

\section{Les roches du Haut-Empire}

Les échantillons de roches étudiées pour la période du Haut-Empire sont composés de moellons du parement interne d'une cave, d'éléments de placage découverts en remblai de grandes fosses ou fossés, et de blocs utilisés en calage de trou de poteau, dont voici 
quelques exemples. Ils ont tous fait l'objet d'une étude microfaciologique dont les résultats sont synthétisés (tabl. 1).

Tabl. 1. - Citadelle d'Amiens (Somme) : échantillons prélevés sur éléments de construction antique, étudiés en lames minces.

\begin{tabular}{|c|c|c|c|c|}
\hline $\begin{array}{l}\mathrm{N}^{\circ} \quad \text { lame } \\
\text { mince }\end{array}$ & Contexte & Objet & Diagnose & Datation roche \\
\hline CIT2172-5 & Fossé & $\begin{array}{l}\text { Élément de } \\
\text { placage }\end{array}$ & Packstone à milioles & Lutétien \\
\hline CIT0554-3 & $\begin{array}{l}\text { Calage de trou } \\
\text { de poteau }\end{array}$ & Bloc & $\begin{array}{l}\text { Grès ferrugineux à débris } \\
\text { végétaux }\end{array}$ & $\begin{array}{l}\text { Thanétien supérieur } \\
\text { à Yprésien }\end{array}$ \\
\hline CIT3160-5 & $\begin{array}{l}\text { Décapage } \quad d u \\
\text { secteur } 2\end{array}$ & $\begin{array}{l}\text { Élément de } \\
\text { placage }\end{array}$ & $\begin{array}{ll}\text { Grès } & \text { bioclastique } \\
\text { glauconieux } & \end{array}$ & $\begin{array}{l}\text { Thanétien supérieur } \\
\text { à Yprésien }\end{array}$ \\
\hline CIT2431-8 & Fosse & Moellon & \begin{tabular}{|lll} 
Calcaire à Ditrupa et \\
Orbitolites
\end{tabular} & Lutétien inférieur \\
\hline СIT0015-4 & Voirie & $\begin{array}{l}\text { Moellon en } \\
\text { réemploi }\end{array}$ & $\begin{array}{l}\text { Grès à huîtres et extraclastes } \\
\text { de craie santonienne }\end{array}$ & $\begin{array}{l}\text { Base transgressive } \\
\text { du Tertiaire }\end{array}$ \\
\hline CIT6059-1 & $\begin{array}{l}\text { Parement } \\
\text { interne de cave }\end{array}$ & Moellon & $\begin{array}{l}\text { Craie à Globotruncata et } \\
\text { spicules d'éponge }\end{array}$ & Coniacien \\
\hline CIT7297-1 & Silo & $\begin{array}{l}\text { Élément de } \\
\text { placage }\end{array}$ & $\begin{array}{l}\text { Marbre à calcite indentée } \\
\text { homogène de grain fin }\end{array}$ & Type Carrare \\
\hline
\end{tabular}

Il s'agit ici principalement de roches de provenance locale, appartenant à la craie du Santonien et $\mathrm{du}$ Coniacien, à des grès et des calcaires du Paléogène (Thanétien, Yprésien et Lutétien). Un marbre exotique a aussi été étudié. Les matériaux lithiques locaux ont été reconnus et replacés dans la stratigraphie régionale.

11 La craie santonienne (fig. 2a) affleure sur le site de la citadelle et a probablement fait l'objet d'exploitations à ciel ouvert sur site. La craie coniacienne est présente sur site mais en profondeur, comme dans les carrières souterraines, ou encore à flanc de vallée, au pied de la citadelle, où une fosse d'extraction, peut-être abandonnée dès le $\mathrm{II}^{\mathrm{e}}$ siècle, a été reconnue ${ }^{13}$. Par ailleurs, il semble que les carrières souterraines de la citadelle ou des quartiers voisins n'ont pas été exploitées au Haut-Empire. 
Fig. 2. - Citadelle d'Amiens (Somme) : les roches ouvrées de la craie.

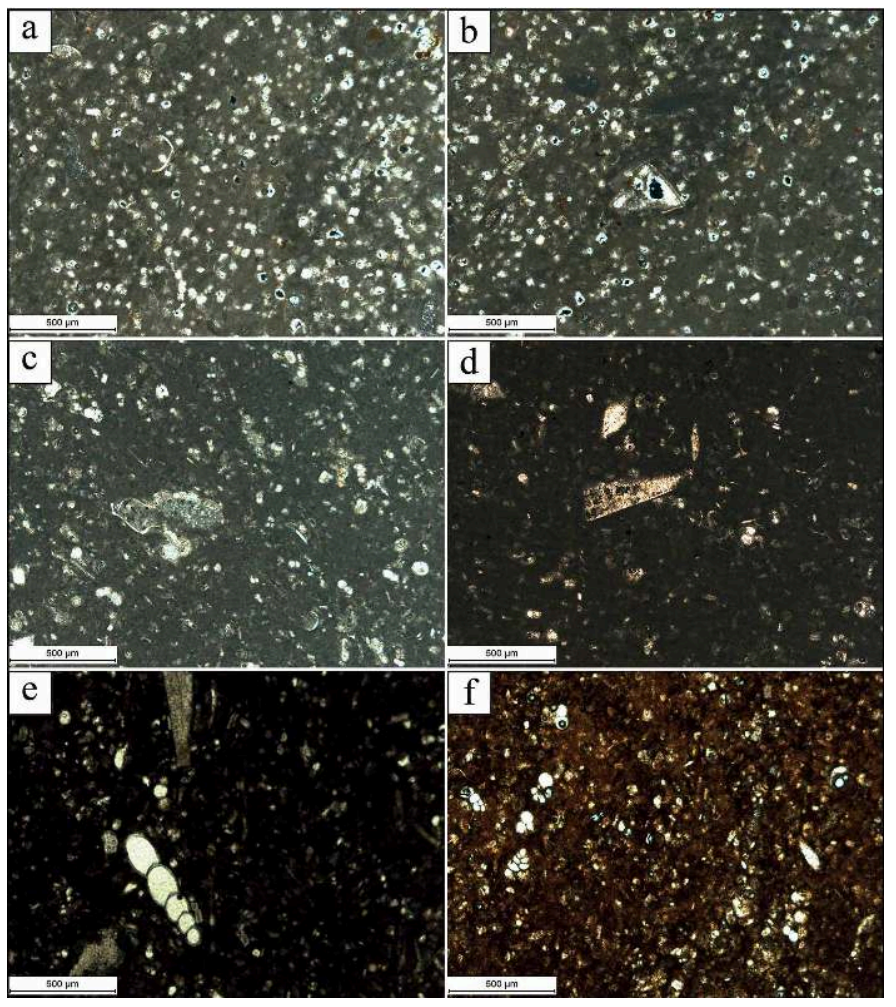

A : craie jaune magnésienne santonienne $(L N)$, wackestone à ostracodes partiellement dolomitisé (LM : CIT 0226-15). B : craie jaune magnésienne santonienne (LN), wackestone à ostracodes et Globotruncana, partiellement dolomitisé (LM : CIT 0226-15). c : craie coniacienne (LN), wackestone à Globotruncana, Heterohelix, ostracodes, spicules d'éponge (LM : CIT 6059-1). D : craie coniacienne (LN), wackestone à Inoceramus, Globotruncana, Heterohelix, ostracodes, spicules d'éponge (LM : CIT 6059-1). E : craie coniacienne (LP), wackestone à Globotruncana, Heterohelix, ostracodes, Inoceramus, spicules d'éponge (LM : CIT 8015-2). F : craie coniacienne (LN), wackestone à petits foraminifères, spicules d'éponge (LM : CIT 8015-2). LM : lame mince ; LN : lumière naturelle ; LP : lumière polarisée.

(c) Pascal Barrier et Pauline Leconte.

12 Concernant les calcaires et les grès tertiaires, ils ont été précisément reconnus et replacés, à l'échelle du banc, dans la stratigraphie régionale. En surface, ces bancs n'affleurent pas sur le site de la citadelle mais à quelques kilomètres plus au nord, dans la vallée de l'Hallue. Ce bassin gressier a ainsi livré nombre de carrières, en particulier exploitées tout au long du $\mathrm{Xv}^{\mathrm{e}}$ siècle, en raison des besoins considérables imposés alors par l'activité de pavage à Amiens et ses environs ${ }^{14}$. Cela a conduit dans un premier temps à supposer que, dès le Haut-Empire, des roches de gîtes primaires exploitées à ciel ouvert le long des rives de l'Hallue ont ensuite transité par voie d'eau jusqu'à la Somme avant d'être remontées à la Citadelle. Il faut probablement faire l'impasse sur cette première hypothèse, puisqu'il apparaît que ces mêmes roches tertiaires sont bien présentes sur les pentes de la citadelle, emballées dans les alluvions anciennes et les colluvions de la pente nord de la vallée de la Somme. En effet, on retrouve en grand nombre dans les sédiments argilo-sableux colluvionnés des blocs de grès quartzitiques thanétiens, des blocs de calcaires et grès lutétiens, et des blocs de calcaires silicifiés à restes de palmiers paléogènes ${ }^{15}$ (fig. 3). 
Fig. 3. - Citadelle d'Amiens (Somme) : les roches ouvrées du Tertiaire.

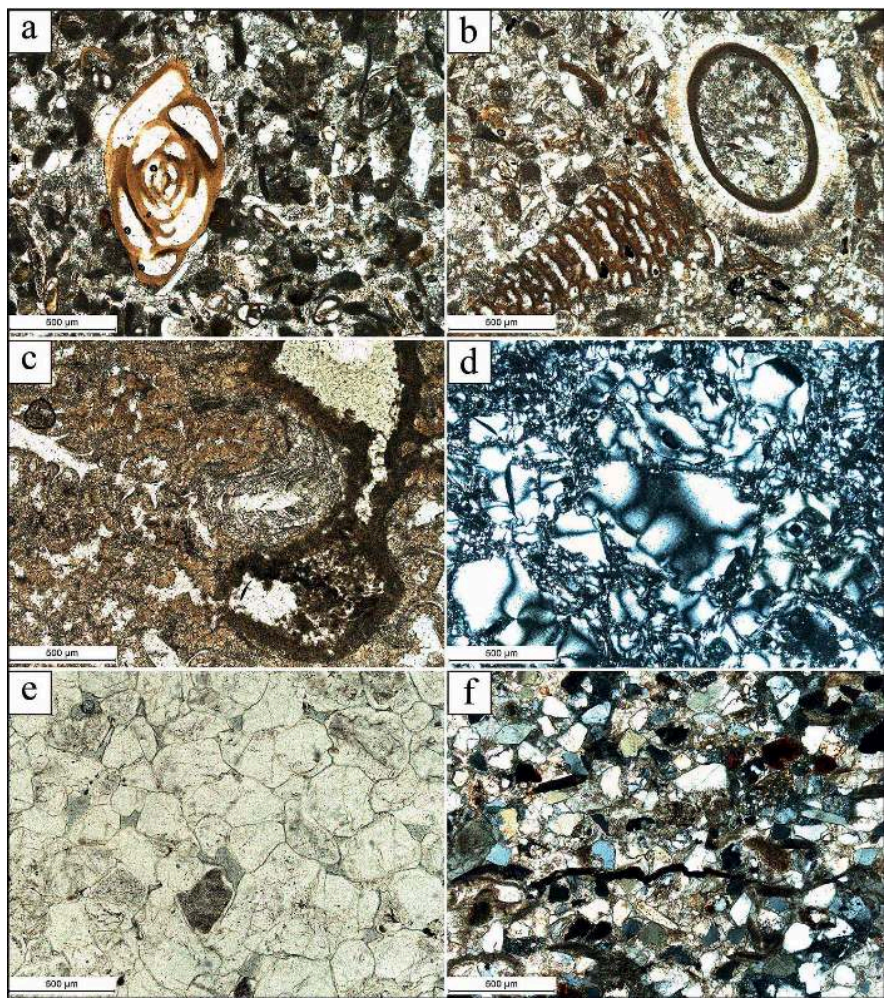

A : calcaire lutétien à milioles (LN), packstone bioclastique à intraclastes, quartz et glauconie (LM : CIT 2172-5). B : calcaire du Lutétien inférieur (LN), floatstone à Ditrupa, Orbitolites, ostracodes, quartz et pelletoïdes (LM : CIT 2437-8). c : travertin silicifié de la base du Tertiaire (LN), boundstone silicifié à stipes de palmier, cyanobactéries, nannocodium (LM : CIT 0523-10). D : silcrète de la base du Tertiaire $(\mathrm{LP})$, boundstone à pisolithes vadoses, stipes de palmier de paléosol travertineux silicifié (LM : CIT 0407-9). E : grès quartzitique thanétien à graviers de craie phosphatée $(L N)$, grès à huîtres et extraclaste de craie phosphatée à ciment quartzitique de la base transgressive du Tertiaire (LM : CIT 2685-8). F : grès ferrugineux du Thanétien supérieur/Ypréssien (LP), grès à ciment calcaire, strates obliques et débris de végétaux (LM : CIT 0554-3). LM : lame mince; $L N$ : lumière naturelle; $L P$ : lumière polarisée.

(c) Pascal Barrier et Pauline Leconte.

13 Il est donc plus vraisemblable que dès le Haut-Empire ces blocs ont été l'objet, sur site ou à proximité immédiate, d'exploitations de surface ou de ramassage sur les pentes. Il convient de signaler que, parmi les roches tertiaires utilisées, l'une d'elles est très rare dans le Tertiaire du bassin de Paris et est extrêmement bien localisée. Il s'agit des travertins silicifiés à stipes de palmier et de paléosols silicifiés (silcrète) (fig. $3 c$ et $3 \mathrm{~d}$ ). C'est probablement la première fois que ces roches sont signalées comme utilisées à l'époque romaine.

14 Concernant la roche exotique, il s'agit d'une roche métamorphique de type marbre, à cristaux de calcite indentée de grain fin. Sa texture rappelle celle des marbres blancs de Carrare, mais cette hypothèse serait à confirmer par cathodoluminescence.

\section{Périodes médiévale et moderne}

Les échantillons analysés correspondant aux maçonneries des périodes médiévale et moderne ont été prélevés directement sur les parements internes et externes des murs 
des aménagements défensifs. De nombreux prélèvements de mortiers ont également été effectués dans ces maçonneries (tabl. 2).

Tabl. 2. - Citadelle d'Amiens (Somme) : échantillons prélevés sur éléments de construction pour les périodes médiévale et moderne, étudiés en lames minces.

\begin{tabular}{|c|c|c|c|c|}
\hline $\begin{array}{l}\mathrm{N}^{\circ} \text { lame } \\
\text { mince }\end{array}$ & Contexte & Objet & Diagnose & Datation roche \\
\hline CIT9049-1 & $\begin{array}{l}\text { Blocage interne de la } \\
\text { tour du boulevard Louis- } \\
\text { XI, bas Moyen Âge }\end{array}$ & Mortier & $\begin{array}{l}\text { Mortier sableux (quartz, } \\
\text { muscovite et granules de } \\
\text { craie), identique à } \\
\text { CIT4625-2 et CIT4622-1 }\end{array}$ & $\begin{array}{l}\text { Matériaux provenant } \\
\text { de la base du Tertiaire } \\
\text { discordante sur la craie }\end{array}$ \\
\hline CIT5007-1 & $\begin{array}{l}\text { Niveau de préparation } \\
\text { de la chaussée d'Arras, } \\
\text { bas Moyen Âge }\end{array}$ & Mortier & $\begin{array}{l}\text { Mortier gravillonneux } \\
\text { (quartz émoussés, galets } \\
\text { de craie et silex) }\end{array}$ & $\begin{array}{l}\text { Matériaux provenant } \\
\text { de la base du Tertiaire } \\
\text { discordante sur la craie }\end{array}$ \\
\hline CIT5112-4 & $\begin{array}{l}\text { Parement du mur nord- } \\
\text { ouest, tour nord de la } \\
\text { porte du boulevard } \\
\text { Louis-XI, bas Moyen Âge }\end{array}$ & Mortier & $\begin{array}{l}\text { Mortier gravillonneux } \\
\text { (quartz, glauconie, galets } \\
\text { de craie), proche de } \\
\text { CIT5007-1 }\end{array}$ & $\begin{array}{l}\text { Matériaux provenant } \\
\text { de la base du Tertiaire } \\
\text { discordante sur la craie }\end{array}$ \\
\hline СIT8016-1 & $\begin{array}{l}\text { Blocage interne, porte } \\
\text { Montrescu, salle basse } \\
\text { est, tourelle d'escalier, } \\
\text { bas Moyen Âge }\end{array}$ & Mortier & 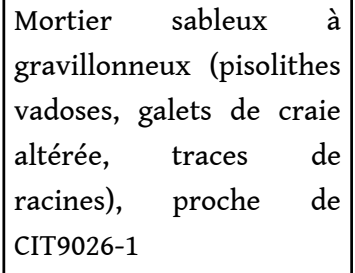 & $\begin{array}{l}\text { Matériaux provenant } \\
\text { de l'altérite du toit de } \\
\text { la craie }\end{array}$ \\
\hline CIT9026-1 & $\begin{array}{l}\text { Blocage interne de la } \\
\text { courtine du boulevard } \\
\text { Louis-XI, bas Moyen Âge }\end{array}$ & Mortier & $\begin{array}{l}\text { Mortier sableux à } \\
\text { gravillonneux } \quad \text { (quarts } \\
\text { émoussés, pisolithes } \\
\text { vadoses, galets de craie, } \\
\text { calcaire sableux) }\end{array}$ & $\begin{array}{l}\text { Matériaux provenant } \\
\text { d'un mélange des } \\
\text { sables r tertiaires } \\
\text { discordants sur la craie } \\
\text { et de l'altérite du toit } \\
\text { de la craie }\end{array}$ \\
\hline CIT8008-1 & $\begin{array}{l}\text { Blocage de maçonnerie, } \\
\text { porte Montrescu, salle } \\
\text { basse ouest, angle sud- } \\
\text { ouest, bas Moyen Âge }\end{array}$ & Mortier & $\begin{array}{l}\text { Mortier sableux à } \\
\text { gravillonneux } \\
\text { craie) }\end{array}$ & $\begin{array}{l}\text { Matériaux provenant } \\
\text { des sables de la base du } \\
\text { Tertiaire discordante } \\
\text { sur la craie }\end{array}$ \\
\hline СIT8015-2 & $\begin{array}{l}\text { Parement interne de la } \\
\text { tourelle d'escalier, porte } \\
\text { Montrescu, bas Moyen } \\
\text { Âge }\end{array}$ & Moellon & $\begin{array}{l}\text { Craie partiellement } \\
\text { dolomitisée }\end{array}$ & Coniacien \\
\hline СIT8001-1 & $\begin{array}{l}\text { Fondations de la porte } \\
\text { Montrescu, salle basse } \\
\text { ouest, bas Moyen Âge }\end{array}$ & Mortier & $\mid \begin{array}{lr}\text { Mortier } \quad \text { sableux } & \text { à } \\
\text { gravillonneux (galets } & \text { de } \\
\text { craie), identique } & \text { à } \\
\text { CIT8008-1 } & \end{array}$ & $\begin{array}{l}\text { Matériaux provenant } \\
\text { de la base du Tertiaire } \\
\text { discordante sur la craie }\end{array}$ \\
\hline CIT5117-3 & $\begin{array}{l}\text { Parement externe, mur } \\
\text { d'escarpe du fossé, bas } \\
\text { Moyen Âge }\end{array}$ & Moellon & Grès quartzitique & Thanétien supérieur \\
\hline
\end{tabular}




\begin{tabular}{|c|c|c|c|c|}
\hline CIT4014-1 & $\begin{array}{l}\text { Parement externe du } \\
\text { mur de fondation du } \\
\text { boulevard François-I } \mathrm{I}^{\mathrm{er}} \text {, } \\
\text { époque moderne }\end{array}$ & Moellon & $\begin{array}{l}\text { Grès avec remaniement } \\
\text { de craie santonienne, } \\
\text { identique à CIT0015-4 }\end{array}$ & $\begin{array}{l}\text { Base érosive du } \\
\text { Tertiaire }\end{array}$ \\
\hline CIT4625-1 & $\begin{array}{l}\text { Parement ouest, } \\
\text { boulevard François- } \mathrm{I}^{\mathrm{er}} \text {, } \\
\text { galerie de contre-mine; } \\
\text { chambre de tir est, mur } \\
\text { de refend, époque } \\
\text { moderne }\end{array}$ & Mortier & $\begin{array}{l}\text { Mortier sableux (quartz, } \\
\text { muscovite et granules de } \\
\text { craie) }\end{array}$ & $\begin{array}{l}\text { Matériaux provenant } \\
\text { de la base du Tertiaire } \\
\text { discordante sur la craie }\end{array}$ \\
\hline CIT4622-1 & $\begin{array}{l}\text { Parement interne, } \\
\text { boulevard François-I }{ }^{\mathrm{er}} \text {, } \\
\text { galerie de contre-mine; } \\
\text { galeries sud et est, } \\
\text { époque moderne }\end{array}$ & Mortier & $\begin{array}{l}\text { Mortier sableux (quartz, } \\
\text { muscovite et granules de } \\
\text { craie), identique à } \\
\text { CIT4625-1 }\end{array}$ & $\begin{array}{l}\text { Matériaux provenant } \\
\text { de la base du Tertiaire } \\
\text { discordante sur la craie }\end{array}$ \\
\hline
\end{tabular}

16 Les analyses pétrographiques réalisées montrent, comme pour la période du HautEmpire, une production sur site des matériaux. C'est le cas des moellons, mais aussi des mortiers, qui sont fabriqués sur site avec les produits présents dans les altérites de la craie (fig. 4). 
Fig. 4. - Citadelle d'Amiens (Somme) : matériaux des mortiers.

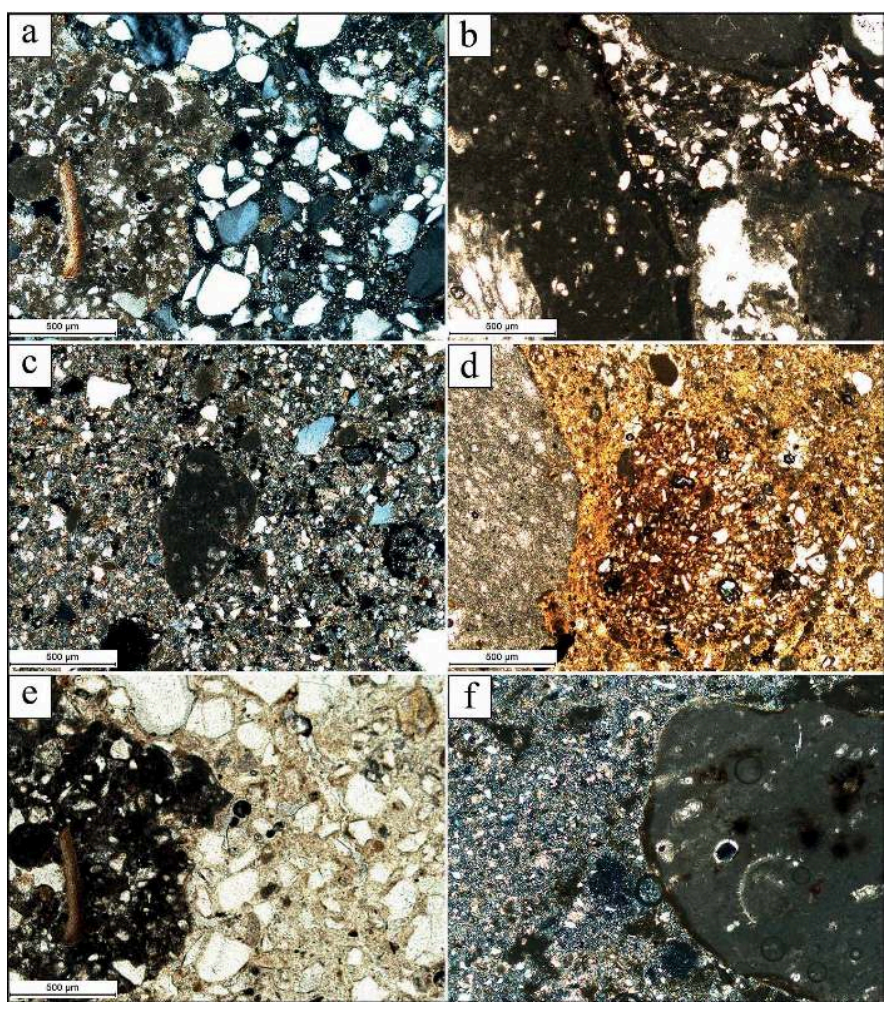

A : argile à graviers provenant de la base érosive du tertiaire (LN), quartz, graviers de craie sénonienne et silex (LM : CIT 5007-1). B : argile à graviers de craie sénonienne (LP) : quartz, bryozoaire, glauconie provenant des sables tertiaires thanétiens érosifs sur la craie (LM : CIT 5112-4). c : argile à quartz, muscovite et graviers de craie $(L N)$ provenant des sables thanétiens érosifs sur la craie sénonienne (LM : CIT 9049-1). D : argile à graviers de craie sénonienne (LN) : quartz, pisolithes vadoses, traces de racines provenant de l'atérite argileuse du toit de la craie (LM : CIT 8016-1). E : argile à quartz, graviers de craie (LN), pisolithes vadoses issus d'un mélange de sables thanétiens et d'altérite du toit de la craie (LM : CIT 9026-1). F : argile à quartz et graviers (LP) provenant des sables de la base érosive du Tertiaire sur la craie sénonienne (LM : CIT 8008-1). LM : lame mince ; LN : lumière naturelle ; LP : lumière polarisée.

(c) Pascal Barrier et Pauline Leconte.

17 Ainsi, les moellons de craie proviennent en grande partie des bancs coniaciens identiques à ceux présents dans les carrières souterraines de la citadelle (fig. 2b, 2c). Cette affirmation repose sur la comparaison des lames minces d'échantillons prélevés dans les carrières souterraines avec les lames minces effectuées dans chacun des éléments de construction étudiés. Il n'y a donc à présent aucun doute sur le fait que ces pierres de taille employées dans les boulevards défendant la porte Montrescu aux xve et $\mathrm{XVI}^{\mathrm{e}}$ siècles proviennent directement de ces carrières souterraines.

Quant aux moellons de grès et de calcaire tertiaires (fig. 3) issus de ces constructions médiévales et modernes, ils ont précisément la même nature que ceux présents dans les édifices du Haut-Empire et proviennent certainement des mêmes gisements primaires, c'est-à-dire les alluvions anciennes de la Somme et les colluvions de pente situées directement à l'amont du site. Les auteurs de la notice de la carte géologique du BRGM, échelle $1 / 50000$, signalent, sans citer leurs sources, que ces colluvions et alluvions ont été largement exploitées pour extraire la pierre au Moyen Âge ${ }^{16}$.

19 L'extraction de matériaux locaux est aussi envisagée pour les mortiers. Les matériaux qui les constituent sont tous potentiellement présents sur le site. Les inclusions de 
pisolithes vadoses, granules de craie, graviers de craie à base de racine, présentes dans les argiles des mortiers, démontrent clairement qu'elles proviennent des altérites de la craie. Le sable utilisé comme dégraissant est aussi celui de la base du Tertiaire, avec sa glauconie et ses bioclastes caractéristiques (fig. 4).

De manière générale, l'extraction des matériaux lithiques semble également se rationaliser à cette période, comme le démontre l'omniprésence de signes lapidaires sur les parements d'édifices datés de la fin du XIV siècle, telles les fondations de la porte Montrescu ${ }^{17}$.

\section{Les carrières de craie de la citadelle d'Amiens: exploitations antiques et médiévales}

21 L'apport principal de l'étude pétrographique reste donc la détermination d'une origine locale de la plupart des matériaux de construction, en particulier la craie du Coniacien présente in situ dans le sous-sol ${ }^{18}$. L'utilisation de ce dernier matériau a, par exemple, été observée pour le parement d'une cave datée du $\mathrm{II}^{\mathrm{e}}$ siècle $^{19}$ ou encore pour celui de la tourelle d'escalier de la porte Montrescu, édifice daté de la fin du XIve / courant $\mathrm{Xv}^{\mathrm{e}}$ siècle $^{20}$. Il faut également signaler l'emploi systématique de nombreux éclats de silex noir dans le blocage interne des tours défendant la porte Montrescu, ainsi que dans les ouvrages avancés successifs défendant le site jusqu'à la fin du XvI ${ }^{e}$ siècle ${ }^{21}$. Or, le silex noir est reconnu comme étant associé à la craie du Coniacien observée à Amiens et est, très probablement, issu de l'extraction de ce matériau.

Le développement précis de ce réseau de carrières au cours du temps reste également mal connu à ce jour. L'exploitation des carrières est attestée de manière certaine à partir de la fin du XIV ${ }^{e}$ siècle $^{22}$, tandis que les sources comptables des maitres d'œuvre font régulièrement état de fournitures provenant des carrières de Saint-Maurice et de travaux d'extraction à même les fossés, au-devant de la porte Montrescu, dès la première moitié $d u \mathrm{Xv}^{\mathrm{e}}$ siècle, et ce jusqu'au dernier quart du $\mathrm{XvI}^{\mathrm{e}}$ siècle ${ }^{23}$. D'un point de vue archéologique, le principal témoignage de cette exploitation de masse reste la quantité considérable de matériaux crayeux et de silex employés, autant dans les parements et blocages internes que dans les recharges de voiries, de l'Antiquité jusqu'au XvII ${ }^{e}$ siècle. Il convient de ne pas oublier la production de chaux pour la confection du mortier ; l'existence de structures liées à cette activité est attestée autant pour la période antique ${ }^{24}$ que pour la période médiévale ${ }^{25}$.

Nous pouvons par conséquent entrevoir l'existence d'une activité d'extraction souterraine et d'exploitation de la craie intensive et très structurée, au moins pour la période médiévale, qui tire peut-être son origine d'exploitations antiques plus localisées à ciel ouvert, mais néanmoins bien présentes. La question d'une continuité de cette exploitation reste difficile à résoudre et rejoint les lacunes archéologiques observées pour le haut Moyen Âge lors des fouilles de la citadelle ${ }^{26}$. Néanmoins nous observons, indifféremment de la période considérée, une grande variété des déclinaisons du matériau crayeux, qui permet de conclure que l'extraction en carrière est accompagnée d'une logique de tri du matériau et des déchets de taille, ce qui implique une rationalisation poussée de la chaîne opératoire, de l'extraction à la pose du produit fini. 


\section{Les signes lapidaires : regard sur un chantier de construction de la seconde moitié du $\mathrm{XV}^{\mathrm{e}}$ siècle}

24 Cette rationalisation est à généraliser jusqu'au stade du chantier de construction, en particulier pour les grands ouvrages avancés défendant la porte Montrescu à la fin du Moyen Âge (fig. 5 et 6). Les principaux témoins de cette organisation très structurée des corps de métiers restent les nombreux signes lapidaires ${ }^{27}$ (fig. 7) observés sur chacune des pierres à bâtir en craie.

Fig. 5. - Citadelle d'Amiens (Somme), ouvrages avancés de la porte Montrescu : répartition des signes lapidaires.

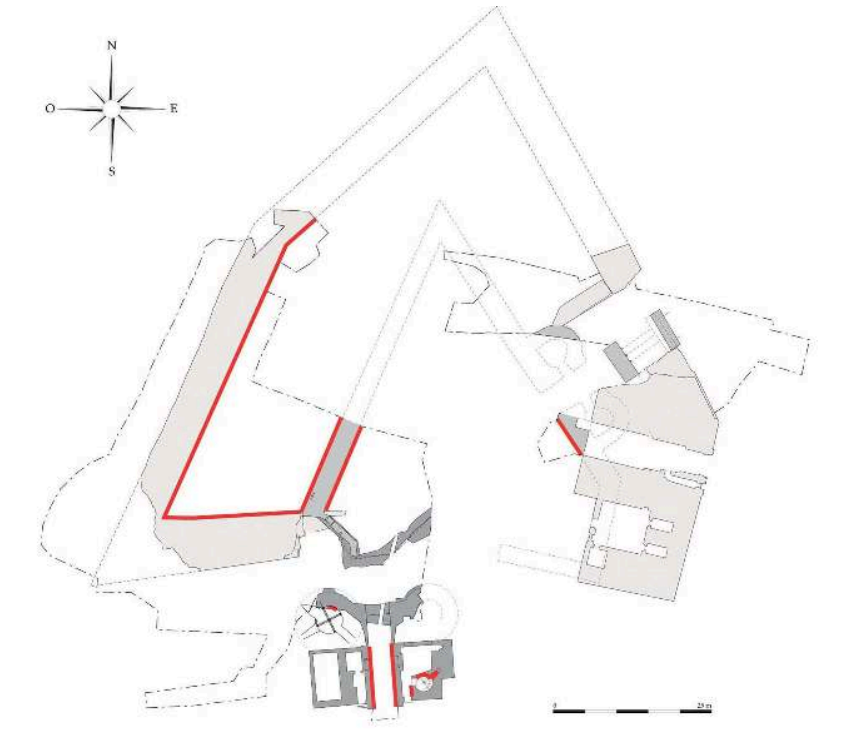

Porte Montrescu (Fin XIVe s.)

Boulevard de Louis XI (1471-1476)

Boulevard de François $1^{\mathrm{er}}$ (Première moitié XVIe s.)

Répartition des signes lapidaires

Topographie Erick Mariette, DAO Maël Pacaud. 
Fig. 6. - Citadelle d'Amiens (Somme) : vue d'ensemble du secteur 4.

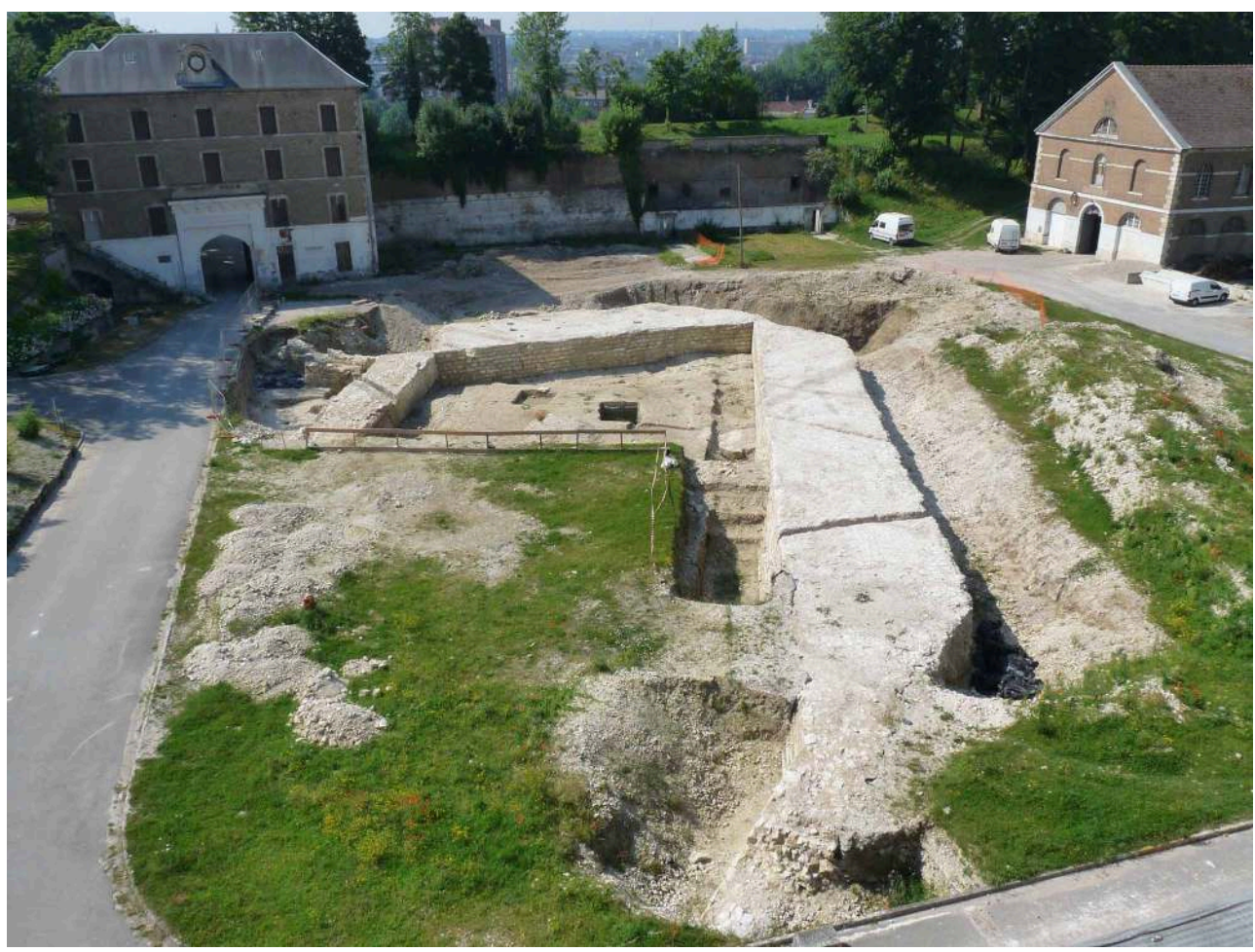

(c) Service d'archéologie préventive d'Amiens métropole.

Fig. 7. - Citadelle d'Amiens (Somme) : vue de détail sur un signe lapidaire.

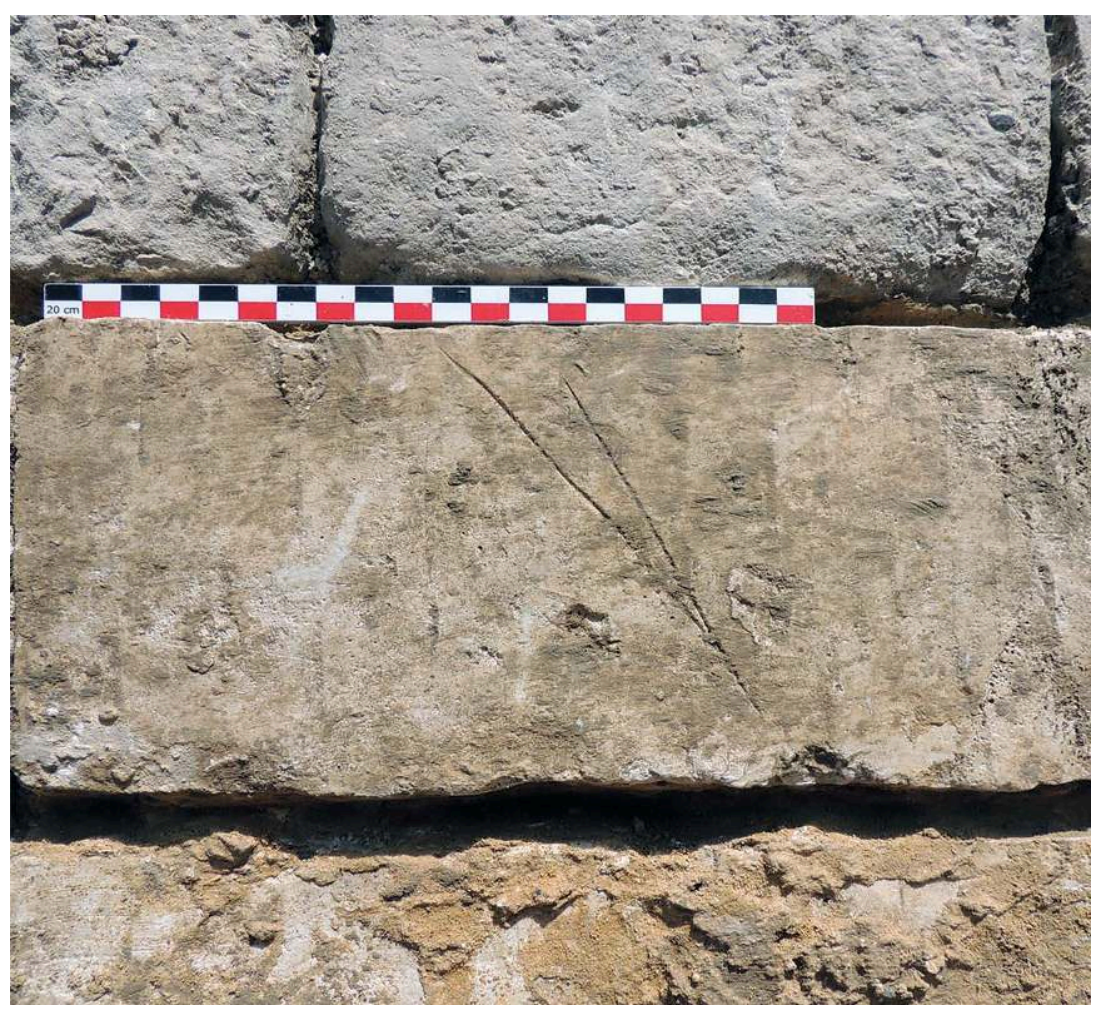

(c) Service d'archéologie préventive d'Amiens métropole. 
quasi-totalité de cet ensemble prend la forme de chiffres romains directement incisés sur le bloc, de "I» à "IX». En ce qui concerne les ouvrages qui nous intéressent, ce procédé de marquage rudimentaire - avec parfois des ratés et des réécritures - semble être employé dès la fin $d u$ XIV$^{\mathrm{e}}$ siècle, dans les fondations de la porte Montrescu, et au moins jusqu'à la première moitié du $\mathrm{xVI}^{\mathrm{e}}$ siècle, dans les fondations du boulevard de François $\mathrm{I}^{\mathrm{er}}$. Il apparaît que leur emploi dépasse largement le cadre de ces constructions civiles. De plus, ces marques ont été maintes fois identifiées dans l'Amiénois, indépendamment de la fonction et du statut de l'édifice: civil, privatif, religieux, etc. ${ }^{28}$. Une première étude exhaustive des parements avait notamment été entreprise au château de Boves $^{29}$, situé à 8 kilomètres au sud-est d'Amiens : l'enquête avait conclu à l'omniprésence de ces marques de calibrage sur les ouvrages édifiés entre le $\mathrm{XII}^{\mathrm{e}}$ et le $\mathrm{XVI}^{\mathrm{e}}$ siècle ${ }^{30}$. Ces dernières années, de nombreux cas ont été signalés en dehors de la Picardie, dans un vaste champ d'observation qui se superpose à la carte de répartition des crayères du Bassin parisien. Parmi nombre de sites d'importance pour cette question, l'on peut mentionner le château de Gisors (Eure), dans le Vexin français ${ }^{31}$, celui de Montsoreau (Maine-et-Loire), en Anjou ${ }^{32}$, ou encore l'abbaye Saint-Remi de Reims (Marne) pour la région champenoise ${ }^{33}$.

Au sujet de la fonction de ces signes, leur emploi systématique oriente vers un signe à vocation utilitaire, voué à transmettre une information concernant le bloc manipulé ${ }^{34}$. Une corrélation très nette entre ces marques et un panel de hauteurs d'assise distinctes est constatée pour les maçonneries les mieux représentées, telles celles du boulevard Louis-XI, édifiées dans la décennie 1470 (fig. 8).

Fig. 8. - Citadelle d'Amiens (Somme), parement interne des fondations du boulevard Louis-XI : répartition des signes lapidaires.

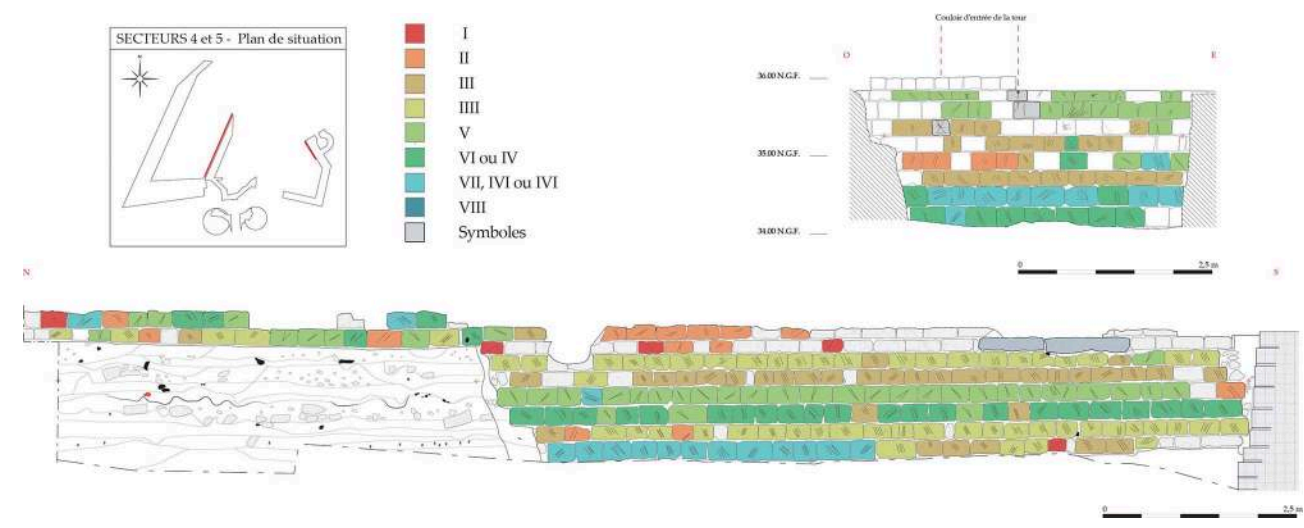

(c) Service d'archéologie préventive d'Amiens métropole.

Les blocs examinés y sont marqués après taille et avant leur pose par les maçons, les hauteurs d'assise étant réparties de 15 à $25 \mathrm{~cm}$, soit 6 à 10 pouces. Ces constats trouvent ici un parallèle fort avec ceux effectués en 2005 par le service archéologique départemental de Maine-et-Loire, lors de l'étude du bâti engagée au château de Montsoreau, édifié de 1450 à $1462^{35}$. Un système de signes lapidaires identiques et gravés sommairement après taille y avait été observé sur un certain nombre de pierres de taille en tuffeau. Ce système y avait également été mis en correspondance avec l'emploi de différentes valeurs de module de hauteur. Les auteurs soulignaient d'ailleurs que la même observation avait fréquemment été faite sur de nombreux édifices du val de Loire érigés au moins à partir du XIv ${ }^{\mathrm{e}}$ siècle, voire antérieurement ${ }^{36}$. 
Toutefois, la valeur des hauteurs mesurées à Montsoreau, autour de $30 \mathrm{~cm}$, est plus importante que celle observée sur le boulevard Louis-XI à Amiens, dont l'édification est quasiment contemporaine. Cela pourrait être lié à la densité du matériau : le tuffeau employé à Montsoreau est fortement poreux ${ }^{37}$ et permet vraisemblablement l'élaboration de pierres de taille plus légères et manœuvrables par un ou deux maçons. Plus près d'Amiens, des modules bien plus petits - autour de $16 \mathrm{~cm}$ de hauteur - étaient employés à Douai, sur les parements des fortifications urbaines, où les dimensions des pierres dites « communes » en grès, et de ce fait plus denses, étaient déterminées dès la seconde moitié du XIII ${ }^{\mathrm{e}}$ siècle par un ban échevinal ${ }^{38}$.

D'autres données conduisent à envisager ici que ce système de signes lié à des valeurs de hauteur de module est très spécifique à cette période de la seconde moitié $d u \mathrm{xv}^{\mathrm{e}}$ siècle. En effet, ces valeurs sont bien plus élevées pour les blocs constituant les ouvrages postérieurs du boulevard François- $\mathrm{I}^{\mathrm{er}}$ et de la citadelle, et ne semblent pas être partagées par les ouvrages antérieurs de la porte Montrescu. Cela illustre que certaines habitudes de construction sont, dans le cas de la citadelle d'Amiens, soumises à des changements entre le bas Moyen Âge et l'époque moderne. Ainsi, le moyen module employé dans les chantiers de la décennie 1470 correspond à celui d'une pierre de taille manœuvrable par un seul homme, alors qu'il faut vraisemblablement avoir recours à des engins de levage pour manipuler les blocs de grand module employés dans les chantiers du Xvi ${ }^{e}$ siècle. À Boves, Pierre Gillon avait constaté la permanence de certains étalonnages entre le $\mathrm{XII}^{\mathrm{e}}$ et le $\mathrm{xV}^{\mathrm{e}}$ siècle, tel le signe « V », correspondant à une hauteur d'assise d'environ $19 \mathrm{~cm}^{39}$. Le même auteur avait également relevé de grandes variations d'une maçonnerie à l'autre, ce qui l'a amené à supposer que le calibrage était défini et réalisé à pied d'œuvre, selon la fonction de l'ouvrage ${ }^{40}$.

Aussi, loin de limiter ce phénomène au seul pays de Somme, il faut peut-être envisager un mode de communication lié à l'exploitation de plus en plus intensive de matériaux calcaires durant la période médiévale, étendu aux crayères du Bassin parisien. En ce qui concerne le val de Loire, la généralisation de ce système avait été mise en relation avec une volonté d'exploiter au mieux le matériau extrait de la carrière en fonction de la fissuration de la roche et des techniques d'extraction ${ }^{41}$. Le même constat peut être fait pour les carrières d'Amiens, où les exploitants ont pu transmettre à travers le temps un savoir autant technique qu'opératoire, et l'adapter ou le modifier en fonction des mutations de l'industrie du bâtiment durant les périodes médiévale et moderne.

La mise en commun des études réalisées à l'issue des fouilles du site de la citadelle d'Amiens, autant sur les matériaux de construction que sur le bâti préservé, a mis en exergue un réseau d'approvisionnement local en matériaux de construction probablement très actif dès la période antique. Objectivement, l'éventuelle continuité de cette exploitation jusqu'à la période médiévale n'est, en l'état actuel des connaissances, pas démontrée. Cependant, l'identification de roches communes à ces occupations successives - notamment les grès tertiaires - laisse supposer une persistance de l'activité locale des carriers sur certains matériaux de construction, privilégiant ainsi les « circuits courts ».

31 Quant aux signes lapidaires recensés en nombre sur les ouvrages fortifiés édifiés du XIV $\mathrm{au} \mathrm{XVI}^{\mathrm{e}}$ siècle, ils témoignent de la mise en place et de la poursuite sur le long terme 
d'une exploitation intensive et optimisée, davantage orientée vers les matériaux crayeux. Les sources échevinales d'Amiens rendent compte d'un arrêt subit de cette exploitation en 1579 , lorsque le comblement des carrières et fours à chaux « hors la porte Montrescu » fut imposé par les autorités scabinales ${ }^{42}$.

Nul doute qu'une systématisation de ces observations sur les opérations archéologiques à venir sur Amiens pourrait affiner notre compréhension de ce vaste réseau d'approvisionnement local et, de plus, enrichir la réflexion sur l'organisation des chantiers de construction durant les périodes antique, médiévale et moderne.

\section{BIBLIOGRAPHIE}

BARRIER P., 2015, « Diagnoses pétrographiques de roches ouvrées et de matériel céramique », rapport d'analyses, Beauvais, institut polytechnique LaSalle.

BÉGHIN M., 2015, « "Pour le bien et utilite de ladite ville et du pays environ" : l'activité de pavage à Amiens dans ses faubourgs et sa banlieue au $\mathrm{Xv}^{\mathrm{e}}$ siècle », Bulletin de la Société des antiquaires de Picardie, t. 70, nº 715-716, p. 774-814.

DUPUIS C. et KUNTZ G., 1972, Carte géologique à 1/50 000, Amiens, feuille XXIII-8, Orléans, Éditions du BRGM.

GEHMEL D., 2000, « Amiens, “citadelle”, 03/07/2000-29/12/2000 », rapport de diagnostic archéologique, Amiens, AFAN, Antenne interrégionale Nord-Picardie.

GILLON P., 2012, « Une étape dans la rationalisation de la construction au Moyen Âge : les marque de calibrage ", dans Racinet P. (dir.), Recherches pluridisciplinaires sur un terroir picard de l'époque antique à la Révolution française : Boves. Étude du mobilier 1996-2006), Senlis, Revue archéologique de Picardie (n 1-2) p. 189-194.

gosselet J., CAyeuX L., Mercey N. de, 1894, Carte géologique détaillée de la France 1/80 000, Amiens, feuille 12, Paris, Service de la carte géologique de la France.

HAMON É., 2008, Un chantier flamboyant et son rayonnement : Gisors et les églises du Vexin français, Besançon, Presses universitaires de Franche-Comté.

HUNOT J.-Y., LITOUX E., PRIGENT D., 2008, « Un chantier de construction du Xve siècle : le château de Montsoreau (Maine-et-Loire). La progression des travaux à partir de l'étude des maçonneries ", dans Blary F., Gély J.-P., Lorenz J. (dir.), Pierres du patrimoine européen : économie de la pierre de l'Antiquité à la fin des Temps modernes, Paris, Éditions du CTHS / Château-Thierry, Patrimoine vivant, p. 196-206.

LASCOUR V., 2012, « Amiens, avenue Charles-de-Gaulle », vol. 1 : « Texte », rapport de fouille archéologique, Amiens, INRAP Nord-Picardie.

LECONTE P., 2017, « La citadelle : arrière nord, Amiens, Somme. Rapport final d'opération », Amiens, Service d'archéologie préventive d'Amiens métropole (SAAM).

MILLEREUX-LE BÉCHENNEC J., 2016, « La citadelle, Amiens, Somme : secteurs 1, 2 et 6. Rapport final d'opération », Amiens, Service d'archéologie préventive d'Amiens métropole (SAAM). 
PINSARD C., 1889, « Marques de tâcherons tailleurs de pierre sur les constructions du département de la Somme », Bulletin de la Société des antiquaires de Picardie, t. 16, p. 20-22.

PRIGENT D., 1997, « Exploitation et commercialisation du tuffeau blanc ( $\mathrm{XV}^{\mathrm{e}}$-XIX $\mathrm{X}^{\mathrm{e}}$ siècles) », Annales de Bretagne et des pays de l'Ouest, t. 104, $\mathrm{n}^{\circ}$ 3, p. 67-80.

PRIGENT D., 2003, «Évolution de la construction médiévale en pierre en Anjou et Touraine », dans MacNeill J. et Prigent D. (dir.), Anjou medieval art, architecture and archaeology, Leeds, British Archaeological Association, p. 14-33.

RAPONE F., 2016, « La citadelle, Amiens, Somme : l'occupation médiévale et moderne (secteurs 4, 5 et 8). Rapport final d'opération ", Amiens, Service d'archéologie préventive d'Amiens métropole (SAAM).

ROLAND R. et ROLAND M., 1990, Amiens : des carrières, de la craie et des hommes, Amiens, Bibliothèque municipale.

SAlamagne A., 2001, Construire au Moyen Âge : les fortifications de Douai, Lille, Presses universitaires du Septentrion.

TOURTEBATTE P., 1996, « Ville de Reims, voie des sacres : les carrières souterraines de craie à Reims », dans Lorenz J. (dir.), Carrières et constructions en France et dans les pays limitrophes, t. 3 , Paris, Éditions du CTHS, p. 119-133.

VAN BELLE J.-L., WAROUX R., PETROONS R. (dir.), 1994, Signes lapidaires : nouveau dictionnaire. Belgique et nord de la France, Braine-le-Château, Artel.

\section{NOTES}

1. Gehmel $2000: 1-66$.

2. Millereux-Le Béchennec 2016 : 520-521.

3. Ibid.

4. Ibid.

5. Leconte $2017: 238$.

6. Rapone $2016: 209-210$ et 47-55.

7. Ibid.

8. Millereux-Le Béchennec 2016 : 166.

9. Roland et Roland $1990: 16-17$.

10. Données SIG Amiens métropole.

11. Rapone $2016: 35$.

12. Dupuis et Kuntz 1972 ; Gosselet et al. 1894.

13. Lascour $2012: 12$ et 14.

14. Béghin 2015 : 774-814.

15. Dupuis et Kuntz 1972 ; Gosselet et al. 1894.

16. Dupuis et Kuntz 1972.

17. Rapone $2016: 59$ et 138.

18. Barrier 2015 : 33. 
19. Millereux-Le Béchennec 2016 : 221-231.

20. Rapone $2016: 74$.

21. Ibid. : 60.

22. Roland et Roland $1990: 17$

23. Ibid.

24. Rapone $2016: 35$.

25. Roland et Roland $1990: 17$.

26. Rapone $2016: 30$.

27. Rapone 2016 : 135-147.

28. Pinsard $1889: 21$.

29. Gillon 2012 : 189-194.

30. Ibid. : 191.

31. Hamon $2008: 485$.

32. Hunot et al. 2008 : 195-206.

33. Tourtebatte $1996: 130$.

34. Van Belle et al. $1994: 10$.

35. Hunot et al. $2008: 195$.

36. Ibid. : 201

37. Prigent $1997: 68$.

38. Salamagne $2001: 155$.

39. Gillon 2012 : 191.

40. Ibid. : 189

41. Hunot et al. 2008 : 201 ; Prigent 2003 : 14-33.

42. Roland et Roland $1990: 17$.

\section{RÉSUMÉS}

Les fouilles menées de 2011 à 2015 à la citadelle d'Amiens (Somme) par le Service d'archéologie préventive d'Amiens métropole (SAAM) ont révélé un site densément occupé depuis le HautEmpire. Implanté sur un plateau crayeux dominant en rive droite de la Somme, ce site stratégique a livré les vestiges d'un quartier suburbain et d'une zone funéraire antiques, puis d'un réseau de carrières souterraines de craie exploitées au Moyen Âge. Cette densité est aussi exprimée par la variété des pierres de construction. Un inventaire pétrographique visant à déterminer la provenance des matériaux utilisés a été réalisé. L'étude du microfaciès des roches démontre leur provenance locale : craie et son altérite, ainsi que différentes roches de la couverture tertiaire issues des colluvions de pente. L'exploitation de ce gisement dès l'Antiquité devient intensive et rationalisée au Moyen Âge, comme le démontre, de plus, l'omniprésence des 
signes lapidaires; à tel point que les roches tertiaires amiénoises ne sont plus visibles que dans les vestiges des périodes anciennes.

INDEX

Mots-clés : géoarchéologie, provenance des matériaux, citadelle, époque romaine, Moyen Âge Index géographique : Amiens

\section{AUTEURS}

PASCAL BARRIER

Institut polytechnique UniLaSalle

\section{PAULINE LECONTE}

Service d'archéologie préventive d'Amiens métropole

MAËL PACAUD

Service d'archéologie préventive d'Amiens métropole 


\title{
Des pierres pour une ville disparue au XVI ${ }^{\mathrm{e}}$ siècle : Thérouanne (Pas-de- Calais)
}

\author{
François Blary et Jean-Pierre Gély
}

\section{Problématique}

1 L'étude de l'approvisionnement en matériaux de construction d'une ville apporte un éclairage particulier à l'histoire matérielle sur un temps long au fil de l'évolution urbaine $^{1}$. Localisée à une quinzaine de kilomètres de Saint-Omer (Pas-de-Calais), la ville de Thérouanne a un passé particulièrement riche. Elle fut chef-lieu de la cité des Morins, et s'étendait à la fin du $\mathrm{III}^{\mathrm{e}}$ siècle sur presque 140 hectares. Le statut et l'importance de la ville au Moyen Âge sont révélés par la mention de l'existence d'un groupe épiscopal à partir du $\mathrm{VII}^{\mathrm{e}}$ siècle et d'une cathédrale édifiée dès l'époque carolingienne. Elle contrôle une partie de l'accès au littoral et souffre de nombreux assauts, notamment durant la guerre de Cent Ans. Au début du Xvi ${ }^{\mathrm{e}}$ siècle, elle constitue une enclave royale française en territoire impérial des Pays-Bas. Assiégée sans succès en 1513 et en 1537, elle finit par se rendre à Charles Quint, après deux mois de siège en 1553. La ville est alors intégralement rasée et toute reconstruction y est interdite. Depuis, le site de la «Vieille Ville » a été rendu à l'agriculture. La ville de Thérouanne constitue ainsi un gisement exceptionnel pour la connaissance de l'histoire antique et médiévale. Elle offre un cas d'étude particulier où l'état de son abandon a été figé. Elle fait depuis un siècle l'objet de fouilles archéologiques, en l'absence de tout reste architectural encore en élévation. Du fait de la récupération des matériaux lors de sa destruction, les niveaux de démolitions ne renferment que des débris architecturaux qui scellent des murs arasés. Néanmoins, cet état permet d'appréhender la persistance ou non des sources d'approvisionnement depuis sa fondation jusqu'à l'aube des Temps modernes, dans une région frontalière entre l'Artois et la Flandre.

2 L'étude des matériaux lithiques a été menée dans le cadre d'une étude pluridisciplinaire d'un projet collectif de recherche (PCR) : «PCR Thérouanne : ville 
antique et médiévale 2015-2017 ». En 2014, à la demande de Stéphane Révillon, alors conservateur régional pour l'archéologie de la région Nord-Pas-de-Calais, ce PCR a été lancé afin de mener l'étude de la ville antique et médiévale de Thérouanne. Un large panel de personnalités, de chercheurs d'horizons divers, d'acteurs locaux, aux compétences reconnues et complémentaires, a été constitué. Pendant les trois années de ce PCR, la recherche a été menée en réunissant les membres par petits groupes, voire en échanges ciblés, afin de rendre compte du travail de chacun, restitué dans les rapports remis annuellement ${ }^{2}$. Placé sous la direction de François Blary, ce PCR rassemble une équipe pluridisciplinaire (archéologues, géologues, géophysiciens, historiens, historiens de l'art) dont l'objectif est d'aboutir à une meilleure connaissance de la cité des Morins en mutualisant leurs savoirs et en menant des prospections archéologiques utilisant les techniques les plus modernes: résistivité électrique, magnétique, électromagnétique couplées de dernière génération. Les prospections micro-topographiques et géophysiques ont été réalisées intégralement, tel que le projet initial avait été défini. L'ensemble a donné de bons résultats, qui ont largement confirmé la faisabilité de l'étude urbaine de la ville de Thérouanne et l'apport indéniable des méthodes géophysiques en la matière. Depuis 2018, un nouveau cycle d'études est engagé, le PCR 2018-2022, qui a pour but la publication des données réunies et la mise en œuvre de bases de données accessibles en ligne.

3 Une reconnaissance macroscopique des différentes natures et faciès de pierre sur les blocs architecturaux découverts en fouilles archéologiques et déposés dans les dépôts lapidaires de Thérouanne et d'Arras a été réalisée. Parallèlement, les carrières entourant la ville ont été reconnues par une campagne LiDAR, à la suite d'une enquête de terrain. À l'échelle régionale, une recherche bibliographique des centres carriers historiques ayant pu contribuer à approvisionner la ville a été entreprise. L'étude conjointe des centres carriers et des monuments de la ville permet in fine de dresser la carte d'approvisionnement des chantiers urbains pour chaque grande période historique.

\section{Les ressources lithiques disponibles}

4 La ville de Thérouanne est située dans la vallée de la Lys, à la traversée des collines de l'Artois, quelques kilomètres avant d'atteindre la plaine de Flandre. La vallée est encaissée dans la craie blanche à silex du Coniacien, le plus souvent recouverte par des altérites, des colluvions de flanc de coteau, des limons et des lœss sur les plateaux. La craie saine n'affleure pas, il faut nécessairement creuser une dizaine de mètres pour la rencontrer. La ville est dominée au nord par de petites collines, buttes-témoins formées d'argiles et de sables du Landénien (Thanétien), dont les sables sont parfois cimentés en grès froids.

5 La craie, le sable et l'argile sont donc les matières minérales répandues sur tout le territoire. Le simple moellon brut, ici le silex de la craie, issu du ramassage en plein champ, sur affleurement naturel ou dans de petites carrières, immédiatement autour $\mathrm{du}$ chantier de construction, est abondant. L'approvisionnement en chaux dans une région largement pourvue en craie et en ressource en bois est aisé. Mais l'élément constructif le plus recherché reste la belle pierre d'appareil, dans une région où ne sont disponibles que la craie tendre et un peu de grès froids difficiles à tailler. 
6 De l'accessibilité, de la qualité et de l'abondance de la ressource en pierres dimensionnelles dépendront l'ambition du programme architectural et les efforts financiers consentis par le commanditaire de l'œuvre, ainsi que la durée des travaux. Dès lors se pose la question du choix des matériaux au regard des ressources proches ou lointaines disponibles autour des grands chantiers, à l'exemple de la cathédrale de Saint-Omer ${ }^{3}$ (Pas-de-Calais), la ville la plus proche de Thérouanne.

\section{Les ressources lithiques sollicitées à l'Antiquité}

\section{La pierre de Marquise (Pas-de-Calais)}

7 Peu d'éléments architecturaux de la période antique de la cité des Morins, qui deviendra Thérouanne au Moyen Âge, nous sont parvenus, et aucun monument public n'a encore été identifié. D'après Camille Enlart, qui a fouillé au début du $\mathrm{xx}^{\mathrm{e}}$ siècle le chœur et le transept de la cathédrale consacrée en 1133 :

«[...] un gros mur composé de pierres énormes qui traversait le transept de bout en bout. C'était, sans nul doute, l'ancien mur d'enceinte [du Bas-Empire], et la primitive cathédrale correspondant à la nef de celle qui nous occupe, y appliquait son chevet. Plus tard, le mur fut démoli et la cathédrale, comme la ville elle-même, le dépassèrent pour s'étendre à l'est ${ }^{4}$.»

8 Ce point est confirmé par Honoré Bernard, qui a poursuivi les fouilles dans les années 1970 et $1980^{5}$.

9 Si l'on se réfère aux qualités de roche privilégiées dans les constructions monumentales de la Gaule du nord, le grand module était taillé dans de la pierre assez tendre pour être facilement façonnée et assez ferme pour supporter des élévations parfois de plusieurs dizaines de mètres. Aucune ressource locale ne répond à cette exigence. Les architectes romains des monuments publics devaient nécessairement importer de la pierre de grand module.

10 C. Enlart reconnaît ainsi la pierre de Marquise, qui a largement diffusé aux confins septentrionaux de l'empire romain :

«Les débris de monuments gallo-romains ne sont plus en place, mais remployés dans les fondations des $\mathrm{XII}^{\mathrm{e}}$ et XIII ${ }^{\mathrm{e}}$ siècles. Thérouanne étant dépourvue de bonne pierre, c'est au nord de Boulogne, à Marquise, que les constructeurs étaient allés chercher leurs matériaux dès le III e siècle au moins ${ }^{6}$.»

11 Le grand chapiteau romain découvert le long de la chaussée Brunehaut ${ }^{7}$ et les blocs architectoniques conservés au centre archéologique d'Arras ont tous été sculptés dans un calcaire ooïdique plus ou moins grossier, crème, à lits sédimentaires bien visibles, contenant des débris d'échinodermes. Cette roche est caractéristique de la formation géologique des calcaires de Marquise-Rinxent, affleurant dans le Boulonnais et d'âge Bathonien supérieur (Jurassique moyen) ${ }^{8}$. Ces calcaires ont été exploités à Marquise dans les carrières des Calhaudes et des Warennes ; à Leulinghen (Pas-de-Calais) dans les carrières de la Pierre Bleue et de la Queue du Gibet, et au nord d'Hardenthun (commune de Marquise) jusqu'au début du $\mathrm{xx}^{\mathrm{e}}$ siècle (fig. 1) 
Fig. 1. - Schéma d'approvisionnement de la ville de Thérouanne (Pas-de-Calais) placée sur une carte géologique simplifiée.

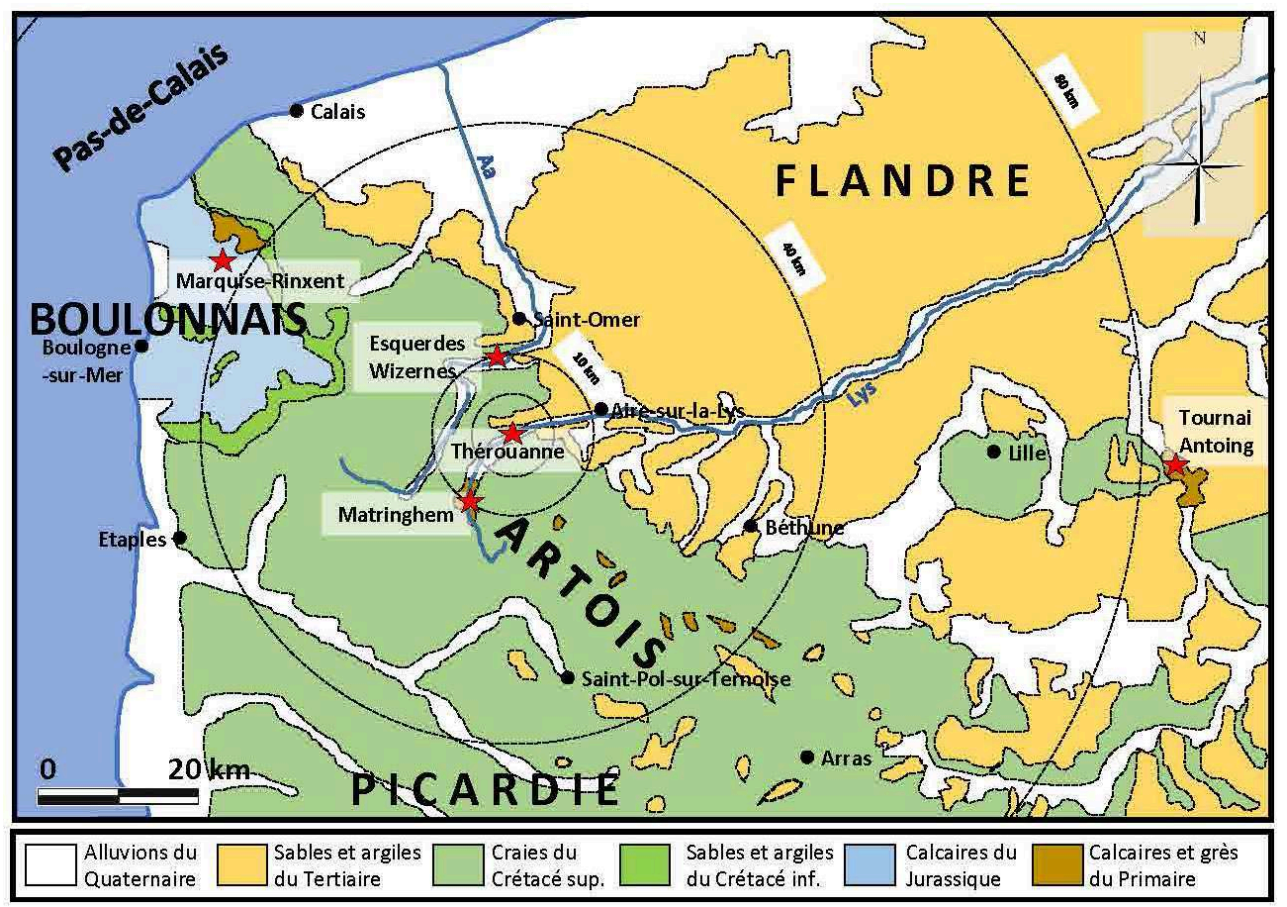

(c) Jean-Pierre Gély.

12 Ce grand centre carrier a exporté ses pierres de grand appareil dès le Haut-Empire, par cabotage le long des côtes picardes et des Flandres, mais également en Angleterre (Dover, Richborough) ${ }^{9}$. Le transport par cabotage à travers le détroit du Pas-de-Calais jusqu'à l'embouchure de l'Aa, puis la remontée du fleuve un peu au-delà de Saint-Omer permettaient un transport par voie de terre sur 15 kilomètres seulement jusqu'à la cité des Morins, comme le note déjà C. Enlart en $1906^{10}$. Le transport pouvait également se faire en totalité par voie terrestre, sur une distance d'une cinquantaine de kilomètres, le réseau routier antique entre Boulogne et Arras passant par Thérouanne (Tervanna) ${ }^{11}$.

\section{La pierre de Matringhem (Pas-de-Calais)}

Si le grand appareil antique provient des calcaires du Boulonnais, la découverte récente d'un mur d'une grande construction en opus mixtum (parcelle cadastrale $A B 25$ ) en grès est unique à ce jour. Le mur est bâti en moellons équarris et en plaquettes d'un centimètre d'épaisseur environ de grès fin, gris verdâtre, dur, parfois finement lité, dépourvu de fossiles. Ce grès est différent des grès massifs du Landénien qui ont été extraits sur les buttes-témoins aux alentours de Thérouanne. Le long du cours amont de la Lys à partir de Thérouanne, ce grès fin a été identifié dans les premières assises des murs de l'église de Dennebrœucq. C'est effectivement à partir de cette commune qu'affleure le grès de Matringhem, d'âge Siegénien inférieur (Dévonien inférieur). Cette formation gréseuse affleure largement dans la région de Matringhem et constitue l'essentiel du massif primaire de Matringhem (fig. 1). Ce sont des grès le plus souvent blancs à gris verdâtre, plus rarement rouges, en bancs réguliers, admettant quelques intercalations schisteuses ou argileuses rouges ou blanches. 
Le transport des moellons équarris et des plaquettes retrouvées dans le mur de l'édifice antique s'est effectué sur une distance de 10 kilomètres, le long de la vallée de la Lys. Cela reste à ce jour le seul exemple d'utilisation de ce matériau à Thérouanne.

\section{Les ressources lithiques locales utilisées au Moyen Âge}

\section{La craie blanche à silex noirs}

En absence de témoin archéologique, il n'est pas possible d'affirmer que les GalloRomains utilisaient la craie blanche à silex comme pierre d'appareil à Thérouanne. Cependant, C. Enlart mentionne :

«À l'Antiquité chrétienne, on ne peut attribuer qu'un très infime fragment de mur de petit appareil retrouvé à $3 \mathrm{~m} 35$ au-dessous du sol du sanctuaire [la cathédrale]. Il n'en restait que deux assises formées de petits cubes de craie dont la face extérieure portait de grosses stries disposées en losanges et rappelant certains sarcophages du VII ${ }^{\mathrm{e}}$ siècle, notamment celui de saint Erkembode, de Saint-Omer, qui provient de Thérouanne ${ }^{12}$. »

En revanche, appartenant au Moyen Âge classique, plus de cinquante fragments de blocs d'architecture, comme du moellon, de la simple pierre dimensionnelle, des colonnes, des colonnettes engagées, des remplages ou des claveaux, mais également des éléments de mobiliers polychromes, sont formés d'une craie blanche à très légèrement grise. Cette craie contenant quelques silex noirs disséminés dans la masse, est identique à celle qui a servi à la construction de l'église de Nielles-lès-Thérouanne, rare édifice médiéval ayant subsisté dans les environs immédiats de Thérouanne. Ce matériau est de loin le plus abondant pour les blocs architecturaux. Il correspond à un approvisionnement proche de la ville.

Effectivement, des extractions de craie blanche du Coniacien sont signalées dans le vallon sec du Petit Cavin, aux Fosses Machaut, à 3 kilomètres au sud de Thérouanne, sur la carte topographique d'état-major de la première moitié du $\mathrm{xIX}^{\mathrm{e}}$ siècle. Une reconnaissance de terrain a permis de localiser précisément le centre carrier de Nielles, qui avait été reconnu et prospecté dans les années $1990^{13}$. En arrière d'anciennes entrées en cavage bouchées, les carrières effondrées peuvent être rapportées à la période médiévale. Elles ont provoqué de légères ondulations en surface qui sont bien visibles en reconnaissance LiDAR (fig. 2). En continuité de ces carrières effondrées, des carrières à piliers tournés ont été exploitées pour la pierre de construction et peuvent être datées du début des Temps modernes. Par la suite, plus profondément situées sous le plateau et plus au sud, immédiatement à l'est du pont de la Folie, des carrières en bouteille avec accès par puits appelés «catiches ${ }^{14}$ » sont datées de la fin des Temps modernes au XIX ${ }^{e}$ siècle. 
Fig. 2. - Extension du centre carrier de Nielles-les-Thérouanne (Pas-de-Calais) interprétée sur l'image LiDAR (MNT 5 m_MULTI-HS_D64_H35_Ve3.0_RGB).

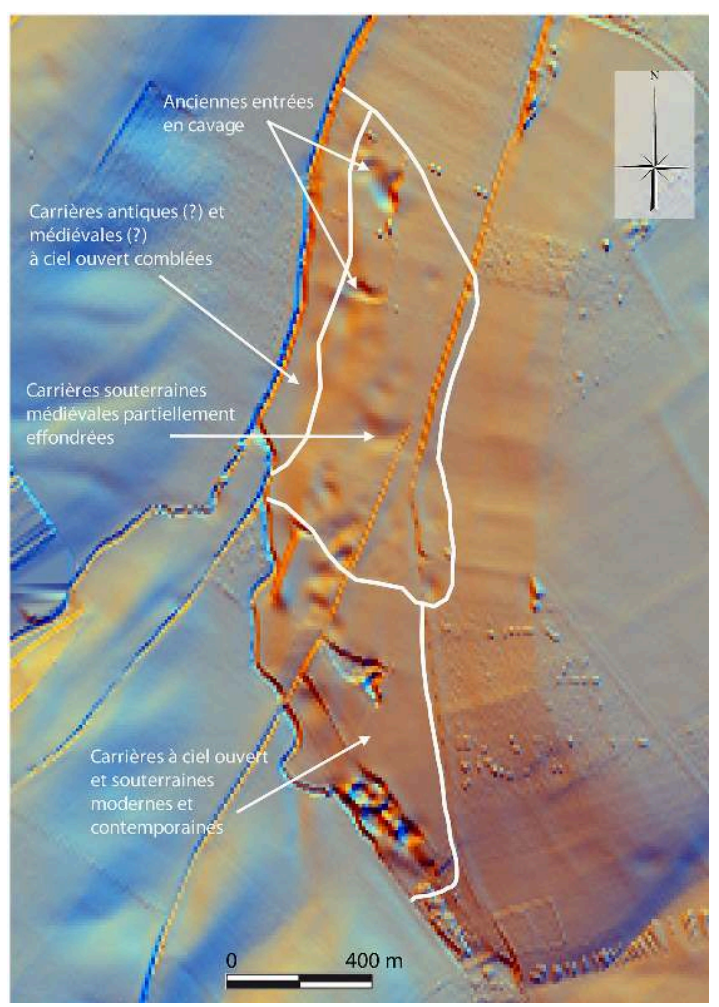

(c) Jean-Pierre Gély.

Lors des prospections en carrières souterraines, il a été trouvé des pierres en attente ayant subi une première taille, et même, pour l'une d'entre elles, la forme préparatoire d'un élément d'un escalier à vis, avant la phase de finalisation effectuée sur le chantier de construction ${ }^{15}$ (fig. 3). 
Fig. 3. - Nielles-lès-Thérouanne (Pas-de-Calais), réseau 1 des carrières souterraines : ébauche de marche d'escalier à vis découverte avec d'autres pierres d'appareil : craie blanche, fine, traçante, avec silex noirs (élément lapidaire $n^{\circ} 26 r$ ).

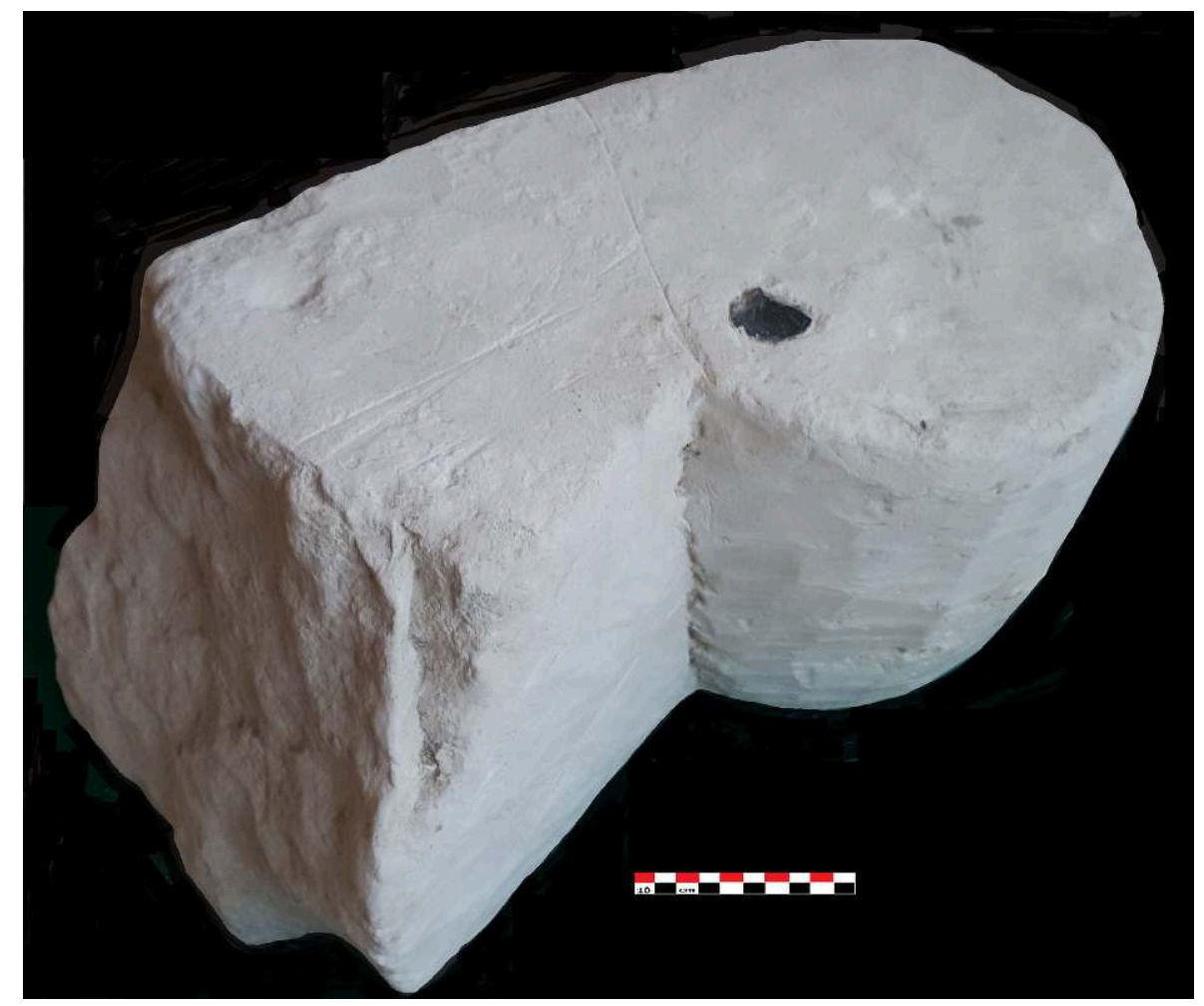

(c) Jean-Pierre Gély.

19 D'autres centres carriers éloignés de moins 10 kilomètres pouvaient également alimenter en craie blanche à silex du Coniacien les chantiers de la ville de Thérouanne. À 8 kilomètres à l'ouest de Thérouanne, le centre carrier de Cléty a pu fournir de la pierre dimensionnelle. Nous savons que le centre d'Estrée-Blanche, situé à 7 kilomètres au sud-est de Thérouanne, sur la route d'Arras, alimentait dans les premières années du $\mathrm{XVII}^{\mathrm{e}}$ siècle la ville d'Aire-sur-la-Lys ${ }^{16}$. En revanche, le centre carrier de Saint-HilaireCottes, fournissant la " pierre de Cottènes ", qui alimentait également Aire-sur-la-Lys à la même époque ${ }^{17}$, est situé à plus de 10 kilomètres de Thérouanne. Dans l'état actuel de nos connaissances et dans l'incapacité de prospecter les anciennes carrières, aujourd'hui inaccessibles, il est impossible de différencier les craies de ces différents centres carriers.

\section{Les grès du Landénien}

La formation géologique des sables et grès d'Ostricourt (Landénien supérieur) renferme des lentilles et amas de grès quartzeux très dur, propre à fournir de belles pierres d'appareil et des pavés extraits dans des carrières appelées "gresseries " dans les textes anciens. Des sablières sont indiquées sur les buttes-témoins dominant la rive gauche de la vallée de la Lys au nord de Thérouanne, au Mont-Saint-Martin et au bois d'Enfer. Le sable a pu être utilisé pour l'élaboration des mortiers et pour l'alimentation de verreries. Aux alentours de Thérouanne, dans les églises médiévales ou du début des 
Temps modernes, les soubassements des murs sont systématiquement appareillés en grès landéniens, avant de présenter une élévation en craie blanche à silex noirs.

21 Dans le lapidaire de Thérouanne, aucune pierre en grès n'est présente. Elles ont été soit systématiquement récupérées lors de la destruction de la ville, soit, n'étant pas sculptées, non prélevées et non conservées lors de leur découverte dans les fouilles archéologiques anciennes. Seuls des boulets calibrés de canon médiévaux en grès d'Ostricourt sont conservés dans le lapidaire de Thérouanne.

\section{Les ressources régionales et inter-régionales sollicitées à la période médiévale}

\section{La craie légèrement glauconieuse}

Dans le nord de la France et jusqu'en haute Normandie, la limite Turonien supérieurConiacien inférieur est représentée par des craies compactes ayant localement subi des phénomènes diagénétiques qui en font de bonnes pierres d'appareil. Les bancs de craies du Coniacien inférieur, au voisinage du Turonien supérieur auquel ils passent sans limite précise, sont formés d'une craie grise ou grossière, parfois très légèrement glauconieuse. Vers la base, les silex sont généralement plus petits et moins régulièrement répartis en lits; une patine rose paraît les caractériser. Ces bancs massifs ont été exploités localement comme pierre de taille. Ces craies compactes n'affleurent pas dans la vallée de la Lys mais plus au nord, dans la vallée voisine de l'Aa. Cette craie a été exploitée comme pierre de taille dans de grands centres carriers, à Esquerdes et à Wizernes notamment, jusqu'à la fin du XIX ${ }^{e}$ siècle (fig. 1).

Le bassin carrier d'Esquerdes-Wizernes, situé à proximité du chemin médiéval de SaintOmer à Thérouanne, a alimenté les chantiers de construction des villes d'Arques et de Saint-Omer pendant le Moyen Âge et les Temps modernes. L'un des portails de la cathédrale de Saint-Omer a été construit en pierre de Wizernes ${ }^{18}$.

Une craie légèrement glauconieuse, indurée, à terriers remplis de craie glauconieuse jaune verdâtre pouvant être attribués à ces couches de passage Turonien-Coniacien, exploitée notamment à Wizernes et à Esquerdes, a été reconnue sur six éléments de mobilier intérieur de la cathédrale (tombeau, jubé ?) (fig. 4). 
Fig. 4. - Thérouanne (Pas-de-Calais) : débris de moulure, craie légèrement glauconieuse, indurée, jaune verdâtre (élément lapidaire $n^{\circ} 38 \mathrm{r}$ ).

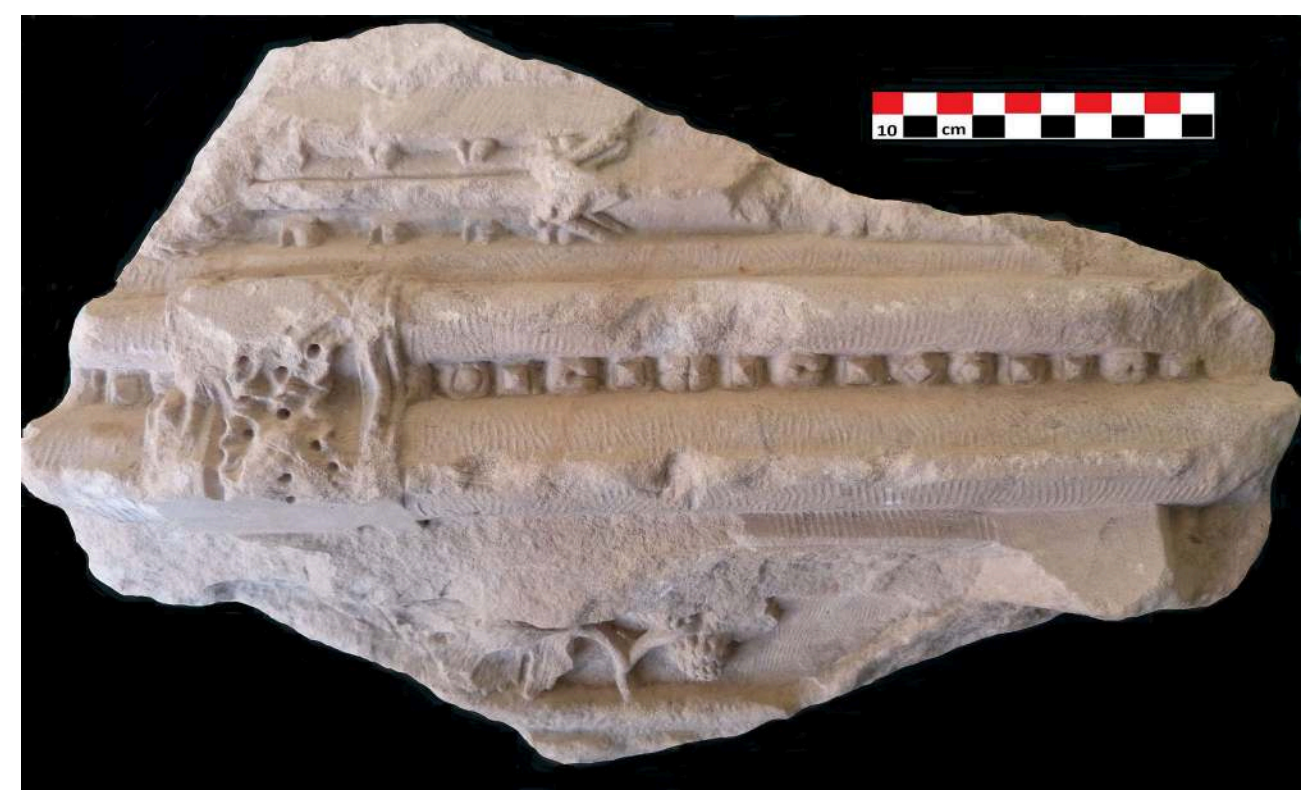

(c) François Blary.

\section{La pierre noire marbrière de Tournai, dite « pierre bleue »}

Nous savons que la pierre de Tournai a été largement utilisée dans la cathédrale. D’après C. Enlart :

« La pierre de Tournai se mêle à celle de Marquise, comme à N.-D. de Saint-Omer, dans les travaux $\mathrm{du} \mathrm{XII}^{\mathrm{e}}$ siècle, qui comprirent la reconstruction de l'abside, le transept et le grand portail. L'abside du XIII ${ }^{\mathrm{e}}$ siècle, analogue à celle de l'ancienne cathédrale d'Arras, avait des colonnes couplées en pierre noire de Tournai [de 69 $\mathrm{cm}$ de diamètre $]^{19}$.

Seulement trois éléments conservés dans le dépôt lapidaire de Thérouanne sont sculptés dans un calcaire marbrier gris noir, à passées très légèrement schisteuses, à patine gris beige, ferme à dur, rapporté au calcaire du Tournaisien des environs de Tournai, en Belgique (fig. 1). Ils appartiennent probablement à un mobilier funéraire de la cathédrale (fig. 5). 
Fig. 5. - Thérouanne (Pas-de-Calais) : débris de moulure, calcaire marbrier gris noir (élément lapidaire $\mathrm{n}^{\circ}$ 80r).

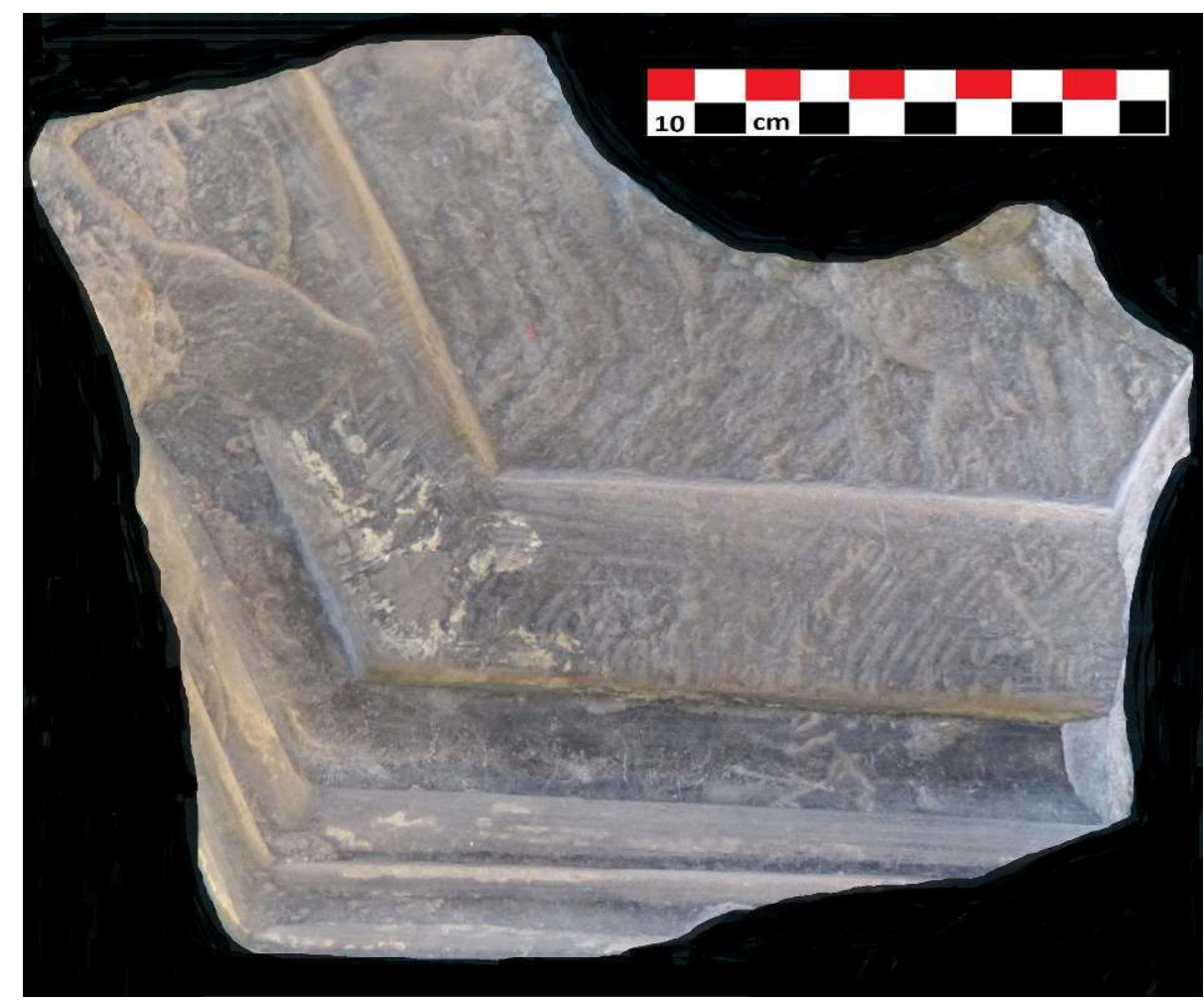

(c) François Blary.

La pierre de Tournai a très largement été diffusée dès le Haut-Empire ${ }^{20}$, puis tout au long du Moyen Âge ${ }^{21}$. Sa diffusion sous forme de mobilier religieux et funéraire a même atteint Saint-Denis-en-France à l'époque carolingienne ${ }^{22}$.

En revanche, il n'a pas été identifié à Thérouanne de pierre d'Écaussinnes (Belgique), dite "petit granit». Il est vrai que cette pierre de l'Ardenne commence à diffuser seulement à partir de la fin de la première moitié $\mathrm{du} \mathrm{xv}^{\mathrm{e}}$ siècle, d'abord en Flandre, puis en Artois $^{23}$. Par exemple, huit colonnes et bonne quantité de blocs en pierre d'Écaussines arrivèrent par voie d'eau du port de Gand à Aire-sur-la-Lys en $1600^{24}$.

\section{La pierre de Marquise}

29 Toujours d'après C. Enlart,

«Des fragments d'arcature pourraient avoir formé un triforium trapu en pierre de Marquise, dont les arcs en plein cintre redentés retombaient sur de courtes colonnettes et sur des piédroits garnis de crochets, comme ceux des tours de NotreDame de Paris ${ }^{25}$.»

Nous savons que le centre carrier de Marquise-Rinxent était très actif à l'époque médiévale ${ }^{26}$. La pierre de Marquise est reconnue dans de nombreux monuments médiévaux du nord de la France et de la Belgique.

Plus de soixante blocs en pierre de Marquise ont été répertoriés dans le dépôt lapidaire de Thérouanne. Certains blocs sont des débris d'éléments architectonique de bâtiment religieux de grande qualité, d'autres appartiennent à un mobilier d'intérieur (funéraire, jubé ?) (fig. 6). 
Fig. 6. - Thérouanne (Pas-de-Calais) : chapiteau du XII siècle avec des encoches de crampons de scellement et les traces de bretture effectuées lors d'une repose (?) : calcaire ooïdique, crème, avec quelques débris d'échinodermes (élément lapidaire $n^{\circ} \mathrm{OES} 1$ ).

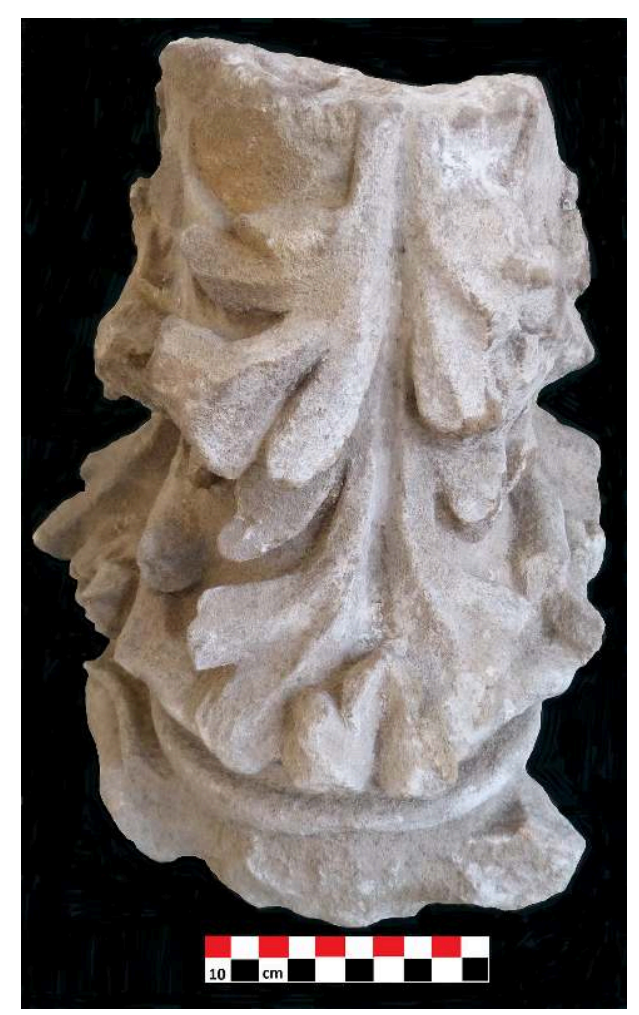

(c) François Blary.

Un dernier groupe de blocs reconnu dans le dépôt lapidaire de Thérouanne est issu d'un dallage de très haute qualité appartenant à la cathédrale. La cathédrale fut terminée seulement par l'évêque Henri I ${ }^{\text {er }}$ des Murs, qui mourut en 1280. Son épitaphe, publiée dans le Gallia christiana, dit qu'il fit faire le pavement. C. Enlart décrit ainsi ce pavement :

"Quant au pavement, nous en avons retrouvé un grand nombre de débris. C'est, comme ceux de Notre-Dame et de Saint-Bertin de Saint-Omer et jadis celui de la cathédrale d'Arras, un assemblage de dalles de pierre de Marquise ornées de dessins en champlevé, dont les creux sont remplis d'un mastic noir. Ces dalles portent le plus souvent des médaillons cantonnés d'écoinçons et entourés d'un cadre à inscription. Les sujets sont l'histoire d'Adam, celle de Noé, celle de Joseph, et d'autres scènes trop mutilées pour permettre une identification certaine, puis, sur des dalles de moindres dimensions, des fantaisies, des monstres comme l'Évêque de Mer, des scènes réelles, comme le Vigneron, qui a dû faire partie de la série des travaux des Mois, accompagnant un zodiaque. Enfin une large frise de rinceaux formait un encadrement.

"Tous ces pavements sont d'un style et d'un dessin excellents ; figures, animaux, ornements et caractères d'inscriptions sont plus beaux que dans aucun des pavements similaires que l'on conserve; malheureusement, la plupart sont brisés en menus morceaux ${ }^{27}$. »

Les éléments encore conservés confirment pleinement les déterminations de C. Enlart (fig. 7). 
Fig. 7. - Thérouanne (Pas-de-Calais) : débris de dalle de la cathédrale incrusté de mastic, calcaire ooïdique à débris d'échinodermes, dur, crème foncé, supportant le polissage (élément lapidaire $\mathrm{n}^{\circ}$ H12 65).

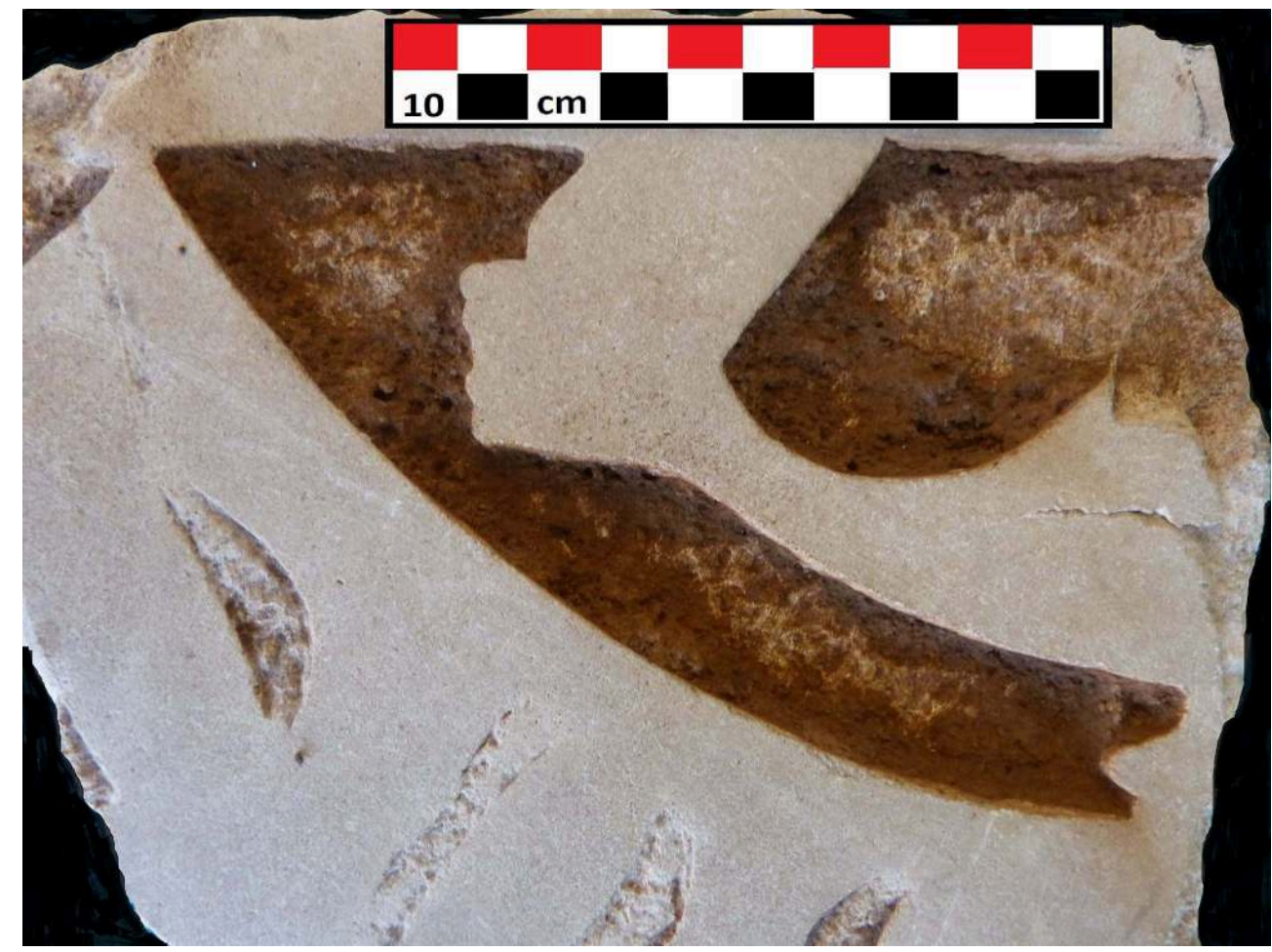

(c) François Blary

Lors de la destruction de la ville et de ses monuments, la récupération des matériaux de construction fut probablement massive, à l'exemple bien connu du portail de la cathédrale. Ainsi, dans les comptes de la ville d'Aire-sur-la-Lys en ces premières années du XvII ${ }^{\mathrm{e}}$ siècle, un dénommé J. Cousin de Thérouanne livre 46 pierres [de Marquise]. Il semble qu'il y ait eu un dépôt à Thérouanne; seraient-ce encore des matériaux de l'ancienne cathédrale? Question que pose A. Lavoine ${ }^{28}$.

\section{L'évolution du schéma d'approvisionnement de Thérouanne}

Localement, la ville de Thérouanne a bénéficié de deux ressources lithiques abondantes en son terroir: la craie blanche à silex du Coniacien et les grès du Landénien. La première est fragile et gélive, mais facile à tailler et à sculpter. La seconde est dure à froide, résistante à l'écrasement et à l'altération météorique, mais très difficile à tailler et à sculpter.

Ainsi, dès l'époque du Haut-Empire, les bâtisseurs de monuments publics à Thérouanne font appel à la pierre de Marquise, qui connaît une importante diffusion régionale à inter-régionale. Cette utilisation architecturale et cette large diffusion perdurent à l'époque médiévale. L'approvisionnement en pierres dimensionnelles s'enrichit avec l'importation du calcaire marbrier noir de Tournai, très réputé, et est complété dans une moindre mesure par la craie finement glauconieuse du bassin carrier d'EsquerdesWizernes. 
On peut ainsi reconstituer l'approvisionnement en pierres dimensionnelles et sculptées, sur un temps long, des grands monuments d'une ville aujourd'hui totalement disparue, située à la frontière entre l'Artois et la Flandre.

\section{BIBLIOGRAPHIE}

AMAND M., 1984, «L'industrie, la taille et le commerce de la pierre dans le bassin du Tournaisis à l'époque romaine ", Revue du Nord, vol. 66, nº 260, p. 209-219.

BERNARD H., 1988, « Une restitution de l'ancienne cathédrale de Thérouanne », Archéologie médiévale, vol. 18, p. 141-177.

BLAMANGIN O., DEVRED V., LERICHE B., 2011, « L'apport de l'archéologie préventive à la connaissance de la topographie antique de la ville de Thérouanne », Revue du Nord, nº 393, p. 37-77.

BLANC A., 1996, «Les matériaux de construction de la cathédrale de Saint-Omer », dans Lorenz J. (dir.), Carrières et constructions en France et dans les pays limitrophes, t. III : Actes du $119^{e}$ Congrès national des sociétés savantes (Amiens, 1994), Paris, Éditions du CTHS, p. 27-38.

BLARY F. et al., 2015, « PCR Thérouanne : ville antique et médiévale, rapport 2014 », Lille, Direction régionale des affaires culturelles Nord-Pas-de-Calais.

BLARY F. et al., 2016, « PCR Thérouanne : ville antique et médiévale 2015-2017, rapport intermédiaire. Première année de triennale 2015 », Lille, Direction régionale des affaires culturelles Nord-Pas-de-Calais.

BLARY F. et al., 2017, « PCR Thérouanne : ville antique et médiévale 2015-2017, rapport intermédiaire. Deuxième année de triennale 2016 », Lille, Direction régionale des affaires culturelles Nord-Pas-de-Calais.

BLARY F. et al., 2018, « PCR Thérouanne : ville antique et médiévale : 2015-2017, rapport de troisième année final de synthèse ", Lille, Direction régionale des affaires culturelles Nord-Pasde-Calais.

CHEVALIER H., 1997, Les anciennes carrières souterraines de Nielles-les-Thérouanne, Thérouanne, Office culturel et touristique de Thérouanne, $20 \mathrm{p}$.

DOURDIN L., 2011, « La pierre du pays de Marquise au long des siècles », dans Clauzel-Delannoy I. (dir.), De la carrière au monument : la pierre des bâtisseurs en Nord-Pas-de-Calais au long des siècles, Saint-Martin-Boulogne, Cercle d'études en pays boulonnais, p. 101-124.

ENLART C., 1905, « Nos cathédrales disparues : Thérouanne, Arras, Boulogne », dans Actes du Congrès des sociétés savantes tenu à Arras les 7, 8, 9 et 10 juillet 1904, Arras, impr. Rohard-Courtin, p. 291-312.

ENLART C., 1906, « Rapport sur les fouilles sur l'emplacement de l'ancienne cathédrale de Thérouanne (Pas-de-Calais) » rapporté par Maurice Prou, Bulletin archéologique du Comité des travaux historiques et scientifiques, p. XLI-XLVII.

ENLART C., 1920, Villes mortes du Moyen Âge, Paris, de Boccard, 162 p. (« Térouanne », p. 15-29). 
GÉLY J.-P., 2014, « Du centre carrier au centre urbain, stratégie d'approvisionnement en pierres d'appareil des chantiers de construction : l'exemple du Bassin parisien », dans Lorenz J., Blary F., Gély J.-P. (dir.), Construire la ville : histoire urbaine de la pierre à bâtir, Paris, Éditions du CTHS (CTHS Sciences, 14), p. 62-82.

GROESSENS É., 2008, « Exemple d'extraction et d'approvisionnement des chantiers en Belgique aux époques antique et médiévale ", dans Blary F., Gély J.-P., Lorenz J. (dir.), Pierres du patrimoine européen : économie de la pierre de l'Antiquité à la fin des Temps modernes, Paris, Éditions du CTHS (Archéologie et histoire de l'art, 28) / Château-Thierry, Patrimoine vivant, p. 275-284.

LAVOINE A., 1932, « Le corps de garde ou bailliage d'Aire-sur-la-Lys : documents inédits ». Bulletin de la Commission départementale des monuments historiques du Pas-de-Calais, t. V, $2^{\mathrm{e}}$ livraison, p. 349-384.

LEPLAT J., 1973, « Les cavités souterraines de la craie dans le nord de la France », Bulletin de liaison du Laboratoire des Ponts et chaussées, $\mathrm{n}^{\circ}$ 63, réf. 1271, p. 29-56.

MANSY J.-L., GUENNOC P., ROBASZYNSKI F., AMÉDRO F., AUFFRET J.-P., VIDIER J.-P., LAMARCHE J., LEFÈVRE D., SOMMÉ J., BRICE D., MISTIAEN B., PRUD'HOMME A., ROHART J.-C., VACHARD D., 2007, Notice explicative de la Carte géologique de la France (1:50 000), feuille Marquise (2éd.), nº 5, Orléans, BRGM, 213 p.

NYS L., 1993, La pierre de Tournai : son exploitation et son usage aux XIII', XIV et XVe siècles, Tournai, archives du Chapitre cathédral / Louvain-la-Neuve, université catholique de Louvain (Tournaiart et histoire, 8), $411 \mathrm{p}$.

PLATELLE H., 1973, « Les carrières de Marquise dans le Boulonnais (P. de C.) au XI siècle », dans Actes du $98^{e}$ Congrès national des sociétés savantes (Saint-Étienne, 1973). Archéologie minière, Forez et Massif central, Paris, Éditions du CTHS, p. 199-208.

SALAMAGne A., 2011, «L'industrie de la pierre dans les anciens Pays-Bas au Moyen Âge et à la Renaissance (Artois, Flandre, Hainaut)», dans Clauzel-Delannoy I. (dir.), De la carrière au monument : la pierre des bâtisseurs en Nord-Pas-de-Calais au long des siècles, Saint-Martin-Boulogne, Cercle d'études en pays boulonnais, p. 57-71.

STEBBING W. P. D. 1928, « Richborough Castle », Archaeologia Cantiana, vol. 40, p. 181-184.

TOURNEUR F., 2017, « Les variétés de pierres utilisées à Notre-Dame de Saint-Omer », dans Nys L. et Van den Bossche B. (dir.), Sculpture gothique aux confins septentrionaux du royaume de France, Lille, Université de Lille (Revue du Nord, hors-série ; collection Art et archéologie, 25), p. 91-95.

WYSS M., BLANC A., GROESSENS É., 2008, « Témoignages de l'importation du calcaire de Tournai à Saint-Denis », dans Blary F., Gély J.-P., Lorenz J. (dir.), Pierres du patrimoine européen : économie de la pierre de l'Antiquité à la fin des Temps modernes, Paris, Éditions du CTHS (Archéologie et histoire de l'art, 28) / Château-Thierry, Patrimoine vivant, p. 81-86.

\section{NOTES}

1. Salamagne 2011, Gély 2014.

2. Blary et al. 2015, 2016, 2017 et 2018.

3. Tourneur 2017.

4. Enlart $1920: 22$.

5. Bernard $1988:$ 141-177. 
6. Enlart 1906 : XLII.

7. Blamangin et al. 2011.

8. Mansy et al. 2007 : 55-56.

9. Stebbing 1928.

10. Enlart 1906 : XLII.

11. Blamangin et al. 2011.

12. Enlart 1906 : XLIII.

13. Chevalier 1997. Nous remercions Hugues Chevalier de nous avoir guidés sur les lieux des anciennes carrières souterraines, aujourd'hui totalement obstruées.

14. Leplat 1973.

15. Chevalier 1997.

16. Lavoine $1932: 369$.

17. Ibid. : 367.

18. Blanc 1996.

19. Enlart $1920: 23,1905: 305$.

20. Amand 1984, Groessens 2008.

21. Nys 1993.

22. Wyss et al. 2008.

23. Groessens 2008.

24. Lavoine 1932 : 368.

25. Enlart 1920 : 23, 24.

26. Platelle 1973, Dourdin 2011.

27. Enlart 1906 : XLV.

28. Lavoine 1932 : 369.

\section{RÉSUMÉS}

L'étude de l'approvisionnement en matériaux de construction de la ville disparue de Thérouanne (Pas-de-Calais) apporte un éclairage particulier à l'histoire matérielle sur un temps long au fil de l'évolution urbaine. La ville a bénéficié de deux ressources lithiques abondantes en son terroir : la craie blanche à silex du Coniacien et les grès du Landénien. La première est fragile et gélive, mais facile à tailler et à sculpter. La seconde est dure à froide, résistante à l'écrasement et à l'altération, mais très difficile à tailler et à sculpter. Aussi, dès l'époque du Haut-Empire, les bâtisseurs de monuments publics à Thérouanne font appel au calcaire de Marquise, transporté sur une quarantaine de kilomètres. Cette utilisation architecturale et cette large diffusion perdure à l'époque médiévale. L'approvisionnement en pierres dimensionnelles s'enrichit avec l'importation du calcaire marbrier de Tournai (Belgique) et est complété dans une moindre mesure par la craie finement glauconieuse du bassin carrier d'Esquerdes-Wizernes (Pas-deCalais). 
INDEX

Index géographique : Thérouanne, Esquerdes, Wizernes, Pas-de-Calais

Mots-clés : craie, grès, pierre de Marquise, pierre de Matringhem, marbre de Tournai, Antiquité, Moyen Âge

\section{AUTEURS}

\section{FRANÇOIS BLARY}

Université libre de Bruxelles (ULB), CREA-Patrimoine

JEAN-PIERRE GÉLY

Université Paris I - Panthéon-Sorbonne, Laboratoire de médiévistique occidentale de Paris (LAMOP, UMR 8589 du CNRS) 


\title{
Le mortier de tuileau en France de l'Antiquité à l'époque moderne : héritage ou réinvention permanente?
}

\author{
Stéphane Büttner
}

1 Il faut définir le «mortier de tuileau » comme un mortier dont la charge en terre cuite broyée, le tuileau, apparaît suffisante pour que l'on puisse dire qu'elle correspond à un ajout intentionnel. Il s'agit ainsi de ne pas considérer les mortiers ne contenant que de rares fragments de telle nature comme un matériau remarquable. Dans ce dernier cas, ce sont plus vraisemblablement de simples pollutions, faits relativement fréquents dans ce type de liant de maçonnerie; on parlera alors plus volontiers de «mortier à tuileau ».

2 Les Anglo-Saxons qualifient ce type de mortier, riche en fragments de tuileaux, de «béton romain ${ }^{1}$ ». Cela illustre combien les qualités de durabilité et l'origine antique de ce matériau original sont profondément ancrées chez les historiens et archéologues du bâti, antiquisants comme médiévistes, qui y sont très souvent confrontés. Résistants et imperméables, ces mortiers particuliers ont effectivement traversé les âges, depuis l'Antiquité jusqu'à nos jours, tant par la récurrence de leurs utilisations que par leur relative inaltérabilité. On les retrouve souvent et effectivement comme constituants d'aménagements présentant de très bons états de conservation.

3 Relativement courant à toute époque, il s'agit d'un mortier aux propriétés particulières à condition qu'il soit élaboré dans les règles de l'art: ses qualités dépendent en effet d'une parfaite connaissance des composants et de leurs proportions respectives. De fait, la question de la part de l'empirisme, de l'oralité et de l'écrit dans la transmission des savoir-faire liés à ce matériau particulier peut effectivement se poser. 


\section{Chaux hydraulique naturelle, chaux hydraulique artificielle et mortier de tuileau}

4 En tout premier lieu, il est donc nécessaire d'aborder quelques considérations chimiques qui vont confirmer la nécessité d'une certaine rigueur dans la préparation $\mathrm{du}$ produit, sous peine d'obtenir un mortier qui ne présente pas les qualités escomptées.

5 Les recherches réalisées sur les mortiers anciens, antiques ou médiévaux, montrent que les chaux utilisées étaient assez systématiquement de nature aérienne, c'est-à-dire obtenues par la calcination, vers 800 à $900^{\circ} \mathrm{C}$, de calcaires contenant donc très peu d'impuretés argileuses ${ }^{2}$. Cet usage privilégié des chaux aériennes paraît être un écho aux préconisations de Vitruve qui, pour faire un bon mortier de maçonnerie, recommande d'utiliser les pierres les plus dures et les plus blanches possibles pour la fabrication des chaux ${ }^{3}$. Ces chaux aériennes conviennent parfaitement à la construction de maçonneries hors sol, qui ont besoin de « respirer ».

6 Mais dans certaines fonctions architecturales particulières, l'utilisation d'un mortier aux propriétés spécifiques apparait nécessaire. C'est particulièrement le cas de ceux utilisés dans les constructions liées à l'eau (citernes, bassins, canalisations) ou fortement exposées aux intempéries (toitures) et qui doivent, de fait, présenter une certaine étanchéité. C'est aussi le cas des mortiers qui vont être soumis à d'importantes contraintes mécaniques, comme ceux constituant les sols ou les soubassements des édifices.

7 Les chaux hydrauliques naturelles répondent à ces caractéristiques. Celles-ci sont élaborées en calcinant des calcaires contenant de 8 à $20 \%$ d'impuretés argileuses. Se forment alors des silicates, alumino-silicates et ferro-silicates de calcium qui, au contact de l'eau, constituent des insolubles conférant à la chaux des propriétés hydrauliques. Le mortier constitué à partir de cette chaux a pour propriété de pouvoir «durcir » sous l'eau - d'où le qualificatif « hydraulique » - ; en effet, contrairement au mortier de chaux aérienne, sa prise ne nécessite pas la présence de dioxyde de carbone et peut donc se faire en absence d'air. Ce mortier présente effectivement une certaine étanchéité et une bonne résistance mécanique. Cependant, pour obtenir une chaux hydraulique de bonne qualité, les températures à atteindre doivent dépasser les $1000^{\circ} \mathrm{C}$ et, en réalité, les technologies de calcination alors exigées ne seront véritablement et pleinement maîtrisées qu'à partir du xvIII ${ }^{\mathrm{e}}$ siècle. C'est la raison pour laquelle les rares mortiers de chaux hydraulique artificielle identifiés dans des maçonneries anciennes, souvent de piètre qualité, sont plutôt à considérer comme un fait exceptionnel, voire accidentel, et sont surtout liés à la faible variabilité des faciès géologiques dans l'environnement proximal du chantier.

8 Vitruve évoque cependant certains adjuvants qui, associés à une chaux aérienne, permettent d'obtenir un mortier aux propriétés hydrauliques ${ }^{4}$. Il faut alors insister sur le terme de "mortier hydraulique», car ce n'est pas la chaux qui présente intrinsèquement ces qualités, mais la préparation dans son ensemble, du fait de l'ajout de certains composants. C'est d'abord le cas des pouzzolanes, scories volcaniques, nombreuses à proximité du Vésuve, région bien connue de Vitruve. Celui-ci soulignait que mêlées «à la chaux et aux moellons, non seulement elles assurent la solidité des différentes constructions, mais plus particulièrement aussi, [elles font] s'affermir sous 
l'eau la maçonnerie des digues de mer $^{5}$ ». Comme l'architecte antique le fait remarquer, sans bien évidemment établir un parallèle chimique, c'est aussi le cas des argiles cuites qui composent les tuiles ou briques et que l'on retrouve fréquemment broyées dans certains mortiers : les fameux mortiers de tuileau. L'ajout de fragments de terre cuite à la chaux hydratée engendre effectivement une réaction que l'on qualifie de "pouzzolanique» du fait de la similitude avec celle provoquée par les scories volcaniques ${ }^{6}$. Le processus a été très bien décrit par certains auteurs ${ }^{7}$ : les argiles cuites, à l'instar des pouzzolanes, deviennent des verres amorphes, qui conservent une forte teneur en silice et en alumine et qui peuvent réagir rapidement avec le carbonate de calcium (la chaux aérienne) en présence d'eau (l'eau de gâchage) et à température ambiante.

9 Cependant, de récentes études montrent que la nature de la matière première (nature de l'argile) et surtout les températures de cuisson vont jouer un rôle sur les propriétés pouzzolaniques des terres cuites: il a été ainsi démontré que des températures dépassant les $900^{\circ} \mathrm{C}$ les annihilent ${ }^{8}$. De fait, tous les fragments de terre cuite ne vont pas nécessairement engendrer la réaction recherchée. D'autres analyses montrent que cet ajout de tuileau à une chaux aérienne augmente bel et bien la résistance mécanique du mortier9. Mais elles révèlent surtout que plus le broyat est fin - c'est-à-dire plus la surface spécifique de contact entre la chaux et les composants pouzzolaniques est importante - plus la rapidité de prise et la durabilité du produit augmentent. C'est particulièrement le cas des mortiers "roses", composés de chaux aérienne et de tuileau fin, qui sont en fait les seuls mortiers parfaitement étanches; ils apparaissent aussi davantage résistants aux contraintes mécaniques. À l'inverse, l'utilisation d'un broyat de tuileau grossier, fait très fréquent dans certains mortiers anciens, réduit la surface spécifique de réaction. Dans ce cas, les réactions pouzzolaniques sont limitées aux seules bordures des fragments de terre cuite ${ }^{10}$. Cependant, cette zone de réaction peut suffire à conférer une remarquable résistance globale au produit fini et justifier son usage dans des fonctions architecturales particulières.

10 Les qualités d'un mortier de tuileaux dépendent donc de ces paramètres liés à la chimie et à la physique des matériaux. Ces principes n'apparaissent pas dans les traités d'art à bâtir. Vitruve, en particulier, ne parle que de proportions et n'évoque pas la dimension des tuileaux, ni la nature des argiles cuites. Et pour autant, dans certaines réalisations anciennes, la prise en compte effective de ces principes par les maçons indique qu'ils ont été acquis vraisemblablement par expérimentation et/ou transmission. Il semble donc que chaque artisan possède un savoir-faire, propre ou hérité, qui lui permet de maitriser toute la chaîne opératoire : la qualité des matières premières (pierre à chaux, tuileau), leur conditionnement (cuisson, broyage) et leur dosage.

\section{L'usage des mortiers de tuileau à travers les âges}

11 L'usage des mortiers de tuileau est une réalité bien avant Vitruve. Certains auteurs évoquent les enduits de citernes contemporaines du temple de Salomon à Jérusalem, datées entre le $\mathrm{x}^{\mathrm{e}}$ et $\mathrm{VI}^{\mathrm{e}}$ siècle avant $\mathrm{J} .-\mathrm{C}^{.11}$. La technique est assurément déjà en œuvre dans le monde punique ${ }^{12}$ et en Grèce antique ${ }^{13}$, en particulier pour les structures étanches et pour les sols. C'est aussi dans ces mêmes fonctions que les mortiers de tuileau vraisemblablement les plus anciens de Gaule ont été identifiés à Marseille, dans des aménagements de la période hellénistique datés des $\mathrm{IV}^{\mathrm{e}}$-III ${ }^{\mathrm{e}}$ siècles avant J.-C. ${ }^{14}$. 


\section{En Gaule romaine}

Vitruve décrit parfaitement la manière dont un sol de mortier doit être constitué ${ }^{15}$. Sur un niveau damé est disposé un radier de pierres monté à sec (statunem). L'auteur préconise ensuite la mise en place d'une couche intermédiaire (rudus), composée d'un mélange de chaux et de sable dans un rapport de 1 pour 3 , auquel on rajoutera un volume de tuileau s'il s'agit d'un sol extérieur. Enfin, la couche de circulation (nucleus) doit être composé de chaux et de tuileau, toujours dans un rapport de 1 pour 3 . Ce dernier niveau peut éventuellement être recouvert d'une fine couche de finition, composée de chaux et de sable, qui pourra, au cas échéant, sceller des tesselles de mosaïque. En réalité, il existe de très nombreux sols antiques composés sans tuileau. C'est par exemple le cas dans des villas d'Allones (Sarthe) ou d'Escolives-Sainte-Camille (Yonne). Si les sols élaborés avec du tuileau apparaissent plus courants, c'est sans doute aussi en raison de leur durabilité, qui les a protégés de l'altération, que cela soit en intérieur ou en extérieur ${ }^{16}$. Évidemment, ces sols sont particulièrement systématiques dans les bâtiments thermaux, qu'il s'agisse des salles de chauffe ou de bain, comme c'est le cas pour les thermes du Vieil-Évreux (Eure) ou de Paris ${ }^{17}$.

Pour autant, les mises en œuvre observées archéologiquement ne suivent que très rarement la composition énoncée par Vitruve, tant dans les proportions relatives des différents constituants que dans le nombre de passes: nucleus et rudus ont ainsi tendance à se confondre (fig. 1). Ce fait constaté révèle bien qu'il existe d'un côté une réalité théorique, énoncée dans les traités, et de l'autre, une certaine réalité pratique, légèrement distincte. Ce n'est cependant pas le cas pour les sols mosaïqués, qui sont quasiment toujours mis en œuvre tel que le recommande l'architecte ${ }^{18}$. 
Fig. 1. - Nîmes (Gard) : sol d'hypocauste du I ${ }^{\text {er }}$ siècle.

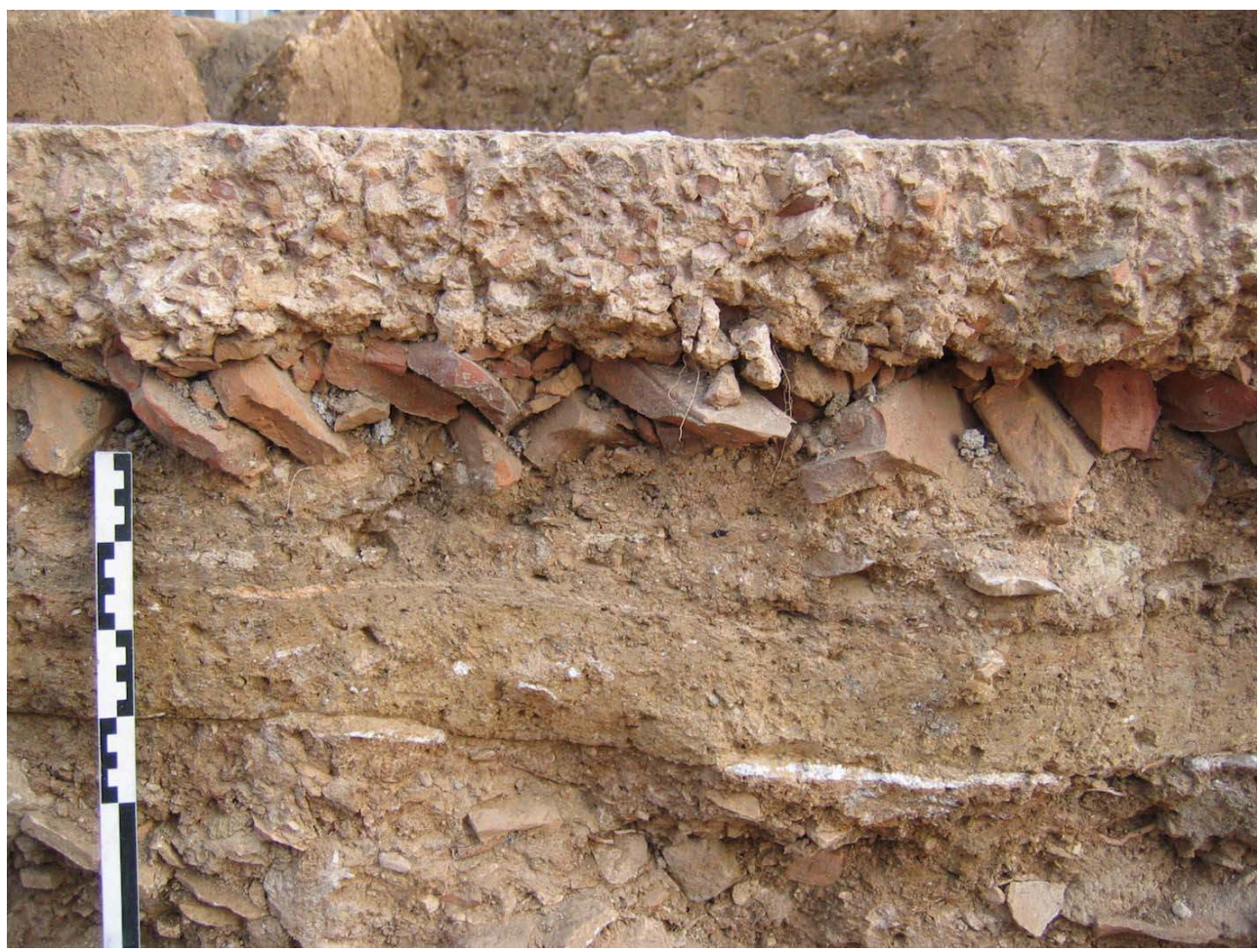

(c) Arnaud Coutelas.

Depuis longtemps, les historiens et archéologues antiquisants ont employé le terme d' opus signinum pour désigner tout type de mortier de sol, voire tout type de mortier contenant du tuileau ${ }^{19}$. Cette appellation reste encore aujourd'hui profondément ancrée chez certains de ces spécialistes, alors que le terme décrit en réalité des sols de mortier sans tuileau et battus, élaborés dans la région de Segni, près de Rome. La technique était également utilisée pour la confection de citernes, et Vitruve recommandait dans ce cas de recouvrir d'un enduit de tuileau ces mortiers en opus signinum. C'est Pline l'Ancien qui a employé ce terme par extension pour décrire les revêtements de sols ou de murs constitués de mortier de tuileau ${ }^{20}$.

Quoiqu'il en soit des textes antiques, l'utilisation du mortier de tuileau est effectivement systématique pour tous les aménagements balnéaires, non seulement pour les sols mais également pour les joints et enduits d'étanchéité (thermes du VieilÉvreux ou de Chassenon, en Charente). Il est aussi très utilisé pour toutes les cuves et citernes liées aux activités artisanales. On peut citer pour exemple les cuves à garum de Douarnenez, dans le Finistère (fig. 2a). En extension de ces aménagements, on le retrouve dans toutes les conduites d'eau, canalisations ou aqueducs ${ }^{21}$. Dans ce dernier cas, une mise en œuvre particulière semble assez récurrente, avec plusieurs passes de mortiers présentant des tuileaux de dimensions différentes (fig. $2 b$ ). En général, les finitions d'étanchéité présentent les éléments les plus fins, en parfaite adéquation avec la chimie de ces matériaux. 
Fig. 2. - Utilisation du mortier de tuileau : cuves et canalisations.

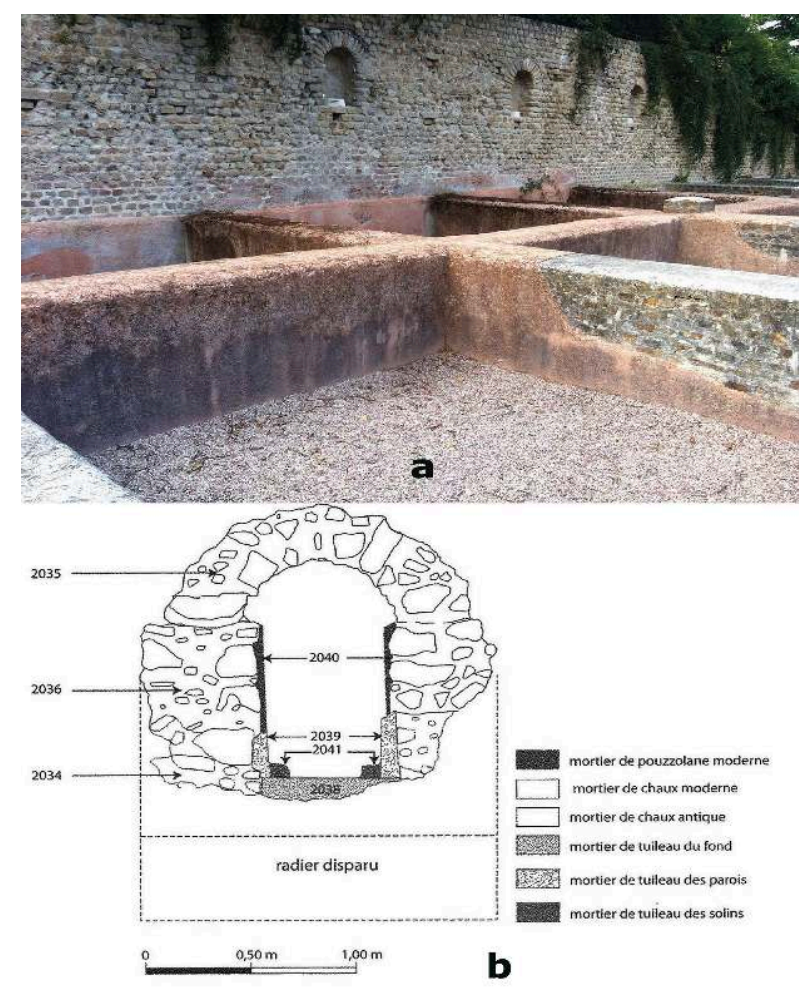

A : Douarnenez (Finistère) : cuves à garum du site de Plormarc'h, datées du er siècle. B : Antibes (Alpes-Maritimes) : coupe de l'aqueduc du $\mathrm{I}^{\text {er }}$ siècle.

(C) Stéphane Büttner (A), Robert Thernot (B).

Le tuileau, alors souvent de granulométrie grossière, est aussi parfois ajouté au mortier de maçonnerie mis en forme en coffrage ou utilisé en blocage entre deux parements appareillés. Le terme opus caementicium définit ce type de mise en œuvre ${ }^{22}$; certains auteurs, par abus de langage, ont tendance à l'utiliser encore une fois comme synonyme de «mortier de tuileau ». En réalité, dans cette mise en œuvre particulière, l'ajout de tuileau a surtout été constaté pour l'élaboration de maçonneries liées à des structures hydrauliques (piscines, aqueducs, etc.).

Si Vitruve préconise l'utilisation du mortier de tuileau pour la construction de remparts, voyant là un moyen de s'assurer de la solidité de la construction ${ }^{23}$, on ne peut que constater que les quelques vestiges d'enceintes urbaines construites en Gaule entre le $\mathrm{I}^{\mathrm{er}}$ et le $\mathrm{II}^{\mathrm{e}}$ siècle de notre ère ont été visiblement élaborés avec des mortiers de chaux ne contenant pas ou contenant peu de fragments de terre cuite ${ }^{24}$. C'est ainsi le cas à Nîmes (Gard) ou à Arles (Bouches-du-Rhône). Pour autant, l'analyse de Vitruve sur le bien-fondé de cet usage du mortier de tuileau pour l'édification de murs épais se justifie scientifiquement. En effet, dans le cas d'un mortier élaboré avec une chaux aérienne, le processus de prise, qui est conditionné par la présence de dioxyde de carbone, va progresser de l'extérieur vers l'intérieur du mur. En conséquence, le cœur de la maçonnerie va se trouver rapidement isolé de l'air ambiant et le mortier n'y fera alors pas prise. À l'inverse, l'utilisation d'un mortier de tuileau aux propriétés hydrauliques permet de s'assurer de sa prise uniforme dans toute l'épaisseur du mur, puisque celle-ci s'effectue en absence d'air. Il est donc effectivement et théoriquement préférable 
d'utiliser un tel type de mortier pour l'élaboration de murs présentant de larges épaisseurs.

\section{De la chute de l'Empire romain à la Renaissance carolingienne}

18 Après la chute de l'Empire romain, l'usage du mortier de tuileau se perpétue. Outre le fait que le bâti antique est encore là, éventuellement fonctionnel et pouvant faire valeur d'exemple, la technique est particulièrement mise en œuvre dans des aménagements exceptionnels. Ainsi, et à contrario de ce qui a été constaté pour les remparts des $\mathrm{I}^{\mathrm{er}}$ et $\mathrm{II}^{\mathrm{e}}$ siècles, l'usage de ce matériau apparaît quasiment systématique dans les enceintes urbaines qui ont été édifiées autour de nombreuses villes de l'Antiquité tardive. C'est par exemple le cas de Mâcon, en Saône-et-Loire, d'Auxerre, dans l'Yonne (fig. 3) et du Mans, dans la Sarthe. Durant cette période, on observe en Gaule un phénomène généralisé de rétractation des villes lié à un contexte politique et socio-économique difficile. De fait, ces remparts dressés aux alentours des $\mathrm{III}^{\mathrm{e}}$ et $\mathrm{IV}^{\mathrm{e}}$ siècles font la part belle au remplois prélevés sur les bâtiments ruinés situés en dehors de la nouvelle ville restreinte ${ }^{25}$. Si, comme l'évoquait Vitruve, l'ajout de tuileau dans les mortiers de murs épais augmente effectivement leur durabilité, il est très vraisemblable que c'est la grande disponibilité en tuiles de récupération qui a aussi favorisé la généralisation de ce type de mise en œuvre à cette période.

Fig. 3. - Auxerre (Yonne) : lame mince réalisée dans le liant de maçonnerie du castrum daté des III et IV siècles.

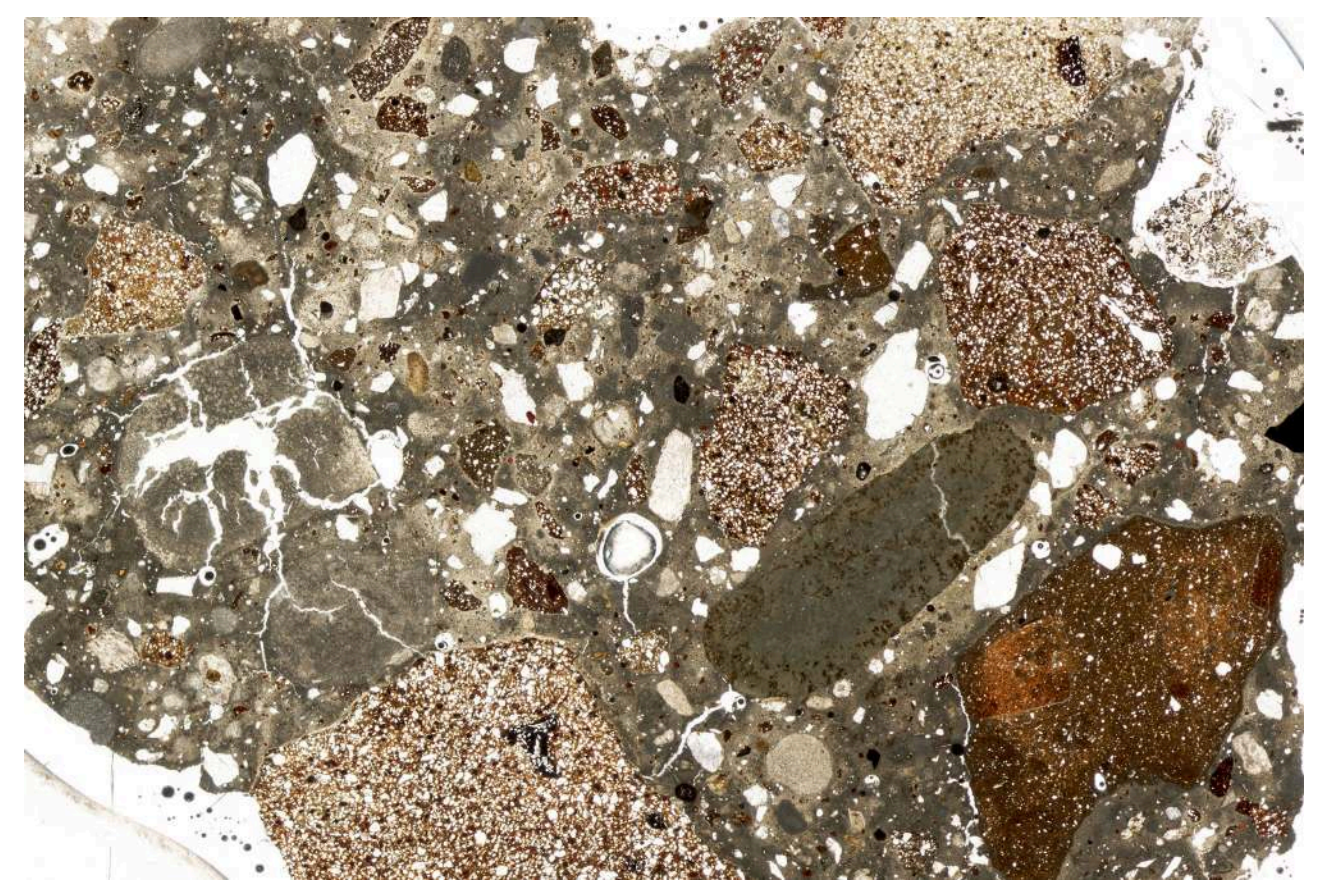

(c) Stéphane Büttner.

19 Le mortier de tuileau est bien entendu toujours utilisé pour l'élaboration de structures liées à l'eau: si la tradition des bains semble persister encore par endroit (Moissac, Tarn-et-Garonne), ce sont surtout les nombreux baptistères se multipliant à l'époque paléochrétienne qui témoignent de la permanence de cet usage (Roanne, dans la Loire ; Poitiers, dans la Vienne ; Fréjus, dans le Var). 
La tradition des sols de mortier de tuileau apparaît également continue durant l'Antiquité tardive et le haut Moyen Âge. Les canons de réalisation définis par Vitruve ne sont alors généralement pas suivis. Il s'agit bien souvent d'une simple passe de mortier, épaisse de quelques centimètres, contenant un tuileau fin parfois associé à quelques éléments grossiers de fragments de terre cuite. Ce mortier est éventuellement coulé sur un radier de pierres sèches ou sur un simple niveau de terre damée, comme cela fut observé lors des fouilles menées sur l'ancienne église Saint-Martin à Luxeuilles-Bains, dans la Haute-Saône (fig. 4) ou dans la crypte de la basilique de SaintQuentin, dans l'Aisne (fig. 5). Par contre, les sols mosaïqués, quant à eux, répondent rigoureusement dans leur mise en œuvre à la tradition antique (Saint-Quentin).

Fig. 4. - Luxeuil-les-Bains (Haute-Saône) : sol de mortier de tuileau daté des VIII et IX ${ }^{\mathrm{e}}$ siècles venant recouvrir un sarcophage mérovingien.

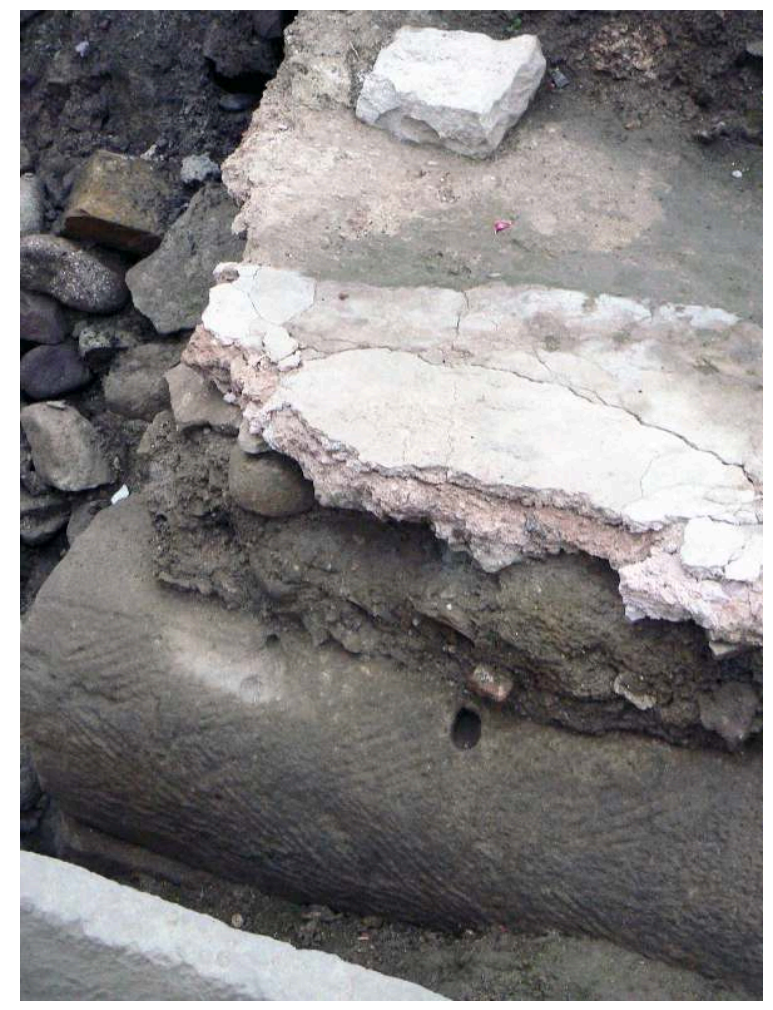

(c) Stéphane Büttner. 
Fig. 5. - Saint-Quentin (Aisne) : succession de sols de mortier de tuileau (US 160 et 164) datés du IV ${ }^{\mathrm{e}}$ au VIII ${ }^{\mathrm{e}}$ siècle.

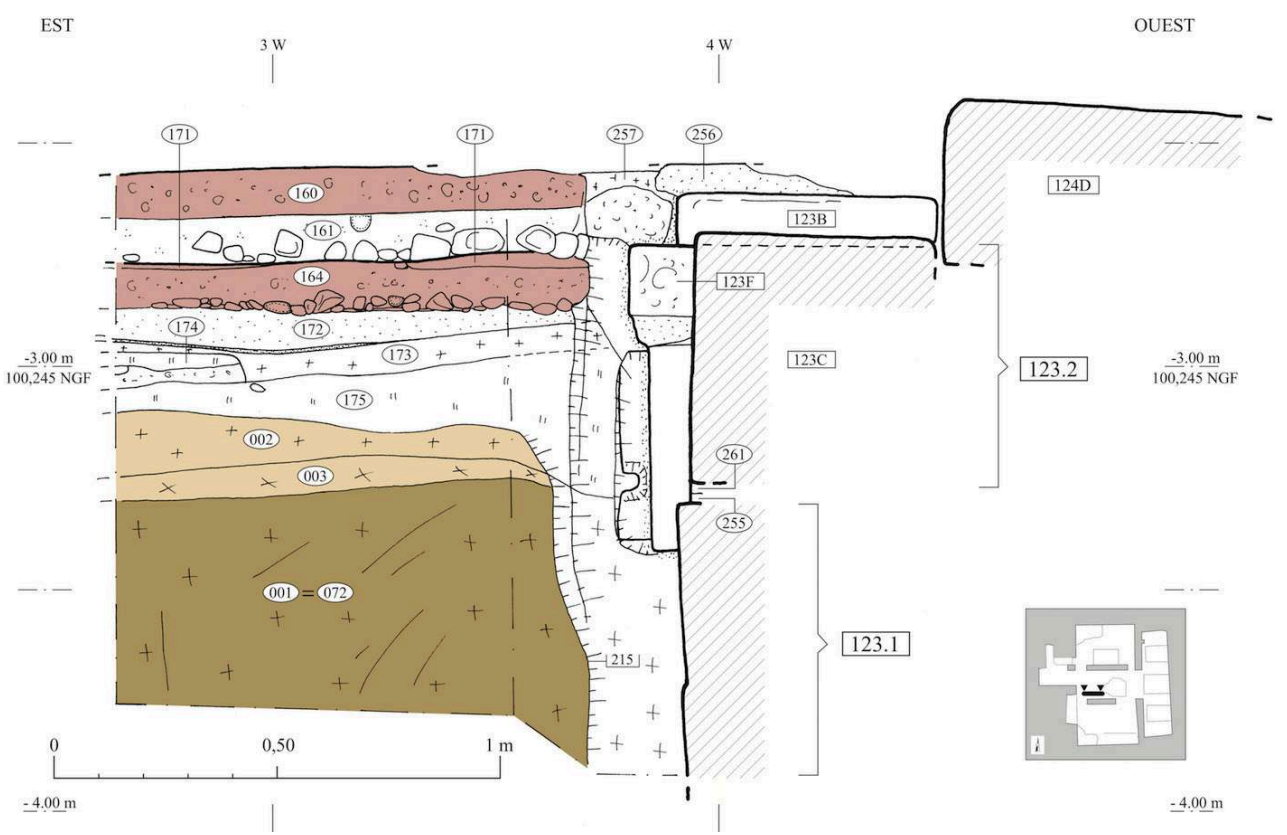

(c) Gilles Fèvre.

À une époque que certains auteurs définissent comme la Renaissance carolingienne, on observe que quelques édifices monumentaux font la part belle à l'usage du mortier de tuileau comme liant de maçonnerie. C'est particulièrement le cas de la chapelle Palatine, à Aix-la-Chapelle (Allemagne) ${ }^{26}$. Dans ce cas, la référence à l'architecture antique ne peut être réellement évoquée puisque les constructions monumentales gallo-romaines sont généralement élaborées avec de simples mortiers de chaux aérienne. À l'instar du modèle architectural développé à Aix-la-Chapelle, l'influence du modèle byzantin est sans doute primordiale, d'autant que dans ce contexte oriental, l'usage du mortier de tuileau comme liant de maçonnerie est alors extrêmement fréquent $^{27}$.

\section{Du Moyen Âge à l'époque moderne}

Pour l'architecture monumentale, l'usage du mortier de tuileau en liant de maçonnerie se perpétue au tournant de l'An mil et durant toute l'époque romane. C'est le cas pour quelques donjons du tout début du $\mathrm{XI}^{\mathrm{e}}$ siècle, comme par exemple celui de Loches, en Indre-et-Loire (fig. 6a) et plus particulièrement celui de structures de soubassement de certains grands édifices religieux construits aux $\mathrm{XI}^{\mathrm{e}}$ et XII ${ }^{\mathrm{e}}$ siècles. On peut évoquer pour exemple les cathédrales d'Auxerre (Yonne - fig. 6b), de Chartres (Eure-et-Loir), ou encore le martyrium de la crypte de Saint-Aignan à Orléans (Loiret). Le cas des fondations des piles du XII ${ }^{\mathrm{e}}$ siècle, visibles depuis la crypte de la cathédrale Notre-Dame de Clermont (Puy-de-Dôme), apparait comme un cas tout à fait particulier. L'usage de véritables pouzzolanes est très systématique dans la construction médiévale clermontoise (basilique Notre-Dame-du-Port), pour la bonne et simple raison que ces scories volcaniques sont une source locale de sable évidente. À la cathédrale, ces fondations de piles ont pour particularité de présenter des joints montants réalisés au 
mortier de pouzzolane, tandis que les joints horizontaux sont constitués de mortier de tuileau (fig. 6c).

Fig. 6. - Usage du mortier de tuileau en liant de maçonnerie.

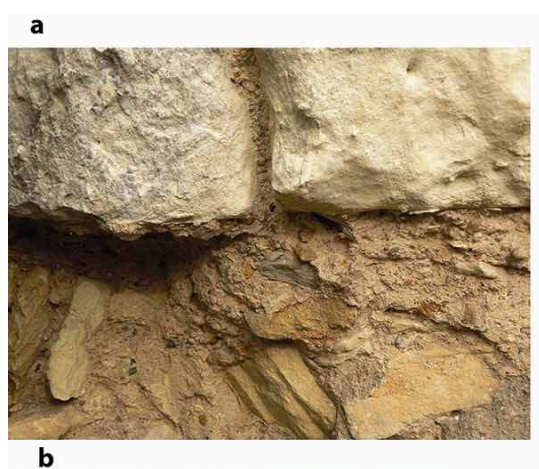

b

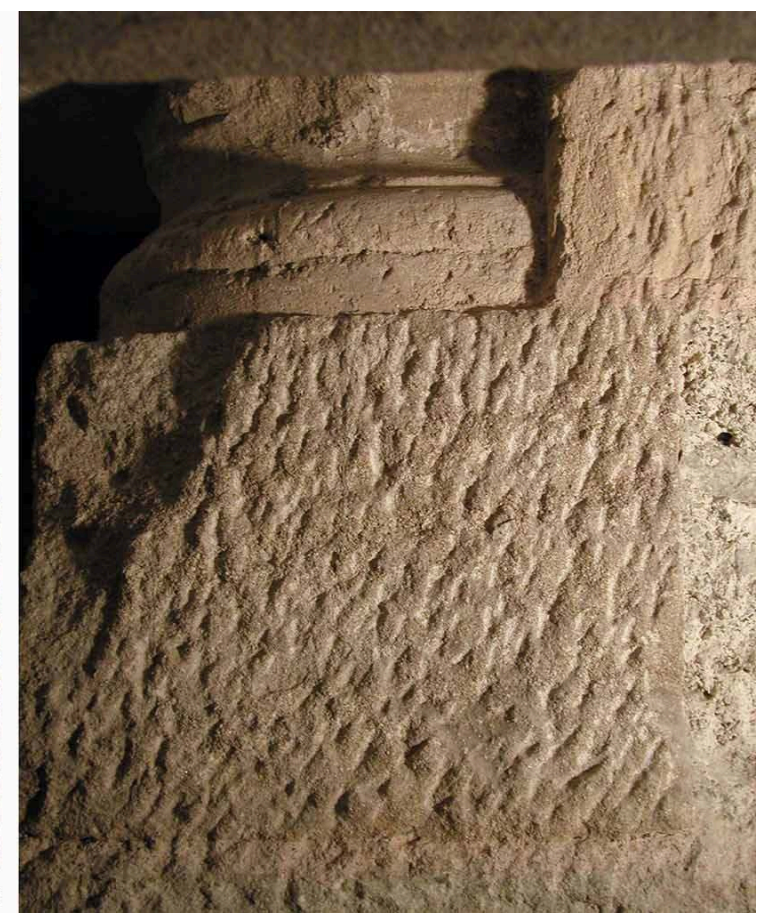

A : Loches (Indre-et-Loire) : mortier du donjon du début du xie siècle. B : Auxerre (Yonne), crypte de la cathédrale : mortier d'une des piles du xl ${ }^{e}$ siècle. c : Notre-Dame de Clermont (Clermont-Ferrand, Puyde-Dôme) : fondation d'une des piles du xı siècle. Les joints horizontaux sont au mortier de tuileau, les joints montants au mortier de pouzzolanes.

(c) Stéphane Büttner.

Au-delà de la mise en œuvre soignée et sans doute fastidieuse, on comprend là que le pouvoir hydraulique des pouzzolanes n'était pas envisagé. La réalisation du mortier de tuileau dans les joints horizontaux répond certainement à une inspiration; on a fait « à la manière de... » comme cela doit être fait lorsque c'est bien fait. Si l'intégralité de ces fondations n'a pas été maçonnée avec ce mortier, c'est sans doute que le tuileau est relativement rare, et par conséquent onéreux. Si la question du prix de cette matière première peut être étendue à toute la construction médiévale, elle ne peut être réellement abordée que par les documents de comptabilité, tant le cas archéologique de la cathédrale de Clermont reste particulier par le procédé de montage mis en œuvre.

Toujours à l'époque romane, certains joints de mortier de tuileau, par leur couleur et par une mise en œuvre qui peut être dans ce cas extrêmement soignée, participent de manière certaine à la volonté de mettre en évidence des appareillages très élaborés ${ }^{28}$. C'est ainsi le cas dans la crypte de Jouarre (Seine-et-Marne) ou en façade de l'église de La Chapelle-Saint-Mesmin, dans le Loiret (fig. 7a). Ce peut être également le cas pour des compositions sculptées, comme par exemple pour le portail du cloître de l'abbaye Saint-Aubin d'Angers, en Maine-et-Loire (fig. 7b). 
Fig. 7. - Joints de mortier de tuileau.

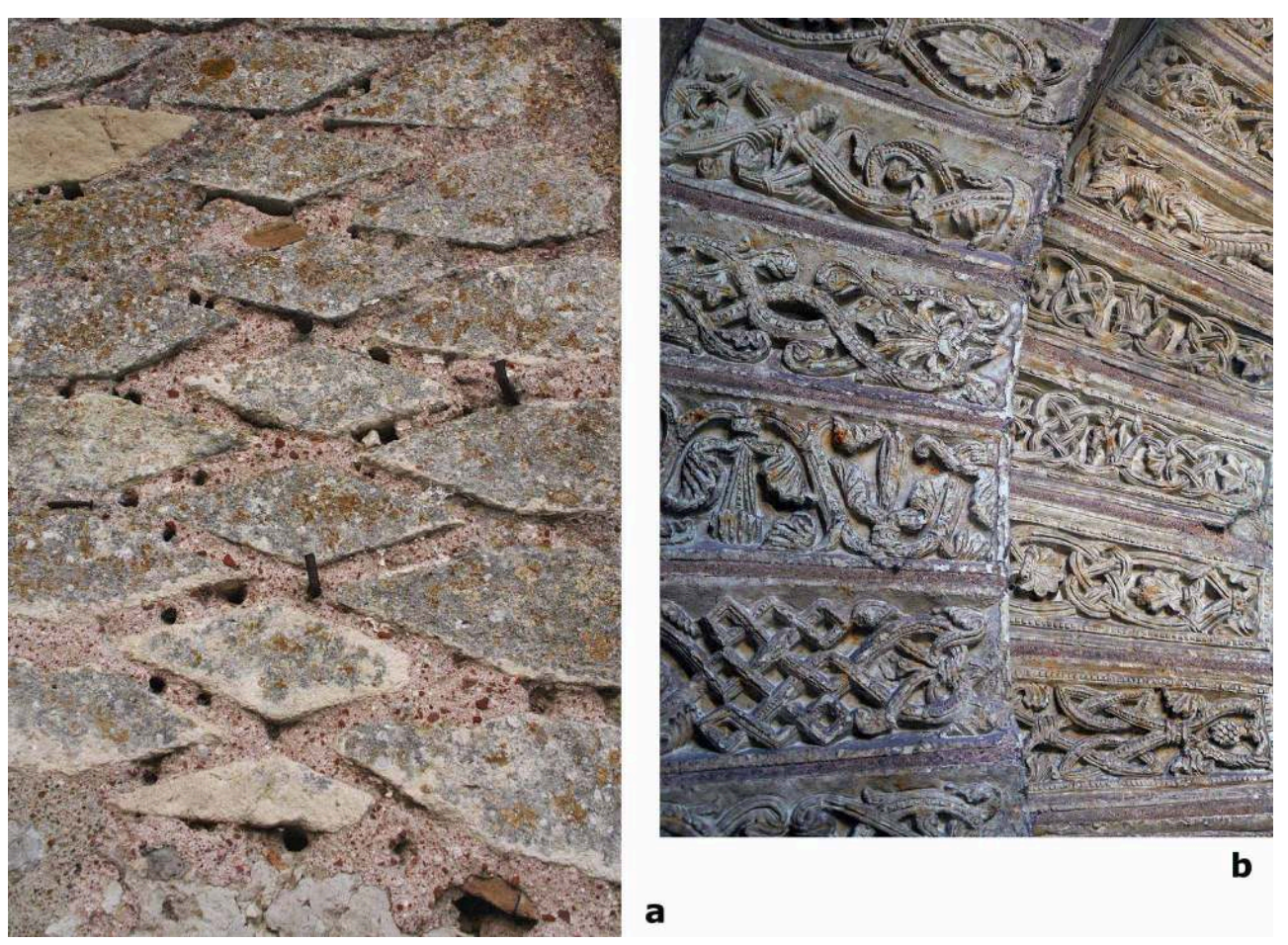

A : La Chapelle-Saint-Mesmin (Loiret), façade de l'église Saint-Mesmin : appareil réticulé daté du xi ${ }^{\mathrm{e}}$ siècle. B : Angers (Maine-et-Loire), abbaye Saint-Aubin : voussures du portail du cloître daté du x\| ${ }^{\mathrm{e}}$ siècle.

(c) Stéphane Büttner.

Pour la réalisation des sols, l'utilisation de ce mortier reste encore très courante jusqu'au $\mathrm{XII}^{\mathrm{e}}$ siècle. Encore une fois, les cas varient de la simple chape, parfois très fine (abbaye de Marmoutier, en Indre-et-Loire: fig. 8), parfois coulée sur de grandes surfaces (cathédrale de Tournai, en Belgique ; abbaye de Moutier-Grandval, en Suisse), au sol plus élaboré, parfois mosaïqué (abbaye Saint-Philibert de Tournus, en Saône-etLoire - fig. 9 ; abbaye de Fleury, à Saint-Benoît-sur-Loire, dans le Loiret). 
Fig. 8. - Tours (Indre-et-Loire), déambulatoire de l'abbaye de Marmoutier : sol en coupe daté du Xl siècle.

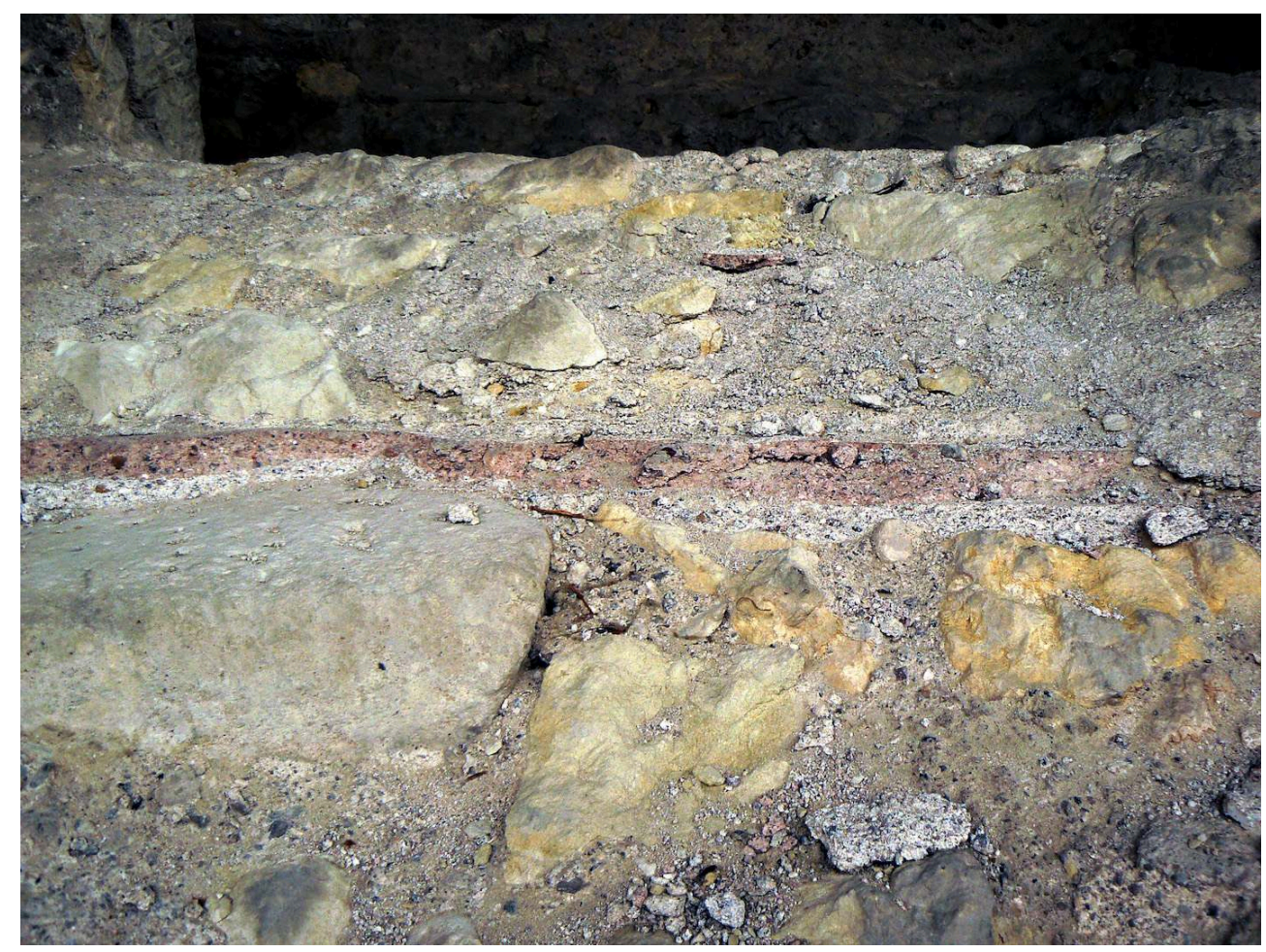

(c) Stéphane Büttner.

Fig. 9. - Tournus (Saône-et-Loire), déambulatoire de l'abbaye Saint-Philibert : détail de la mosaïque datée du XII siècle.

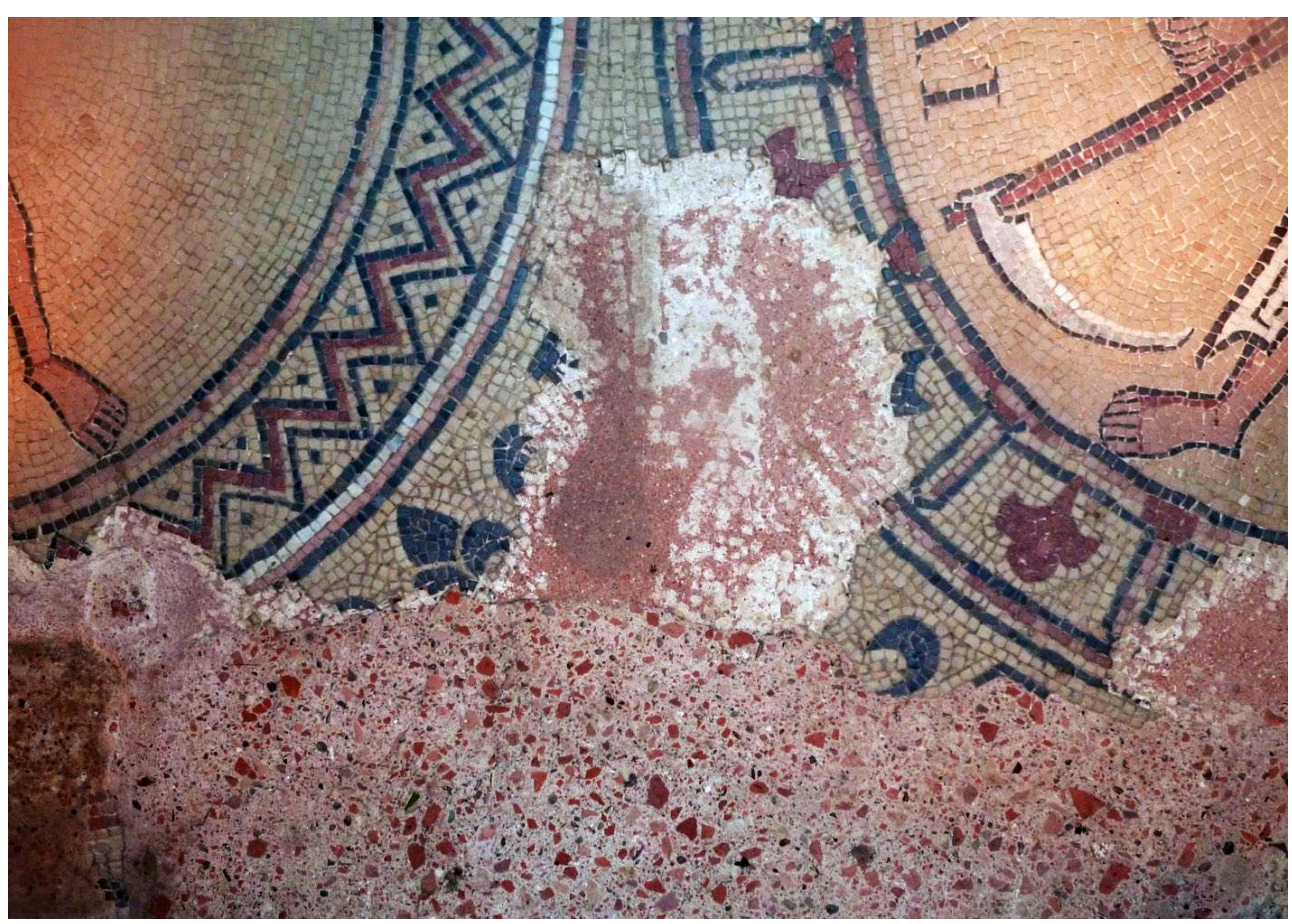

(c) Stéphane Büttner. 
En ce qui concerne les recettes liées aux mortiers d'étanchéité, Villard de Honnecourt évoque, dans son célèbre carnet rédigé au XIII siècle, l'utilisation d'un broyat de «tuiles de païens » (tuiles gallo-romaines ?) et l'ajout d'huile de lin pour la construction de «vaisseaux » servant à contenir de l'eau ${ }^{29}$. En effet, à partir de la fin du XII ${ }^{e}$ siècle, l'utilisation du mortier de tuileau semble davantage se limiter à la fabrication des bassins, citernes et conduites d'eau. Pour ces dernières, finalement assez courantes jusqu'au XvIII ${ }^{e}$ siècle, les mises en œuvre observées apparaissent très complexes, voire "savantes", et les analyses réalisées sur les mortiers composant ces structures montrent des recettes très élaborées, associant tuileaux de différentes dimensions et des ajouts très divers, comme par exemple de la limaille de fer ${ }^{30}$ (fig. 10). Les nouveaux traités d'art à bâtir et d'architecture hydraulique, qui fleurissent à partir de la fin du Moyen Âge et surtout durant l'époque moderne, font fortement écho à ces observations ${ }^{31}$.

Fig. 10. - Paris, enclos du Temple : tronçon d'une canalisation du XIV e siècle issu des fouilles, en mortier de tuileau avec ajout de limaille de fer.

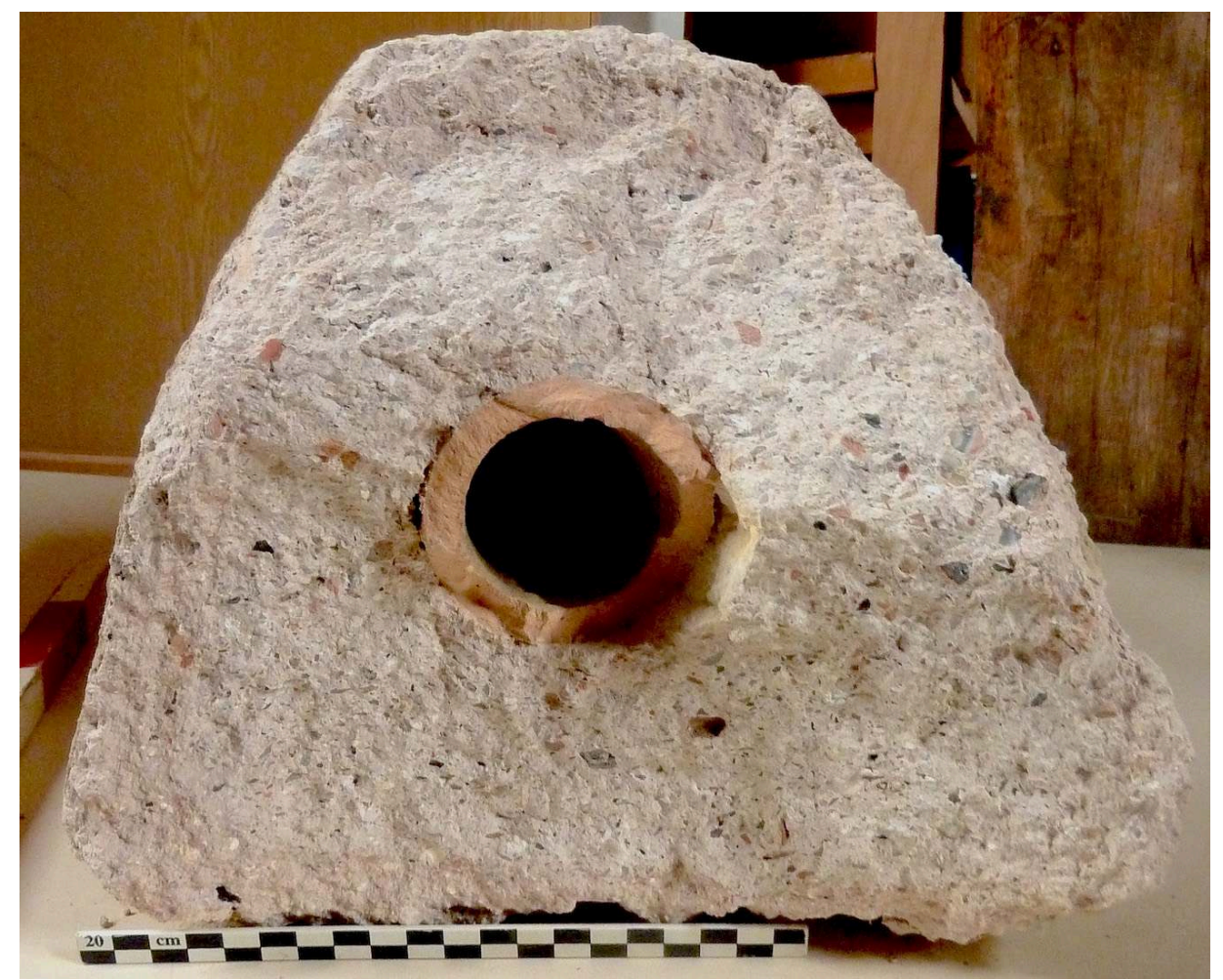

(c) Stéphane Büttner.

Enfin, les documents de comptabilité disponibles pour la fin du Moyen Âge, et sur lesquels se sont penchés certains historiens, apportent des informations capitales non seulement sur l'usage du mortier de tuileau, mais aussi sur l'aspect économique de cette matière première - alors même que ce dernier point reste bien difficile à aborder d'un point de vue strictement archéologique. C'est le cas, par exemple, de l'utilisation du mortier de tuileau pour les toitures (solins, scellements de tuiles), contexte dans lequel les témoignages matériels demeurent extrêmement résiduels. Pour autant, cet usage régulier est bien confirmé par des sources manuscrites, comme au château d'Argilly (Côte-d'Or) pour l'élaboration de solins au xIV siècle $^{32}$, ou à Aix et à Avignon à 
la même époque, pour jointoyer des dalles de couverture ${ }^{33}$. L'utilisation de ce type de mortier pour étanchéifier des zones de toiture fortement soumises aux potentielles infiltrations va perdurer au moins jusqu'au XVII ${ }^{\mathrm{e}}$ siècle, à l'image des toits en terrasses du château de Chambord, qui furent en partie restaurés à l'aide de ce matériau ${ }^{34}$. Mais l'essentiel de ces mentions concernant l'usage du tuileau évoque surtout mastics, enduits, mortiers pour la réalisation de cuves à vin, fosses septiques, tanneries, citernes, etc. Il semble alors que dans cette fin du Moyen Âge, les mortiers de tuileau sont l'œuvre d'artisans clairement spécialisés. Le tuileau est alors devenu une marchandise à part entière, et son commerce, au moins à l'époque moderne, a engendré la création d'un corps de métier spécialisée ${ }^{35}$. Les filières médiévales demeurent quant à elles encore obscures, mais le produit, d'un coût élevé, a bel et bien fait l'objet de transactions commerciales, comme le montrent certaines sources écrites. On serait tenté de voir là, pour des artisans tuiliers-briquetiers, un moyen opportun d'écouler des rebuts de production; mais ce serait oublier que tous les traités et certains documents comptables évoquent l'utilisation de tuiles anciennes, donc de récupération, pour l'élaboration de cette matière première.

\section{Conclusions}

«La préparation des mortiers romains a toujours fait l'objet d'une grande admiration, souvent teintée de secret technique jamais dévoilé. En réalité, les seules constructions en maçonnerie concrète (c'est-à-dire liées au mortier de chaux) qui nous soient parvenues en bon état sans jamais avoir été protégées par l'enfouissement, sont celles dont l'édification avait à tous égards été particulièrement soignée, faisant appel à de la chaux de qualité [...]. On ne saurait parler des constructions médiocres innombrables, puisque celles qui étaient demeurées à l'air libre ont disparu en raison même de leur vulnérabilité ${ }^{36}$. »

Cette affirmation de Jean-Pierre Adam voit sa pertinence encore confirmée si l'on considère le mortier de tuileau. En effet, ce matériau aux propriétés particulières présente une exceptionnelle durabilité, qui explique certainement le bon état de conservation des structures maçonnées qu'il constitue, entraînant de fait une certaine surreprésentation de ces vestiges par rapport à des aménagements élaborés au mortier de chaux aérienne, plus vulnérables. C'est sans doute la raison pour laquelle ce type de mortier fut défini par certains auteurs, un peu de façon péremptoire, comme le «mortier romain » ou le «béton romain » par excellence. En observant l'utilisation du mortier de tuileau sur la diachronie, on comprend qu'il n'a en réalité rien d'une spécificité romaine, même si la pérennité des vestiges antiques ainsi construits a sans doute constitué une valeur d'exemple.

Bien que l'usage du mortier de tuileau soit continu depuis l'Antiquité, on constate un léger hiatus correspondant à la période mérovingienne, pour laquelle seuls quelques vestiges de sols nous sont parvenus. Il faut souligner que ces temps sont marqués par une crise démographique et socio-économique majeure; de fait, la construction maçonnée a connu un net recul général entre les $\mathrm{V}^{\mathrm{e}}$ et VIII ${ }^{\mathrm{e}}$ siècles. Il en va de même de l'usage du mortier de tuileau. À partir de l'époque carolingienne, on constate une recrudescence de son utilisation pour l'élaboration de sols mosaïqués ou non, ou comme liant de maçonnerie d'édifices monumentaux. Si l'on connaît bien les nombreuses références à l'Antique durant cette période, et en particulier une 
redécouverte des auteurs romains, l'influence du monde byzantin pourrait également expliquer le regain de l'utilisation de ce type de mortier.

Cet usage comme liant de maçonnerie est aussi attesté pour de nombreux édifices romans. E. Viollet-le-Duc avait ainsi noté dans son dictionnaire que «le mortier employé dans les monuments romans antérieurs au $\mathrm{XII}^{\mathrm{e}}$ siècle est quelquefois mélangé de débris de tuileaux, surtout pendant le $\mathrm{x}^{\mathrm{e}}$ siècle et avant ${ }^{37}$ ». Pour M. Aubert, il s'agit d'une caractéristique des époques mérovingiennes et carolingiennes ${ }^{38}$. M. de Boüard note, quant à lui, que «dans une bonne partie du nord de la France, les spécimens les plus récents pourraient dater du milieu du $\mathrm{XI}^{e}$ siècle $^{39}$ ». D'après des constatations récentes, et la remise en question de la datation de certains édifices, il semble que ce phénomène pourrait effectivement se mettre en place à partir du IX ${ }^{e}$ siècle, de façon certaine durant le $\mathrm{x}^{\mathrm{e}}$ siècle, et finalement perdurer jusqu'à la fin du XII ${ }^{\mathrm{e}}$ siècle. Le XII siècle, par ailleurs, marque un tournant dans l'usage du mortier de tuileau qui, à partir de ce moment, apparaît être uniquement réservé aux structures hydrauliques.

De tout temps, et déjà en Grèce antique, on observe justement une certaine permanence de la technique dans ces fonctions spécifiques: sols et structures hydrauliques. Ce qui tendrait à prouver qu'il s'agit d'une technique particulièrement maîtrisée par des artisans spécialisés. Si l'élaboration des sols au mortier de tuileau tend à disparaître après le $\mathrm{XII}^{\mathrm{e}}$ siècle, les artisans spécialistes des structures hydrauliques vont quant à eux exercer leur art jusqu'à l'aube du XIX ${ }^{e}$ siècle. Certains traités d'art à bâtir de cette époque vont d'ailleurs jusqu'à désigner le mortier de tuileau, alors utilisé pour ses propriétés d'étanchéité, comme le " ciment de fontainier ${ }^{40}$ ». Ce corps de métier, nécessaire et donc à l'œuvre durant presque toutes les périodes historiques, comme le prouve l'archéologie, a été vraisemblablement l'un des gardiens d'un savoir-faire jamais démenti. Les travaux des historiens des textes semblent aussi aller dans ce sens.

En ce qui concerne l'élaboration de ces mortiers de tuileaux, la référence aux écrits de Vitruve est permanente, tant dans l'historiographie que dans les traités d'art à bâtir. Ces écrits font toujours aujourd'hui valeur de dogme chez certains spécialistes de l'architecture antique; ceux-ci s'évertuent encore, sans doute vainement, à faire corroborer aux préconisations de l'architecte antique une réalité archéologique des plus variées ${ }^{41}$. Il faut d'ailleurs souligner que Vitruve n'est pas un inventeur mais un témoin, non exhaustif, rapportant des pratiques de son temps observées très vraisemblablement dans une partie de l'Italie.

Les traités d'arts à bâtir et d'architecture sont en réalité nombreux dès l'Antiquité et font également part de l'élaboration de ce type de mortier ${ }^{42}$. Force est de constater que les auteurs qui succèdent à Vitruve, même directement comme Pline, ont une fâcheuse tendance à le reprendre quasiment mot pour mot. On peut d'ailleurs se demander si cette tradition de « copiste » chez les auteurs de traités n'a pas été continue jusqu'à la fin de l'époque moderne, tant l'influence de Vitruve est encore décelable dans les ouvrages de cette période ${ }^{43}$.

L'analyse archéologique de l'usage du mortier de tuileau depuis l'Antiquité montre que la pratique technique et son développement empirique ont, dans une certaine mesure, pris le dessus sur la théorie " livresque », qui a finalement stagné. C'est un fait jusqu'au siècle des Lumières, moment à partir duquel la pensée scientifique fait un véritable bond: la connaissance des phénomènes chimiques liés au mortier de tuileau, et plus 
généralement la compréhension de l'effet pouzzolanique, a alors conduit au développement des chaux hydrauliques artificielles, puis des ciments de type portland ${ }^{44}$.

L'apport des données manuscrites, en particulier les documents de comptabilité de la fin du Moyen Âge, reste primordial quant à la question de la marchandisation du tuileau. Les données archéologiques restent pour l'heure en grande partie discrètes quant à cet aspect. Mais le développement des analyses archéométriques pourrait dans un futur proche apporter de nouveaux éléments de compréhension. Des datations par thermoluminescence permettraient ainsi de vérifier que l'emploi d'un broyat de tuiles anciennes, de "tuiles de païens », constituait effectivement la norme, quelle que soit la période envisagée.

Malgré l'invention des ciments à l'aube du XIX siècle, l'utilisation du mortier de tuileau n'a pas complètement disparu à cette époque. On retrouve ainsi ce matériau appliqué très fréquemment en reprise de joints ou d'enduit des parties basses des murs anciens, comme on l'a fait ensuite avec le goudron ${ }^{45}$. Encore aujourd'hui, le tuileau est produit industriellement à partir du broyage de briques à pâte molle (cuites à une température inférieure à $850^{\circ} \mathrm{C}$ ). Ce matériau, lié avec du sable et de la chaux aérienne ou hydraulique naturelle, connaît, en ce début $\mathrm{du} \mathrm{xxI}^{\mathrm{e}}$ siècle, une popularité croissante pour ses caractéristiques techniques qui le rendent particulièrement adapté à la restauration du patrimoine, mais aussi pour à la bioconstruction, actuellement très en vogue. L'histoire du mortier de tuileau n'est donc pas achevée.

\section{BIBLIOGRAPHIE}

ADAM J.-P., 2011, La construction romaine : matériaux et techniques, $6^{\mathrm{e}}$ éd., Paris, Picard.

AUBERT M., 1960, « La construction au Moyen Âge », Bulletin monumental, nº 119, p. 297-323.

AVILER Augustin-Charles d', 1755, Dictionnaire d'architecture civile et hydraulique et des arts qui en

dépendent, Paris, C. A. Jombert.

BARIONO G., BINDA L., LOMBARDINI N., 1997, « The role of brick pebbles and dust in conglomerates based on hydrated lime and crushed bricks ", Construction and Building Materials, vol. 11, $\mathrm{n}^{\circ} 1$, p. 33-40.

BECK P., 2000, « De l'atelier au château : production et consommation de briques en Bourgogne au $\mathrm{XIV}^{\mathrm{e}}$ siècle, l'exemple de la châtellenie d'Argilly », dans Boucheron P., Broise H., Thebert Y. (dir.), La brique antique et médiévale : production et commercialisation d'un matériau, Rome, École française de Rome / Saint-Cloud, Centre d'histoire urbaine de l'École normale supérieure de Fontenay Saint-Cloud, p. 357-370.

BERNARDI P., 2000, « Récupération et transformations : les produits dérivés de la brique et de la tuile dans le bâtiment au Moyen Âge ", dans Boucheron P., Broise H., Thebert Y. (dir.), La brique antique et médiévale : production et commercialisation d'un matériau, Rome, École française de Rome / 
Saint-Cloud, Centre d'histoire urbaine de l'École normale supérieure de Fontenay - Saint-Cloud, p. 401-409.

BERNARDI P., 2011, Bâtir au Moyen Âge, Paris, CNRS éditions.

BINDA L., BARONIO G., TEDESCHI C., 2000, « Experimental study on the mechanical role of thick mortar joints in reproduced Byzantine masonry », dans Bartos P., Groot C., Hughes J. J. (dir.), International RILEM Workshop on Historic mortars : characteristics and tests, Paris, RILEM, p. 227-247.

BOSC E., 1877-1880, Dictionnaire raisonné d'architecture et des sciences et arts qui s'y rattachent, Paris, Firmin-Didot.

BOÜARD M. de, 1975, Manuel d'archéologie médiévale : de la fouille à l'histoire, Paris, Société d'édition d'enseignement supérieur.

BOUIRON M. et MELLINAND P., 2013, Quand les archéologues redécouvrent Marseille, Paris, Gallimard / Inrap.

BOURGÈs A. 1999, « Archéomatériaux et techniques anciennes : étude de mortiers et d'enduits d'étanchéité de bassins de décantation du Laurium antique (Grèce) et d'une citerne médiévale de Sabra Al-Mansouriya (Tunisie) », mémoire de DESS, Talence, université Bordeaux I et université Bordeaux III.

BRUN G., 2016, « Recettes de l'Antiquité et du Moyen Âge pour mortiers et enduits : récupération, interprétations et comparaisons avec les sources manuscrites », dans Fleury F., Baridon L., Mastrorilli A., Mouterde R., Reveyron N. (dir.), Les temps de la construction : processus, acteurs, matériaux. Vaulx-en-Velin, France, Paris, Picard, p. 1113-1122.

BÜTTNER S., 2012, «The use of the "already there": reuse and recycling for monumental building in the west in late Antiquity and the medieval period ", dans Carvais R., Guillerme A., Nègre V., Sakarovitch J. (dir.), Nuts \& bolts of construction history: culture, technology and society, Paris, Picard, p. 461-468.

BÜTTNER S. et COUTELAS A., 2011, « Mortiers de chaux et décors architecturaux en Gaule de l'Antiquité au haut Moyen Âge ", dans Balmelle C., Eristov H., Monier F. (dir.), Actes du colloque "Décors et espace architectural en Gaule : mosaïques, peinture, stuc, entre l'Antiquité et le haut Moyen Âge» (Toulouse, 9-12 octobre 2008), Talence, Fédération Aquitania (Aquitania, suppl. 20), p. 663-673. BÜTTNER S. et PRIGENT D., 2007, « Archéologie des liants de maçonnerie : entre traités et réalité », dans Medieval Europe Paris 2007, $4^{e}$ Congrès international d'archéologie médiévale et moderne, Paris, université Paris I, p. 14.

COUTELAS A., 2005, « Les mortiers et enduits des sites gallo-romains en Bourgogne », Revue archéologique de l'Est, $\mathrm{n}^{\circ}$ 54, p. 327-335.

COUTELAS A., 2019, «L'hydraulicité des mortiers antiques, entre préconçus et réalité : l'exemple des mortiers de tuileau et autres matériaux de Gaule romaine », dans Fumadó I. et Bouffier S. (dir.), Mortiers et hydraulique en Méditerranée antique, Aix-en-Provence, Presses universitaires de Provence (Archéologies méditerranéennes), p. 17-30.

COUTELAS A., GUYARD L., DAVID C., 2000, « Pétroarchéologie des mortiers gallo-romains : application des méthodes analytiques à l'étude des thermes du Vieil-Évreux (Eure) », Les Nouvelles de l'archéologie, $\mathrm{n}^{\circ}$ 81, p. 31-36.

COUTELAS A., GODARD G., BLANC P., PERSON A., 2004, « Les mortiers hydrauliques : synthèse bibliographique et premiers résultats sur des mortiers de la Gaule romaine ", Revue d'archéométrie, nº 28, p. 127-139. 
COUTELAS A., BÜTTNER S., OBERLIN C., PALAZZO-BERTHOLON B., PRIGENT D., SUMERA F., 2009, Le mortier de chaux, Paris, Errance.

DAVIDOVITS F., 1992, « Les mortiers de pouzzolanes artificielles chez Vitruve : évolution et historique architecturale », mémoire de DEA, Saint-Quentin, Geopolymer Institute.

DELOYE F.-X., 1993, « Hydraulicité et pouzzolanicité », Bulletin de liaison des laboratoires des Ponts et chaussées, $\mathrm{n}^{\circ} 184$, p. 94-95.

DESGUINE A., 1952a, « Pierres, mortiers et briques du palais des thermes (Paris) », Gallia, t. X, p. 57-64.

DESGUINE A., 1952b, À propos de l'ancien aqueduc d'Arcueil-Cachan : ciment et béton du temps des Romains, La Journée du bâtiment, travaux publics, architecture, $4^{\mathrm{e}}$ trimestre.

DRON R., 1978, « L'activité pouzzolanique », Bulletin de liaison des laboratoires des Ponts et chaussées, $n^{\circ} 93$, p. 66-69.

FOREST DE BELIDOR B., 1737, Architecture hydraulique, ou l'art de conduire, d'élever et de ménager les eaux pour les différents besoins de la vie, Paris, C. A. Jombert.

FRIZOT M., 1975, Mortiers et enduits peints antiques : étude technique et archéologique, Dijon, Université de Dijon, Centre de recherches sur les techniques gréco-romaines.

FURLAN V. et BISSEGER P., 1975, « Les mortiers anciens : histoire et essais d'analyse scientifique », Revue suisse d'art et d'archéologie, $\mathrm{n}^{\circ} 32$, p. 166-178.

GAZAGNE D., CAILLOT I., L'HÉRITIER M., BÜTTNER S., 2017, « Adduction, évacuation et gestion de l'eau dans l'enclos du Temple de Paris : approches archéologiques et techniques », Archéologie médiévale, $\mathrm{n}^{\circ}$ 47 , p. 9-32.

GROS P., 2003, « L'opus signinum selon Vitruve et dans la terminologie archéologique contemporaine ", dans G. Ciotta (dir.), Vitruvio nella cultura architettonica antica, medievale e moderna. Atti del convegno internazionale di Genova, 5-8 nov. 2001, Gênes, De Ferrari, p. 142-152. HASSINE FANTAR M., 1987, Kerkouane, une cité punique au cap Bon, Tunis, Maison tunisienne de l'édition.

HERRING B. et MILLER S., 2002, « The Secrets of Roman Concrete », Constructor, p. 13-14. HUGHES J. J. et SUGDEN D., 1999, « The use of brick dust as a pozzolanic addition to hydraulic lime mortars ", dans Bartos P., Groot C., Hughes J. J. (dir.), International RILEM Workshop on Historic mortars : characteristics and tests, Paris, RILEM, p. 351-360.

KARATASIOS I., WATT D., COLSTON B., 2002, « Characterisation and development of mortars for the conservation of byzantine floor mosaics », dans Joyce H. (dir.), Conservation science 2002, Londres, Archetype Publications, p. 121-126.

LA FAYE de, 1777, Recherches sur la préparation que les romains donnaient à la chaux dont ils se servaient pour les constructions et sur la composition et l'emploi de leurs mortiers, Paris, Impr. royale.

LAMPRECHT H. O., 1984, Opus caementicium : Bautechnik der Römer, Düsseldorf, Beton-Verlag.

LECHTMAN H. N. et HOBBS L. W., 1987, « Roman concrete and the Roman architectural revolution », Ceramics and Civilization, $\mathrm{n}^{\circ} 3, \mathrm{p} .81-128$.

MACIAS A., PALOMO A., PUERTAS F. BLANCO VARELA M., 1992, « Study of support romain mortars of Italica's mosaics », dans Delgado Rodrigues J. et Telmo Jeremias F. (dir.), 7th International congress 
on deterioration and conservation of stone, Lisbonne, Laboratorio nacional de engenharia civil, p. 1299-1305.

MALINOWSKI R., 1979, « Concretes and mortar in ancient aqueducts », Concrete International, p. 66-79.

MOROPOULOU A., CAKMAK A., BISCONTIN G., 2011, « Crushed brick / lime mortars of Justinian's Hagia Sophia », MRS Online Proceedings Archives, $n^{\circ}$ 462, p. 307-316.

PAPAJANNI K. et LEY J. (dir.), 2016, Karolingerzeitliche Mauertechnik : in Deutschland und in der Schweiz, Regensburg, Schnell \& Steiner.

PLINE L'ANCIEN, 2013, Histoire naturelle, Schmitt S. (éd.), Paris, Gallimard (Bibliothèque de la Pléiade).

PONSOT P., 2007, « Les terrasses du donjon de Chambord : un projet de Léonard de Vinci ? », Bulletin monumental, vol. $165, \mathrm{n}^{\circ} 3$, p. 249-261.

PUERTAS F., PALOMO A., BLANCO VARELA M., 1993, « Characterization of ancient lime mortars : bedding mortars in roman mosaics ", dans $2^{\text {nd }}$ International Eurolime meeting, Copenhagen, 20th-23rd August 1993, Eurolime, Development and manufacturing of lime for preservation of monuments, Karlsruhe, Eurocare, p. 44-46.

RASSINEUX F., PETIT J.-C., MEUNIER A., 1989, « Ancient analogues of modern cement: calcium hydrosilicates in mortars and concretes from Gallo-Roman thermal baths of Western France », Journal of the American Ceramic Society, vol. 72, nº 6, p. 1026-1032.

RONCUZZI FIORENTINI I., MAMBELLI R., FABBR B., DONATI F., 1985, « “Opus signinum” : composition, dégradation et conservation ", dans $5^{2}$ Congrès international sur l'altération et la conservation de la pierre, Lausanne 25-27.9.1985, Lausanne, Presses polytechniques romandes, p. 341-350.

ROYER A., 2004, Le ciment romain : étude d'un matériau et de son utilisation dans les restaurations de monuments historiques au XIX siècle : les cathédrales d'Amiens et de Bourges, Paris, École du Louvre (Monographies de l'École du Louvre).

TEUTONICO J. M., ASHALL G., GARROD E., YATES T., 2000, « A comparative study of hydraulic lime based mortars », dans Bartos P., Groot C., Hughes J. J. (dir.), Historic mortars : characteristics and tests. International RILEM Workshop, Paris, RILEM, p. 339-349.

VASSAL V., 2011, « Opus signinum : un héritage de l'Antiquité », Les Dossiers d'archéologie, nº 346, p. 84-89.

VIOLLET-LE-DUC E., 1854-1858, Dictionnaire raisonné d'architecture française du $\mathrm{XI}^{e}$ au XVI ${ }^{e}$ siècle, Paris, Bance-Morel.

VITRUVE, 1995, De architectura : les dix livres d'architecture, Poitiers, Picon.

\section{NOTES}

1. Le terme anglo-saxon roman concrete, que l'on peut traduire littéralement par « béton romain ", qualifie en réalité l'ensemble des mortiers hydrauliques, que les ajouts qui confèrent cette hydraulicité soient des pouzzolanes ou du tuileau. Voir Herring et Miller 2002, Lechtman et Hobbs 1987.

2. Coutelas et al. 2009, Frizot 1975.

3. Vitruve 1995, LII, 5. 
4. Ibid., II, 5.

5. Ibid., II, 6.

6. Deloye 1993, Dron 1978.

7. Coutelas et al. 2004, Coutelas 2019, Hughes et Sugden 1999.

8. Binda et al. 2000.

9. Bariono et al. 1997, Teutonico et al. 2000.

10. Coutelas et al. 2004, Coutelas 2019.

11. Furlan et Bisseger 1975.

12. Hassine Fantar 1987.

13. Bourgès 1999.

14. Bouiron et Mellinand 2013.

15. Vitruve, 1995, II, 7.

16. Coutelas et al. 2009, Coutelas 2005.

17. Coutelas et al. 2000, Rassineux et al. 1989, Desguine 1952a.

18. Puertas et al. 1993, Macias et al. 1992.

19. Roncuzzi Fiorentini et al. 1985, Vassal 2011.

20. Pline, 2013, XXXV, 46.

21. Malinowski 1979, Desguine $1952 b$.

22. Lamprecht 1984.

23. Vitruve 1995, II, VIII.

24. Adam 2011, Lamprecht 1984.

25. Büttner 2012.

26. Papajanni et Ley 2016.

27. Karatasios et al. 2002, Moropoulo et al. 2011.

28. Büttner et Coutelas 2011.

29. Bernardi 2011.

30. Coutelas et al. 2009, Gazagne et al. 2017.

31. Forest de Belidor 1737, Aviler 1755.

32. Beck 2000.

33. Bernardi 2000.

34. Ponsot 2007.

35. Bernardi 1995.

36. Adam $2011: 77$.

37. Viollet-le-Duc 1854-1858 : 402.

38. Aubert 1960.

39. Boüard $1975: 60$.

40. Bosc $1877-1880$.

41. Gros 2003, Davidovits 1992.

42. Brun 2016 .

43. Büttner et Prigent 2007. 
44. La Faye 1777.

45. Royer 2004.

\section{RÉSUMÉS}

Le mortier de tuileau, parfois appelé «ciment romain » ou «béton romain », est un mortier de chaux additionné d'une part de fragments de terre cuite architecturale qui confère au matériau des propriétés hydrauliques. Pouvant prendre sous l'eau, le produit final présente une résistance mécanique et une imperméabilité remarquables. De l'Antiquité à l'époque moderne, il fut alors d'usage courant dans la construction de structures liées à l'eau, de certains sols, ou encore de murs aux fonctions architecturales particulières. Les recommandations formulées par Vitruve dans son traité d'architecture au sujet de l'élaboration de ces mortiers sont bien souvent évoquées par les historiens du bâti comme référence principale. L'archéologie montre une réalité sans doute plus complexe : des recettes et des mises en œuvre diverses qui semblent faire la part belle à un empirisme récurrent à travers les siècles. Dans le courant du XVIII ${ }^{e}$ siècle, la considération scientifique des "ciments romains" va cependant conduire à l'invention des chaux hydrauliques artificielles et finalement des ciments portland.

\section{INDEX}

Mots-clés : mortier, chaux hydraulique, mortier hydraulique, pouzzolane, tuileau

\section{AUTEUR}

\section{STÉPHANE BÜTTNER}

Centre d'études médiévales Saint-Germain, ville d'Auxerre ; membre associé au laboratoire Archéologie, terre, histoire, sociétés (ARTEHIS, université de Bourgogne, UMR 6298 du CNRS) 


\section{Les jardins et les parcs de l'île-de- France du XVI ${ }^{\mathrm{e}}$ au XVIII ${ }^{\mathrm{e}}$ siècle : données environnementales et mise en œuvre des matériaux (pierres et bois)}

Jean-Claude Koeniguer

Je suis très reconnaissant à Isabelle Tarier pour la relecture attentive de cet article ainsi que pour ses remarques et suggestions, dont j'ai tenu le plus grand compte.

\section{Généralités : remarques géobotaniques sur la végétation, la biomasse végétale et l'évolution du climat au cours des Temps modernes}

1 À partir $\mathrm{du} \mathrm{xVI}^{\mathrm{e}}$ siècle survinrent des fluctuations climatiques décennales, et notamment des hivers froids et rudes dans les années 1590,1640,1740 et 1790 (températures moyennes de $-1^{\circ} \mathrm{C}$ environ); par contre, une période plus douce s'est instaurée entre 1710 et $1740^{1}$.

2 Ces variations climatiques sévères ont pu ici ou là contrarier, ou au contraire favoriser, la reprise de diverses plantations dans les jardins. Ainsi, par exemple, d'éventuelles plantations de chênes sessiles au lieu de chênes pédonculés afin de restituer des bosquets subnaturels auraient pu échouer lors de ces fluctuations climatiques; en effet, la distinction botanique de ces deux espèces ne remonte pas avant le xix siècle, et par ailleurs la plus grande capacité d'adaptation écologique des seuls chênes pédonculés n'est connue que depuis quelques décennies ${ }^{2}$; de plus, les caractéristiques des sols et des formations superficielles étaient tout aussi ignorées à ces époques. Ces faits pourraient par exemple expliquer l'échec des reboisements en chênes dans le domaine 
de Versailles au cours de la deuxième moitié du XvII siècle, qui auraient conduit aux grands abattages des années 1770 .

3 Nos connaissances sur la biogéographie historique des forêts de la façade atlantique sont encore très aléatoires, qu'elles soient naturelles (les séries de végétations, les essaims climaciques) ou subnaturelles (les sylvo-systèmes et les sylvofaciès ${ }^{3}$ ).

4 Maints travaux en palynologie et en carpologie ont permis la reconnaissance de nombreuses espèces de la végétation forestière du centre du Bassin parisien au cours de ces derniers siècles ; cependant, ces recherches n'ont pas atteint l'exhaustivité, du fait de la non-fossilisation de restes végétaux ou encore de convergences de formes (les pollens de graminées, les chênes à feuilles caduques par exemple). En raison de cet état de fait, les composantes des forêts tempérées naturelles ou subnaturelles restent encore bien mal connues 4 . Une assez grande diversité, plus ou moins en mosaïque, devait être l'une de leurs caractéristiques. Jusqu'au premier tiers du $\mathrm{XVIII}^{\mathrm{e}}$ siècle, les arbres n'étaient considérés, dans les descriptions, que comme des sujets isolés ${ }^{5}$; ce n'est que dans le courant de ce siècle que se sont posés des questionnements à propos des arbres et arbustes, tels que celui de leur mode de croissance diamétral ou encore le pourquoi et le comment du développement des systèmes racinaires, qui ne trouvèrent de réponse qu'au cours du xix ${ }^{e}$ siècle.

5 L'une de ces interrogations est celle de la physionomie des sous-bois de ces forêts au cours des siècles derniers; ceux-ci, à mon sens, ont dû être d'une grande densité, et même difficilement pénétrables, donc rester dans un état naturel plus longtemps que la strate arborée, très exploitée de longue date. Ces sous-bois pouvaient comporter jusqu'à une trentaine de genres et une quarantaine d'espèces d'arbustes et d'arbrisseaux (noisetiers, aubépines, sureaux, cornouillers, chèvrefeuilles, genêts, ajoncs, cytises...) dont quelques lianes omniprésentes (clématites, lierre, vigne), auxquels se joignaient de très nombreuses plantes herbacées, fougères, mousses et lichens.

6 Ce point de vue intuitif de prime abord semble trouver un certain écho dans les descriptions de paysages d'écrivains de la fin du XvIII siècle et des premières décennies $\mathrm{du} \mathrm{XIX}^{\mathrm{e}}$ (Rousseau, Rêveries du promeneur solitaire, cinquième promenade; Balzac, Les Paysans), ainsi que dans des plaines plus lointaines des environs d'Hyères (Michelet) ou d'Athènes (Chateaubriand), où ces derniers auteurs ont souligné le caractère bocager de ces terroirs (forêts linéaires).

7 Pendant les quelques siècles du haut Moyen Âge ( $\mathrm{vi}^{\mathrm{e}}-\mathrm{x}^{\mathrm{e}}$ siècle), les diverses phases de reforestation consécutives à la récession socio-économique de l'Antiquité tardive laisse suggérer un retour à une dynamique forestière d'ensemble semi-naturelle dans le nord de la France, qui pourrait s'expliquer du fait d'une certaine densité de la végétation des sous-bois restés, ici ou là, dans un état subnaturel.

8 Un phénomène analogue, plus bref, a dû survenir au cours de la guerre de Cent Ans (1340 à 1450) pour les mêmes raisons, c'est-à-dire l'existence de sous-bois par places plutôt denses, diversifiés et aux sols profonds et bien structurés, et donc favorables à une reprise de la strate arborée de la végétation forestière. Ces faits événementiels naturels expliquent les fluctuations corrélatives de la disponibilité du bois de

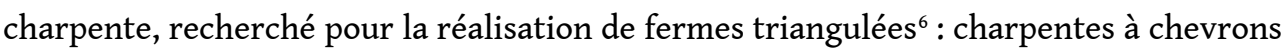
au cours du XIII ${ }^{\mathrm{e}}$ siècle, à la suite des déforestation excessives du début du second millénaire; charpentes triangulées $d u x^{e}$ et $d u x v I^{e}$ siècle, du fait d'une certaine 
disponibilité en pièces de bois suffisamment longues et d'un bon diamètre; puis charpentes à courtes pièces, dites "à la Philibert Delorme", suite à une seconde crise du bois de charpente à la fin du Xvi ${ }^{\mathrm{e}}$ siècle.

\section{Les premiers grands jardins historiques et le monde végétal}

9 Si bien des jardins romains étaient de plan régulier, certains étaient composés en "groupements» végétaux et architecturaux diversifiés, excluant toute rigidité et devenant ainsi plus ou moins des dépendances architecturées de la villa ${ }^{7}$. Cette esthétique, qui refusait les effets d'ensemble, se situait à l'opposé du parc « régulier » et était plutôt proche de celle des parcs anglais du XviII ${ }^{\mathrm{e}}$ siècle ${ }^{8}$. Ainsi la villa d'Hadrien (première moitié $\mathrm{du} \mathrm{II}^{\mathrm{e}}$ siècle) présente des plans curvilignes et des espaces ondulatoires ${ }^{9}$.

10 En Italie, au cours $\mathrm{du} \mathrm{xV}^{\mathrm{e}}$ siècle, s'est créée une architecture des jardins à terrasses, aqueducs, escaliers, bosquets, pergolas et sculptures, dont s'inspirèrent des maîtres d'ouvrage et des maîtres d'œuvre dans les vallées de la Seine et de la Loire (Gaillon, dans l'Eure, Cheverny, dans le Loir-et-Cher) au début du xvI siècle, avant que ne s'inventent les jardins de talwegs et d'eaux ${ }^{10}$.

11 La création de tous ces jardins, du fait de leur intégration " naturelle » obligée au sein de paysages complexes, a impliqué une maîtrise progressive des équilibres géomorphologiques environnants (éboulis, fluages, altérations des roches...), des affleurements géologiques, de l'hydrodynamisme des nappes phréatiques, des climats régionaux et des microclimats éventuels (le climat insubrien des lacs italiens par exemple). Qui plus est, il a été évidemment inévitable que les domaines boisés, intégrés, fondés ou protégés aux alentours se soient réintégrés dans une dynamique forestière proche de celle des forêts naturelles de la contrée concernée. Par ailleurs, il faut aussi se souvenir de la luxuriance, à ces époques, du monde végétal encore semi-naturel en termes de biomasses, et ce de plus dans les conditions des aléas climatiques du Petit Âge glaciaire, notamment en ce qui concerne des végétaux aquatiques et riverains tels que des cyanophytes, des algues vertes, des charophytes, les fluviales, des graminées, des joncs..., ainsi que des champignons, des lichens, des fougères... Toutes les caractéristiques ici évoquées sont à prendre en compte lorsque se posent les questions des devenirs géohistoriques de ces jardins. On ne peut que suggérer et encourager des phyto-sociologues à analyser tous ces paramètres relevant de l'archéologie environnementale et des archéosciences.

12 Ce n'est que vers la fin du XviI ${ }^{\mathrm{e}}$ siècle, et surtout au cours du siècle suivant, que l'on a perçu l'existence de groupements naturels de végétaux et leur écologie. De nouvelles approches des relations à la fois esthétiques et scientifiques entre les hommes et le monde végétal se firent jour peu à peu et conduisirent à rechercher des lignes directrices courbes et serpentines, et même des dissymétries rappelant les thèmes de prédilection maniéristes des compositions. 


\section{Les jardins historiques de la fin du $\mathrm{Xv}^{\mathrm{e}}$ siècle et des premières décennies du $X \mathrm{~V} \mathrm{l}^{\mathrm{e}}$ siècle (première École de Fontainebleau)}

13 Les tout premiers jardins d'agrément semblent avoir été réalisés en Grande Grèce au cours de la période hellénistique (Palerme, Syracuse), en prenant même parfois l'aspect de parcs publics, à l'image du seul d'entre eux qui subsiste encore à Rhodes, le parc Rhodini (III ${ }^{\mathrm{e}}$-II ${ }^{\mathrm{e}}$ siècles).

Un élan novateur dans la mise en valeur des aspects paysagers des constructions a marqué la civilisation occidentale, avec l'invention des villas maritimes, tout d'abord en Campanie dès le $\mathrm{II}^{\mathrm{e}}$ siècle avant notre ère, puis dans toute la Méditerranée occidentale. À la fin du Xve siècle, on assiste au passage de jardins en partie utilitaires à des jardins essentiellement décoratifs ${ }^{11}$. Puis au XVI ${ }^{\mathrm{e}}$ siècle, l'art des jardins redevient un art à l'égal de l'architecture ${ }^{12}$; aussi I. Lauterbach a-t-elle-pu écrire que « Les jardins sont des lieux dessinés, architecturés où s'entrecroisent les arts et la nature ${ }^{13}$ ".

15 Les architectures des grands jardins romains, puis italiens, furent donc les modèles de ceux qui ont été inventés dans les quelques décennies de la fin $d u \mathrm{Xv}^{\mathrm{e}}$ siècle et du début du Xvi ${ }^{e}$ dans le val de Loire et dans les basses vallées de la Seine et de l'Eure : jardins de pentes axialisés, à terrasses et à points de vue ${ }^{14}$, Villandry (Indre-et-Loire), Gaillon...

16 Au cours du Xvi ${ }^{e}$ siècle, l'invention et le devenir de ces jardins furent ceux de jardins de plaines, de talwegs, de plans d'eau et de fossés ${ }^{15}$; ces jardins ne pouvaient pas se concevoir sans un choix bien fondé de sites dont la topographie et les ressources en eau se devaient de correspondre aux projets envisagés et imaginés. Ces innovations de la Renaissance sous-entendent des progrès continus dans la recherche des lignes de sources, ainsi que dans l'appréciation des terrassements à mettre en œuvre. Cette évolution de l'art des jardins a nécessairement impliqué une maîtrise certaine de l'hydraulique (aqueducs, réservoirs, bassins, canaux...), favorisée par l'emploi de pierres fermes, résistantes à l'hydrolyse (calcaires et grès non fracturés, calcaires marbriers) ainsi que de bois durables à l'eau. Les tracés de tous ces jardins axialisés n'étaient en fait pas toujours aussi symétriques et rigoureux que dans les représentations qui en ont été données dans les gravures sur cuivre.

17 Au cours de ce siècle, les axes des jardins furent quelquefois prolongés au-delà de leurs limites dans les campagnes et les forêts, par la mise en place de larges allées d'arbres : Bonnivet (Vendeuvre-du-Poitou, Vienne), en 1520 ; Villers-Cotterêts (Aisne), en 1535 ; Montargis (Loiret), en 1570 ; Fontainebleau (Seine-et-Marne) sous le règne d'Henri IV ${ }^{16}$.

18 Le maniérisme (la "bella maniera», la "maniera moderna ${ }^{17}$ ») s'est traduit par des qualités exceptionnelles: beauté, harmonie, mesure, imagination, fantaisie, savoirfaire, perfection, raffinement, subjectivité et expression ${ }^{18}$. Cette nouvelle manière a bien sûr touché l'art des jardins en France, ainsi que l'architecture monumentale (invention des galeries donnant sur les jardins, escaliers doubles en demi-cercle ${ }^{19}$ ) et a conduit à un style rustique novateur, en fait inventé au cours du $\mathrm{I}^{\mathrm{er}}$ siècle $^{20}$.

19 À Fontainebleau, le portail de la cour de l'hôtel de Ferrare (Sebastiano Serlio, 1541-1543) a donné le ton à ce courant artistique par son dessin, et par le traitement des pierres de grès afin de créer des effets que l'on peut voir dans les affleurements naturels de cette roche : bossages massifs, nodules, cupules, piquetages, couleurs allant 
des gris aux ocres et même parfois à des tons orangés ou violacés. On retrouve ce style dans l'ancien portail de la cour du Cheval-blanc, devenu après remontage la porte du Dauphin, ainsi qu'à la porte Dorée.

De la sorte apparurent dans les jardins des thèmes de plus en plus variés, notamment dans les grottes évoquant des grottes naturelles et des paysages ${ }^{21}$ (topothésies ${ }^{22}$, tableaux, décors de coquillages...). Selon les observations et les progrès des connaissances, on eut recours à des matériaux aux formes surprenantes : stalactites calcaires, gogottes ${ }^{23}$ de grès, calcaires perforés de tubulures (racines), meulières de diverses couleurs... On inventa des bassins et des jeux d'eaux de plus en plus complexes, et on rechercha des tracés variés, des allées serpentines, des jeux d'ombres et de lumière et on joua même avec l'inachevé (la « mise en réserve »).

Parmi les sculpteurs, dessinateurs et graveurs, un même processus de "laïcisation ${ }^{24}$ " se fit jour chez bien des artistes (expressions des mouvements, préciosité des gestes...). La façade de la grotte du jardin des Pins, à Fontainebleau (Serlio ou le Primatice, 1541), en pierres de grès, est également une référence en sculpture par ses atlantes et ses termes ${ }^{25}$ en grès qui ont sans doute dû inciter à une recherche dans le sens d'une simplification des formes et d'une certaine "stylisation ». À proximité de cette grotte s'élevait, dans le jardin des Pins, le pavillon de Pomone, en grès fort probablement, décoré de fresques de Rosso et du Primatice.

De nombreux aménagements hydrauliques ont été mis en œuvre au cours du XVI ${ }^{e}$ siècle dans le domaine de Fontainebleau : consolidation de la digue médiévale de l'étang et de ses berges en pierres de grès, aqueducs édifiés sous les règnes de François I ${ }^{\text {er }}$ (grès), $d^{\prime} H e n r i$ II (grès et briques) et d'Henri IV (grès), ainsi que plusieurs fontaines ${ }^{26}$. Parmi celles-ci, la fontaine d'Hercule ${ }^{27}$ (1543), haute de plus de six mètres, fut un chef-d'œuvre réalisé en pierres de grès, dont l'élévation comprenait au premier niveau quatre colonnes en marbre ou grès blanc, quatre caryatides en grès stampien, dont l'une est conservée à Fontainebleau dans une collection privée, et une source rustique en gogottes gréseuses ou peut-être en travertin. Un lanternon coiffait la couverture en doucine de grès gris, et peut-être ocre en alternance (?), qui supportait la statue d'Hercule de Michel-Ange en marbre blanc (disparue).

Dans le courant du Xvi ${ }^{e}$ siècle, des grottes ont été aménagées dans le jardin des Tuileries à Paris, en briques et pierres calcaires (Lutétien sans doute) et ornementées de céramiques (dessins de Bernard Palissy), ainsi qu'à Montceaux-lès-Meaux (Seine-etMarne), Meudon (Hauts-de-Seine), Anet (Eure-et-Loir), Tanlay (Yonne)...

Toujours à Fontainebleau, La fontaine Belle-Eau, aménagée en 1527, était protégée par un voûtain "faisant grotte ${ }^{28}$ ", sans doute en pierres de grès (ou en calcaire silicifié d'Étampes ?) ; cette fontaine aurait dû être réaménagée selon un plan carré et pourvue d'un double escalier et de sculptures allégoriques (Benvenuto Cellini, 1544). Dans le jardin des Pins a été proposée l'édification d'un pavillon des Bains (Serlio), de plan carré d'une vingtaine de mètres de côté, qui aurait dû comporter un étage à colonnades, sûrement en pierres de grès, peut-être de diverses couleurs, à l'instar des matériaux mis en œuvre au rez-de-chaussée de la porte Dorée.

Le jardin de Fleury-en-Bière (Seine-et-Marne) a été l'un des premiers à être agrémenté d'un canal de près d'un kilomètre de longueur, que dominent plusieurs terrasses, et aux extrémités en forme d'hémicycle ; les rives ont été consolidées par des blocs de grès de 0,3 à 0,4 mètre de longueur. Plusieurs sculptures de pots de fleurs et de fruits en grès ornementent le jardin face au château. Un portail monumental donnant sur la 
campagne, au nord du parc, a été entièrement édifié en grès, avec des décors en volutes à la base. À Courances (Essonne), le parc comporte dix-sept bassins que relient les uns aux autres des systèmes de canalisations en terre cuite ou en pierre (de grès fort probablement) et de « gueulards » en grès.

On peut s'étonner de ne pas trouver de pierres de travertins dans ces ouvrages; pourtant Catherine de Médicis avait tenté de faire venir des matériaux extraits des carrières de Marseille ${ }^{29}$, mais même les gisements de travertin de la vallée de la Seine (La Celle, en Seine-et-Marne, La Saulsotte, dans l'Aube, Sézanne, dans la Marne) avaient certainement été considérés comme trop éloignés pour raisonnablement approvisionner les chantiers du sud-est de l'île-de-France.

Exception faite des sculptures de grottes, des portes et de quelques fontaines, la présence et l'éventuelle importance de la statuaire dans les jardins eux-mêmes ne semblent pas bien connues. On devait probablement y trouver pour le moins des sculptures ornementales, à l'image du petit obélisque richement décoré, en grès à grain fin, d'Henri II et Diane de Poitiers, aujourd'hui installé à l'entrée du parc de Chamarande (Essonne) depuis le village.

Dans le jardin de la Reine, à Fontainebleau, parallèlement à la galerie de la cour de la Fontaine, avait été édifiée, au milieu du siècle, une pergola comportant vingt-deux colonnes et un entablement en bois (de chêne sûrement) selon un dessin de sept travées en façade et de deux ailes de deux travées (vue du palais du côté du bourg Jacques Androuet du Cerceau, 1579) qu'ornementaient sur la corniche une vingtaine de statues également en bois de Germain Pilon, Dominique Florentin et Frémin Roussell.

Des aménagements de canaux orthogonaux dessinaient dans de nombreux jardins des grilles d'eau et des îles et îlots parfois arborés; ces jardins d'eau ont été créés notamment à Fontainebleau (une grande île et trois petites), dans le val de Loire, à Chenonceau (Indre-et-Loire) vers 1550, dans dix-huit « logis » sur vingt-six en Vendée ${ }^{30}$, ainsi qu'en 1555, dans le parc du château de Dampierre-en-Yvelines (1528-1535, briques et pierres de calcaire), auquel a été ajoutée une île pourvue de quelques pavillons, au sud de l'étang (André Le Nôtre) lors du remaniement du château (Jules HardouinMansart, 1675-1685).

\section{Les jardins et la seconde École de Fontainebleau}

Sous Henri IV, les embellissements des jardins de Fontainebleau prirent une ampleur sans précédent. Les pierres de grès y furent largement utilisées en raison de leurs qualités hydrauliques. Hormis le grand canal, maçonné en grès sur 1400 mètres de longueur et 40 mètres de largeur, nombre de ces ouvrages et œuvres disparurent après cette époque : le jardin de l'Étang (1594), bastion carré de 68 mètres de côté dont les bases de fondations existent encore; deux fontaines, dont la fontaine Belle-Eau, ainsi que deux canaux dans le jardin des Pins ; un troisième canal dans le jardin du Roi ainsi qu'une fontaine centrale en pierre de Senlis (peut-être à fondations en grès ?) ; une fontaine dans la cour de la Fontaine, ornée d'une sculpture de Persée; deux fontaines le long du fossé de la cour du Cheval-blanc, à piédestaux en grès.

31 Dans le jardin anciennement dénommé jardin de la Reine a été édifiée une fontaine en marbre blanc que surmontait une sculpture de Diane, également en marbre blanc, qui a été remplacée par le bronze actuel, coulé à la fin du XVII ${ }^{e}$ siècle. Au sud-est du domaine 
bellifontain, la fontaine de la statue du Tibre, en bronze, a été édifiée (1603) sans doute en grès, et ornementée d'une rocaille en partie, fort probablement, en grès; quatre aiguières en bronze (aujourd'hui conservées au musée du Louvre) ornaient les angles de cette fontaine. Il est à noter que les pierres en grès des assises supérieures des margelles de ces canaux et bassins montrent un léger ressaut en encorbellement sur leur face intérieure.

Prolongeant la chaussée de l'étang, le mail, récemment restauré, où l'on jouait au maillet, est pavé en pierres de grès à disposition harpée sur les marges de l'allée ; celleci est large de quatre mètres et longue de huit cents mètres, bordée au niveau du rocher d'Avon de confortations inclinées, en pierres de grès à section oblique, distantes d'une vingtaine de mètres en largeur et atteignant sept à huit mètres de hauteur ; la source d'extraction du matériau ne pouvait être plus proche!

Se pose la question des sites d'extraction des pierres de grès taillées pour l'édification $\mathrm{du}$ palais et des premiers jardins dans la première moitié du $\mathrm{XVI}^{\mathrm{e}}$ siècle. Le chemin de Fontainebleau à Melun, d'une part, et les marais du ru de Changis, d'autre part, rendirent sans doute plus accessibles les blocs du chaos de la base du versant sud du mont Ussy, alors que ceux du rocher d'Avon ne devinrent plus proches des chantiers que lors des travaux d'aménagements des jardins, à partir de 1535. Par contre, le chaos $d u$ rocher $d$ 'Avon ne semblant pas receler des grès ferrugineux, les pierres de ces grès ont donc nécessairement dû être extraites des sommets des bancs massifs de grès du mont Ussy, mais aussi de certains blocs de ces mêmes bancs éboulés du chaos de versant de ce gisement.

D'imposants jardins en terrasses ont été aménagés à Saint-Germain-en-Laye (Yvelines) de 1594 à 1595, sur quatre niveaux pourvus de spectaculaires colonnades. Deux grottes à décors de coquillages furent édifiées sur la deuxième terrasse, et des jeux d'eau agrémentaient tout particulièrement la basse terrasse, où avaient été creusés deux canaux. Ces constructions ont été édifiées en calcaire lutétien extrait d'une carrière située en contrebas de la future grande terrasse $\mathrm{du}_{\mathrm{XVII}}^{\mathrm{e}}$ siècle, dont on peut voir des vestiges, envahis par la végétation, apparaître au nord de la rampe septentrionale. C'est dans ces jardins que pour la première fois en France ont été aménagées des bordures de buis, espèce bien représentée dans les régions calcaires du sud de la France, mais aussi connue dans un certain nombre de sites du Bassin parisien. Au XVII ${ }^{\mathrm{e}}$ siècle, la galerie dorique a été réaménagée en arcades que séparent des colonnes géminées (Louis Le Vau), ainsi que deux longues rampes (le mur des Lions) ornées de médaillons et de pilastres (calcaire lutétien à pierres traitées de manière rustique); les murs de soutènement ont été décorés par des tables triangulaires de quelques dizaines de mètres de longueur, en meulières taillées cubiques rougeâtres et orangées, que soulignent des bandeaux à section arrondie en calcaire.

\section{Les jardins du XVII siècle}

Aux XVII et $\mathrm{XVIII}^{\mathrm{e}}$ siècles, le recours aux meulières de Montmorency et de Brie ajoute aux éléments décoratifs des constructions des jeux de couleurs inédits jusqu'alors. Il en est ainsi à Vaux-le-Vicomte (Le Nôtre, 1652-1660 ${ }^{31}$ ) dans la grotte (voûte en meulières de Brie, porche en pierres de grès) et au portail d'entrée du potager (pilastres en alternances de pierres de grès et de meulières de Brie, encadrement de la niche centrale). Par contre, les petits buffets d'eau, qui devaient avoir été quasiment ruinés 
(?), ont été en fait reconstruits, et non pas restaurés, au xxe siècle, en pierres de calcaire silicifié (calcaire de Champigny sans doute) qui affleure au sud, vers Melun. Il en a été de même, semble-t-il, en ce qui concerne les cascades du Grand Canal ; par contre, les superbes grottes aux sculptures d'atlantes, en pierres de grès, semblent avoir résisté aux agressions météoriques. Un peu plus tard (1661-1664), Le Nôtre a choisi de faire édifier les cascades du jardin de Fontainebleau en pierres de grès, qu'ornementent des tables en pierres de calcaire d'Étampes, criblées de moulages racinaires, disposées en délit; quelques meulières de Brie se voient ici et là dans ce décor. Si divers marbres, des bronzes et une riche statuaire (marbres) concourent à faire de Versailles un des plus fastueux jardins qui soient, néanmoins quelques matériaux locaux n'ont pas été négligés (calcaire lutétien, grès stampiens, meulières); de nombreux murs de clôture et de soutènement ont été essentiellement édifiés en meulières. La salle de bal (Le Nôtre, 1680-1685) présente un beau décor en meulières de Montmorency (carrières de Satory, au sud de Versailles) en petites dalles compactes, de couleurs chaudes, disposées verticalement en écailles accrochées à la maçonnerie par des fils métalliques ${ }^{32}$; le décor de cette salle se compose également de motifs à coquilles de strombes des Indes et de gogottes de grès au bas des rocailles; les entrées sont pavées de petits silex.

Au nord du domaine de Marly (Yvelines), un dispositif analogue à celui de la salle de bal de Versailles, mais en meulières caverneuses plus grandes $(0,2$ à $0,4 \mathrm{~m})$ fixées par des tenons métalliques et un mortier, ornemente l'imposant abreuvoir au nord du domaine (Hardouin-Mansart, 1687-1698 ${ }^{33}$ ); de nombreux murs de soutènement de ce domaine ont également été édifiés en dalles de meulières compactes; quelques meulières ont aussi été employées dans les douves et les contre-murs des bassins.

À Versailles, la pièce d'eau des Suisses, aménagée dans les alluvions modernes, montre des murets de douves en blocs massifs de meulières, d'un à deux décimètres de longueur, sur environ deux mètres de hauteur, dont un mètre hors d'eau, jointoyés par un mortier, que couronnent deux assises de meulières taillées d'environ deux décimètres de longueur puis un mortier de lissage. Les fondations des douves de nombreux bassins des jardins, parmi lesquels ceux de Neptune, d'Apollon et du Grand Trianon sont en pierres de meulières taillées, les margelles étant en calcaire lutétien, en marbre rouge du Languedoc (Grand Trianon) ou en marbre blanc. Les fonds des bassins sont souvent pavés de grès stampiens, et parfois de motifs en silex taillés, comme dans les bassins du Pavillon frais ${ }^{34}$.

Les premiers travaux ayant pour but un approvisionnement en eau du domaine de Versailles furent l'aménagement d'étangs (une quinzaine) et de rigoles sur le plateau de Trappes (de 1675 à $1684^{35}$ ) et donc pour une part dans les argiles à meulières de cette région ; 170 kilomètres de rigoles furent ainsi creusés, et les meulières ainsi extraites servirent à l'édification de retenues (étangs de Trappes, de Bois-d'Arcy, de Saclay et de Rambouillet).

La machine de Marly ${ }^{36}$ a été construite sur une plateforme $(70 \times 65 \mathrm{~m})$ de bois de chêne reposant sur d'innombrables pieux confortés par des contreventements et des blocages de calcaire (lutétien ?); une estacade protégeait la machine des glaces hivernales charriées par le fleuve ${ }^{37}$. Les premières canalisations étaient en troncs de chênes évidés, puis en plomb, en fonte et en fer ; les joints étaient faits de cuir. La machine comportait quatorze roues en bois (chêne) de douze mètres de diamètre; les axes devaient être en bois durs et à faible texture (houx, frêne, orme, cornouiller ?). Ces chantiers ont nécessité 85000 tonnes de bois, 17000 tonnes de fer et 850 tonnes de plomb. Des 
réservoirs d'un à dix hectares, profonds de trois à quatre mètres, à murs et contremurs, ont dû être maçonnés dans le périmètre de ces ouvrages.

Afin d'alimenter rapidement Versailles en eau, avant l'achèvement de l'aqueduc, a été édifiée en 1681 une tour provisoire (la tour de Marly) en forme de pyramide, en bois de chêne (assurément et en bois de chêne pédonculé fort probablement, à forte texture) d'une hauteur de 40 mètres; cette solide charpente, pourvue d'un escalier de 187 marches, a été démontée, transportée et remontée à l'observatoire de Paris (1685-1688) pour installer à son sommet une lentille à longue focale. Les observations se faisaient au sol avec un oculaire. Cette tour visible sur des gravures de la collection de l'observatoire de Paris disparut après quelques dizaines d'années.

41 Le château d'eau de Versailles, situé dans le quartier des réservoirs du palais, récemment restauré, est entouré d'une galerie qui abrite un réservoir en plomb d'environ trois mètres de profondeur, que confortent des poutraisons horizontales d'une dizaine de pièces en hauteur et de raidisseurs de trois à quatre pièces obliques à contrefiches, cet ouvrage étant assurément en chêne (pédonculé sans doute).

Les bois les plus appropriés pour des ouvrages souterrains (radiers, canalisations, réservoirs...) dans des jardins sont ceux qui sont durables à l'eau et à l'air, ainsi qu'en charpenterie de marine ${ }^{38}$, et tout particulièrement celui du chêne pédonculé - si, toutefois, des charpentiers ont pu effectuer ce choix selon des critères empiriques? Et ce depuis quelle époque?

L'aqueduc de Marly (1684) a également été édifié en dalles de meulières compactes, les arcs des ouvertures de l'aqueduc sont en pierres de calcaire lutétien de Saint-Leud'Esserent (Oise), de grand appareil, et des arcs de décharge ont été bâtis en meulières taillées. L'aqueduc de Buc (Yvelines) se compose à la base de deux à trois assises de pierres de meulières taillées en moyen appareil, puis de meulières plates avec de courtes assises de réglage de meulières plus plates encore, et de chaînages d'angles en calcaire lutétien.

Dans les bois de Meudon et de Chaville (Hauts-de-Seine), et de Viroflay (Yvelines) ${ }^{39}$, de multiples aménagements hydrauliques en meulières ont été réalisés. Un aqueduc souterrain de 840 mètres de longueur et d'un mètre de largeur a été récemment restauré. La grande terrasse de Meudon (Louis Le Vau, Abel Servien) présente d'imposants décors en tables de meulières. Là encore, les murs de soutènement sont en meulières.

Quelques grottes rustiques en gros blocs de meulières et de grès sembleraient dater $\mathrm{du}$ $\mathrm{XVII}^{\mathrm{e}}$ siècle, telle celle, très remaniée au XIX ${ }^{\mathrm{e}}$ siècle, d'un jardin de pente à Juvisy-surOrge (Essonne), d'une trentaine de mètres de large, édifiée au niveau d'une source (Stampien inférieur) qui alimentait une cascade.

L'aménagement des jardins du domaine de Chantilly (Oise), essentiellement dû à Le Nôtre, se caractérise par un grand axe est-ouest selon le cours de la Nonette et suivant des perpendiculaires à celui-ci ${ }^{40}$; ce parc aux pièces d'eaux d'une superficie sans égale en France est alimenté par la Nonette et par un aqueduc de six kilomètres, en grande partie souterrain, à appareillage en pierres de calcaire lutétien jointoyées par un ciment hydraulique à fragments de briques et tuiles pilées ${ }^{41}$. Plusieurs autres ouvrages, dont les terrasses du pavillon de Sylvie entre autres, reposent sur des radiers en bois de chêne sûrement, d'orme et d'aulne le cas échéant. Une machine élévatoire (le pavillon de Manse, 1676-1677), à toit en bois courbants, a été édifiée au sud d'un canal 
creusé à partir de l'écluse du Grand Canal. Cette machine comporte une roue en bois de chêne de huit mètres de diamètre et est pourvue de six pompes desservant le réservoir en pierres de calcaire lutétien, récemment restauré, aménagé sur le rebord du plateau de la pelouse. Les tuyaux pour le refoulement de l'eau étaient en fer et en cuivre; l'alimentation des pièces et des jeux d'eaux à partir de ce réservoir se faisait par des conduites en poterie ("grès») et en bois (chêne, aulne, orme ${ }^{42}$ ). Avant la transformation de la cascade de la tête du Grand Canal en 1680, un bâtiment en bois de chêne fort probablement, évoquant une grande estrade, avait été édifié en amont; d'imposants treillages et berceaux en bois d'essences de moindre dureté remplacèrent ce premier aménagement ${ }^{43}$.

47 La symétrie dominante des jardins de Versailles était en fait sensiblement atténuée par l'aménagement des abords du parc par Le Nôtre. Au nord-ouest, les arbres avaient été conservés dans leur état naturel, de manière à protéger les parterres et les promeneurs des vents froids. Au sud-ouest, au contraire, les grands arbres avaient été étêtés et de petits arbres plantés afin d'éviter une ombre portée trop importante sur les parterres et de dégager la vue depuis la grande terrasse sur le paysage des collines dans cette direction $^{44}$. Les chablis de 1999 et les replantations dans ce secteur donnent une bonne idée de ce qu'il en était dans la seconde moitié du XVII ${ }^{e}$ siècle.

Cette tendance à s'affranchir d'une symétrie trop rigoureuse se constate dans les aménagements de Le Nôtre à Fontainebleau et à Chantilly, où les axes majeurs ont été déterminés par les talwegs des rivières, le Changis et la Nonette, et non pas par des tracés à partir des châteaux. Ainsi que l'a formulé Le Nôtre : "Il ne faut pas trop contraindre la nature ». À l'instar de ce qu'il en était en Italie (jardin de la villa Reale di Marlia, à Lucques, 1652) des théâtres de verdure (jardin des Tuileries à Paris, Le Nôtre, 1664) et des "chambres vertes" (Versailles), où se donnèrent bien des pièces, des concerts et des ballets, furent aménagés dans la seconde partie du XvII siècle et vont se multiplier tout au long du XviII ${ }^{e}$ siècle (le Désert de Retz à Chambourcy, dans les Yvelines ; Ermenonville, dans l'Oise, Le Bocage, dans l'Orne ${ }^{45}$...).

Enfin, même à Versailles, les choix architecturaux et paysagers n'étaient pas définitivement fixés sur le papier, et la composition même de grandes lignes des projets pouvait s'effectuer le cas échéant sur le terrain ${ }^{46}$.

Les jardins de manoirs et de châteaux peu connus recèlent parfois des architectures et des aménagements à connaître. Dans le parc du château de Fleury-en-Bière (Seine-etMarne), un canal servit de modèle pour le grand canal du parc de Fontainebleau; plusieurs captages (dallés en grès ?) alimentant ce canal et le grand bassin ont été mis au jour.

51 À Héricy (Seine-et-Marne), sur les rives droites de la Seine, au nord de Fontainebleau, ont été édifiées les résidences des colonels des gardes suisses : un «vieux logis» de style Louis XIII et un manoir de la fin du XVII ${ }^{\mathrm{e}}$ siècle, ainsi qu'un jardin dans le style de ceux de Le Nôtre. On peut voir, sur les piliers de l'entrée du vieux logis, les sculptures en grès, très dégradées, de deux lionceaux et de deux caryatides accroupies. Les murs et les pavillons d'angles, sur la rive du fleuve, ont été édifiés en moellons de meulière de Brie et de calcaire silicifié de Champigny, affleurant alentour, et le rebord en dalles de grès. 
52 À Beauvoir (Seine-et-Marne), au sud-ouest de Chaumes-en-Brie, seul subsiste du XVII ${ }^{\mathrm{e}}$ siècle un pavillon d'entrée en pierres de grès stampien, que décore à l'étage une dalle en grès sculptée en forme de coquille, ornementée d'une tête féminine.

À Raray (Oise), au nord-est de Senlis, deux portiques d'une quinzaine d'arcades, en calcaire lutétien, à décor animalier, séparent la cour du château du parc.

Dans le nord-ouest du Vexin français, à Boury-en-Vexin (Oise), le manoir du XVII siècle présentait, d'après une gravure, de part et d'autre de l'édifice, deux arcatures de trois arcades séparant la cour du parc; dans celui-ci, une glacière monumentale a été creusée dans les colluvions et édifiée en calcaire lutétien. On accède aux salles voûtées par un large escalier orné de deux colonnes surmontant un parapet.

La «maison » de Charles Le Brun à Montmorency (Val-d'Oise) était prolongée selon un axe nord-sud par deux arcatures de cinq ouvertures séparant le jardin ouest du canal situé à l'est (gravures d'I. Silvestre).

56 L'histoire de quelques résidences de second plan se dessine peu à peu à la suite de nouvelles recherches. Il en est ainsi du château de Limours (Essonne), aujourd'hui détruit, qui dans un premier temps fut remanié à la fin du $\mathrm{Xv}^{\mathrm{e}}$ siècle, puis de nouveau au milieu du siècle suivant (Philibert Delorme, vers 1554) : agrandissement en pierres (grès ? grès et briques peut-être ?), charpentes en carènes de petits bois, décors de lambris, fontaine alimentée par plus d'une centaine de tuyaux en terre cuite ${ }^{47}$. De 1623 à 1626, un premier parterre orné de sculptures italiennes (en marbre probablement) a été voulu par Richelieu. De 1630 à 1651, le jardin a été agrandi (François Mansart) et pourvu de terrasses et d'un parc boisé agrémenté d'une grande perspective ; des murs de soutènement, des balustrades et deux escaliers de forme ovale sont édifiés. Des achats de pierres (calcaires, grès?) sont connus par des devis, parmi lesquelles des chaînages en " gresseries bien piquetées et des pierres à bossages » (grès ?).

Le château et le jardin de pente d'Auvers-sur-Oise (Val-d'Oise) furent édifiés en 1635 par Zanobi Lioni, financier de l'entourage de Marie de Médicis. Le toit en terrasse à l'italienne offrait certainement une vue étendue sur la vallée de l'Oise. Les jardins se composent de terrasses successives, dont la plus haute comporte une dizaine de draperies à exutoires, aujourd'hui taris, en forme de masques, et latéralement deux imposants piédestaux qui laissent penser qu'ils supportaient deux sculptures qui étaient de conséquence. Quelques bassins, dont un bassin central à vasque, un belvédère carré couvert, de quelques mètres de côté, ainsi qu'une orangerie souterraine achèvent cet ensemble. Tous ces ouvrages ont été édifiés en et sur les calcaires lutétiens. Le château a été remanié avec une toiture "à la française » en 1662. Une grotte souterraine « classique » à nombreux coquillages (ormeaux ou haliotides...), silex diversement colorés et éclats de marbre a été aménagée au nord du château.

Les jardins monumentaux du XVII ${ }^{\mathrm{e}}$ siècle furent les œuvres non seulement d'architectes et de dessinateurs, mais aussi de savants et d'hommes de lettres sollicités par les commanditaires. Ainsi Fouquet avait-il constitué un conseil de réflexion pendant les travaux du domaine de Vaux, un cénacle où siégèrent notamment Paul Scarron et Georges de Scudéry. À Versailles, on fit appel à des savants en hydraulique (Edme Mariotte) et à des ingénieurs cartographes, qui étudièrent en détail le paysage en procédant à des visées par triangulation qui contribuèrent à la définition de certains tracés et firent ainsi progresser les méthodes de cet $\operatorname{art}^{48}$. 
59 Pour M. et C. Vercelloni ${ }^{49}$, ce n'est que vers la fin du $\mathrm{XVII}^{\mathrm{e}}$ siècle que l'on tient véritablement compte dans l'art des jardins des connaissances botaniques acquises à cette époque; mais l'on est encore loin d'une approche réaliste des conditions écologiques de vie des végétaux, ne fût-ce qu'en ce qui concerne les arbres et arbustes notamment, et plus encore les associations végétales, encore insoupçonnées avant les recherches de botanistes au cours du $\mathrm{xx}^{\mathrm{e}}$ siècle.

Néanmoins, une nouvelle perception des relations à la fois esthétiques et scientifiques entre les hommes et le monde végétal prend peu à peu un certain essor au XVII ${ }^{\mathrm{e}}$ siècle, ce qui se traduisit au cours du XviII ${ }^{e}$ siècle dans la composition de jardins reposant sur des lignes courbes et serpentines rappelant les thèmes de prédilection du maniérisme.

\section{Les jardins du siècle des Lumières}

«Il faut faire céder l'art à la nature. » (Dezallier d'Argenville, 1739.)

"C'est en poète et en peintre qu'il faut composer des paysages. (Marquis de Girardin, 1777.)

$61 \mathrm{Au}$ XVIII ${ }^{\mathrm{e}}$ siècle, l'évolution des savoirs, des mentalités et des idées - le Telliamed de Benoît de Maillet, le transformisme - font que l'on a été amené à mieux connaître et comprendre la nature.

62 L'une des finalités des jardins historiques des Temps modernes fut de donner une certaine importance à la végétation et d'exprimer les rapports, non sans un certain sensualisme, entre les hommes, la nature et l'idée omniprésente de la beauté5 ${ }^{50}$. Par exemple, s'imposa peu à peu un goût très prononcé pour les arbres au port libre, ou encore un certain intérêt fut porté aux événements naturels et aux intempéries. Parfois, le devenir de ces jardins a pu être plus ou moins aléatoire, d'une manière imprévisible pour l'époque, du fait de la méconnaissance de la dynamique des milieux forestiers et boisés, qui ne sera dépassée qu'au milieu du $\mathrm{xx}^{\mathrm{e}}$ siècle.

63 Les jardins devinrent des lieux, avec les cabinets de curiosités, qui attirèrent un large public ayant acquis un certain goût pour tous les domaines relevant des sciences, et qui intéressèrent également bien des écrivains: Jean-Jacques Rousseau, Victor Hugo, George Sand...

64 Au gré des découvertes de plans de ces jardins, il apparait que l'opposition classique entre jardins « à la française » et jardins « à l'anglaise » ait en fait évolué d'une manière discrète et cumulative. De nouvelles caractéristiques se firent jour dans nombre de ces jardins : recherche de contrastes, sources de beauté, compositions comparables à celles des peintures, serpentements et enchaînements de formes, rivières sinueuses, bassins irréguliers, sauts-de-loup ou ha-ha, nombreuses sculptures ${ }^{51}$.

65 Les premiers parcs qui influencèrent l'art des jardins au cours de la Régence semblent avoir été des jardins néerlandais sans plan axial (Dyrham Park, Royaume-Uni, vers 1720), ainsi que des jardins anglais dans lesquels dominaient les allées et leurs terrasses aux lignes courbes. Des reconstitutions paysagères influencées par la géologie et la géomorphologie locales se multiplièrent: topothésies, évocation de milieux plus ou moins lointains, sites associant roches, coquillages, peintures, sculptures, rivières anglaises ${ }^{52} \ldots$

66 C'est dans cette continuité que se créèrent à la fin du XVIII siècle et dans les premières décennies du XIX ${ }^{e}$ siècle les jardins romantiques : Arlay, dans le Jura; La Malmaison, à 
Rueil-Malmaison (Hauts-de-Seine) ; Ferrières-en-Brie (Seine-et-Marne) ; la Vallée aux Loups, à Chatenay-Malabry (Hauts-de-Seine).

Parmi les jardins pittoresques, on peut considérer celui d'Arlay (Jura), au nord de Lonsle-Saulnier, comme un archétype remarquable : ancien oppidum gallo-romain, devenu citadelle mérovingienne, puis puissante forteresse de Franche-Comté, le manoir actuel fut édifié dès 1774. Le jardin, aménagé sur huit hectares, présente toutes les caractéristiques que l'on attend d'un jardin du siècle des Lumières : vestiges historiques authentiques, points de vue remarquables sur la plaine de la Bresse et sur le Jura, boulingrin, grotte, glacière, cascade verte, théâtre de verdure, bosquets, allées de tilleuls, roseraie, bergerie...

L'évolution du goût et de l'intérêt portés à la statuaire dans les jardins transparaît dans les nombreux déplacements attestés des œuvres dans les jardins de Marly au cours de la fin du XVIII ${ }^{e}$ siècle $^{53}$. Le grand inventaire des collections de Marly, en 1695, montre qu'elles étaient à cette époque surtout constituées de bustes et de statues antiques (originaux et copies) en marbre, et de quelques bronzes. Par contre, à partir de 1698, ce sont des créations qui prennent le pas sur les antiques: de nombreuses divinités fluviales (aujourd'hui disparues), des groupes spectaculaires telles les Renommées d'Antoine Coysevox, disposées à l'abreuvoir, des nymphes allongées, des «coureurs féminines » dont les draperies accentuent les mouvements, et plusieurs bronzes, dont l'Aurore.

\section{Les jardins d'Ermenonville (Oise) et de Versailles}

69 Le parc d'Ermenonville, l'un des plus anciens jardins «à l'anglaise » en France, fut aménagé de 1754 à 1772 à l'initiative du marquis de Girardin. Une ancienne carrière dans les sables et grès bartoniens, encore visible au sud du parc, a fourni une partie des pierres mises en œuvre depuis le $\mathrm{XVII}^{\mathrm{e}}$ siècle et au premier chef pour le jardin pittoresque : le faux dolmen en blocs bruts de la carrière, soubassement en dalles, pierres du mur intérieur et gargouilles du temple de la Philosophie, volontairement inachevé, dédié à Montesquieu, Montaigne, Newton et Descartes. Les colonnes et l'entablement sont en calcaire lutétien; les arcades et blocs de la grotte en grès et en calcaire.

70 C'est à Versailles que furent aménagés et restaurés au mieux de vastes espaces dans le goût du siècle des Lumières. Le dernier aménagement d'un jardin régulier à Versailles fut celui du Pavillon frais (1749 et $1750^{54}$ ) ; deux bassins y furent creusés. Des fouilles ont apporté des précisions quant à l'emploi des matériaux : murs de douve en calcaire lutétien reposant sur un radier en chêne fort probablement, corroi d'argile, margelles en marbres rouge du Languedoc, pavage bicolore en grès et à motifs circulaires en pavés de silex (bassin est), fond en lit de briques recouvert de feuilles de plomb (bassin ouest). Des charmes (charmilles), des tilleuls, des érables, des chênes et des arbres fruitiers avaient été plantés entre des arcades de treillages (en bois encore non déterminé). Les parterres étaient fleuris d'œillets, de giroflées, de jacinthes, de narcisses, de pivoines... végétaux encore communément plantés dans les jardins publics et privés dans les années 1950, et dont un bon nombre étaient des plantes communes à l'état naturel dans le nord de la France.

71 Le jardin du Petit Trianon a été inspiré par des études de Hubert Robert. Il comporte un rocher (1783) édifié en blocs de calcaire lutétien, avec en arrière des confortations en 
blocs de meulières d'environ un demi-mètre de longueur; à proximité, un belvédère octogonal entouré de huit sphinges en marbre blanc; plus loin un temple de l'Amour (1777-1778) et une rivière anglaise (1783) prenant sa source dans une grotte de quatre mètres de hauteur et de six mètres de largeur, en blocs de meulières métriques, conduisant à une autre grotte plus petite.

Le hameau de la Reine (Richard Mique, 1784-1788) a été réalisé à l'imitation de celui du jardin anglais de Chantilly (1772-1775). On y reconnaît des constructions montées en moellons de calcaire lutétien et de meulière à chaînages en pierres taillées de calcaire, parfois en briques (cheminées) et à pans de bois, la tour de Marlborough en meulières, une petite rivière rustique, un pont en meulières caverneuses. Près de l'étang, un bloc métrique d'un grès conglomératique à nombreux petits galets de silex de la craie a été dressé. Considéré comme curiosité lithologique, il semble avoir attiré l'attention; il devrait provenir des affleurements d'une formation superficielle tertiaire de la vallée de l'Eure - ou de plus loin vers l'ouest?

\section{Le parc du château de Chamarande (Essonne)}

73 L'histoire de ce jardin a tout particulièrement été bien étudiée ${ }^{55}$. Le premier jardin était au début $d u \mathrm{xVII}^{\mathrm{e}}$ siècle un verger et une vaste aulnaie. Une première composition importante date de la fin $\mathrm{du} \mathrm{xvII}^{\mathrm{e}}$ siècle, son axe était parallèle à la Juine et d'importants travaux de drainage ont été effectués selon un réseau de canaux orthogonaux bordés de peupliers. C'est à partir de 1725 et surtout des années 1740 à 1760 que le jardin actuel a été mis en œuvre : parterre, canal, compositions gazonnées et allées courbes, boulingrins, sauts-de-loup; plantations de chênes (pédonculés ou sessiles ?), ormes, charmes, aubépines et ifs; doublement des rangées d'arbres de l'avenue d'arrivée au château (ormes et châtaigniers). Des salles de verdure sont aménagées, ainsi qu'un pavillon rustique sur une petite île plantée d'aulnes. Des bancs à dossier en bois peint étaient disposés çà et là.

Plusieurs constructions ont été édifiées, dans lesquelles le grès stampien, affleurant en abondance dans la vallée de la Juine, est omniprésent : une glacière, une cascade (aux margelles et parapets en pierres calcaires) décorée de tables de petites meulières rougeâtres, et un jeu de l'oie à allées en dalles de grès, dont la palissade était en bois de houx, conduisant au pavillon central à quatre colonnes toscanes en grès, ainsi qu'un réservoir octogonal où une niche abritait trois bustes (les Grâces, 1759).

De nombreuses sculptures ornementaient ce jardin: une statue de bacchante en "pierre de Torfou " (grès ?), une Diane en calcaire et une Diane en terre cuite, un silène, un sanglier, deux grands vases (en marbre probablement), quatre statues colossales des saisons, quatre statues et groupes en bronze. Un petit obélisque au décor raffiné, dédié à Henri II et Diane de Poitiers, en grès à grain fin, provient de SaintSulpice-de-Favières (Essonne). Toutes ces sculptures étaient disposées sur des piédestaux en grès stampien.

76 Le château voisin de Segrez, à Saint-Sulpice-de-Favières, construit en 1750, possède un jardin paysager aux lignes sobres avec un grand miroir, deux bassins ronds et une grotte à rochers en grès et coquillages. Dans ce parc ont été introduits des cyprès chauves nord-américains et des faux de Verzy (hêtres de la région de Reims). 


\section{Le parc du château de Méréville (Essonne)}

77 Le château fort de Méréville ( $\mathrm{xv}^{\mathrm{e}}$ siècle) a été transformé en résidence de plaisance en 1768. Dans l'axe de celui-ci fut aménagé un jardin régulier, qui s'effaça bien vite. Le domaine a été acheté par Jean-Joseph de Laborde, qui décida de créer un parc à l'anglaise ; c'est à François-Joseph Bélanger, qui a étudié en Angleterre les jardins paysagers, que fut confié le soin d'entreprendre les travaux. C'est à ce dernier que l'on doit la composition d'ensemble de nouveaux parcs, le méandrage de la Juine, le grand lac, les tracés des allées serpentines, le moulin, le pont des roches et un pont en acajou. En 1786, Hubert Robert, assisté de l'architecte Jean Benoît Vincent Barré, a dessiné les fabriques et intégré tous les nouveaux éléments dans le paysage. On lui doit aussi le grand rocher et la laiterie notamment.

Les carrières, ouvertes pour les travaux, de calcaire de Beauce, d'argile, de galets de silex de la craie remaniés dans les sables stampiens et de meulières, ont été reconnues.

Une vingtaine de sondages ont été effectués de manière à retrouver les traces du parcours ancien et du méandrage terrassé de la Juine; il résulte de ces recherches archéologiques que le lac ne sera pas restitué, en raison d'un trop grand échauffement de ses eaux, qui dut être, et qui serait, néfaste pour plusieurs plantes aquatiques ainsi que sur le plan d'un alluvionnement inopportun. Les aménagements hydrauliques comprenaient un aqueduc en amont, alimentant le pont des roches et plusieurs autres grottes, dont les vestiges ont été retrouvés ${ }^{56}$.

La méthode adoptée afin d'étudier au mieux la répartition des bosquets et des fabriques dans le paysage du parc mérite d'être soulignée pour sa perspicacité : il a été demandé à un bon dessinateur de restituer, à partir des dessins et des peintures de Hubert Robert (une cinquantaine d'œuvres), les emplacements réels des bosquets et des aménagements divers dans la topographie et le paysage du site, c'est-à-dire la recomposition réelle du jardin paysager tel qu'il était à la fin du XVIII ${ }^{e}$ siècle à partir des compositions du peintre.

81 Sur le rebord du plateau de Beauce, un obélisque à l'antique, en calcaire de Chartres, domine le parc du haut de ses 30 mètres (1790-1792).

L'importance accordée aux végétaux, que signalent ici ou là divers auteurs, se devait de susciter des contrastes harmonieux entre leur vitalité, leurs conditions écologiques, leur éventuelle mise en œuvre en tant que matériaux (les bois, les chaumes...) et les éléments minéraux. Au fil des recensions, on trouvait dans ce parc des peupliers, des hêtres fastigiés, des catalpas d'Amérique du Nord, des vignes, des vignes vierges, et sans nul doute des chênes pédonculés.

\section{Le jardin pittoresque de la folie Saint-James (Neuilly, Hauts-de- Seine)}

83 Le baron Saint-James ${ }^{57}$ commandita la construction de cette folie et d'un jardin d'une vingtaine d'hectares (trois de nos jours) qui s'étendait depuis la folie jusqu'à la Seine. Les travaux, menés de 1770 à 1790, furent confiés à l'architecte François-Joseph Bélanger. La folie comporte une loggia donnant sur la vallée du fleuve, supportée par six colonnes monoxyles, en chêne sans doute (chêne pédonculé peut-être), ornementées de motifs végétaux sculptés en forme d'écailles; au niveau du balcon, un 
bâti de planches est recouvert de stucs qui représentent à l'extérieur quatre victoires ailées et un beau décor sous le balcon. Des tables de meulières taillées, souvent celluleuses, décorent le rez-de-chaussée, au-dessus du soubassement en pierres de calcaire lutétien.

Un canal de 300 mètres, aujourd'hui disparu, a été creusé depuis le sud de la folie vers la Seine : en tête, une rocaille et une cascade (détruites) avaient été édifiées.

Plus en aval, sur la rive droite du canal, le Grand Rocher est l'un des deux monuments remarquables du site. Large en façade de 42 mètres, profond de 18 mètres et haut de 12 mètres, ce rocher présente au centre un prostyle de six colonnes cannelées en calcaire lutétien supportant un fronton triangulaire décoré d'un aigle. Une arcade imposante de 12 mètres de hauteur, en blocs de meulières clavés de deux mètres de longueur environ, surplombe la construction à l'antique. Deux entrées et escaliers latéraux donnent accès aux salles, parmi lesquelles une salle de bain pourvue de deux baignoires en cuivre, couverte par une voûte à caissons et rosaces, et que surmonte un réservoir de 50 mètres cubes. Les eaux s'écoulaient en façade par cinq fontaines. Au sud, une façade monumentale en moellons de meulières et chaînages en pierres de calcaire lutétien donnait sur le canal. Au sommet, une terrasse domine le parc et le paysage.

Parmi les innombrables blocs de grès stampiens du Grand Rocher transportés depuis le massif de Fontainebleau et de ses environs, tous les faciès ou presque semblent avoir été choisis pour leurs caractéristiques singulières, qui n'ont pas échappé aux observations des commanditaires : blocs de grès francs à stratification plus ou moins marquée, blocs à cupules et nodules, grès quartzites, blocs à sur-silicifications, grès à traces de racines, grès ferrugineux, grès quartzitiques à silex roulés remaniés provenant de la craie. On remarque quelques blocs à faciès de silcrètes ressemblant à ceux de l'Yprésien que l'on trouve dans les alluvions anciennes de la Seine, en amont de Melun, ainsi que quelques blocs quartzitiques conglomératiques provenant de l'ouest du Bassin parisien.

Au nord du domaine ont été édifiés une serre chaude et au-delà un salon de musique et d'histoire naturelle (visible de la rue Berthier) à plan basilical en plein cintre, et deux absidioles qu'éclairent des oculi.

Le jardin lui-même s'étendait selon un aménagement d'ondulations du terrain que séparaient des méplats. Les fontaines du Grand Rocher donnaient sur une pièce d'eau lobée. Une rivière anglaise s'écoulait d'est en ouest, franchie par une dizaine de ponts et ponceaux, dont l'un, le pont Palladien, en pierres lutétiennes, a été restauré. En revanche, le pont des Roches, ainsi que les autres ponts, a été détruit; seuls quelques blocs épais de grès et de meulières ont été retrouvés. De nombreuses statues en marbre agrémentaient les allées et les fabriques, dont une statue de Jean-Jacques Rousseau et un groupe de Jean-Baptiste Lemoyne (Zéphir et Flore). Un kiosque chinois en bambou, une glacière, une laiterie, un potager, des vignes, une melonnière, un couloir en bois (treillage ?) et des bancs circulaires massifs en bois (chêne) complétaient cet ensemble. Des matériaux (calcaires, grès, briques) du jardin classique pourraient avoir été réemployés au cours de l'édification en 1922 du temple de l'Amour et du bassin attenant, situés à l'entrée du parc actuel ${ }^{58}$. 


\section{Le Désert de Retz (Chambourcy, Yvelines)}

89 Le plan du jardin du domaine de Retz ${ }^{59}$ (une quarantaine d'hectares) a été imaginé et levé par son propriétaire, Racine de Montville ; ce parc voulait exprimer une symbiose des aspirations des hommes du $\mathrm{XvIII}^{\mathrm{e}}$ siècle dans leurs recherches de connaissances et d'une nouvelle harmonie, de sensibilité toute rousseauiste, avec la nature ${ }^{60}$. Le positionnement des 17 fabriques repose sur des alignements et sur des triangles particuliers : triangles isocèles sublimes $\left(36^{\circ}, 72^{\circ}\right.$, le nombre d'or) et isocèles du delta lumineux $\left(108^{\circ}\right.$ et $\left.36^{\circ}\right)$.

Le premier édifice construit a été la Maison chinoise (1775), édifiée en bois de teck et de bambou, essences asiatiques très durables à l'eau et à l'air. Le second fut le temple du dieu Pan, composé d'une demi-rotonde adossée à une salle carrée (le salon de musique). La demi-rotonde se composait de quatre colonnes à l'antique, qu'ornementaient deux statues au rez-de-chaussée et quatre au-dessus de la corniche; une vingtaine de peupliers et des hêtres entouraient cet édifice. En 1777 furent aménagés la pyramideglacière (élévation en moellons de meulières avec des chaînages, arcade de l'entrée et escaliers latéraux en calcaire lutétien), une serre chaude et un grand obélisque en tôles de fer.

91 Au sud, à l'entrée du domaine par la forêt de Marly, a été édifiée une grotte en dalles de calcaire ou de meulières (?). D'après une gravure, elle était entourée d'un boisement de pins (sylvestres ?), de mélèzes (conifères des Alpes du sud à feuillage caduc) et de hêtres.

La "Colonne détruite », la résidence haute de quatre étages, de 15 mètres de diamètre et de 25 mètres de hauteur, montre bien l'intérêt que l'on portait à l'archéologie et à l'histoire de l'Antiquité. Des fissures factices partent du sommet de la tour et éclairent l'intérieur; dans les seize cannelures se situent les portes-fenêtres, les fenêtres et les œils-de-bœuf; dans l'escalier hélicoïdal rappelant du lierre étaient installés des vases de fleurs rares entre les balustres (en bois dur ou en métal ?) donnant l'impression d'une omniprésence des végétaux. Un mobilier en acajou (d'Afrique ou d'Amérique ?) agrémentait l'escalier aux marches en châtaignier (?). La base de la tour et le tore sont en pierres de calcaire lutétien et le fût est en moellonage de meulières recouvert d'un parement en pierres de taille calcaires à grain fin (?). Au sommet de la tour étaient installées de nombreuses plantes (près de deux centaines de pots) dont des végétaux lianescents retombant sur la muraille de la tour.

L'état subnaturel de la végétation du parc de Retz devait être celui des successions de végétations de la chênaie pédonculée-charmaie, de la chênaie mixte-charmaie, de la chênaie sessiliflore-charmaie et de la hêtraie-chênaie sessiliflore à charmes. Aux quelques incises évoquées plus haut à propos des essences conservées ou introduites, il convient d'ajouter ${ }^{61}$ de grands ormes autour du théâtre de plein air, des peupliers d'Italie, des marronniers de Grèce et beaucoup de petits arbres dont des arbres de Judée (Cercis), des faux ébéniers (cytises, papilionacées de l'est du Bassin parisien, aux belles floraisons) et peut-être une variété ornementale de sumac de contrées orientales (?). Sur les marges du domaine, des buis ont été plantés le long des murs (en meulières peut-être ?) et un saut-de-loup a été aménagé au nord, permettant ainsi de contempler une vue dégagée vers le paysage des collines du Hurepoix. 


\section{Le parc de Mauperthuis (Seine-et-Marne)} soubassements sont voûtés, en pierres de calcaire lutétien. Les décors des bases des façades ouest et sud sont réalisés en tables de petites meulières rougeâtres de quelques centimètres (une dizaine au plus) de section, celles de la terrasse sud ayant été sciées avec soin. À l'entrée du parc ont été réunies dans une salle de verdure une dizaine de statues, en calcaire lutétien, dues au sculpteur Philippe-Laurent Rolland. Vers le nordest, un grand rocher et une cascade semblent avoir été édifiés en blocs de meulières.

D'après des gravures, à Paris, dans le parc de l'hôtel de Beaumarchais, Bélanger avait aménagé une grotte, probablement en grès stampien. À l'hôtel Thélusson, œuvre de Ledoux en 1778 à Paris, rue de Provence, là encore un ensemble de blocs rocheux 
mamelonnés évoquant des blocs de grès stampiens entourait la rotonde de la façade, constituant ainsi une transition entre l'hôtel et le jardin.

Dans le jardin régulier de trois hectares du «Petit Trianon" de l'hôtel Matignon, à Paris, un groupe de quatre statues en terre cuite évoque les saisons. À Passy, de nos jours un quartier de Paris, sur la haute terrasse de la façade sur jardin de l'hôtel de Verrières, des groupes de statues en terre cuite ornementent la corniche de l'édifice ; une statue, également en terre cuite, se trouve être aujourd'hui sur la terrasse du rezde-chaussée ; il n'est donc pas impossible que des sculptures dans ce matériau aient été installées dans ce jardin.

101 À Versailles, au sud du potager, l'architecte Jean-François Chalgrin a édifié de 1785 à 1787 un hôtel malheureusement vite démoli, pour la comtesse de Balby (ou Balbi). Dans le parc a été construite une imposante grotte en blocs de grès de Fontainebleau (plusieurs centaines) dessinant une exèdre "rustique» de faible courbure sur près d'une centaine de mètres. L'entrée de la grotte, conduisant à une salle de fraîcheur haute de cinq à six mètres et profonde d'une vingtaine de mètres, comporte trois arcs de blocs métriques rustiquement équarris. Des chemins agrémentés de bancs de pierre parcourent l'édifice et mènent à un belvédère où a été bâti un petit pavillon de plan trilobé (selon un document de cette époque) que l'on a sans doute remanié au cours du $\mathrm{XIX}^{\mathrm{e}}$ siècle. On peut aussi voir dans ce parc une base de colonne en pierres taillées de grès, disposée au sommet d'une petite éminence, et quelques blocs de fondation ou décoratifs (?) à l'emplacement des petits ponts (de bois ?) qui permettaient d'accéder aux îlots de l'étang.

102 À l'est de Versailles, le parc du manoir de Montreuil, en Seine-Saint-Denis (Chalgrain, 1770), domaine de Madame Élisabeth, sœur de Louis XVI, était l'un des plus beaux jardins de l'époque. Il se compose d'une rivière serpentine, d'un théâtre de verdure dont ne subsistent que quelques blocs métriques de calcaire lutétien et les traces de deux gradins, et d'une allée serpentine bordée de hautes charmilles et d'ifs, qui agrémente le jardin paysager où furent plantés un certain nombre d'arbres remarquables originaires de l'Amérique du Nord, ainsi que d'une orangerie et une laiterie. Au sud, une longue terrasse-promenade, en meulières de Montmorency, longe l'imposante avenue de Paris et offre une large vue sur les collines de Viroflay, malheureusement plus réduite de nos jours du fait de constructions récentes. Cet aménagement a dû impliquer d'importants terrassements, ainsi qu'en témoignent les barbacanes métriques, qui se voient depuis l'avenue de Paris. À l'angle sud-est de la terrasse se trouve une grotte, profonde d'une petite dizaine de mètres, voûtée en plein cintre par des blocs de meulières métriques. À peu de distance de ce domaine subsistent quelques vestiges du parc de la comtesse de Provence, où est situé un rare colombierlaiterie (par Chalgrain, 1789).

103 À Ville-d'Avray, dans le parc du château de la fin du XVIII siècle, a été édifiée sur le flanc nord de la colline une grotte de sept mètres de hauteur et d'une vingtaine de mètres de largeur, en blocs métriques retaillés de meulières de Montmorency.

Les murs du domaine de Mme du Barry (Louveciennes, Yvelines) présentent, à leur base, sur environ un mètre de hauteur, des meulières massives d'un ocre clair, d'un à trois décimètres de diamètre, retaillées en formes évoquant des rosaces disposées en délit et ceinturées par un rocaillage de petites meulières celluleuses rougeâtres noyées dans un épais mortier. 
105 À l'entrée sud du parc du château de Vaux-le-Pénil (Seine-et-Marne), à l'est de Melun, un pavillon circulaire a été bâti à la fin du XviII ${ }^{e}$ siècle en pierres courbes de calcaire de Champigny silicifié, dont la carrière se situe à quelques dizaines de mètres de cette construction.

106 Aux confins de la Bourgogne, le jardin du château de La Motte-Tilly, édifié en $1754^{65}$, se compose d'un jardin à la française dans l'axe du château, d'un miroir et de deux allées doubles de tilleuls, qu'une haute charmille ferme le long de la Seine et qu'environne un grand parc à l'anglaise (1780 à 1783). Dans ce parc, une grotte en travertin de Resson, d'une superbe architecture, a été creusée dans la craie. Elle est éclairée par un lanternon et pourvue d'une entrée et de trois niches en plein cintre à banquettes que décorent des reliefs en formes de stalactites, des oves sur les pilastres et une frise de losanges et de rosettes; des encadrements en tuf calcaire plus récent que le travertin (âge des métaux), plus clairs, soulignent les décors ${ }^{66}$. Ce parc a été planté, à la fin du XVIII ${ }^{e}$ siècle, de 35000 pieds de bouleaux, de houx (1 600 pieds) et de diverses essences rares : pins d'Autriche, thuyas, cèdres bleus de l'Atlas.

\section{Les thèmes des jardins paysagers}

107 Le traitement des perspectives, connu depuis la Renaissance, ainsi que la maîtrise de l'hydraulique des jardins de plaines, acquise au cours de la deuxième moitié du $\mathrm{XvI}^{\mathrm{e}}$ siècle, ont permis de voir se diversifier des choix relevant de l'esthétique, parmi lesquels la recherche de pierres de couleur (les grès de Fontainebleau gris, blancs et ocres dès le $\mathrm{xv}^{\mathrm{e}}$ siècle, les meulières ocres et rougeâtres à partir du XVII ${ }^{\mathrm{e}}$ siècle...). Des caractéristiques des jardins, devenues classiques, se mirent en place peu à peu : murs, portails, douves, sauts-de-loup... Les découvertes, en Italie, de chefs-d'œuvre de la statuaire antique suscitèrent très vite chez les sculpteurs du nord de la France de nouvelles manières d'exprimer leurs sentiments esthétiques, et ce dans divers matériaux (marbres, calcaires marbriers, terres cuites, bois...), ce qui séduisit les publics férus de mythologie gréco-romaine.

108 Le recours à tous les arts décoratifs devint de plus en plus recherché : édification de grottes spectaculaires aux décors peints et à coquillages, nymphées ${ }^{67}$, vases en marbre, pots à feu, à fleurs et à fruits. Des obélisques et des colonnes ornementales se multiplient dès le XVII ${ }^{e}$ siècle (château de Richelieu, Indre-et-Loire) dans le sud et l'est du bassin de Paris plus particulièrement. Des jeux sont imaginés : mails (Fontainebleau, fin du xvI ${ }^{e}$ siècle), labyrinthes (xvII ${ }^{\mathrm{e}}$ siècle), jeux de l'oie (xvIII ${ }^{\mathrm{e}}$ siècle).

109 Les aménagements mobiliers en bois, dont les essences n'ont été que très rarement mentionnées (pins, houx...), furent, au XVIII ${ }^{\mathrm{e}}$ siècle, d'une diversité remarquable dans les jardins paysagers ${ }^{68}:$ loggias sur piliers en troncs de pins, tonnelles en fûts de troncs soutenant un toit de chaume, gloriettes et belvédères, pavillons en bois sculpté de style gothique ou antique, pergolas en forme de tours, pavillons rustiques, treillages en arcades, pergolas en demi-cercle, barrières diversement originales, chaises et bancs de jardins, tables sculptées dans la masse de pièces de bois, meubles à plantes des orangeries, manèges, barques, embarcadères... Des pièces de mobilier semblables ont également été fabriquées en fer ; d'ailleurs, fer et bois ont été assez souvent associés.

110 Quelques remarques sur les nymphées et les obélisques semblent être d'un certain intérêt. Les nymphées deviennent à la mode, comme dans le parc du château (disparu) 
des Conti à L'Isle-Adam (Val-d'Oise), qui a été réaménagé dans le style anglais à partir de 1742, et dont seul le pavillon chinois a été conservé et restauré. On y voit à sa base, des tables ornementales à meulières massives de Montmorency ocres et rougeâtres, ainsi que des silex de la craie et des fragments de faïences vertes témoignant d'une recherche de matériaux aux couleurs complémentaires. Le nymphée de l'orangerie du château d'Auvers-sur-Oise (Val-d'Oise) montre des décors semblables, à petits moellons de meulières celluleuses rougeâtres et coquillages (ormeaux); les pavements sont en dalles d'un calcaire marbrier alternant avec un dallage de petits silex sombres. Autre exemple, l'imposant nymphée de Chatou, dans les Yvelines (Jacques-Germain Soufflot, 1740-1780) se compose de murs de soutènement à revêtements de galets calcaires et de colonnes en calcaire (lutétien?) aux bagues de petites pierres de meulières noyées dans un laitier de scories siliceuses bleuâtres à noires et à coquillages de l'Atlantique.

$\mathrm{Au}$ cours du XVIII ${ }^{\mathrm{e}}$ siècle ont été édifiés des obélisques quadrangulaires (pyramides) ou en forme de colonne. Les plus anciens en Île-de-France semblent avoir été celui de Henri II à Chamarande (Essonne) et ceux du château de Richelieu, qui ornementent de nos jours la façade ouest de la Malmaison. Certains semblent indiquer, de loin, des domaines tel celui, en grès, de Mauperthuis ou encore la colonne trajane de Méréville, en calcaire lacustre miocène, œuvre de Hubert Robert, qui offre une splendide vue sur le paysage. La pyramide du bois de Vincennes (1731), superbement décorée de sculptures décoratives, fut élevée lors d'importants travaux forestiers. Celle de Fontainebleau et ses belles bornes en grès indiquent les directions des villes importantes de la région (Sens, Orléans), tout comme, peut-être, celle de la forêt de Crécy (Seine-et-Marne). Des colonnes dressées se voient ici et là dans des jardins à l'anglaise, par exemple celle marquant la source de la fontaine Belle-Eau à Fontainebleau (marbre du Languedoc), ou encore dans le parc Saint-James, à Neuillysur-Seine, dans les Hauts-de-Seine (colonne en granite). À Moissy-Cramayel (Seine-etMarne), seul vestige d'un manoir détruit, s'élève une pyramide dédiée à l'épouse d'un des derniers propriétaires. Certains obélisques évoquent le souvenir d'un événement singulier, tel l'obélisque de la Reine, sur la D 606, près de Montarlot (Seine-et-Marne), qui a été édifié sur un sommet dominant les vallées de la Seine et du Loing en hommage à Marie Leszczynska ${ }^{69}$, le soubassement se compose de trois degrés en pierres de grès stampien entouré de huit bornes également en grès, la colonne monolithique étant en marbre rouge du Languedoc et le chapiteau en marbre blanc.

112 Cet engouement extraordinaire pour de tels jardins ne semble pas avoir franchi les premières décennies $d u$ xix siècle; peut-être $d u$ fait d'un romantisme plus contemplatif de la nature?

$113 \mathrm{Au}$ cours du XVIII siècle s'est manifesté un intérêt croissant de la part des voyageurs et des savants pour des paysages singuliers, parmi lesquels des chaos de blocs de grès erratiques du sud du bassin de Paris, du Hurepoix, du Valois et de l'ouest du Bassin parisien, qui devaient être considérés comme plus impressionnants et mystérieux que de nos jours, et ce d'autant plus qu'ils étaient plus vastes qu'à présent. "Le grès est la pierre la plus amusante et la plus étrangement pétrie qu'il y ait... Il a toutes les figures ${ }^{70}$ ", ainsi Victor Hugo a-t-il bien exprimé cet intérêt porté à ces paysages, que de nombreux artistes ont peints, tels Jean-Baptiste Corot, Charles-François Daubigny, Théodore Rousseau, Alexandre Desgoffe et Félix Ziem. Ce sont ces peintres et des écrivains (Victor Hugo, George Sand, Jules Michelet...) qui réclamèrent un classement de réserves artistiques dans le massif bellifontain, qui avait tout autant pour but de 
protéger les chaos de grès que les plus beaux peuplements forestiers ${ }^{71}$. Cette importante ressource en matériaux très résistants du point de vue mécanique autant que vis-à-vis des altérations a donc été très exploitée en raison de leur accessibilité, ainsi qu'il en a été dans le passé dans la région de Palluau et de Challans, en Vendée, où des milliers de blocs et de dalles de grès à palmiers, pouvant atteindre 7 mètres de long et 3 mètres de haut parsemaient encore la campagne au milieu du $\mathrm{xx}^{\mathrm{e}}$ siècle ${ }^{72}$.

\section{Les jardins et les parcs romantiques (XIX ${ }^{\mathrm{e}}$ siècle)}

«Les arbres arrangent et animent tout. » (Auguste Rodin, 1914.)

Le premier parc public encore existant a été fondé à Rhodes au cours de la période hellénistique (II siècle). Puis, à Rome, à la fin du régime républicain, quelques jardins ont été dévolus à la population, dont celui de César. Les parcs et promenades publics impliquent au cours de leur histoire des aspects esthétiques, mais aussi sociologiques ${ }^{73}$. L'un des plus anciens de ces promenoirs semble bien être la promenade du Peyrou, à Montpellier (Hérault), mais ils ne prirent en Europe occidentale un certain essor qu'au cours du XIX siècle et n'ont pas apporté de traits majeurs par leur architecture, ni d'originalité particulière dans le choix des essences plantées, si ce n'est de donner une image d'une végétation arborée et ombragée. Les jardins à l'anglaise de la fin du XviII et du début du XIX ${ }^{e}$ siècle, assez nombreux à être restés en assez bon état jusqu'à nos jours, peuvent de ce fait contribuer à mieux comprendre l'évolution des goûts des commanditaires aussi bien que des architectes intéressés par le nouvel art des jardins ${ }^{74}$, à l'instar des créateurs de jardins aux Pays-Bas et en Angleterre. Cette évolution s'est traduite de toute évidence par l'émergence d'une sensibilité préromantique, ainsi que par un grand intérêt porté à la vie des végétaux dans divers milieux, aussi bien qu'à celle des animaux venus peupler ces parcs.

115 Le domaine de la Malmaison (château du XvII siècle), acquis par Joséphine en 1799, couvrait 400 hectares (une dizaine actuellement, y compris celui de la Petite Malmaison). Il a été aménagé en parc à l'anglaise par Charles Percier et Pierre Fontaine, puis par Louis-Martin Berthault, qui fut chargé de construire la Petite Malmaison ainsi qu'une serre chaude (la plus importante en ce début de siècle) en bois de chêne sans doute. Tous les agréments classiques des jardins romantiques se rencontrent dans ce parc : la rivière anglaise menant à la Petite Malmaison, deux obélisques en brèche de Dinant reposant sur leurs piédestaux par quatre boules en bronze, de petits temples... Passionnée de botanique, Joséphine recevait dans ces lieux Alexandre de Humboldt et Aimé Bonpland et fit introduire dans le parc de nombreuses essences qui firent de ce jardin une référence tout au long du XIX ${ }^{e}$ siècle : cèdres, mélèzes, pins, cyprès chauves, hibiscus, pivoines arbustives, camélias, dahlias, hêtres pourpres, une essence rare de frêne. Le parc actuel de la Petite Malmaison abrite encore aujourd'hui un bon nombre de plantes herbacées autochtones protégées (espace naturel sensible, désherbage manuel).

À Saint-Leu-la-Forêt (Val-d'Oise), le parc du château de la reine Hortense ( 80 hectares en 1802, 20 hectares de nos jours), d'après le circuit établi par la Société d'histoire de Saint-Leu, se situait sur le flanc exposé au sud de la forêt de Montmorency. Une fois aménagé, il était couvert de bosquets de châtaigniers (introduits au cours de la première moitié du XVII ${ }^{e}$ siècle), de chênes et de hêtres sans doute, qu'isolaient de vastes prairies; des allées serpentines bordées d'arbustes (charmes, houx, 
noisetiers... ?) et de plantes à fleurs reliaient plusieurs belvédères, d'où l'on pouvait contempler la vallée de Montmorency, Paris, les buttes de Cormeilles, le confluent de l'Oise et de la Seine et le sud du Vexin. On peut encore voir les traces de quelques aménagements : sauts-de-loup sur le rebord du plateau, chaumière à pans de bois couverte d'un toit de chaume ${ }^{75}$, "chapelle " rustique (une pierre taillée de calcaire lutétien de deux décimètres et des débris de pavement subsistent sur ce site). Au niveau de la ligne de source des argiles du Stampien inférieur avait été aménagé, par une digue, un étang $(140 \times 60 \mathrm{~m})$ dont on peut encore voir la ligne de rivage à la faveur d'un récent déboisement de la châtaigneraie actuelle. À l'ouest de l'étang avaient été édifiés quelques ouvrages en bois de chêne : un pont, un embarcadère et un abri charpenté pour des embarcations. Sur la rive nord de l'étang une grande grotte, où s'écoulaient les eaux d'une cascade, avait été érigée en blocs métriques de grès stampiens affleurant sur le versant de la colline qu'un récent chantier vient de faire réapparaître. Cette grotte comportait au moins une dizaine de blocs importants d'après un dessin de l'époque; au milieu du $\mathrm{XIX}^{\mathrm{e}}$ siècle, elle a été démontée, transportée et réédifiée, au moins pour partie, dans la grande cascade du bois de Boulogne.

Dans la vallée de la Viosne, le jardin et le château d'Osny, dans le Val-d'Oise (fin du $\mathrm{XVIII}^{\mathrm{e}}$ et début du XIX ${ }^{\mathrm{e}}$ siècle), exposés au sud, ont été aménagés au pied d'une ancienne carrière de calcaire lutétien sur la rive gauche de la rivière. Le parc comprend des terrasses à l'est et au sud-est (vergers) à chaînages de type "cyclopéen » (calcaire lutétien) et à l'ouest, d'un jardin proprement dit montrant un temple circulaire en calcaire lutétien, un bassin du même calcaire entouré de blocs calcaires et de grès auversiens, une copie en marbre d'une vénus de Christophe-Gabriel Allegrain (l'original est exposé au Louvre), et au sud un pont en calcaire lutétien qui franchit la Viosne et dont les parapets sont décorés de tables à silex d'un ocre clair et de petites grésifications aux formes contournées (Auversien).

À Orsay, en Essonne, un grand canal de 1200 mètres réunissait le manoir (1759), à l'ouest, à la «folie » du temple de la Gloire (1801), à l'est, dont seule subsiste la tête au pied de cette construction de style palladien; les arbres qui environnent celle-ci sont surtout des peupliers et des tilleuls.

119 L'essai de synthèse entrepris dans cet article demeure encore bien incomplet, ne fût-ce que sur les jardins évoqués qui sont accessibles, et ce notamment par des recherches dans les archives de ces domaines. En ce qui concerne ceux du XIX ${ }^{e}$ siècle, le parc de Ferrières-en-Brie et de son arboretum, fermé au public à l'heure actuelle, ou encore le parc du château d'Andrezel (Seine-et-Marne) et son imposante entrée franchissant un faux canal semi-circulaire en meulières de Brie, par exemple, mériteraient sans doute d'être considérés avec attention.

\section{Conclusions}

La nature des végétaux étant d'une complexité extrême, l'art des jardins, comme tout art d'ailleurs, ne peut que refléter celle-ci. Il en résulte que, si l'on voulait éviter l'ennui (voir Voltaire ${ }^{76}$ ), les compositions des jardins ne pouvaient évoluer que vers l'inattendu, le surprenant et la beauté des lignes, des formes, des valeurs et des couleurs, inspirés par les végétaux, et dont l'acmé ne pouvait être que les jardins paysagers "à l'anglaise ", déjà présents dès l'époque romaine. Cette évolution géohistorique serait à 
approfondir dans le sens des propos poétiques et phénoménologiques évoqués par Gaston Bachelard ${ }^{77}$.

Avant le milieu du $\mathrm{xx}^{\mathrm{e}}$ siècle, les savoirs dans les domaines relevant des sciences de la nature, et en particulier en écologie des végétaux, n'étaient que balbutiants parmi les élites elles-mêmes ${ }^{78}$ et très empiriques chez les charpentiers et ébénistes. Aussi les connaissances sur les bois et les plantes étaient-elles bien déficientes; la question de l'accroissement diamétral des bois, par exemple, n'a été comprise qu'au cours du XIX siècle; autre exemple, l'importance des systèmes racinaires dans les sols n'a été véritablement perçue qu'à la fin du $\mathrm{xx}^{\mathrm{e}}$ siècle $^{79}$. On était bien loin d'envisager que dans un parc ou dans la nature un lieu soit un milieu ${ }^{80}$, ce qu'avaient sans doute pressenti Le Nôtre et Antoine Dezallier d'Argenville ${ }^{81}$.

Les grands jardins historiques étaient et demeurent des entités singulières pouvant, le cas échéant, reconstituer des sylvosystèmes ou regrouper des écosystèmes.

Ainsi que l'évoque A. Allimant-Verdillon ${ }^{82}$, il convient si l'on veut comprendre au mieux la géohistoire des parcs et des jardins séculaires et même antiques, de mettre en œuvre toutes les méthodes d'études devenues classiques (palynologie, anthracologie...), auxquelles il faut adjoindre l'épidermologie, les relevés phytosociologiques ainsi que les aspects phytogéographiques, géomorphologiques, hydrauliques et archéopédologiques.

Il faudrait donc chercher à restituer les caractéristiques des milieux arborés (écosystèmes et/ou sylvo-systèmes) des paysages au fil des derniers siècles, et par conséquent des ressources en bois susceptibles d'avoir été exploitées. Les cartes de la végétation potentielle peuvent être utilisées avec profit à ce sujet ${ }^{83}$.

Les aménagements de pièces d'eau n'ont sans doute pas été sans susciter des difficultés à cause de la végétation des milieux humides, qu'ils soient riverains, sur sols argileux ou sablonneux, ou aquatiques; ces aménagements ont dû être autrefois périodiquement envahis par des équisétales (prêles), des graminées aquatiques, des lentilles d'eau, des algues...; l'envahissement récent du canal sud du domaine de Fontainebleau par des charas ${ }^{84}$ sur au moins un mètre d'épaisseur en a donné une image.

6 Ces jardins ont pu redevenir des écosystèmes très localisés, ainsi que l'illustre le boisement du déversoir du grand canal de Fontainebleau (frênaie), et parfois même des refuges pour quelques plantes menacées par les temps modernes, tel que dans les jardins historiques à Rome; ce retour à la nature de jardins et de parcs a impliqué des évolutions phytodynamiques de groupements forestiers qui relèvent tout autant d'écosystèmes que de sylvo-systèmes résultant de l'introduction d'essences inadéquates, de châtaigniers en lieu et place de chênes pédonculés entre autres.

Ces cas de figure furent pressentis dès la fin du XVII ${ }^{e}$ siècle, par exemple par Le Nôtre, et surtout au cours du xvIII ${ }^{e}$ siècle (Dezallier d'Argenville). L'imitation de la nature dans les arts, la mimésis, pratiquée depuis le $\mathrm{XvI}^{\mathrm{e}}$ siècle et même dès l'Antiquitée ${ }^{85}$, a été plus marquée dans l'architecture des jardins que dans celle du bâti ${ }^{86}$, peut-être du fait qu'elle était redoutée à cause des inconnues qu'elle recèle, ainsi que les peintres l'ont tout particulièrement exprimé (Antoine Watteau, Hubert Robert).

$\mathrm{Au}$ cours du XvI $\mathrm{e}^{\mathrm{e}}$ siècle, les pièces d'eau prirent un certain essor dans la composition des grands jardins du val de Loire et d'île-de-France : jeux d'eaux, carrés d'îles, canaux orthogonaux ou non, miroirs, îles et îlots arborés ou non devinrent des figures 
recherchées; ce qui a impliqué des observations attentives des milieux environnants et une meilleure maîtrise des sources, des aqueducs, des réservoirs et des ouvrages de régulation, parachevée les siècles suivants.

Par contre, au cours des Temps modernes, les ressources en pierre semblent être restées plus accessibles dans une certaine mesure (les bassins carriers). De nos jours, quelques affleurements et des mises au jour fortuites lors de travaux permettent de pallier le manque de carrières locales, devenues bien rares depuis quelques décennies. Il en est ainsi, par exemple, à proximité du parc de la reine Hortense, à Saint-Leu-laForêt, où de récents travaux ont fait affleurer dans le Stampien supérieur sableux le niveau à grès qui a fourni les blocs utilisés pour bâtir le grand rocher surplombant le lac du jardin.

130 Les données relevant de l'hydraulique sont quant à elles, plus aléatoires, ne fût-ce que du fait de leurs relations d'immédiateté avec les fluctuations climatiques du Petit Âge glaciaire en particulier.

131 Les voyages des artistes et des architectes entre l'Europe du nord-ouest et l'Italie ainsi que des encyclopédistes ont dû favoriser les échanges d'idées, de concepts et de savoirs, notamment sur les propriétés et les qualités des matériaux, à l'instar des transferts artistiques dans l'Europe gothique ${ }^{87}$.

Dès la fin du XVII ${ }^{\mathrm{e}}$ siècle et au XVIII ${ }^{\mathrm{e}}$ siècle, la statuaire devient une création multiforme ${ }^{88}$ : hymne à la nature, recherche de liberté, créations incessantes de bosquets, de perspectives, qui donnent lieu à des installations et désinstallations de statues.

133 À la fin du XVIII ${ }^{e}$ siècle émerge un nouveau genre de vie, et en particulier un certain sensualisme dans le plaisir, par exemple, de pouvoir contempler les paysages et les lointains et donc de se donner sans doute une raison de plus de se sentir exister ; ainsi s'est-on acheminé vers les jardins romantiques du XIX siècle.

\section{BIBLIOGRAPHIE}

ALLIMANT-VERDILLON A., 2016, « Par art ou par nature : comment et pourquoi fouiller un jardin, les jardins sous l'œil de l'archéologue. Le jardin des Tuileries ", Dossiers d'archéologie, n 375, p. 6-13 et p. 52-55.

BACHELARD G., 1957, La poétique de l'espace, Paris, Presses universitaires de France.

BALLU J.-M., 2000, Bois de marine : les bateaux naissent en forêt, Paris, Éd. du Gerfaut.

BARITOU J.-L. ET FOUSSARD D. (dir.), 1987, Chevotet-Contant-Chaussard : un cabinet d'architectes au siècle des Lumières, Lyon, La Manufacture.

BÉGUIN S., 1968, « Le maniérisme », dans Encyclopaedia universalis, Londres, Encyclopaedia

Britannica, vol. 10, p. 439-447.

BRESC-BAUTIER G., 2008, « Une promenade à Marly », Grande galerie, nº 4, p. 34-47.

BRUNON H. et MOSSER M., 2014, L'imaginaire des grottes dans les jardins européens, Paris, Hazan. 
CLOUET T., 2012, « Fontainebleau de 1541 à 1547 », Bulletin monumental, nº 170, p. 195-234.

COJANNOT A. et FAISANT E., 2016, « Au château de Limours : S. de Brosse, F. Mansart et A. Le Nôtre », Bulletin monumental, $\mathrm{n}^{\circ} 174$, p. 165-186.

COPPENS Y., 1990, «L'environnementalisme », Annuaire du Collège de France. Résumés des cours et travaux, année 1989-1990.

CoRvol A., 1991a, « Préface ", dans Corvol A. (dir.), La forêt, actes du Congrès national des sociétés savantes (113, Strasbourg, 1988), Paris, Éditions du CTHS, p. 5-12.

CORVOL A., 1991b, «Exploitation sylvicole et botanique forestière aux XVII ${ }^{\mathrm{e}}$ et XVIII ${ }^{\mathrm{e}}$ siècles ", dans Corvol A. (dir.), La forêt, actes du Congrès national des sociétés savantes (113, Strasbourg, 1988), Paris, Éditions du CTHS, p. 295-306.

CROZIER M. et BÉCHER S. 2017, « Le parc de Méréville : du tableau au projet. Problématiques et méthodologie d'intervention ", dans Recueil des résumés, colloque Robert des Ruines : revoir, réinterpréter, restaurer (La Roche-Guyon, 18 nov. 2017).

DACH M., 1979, Le Désert de Retz à la lumière d’un angle particulier, [Chambourcy], M. Dach.

DE BAy P. et BOLTON J., 2001, Garden mania, Arles, Actes sud.

DUBOIS J., GILLOUËT J.-M., VAN DEN BOSSCHE B., 2014, Les transferts artistiques dans l'Europe gothique : repenser la circulation des artistes, des œuvres, des thèmes et des savoir-faire (XII ${ }^{e}-\mathrm{XVI}^{e}$ siècle), Paris, Picard.

FALGUière P., 2012, « Préface » et « Postface », dans Schlosser J. von, Les cabinets d'art et de merveilles de la Renaissance tardive : une contribution à l'histoire du collectionnisme, Paris, Macula.

GALLET M., 1979, Ledoux et Paris, cat. exp. (Paris, Rotonde de La Villette, 1979), Paris, Impr. municipales (Cahiers de la Rotonde, 3).

GARNIER-PELLE N., 2013, André Le Nôtre et les jardins de Chantilly aux XVII et XVIII siècles, cat. exp. (Chantilly, musée Condé, 2013), Paris, Somogy.

GÉRARD F., KOENIGUER J.-C., GALOYER A. 1995, « La fabrique souterraine en tuf de Resson du parc du château de La Motte-Tilly », dans J. Lorenz, P. Benoit, D. Obert (dir.), Pierres et carrières : géologie, archéologie, histoire, actes des journées Claude Lorenz (17-18 novembre 1995), Paris, Association des géologues du Bassin parisien, p. 209-213.

GRIMAL P., 1984, Les jardins romains, Paris Presses universitaires de France.

GUILLAUME J., 2006, « Le jardin français de la Renaissance », dans Lataste C. et Renaud J.-P. (dir.), Vendée côté jardin : promenade au cour d'un patrimoine, Saint-Sulpice-Le Verdon, Logis de La Chabotterie / Paris, Somogy / La Roche-sur-Yon, Département de la Vendée, p. 67-74.

HALLÉ F., 1999, Éloge de la plante : pour une nouvelle biologie, Paris, Le Seuil (Points).

HeITZMANN A., 2016, « Un jardin pour Louis XV : le Pavillon frais à Trianon », Dossiers d'archéologie, $n^{\circ} 375$ (« Les jardins de la Grèce antique à l'époque moderne »), p. 56-59.

HÉRAUD M.-E., 2006, « Les carrés en îles ou les jardins oubliés de la Renaissance », dans Lataste C. et Renaud J.-P. (dir.), Vendée côté jardin : promenade au cœur d'un patrimoine, Saint-Sulpice-Le Verdon, Logis de La Chabotterie / Paris, Somogy / La Roche-sur-Yon, département de la Vendée, p. 51-65. 
HOOG S. et BOSSARD R. (dir.), 1992, Les jardins de Versailles et de Trianon, d'André Le Nôtre à Richard Mique, cat. exp. (Versailles, musée national des Châteaux de Versailles et de Trianon, 15 juin-27 septembre 1992), 1992, Paris, Réunion des musées nationaux.

HOUZARD G., 1993, «L'approche du biogéographe », dans Dubois J.-J. et Géhu J.-M. (dir.),

Phytodynamique et biogéographie historique des forêts, actes du Colloque phytosociologique (XX, Bailleul, 1991), Berlin, J. Cramer, p. 1-6.

KOENIGUER J.-Cl. et BLANC A., 2014, « Les grès et le bâti, la sculpture et les jardins ", Coré, $\mathrm{n}^{\circ}$ 30, p. 5-13.

LAUTERBACH I., 2010, « L'ornement dans les parterres des jardins : $\mathrm{XV}^{\mathrm{e}}$-XVIII ${ }^{\mathrm{e}}$ siècles ", Perspective, 2010-2011, n 1, p. 144-150.

LAŸ J. et LAŸ M., 1998, La machine de Marly, cat. exp. (Bougival, 1998), [Louveciennes], J. Laÿ.

LE ROY LADURIE E., 2020, Histoire du climat depuis l'an mil, Flammarion, Paris.

MARIAGE T., 1992, « De la validité des documents graphiques pour juger de l'évolution des jardins de Versailles ", dans Hoog S. et Bossard R. (dir.), Les jardins de Versailles et de Trianon, d'André Le Nôtre à Richard Mique, cat. exp. (Versailles, musée national des Châteaux de Versailles et de Trianon, 15 juin-27 septembre 1992), Paris, Réunion des musées nationaux, p. 55-74.

MAROTEAUX V. 2006, «De Bonnes à Chamarande : naissance et développement d'un jardin (XVII ${ }^{\mathrm{e}}$ XVIII ${ }^{\mathrm{e}}$ siècles) », Polia, vol. 3, $\mathrm{n}^{\circ}$ 5, p. 55-74.

MÉNARD J., 2003, L'étonnante histoire des jeux d'eau et du réseau hydrographique du domaine royal de Meudon, 1654-2000, Meudon, Le Taureau volant.

MOREL P., 1998, Les grottes maniéristes en Italie au XVI : théâtre et alchimie de la nature, Paris, Macula. MOULIN J., 2014, Les jardins de Vaux-le-Vicomte : histoire, légendes et métamorphoses d'un chef-d'œuvre d'André Le Nôtre, Paris, Spiralinthe (recension de M. H. Bénetière, 2016, Bulletin monumental, vol. 174, $\mathrm{n}^{\circ} 2$, p. 227-228).

NOLHAC P. de, 1992, «Les jardins de Versailles », dans Hoog S. et Bossard R. (dir.), Les jardins de Versailles et de Trianon, d'André Le Nôtre à Richard Mique, cat. exp. (Versailles, musée national des Châteaux de Versailles et de Trianon, 15 juin-27 septembre 1992), Paris, Réunion des musées nationaux, p. 13-14.

PARISOT C., 1878, Notice historique et géographique sur Bois-le-Roi, Melun, Charriou, 44 p.

PLAZIAT J.-C. et LOzouet P., 2012, « Le Stampien et l'homme », dans Lozouet P. (dir.), Stratotype stampien, Paris Muséum national d'histoire naturelle / Mèze, Biotope, p. 321-348.

PORTES R., 2006, « Les aménagements hydrauliques à Chantilly au XVII ${ }^{\mathrm{e}}$ siècle », Polia, nº 5, p. 31-54.

RAMEAU J.-C., 1991a, « Actualisation des concepts de climax et d'essaims climatiques », dans

Corvol A. (dir.), La forêt, actes du Congrès national des sociétés savantes (113, Strasbourg, 1988), Paris, Éditions du CTHS, p. 135-152.

RAMEAU J.-C., 1991b, « Phytodynamique forestière : l'approche du phytoécologue forestier », dans Dubois J.-J. et Géhu J.-M. (dir.), Phytodynamique et biogéographie historique des forêts, acte du Colloque phytosociologique (XX, Bailleul, 1991), Berlin, J. Cramer, p. 29-71.

Rostaing A. 2010, Les jardins de Le Nôtre en Île-de-France, Paris, Éditions du patrimoine.

TERS M., VERGER F., MATHIEU G., 1972, « Palluau, île d'Yeu », dans Carte géologique détaillée de la France 1:80 000, Orléans, BRGM, f. 128-129. 
SCHLOSSER J. von, 2012, Les cabinets d'art et de merveilles de la Renaissance tardive : une contribution à l'histoire du collectionnisme, Paris, Macula.

VERCELLONI M. et VERCELLONI V. 2009, L'invention du jardin occidental, Rodez, Rouergue.

VERLET H., 2007, Fontainebleau : par le grès pour la chasse, Fontainebleau, Amis du château de Fontainebleau (Dossiers, 1).

VERLET H., 2012, Les belles eaux de Fontainebleau, Fontainebleau, Amis du château de Fontainebleau (Dossiers, 6).

\section{NOTES}

1. Le Roy Ladurie 2020.

2. Rameau 1991a et $1991 \mathrm{~b}$.

3. Houzard 1993.

4. Corvol 1991a et 1991b.

5. Ibid.

6. P. Benoit, comm. orale.

7. Grimal $1984: 247-248$.

8. Ibid.

9. P. Gros, comm. orale, 1999.

10. Guillaume 2006.

11. Héraud 2006.

12. Guillaume 2006.

13. Lauterbach $2010: 144$.

14. Guillaume 2006, Vercelloni et Vercelloni 2009.

15. Guillaume 2006.

16. Ibid.

17. Giorgio Vasari, Le Vite de' più eccellenti architetti, pittori et scultori italiani, da Cimabue insino a' tempi nostri, Florence, 1550.

18. Béguin 1968.

19. Von Schlosser 2012, Falguières 2012.

20. Voir l'aqueduc de l'Aqua Claudia (Rome), à pierres à bossages, construit entre 38 et 52.

21. Brunon et Mosser 2016

22. Topothésie : transcription dans l'espace d'un lieu fictif.

23. Gogotte : concrétion gréseuse à ciment siliceux, qui adopte des formes tourmentées et originales.

24. Béguin 1968.

25. Termes : grandes figures sculptées d'inspiration égyptienne.

26. Koeniguer et Blanc 2014, Verlet 2007.

27. Clouet 2012. 
28. Verlet 2012.

29. Morel 1998.

30. Héraud 2006.

31. Les travaux des jardins de Vaux-le-Vicomte ont en fait débuté dès 1652, bien avant l'ouverture du chantier du château (1656) et ne seraient peut-être pas dus au seul Le Nôtre (Moulin 2014). Le jardin régulier était encore bien conservé en 1764.

32. Plaziat et Lozouet 2012.

33. Rostaing 2010.

34. Heitzmann 2016.

35. Laÿ et Laÿ 1998.

36. Machine de Marly: dispositif de pompage des eaux de la Seine destiné à l'alimentation hydraulique des jardins du château de Marly et du parc de Versailles.

37. Laÿ et Laÿ 1998.

38. Ballu 2000.

39. Ménard 2013.

40. Garnier-Pelle 2013.

41. Portes 2006.

42. Ibid.

43. Voir les gravures de Gabriel Pérelle dans Garnier-Pelle 2013 : 68-69.

44. Nolhac 1992.

45. Voir dans Vieilles maisons françaises, le dossier « Le Bocage dans l'Orne », 2014, nº 255 («Orne »), p. 24-91.

46. Mariage 1992.

47. Cojannot et Faisant 2016.

48. Hoog et Bossard 1992.

49. Vercelloni et Vercelloni 2009.

50. M.-C. Pozzana, comm. orale, 1996.

51. Brunon et Mosser 2017.

52. Brunon et Mosser 2016.

53. Feuillets du musée du Louvre, « Cour de Marly » (G. Bresc-Bautier, 2008).

54. Heitzmann 2016.

55. Maroteaux 2006.

56. S. Bécher et M. Crozier 2017, comm. orale lors du colloque «Robert des ruines : revoir, réinterpréter, restaurer », La Roche-Guyon, 18 nov. 2017. La restauration du domaine est actuellement conduite par S. Bécher, responsable scientifique, et M. Crozier, architecte.

57. La carrière du baron Claude Baudard de Saint-James a débuté dans une manufacture de toiles pour les voiles de navires, puis s'est poursuivie à la Compagnie du Creusot, puis à la Compagnie des eaux de Paris. Il s'intéressa aux sciences, à l'électricité et aux recherches minières et était membre des Philalèthes (les amis de la vérité).

58. Un certain nombre de données citées dans ce texte proviennent des panneaux sur l'histoire de ce jardin dus au cabinet d'architecture Gatier. 
59. Voir Dach 1995.

60. De nombreux invités et visiteurs se sont rendus dans ce parc: le prince de Ligne, Philippe d'Orléans, Marie-Antoinette, Mme Vigée Le Brun, Mme du Berry, Thomas Jefferson, Colette...

61. Dach 1995.

62. Gallet 1979.

63. Beck-Saiello et al., comm. orale lors des Journées de l'histoire de l'art de Fontainebleau, 2013.

64. Gallet 1979.

65. Gérard et al. 1995.

66. Ibid.

67. Nymphée : grotte abritant une source ou une fontaine; sanctuaire consacré aux nymphes.

68. Nombreuses figures dans De Bay et Bolton 2001.

69. Marie Leszczynska (1703-1768), fille du roi de Pologne Stanislas Leszczynski, épouse de Louis XV.

70. Cité par Bachelard $1957: 187$.

71. Parisot 1878.

72. Ters et. al. 1972.

73. Un cycle de conférences intitulé «Du jardin royal au parc public »a été organisé par le musée du Louvre en 1996 sous la direction de M. Mosser.

74. Baritou et Foussard 1987.

75. La dénomination vernaculaire de "chaume » désigne aussi bien des tiges ligneuses de phragmites (roseaux, Graminées) que de typhas (joncs des tonneliers, Typhacées) ou encore de carex (Cypéracées).

76. Voltaire, Correspondance, épître 54, « Au prince royal de Prusse », 1738.

77. Bachelard 1957, chap. X.

78. Corvol 1991b.

79. Hallé 1999 : un plan de seigle peut développer 500 kilomètres de racines.

80. Coppens 1990.

81. Antoine Joseph Dezallier d'Argenville (1680-1765), naturaliste, collectionneur et historien d'art.

82. Allimant-Verdillon $2016: 52-55$.

83. Voir les cartes de la végétation potentielle de la France au 1/200 000 (CNRS), cartons botaniques.

84. Charas (charophytes): végétaux des eaux douces et claires, d'une dizaine de centimètres de hauteur; ils se composent d'une tige pourvue de rameaux en verticilles qui se calcifient peu à peu. Les charophytes ne sont pas véritablement des algues vertes en raison de nombreux genres et espèces qui se sont succédé depuis le milieu de l'ère primaire.

85. Grimal 1984.

86. Salom 2017, comm. orale. 
87. Dubois et al. 2014.

88. Bresc-Bautier 2008.

\section{RÉSUMÉS}

La composition d'un jardin ou d'un parc paysager implique des savoirs concernant les végétaux, les sols, le substrat géologique, l'hydraulique, l'évolution géomorphologique et le régime climatique du site considéré. Divers aléas peuvent conduire à ce que des associations végétales ou des sylvo-systèmes reprennent leur dynamique semi-naturelle; qui plus est du XIV au milieu du $\mathrm{XIX}^{\mathrm{e}}$ siècle, en fonction de la fluctuation climacique du Petit Âge glaciaire. De nombreux et intéressants travaux ont été consacrés à l'histoire de l'art des jardins depuis l'Antiquité et la Renaissance; il n'en reste pas moins que la nature des matériaux mis en œuvre dans les architectures (fabriques, grottes, obélisques...) aussi bien qu'en ce qui relève des arts décoratifs (ornements, couleurs, formes naturelles) ont été bien souvent négligés. Cet article complète les données acquises sur les pierres et les bois des aménagements de plusieurs jardins et parcs de l'Île-de-France.

\section{INDEX}

Mots-clés : géohistoire, architecture des jardins, matériaux, Renaissance, Temps modernes Index géographique : Bassin parisien

\section{AUTEUR}

\section{JEAN-CLAUDE KOENIGUER}

Maître de conférences honoraire des universités Paris VI et Paris I 


\title{
Les usages du plâtre dans la construction en Île-de-France de l'Antiquité à l'époque contemporaine
}

\author{
Ivan Lafarge
}

1 Le plâtre est longtemps resté en dehors des questionnements des archéologues parce que ces derniers ne semblent pas s'être émus de l'usage qui était fait anciennement d'un matériau si courant. Il passait inaperçu, malgré sa récurrence dans toutes sortes de vestiges, et n'a pas fait véritablement l'objet d'études spécifiques, malgré quelques mentions ${ }^{1}$. La fréquence de ses usages a commencé à faiblir à partir de la Reconstruction, dans la seconde moitié des années 1940. Du xIXe siècle aux années 1950, ce matériau courant n'a ainsi pas vraiment suscité d'études spécifiques de la part des archéologues. La situation change au tournant de l'après-guerre avec l'industrialisation, mais surtout dans les années 1970-80: on s'y intéresse à la faveur des fouilles de plusieurs nécropoles mérovingiennes et de l'observation de vestiges en lien avec l'essor de l'archéologie urbaine.

Dans les années 1980 se met en place une première phase d'études importantes autour de l'archéologie de ce matériau; elle s'arrête après quelques travaux de qualité, mais souvent confidentiels ${ }^{2}$. Le musée du Plâtre est créé à Cormeilles-en-Parisis en 1982, d'abord musée associatif de la mémoire d'entreprise de la carrière et de l'usine Lambert, constitué d'anciens salariés. Il est aujourd'hui un centre de ressources de premier plan en ce qui concerne le plâtre. Toutefois, à la fin des années 1980, l'intérêt retombe, et après pratiquement une décennie où les publications archéologiques sur le plâtre se comptent sur les doigts d'une main, les années 2000 voient un redémarrage de ces études et de l'intérêt pour le matériau : colloques et publications reprennent. La création du Groupe de recherche sur le plâtre dans l'art (GRPA) à la fin des années 1990 permet la tenue de deux importants colloques à Pontoise et Digne ${ }^{3}$. À partir de 2005, nous avons personnellement contribué à ce renouvellement des études par la mise en œuvre d'une première expérimentation archéologique de four à plâtre ${ }^{4}$, la réalisation 
d'un master ${ }^{5}$ puis d'une thèse sur le plâtre sous l'angle de l'archéologie et de l'histoire des techniques ${ }^{6}$. Puis les travaux de Tiffanie Le Dantec ${ }^{7}$ et de Jean Ducasse-Lapeyrusse (en cours) au sein de la Conservation régionale des Monuments historiques et le cycle de rencontres également en cours intitulé "Le plâtre et la couleur " par le GRPA ${ }^{8}$ complètent cette reprise des études sur le plâtre, ainsi que d'autres colloques d'envergure nationale ou internationale?

\section{Petite mise au point : la géologie et la chimie}

Le plâtre est une ressource naturelle importante dans le Bassin parisien. Il entre dans les ressources constructives dès l'Antiquité ; il est donc potentiellement présent dans l'ensemble des sites construits depuis l'époque gallo-romaine, puis, au Moyen Âge, il est aussi présent dans le bâti en élévation. Tenter d'inventorier systématiquement les sites où l'usage du plâtre est attesté reviendrait presque à dénombrer les lieux habités.

Depuis 2008, nous avons étudié à divers degrés des vestiges de plâtre pour plus d'une soixantaine (67) de sites répartis sur une trentaine de communes dans l'ensemble de l'île-de-France.

5 Géologiquement, le gypse d'Île-de-France s'est déposé dans une lagune endoréique épisodiquement en relation avec le domaine marin pendant le Priabonien (Ludien des géologues français - ère tertiaire, Éocène 38 à 33,9 Ma). Une importante sédimentation évaporitique a donné quatre masses de gypse intercalées de couches de marne (boues argilo-calcaires). Ces masses, contrairement à l'habitude des géologues, sont notées du haut vers le bas. La première, ou haute masse, mesure une vingtaine de mètres d'épaisseur en moyenne; la seconde peut atteindre quatre à huit mètres; la troisième deux mètres en moyenne; enfin la quatrième, plus profonde et plus ancienne, est la moins épaisse, environ un mètre, mais elle est souvent très dégradée et inexploitable. Dans les marnes infra-gypseuses, on trouve très régulièrement de grands cristaux de gypse fer de lance, mesurant jusqu'à un mètre de long.

Ces dépôts forment une importante lentille entre les vallées de l'Oise, de la Seine et de la Marne jusque dans la région de Reims, à Ludes (département de la Marne), site éponyme des gypses d'île-de-France (fig. 1). Cette lentille gypseuse se superpose stratigraphiquement et topographiquement au-dessus du calcaire grossier du Lutétien. D'ailleurs, ces matériaux sont souvent associés en construction. Au XviII ${ }^{\mathrm{e}}$ siècle, on dénombre sur la seule carte de l'abbé Delagrive (1740) dans le quart nord-est de la banlieue parisienne et dans un rayon de 20 kilomètres, une cinquantaine de plâtrières associées à leur carrière (fig. 2). 
Fig. 1. - Extension des masses du gypse du Bassin parisien.

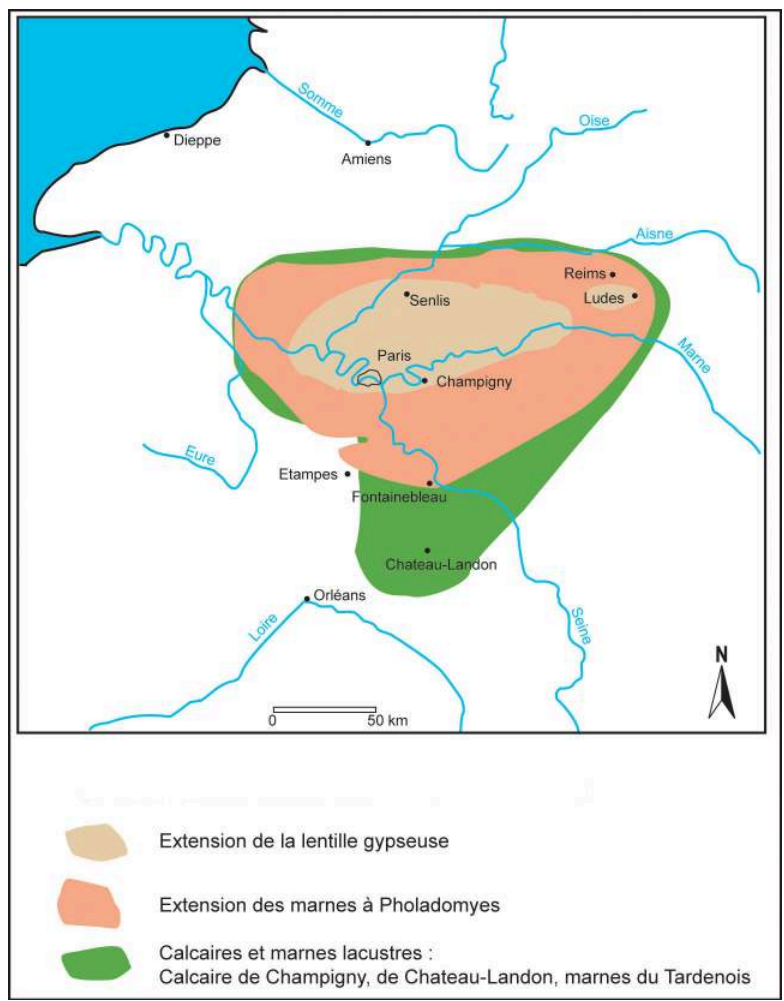

Dessin Ivan Lafarge, d'après Ajot et Daligand 1988.

Fig. 2. - Les exploitations du gypse aux abords de Paris au XVIII ${ }^{\mathrm{e}}$ siècle : 45 plâtrières, 6 sablières, 6 carrières de pierre.

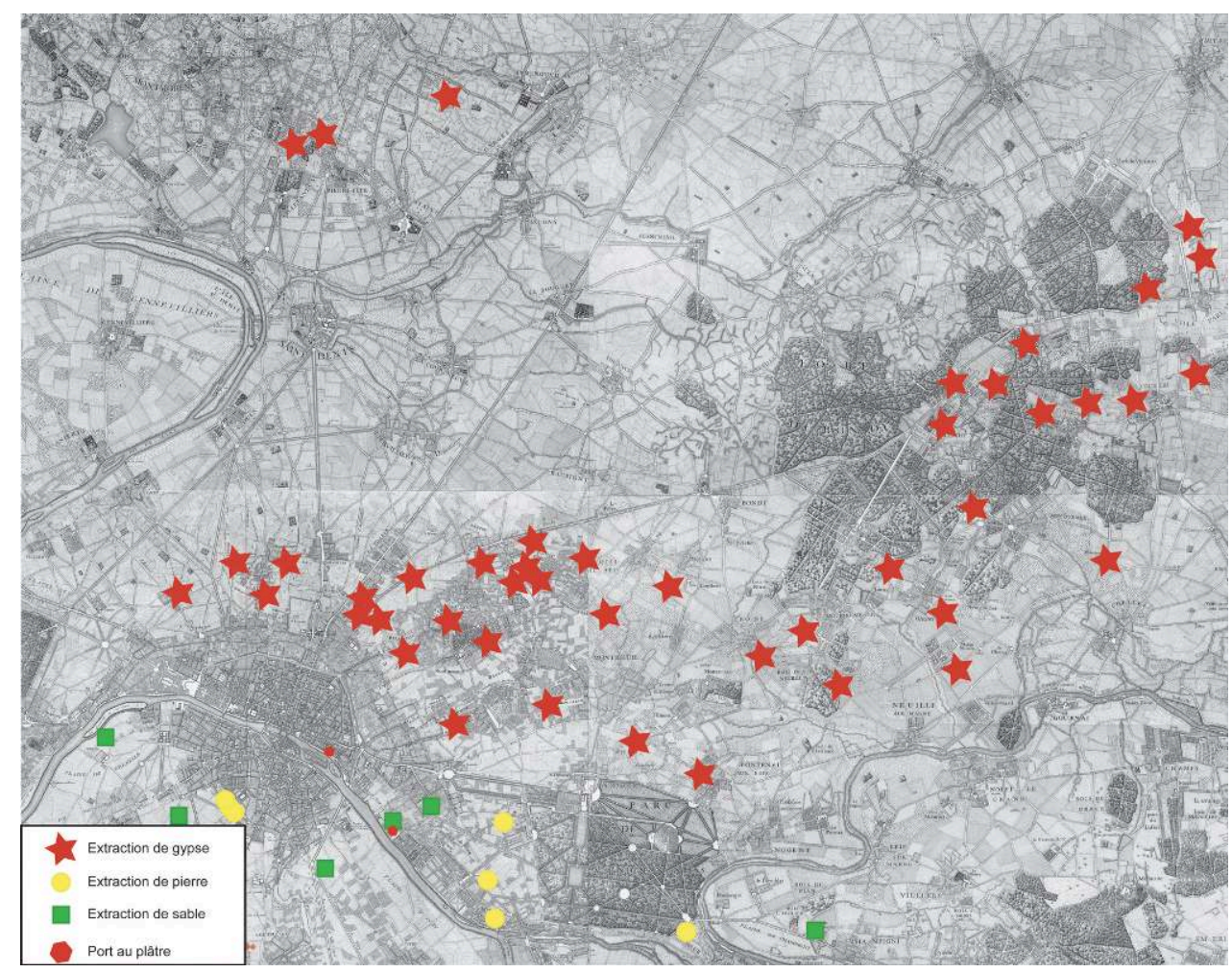

(c) Ivan Lafarge. Fond de carte de l'abbé Delagrive (1740), Bureau du patrimoine de Seine-Saint-Denis. 
7 Chimiquement, le gypse est du sulfate de calcium dihydrate $\left(\mathrm{CaSO}_{4} 2 \mathrm{H}_{2} \mathrm{O}\right)$ qui se déshydrate à partir de $120^{\circ} \mathrm{C}$ pour donner lieu à de la bassanite $\left(\mathrm{CaSO}_{4}{ }^{1 / 2} \mathrm{H}_{2} \mathrm{O}\right)$, qu'on appelle communément le plâtre. Une déshydratation de $75 \%$ suffit, puisque que le semi-hydrate fait prise lorsqu'on le remouille. Cependant, la cuisson peut permettre de produire des anhydrites, solubles ou non, des surcuits. C'est le mélange des différents niveaux de cuisson qui fait les qualités du plâtre préindustriel. Une fois réduit en poudre, si on mouille le plâtre, il fait prise et durcit, reprenant sa composition chimique initiale : c'est ce qu'on appelle la prise. Il faut bien distinguer le phénomène de la prise de celui du séchage (fig. 3).

Fig. 3. - Le cycle chimique du plâtre.

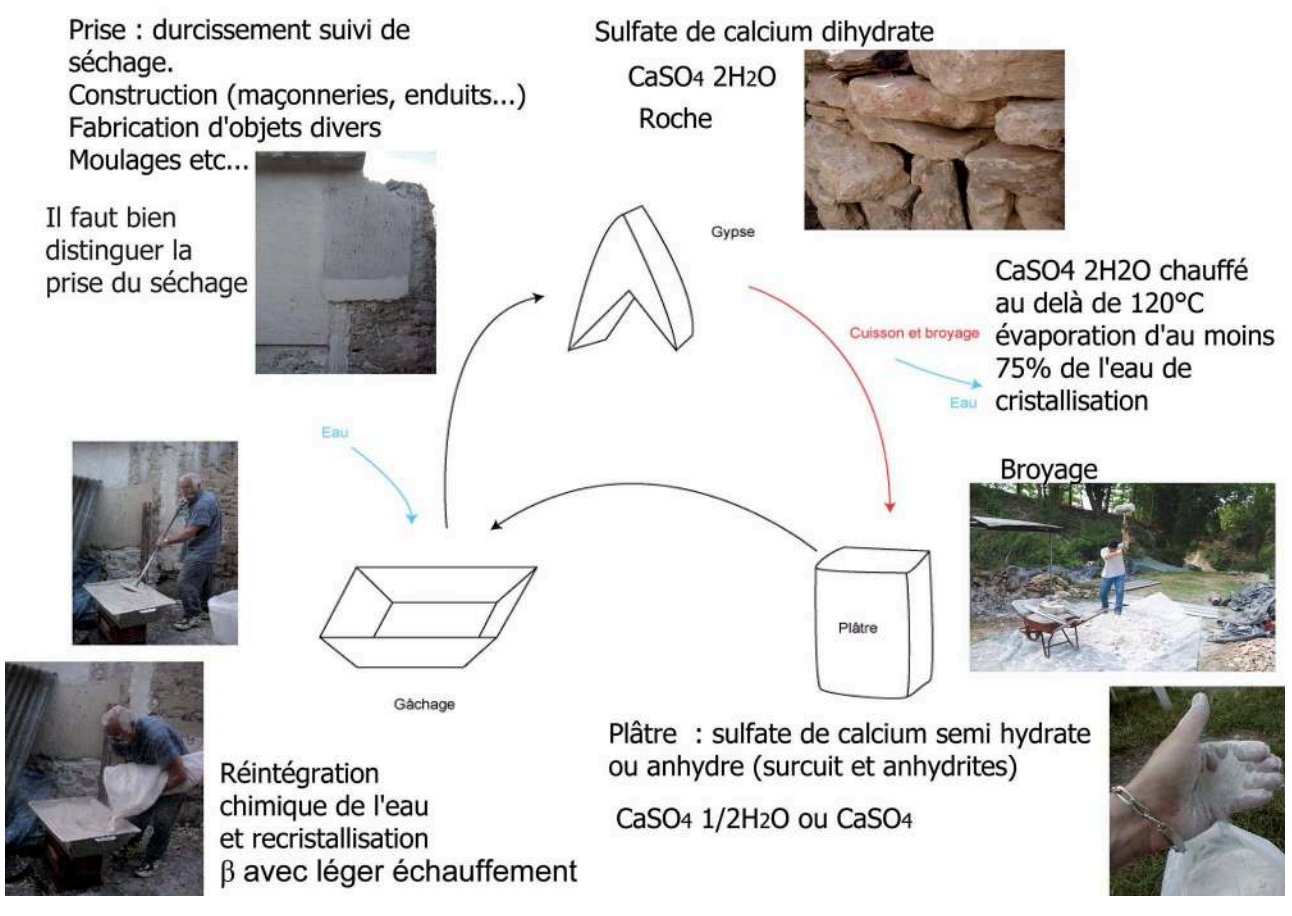

(c) Ivan Lafarge.

\section{Le plâtre dans l'Antiquité}

Dès l'Antiquité, le plâtre est d'usage courant dans la construction : on utilise le gypse en maçonnerie et le plâtre comme liant, mais aussi pour former des briques, des dalles, des tuiles, etc. Outre l'usage qui en est fait en maçonnerie, il sert à la couverture. De nombreuses tegulae portent la trace de l'érosion hydrique due à leur exposition. Contrairement à ce qui a pu être parfois avancé, il se trouve que les artisans romains maîtrisaient bien les techniques de ce matériau, et la forte granulométrie observée sur des éléments de plâtre gallo-romain correspond à un usage contrôlé et à une manifeste volonté de produire du plâtre gros.

9 Le second œuvre se caractérise souvent par des éléments décoratifs. Bien que les Romains fassent peu d'enduits en plâtre, ils étaient friands de décors de stucs. On note que ces dernières années, de nombreux sites ont livré des stucs, qui commencent à être systématiquement étudiés, et on doit noter qu'en île-de-France, le plâtre est majoritairement représenté dans les stucs antiques (Richebourg, dans les Yvelines; 
Paris ; Saint-Denis, en Seine-Saint-Denis). Cependant cette constatation a priori doit être encore être confirmée par une étude systématique.

\section{Le haut Moyen Âge}

Au haut Moyen Âge, les usages de la construction maçonnée perdent en qualité et en fréquence. Quelques édifices sont pourtant à mentionner, même si le plâtre n'y est pas fréquent en premier œuvre, à en croire les données actuellement disponibles. En revanche, le plâtre s'avère un matériau de bonne qualité pour les usages funéraires, il sert régulièrement pour la réalisation par moulage de cuves de sarcophages décorés. Très étudiés dans les années 1980, ces produits sont aujourd'hui réexaminés et on peut mettre en avant plusieurs groupes de production, déterminés par leurs décors, qui correspondent à des modalités de diffusion particulières. Ces données récentes permettent de sortir d'une vision qui restait jusque-là trop centrée sur Paris, et on constate l'éminence des vallées fluviales dans la diffusion de ces éléments ${ }^{10}$ (fig. 4).

Fig. 4. - Carte schématique de la diffusion des sarcophages en plâtre dans et autour de la région parisienne et approche des groupes de production.

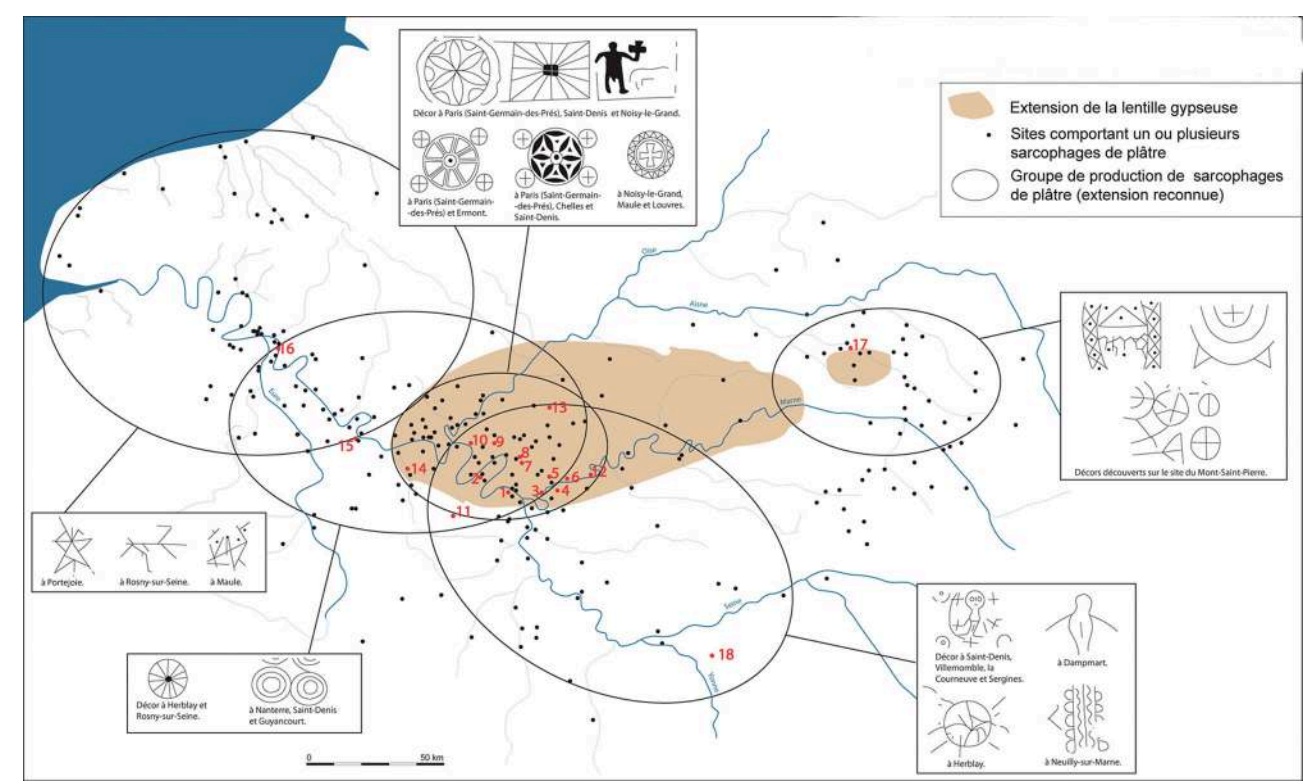

1 : Saint-Germain des-Prés (Paris). 2 : Nanterre (Hauts-de-Seine). $\mathbf{3}$ : Neuilly-sur-Marne (Seine-SaintDenis). 4 : Noisy-le-Grand (Seine-Saint-Denis). $\mathbf{5}$ : Villemomble (Seine-Saint-Denis). $\mathbf{6}$ : Chelles (Seineet-Marne). 7 : La Courneuve (Seine-Saint-Denis). 8 : Saint-Denis (Seine-Saint-Denis). 9 : Ermont (Vald'Oise). 10 : Herblay (Val-d'Oise). 11 : Guyancourt (Yvelines). 12 : Dampmart (Seine-et-Marne). 13 : Louvres (Val-d'Oise). 14 : Maule (Yvelines). 15 : Rosny-sur-Seine (Yvelines). 16 : Porte-Joie (Eure). 17 : site du mont-Saint-Pierre (Villers-Stoncourt, Moselle). 18 : Sergines (Yonne).

(c) Pierre Langlois et Ivan Lafarge. Fond de carte Département de la Seine-Saint-Denis, Bureau du patrimoine archéologique.

11 Les usages funéraires ne se limitent pas aux sarcophages mérovingiens, ils perdurent et dès le $\mathrm{IV}^{\mathrm{e}}$ siècle d'ailleurs, l'usage de tombes à fosses maçonnées se généralise parallèlement à celui des sarcophages, alors qu'à l'évidence la fonction sociale des ces tombes n'est pas la même que celle des sarcophages. Les tombes à fosse maçonnées connaissent un essor important à l'époque carolingienne et leur usage perdure jusqu'à 
l'époque moderne, si bien qu'un réexamen attentif permet aujourd'hui d'établir une chronotypologie de ces structures ${ }^{11}$.

12 Mais dès le haut Moyen Âge et malgré le recul de la construction maçonnée que l'archéologie met en avant, un nombre important d'édifices « de qualité » subsiste et des églises sont, à l'instar de Saint-Germain-des-Prés à Paris, construites en pierre liée au mortier. Le plâtre dans ces constructions est en réalité très peu représenté au vu des connaissances actuelles. Ces édifices dans leur majorité héritent des traditions constructives de l'Antiquité. Quoi qu'il en soit, on connaît deux usages du plâtre qui perdurent durant le haut Moyen Âge. D'une part au sein de ces constructions essentiellement ecclésiastiques de qualité qu'on vient d'évoquer, des décors de stuc, pour lesquels le plâtre est le matériau de base. D'autre part, dans les constructions à structure porteuse en bois pour des hourdages sur clayonnage. Leur nombre toutefois est relativement restreint $\mathrm{du} \mathrm{VI}^{\mathrm{e}}$ au XI $\mathrm{Xl}^{\mathrm{e}}$ siècle, ce qui laisse supposer que cet usage était réservé à des bâtiments d'une certaine qualité, voire à des usages particuliers (lien avec des cheminées par exemple). On l'a dit, en Île-de-France les stucs se démarquent par la prédominance de l'usage du plâtre; il faut cependant admettre que Paris (Lutèce) reste une des villes antiques, puis mérovingiennes, où les stucs font le plus défaut, certainement par manque de documentation. De tels stucs sont attestés à Richebourg pour l'époque gallo-romaine, à Saint-Denis ${ }^{12}$ et à Chelles ${ }^{13}$ (Seine-et-Marne) pour le haut Moyen Âge, du VI ${ }^{\mathrm{e}}$ au $\mathrm{IX}^{\mathrm{e}}$ siècle. On note que le seul fragment de stuc plâtre de l'actuel espace parisien est issu de l'église Saint-Germain de Charonne (Paris), dont le contexte de découverte est un remblai ne permettant guère mieux qu'une datation entre le haut Moyen Âge et le XII siècle (fig. 5). 
Fig. 5. - Fragments de stuc.

a
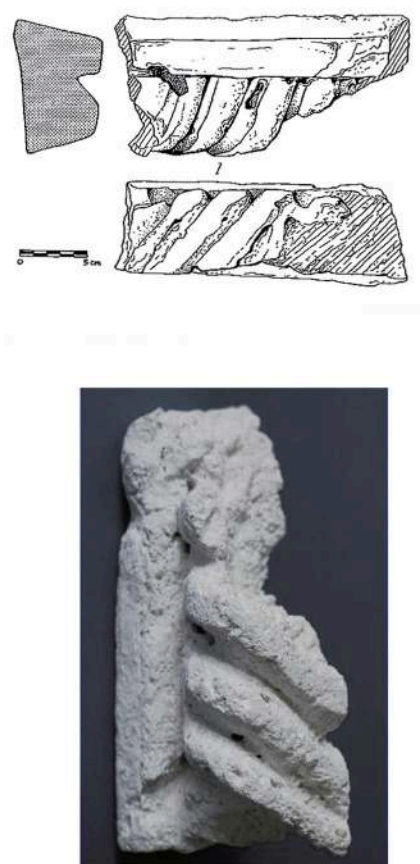

b

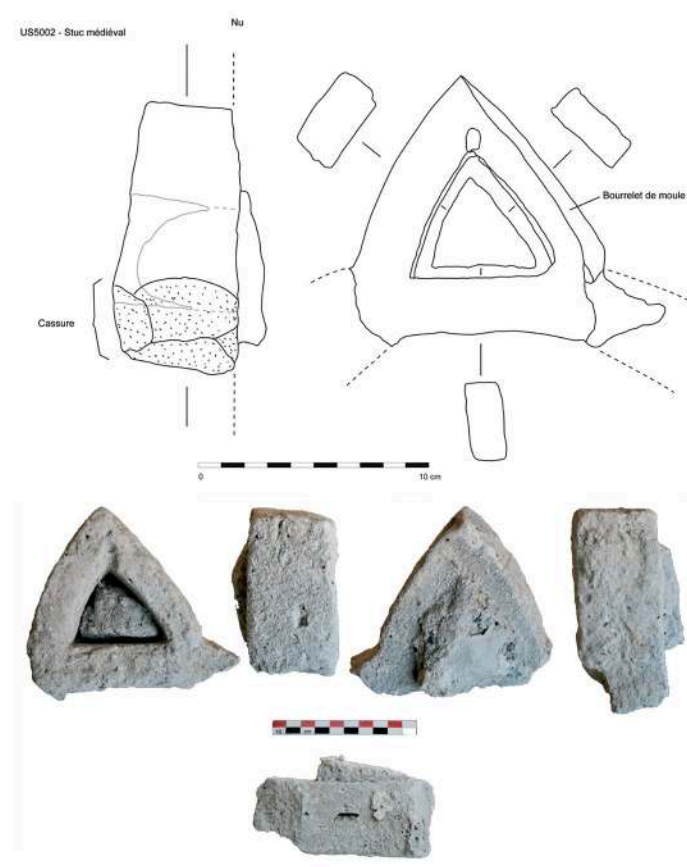

A : église Saint-Georges (Chelles, Seine-et-Marne), Ix siècle. B : Saint-Germain-de-Charonne (Paris), x॥ siècle au plus tard.

Dessin Christiane Hochstrasser-Petit (D.R.), photo José Ajot (A), DAO Ivan Lafarge (B).

\section{Le bas Moyen Âge}

À partir du XIII ${ }^{e}$ siècle, on observe un véritable phénomène de pétrification du bâti - au sens où la construction, jusque-là majoritairement en bois, est remplacée par une construction à structure maçonnée. Ce phénomène difficile à mettre en évidence à Paris même est largement attesté dans de nombreux sites proches de la capitale : en Seine-Saint-Denis, Aubervilliers, Saint-Denis, Gagny, Tremblay-en-France ; dans le Vald'Oise, Villiers-le-Bel, Louvres, Gonesse ${ }^{14} \ldots$... Dans ce nouveau mode constructif, le plâtre joue un rôle important: on le retrouve largement dans les maçonneries, depuis les fondations jusqu'au second œuvre. On note que les cloisonnements sont très souvent en plâtre sur pans de bois, et les couvertures sont également liées au plâtre. D'ailleurs la réglementation des métiers parisiens au xiII ${ }^{\mathrm{e}}$ siècle fait largement référence aux plâtriers, qui appartiennent à la même corporation que les maçons, mortelliers et carriers (les maçons sont plâtriers et vice-versa ${ }^{15}$ ); ils sont également carriers, car ils exploitent souvent eux-mêmes les carrières.

Ce mode constructif entraîne, en même temps que se développe l'architecture gothique et que s'autonomisent les métiers du bâtiment, en particulier en milieu rural, un rapport assez ferme entre matériau et forme du bâti ; ainsi la récurrence de murs présentant un léger fruit, systématiquement enduits, animés de larmiers et couronnés de corniches. Les corniches ont pour fonction de supporter un coyau en bas de rampant pour casser la pente du toit et augmenter la portée du jet d'eau afin d'éviter 
l'écoulement des eaux de pluie le long du nu des murs gouttereaux. Ces corniches sont le prétexte, ainsi que les larmiers, à des formes décoratives qui peuvent faire référence à l'Antiquité dès l'époque médiévale. Ces éléments sont moulurés, et une technique particulière de mise en forme se développe: le tirage (ou traînage) au calibre. On retrouve aussi le plâtre comme matériau préférentiel pour la mise en œuvre de fumisterie, et les conduits de cheminée sont très fréquemment attestés, tant dans l'archéologie que dans l'iconographie (fig. 6).

Fig. 6. - Exemples de témoignages archéologiques et iconographiques de conduits de cheminées.
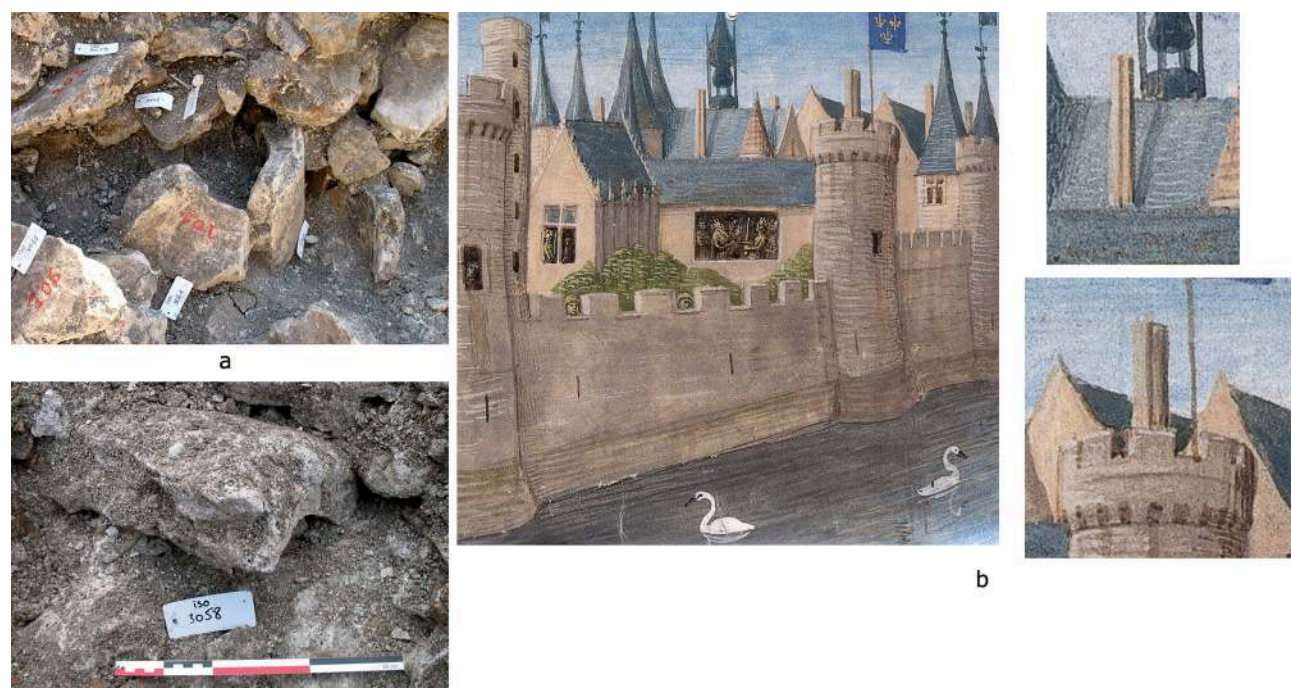

A : château d'Orville (Louvres, Val-d'Oise), fouille de la zone 6 en 2006. Couche de démolition constituée de fragments de cheminée. B : enluminure représentant le palais de la Cité à Paris ; les souches de cheminée figurées sont à double conduit.

Clichés Isabelle Caillot (A). Extrait de Grandes Chroniques de France, vers 1455-1460, BNF, Manuscrits, Fr. 6465, fol. 25, source gallica.bnf.fr / Bibliothèque nationale de France (B).

Les enduits intérieurs comme extérieurs sont également préférentiellement en plâtre. Les enduits, en particulier ceux provenant des intérieurs, sont très souvent porteurs de décors et de graffitis. Le plâtre est de fait un bon support de peinture, et on retrouve fréquemment des fragments d'enduits intérieurs peints. Les enduits extérieurs montrent plus rarement la présence de peintures, mais la part de l'érosion reste souvent difficile à quantifier. À la fin du Moyen Âge, on note qu'au sein des enduits intérieurs peints se développe l'usage des techniques de peinture à l'huile ${ }^{16}$. Les graffitis sont souvent attestés, mais rarement complètement lisibles. Outre des signatures ou inscriptions diverses, on observe souvent des dessins, parfois ayant trait à l'environnement du site; dans ces cas, les graffitis constituent une véritable source iconographique (fig. 7). 
Fig. 7. - Château d'Orville (Louvres, Val-d'Oise) : fragment de piédroit de fenêtre graffité.

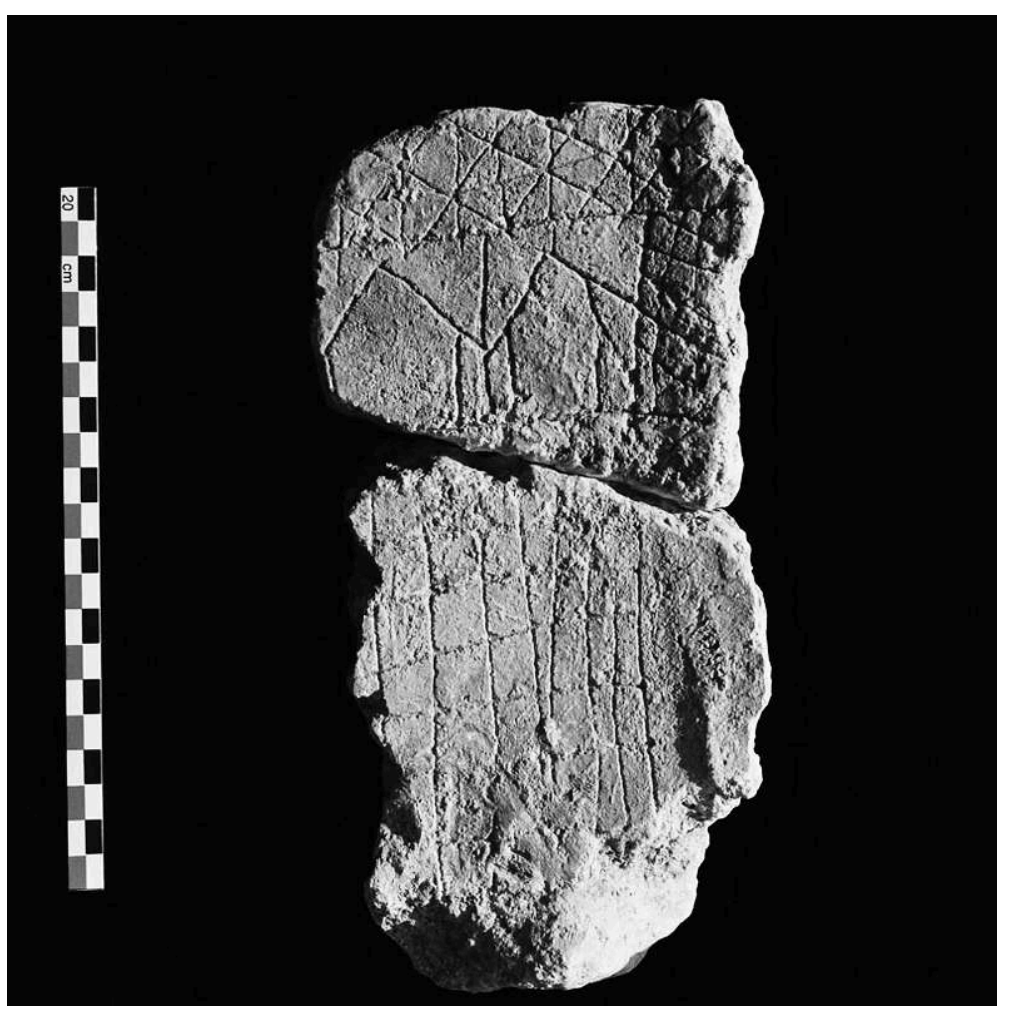

(c) Emmanuelle Jacquot.

16 L'usage du plâtre en enduit intérieur permet aussi la mise en place de décors plastiques, sans nécessairement qu'il s'agisse de stucs. Il s'agit le plus souvent de systèmes de moulures qui ne relèvent pas systématiquement de la modénature; on parle alors souvent de gypseries, qui peuvent dès l'époque médiévale marquer des limites de lambris, des cimaises, etc. Le plâtre est également utilisé pour constituer des planchers intérieurs (aires) ${ }^{17}$, et en maçonnerie pour faire des remplages de baies, des supports ou fixation de tuyauteries (gouttières, descentes de latrines et adductions avec tuyaux en terre cuite...), et même des parpaings pour remplacer certains blocs de pierre (fig. 8). 
Fig. 8. - Fragments de plâtre d'usages divers.

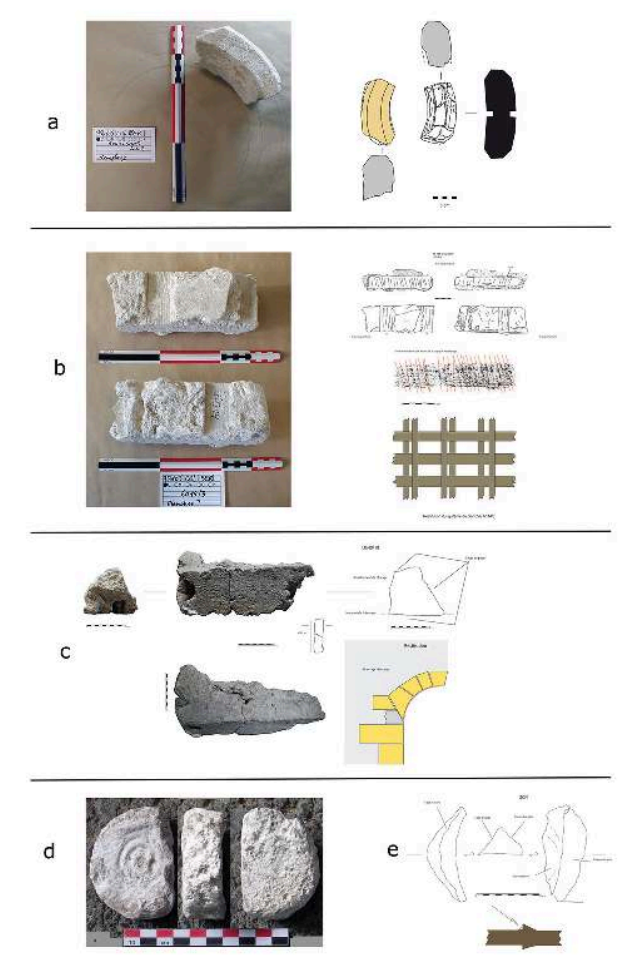

A : fragments de remplage, $\mathrm{xIII}^{\mathrm{e}}-\mathrm{xIV}{ }^{\mathrm{e}}$ siècles (couvent des Bernardins, Paris). B : chape de sol sur solives, xIII-xIV ${ }^{e}$ siècles (couvent des Bernardins, Paris). c : parpaing-sommier, xIII siècle (Saint-Martin-duTertre, Val d'Oise). D : joint de remplage (Carreau du Temple, Paris). E : joint de tuyauterie, $x{ }^{e}{ }^{e}$ siècle (Saint-Martin-du-Tertre).

(c) Ivan Lafarge.

17 Le bas Moyen Âge voit le développement d'usages particuliers du plâtre dans la construction pour alléger la masse de maçonnerie dans certains voûtements ou parties hautes de murs (voûtement du réfectoire des Bernardins à Paris - information orale Marc Viré -, parties hautes des murs gouttereaux à l'église de Montreuil-sous-Bois, en Seine-Saint-Denis). On observe ainsi de nombreux cas de voûtements en plâtre avec des nervures en bois et/ou en plâtre (Montreuil-sous-Bois, église Saint-Médard à Paris, église Saint-Georges à Chelles... du XIV ${ }^{\mathrm{e}}$ au XVI ${ }^{\mathrm{e}}$ siècle $\left.{ }^{18}\right)$.

\section{Le plâtre aux Temps modernes}

Le plâtre teinté dans la masse est peu, voire pas attesté à l'époque médiévale; il se développe apparemment à partir de la Renaissance, mais connaît à l'évidence un essor sans précédent avec le renouveau architectural du $\mathrm{XVII}^{\mathrm{e}}$ siècle. Les façades de la place des Vosges, de la place Dauphine au début du $\mathrm{XVII}^{\mathrm{e}}$ siècle, puis des châteaux de Versailles et Marly, pour ne citer que des exemples prestigieux à la fin du siècle, en sont significatifs (fig. 9). 
Fig. 9. - Pavillon royal de Marly-le-Roi (Yvelines), c. 1680.

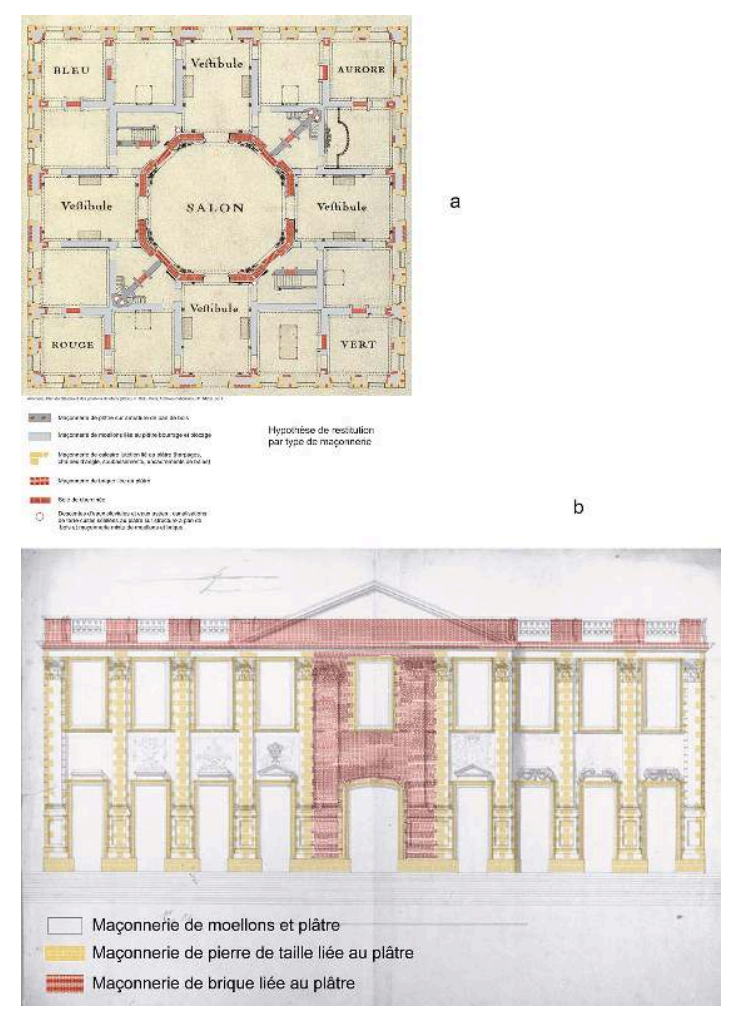

A : plan structurel des maçonneries du pavillon. B : restitution de la structure des façades. École de Charles Le Brun, « Projet pour la décoration à fresque du pavillon royal », Paris, musée du Louvre, département des arts graphiques, inv. 30272Ro (GM8412).

Cliché Ivan Lafarge (D.R.).

La structure de ces constructions fait d'ailleurs la part belle au plâtre, choix technique d'ailleurs largement commenté par les traités de construction de l'époque ${ }^{19}$. Ce mode constructif illustre plus clairement qu'à l'époque médiévale le bénéfice qu'apporte ce matériau. En effet, le plâtre permet une construction moins chère que la construction en pierre de taille, son utilisation comme liant autorise une exécution plus rapide, le temps de prise du plâtre étant sensiblement plus court que celui de la chaux; les chantiers avancent plus vite.

Divers travaux d'archéologie expérimentale sont réalisés de 2005 à 2010 : plusieurs fours à plâtre, tests de mise en œuvre et essais en laboratoire, présentés dans notre travail de thèse ${ }^{20}$, ont également permis d'échanger avec l'homme de l'art (maçon plâtrier en retraite), ce qui nous a permis une approche fine des outils traditionnels des plâtriers. Les informations recueillies par ce biais, vérifiées dans la bibliographie ${ }^{21}$, apparaissent cohérentes avec les observations de terrain. Ces éléments ont permis d'entamer une reconstitution de l'attirail traditionnel des plâtriers. Notre travail est largement complété à cet égard par la recherche de Tiffanie Le Dantec en matière de bibliographie, en particulier par son dépouillement d'ouvrages des XVII et XVIII ${ }^{e}$ siècles ${ }^{22}$, mais cette démarche est encore à approfondir, notamment du fait que le référentiel des traces d'outils est pauvre. 


\section{L'époque contemporaine}

21 L'industrialisation tardive des modes de productions du plâtre, plus marquée par l'évolution des modes de transports et la mécanisation que par l'évolution technique elle-même, a été étudiée lors de nos travaux universitaires ${ }^{23}$, ainsi que le parallèle avec des modes de mise en œuvre marqués par de très fortes permanences techniques. Dans un cas comme dans l'autre, le tournant le plus significatif, malgré des prémices à partir de la seconde moitié du XIX ${ }^{\mathrm{e}}$ siècle, est celui de la Reconstruction, à partir des années 1950, où une influence de l'industrie plâtrière américaine est particulièrement sensible. Ainsi, les premiers brevets pour les plaques de plâtre cartonné sont déposés aux ÉtatsUnis à la fin du XIX ${ }^{e}$ siècle ; en France, il faut attendre 1946 pour en voir l'équivalent, sous la forme de brevets publics dans le cadre de la Reconstruction. Ces dispositions entraînent cependant de nouveaux usages du plâtre, dans un contexte constructif au sein duquel l'usage du béton et du parpaing de ciment devient prédominant, reléguant le plâtre au domaine du second œuvre et de l'aménagement intérieur (plaque cartonnée et carreau de plâtre). Une des conséquences induites par ces évolutions est la perte partielle des savoir-faire directement liés à la maçonnerie de plâtre, parfois assez spécifiques. Cependant, l'approche patrimoniale a permis une relative conservation, et on observe depuis quelques années un nouvel intérêt pour les formes de maçonnerie traditionnelle mettant en œuvre ce matériau.

La prise en compte de l'ensemble du complexe technique de la production plâtrière au fil du temps oblige à considérer les productions et activités économiques engendrées par celles du plâtre: production d'objets mobiliers en plâtre (mortier médiévaux, statuaire non monumentale), production d'objets associés à d'autres productions, tels que les moules, bassins, etc.; mais aussi briqueteries (fig. 10), marché de la pierre à moellonner, usages agricoles (production champignonnière et élevage, amendement des terres, grands consommateurs de plâtre mort). Par leur variété d'identification sociale et chronologique, les exemples présentés ici montrent à quel point les approches sont variées et complémentaires. L'archéologie du bâti et l'étude du matériel, mobilier ou non, issu des fouilles, ne valent pas seulement par elles-mêmes, mais demandent à être menées conjointement et croisées avec les autres sources disponibles. En outre, le corpus de sites et la collection archéologique, continuellement en augmentation, au-delà d'une démarche d'inventaire, à laquelle on n'a pas voulu céder, doivent être référencés pour une meilleure appréciation de la morphologie du bâti, faisant la part de la destination des bâtiments en relation avec l'emploi des matériaux et les évolutions des modes de mise en œuvre. 
Fig. 10. - Périphérie de Montreuil et de Bagnolet (Seine-Saint-Denis) : plâtrières des Beaumonts associées à une briqueterie.

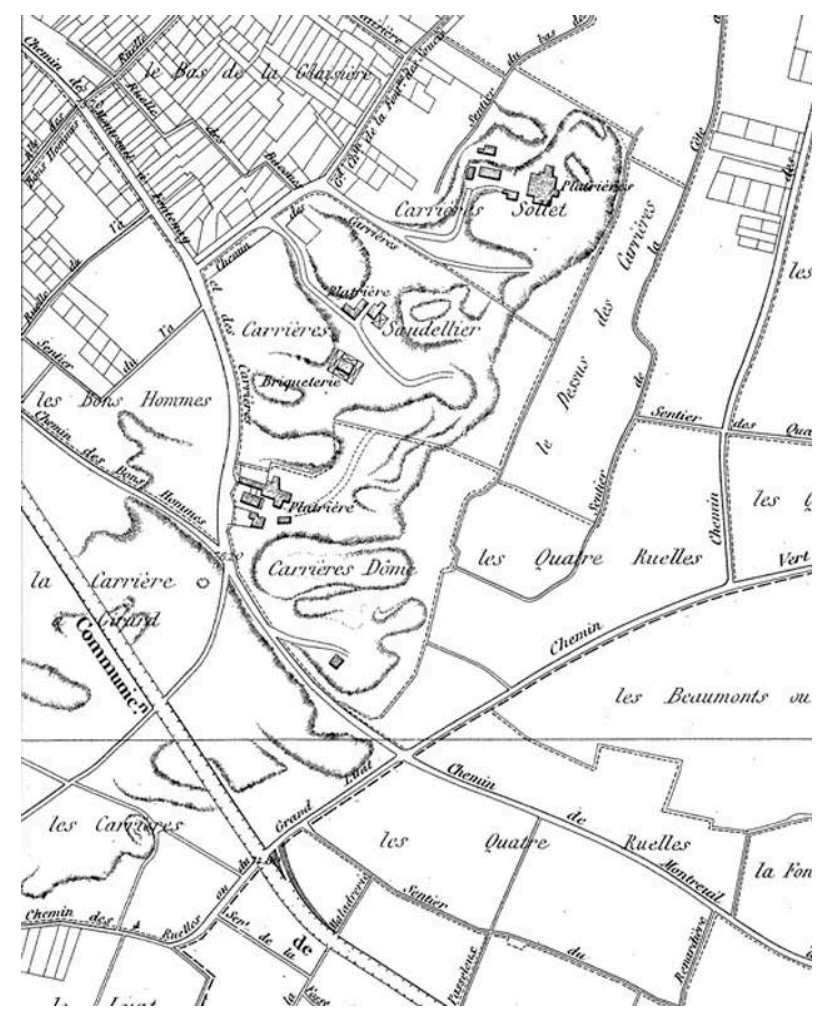

Extrait de l'Atlas des communes du département de la Seine, 1854, feuilles de Montreuil 42a. Cliché Ivan Lafarge (D.R.)

Pour finir, on doit noter que l'étude des vestiges de plâtre en contexte archéologique est souvent compliquée par le statut même des vestiges; en dehors des restes architecturaux en place, il s'agit le plus souvent de vestiges issus de démolition. Cela pose plusieurs problèmes, à commencer par les choix à faire en matière de fouille des démolitions elles-mêmes, la capacité d'interprétation architectonique des fragments, la difficulté d'apporter des datations précises pour des éléments démolis (si on peut relativement facilement dater les démolitions, les fragments se rapportent aux phases constructives, qui peuvent parfois être multiples ou faire l'objet de remplois). Enfin, la question des choix et contraintes de conservation est systématiquement à prendre en compte.

\section{BIBLIOGRAPHIE}

ASSOCIATION FRANÇAISE D'ARCHÉOLOGIE MÉROVINGIENNE, 1981, Les applications funéraires du plâtre au Moyen Âge ( $\mathrm{VI}^{e}-\mathrm{XV} \mathrm{V}^{e}$ s.) : actes des journées d'études de La Courneuve (25-26 octobre 1980), Saint-Germainen-Laye, AFAM (Bulletin de liaison de l'AFAM, 5). 


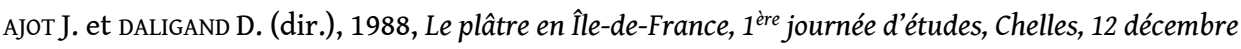
1987, Chelles, ville de Chelles.

BABELON J.-P., 1965, Demeures parisiennes sous Henri IV et Louis XIII, Paris, Éditions du temps. BARDIN F., 1982, Le plâtre : sa production et son utilisation dans l'habitat, Paris, Ministère de la coopération et du développement (Dossier technologies et développement du groupe de recherches et d'échanges technologiques).

BARTHE G.-L. (dir.), 2001, Le plâtre : l'art et la matière. Actes du colloque organisé par le Groupe de recherches sur le plâtre dans l'art (Cergy-Pontoise, octobre 2000), Paris, Créaphis.

BARTHE G.-L. (dir.), 2017, Le plâtre et la couleur, vol. 1 : Le plâtre teinté dans la masse, actes de la journée d'étude du Groupe de recherches sur le plâtre dans l'art (1 ${ }^{\text {er }}$ avril 2016), Cormeilles-en-Parisis, musée du Plâtre.

BARTHE G.-L. (dir.), 2019, Le plâtre et la couleur, vol. 2 : Le plâtre peint, actes de la journée d'étude du Groupe de recherches sur le plâtre dans l'art (23 mars 2018), Cormeilles-en-Parisis, musée du Plâtre.

BENET R., 1977, « Les maçons de Montfermeil et Coubron », Le vieux Montfermeil et sa région, $\mathrm{n}^{\circ}$ 78, $4^{\mathrm{e}}$ trim., p. 4-8.

BENHAMOU G., 1981, Le plâtre, Paris, Baillière.

DA CONCEIÇAO S. (dir.), 2005, Gypseries : gipiers des villes, gipiers des champs. Actes du colloque organisé par l'Association pour la valorisation du gypse et du plâtre dans les Alpes du sud (GYP art et matière) et le Groupe de recherches sur le plâtre dans l'art (Digne-les-Bains, octobre 2003), Paris, Créaphis.

INIZAN C., 2017, Plâtre, sols et couvrements intérieurs du XIII ${ }^{e}$ au XIXe siècle, Paris, Éditions du patrimoine (Albums du CRMH).

LAFARGE I., 2008a, « Du gypse au plâtre aux abords de Paris, observations archéologiques et approche expérimentale », dans Blary F., Gély J.-P., Lorenz J. (dir.), Pierre du patrimoine européen : économie de la pierre de l'Antiquité à la fin des Temps modernes, actes du colloque de Château-Thierry (18-21 octobre 2005), Paris, Éditions du CTHS (Archéologie et histoire de l'art, 28), p. 411-422.

LAFARGE I., 2008b, « Le plâtre dans la construction en Île-de-France : technologie, morphologie, économie, $\mathrm{XII}^{\mathrm{e}}$-XIX ${ }^{\mathrm{e}}$ siècle », mémoire de master en histoire des techniques, Paris, université Paris I - Panthéon-Sorbonne.

LAFARGE I., 2009, « Expérimentations de cuisson du plâtre et réflexion sur les fours à plâtre du haut Moyen Âge », Revue archéologique de Picardie, n 1-2 (« Les apports de l'expérimentation à l'archéologie mérovingienne : l'actualité de l'archéologie du haut Moyen Âge en Picardie. Actes des XXIX journées internationales d'archéologie mérovingienne »), p. 101-114.

LAFARGE I., 2013, « Le plâtre dans la construction en Île-de-France : techniques, morphologie et économie avant l'industrialisation ", thèse d'histoire des techniques, Paris, université Paris I Panthéon-Sorbonne, 2 vol.

LAFARGE I., 2017, « Éléments d'approche typologique pour les tombes construites et les tombes maçonnées en Île-de-France durant la période médiévale ", Revue archéologique d'île-de-France, $\mathrm{n}^{\circ}$ 9, p. 203-232.

LAFARGE I., 2019, « L'église Notre-Dame et Saint-Sulpice : bilan des surveillances archéologiques des restaurations ", Revue archéologique d'île-de-France, $\mathrm{n}^{\circ}$ 10, p. 71-138.

LAFARGE I. et LANGLOIS P., 2016, « Problèmes d'économie des sarcophages de plâtre moulé : diffusion et répartition à partir de la moyenne vallée de la Seine ", dans Peytremann E. (dir.), Des fleuves et 
des hommes à l'époque mérovingienne : territoire fluvial et société au premier Moyen Âge, $V^{e}$-XII siècle. Actes des $33^{e}$ Journées internationales d'archéologie mérovingienne (Strasbourg, 28-30 septembre 2012), Caen, AFAM (Mémoires, 32) / Dijon, Société archéologique de l'Est (Revue archéologique de l'Est, suppl. 42), p. 141-154.

LAFARGE I. et LE DANTEC T., 2017, « L'usage du plâtre dans le château de Marly, de la construction au décor ", Bulletin du Centre de recherche du château de Versailles [en ligne], mis en ligne le 23 décembre 2017, consulté le 13 septembre 2018. http://journals.openedition.org/crcv/14107 ; DOI : $10.4000 / \mathrm{crcv} .14107$.

LAFARGE I., CONFALONIERI J., RICHARD C., COLLOT C., 2006, avec la collab. de Lemaire J. et Mage P., Une expérience de cuisson du gypse sur les parcelles des murs à pêches (Montreuil, 93) les 16 et 17 juin 2005, Épinay-sur-Seine, Conseil général de Seine-Saint-Denis, DCJS, Bureau du patrimoine, Centre d'archéologie, $37 \mathrm{p}$.

LE DANTEC T., 2015, « Les enduits au plâtre à Paris et en Île-de-France », mémoire de mise en situation professionnelle, Paris, École de Chaillot.

LE DANTEC T., 2019, « Les façades enduites au plâtre d'île-de-France : le déclin du plâtre extérieur, du XVII ${ }^{\mathrm{e}}$ au Xxe siècle ", thèse d'histoire de l'architecture, Saint-Aubin, université Paris-Saclay.

LESPINASSE R. de et BONNARDOT F. (éd.), 1879, Les métiers et corporations de la ville de Paris, XIII siècle : le Livre des métiers d'Étienne Boileau, Paris, Impr. nationale (Histoire générale de Paris).

STREITH M., 1989, Plâtriers et plâtre-gros du sud picard, Paris, ministère de la Culture, mission du Patrimoine ethnologique.

VIOLLET-LE-DUC E., 1997, Dictionnaire raisonné de l'architecture française du XI ${ }^{e}$ au XVI siècle, édité de 1854 à 1868 à Paris chez Bance et Morel, réimprimé par la Bibliothèque de l'image.

VIRÉ M., 1979, « Les anciennes carrières de gypse à Paris : aperçu géologique, historique, législatif et technique sur les carrières de gypse à Paris et en proche banlieue », mémoire de DEA d'histoire, Paris, université Paris I - Panthéon-Sorbonne.

WYSS M., 1997, « Le plâtre à Saint-Denis et son utilisation au Moyen Âge au travers de l'archéologie ", dans Benoit P., Lorenz J., Obert D. (dir.), Pierres et carrières : textes réunis en hommage à Claude Lorenz, actes des Journées Claude Lorenz (17-18 novembre 1995), Paris, Association des géologues du Bassin parisien / Association pour l'édition et la diffusion des études historiques, p. 247-251.

\section{NOTES}

1. Voir Viollet-le-Duc 1997 par exemple.

2. Viré 1979, Benhamou 1981, Association française d'archéologie mérovingienne 1981, Ajot et Daligand 1988, Bardin 1982, Streith 1989.

3. Barthe 2001, Da Conceiçao 2005.

4. Lafarge et al. 2006, Lafarge 2008a et 2009.

5. Lafarge $2008 \mathrm{~b}$.

6. Lafarge 2013.

7. Le Dantec 2015 et 2019. 
8. $1^{\text {re }}$ session à Cormeilles-en-Parisis en 2016 (Barthe 2017), $2^{\mathrm{e}}$ session à la médiathèque du Patrimoine en 2018 (Barthe 2019), $3^{\mathrm{e}}$ session en préparation.

9. Colloque «Le gypse d'hier et d'aujourd'hui, valeur d'échange de demain », Serres, septembre 2018 (Parc régional des baronnies provençales, association GYP art et matière) ; « Le plâtre en construction », Rambouillet, 26 février- ${ }^{\text {er }}$ mars 2019 (Rempart, GRIF, LRMH).

10. Lafarge et Langlois 2016.

11. Lafarge 2017.

12. Wyss 1997.

13. Ajot et Daligand 1988.

14. Lafarge 2013.

15. Lespinasse et Bonnardot 1879.

16. Voir par exemple Lafarge 2019.

17. Inizan 2017.

18. Lafarge 2008b, Lafarge 2013.

19. Babelon 1965, Lafarge et Le Dantec 2017.

20. Lafarge 2013.

21. Voir notamment Benet 1977, Benhamou 1981.

22. Le Dantec 2015.

23. Lafarge 2008 b et 2013.

\section{RÉSUMÉS}

Le gypse est une ressource naturelle abondante en Île-de-France ; son exploitation et son usage comme matériau de construction ont commencé dès l'époque romaine et perduré jusqu'à l'industrialisation, avec des évolutions techniques. Du XIII au début du xx siècle, ce matériau est resté le plus abondamment utilisé dans la construction à l'échelle de la région. Il demeure pourtant mal connu et souvent dénigré : c'est l'effet des pertes de savoir-faire survenues depuis le milieu du $\mathrm{xx}^{\mathrm{e}}$ siècle, conséquence de l'industrialisation massive de la construction.

\section{INDEX}

Mots-clés : plâtre, ressources, historiographie, usages funéraires, usages en construction, usages en décoration, industrialisation, savoir-faire 


\section{AUTEUR}

\section{IVAN LAFARGE}

Conseil départemental de la Seine-Saint-Denis, Bureau du patrimoine archéologique ; chercheur associé à l'Institut d'histoire moderne et contemporaine (IHMC, université Paris I - PanthéonSorbonne, UMR 8066 du CNRS) et au laboratoire Archéologie et sciences de l'Antiquité (ARSCAN, université Paris I - Panthéon-Sorbonne et université Paris-Nanterre, UMR 7041 du CNRS), membre du comité d'administration du musée du Plâtre et du Groupe de recherche sur le plâtre dans l'art 


\title{
Transmettre sur le temps long: pour une archéologie de papier du chantier de l'église Saint-Sulpice de Paris (1645-1836)
}

\author{
Léonore Losserand
}

Indocti discant et ament meminisse periti ( Que les ignorants apprennent, que ceux qui savent se souviennent » : épigraphe du manuscrit de Simonnet, Le Nouveau Temple de Salomon...)

Le chantier de la construction de l'église Saint-Sulpice à Paris dépasse de beaucoup les normes par son étalement sur près de cent cinquante ans et sur la multiplicité des changements qui y sont advenus en conséquence (fig. 1). 
Fig. 1. - Gravure publicitaire dédiée à la reprise du chantier de l'église Saint-Sulpice à Paris, s.n., s.d. [vers 1710-1720?].

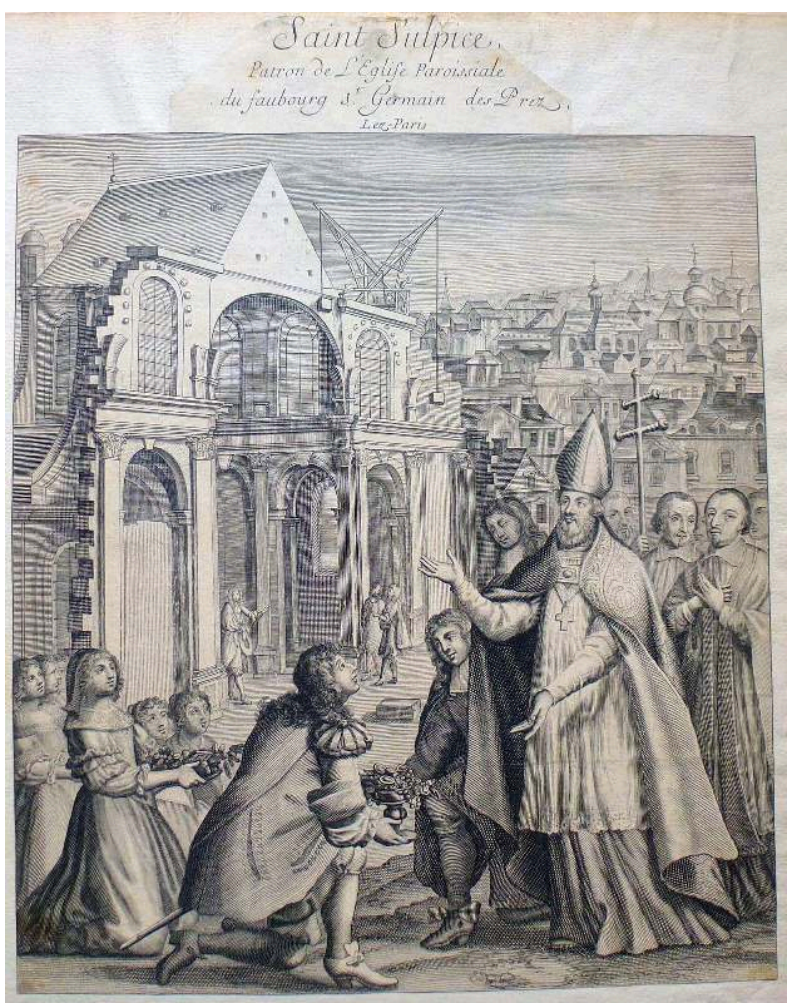

Bibliothèque de la Compagnie des prêtres de Saint-Sulpice, iconographie, grands formats.

Cliché Léonore Losserand (D.R.).

2 Son historiographie n'est pas moins impressionnante pour une église parisienne des $\mathrm{XVII}^{\mathrm{e}}$ et $\mathrm{XVIII}^{\mathrm{e}}$ siècles : vingt-six ouvrages ou articles, si on s'en tient à son histoire architecturale $^{1}$. En réalité, l'intérêt pour l'histoire de cette église est plus ancien que les premières études de la génération d'Arcisse de Caumont et des sociétés savantes de la France du XIX siècle, car il commence au cœur du chantier lui-même. Cette genèse historiographique est l'objet de la présente contribution, en raison de son caractère exceptionnel pour une église paroissiale. Parce qu'elles sont de natures très variées, les sources de cette histoire méritent qu'on sache les distinguer pour s'en servir correctement. En prenant comme fil conducteur la manière de transmettre des informations au cours de ce chantier titanesque, nous voudrions amener à considérer que la littérature historique des églises en général a eu très tôt ce souci d'empêcher l'oubli de prendre le dessus. Le récit de ce chantier est l'inestimable objet de la transmission de la fabrique qui, au fur et à mesure, devient une épopée dont on fait le récit pour les générations futures.

Si les premiers projets remontent à l'année 1636, les travaux pour la construction de la nouvelle église démarrèrent en 1646 et furent repris en 1660 sous la direction de l'architecte Daniel Gittard. En 1678, la fabrique fit faillite et le chantier fut arrêté jusqu'en 1718, date à laquelle le curé Languet de Gergy reprit le flambeau, avec entre autres l'intervention de l'architecte Giovanni Niccolò Servandoni jusqu'en 1766. Les travaux furent achevés de facto lors des épisodes révolutionnaires : la tour sud resta dans son état de 1768, en désaccord avec le profil de la tour nord, œuvre de l'architecte Jean-François-Thérèse Chalgrin, achevée dans les années 1780. 
4 Entre septembre 1659 et décembre 1662 , le chantier représente $40 \%$ des dépenses ${ }^{2}$ et un marguillier comptable est spécialement chargé des comptes du chantier, tandis qu'un autre marguillier s'occupe de la comptabilité ordinaire de la fabrique ; c'est ce dernier qui rassemble l'ensemble lors de la reddition des comptes annuels. Mais les difficultés rencontrées par le comptable du chantier pour gérer des sommes d'argent colossales l'obligent à avancer sur ses deniers personnels. Ceci n'est pas du goût du conseil de fabrique, qui y voit un risque de dérapage, comme en témoigne une délibération de 1645, peu avant la pose de la première pierre :

«Il a esté advisé et délibéré par la Compagnie ${ }^{3}$ que doresnavant, le dernier marguillier qui pourra estre chargé de la despence dudit bastiment, ne pourra de son mouvement faire plus grande despence de sepmaine en sepmaine que des deniers qui luy seront fournis en fin de chacune d'icelle par le marguillier comptable, \& consequemment ne pourra faire avance de ses deniers propres sans ordre exprès et par écrit de ses confrères, autrement sesdictes avances lui demeureront en pure perte \& sans espérance d'aucune répétition ni remboursement et ce affin de prevenir par ce moyen toute confusion et désordre qui pourroient arriver autrement en la dépense dudit bastiment, laquelle despence ne seroit jamais certaine ny connue des autres marguilliers \& ainsi telle conduite ne pourroit estre que ruyneuse \& dommageable à la fabrique ${ }^{4}$. »

5 Or la fréquence des réunions du conseil est aléatoire, bien que le chantier oblige à établir des réunions plus fréquentes; le comptable est donc partiellement livré à luimême au quotidien. En réaffirmant son autorité sur la gestion du chantier, le conseil tente donc d'adapter l'antique fonctionnement de la marguillerie au chantier. Mais l'institution se heurte à un autre problème, celui du renouvellement continuel des marguilliers en charge (qui constituent le bureau exécutif du conseil) en raison de la brièveté des mandats. À Saint-Sulpice, comme dans beaucoup d'autres bureaux de conseils de fabrique, les mandats des marguilliers en charge ne durent que deux ans. Le renouvellement s'opérant par moitié, les deux marguilliers nouvellement élus disposent d'une année pour apprendre le fonctionnement, pour ensuite exercer la charge de comptable, une fois l'autre moitié renouvelée. Or ce qui fonctionne en temps normal n'est plus opérant en temps de chantier, et le conseil décide d'allonger les mandats lors d'une réunion du 8 septembre de la même année 1645 :

«Sur ce qui a esté représenté que les quatre marguilliers ne sont en charge que deux ans, et que les deux derniers n'ont le maniement du revenu de la fabrique que pendant une année, en quoy l'église souffre un notable préjudice. A esté résolu et arresté qu'à l'avenir les marguilliers de cette paroisse demeureront en exercice de leurs charges pendant trois années et que le marguillier comptable en fera la fonction deux ans durant ${ }^{5}$."

6 Mais quelques années plus tard, cette mesure ne suffit plus, car en réalité, c'est la charge de l'ensemble qui est trop lourde pour quatre marguilliers. L'assemblée du 3 janvier 1660, à la veille de poser la nouvelle première pierre, va tenter de proposer une solution plus adaptée. Le problème soulevé est que les réunions du conseil ne laissent pas suffisamment de temps au débat à propos du chantier, en raison du grand nombre de participants aux réunions. Il n'est pas difficile d'imaginer que les problèmes liés au chantier engageaient à de longues discussions s'ajoutant à celles relatives à la gestion ordinaire. Le conseil décida donc la création d'une commission spéciale chargée de débattre des travaux :

«[...] [la reconstruction de l'église] ne se pouvoit faire dans une assemblée de peu de durée \& nombreuse comme celle-ci, \& qu'ainsi ils croyoient à propos, qu'on nommât présentement six ou huit personnes qui comme députés de toute la 
paroisse, verroient avec MM. les curé et marguilliers les plans, élévations, profils \& devis \& les arrestoient après les avoir fait examiner par les meilleurs architectes, que ces mesmes députés pourroient assister MM. les marguilliers, tant à présent en charge qu'à l'advenir, dans la continuation dudict bastiment, ce qui ne seroit pas d'une petite utilité $[. . .]^{6}$. »

7 Les députés aux travaux, au nombre de six, destinés à épauler les marguilliers en charge, se réunirent donc en dehors des réunions du conseil. La création d'une commission ad hoc n'est pas un cas particulier à Saint-Sulpice, puisqu'on retrouve le procédé de la désignation de "députés aux travaux" dans d'autres cas parisiens contemporains, en particulier à Saint-Jacques-du-Haut-Pas en $1629^{7}$. Pour SaintSulpice, ce conseil de chantier pourrait avoir fonctionné jusqu'à la faillite de 1678.

Le rôle de ces paroissiens députés semble avoir été de vérifier les plans, leur conformité aux choix arrêtés par l'assemblée paroissiale, et enfin d'assurer un suivi concret sur le chantier. Pour ce faire, ils se retrouvaient avec les marguilliers, dans les premiers temps du chantier de Saint-Sulpice par exemple, deux fois par mois afin de discuter de l'avancée du chantier et prendre les décisions nécessaires. À nouveau en 1660, les marguilliers en charge décident de déléguer des paroissiens, qui sont " députés », pour suivre le chantier ${ }^{8}$. Or cette simple décision de délégation à des tiers recrutés dans le vivier des anciens marguilliers trouve son origine dans la référence à l'histoire du chantier, qui n'a pas alors trente ans, ce qui est pourtant déjà suffisant pour aller chercher dans les registres l'ancien procédé. La délibération de 1660 évoque ce qui s'est passé en $1636^{9}$ lors du premier démarrage du chantier et en $1643^{10}$ :

«[...] ce qui leur avoit donné lieu de proposer cette nomination [de députés aux travaux] étoit les exemples qu'ils avoient trouvé dans le registre par lesquels on voyoit que toutes les fois que l'on avoit eu quelque bastiment à entreprendre pour l'ornement ou pour l'accroissement de l'église, on avoit député quatre ou six personnes de différentes qualités, pour deux ou trois en l'absence des autres ${ }^{11}$. »

Ainsi, après à peine quinze ans, le souvenir était déjà perdu, et il fallut faire appel aux archives pour trouver un mode de fonctionnement éprouvé. Cette perte de mémoire relative peut s'expliquer par le changement récurrent des marguilliers en charge, déjà évoqué en 1645. Pourtant, le conseil de fabrique étant essentiellement composé des anciens marguilliers en charge, ils étaient les plus à même de conserver la mémoire vivante et conseiller les marguilliers du bureau. Mais si la présence de tous les anciens était requise aux réunions, leur venue était surtout soumise à leur bonne volonté ou à leurs intérêts personnels. Il se peut qu'en quinze ans, épisode de la Fronde aidant, ou simplement déménagement des paroissiens, le conseil ait beaucoup changé de visage. Ce fonctionnement fondé sur un conseil d'aînés décisionnaire et des marguilliers en charge se retrouve dans toutes les paroisses jusqu'à la Révolution.

Le recours des membres du conseil au registre en 1660 vise donc à pallier la perte de la mémoire, qui est un des fondamentaux de la transmission. Or ce recours aux registres, nous le pratiquons nous-mêmes, chercheurs en sciences humaines que nous sommes, pour tenter de retrouver l'histoire oubliée de ces édifices. L'historien travaillant sur les paroisses parisiennes dispose en réalité d'un faible nombre de ces registres de délibérations des fabriques. Saint-Sulpice est parmi les plus sinistrés, n'ayant qu'un seul registre déposé aux Archives nationales et un autre aux archives du diocèse (1784-1793 $)^{12}$. Pourtant, nous avons connaissance d'un nombre très important de délibérations, non par le biais des registres de la fabrique mais par des copies de différentes natures. Ceci nous a amené à considérer ces copies pour elles-mêmes afin de 
saisir leur possible degré d'utilisation mais aussi, en cherchant leur raison d'être, de tenter de comprendre leur finalité.

11 Il y a tout d'abord des transcriptions analytiques de délibérations, que l'on trouve dans un registre unique conservé au département des manuscrits de la Bibliothèque nationale de France ${ }^{13}$. Il s'agit d'une sélection de délibérations entre 1644 et 1682 dont la plupart concernent le chantier, tandis que celles concernant d'autres aspects de la vie paroissiale sont simplement résumées. La dernière délibération date du 28 décembre 1682, soit quatre ans après le début de la faillite de la fabrique, grand scandale public qui mit en sommeil près de quarante ans le chantier de l'église. Ce registre contient également l'«Estat de ce qui est deub aux créanciers [...] suivant l'ordre \& distribution par hipotecque arresté entr'eux le $18^{\mathrm{e}}$ aoust 1682 dont ils poursuivent l'homologation ». Ce miscellanée est donc une copie servant aux marguilliers, archivée dans le trésor de la fabrique. On retrouve un petit nombre de ces miscellanées destinés à un usage interne encore mal déterminé, comme par exemple à la paroisse Saint-Louis-en-l'île ${ }^{14}$. Mais le plus souvent, ce sont des registres de compilation de titres.

12 D'une bien plus grande ampleur, car faisant l'objet d'un programme éditorial, la publication des délibérations de la fabrique de Saint-Sulpice par l'abbé Henri François Symon de Doncourt (1741-1786) ${ }^{15}$ est une œuvre sans précédent et à notre connaissance sans équivalent. Ce prêtre de la paroisse Saint-Sulpice est connu à partir de 1765 par l'édition qu'il fait de cantiques et prières destinés à l'usage des catéchistes de la paroisse dont il aurait eu la charge. En 1773, Nicolas Crapart publie son ouvrage Remarques historiques sur l'église et la paroisse de S. Sulpice, extraites des instructions et prières à l'usage de ladite paroisse. Il s'agit donc d'une histoire de la paroisse, qui se trouvait à l'origine dans un ouvrage religieux. On en trouve un exemple antérieur avec les Offices propres à l'église paroissiale de Saint-Jean en Grève, publiés en 1743. Mais plutôt qu'une histoire de la paroisse, ainsi que le titre de « Remarques historiques » l'indique, l'auteur a placé dans l'ordre chronologique les événements qu'a connus la paroisse. Les faits évoqués sont de natures diverses, allant de l'histoire des prêtres et paroissiens ou des institutions paroissiales à la construction du bâtiment, en passant par l'histoire de Paris en lien avec l'histoire de la paroisse: bénédiction du cimetière, opposition à l'établissement de comédiens, hiver 1709, différents travaux dans l'église, installation du curé Olier, chapelles de confréries, etc. Symon de Doncourt commence par un précis historique sur l'origine de la paroisse et donne, à partir de la page 122, les grands moments par ordre de dates, puis l'histoire de chaque curé et des membres du clergé du séminaire.

13 L'entreprise éditoriale de l'abbé Symon, aboutie en 1773, est en réalité plus complexe que ce simple ouvrage disponible au format in- $12^{\circ}$ dans une douzaine de bibliothèques de France ne le laisse imaginer à première vue. La bibliothèque de la Compagnie des prêtres de Saint-Sulpice, rue du Regard à Paris, conserve en effet deux exemplaires particuliers, peut-être uniques. Le premier se compose de deux volumes avec une reliure noire et le second de trois volumes à la reliure marron clair.

14 L'exemplaire noir en deux volumes est composé pour le premier volume de l'ouvrage ordinaire des Remarques datées de 1773, publié chez Crapart, sans nom d'auteur, in- $18^{\circ}$ de 300 pages avec une table des matières. Son deuxième volume renferme ce qui est en fait la suite des Remarques de 1772, à savoir les Pièces justificatives, sans frontispice, comportant 720 pages et divisé en deux parties. La deuxième partie concerne 
uniquement les délibérations en lien avec le chantier ${ }^{16}$ (fig. 2). L'abbé Symon de Doncourt y retranscrit plusieurs centaines de délibérations de la fabrique et un plus petit nombre d'autres documents, comme des factums, arrêts du Conseil, ou autres documents sources. On remarque au fil de la lecture qu'un certain nombre de délibérations avaient été préalablement imprimées ${ }^{17}$. L'ensemble est rangé dans l'ordre chronologique et chaque acte cité est précédé d'un chapeau ou d'un titre donnant la teneur du document cité. Les citations ne sont pas toujours faites in extenso, mais leur provenance est donnée systématiquement: date et numéro du folio ainsi que l'énonciation des signatures dans le cas des délibérations. Il s'agit donc d'une source de premier ordre puisque les registres de délibérations de la fabrique ont été détruits lors de la Révolution.

Fig. 2. - H. F. Simon de Doncourt, Remarques historiques... vol. 2, p. 106-107.

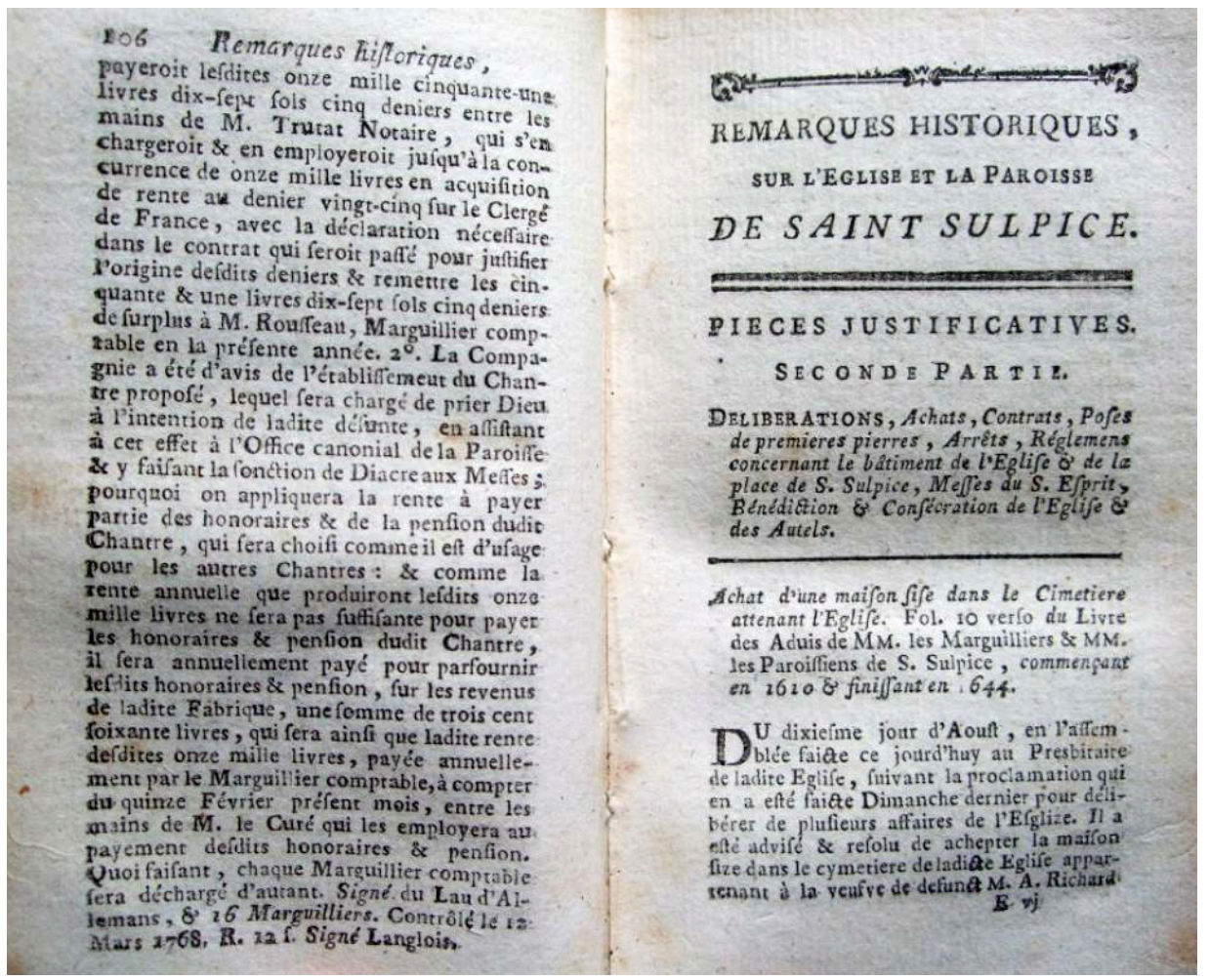

Bibliothèque de la Compagnie des prêtres de Saint-Sulpice.

Cliché Léonore Losserand (D.R.).

Quant à l'exemplaire de reliure marron, il est d'un format in- $12^{\circ}$, soit de quelques centimètres plus grand, ce qui a pour conséquence un changement de pagination par rapport à l'autre exemplaire. Contrairement à l'édition noire, il ne commence pas par les Remarques historiques mais directement par les pièces justificatives, et il est complété d'un troisième volume dont le contenu évoque notamment l'histoire du séminaire. Il convient de préciser que cette édition ne dispose d'aucune table des matières.

On ne comptabilise à ce jour que ces deux exemplaires conservés à la bibliothèque de la Compagnie des prêtres de Saint-Sulpice, ce qui laisse penser que leur diffusion a été relativement confidentielle, probablement en raison du faible intérêt que peuvent représenter ces pièces justificatives pour le public. Nous ne savons rien des motivations de Symon de Doncourt, qui n'a donné aucune indication sur la destination de cet 
ensemble éditorial. Comme l'abbé Symon a été nommé en 1774 « chargé de la direction des travaux » par le curé Dulau d'Allemans, il est permis de penser que c'est ce dernier qui lui demanda de compulser les archives de la fabrique en vue de prendre en charge la direction du chantier. Son travail pourrait avoir été jugé digne d'être publié, à moins que Doncourt ait plutôt eu en vue la célébration de la paroisse, embourbée dans un chantier interminable. Cette entreprise pourrait avoir été une tentative de faire connaître l'église par le livre, à une période critique du chantier. En effet, depuis la mort de Servandoni en 1766, c'est à peine si les tours ont été achevées, et le chantier est encore arrêté. Les projets de Servandoni ne semblent alors plus convaincre, et malgré un appel à projets réalisé par le curé Dulau d'Allemans en 1767 et les avis de l'Académie, le chantier est à l'arrêt ${ }^{18}$. Pourtant, il n'est pas au point mort, puisqu'à partir de 1776, soit trois ans seulement après la parution des Remarques, il reprend. Attirer l'attention sur cette église en remontant à l'appui d'archives les étapes du chantier démarré plus d'un siècle auparavant peut être également vu comme une tentative de restaurer la confiance des paroissiens, voire du roi, pour entamer la phase finale du chantier. S'il n'est fait aucune description de l'église, c'est probablement en raison de l'inachèvement de la façade et de la détérioration de la chapelle de la Vierge, dont le chantier de restauration est en cours dans la décennie 1770. Le monument est encore trop inachevé pour faire l'objet d'une méticuleuse description, à laquelle Doncourt ne sacrifie pas.

Travail éditorial singulier, la publication de l'abbé Symon de Doncourt s'appuie néanmoins sur un précédent inédit: Le nouveau Temple de Salomon ou Description historique de l'église paroissiale de St Sulpice dans ses cinq fondations... ${ }^{19}$. Il a été écrit par un greffier commis des dépôts au Parlement et paroissien inconnu, Jacques Vincent Simonnet, qui dit n'écrire qu'au profit des paroissiens de Saint-Sulpice. Le frontispice de l'ouvrage manuscrit porte la date de 1771 et est aujourd'hui conservé à la même bibliothèque de la Compagnie des prêtres de Saint-Sulpice à Paris. Le lecteur parcourt successivement l'histoire de la paroisse, le bâtiment de son église, qui est décrit pour la première fois, lieu par lieu, mais également l'histoire des hommes et des groupes institutionnels de la paroisse (curés, prêtres, confréries, écoles, etc.) et tout ce qui se trouve sur le territoire de la paroisse (cimetières, le Gros Caillou, rues, etc.). Nous sommes en présence de l'exemplaire avant impression: les 614 pages manuscrites divisées en deux tomes auraient dû être éditées en format in $-12^{\circ}$ et suivi d'un deuxième volume constituant le troisième tome des pièces justificatives, qui semble n'avoir jamais existé. Le parti de Simonnet consiste à mettre en lumière la paroisse en tant que tel, car il commence avec un " Discours préliminaire sur la haute antiquité des paroisse [sic] en général et sur les privilèges qui les distinguent des autres lieux saints », faisant remontrer l'origine de l'institution à « l'établissement de la religion chrétienne », ce qui est ostensiblement partisan. Une tension entre réguliers et paroisses sous-tend en effet de manière continue la vie religieuse urbaine, et ces dernières se cherchent continuellement une légitimité face à ces communautés qui attirent certaines grandes fortunes. Le choix du titre du manuscrit, "Nouveau Temple», est expliqué par son auteur qui veut appeler ainsi les bonnes grâces de Louis XV, "perpétuel bienfaiteur ", considéré comme le nouveau Salomon, le roi bâtisseur du nouveau temple de Jérusalem. Simonnet compare Saint-Sulpice au nouveau Temple, dont Louis XV a permis la construction, comprenez : grâce l'octroi des tirages de loteries. Mais l'auteur ne put jamais faire parvenir ces louanges au souverain, faute d'avoir pu faire éditer l'ouvrage. Car bien que Simonnet fasse une œuvre presque encyclopédique, dans 
laquelle il déclare être le plus exact possible, l'ouvrage n'en recèle pas moins un certain nombre d'erreurs et beaucoup de développements hasardeux. Aussi, l'ouvrage de l'abbé Symon de Doncourt, publié deux ans plus tard dans sa version en trois volumes, est autrement plus précis : son discours construit chronologiquement prend soin d'éviter ainsi les digressions qui ont pu faire que le texte de Simonnet donne l'impression d'un manque de sérieux. Symon de Doncourt connaissait-il l'ouvrage de Simonnet? L'abbé ne cite jamais le travail du paroissien; il n'apparaît pas dans les pièces justificatives, pour la simple et bonne raison qu'il ne s'agit pas d'un document d'archives, à l'époque.

Ces deux travaux de Simonnet et de Doncourt montrent que l'église de Saint-Sulpice peut être regardée pour elle-même, d'un point de vue artistique et pas seulement historique. Néanmoins, une entreprise en certains points semblables a précédé de quelques années l'œuvre sulpicienne. Il s'agit de l'Essai d'une histoire de la paroisse Saint Jacques de la Boucherie, écrit par l'abbé Étienne François Villain et publié en 1758 en format in-12 $2^{\circ}$. L'intérêt de l'ouvrage de Villain, que rejoint celui de Doncourt, est son format, qui le rend abordable financièrement et facile à emporter, à l'instar de guides de Paris comme celui de Germain Brice, dont la première édition in- $12^{\circ}$ remonte à 1685 . Cet « essai », qui n'en est pas moins une véritable histoire d'une très ancienne paroisse parisienne, se vend aussi bien reliée en veau (2 livres) qu'en brochure (pour 2 livres 10 sols). Son auteur destine son travail, d'après son titre, "aux paroissiens et aux amateurs d'Antiquité ", l'objectif est donc de toucher un public n'étant pas forcément scientifique. En cela, nous sommes loin des entreprises éditoriales d'ouvrages d'histoire réalisées par les Mauristes, comme celles de dom Montfaucon ou les luxueux ouvrages autour des Invalides de format in-folio et richement illustrés. L'ouvrage est doté d'une table des matières, et en guise de pièces justificatives l'auteur place en fin d'ouvrage neuf documents comme étant les titres " parmi les plus anciens de la paroisse ». Pour citer ses sources dans le texte lui-même, l'auteur place la référence dans la marge, comme cela se fait ordinairement (procédé que Doncourt n'utilise pas puisque tout se trouve en annexe). L'ouvrage de l'abbé Villain va toutefois plus loin que les travaux sulpiciens précédemment évoqués. Ses sources puisent certes dans les archives de la fabrique, mais la qualité beaucoup plus littéraire de son ouvrage l'amène à citer de nombreux auteurs de référence, comme Sauval ou l'abbé Lebeuf. Comble de précision scientifique offerte au lecteur, Villain propose trois plans chronologiques retraçant les transformations de l'église, une différence fondamentale avec l'ouvrage de Doncourt, qui n'est pas illustré (fig. 3). Avec le travail de Villain sur Saint-Jacques-de-laBoucherie, il est dès lors possible de parler d'une monographie de l'église, avec un appareil critique et des plans chronologiques, destiné à faciliter la compréhension de l'histoire du bâtiment. 
Fig. 3. - «Premier plan de l'église de Saint Jacques de la Boucherie et de ses environs vers le milieu du $13^{\mathrm{me}}$ siècle et dans le $14^{\mathrm{me}}$ ».

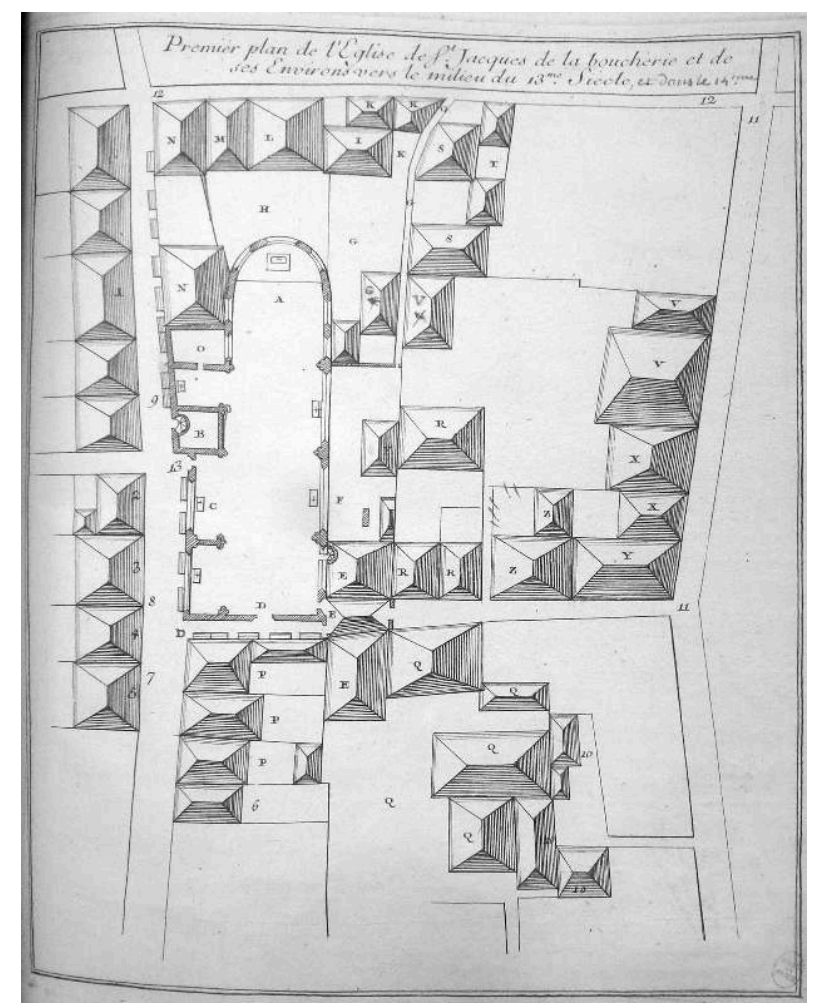

Extrait de [L.-F. Villain], Essai d'une histoire de la paroisse Saint Jacques de la Boucherie..., Bibliothèque historique de la Ville de Paris, planche hors texte $n^{\circ} 1$.

Cliché Léonore Losserand (D.R.).

Ces deux ouvrages de Doncourt et de Villain, par leurs similitudes et leurs divergences, montrent que la monographie d'édifice en est encore à ses débuts et hésite encore entre érudition et pédagogie, probablement parce que son public n'est pas encore clairement défini. Les deux solutions préconisent toutefois la mise en avant du chantier de l'église, c'est-à-dire l'évolution du bâtiment au cours du temps et, tout en voulant attirer l'attention sur leur édifice, ils en transmettent l'histoire. La particularité de la démarche de l'abbé Symon de Doncourt réside dans l'édition d'une compilation, certes non exhaustive, mais où la masse d'annexes ne peut que nous faire nous interroger sur sa finalité. Néanmoins, on doit rendre ici hommage à l'historien qui a su le mieux tirer parti de ce matériau brut des transcriptions littérales, bien que partielles, le sulpicien Émile Malbois, qui acheva en 1913 une histoire demeurée inédite de l'église, elle aussi conservée à la bibliothèque de la Compagnie des prêtres de Saint-Sulpice ${ }^{20}$. Il a synthétisé les informations fournies par l'abbé Symon et Simonnet, ainsi que Leclerc et Nau, dont nous allons désormais parler en guise d'épilogue.

Si donc la finalité du travail éditorial de Doncourt n'est pas encore pleinement élucidée, elle nous semble pouvoir être placée dans une perspective de pratique archivistique des fabriques ${ }^{21}$. La conservation et le classement des archives ont toujours été un souci des fabriques parisiennes, qui devaient conserver leurs titres en cas de succession, litige, ou toute autre nécessité, et plus encore lors du chantier, ainsi que nous l'avons montré pour le cas de Saint-Sulpice dans la première partie de cet exposé. Le travail qui consistait à copier les données jugées importantes dans des registres, voire à les publier, dans le cas exceptionnel de Symon de Doncourt, se retrouve à la veille de la 
Révolution avec l'agent Leclerc. Cet " agent de la fabrique » a été en effet mandaté par les marguilliers pour constituer un «mémorial» de la fabrique, qui nous est heureusement parvenu. Il est conservé sous forme de quatre volumes reliés aux armes de la paroisse ${ }^{22}$ (fig. 4) et divisé en sept parties : histoire de l'église, titres de propriétés, contrats de rente, contrats de fondations, extraits de délibérations, comptes rendus à la fabrique et quittances des dépenses. Les deux dernières parties sont en réalité à peine ébauchées, pour ne pas dire vides : en effet, il ne s'agit pas des registres originaux, mais de copies restituées par Auguste Nau, personnage clé dont nous reparlerons plus loin.

Fig. 4. - Volumes reliés du « Mémorial de l'église Saint-Sulpice de Paris 1610-1793 ».

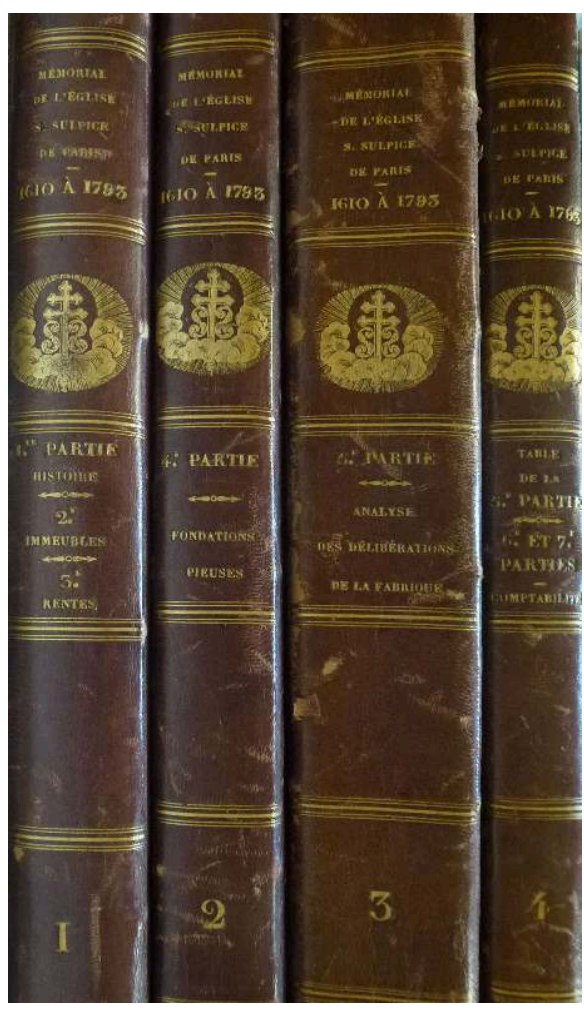

Archives historiques de l'archidiocèse de Paris, Saint-Sulpice, registres 2 à 5.

(c) Léonore Losserand.

21 Malgré les lacunes du travail de Leclerc, les transcriptions des délibérations (deuxième volume) est un complément indispensable aux pièces justificatives de Symon de Doncourt, puisque Leclerc a synthétisé un plus grand nombre de délibérations, sans les citer in extenso ainsi que l'avait fait Doncourt. La finalité du travail de Leclerc est clairement exposée lors de l'assemblée du conseil de fabrique du $1^{\mathrm{er}}$ août 1783 par le notaire et marguillier comptable Jean-Louis $\mathrm{Bro}^{23}$. Après avoir signalé «les abus de toute espèce qui règnent dans l'administration de la paroisse ", il pointe du doigt le même problème qui avait été signalé dès 1645 , à savoir le temps restreint de la durée des mandats des marguilliers comptables (il parle d'expérience), qui ne leur permet pas d'être suffisamment " au fait ». " N'ayant pas sous la main leurs confrères pour profiter des lumières de leur expérience", les comptables n'ont d'autre moyen que de s'instruire auprès du personnel de la fabrique, c'est-à-dire les bedeaux qui, d'après Bro, ont tendance à tirer profit de la situation. Le problème de cette «administration trop passagère » a été réglé dans les paroisses voisines de Saint-Germain l'Auxerrois, Saint- 
Eustache et Saint-Roch, qui ont embauché des agents qui, "veillant sans cesse à l'exécution des délibérations, en préparent de nouvelles et sont toujours à portée d'instruire les marguilliers comptables des principes et usages reconnus dans la fabrique ». La motion est adoptée par le conseil sulpicien, qui désigne ainsi Michel François Le Clerc, un clerc de notaire, devenu plus tard avocat, qui n'est pas un ancien marguillier bénévole mais un agent rémunéré contre un travail pour lequel il a des compétences reconnues. Presque un siècle et demi après, la solution définitive est trouvée au problème du renouvellement constant des marguilliers par le recrutement d'une personne rémunérée. En plus de ce travail quotidien d'assistance au comptable, Leclerc s'attela, sur demande du conseil, à mettre de l'ordre dans les papiers (on ne parle pas encore d'archives) de la fabrique. Il acheva son travail en octobre 1789 et fut chaleureusement remercié et payé.

On peut être étonné par la proximité des entreprises de Symon de Doncourt et de Leclerc, qui pourraient paraître semblables au premier abord. Pourtant, les protagonistes ne travaillent pas pour la même institution. En effet, l'abbé Symon de Doncourt est chargé des travaux pour le curé, tandis que Leclerc est un agent de la fabrique, indépendante, tant s'en faut, des affaires du curé. Cette distinction est fondamentale, car elle permet d'éclairer d'une lumière nouvelle le travail de Doncourt. En retranscrivant les délibérations de la fabrique, auxquelles le conseil de fabrique lui avait permis d'accéder, il accédait au terreau décisionnel de l'histoire du chantier sulpicien avant la faillite de 1678. Après cette date, le chantier s'arrêta et ne reprit qu'en 1718, sous la direction du curé Languet de Gergy. Dès lors, la charge du chantier fut jointe à la charge du curé, alors que celle-ci ne devait théoriquement pas intervenir dans les prérogatives de la fabrique, toutes matérielles. Car s'il est de nombreux curés qui se sont impliqués financièrement dans les chantiers de leur église, et parfois même jusque dans les décisions du conseil de fabrique, la gestion du chantier continuait de rester du domaine de la fabrique. Saint-Sulpice au XviII ${ }^{\mathrm{e}}$ siècle fait partie des exceptions, et ceci pourrait expliquer que les délibérations retranscrites par Doncourt aussi bien que par Leclerc pour cette période ne concernent presque jamais le chantier, puisqu'il n'est alors plus géré par la fabrique, mais par le curé. Le travail de Symon de Doncourt ne concernant pas exclusivement le chantier de l'église, mais également son fonctionnement et son histoire en général, il était logique que les transcriptions des registres continuent pour le XVIII ${ }^{\mathrm{e}}$ siècle. Quant à Leclerc, il travaille exclusivement pour la fabrique et réalise un classement des papiers nécessitant la copie de certains éléments, dont le « Mémorial » est le fruit.

La fabrique fut supprimée en 1793 et dès lors, la survie des archives tient partiellement du miracle: pour la plupart, elles furent saisies par les révolutionnaires et dramatiquement "triées» et versées principalement aux Archives nationales. Pourtant, une petite partie échappa à la catastrophe et resta sur la paroisse : ce sont ces papiers dont hérita la nouvelle fabrique, rétablie grâce au concordat du 8 avril 1802 . À partir de 1836, la fabrique chargea l'avocat Auguste Nau de réaliser un inventaire de ses biens, et Nau entreprit par la même occasion de rassembler le maximum des anciens papiers ayant survécu à la Révolution ${ }^{24}$. Son travail, similaire à celui de Leclerc un demi-siècle plus tôt, fut achevé en 1839. Auguste Nau donna un cadre de classement cohérent à tous ces documents et fit confectionner les cartons de ces archives, estampillées aux armes de la fabrique (fig. 5) ${ }^{25}$. Nau entreprit également de combler les lacunes des destructions révolutionnaires et de dresser un portrait d'une précision 
médicale, à la manière de Maxime du Camp, sur le fonctionnement de la paroisse concordataire. Il écrivit à cette occasion une histoire chronologique de l'église, placée à la fin de son rapport sur les archives, qui reprenait beaucoup du travail de Leclerc (qu'il rassembla et fit relier) et de Simonnet. Il ne semble pas qu'il ait eu connaissance des Pièces justificatives de Symon de Doncourt.

Fig. 5. - Carton d'archives réalisés dans le cadre du classement d'Auguste Nau vers 1836.

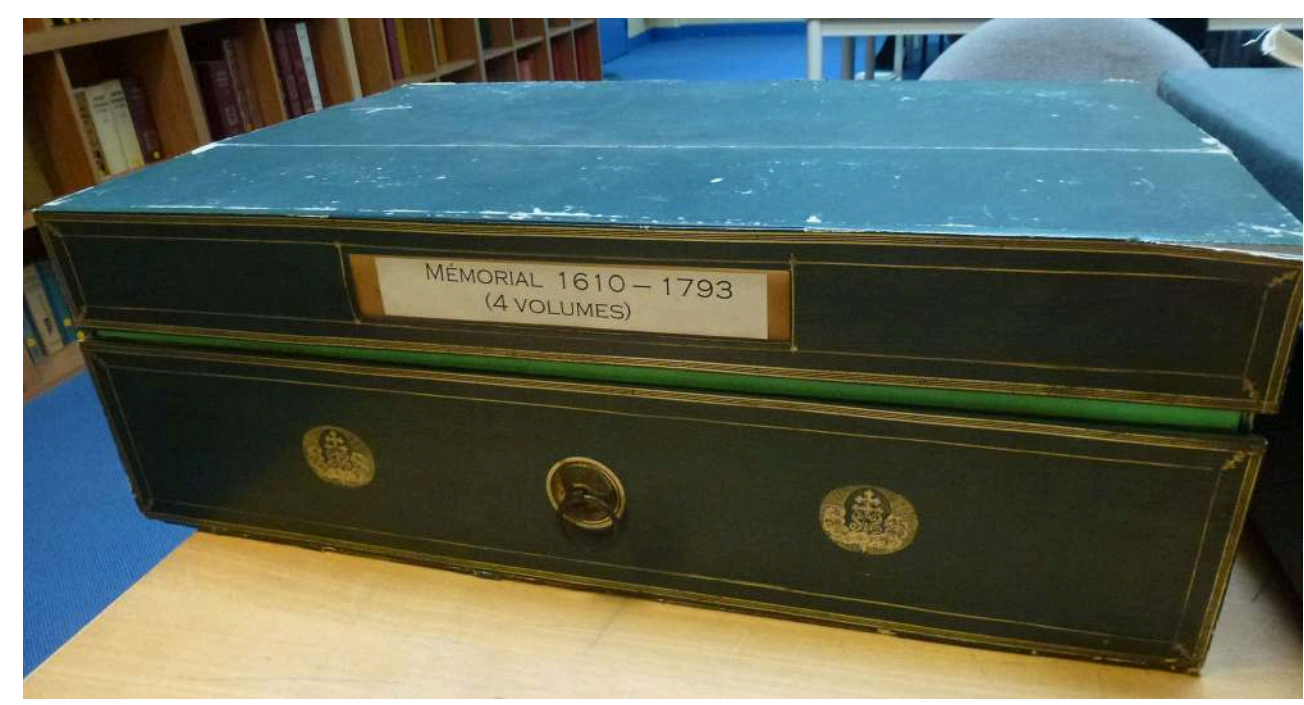

Ces cartons ne sont plus utilisés actuellement du fait de leur fragilité. Archives historiques de l'archidiocèse de Paris, Saint-Sulpice.

(c) Léonore Losserand.

Nau explique au début de son rapport manuscrit la nécessité de son travail destiné à ne pas rompre la chaîne de la transmission :

«Ayant pu apprécier plus que toute autre personne les conséquences fâcheuses de la dispersion des archives de la fabrique, nous avons voulu atténuer pour l'avenir, et à cet effet, dans le but de renouer la chaîne des tems, violemment rompue pendant la grande Révolution, nous avons réuni dans le présent rapport, tous les documents historiques qui se rattachent depuis près de trois siècles jusqu'à ce jour, à la vaste administration confiée aux soins de messieurs les membres de la fabrique; en sorte qu'en supposant une nouvelle dispersion des archives de la paroisse et même leur anéantissement, il suffirait de conserver une des expéditions du présent rapport pour posséder sur chacun des nombreux sujets qui le composent l'ensemble des traditions de la fabrique ${ }^{26}$.»

Trois révolutions, une guerre civile et deux guerres mondiales plus tard, les archives de la fabrique ont atterri aux archives du diocèse de Paris dans la seconde moitié $\mathrm{du} \mathrm{xx}^{\mathrm{e}}$ siècle, subissant quelques petites pertes au passage. Pour faire l'histoire de cette église, l'historien dispose donc d'un solide corpus de sources manuscrites ou imprimées de première main, aux supports variés et géographiquement éclatés. La relative abondance de ces sources et la multiplicité de leurs supports montrent que le souci de préserver la mémoire est un autre inestimable objet de la transmission de l'histoire des pierres. 


\section{BIBLIOGRAPHIE}

BERTRAND Antoine Louis, Bibliothèque sulpicienne, ou histoire littéraire de la Compagnie de Saint-Sulpice, Paris, Picard, vol. 1, 1900.

Bos Agnès, Les archives des fabriques parisiennes à la fin du Moyen Âge et à l'époque moderne, Paris, École des chartes (Bibliothèque de l'École des chartes, 156), 1998, p. 369-405.

LOSSERAND Léonore, "Les chantiers d'églises paroissiales à Paris aux XVII ${ }^{\mathrm{e}}$ et XVII ${ }^{\mathrm{e}}$ siècles ", thèse d'histoire de l'art sous la direction de Claude Mignot, Paris, Sorbonne université, 2017.

LOSSERAND Léonore, "Servandoni en héritage : précisions et rectifications sur le rôle d'Oudot de Mac Laurin dans le chantier de Saint-Sulpice » dans Plouzennec Yvon (dir.), Le métier de l'architecte au XVIII siècle : études croisées, Paris, Groupe histoire architecture mentalités urbaines (Publications en ligne du GHAMU. Annales du Centre Ledoux, nouvelle série, 1), 2020.

LOURS Mathieu (dir.), Paris et ses églises : du Grand Siècle aux lumières, Paris, Picard, 2016.

SIMON DE DONCOURT H. F., Remarques historiques sur l'église et la paroisse de S. Sulpice, tirées du premier volume des instructions et prières à l'usage de ladite paroisse, Paris, N. Crapart, in-18 ${ }^{\circ}, 1773$.

SIMON DE DONCOURT H. F., Remarques historiques sur l'église et la paroisse de S. Sulpice : pièces justificatives, s.l., s.d., 2 vol. et 3 vol. [deux exemplaires uniques à la Bibliothèque de la Compagnie des prêtres de Saint-Sulpice, Paris].

[VILLAIN Louis François], Essai d'une histoire de la paroisse Saint Jacques de la Boucherie où l'on traite des origines de cette église; de ses Antiquités; de Nicolas Flamel \& Pernelle sa femme, \& plusieurs autres choses remarquables; Avec les Plans de la construction \& du territoire de la Paroisse, gravés en Taille-douce. Ouvrage intéressant pour les Paroissiens, \& pour les Personnes qui aiment l'Antiquité. Par M. L*** $V^{* * *}$., in- $12^{\circ}, 1758$.

\section{NOTES}

1. L. Losserand, « Les chantiers d'églises paroissiales à Paris aux XVII ${ }^{\mathrm{e}}$ et XVIII ${ }^{\mathrm{e}}$ siècles ».

2. Arch. historiques de l'archidiocèse de Paris (désormais AHAP), Saint-Sulpice, registre 6 : «Comptes de Jacques Régnier, marguillier comptable ».

3. C'est-à-dire le conseil de fabrique.

4. H. F. Simon de Doncourt, Remarques historiques sur l'église et la paroisse de S. Sulpice. Pièces justificatives, p. 83 : délibération du 30 janvier 1647.

5. BNF, Manuscrits, Fr. 5989, fol. $11 \mathrm{r}^{\circ}$ : délibération du 8 septembre 1645.

6. H.F.Simon de Doncourt, Remarques historiques sur l'église Saint-Sulpice. Pièces justificatives, p. 88 : délibération du 3 janvier 1660.

7. Arch. nat., Minutier central, CIX, 156, fol. $512 \mathrm{v}^{\circ}$ : délibération du 2 juin 1630 . Voir

L. Losserand, Les chantiers d'églises paroissiales à Paris aux XVII et XVIII siècles, vol. 1, p. 140-141.

8. H.F. Simon de Doncourt, Remarques historiques sur l'église Saint-Sulpice. Pièces justificatives, p. 88 : délibération du 3 janvier 1660. 
9. Ibid., p. 67-68 : délibération du 29 mai 1636 : « Il sera dressé un devis et convention au rabais \& moins offrant, \& au meilleur marché que faire se pourra, \& dont la seule direction \& conduitte sera faicte par l'ordre, conseil et prudence de MM. d'Hillerin, de Fleury, Barbier, Sanguin, Pierredan, Germain, de la Nohé \& MM. les marguilliers qui seront en charge, sans qu'il soit besoing dans les rencontres qui naistront \& pourront s'offrir à l'exécution dudict plan, faire nouvelle assemblée des bourgeois et habitans de ceste parroisse ».

10. Ibid., p. 69-71 : délibération du 10 mars 1643.

11. Ibid., p. 88 : délibération du 3 janvier 1660.

12. Arch. nat., LL 950 et AHAP, Saint-Sulpice, registre 1.

13. BNF, Manuscrits, Fr. 5989.

14. Arch. nat., LL 824.

15. Aussi orthographié Simon de Doncourt, notamment dans les publications; sa signature autographe indiquant Symon, c'est cette orthographe que nous avons choisie dans le texte. À son sujet voir A. L. Bertrand, Bibliothèque sulpicienne..., vol. 1, p. 8-10.

16. «Délibérations, achats, contrats, poses de premières pierres, arrêts, réglemens concernant le bâtiment de l'église et de la place S. Sulpice, messes du S. Esprit, bénédiction \& consécration de l'église \& des autels ».

17. "Délibération faite en l'assemblée tenuë en la salle presbitéralle de l'église Paroishiale de Sainct Sulpice à S. Germain Desprez, le 14 septembre 1659. Pour la continuation du bastiment de ladite Paroisse. Copiée sur l'original imprimé » : F. H. Symon de Doncourt, Remarques historiques... Pièces justificatives, vol. 1, p. 86.

18. Voir L. Losserand, "Servandoni en héritage... ».

19. ... et de tout ce qui est relatif à cette église précédé d'un traité abrégé sur la haute antiquité des paroisses en général et sur leurs privilèges distinctifs, dédiée à madame Simonnet par M. Simonnet, greffier..., Bibliothèque de la Compagnie des prêtres de Saint-Sulpice (désormais BCPSS), Ms 98.

20. BCPSS, église Saint-Sulpice, sans cote. Titre exact du manuscrit-tapuscrit: « Histoire et description de l'église de Saint-Sulpice à Paris ».

21. A. Bos, «Les archives des fabriques parisiennes à la fin du Moyen Âge et à l'époque moderne ».

22. AHAP, Saint-Sulpice, registres 2 à 5 : [Leclerc], « Mémorial de l'église Saint-Sulpice de Paris 1610-1793 ", [fin XvIII ${ }^{e}$ siècle], 4 vol. grand in-4 $4^{\circ}$, demi-reliure cuir marron.

23. AHAP, Saint-Sulpice, registre 4, p. 352 et suivantes.

24. AHAP, Saint-Sulpice, Régime concordataire, registres 122 et 123.

25. Ce cadre de classement a été repris par S. de Dainville-Barbiche pour le nouveau classement de ces archives, achevé en 2017 aux AHAP. Voir son introduction de l'inventaire des archives de Saint-Sulpice.

26. AHAP, Saint-Sulpice, registre 122 [Inventaire Nau, 1839], p. 6. 


\section{RÉSUMÉS}

Chantier paroissial exceptionnel par sa taille et son étalement dans le temps, l'église SaintSulpice de Paris a connu plus d'un siècle et demi de travaux. Comment l'institution de la fabrique a-t-elle supporté la gestion de l'intendance de ce chantier extraordinaire en même temps que la vie ordinaire d'une paroisse en pleine croissance démographique et transformation sociale? Cette contribution se propose d'étudier les moyens spécifiques mis en place face à la complexité toujours croissante de la gestion du chantier et même au-delà. Les références au passé sont nombreuses, et les marguilliers tentent d'en garder trace pour la postérité : à la fin du XVIII siècle, les écrits se multiplient pour célébrer ce chantier colossal, ce qui fait écho à une démarche globale d'historiographie des églises parisiennes.

INDEX

Mots-clés : architecture, archives, paroisse, registre, chantier

Index géographique : Paris

\section{AUTEUR}

\section{LÉONORE LOSSERAND}

Chercheur associée à l'École pratique des hautes études, laboratoire Histoire de l'art, des représentations et de l'administration dans l'Europe moderne et contemporaine (HISTARA, EA 7347) 


\title{
La transmission des savoirs chez les compagnons tailleurs de pierre en France aux XVIII et $\mathrm{XIX}^{\mathrm{e}}$ siècles
}

\author{
Jean-Michel Mathonière
}

1 Parler de compagnonnage évoque immédiatement la notion de transmission des savoirs. C'est au demeurant sous l'intitulé descriptif et explicite de: «Le compagnonnage, réseau de transmission des savoirs et des identités par le métier " qu'en 2010 l'Unesco l'a inscrit sur la liste représentative du patrimoine culturel immatériel de l'humanité.

2 Mais il est difficile de définir précisément ce en quoi consiste, au travers des âges, le compagnonnage ${ }^{1}$. À l'image ambiguë de la transmission de maître à disciple de procédés et de tours de main plus ou moins secrets se superpose l'aura mystérieuse de rites initiatiques plongeant leurs racines dans la nuit des temps. Au-delà des clichés romantiques complaisamment colportés et de la confusion fréquente avec la francmaçonnerie ${ }^{2}$, qu'en était-il vraiment, dans un passé pas si lointain, un passé d'avant les grilles de lecture anthropologiques qui, employées sans recul quant à la validité historique des sources, peuvent quelquefois nous entraîner à ériger des totems anachroniques? Peut-on vraiment réduire le mouvement compagnonnique à une transmission de savoirs professionnels? La transmission de rites et de croyances ne serait-elle pas bien plus déterminante de son identité ${ }^{3}$ ?

3 Étudiant depuis plus de vingt ans le cas des compagnons tailleurs de pierre à partir de sources fiables, je vous propose d'en découvrir quelques aspects afin de disposer d'un matériau ne présumant pas de la réponse avant même d'avoir posé les questions.

4 Ce qu'il convient de retenir des avancées récentes sur l'histoire des compagnonnages (j'insiste sur ce pluriel), c'est qu'en réalité, nombre d'usages que l'on croyait très anciens et communs à tous les métiers, par exemple la pratique du chef-d'œuvre de réception ou encore le tour de France, ne le sont pas nécessairement. On devrait éviter de parler du compagnonnage au singulier ${ }^{4}$. 
5 Ainsi, avant le milieu du $\mathrm{xx}^{\mathrm{e}}$ siècle, les tailleurs de pierre ne pratiquaient pas l'épreuve du chef-d'œuvre sous forme de modèle réduit d'un élément d'architecture afin d'être reçus compagnons. Et avant le début du XIX ${ }^{e}$, le tour de France n'était pas chez eux une sorte de périple «initiatique» où, au gré d'un certain nombre d'étapes, ils franchissaient des épreuves afin d'être in fine investis du titre de compagnon. En réalité, ce voyage, qui n'était pas un tour systématique de toute la France, durait alors le temps qu'ils jugeaient nécessaire ou qu'ils pouvaient y consacrer avant de revenir dans leurs foyers pour s'y marier et prendre la succession de l'entreprise familiale. La durée moyenne était généralement de quatre ans, et c'était un tour des grandes métropoles économiques régionales où leur société compagnonnique possédait des sièges, c'est-à-dire que le compagnonnage était avant tout un réseau de solidarité fraternelle auquel on adhérait avant même de partir sur les routes, ainsi qu'en attestent clairement les règlements du XVIII ${ }^{e}$ siècle. C'est seulement à partir du début du $\mathrm{XIX}^{\mathrm{e}}$ que, par un phénomène d'uniformisation des pratiques compagnonniques, s'est instauré chez les tailleurs de pierre un véritable statut préliminaire d'aspirant, d'une durée de plus en plus longue, l'accès au titre de compagnon intervenant au terme de la réalisation d'une partie significative du tour de France.

Oublions un instant ce que l'on croit déjà savoir sur le sujet et portons un regard neuf sur les faits et les documents eux-mêmes.

7 La transmission des savoirs chez les compagnons tailleurs de pierre des XVIII et $\mathrm{XIX}^{\mathrm{e}}$ siècles : pourquoi cette limitation chronologique? Pour la période antérieure, nous ne possédons pas suffisamment de ressources documentaires: on peut penser que les compagnons sont les héritiers directs des "bâtisseurs de cathédrales ", mais pour ce qui concerne leur mode particulier d'organisation, nous n'en avons pas la preuve absolue. Pour la période retenue, nous avons la chance de disposer de ressources documentaires suffisantes. Par ailleurs, je n'ai pas souhaité englober la période contemporaine, car les pratiques ont trop évolué pour qu'il soit possible, en si peu d'espace, d'expliquer pourquoi et comment. On soulignera également que les discours sur la transmission, très «tendance " à l'heure actuelle, contribuent à en modifier la nature réelle.

\section{Quel savoirs?}

8 La première question est bien évidemment : quels savoirs étaient-ils transmis ?

9 Parmi les découvertes ayant le plus contribué à améliorer nos connaissances figurent les archives des compagnons passants tailleurs de pierre d'Avignon, archives qui couvrent de manière à peu près continue la période allant du début du XVIII ${ }^{e}$ siècle à $1870^{5}$. Le document le plus remarquable est un rôle en date du $1^{\mathrm{er}}$ janvier 1782. Le rôle est tout à la fois un document administratif et un document sacré ${ }^{6}: c^{\prime}$ est pendant son dévoilement aux candidats que ceux-ci sont littéralement "sacrés » compagnons. Le frontispice de celui de $1782^{7}$ est d'une ampleur inégalée (fig. 1): il nous présente notamment les savoirs cultivés dans cette société compagnonnique, ou du moins, ceux qui y sont à l'honneur. C'est à partir de ce rôle que nous explorerons ce sujet. 
Fig. 1. - Frontispice du rôle des compagnons passants tailleurs de pierre d'Avignon en date du $1^{\mathrm{er}}$ janvier 1782.

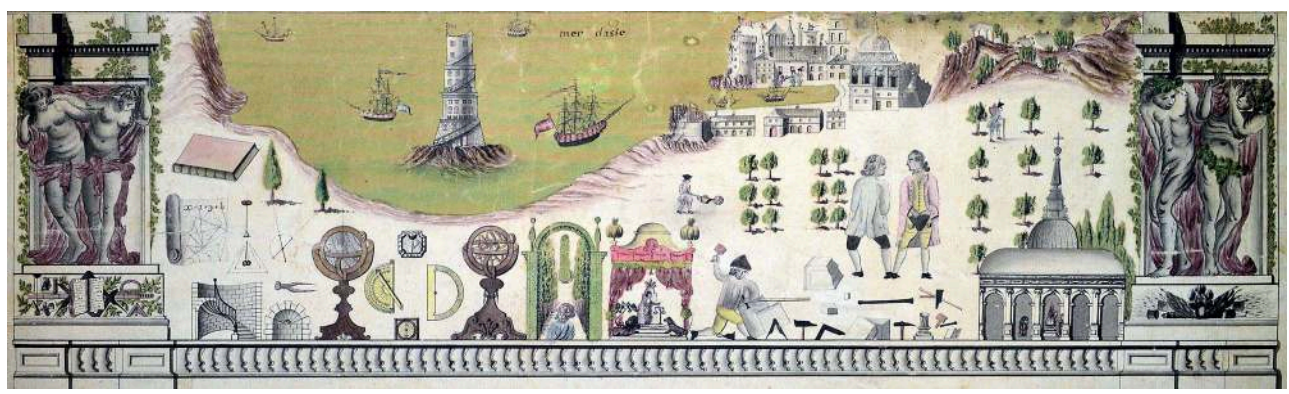

Arch. dép. Vaucluse, 1J 647/4.

Cliché Jean-Michel Mathonière (D.R.).

\section{Le métier de tailleur de pierre}

\section{La taille de pierre}

Pour entrer dans les rangs de la confrérie, il convenait d'être déjà formé, ainsi que le stipule en 1778 l'article premier du règlement des compagnons passants tailleurs de pierre de Bordeaux :

«Tout tailleur de pierre qui se présentera pour être reçu compagnon passant sera tenu de faire preuve [...] de capacité suffisante dans le métier par une ou plusieurs pièces de traits et par le témoignage de compagnons qui cautionneront que l'aspirant est capable de travailler du marteau ${ }^{8}$. "

11 Travailler du marteau, c'est savoir tailler la pierre grâce au marteau-taillant, l'outil principal en dehors du maillet et du ciseau (fig. 2). Très concrètement, cela veut dire être capable de gagner sa vie en exerçant le métier. Car l'apprentissage n'appartient pas à l'association compagnonnique: la formation initiale incombe aux familles qui placent les enfants en apprentissage ou l'effectuent elles-mêmes, de pères à fils ou d'oncles à neveux. Hier comme aujourd'hui encore, même si cela est moins perceptible, la voie du compagnonnage à proprement parler est celle du perfectionnement professionnel et non celle de l'apprentissage.

Fig. 2. - Détail du frontispice du rôle des compagnons passants tailleurs de pierre d'Avignon en date du $1^{\text {er }}$ janvier 1782.

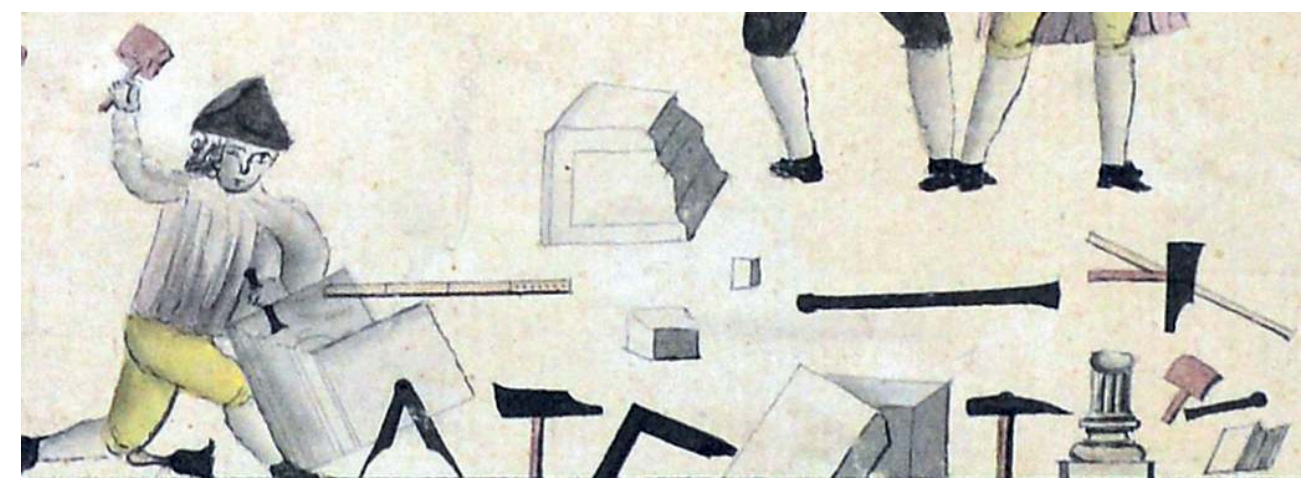

Arch. dép. Vaucluse, 1J 647/4.

Cliché Jean-Michel Mathonière (D.R.). 
12 Faire preuve de capacité suffisante «par une ou plusieurs pièces de traits » signifie que l'aspirant doit aussi démonter ses capacités conceptuelles, via le dessin pour la coupe des pierres, c'est-à-dire la géométrie appliquée à la taille des volumes.

\section{La stéréotomie}

Car le «trait » ou stéréotomie est en réalité le savoir par excellence que cultivent les compagnons tailleurs de pierre. On le voit sobrement évoqué par un escalier et une niche sur le frontispice du rôle de 1782 (fig. 3).

Fig. 3. - Détail du frontispice du rôle des compagnons passants tailleurs de pierre d'Avignon en date du $1^{\mathrm{er}}$ janvier 1782 .

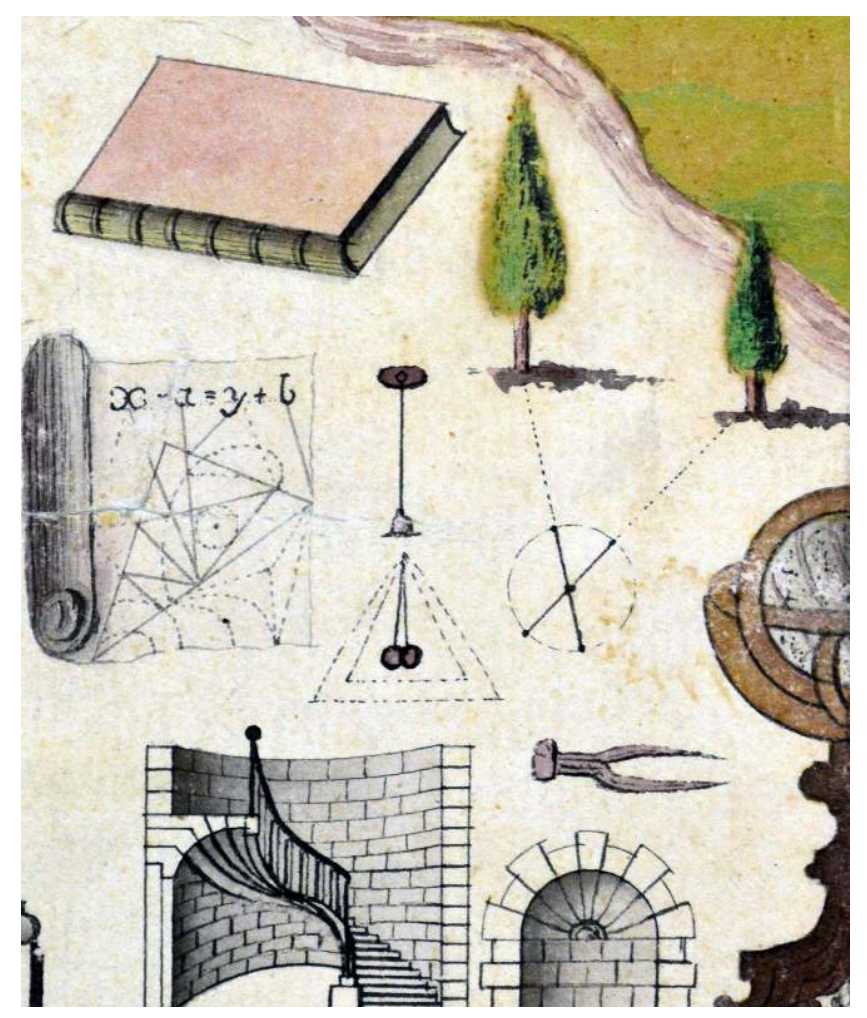

Arch. dép. Vaucluse, 1J 647/4.

Cliché Jean-Michel Mathonière (D.R.).

14 Pour rappel, c'est la maîtrise de cette science qui permettait aux architectes d'antan d'élaborer tous les types de voûtes nécessaires dans les bâtiments (fig. 4). 
Fig. 4. - Exemple d'ouvrage de stéréotomie : planche du Cours d'architecture qui comprend les ordres de Vignole par Augustin-Charles d'Aviler, Paris, 1691.

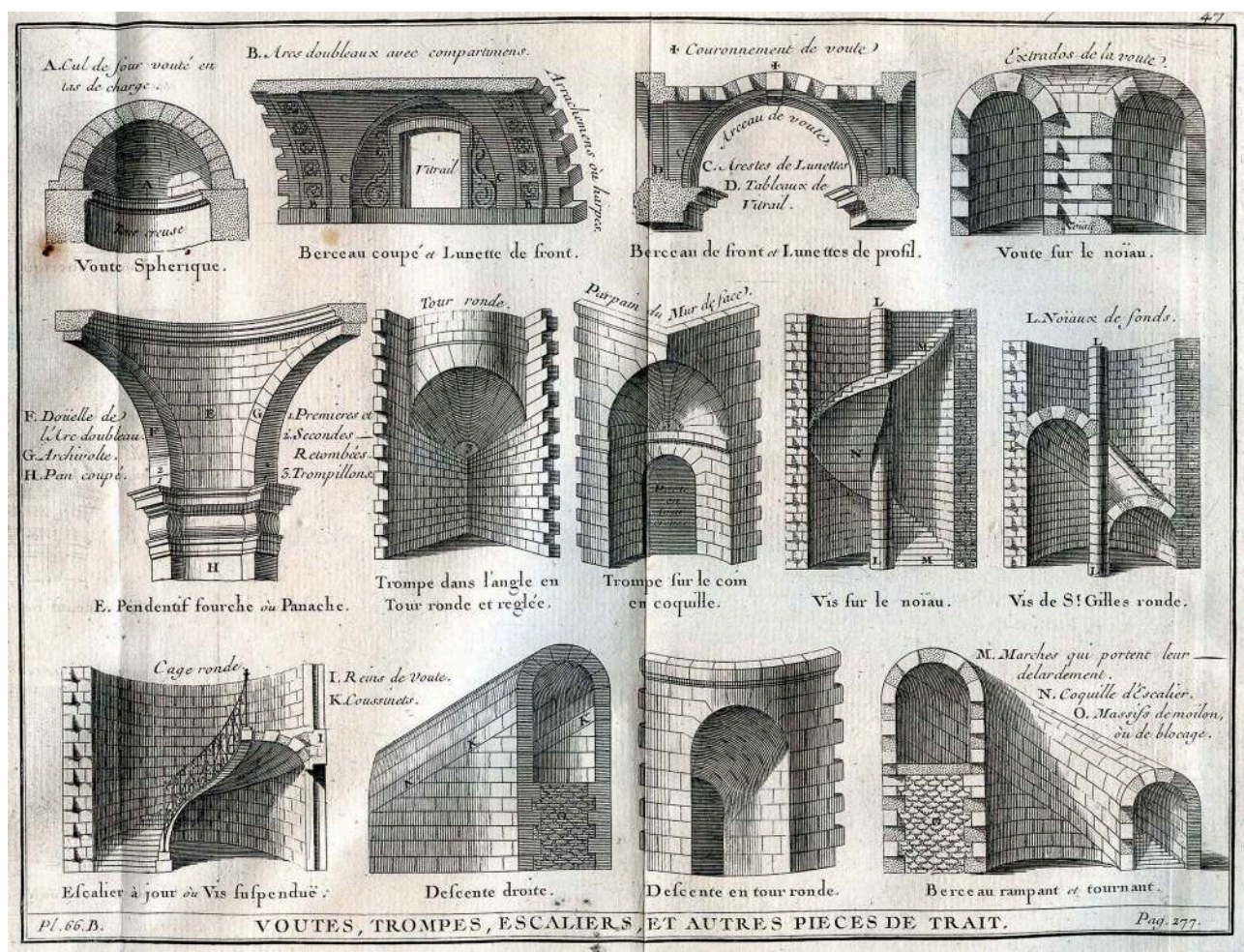

Cliché Jean-Michel Mathonière (D.R.)

La connaissance de base est non seulement le dessin, mais aussi et avant tout la géométrie, ainsi que l'indique un autre détail du frontispice où l'on voit un livre (traité de mathématiques) et un dessin figurant un problème de géométrie théorique (fig. 3).

Dans le rite rival des compagnons passants, celui des compagnons tailleurs de pierre étrangers, mêmes exigences bien sûr quant aux futurs membres :

«Il faudra être reconnu bon ouvrier, laborieux, intelligent, de bonne vie et mœurs, justifier d'une bonne conduite de son passé, posséder les premières notions de géométrie, dessin ou coupe de pierre et en avoir au moins six mois d'études $[. . .]^{9}$ »

\section{Lire et écrire}

La plupart des compagnons tailleurs de pierre d'antan savaient généralement lire et écrire. Et ils n'étaient pas seulement des utilisateurs des ouvrages techniques qu'ils se transmettaient de génération en génération, ils étaient aussi des producteurs de livres.

Je n'évoquerai à ce titre que le remarquable exemple de Jean-Paul Douliot, dit la Pensée d'Avignon, né à Avignon en 1788 et décédé dans la même ville en 1834, au terme d'une trop brève carrière qui l'aura conduit, d'abord comme compagnon passant, des travaux du pont d'Iéna, puis, comme architecte et professeur, à l'enseignement de la coupe des pierres et de l'architecture à l'École royale gratuite de dessin de Paris. De 1825 à sa mort, la Pensée d'Avignon publiera plusieurs volumes d'un cours élémentaire, pratique et théorique de construction, comprenant un traité de coupe des pierres, un traité de charpente, un traité de géométrie et un ouvrage sur la stabilité des édifices ${ }^{10}$. 
19 Mais les allusions aux savoirs cultivés par les tailleurs de pierre ne s'arrêtent pas à la géométrie et à la stéréotomie. Loin de là...

\section{Les autres savoirs professionnels}

\section{L'architecture}

20 Les atlantes qui encadrent la scène du frontispice du rôle des compagnons passants tailleurs de pierre d'Avignon de 1782 (fig. 1) nous rappellent que, finalement, ce n'est pas de taille de pierre qu'il s'agit, mais bien d'architecture dans son ensemble. Ils proviennent directement du Cours d'architecture de Jacques-François Blondel, publié de 1771 à 1777. Le dessinateur du rôle, Joseph Ponge, dit la Douceur d'Avignon, l'avait manifestement sous les yeux, tant la ressemblance est grande. C'est lui qui, quelques années plus tard, construira le grand théâtre de Marseille, un projet validé par MichelJean Sedaine, architecte, secrétaire de l'Académie d'architecture de Paris, auteur dramatique reçu à l'Académie française en 1786 et... reçu compagnon passant tailleur de pierre vers 1740 sous le nom de la Pensée de Paris.

21 Cet intérêt pour l'architecture en général se manifeste chez les compagnons d'antan par la possession fréquente d'un exemplaire de la célèbre « règle » de Vignole sur les cinq ordres d'architecture, l'auteur ayant d'ailleurs inspiré une partie des traits de maître Jacques, l'un de leurs fondateurs légendaires ${ }^{11}$.

\section{La gnomonique}

22 On remarque sans peine la présence d'une sphère armillaire et d'un globe céleste (fig. 5). Ils font surtout allusion à la gnomonique. Cette dernière faisait partie des savoirs que cultivaient les tailleurs de pierre, puisqu'ils réalisaient les cadrans solaires dont l'aristocratie de l'époque était friande. Si c'est souvent aux ecclésiastiques qu'incombaient le calcul et le tracé des cadrans, les compagnons ne demeuraient pas en reste, ainsi qu'en atteste un petit ouvrage de 22 pages publié en 1768, L'Horologiographe universel [...] pour l'usage \& la facilité des Compagnons tailleurs de pierre \& Maçons, qui sont sur le tour de France. On ne saurait être plus explicite! 
Fig. 5. - Détail du frontispice du rôle des compagnons passants tailleurs de pierre d'Avignon en date du $1^{\text {er janvier } 1782 .}$

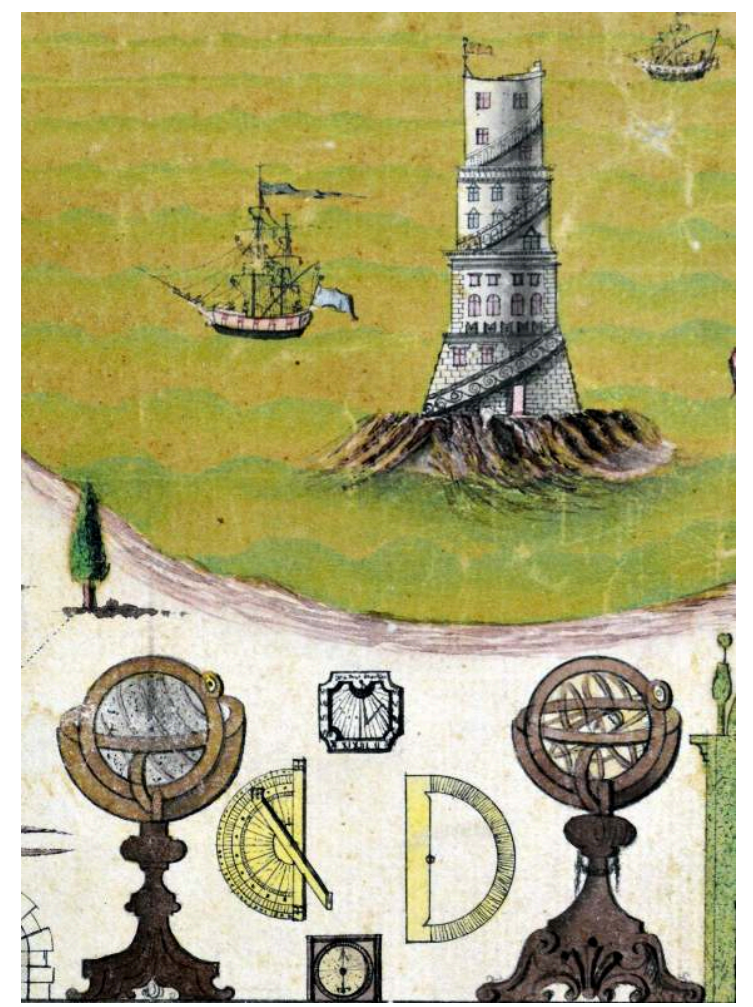

Arch. dép. Vaucluse, 1J 647/4.

Cliché Jean-Michel Mathonière (D.R.).

23 Même s'il concerne aussi l'arpentage, c'est principalement à la gnomonique que fait allusion le phare présent au milieu du frontispice : il est visiblement emprunté au frontispice du plus célèbre traité de l'époque, qui connut de nombreuses éditions entre 1641 et le début du XVIII ${ }^{\mathrm{e}}$ siècle, celui du Traitté d'horlogiographie de Dom Pierre de Sainte-Marie Magdeleine (fig. 6). 
Fig. 6. - Frontispice et page de titre du Traitté d'horlogiographie de Pierre de Sainte MarieMadeleine, 1691.

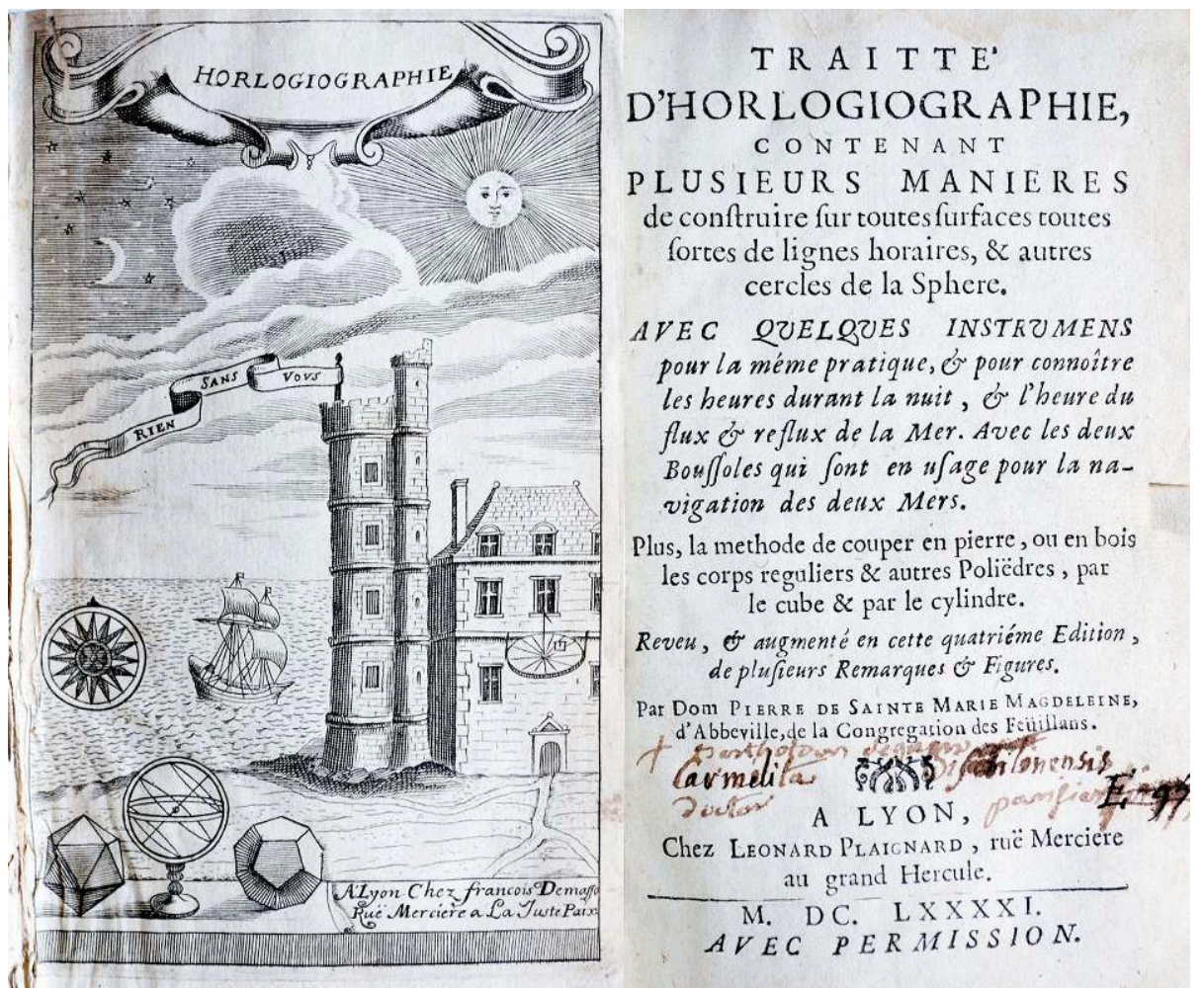

Cliché Jean-Michel Mathonière (D.R.).

\section{L'arpentage}

Entre les globes du frontispice du rôle des compagnons passants tailleurs de pierre d'Avignon (fig. 5) sont rangés plusieurs objets : un cadran solaire, au demeurant du même modèle graphique que ceux de l'opuscule de 1768, puis une boussole, un rapporteur et un graphomètre à pinnules, qui sont des instruments d'arpenteur. Outre ces derniers instruments et le phare, qui illustre nettement un lieu commun qu'est le problème de la mesure de la hauteur des points inaccessibles, l'arpentage est encore évoqué par divers détails. On remarque ainsi, au-dessus de l'évocation de la stéréotomie, le dessin d'une méthode basique d'arpentage employant deux règles et la mesure de l'angle qu'elles forment. Sur la partie droite du frontispice, deux petits personnages évoluent dans un verger. L'un pousse une sorte de brouette: c'est un odomètre, instrument permettant de mesurer les distances; l'autre porte une hotte sur le dos et s'appuie sur une canne : c'est un arpenteur qui plante régulièrement ses jalons afin de fixer les points de mesure.

Plusieurs documents permettent de constater la présence de compagnons tailleurs de pierre parmi les arpenteurs aux XVIII ${ }^{e}$ et $\mathrm{XIX}^{\mathrm{e}}$ siècles. Leur connaissance de la géométrie et de ses applications leur permettait d'exercer sans difficulté ce métier, soit à part entière, soit, au moins, pour les implantations de bâtiments. L'exemple bien documenté d'un compagnon parisien, Pierre Janson dit la Palme (1661-ca 1721), partant travailler en 1688 en Nouvelle-France comme tailleur de pierre et recevant en 1708 une commission d'arpenteur royal en ce pays, permet d'avancer l'hypothèse que les 
compagnons les plus instruits changeaient de profession au gré des opportunités les plus avantageuses ou, plus simplement, des possibilités du moment: tantôt simples tailleurs de pierre, tantôt architectes, ingénieurs ou arpenteurs, ils savaient aussi redevenir entrepreneurs en bâtiment si nécessaire.

\section{L'art des jardins}

À côté des deux globes du frontispice, on remarque un élégant personnage dans l'encadrement d'une allée de parc, avec au fond un jet d'eau sur un bassin circulaire. L'art des jardins fait alors partie intégrante de l'architecture - il est au demeurant lié à l'arpentage - et c'est aussi dans les parcs qu'à cette époque, l'on pose les cadrans solaires (fig. 7).

Fig. 7. - Une planche et le frontispice du Cours d'architecture qui comprend les ordres de Vignole par Augustin-Charles d'Aviler, Paris, 1691.

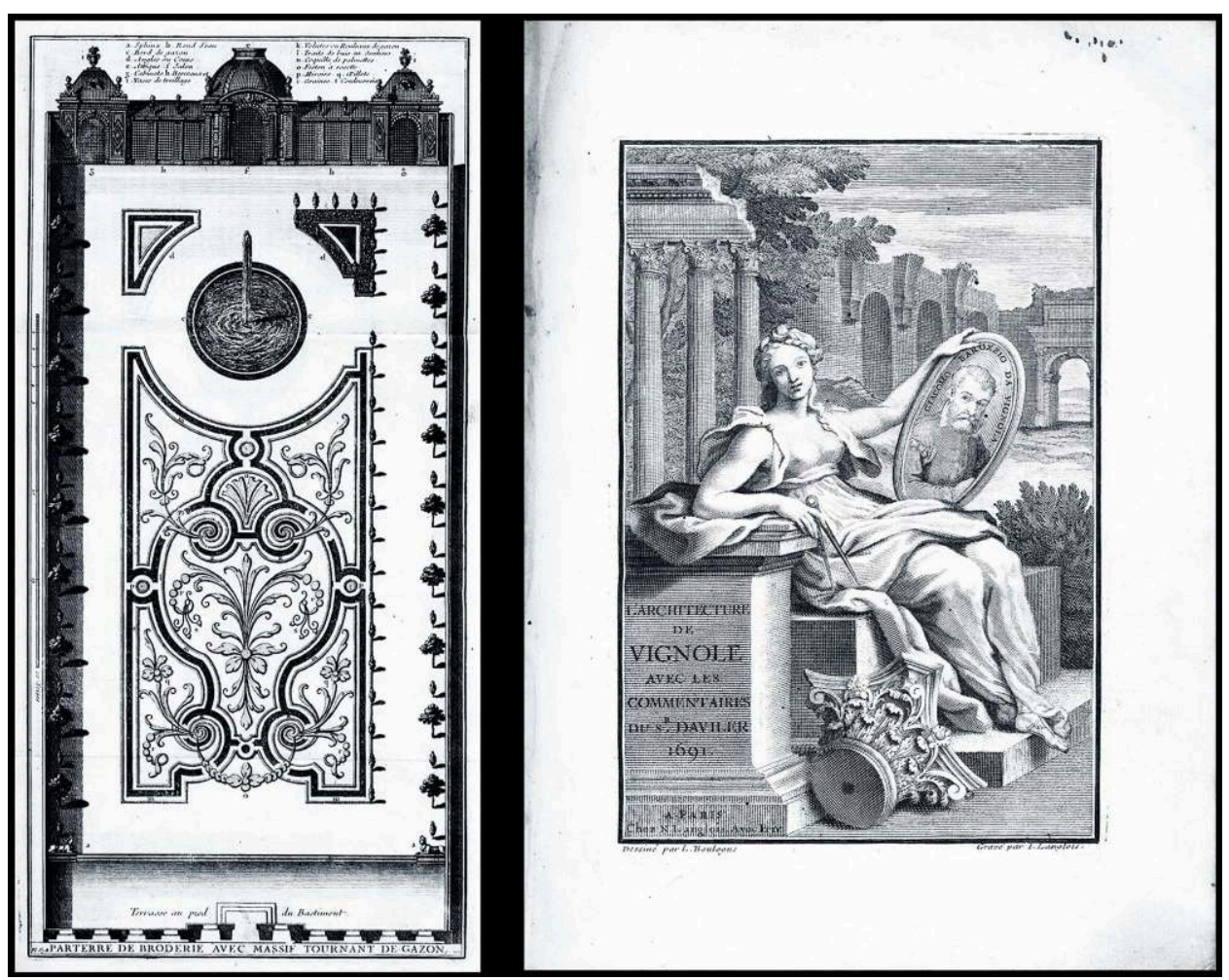

Clichés Jean-Michel Mathonière (D.R.).

Ainsi, les savoirs professionnels cultivés par les compagnons tailleurs de pierre à la fin de l'Ancien Régime étaient la géométrie, la stéréotomie, l'architecture, la gnomonique, l'arpentage et l'art des jardins.

\section{Le savoir-être}

Il est nécessaire de citer pour mémoire le fait qu'en même temps que ces savoirs professionnels, les compagnons se transmettaient également un savoir-être, des symboles, des rites et une gestuelle rituelle. 
Enfin, il n'est sans doute pas inutile de préciser que même si la vision du rôle était réservée aux initiés ${ }^{12}$, les compagnons tailleurs de pierre français des $\mathrm{xVIII}^{\mathrm{e}}$ et $\mathrm{xIX}^{\mathrm{e}}$ siècles ne se transmettaient pas de secrets d'ordre technique. Si secret de métier il a existé auparavant, il touchait le " trait ", ainsi qu'en attestent, par exemple, des articles $\mathrm{du}$ règlement des compagnons tailleurs de pierre germaniques au $\mathrm{Xv}^{\mathrm{e}}$ siècle ${ }^{13}$ ou, pour rester dans le domaine français, le titre même d'un traité de Mathurin Jousse, publié en 1642, Le secret d'architecture découvrant fidèlement les traits géométriques, coupes et desrobements nécessaires dans les bastiments. Mais depuis la publication en 1567 du premier tome de l'Architecture par Philibert Delorme, le secret du trait était déjà bien éventé...

\section{Quels modes de transmission?}

Après avoir défini quels étaient les savoirs en jeu, il convient de poser la question : dans quel cadre et comment les compagnons se les transmettaient-ils? Précisons qu'à cette époque n'existaient pas ces sièges compagnonniques qui, aujourd'hui, regroupent restauration, hébergement et salles de cours. Chez les compagnons du XVIII siècle, la fameuse "mère " était simplement une aubergiste qui, outre des repas et un hébergement à prix préférentiel, assurait aux compagnons la location d'une pièce pour y conserver le coffre de leur société et y tenir réunion le premier dimanche de chaque mois $^{14}$.

\section{Les cours de trait}

31 Ainsi que nous l'avons vu, le savoir professionnel par excellence était - et est toujours le trait pour la coupe des pierres. Selon les villes, son enseignement se faisait soit chez un ancien compagnon, qui percevait de ce fait une rémunération modique, soit dans un cours de dessin gratuit à destination des ouvriers, comme il s'en est créé dès avant la Révolution et durant tout le $\mathrm{XIX}^{\mathrm{e}}$ siècle.

\section{Cours chez les anciens}

Pour ce qui est des cours donnés par les anciens, voici l'émouvant témoignage que nous offre le carnet de comptes tenu par Jean-Jacques Laurès, dit la Tranquillité de Caux ${ }^{15}$, durant son tour de France entre 1838 et 1842. À la date du 5 novembre 1839, il note qu'il « rentre en classe pour le trait chez le sieur Ablin dit la Vertu, compagnon passant maitre maçon à Saintes" et détaille ses achats (fig. 8): la première semaine, 5 chandelles et 6 feuilles de papier ; deux semaines plus tard, le dimanche 19 novembre, il ajoute 4 livres de chandelles, 14 feuilles de papier de dessin, 2 crayons et un tireligne, 320 livres de plâtre en pierre et enfin un peu de bois. 
Fig. 8. - Page du carnet de comptes du compagnon passant tailleur de pierre Jean-Jacques Laurès.

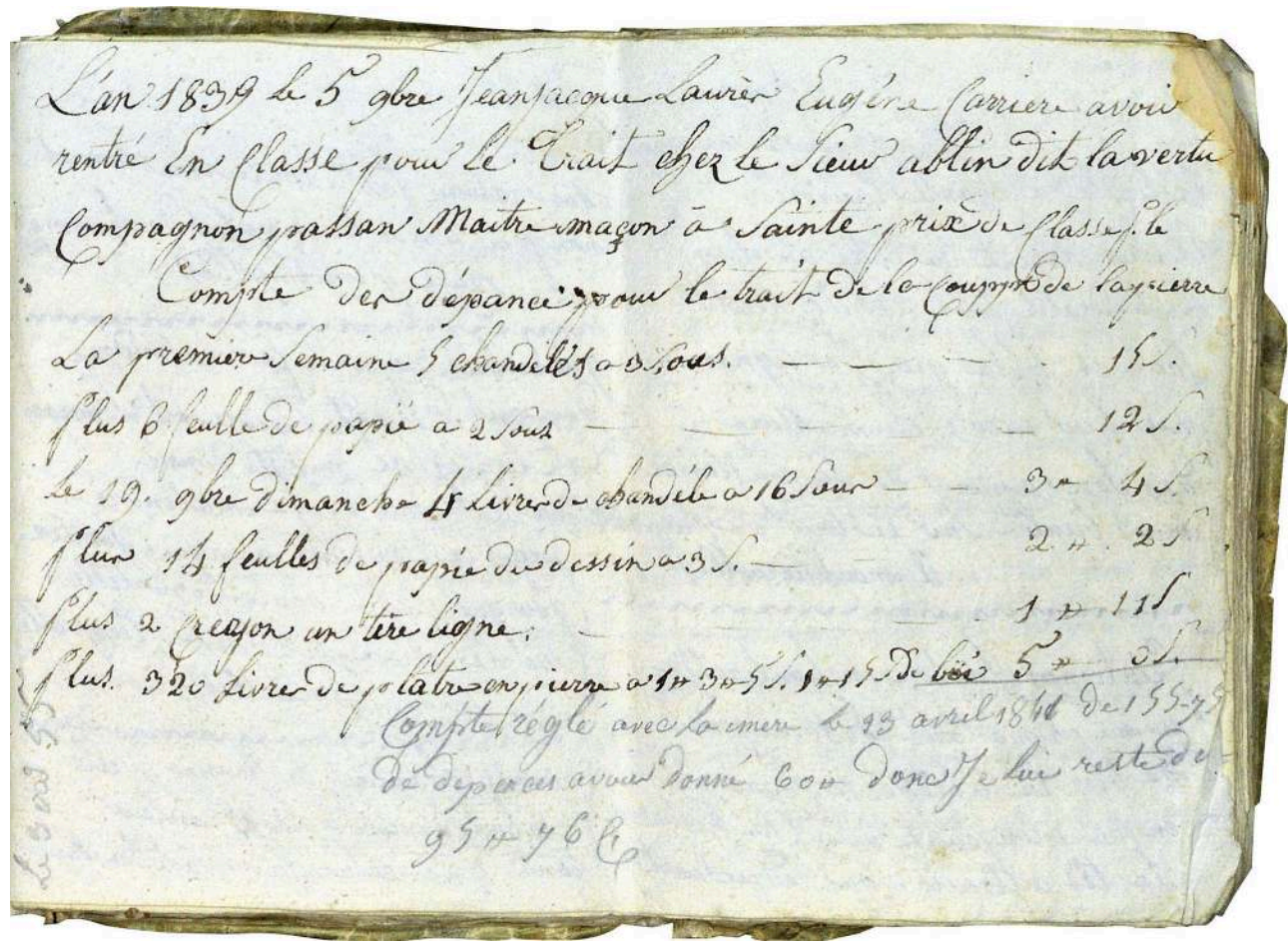

Archives privées.

Cliché Jean-Michel Mathonière (D.R.).

Aux cours du soir, à la lumière des chandelles, s'en ajoutaient donc d'autres le dimanche après-midi, seul réel moment de loisir de la semaine pour l'ouvrier.

Le plâtre en pierre est employé, une fois broyé, à réaliser des maquettes afin de vérifier les épures. Cela évoque nos actuels chefs-d'œuvre ${ }^{16}$ réalisés en pierre, mais cela n'en a aucunement la fonction.

On aura noté la date à laquelle la Tranquillité de Caux commence à suivre ses cours de trait : c'est le début de la saison durant laquelle les journées de travail raccourcissent. On occupe ainsi à s'instruire le temps gagné. Mais l'hiver est aussi la saison où les intempéries peuvent gêner le travail de la pierre. Certains compagnons occupent alors leur chômage à suivre des cours de trait.

\section{Cours du soir dans les écoles de dessin}

Pour ce qui est des cours du soir institutionnels, j'ai déjà évoqué ceux de l'École royale gratuite de dessin, créée en 1767, où enseigna Jean-Paul Douliot de 1818 à 1834. On sait par le témoignage de sa veuve toute l'attention qu'il portait aux compagnons passants, notamment avignonnais, s'efforçant de les aider aussi dans la recherche d'emploi et soulageant leurs misères de sa propre bourse.

De tels cours de trait existaient dans d'autres grandes villes, soit dans le cadre d'écoles religieuses en faveur des ouvriers ou de sociétés philomatiques, comme ici vers la fin du XIX ${ }^{\mathrm{e}}$ siècle à l'École philomatique de Bordeaux (fig. 9), soit encore dans les cours du soir dispensés par les écoles des beaux-arts ou celles d'arts et métiers, dont les professeurs étaient souvent d'anciens compagnons. 
Fig. 9. - Cours de taille de pierre, de modelage et de sculpture à l'École philomatique de Bordeaux, fin du XIX siècle.

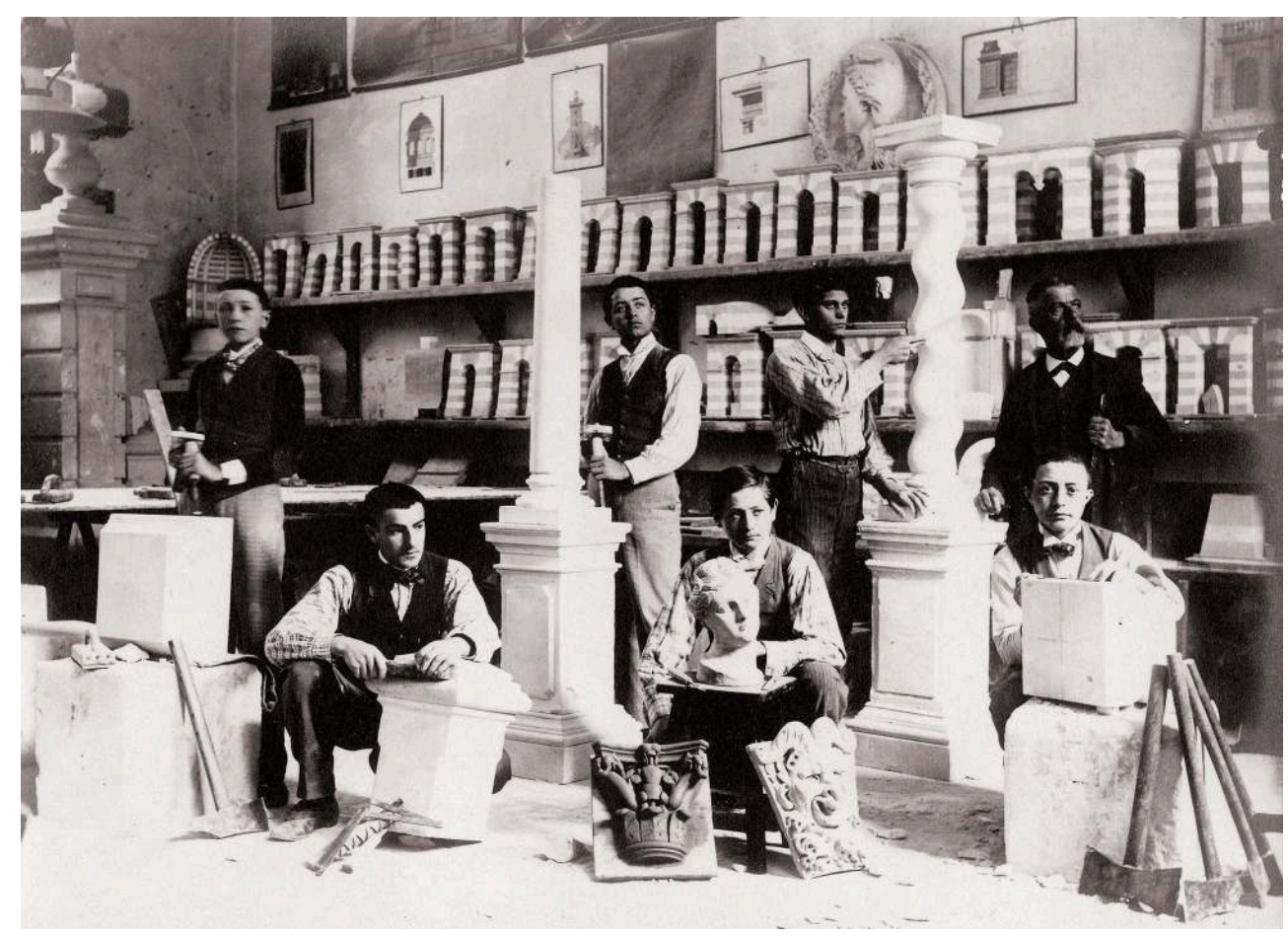

Archives privées.

Cliché Jean-Michel Mathonière (D.R.).

Voici, par exemple, la description par un architecte d'un cours dispensé à titre privé par un compagnon étranger, vers 1840-1845, à Paris :

«En même temps que je faisais mes études d'architecture à l'École des beaux-arts de Paris, je suivais, le soir, un cours de coupe des pierres. C'était dans un vieux quartier central, mais très laid, où, depuis, la démolition a fait son œuvre salutaire, et dans une sorte de boutique, à l'aspect un peu cabaret, servant de réunion pour les tailleurs de pierre. Cette boutique était comme le vestibule d'une grande pièce qui y faisait suite et qui était une école de trait professée par le très habile appareilleur bien connu alors sous son nom de compagnonnage, la Fleur de Coutras $^{17}$, constructeur du pont de Neuilly entre autres, et que venaient souvent consulter les grands architectes. La Fleur de Coutras était bien le type de ce que j'appellerai l'ouvrier savant dans sa spécialité, simple et digne dans ses rapports aussi bien avec les architectes et les ingénieurs qu'avec ses coopérateurs, inspirant le respect et la confiance à tous.

«Des modèles de toute espèce de coupes de pierres, voûtes biaises, rampantes, encorbellements, pénétrations, etc., garnissaient le pourtour de la pièce, et le maître nous faisait exécuter, en plâtre bien entendu, ces différentes œuvres. Ce n'étaient point de simples copies que nous avions à faire; tout était fondé sur l'application exacte de la géométrie descriptive, et nous étions tout étonnés qu'en suivant ses prescriptions nos œuvres en plâtre arrivaient si nettement, je dirai presque si facilement, sans tâtonnement, sans erreur, à réaliser ces coupes, à premier abord si compliquées ${ }^{18}$." 


\section{Les cours compagnonniques}

Dans le cours du XIX ${ }^{e}$ siècle, les compagnons cherchèrent aussi à s'organiser entre eux. Ainsi, en 1846, les compagnons passants tailleurs de pierre de Paris montèrent-ils un cours de trait dont le règlement nous fournit de précieuses indications quant à son organisation et à l'idée qui y préside : lutter contre la perte d'influence de leur société compagnonnique.

Son préambule fait table rase de certaines visions par trop romantiques. Il précise en effet que :

« [...] Comme tous les compagnons ont été jusqu'alors libres de s'instruire selon leur propre vue, ils sont tombés, les uns dans la débauche du vin et des femmes, les autres, plus studieux, se sont instruits, chose assez rare. Mais le libre exercice de ce temps si précieux peut être employé plus utilement pour l'instruction de chaque Compagnon : ce qui ne peut que donner un très beau relief a notre société, et nous procurer une foule d'hommes très capables. Car depuis quelques années les sciences et les arts se propagent, l'étude est une mode acceptée par tout le monde, ce qui tend à amoindrir nos lumières, les mœurs changent. Eh bien, courons au-devant du progrès ! Oui mes chers Coteries, pour que l'illusion continue, pour que la fraternité qui unit tous les Compagnons continue son règne telle qu'elle a existé pendant des milliers d'années, il faut une étude sérieuse qui nous élève et nous fasse rechercher. Si nous le faisons, ce temps pesant et ennuyeux par l'oisiveté deviendra un passetemps agréable. Plus de ces flâneries perpétuelles, plus de ces folles pensées qui dégradent l'esprit. Car le travail diminue les passions, augmente les vertus et prépare un ouvrier honorable ${ }^{19}$.»

Plusieurs articles insistent sur l'enseignement mutuel que se doivent, bénévolement, les compagnons :

« Article 3. - Pour ne pas avoir de profusion de maîtres, ce qui deviendrait trop coûteux, on démontrera le dessin et la coupe de pierre ensemble [tous niveaux confondus], mais les Compagnons les plus instruits sur la coupe de pierre devront en faire part aux autres sans prétendre aucune diminution sur le prix de la classe et que ceux qui feront la coupe de pierre payeront, comme ceux qui feront le dessin, ce qui fera une diminution sur le prix de l'école. "

« Article 5. - L'enseignement sera censé mutuel en l'absence du maître, c'est-à-dire que les plus avancés donneront des conseils aux moins forts, sans cependant que l'on enseigne ceux qui perdent leur temps."

« Article 9. - Tout jeune Compagnon résidant à Paris sera tenu de venir à l'école pour s'instruire sauf qu'il ne soit assez fort sur les parties que l'on démontrera, auquel cas il aura le droit de s'y refuser en montrant ses dessins, ou que les Compagnons attestent de son savoir. Mais il devra se rendre utile pour l'école par ses lumières $[. . .]^{20}$ »

\section{Les défis}

Ces cours trouvaient un prolongement dans les défis que se lançaient parfois les compagnons des deux rites ennemis, les passants d'un côté, les étrangers de l'autre. Si des luttes sanglantes les opposaient fréquemment autour de grands chantiers, pour avoir le monopole des embauches, il arrivait qu'ils cherchent à vider leurs querelles par le biais de défis de stéréotomie. Chaque clan possédait ses champions qui traçaient les épures et taillaient les maquettes en plâtre. Ainsi, en 1771 à Bordeaux, semblable défi oppose la Réjouissance de Tarascon et la Pensée de Sainte-Foy ${ }^{21}$. En 1784, la Douceur d'Avignon, le dessinateur du frontispice de 1782, signe en tant qu'architecte-ingénieur le règlement d'un concours devant être jugé par les membres de l'Académie 
d'architecture de Paris ${ }^{22}$. Il s'agit tout autant, sinon plus, d'architecture que de coupe des pierres. En 1826 encore, semblable concours se tient à Paris, se concluant par la fuite du compagnon passant, pris en flagrant délit de tricherie. L'affaire est longuement rapportée par Agricol Perdiguier dans ses Mémoires d'un compagnon. Le concours, dont le règlement avait été enregistré devant notaire, opposait deux champions désignés par leurs sociétés : Bertrand Caron, dit la Fleur de Coutras (cité plus haut, note 17), pour les compagnons étrangers, et un dénommé Saint-Martin pour les compagnons passants. Les deux concurrents entrèrent dans des chambres gardées par leurs rivaux le 8 août 1826, pour réaliser chacun deux modèles en plâtre, l'un selon un projet fixé par sa société compagnonnique, l'autre par la société rivale. Mais le 6 novembre 1826, un procès-verbal constate que le compagnon passant avait triché, des membres de son compagnonnage lui ayant fait passer par un trou percé dans le mur des toilettes des objets prohibés par le règlement du concours. Saint-Martin prend la fuite et la Fleur de Coutras est donc proclamé vainqueur de ce concours.

\section{Le tour de France et l'émulation}

De manière générale, la fraternité compagnonnique offrait un cadre idéal à l'émulation. Il n'était nul besoin de créer des cours spécifiques pour ces autres savoirs qu'étaient l'architecture, la gnomonique, l'art des jardins ou l'arpentage. Les jeunes compagnons côtoyaient durant leur tour des " anciens » installés comme entrepreneurs, architectes ou ingénieurs, qui leur offraient tout à la fois des modèles sociaux et, le cas échéant, des enseignements dans telle ou telle spécialisation.

On conserve des témoignages intéressants de cette émulation, telle l'incessante quête du savoir de Joseph Teulère (1750-1824), qui, orphelin de père à l'âge de dix ans, débute son parcours comme compagnon passant tailleur de pierre, suit des cours du soir à l'Académie d'architecture de Paris, obtient en 1776 un poste d'ingénieur maritime à Bordeaux, surélève le phare de Cordouan, entretient des contacts avec Gaspard Monge, devient ingénieur-constructeur de la Marine, est nommé en 1800 directeur des travaux maritimes à Rochefort et adresse alors à un négociant de son village natal, Montagnac (Lot-et-Garonne), un courrier où il raconte en détail son parcours pour inciter les jeunes gens à ne cesser de s'instruire ${ }^{23}$. Ou encore l'importante production de traités théoriques et pratiques relatifs à la construction (charpente, taille de pierre, stabilité des édifices, géométrie descriptive, dessin) de Jean-Paul Douliot (1788-1834), dit la Pensée d'Avignon, compagnon passant tailleur de pierre, architecte et professeur d'architecture à l'École royale gratuite de dessin de Paris ${ }^{24}$.

De manière générale, il convient de ne pas sous-estimer la transmission par le biais des livres, nombre de compagnons sachant correctement lire et écrire.

\section{L'idéal vitruvien hérité de la Renaissance}

On soulignera enfin que lors de la cérémonie de la réception dans la confrérie compagnonnique, la vision sacralisée du rôle situait la quête du savoir sur un piédestal. On retrouve là un idéal "vitruvien", et chrétien, qui est clairement expliqué par Philibert de l'Orme à propos d'une gravure de son Premier tome de l'architecture ${ }^{25}$. On y voit, compas en main, un architecte sortir d'une caverne, symbolisant le lieu obscur de la méditation et des études. La devise latine proclame: «De mille peines et mille 
empêchements est retardé l'Artisan docte et sage, quand par son Art, savoir et instruments, il cherche vers la Palme le passage ». Des trois pages d'explications que l'auteur consacre à cet emblème de sa composition, je ne retiendrai que ce qui concerne la palme, figurée par le palmier : c'est le but auquel doit viser l'artisan et elle signifie gloire, honneur et victoire ${ }^{26}$. Et ce but est atteint grâce au savoir.

On retrouve l'essentiel de cette thématique vitruvienne dans le blason même des compagnons tailleurs de pierre ${ }^{27}$. Celui des compagnons passants d'Avignon, dont le plus ancien actuellement recensé date de vers 1710 (fig. 10), en présente l'exemple le plus synthétique: entre les palmes, compas, équerre et règle sont entrecroisés, symbolisant la géométrie, connaissance fondamentale, tandis qu'une couleuvre les entrelace étroitement, symbolisant la Prudence, au sens ancien de l'expérience acquise. Au-dessus, un phylactère porte la devise «Labor - Honor », « travail et honneur ».

Fig. 10. - Blason des compagnons passants tailleurs de pierre d'Avignon. Détail du rôle de vers 1710.

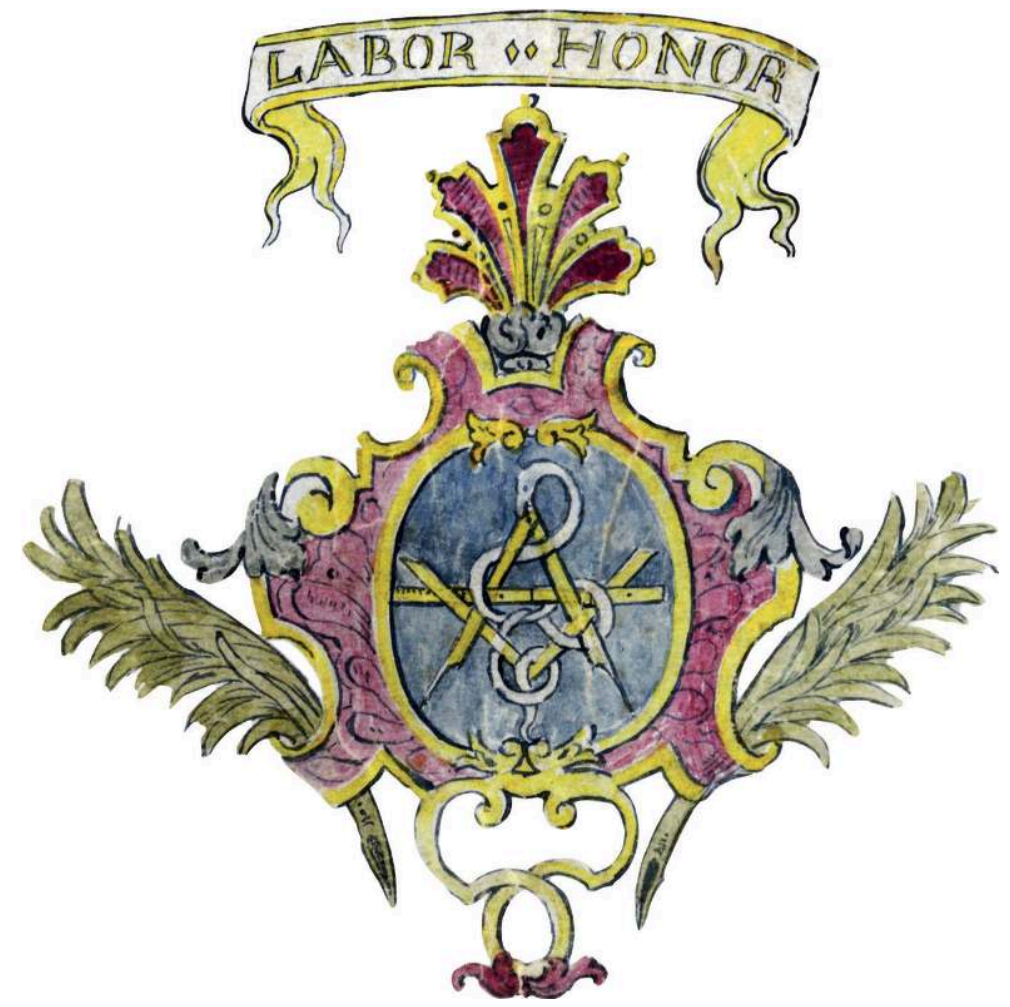

Arch. dép. Vaucluse, 1J 647/2.

Cliché Jean-Michel Mathonière (D.R.).

En conclusion, trois points sont à retenir.

Si la transmission des savoirs constitue aujourd'hui l'aspect le plus remarquable des compagnonnages, ce n'est toutefois pas là leur vocation originelle, qui était la solidarité fraternelle. La naissance des sociétés de secours mutuels, puis des caisses de retraite et enfin de la sécurité sociale est peu à peu venue grignoter cette part de leur raison d'être, laissant ainsi place à l'expansion de la transmission professionnelle, qui est en quelque sorte un « heureux dommage collatéral». 
do, j'espère vous avoir convaincu de l'importance qu'il y a de conjuguer au plurie ce singulier phénomène qu'est le compagnonnage, pour ce qui concerne ses multiples manifestations dans l'histoire. Ne succombons pas à la tentation de certaines lectures anthropologiques, qui, à force de schématiser, réduisent le champ des connaissances plutôt qu'elles ne l'ouvrent.

51

(entrin, nous avons entraperçu l'étendue des savoirs que les compagnons tailleurs de pierre cultivaient sous l'Ancien Régime. Ce faisant, ils s'efforçaient en quelque sorte de mettre en pratique l'injonction de Vitruve dans De Architectura, à propos des qualités que l'architecte doit posséder :

"Il faut qu'il ait de la facilité pour la rédaction, de l'habileté dans le dessin, des connaissances en géométrie; il doit avoir quelque teinture de l'optique, posséder à fond l'arithmétique, être versé dans l'histoire, s'être livré avec attention à l'étude de la philosophie, connaître la musique, n'être point étranger à la médecine, à la jurisprudence, être au courant de la science astronomique, qui nous initie aux mouvements du ciel ${ }^{28}$.»

\section{BIBLIOGRAPHIE}

ANONYME, L'horologiographe universel; ou methode générale, très-juste courte \& facile pour faire toute sortes de montres solaires dans tout l'univers : pour l'usage \& la facilité des compagnons tailleurs de pierre \& maçons, qui sont sur le tour de France; ouvrage néantmoins utile \& à la portée de toute sorte de personnes, Paris, impr. Chardon, 1768.

AVILER Augustin-Charles d', Cours d'architecture qui comprend les ordres de Vignole, avec des commentaires, les figures et descriptions de es plus beaux bâtimens, \& de ceux de Michel-Ange, plusieurs nouveaux desseins...l'art de bâtir avec une ample explication par ordre alphabétique de tous les termes par le sieur A. C. Daviler,... Première partie, Paris, 1691.

BASTARD Laurent et MATHONIÈRE Jean-Michel, Travail et honneur : les compagnons passants tailleurs de pierre en Avignon aux XVIII et XIX ${ }^{e}$ siècles, Dieulefit, La Nef de Salomon, 1996.

BLONDEL Jacques-François, Cours d'architecture, ou Traité de la décoration, distribution et construction des bâtiments : contenant les leçons données en 1750 et les années suivantes, Paris, vve Desaint, 1771-1777.

BRAQUEHAYE C., « Défi des compagnons “passants” et des compagnons "étrangers" jugé par l'Académie de peinture, de sculpture et d'architecture de Bordeaux, le 27 mars 1771 », Bulletin historique et philologique du Comité des travaux historiques et scientifiques, 1901, nº 3-4, p. 493-503. DELORME Philibert, Le premier tome de l'architecture de Philibert de L'Orme conseillier et aumosnier ordinaire du Roy, \& abbé de S. Serge lez Angiers, Paris, F. Morel, 1567.

DоULIOT Jean-Paul, Cours élémentaire, théorique et pratique de construction, Paris, Carilian-Goeury, 1828,4 vol. in $-4^{\circ}$ et planches.

JousSE Mathurin, Le secret d'architecture découvrant fidèlement les traits géométriques, coupes et desrobements nécessaires dans les bastiments, La Flèche, impr. Griveau, 1642. 
MATHONIÈRE Jean-Michel, « Agricol Perdiguier, premier historien du compagnonnage français », Provence historique, T. LVI, fasc. 226, 2006, p. 353-360.

MATHONIÈRE Jean-Michel, « L'ancien compagnonnage germanique des tailleurs de pierre », dans Fragments d'histoire du compagnonnage, vol. 5, Tours, musée du Compagnonnage, 2003, p. 58-105.

MATHONIÈRE Jean-Michel, « Aperçus sur l'histoire des compagnonnages de tailleurs de pierre et maçons en France et en Europe ", dans Association ouvrière des Compagnons du devoir, La maçonnerie et la taille de pierre, vol. VII, Paris, Librairie du compagnonnage, 2011, p. 159-204.

MATHONIÈRE Jean-Michel, « Aperçus sur les compagnonnages français de tailleurs de pierre », dans Actes $d u$ XIX colloque international de glyptographie de Colmar (28 juillet- $1^{\text {er }}$ août 2014), Braine-leChâteau, Centre international de recherches glyptographiques, 2015, p. 375-410.

MATHONIÈRE Jean-Michel, « Les avatars de Maître Jacques », dans Fragments d'histoire du compagnonnage, vol. 11, Tours, musée du Compagnonnage, 2009, p. 113-153.

MATHONIÈRE Jean-Michel, « Franc-maçonnerie et compagnonnage : "tronc commun" ou absence de parenté ? ", dans Blondel J.-F. et al. (dir.), Trois cents ans de franc-maçonnerie, Paris, Grande Loge nationale française / Dervy, 2017, p. 103-129.

MATHONIÈRE Jean-Michel, « Franc-maçonnerie opérative et spéculative », dans Mollier P., Bourel S., Portes L. (dir.), La franc-maçonnerie, Paris, Bibliothèque nationale de France, 2016, p. 29-33.

MATHONIÈRE Jean-Michel, Les interférences entre spéculatifs et opératifs français auX XVIII et XIXe siècles, Paris, Société française d'études et de recherches sur l'Écossisme, 2017.

MATHONIÈRE Jean-Michel, « Jean-Paul Douliot (1788-1834), compagnon passant tailleur de pierre, professeur d'architecture et auteur du Cours élémentaire, pratique et théorique de construction », dans Fleury F. et al. (dir.), Les temps de la construction : processus, acteurs, matériaux, Paris, Picard, 2016, p. 163-174.

MATHONIÈRE Jean-Michel, « Joseph Teulère (1741-1824) ou la quête des lumières ", à paraître, Avignon, La Nef de Salomon.

MATHONIÈRE Jean-Michel, Le Serpent compatissant : iconographie et symbolique du blason des compagnons tailleurs de pierre, Dieulefit, La Nef de Salomon, 2001.

MATHONIÈRE Jean-Michel, « La tradition et sa transmission dans les compagnonnages », Connaissance des religions, 2003, $\mathrm{n}^{\circ}$ 69-70, p. 173-190.

MATHONIÈRE Jean-Michel, La Tranquillité de Caux : le chansonnier et le tour de France (1837-1842) de JeanJacques Laurès dit "La Tranquillité de Caux ", compagnon passant tailleur de pierre, Avignon, La Nef de Salomon, 2005.

MATHONIÈRE Jean-Michel, « La transmission dans les compagnonnages : entre réalité et fantasmes ", dans La Transmission, Paris, Association des amis de Critica (Critica masonica, $\mathrm{n}^{\circ}$ spécial, 2018, p. 53-74.

MATHONIÈRE Jean-Michel, «Vignole et les compagnons du Tour de France », dans Hilaire-Pérez L. et al. (dir.), Le livre technique avant le $\mathrm{XX}^{e}$ siècle : à l'échelle du monde, Paris, CNRS éditions, 2017, p. 149-160.

PERDIGUIER Agricol, Livre du compagnonnage, Paris, Pagnerre, 1841.

PERDIGUIER Agricol, Mémoires d'un compagnon, s.l., 1854. 
SAINTE-MARIE MAGDELEINE Pierre de (dom), Traitté d'horlogiographie, contenant plusieurs manieres de construire sur toutes surfaces, toutes sortes de lignes horaires \& autres cercles de la sphere. Avec quelques instrumens pour la mesme pratique, \& pour cognoistre les heures durant la nuict : \& l'heure du flus \& reflus de la mer. Plus la methode de couper en pierre ou en bois les corps reguliers par le cube \& par le cylindre. Par D. P. de St. M. Magdeleine, fueillent, Paris, Melchior Tavernier, 1641.

VITRUVE, De l'architecture, trad. C.-L. Maufras, Paris, Panckoucke, 1847.

\section{NOTES}

1. La recherche sur les compagnonnages français souffre d'un déficit d'études sérieuses, même si depuis un peu plus de deux décennies ce retard tend à se combler grâce aux travaux d'une poignée de chercheurs, au premier rang desquels L. Bastard, l'érudit directeur (de 1993 à 2018) du musée du Compagnonnage à Tours qui, outre ses propres publications, a publié la série des Fragments d'histoire du compagnonnage reprenant les conférences organisées chaque année par le musée (17 volumes parus).

2. Sur les confusions et interférences entre franc-maçonnerie et compagnonnage, voir $\mathrm{J}$.-M. Mathonière, Les interférences entre spéculatifs et opératifs français aux XVIII et XIX siècles; "Franc-maçonnerie et compagnonnage: "tronc commun" ou absence de parenté ? » et « Franc-maçonnerie opérative et spéculative ».

3. Sur la question de la transmission dans les compagnonnages, voir J.-M. Mathonière, «La transmission dans les compagnonnages: entre réalité et fantasmes» et «La tradition et sa transmission dans les compagnonnages ».

4. C'est A. Perdiguier, premier historiographe des compagnons, qui, en publiant en 1841 son célèbre Livre du compagnonnage, est le responsable initial de ce singulier trompeur. Son objectif étant de pacifier tous ces compagnonnages qui se battaient jusqu'au sang et parfois jusqu'à la mort sur les routes du tour de France, ses écrits ont plutôt insisté sur l'idée d'une origine et d'un idéal communs que sur celle d'une multiplicité de racines quelquefois divergentes. Voir J.-M. Mathonière, « Agricol Perdiguier, premier historien du compagnonnage français ».

5. Découvert en 1996, ce fonds a été étudié par L. Bastard et moi-même et il a fait l'objet d'une publication d'ensemble: L. Bastard et J.-M. Mathonière, Travail et honneur: les compagnons passants tailleurs de pierre en Avignon aux XVIII et XIXe siècles. Sur l'histoire et les usages des compagnons tailleurs de pierre français, voir J.-M. Mathonière, « Aperçus sur l'histoire des compagnonnages de tailleurs de pierre et maçons en France et en Europe » et " Aperçus sur les compagnonnages français de tailleurs de pierre ».

6. Voir chap. "Le rôle", dans L. Bastard et J.-M. Mathonière, Travail et honneur..., p. 38-50.

7. Voir chap. «Le rôle atypique de 1782 ", dans L. Bastard et J.-M. Mathonière, Travail et honneur..., p. 100-119.

8. L. Bastard et J.-M. Mathonière, Travail et honneur..., p. 61-66.

9. Règlement particulier des compagnons étrangers figurant dans un livret imprimé, sans date (vers 1860-1865), qui était remis aux membres itinérants, "jeunes hommes » (équivalent d'aspirant) et compagnons. Transcription à partir d'une photocopie non sourcée communiquée à l'auteur par un compagnon tailleur de pierre des devoirs. Un 
livret de Règlements généraux a par ailleurs été édité en 1865 à Genève à l'imprimerie Blanchard.

10. J.-P. Douliot, Cours élémentaire, théorique et pratique de construction. Voir J.M. Mathonière, «Jean-Paul Douliot (1788-1834), compagnon passant tailleur de pierre... ».

11. Voir J.-M. Mathonière, «Les avatars de maître Jacques ». Parmi les personnalités réelles ou mythiques auxquelles emprunte le personnage syncrétique de maître Jacques, l'une est prépondérante : il s'agit de l'architecte italien Giacomo Barozzi da Vignola (1507-1573) dont la Regola, publiée en 1562, a connu une diffusion exceptionnelle en tant que recueil de modèles d'architecture, notamment en France, et dont l'édition au format de poche, en 1631, a largement touché les milieux compagnonniques. Voir J.-M. Mathonière, «Vignole et les compagnons du Tour de France ».

12. L. Bastard et J.-M. Mathonière, Travail et honneur..., chap. "La réception des honnêtes compagnons ", p. 128-141.

13. J.-M. Mathonière, «L'ancien compagnonnage germanique des tailleurs de pierre ".

14. Rôle de Bordeaux, 1778 , article $1^{\mathrm{er}}$ du chap. II : «Les premiers dimanche de chaque mois, les Compagnons seront tenus de se trouver chez le Père à une heure précise après midi [...] ». Voir L. Bastard et J.-M. Mathonière, Travail et honneur..., p. 61-66.

15. Voir J.-M. Mathonière, La Tranquillité de Cau...

16. Voir J.-M. Mathonière, "Compagnons: de la maquette au chef-d'œuvre", diaporama et communication (non publiée) au séminaire d'histoire de la construction, 2016, Paris, Institut national d'histoire de l'art.

17. Chez les tailleurs de pierre, qu'ils soient du rite des passants ou de celui des étrangers, le nom compagnonnique est au $\mathrm{XIX}^{\mathrm{e}}$ siècle formé d'une vertu ou d'un symbole, suivi du nom de la localité d'origine (voir L. Bastard et J.-M. Mathonière, Travail et honneur..., chap. "Les surnoms compagnonniques des tailleurs de pierre » et «Le palmarès des vertus», p.142-147 et p. 148-151). L'usage de ces surnoms compagnonniques rend souvent difficile l'identification précise des individus. La Fleur de Coutras était un compagnon étranger tailleur de pierre dénommé Bertrand Caron, qui fut l'un des protagonistes d'un des défis de coupe des pierres qui opposaient périodiquement, depuis la seconde moitié du XviII ${ }^{\mathrm{e}}$ siècle, les deux rites ennemis de tailleurs de pierre - en lieu et place des batailles sanglantes qui peu à peu cessèrent. Un autre appareilleur célèbre de la seconde moitié du XIXe siècle ne doit pas être confondu avec la Fleur de Coutras : Jean Gallineau (1847-1914) dit Joli-Cœur de Coutras, reçu compagnon passant tailleur de pierre le 15 août 1869, qui fut notamment l'exceptionnel appareilleur du pont Alexandre III à Paris et enseigna la stéréotomie à l'École des travaux publics d'Arcueil-Cachan. Voir sa notice biographique dans Les muses du tour de France, $\mathrm{n}^{\circ} 4$ (1926), p. 57-58.

18. Gaspard George (1822-1908), président de la Société académique d'architecture de Lyon, dans La Construction lyonnaise, $23^{\mathrm{e}}$ année, $\mathrm{n}^{\circ} 24,1901$, p. 281. Sur G. George, CTHS, annuaire prosoprographique des sociétés savantes: <http://cths.fr/an/savant.php? $\mathrm{id}=101710>$.

19. D'après un document des archives de la Chambre des compagnons passants tailleurs de pierre de Paris, Compagnonnage, $\mathrm{n}^{\circ}$ 274, 1965.

20. Ibid. 
21. Voir C. Braquehaye, «Défi des compagnons "passants" et des compagnons “étrangers" jugé par l'Académie de peinture, de sculpture et d'architecture de Bordeaux, le 27 mars 1771 ».

22. L. Bastard et J.-M. Mathonière, Travail et honneur...,, p. 338-340.

23. Voir J.-M. Mathonière, « Joseph Teulère (1741-1824) ou la quête des lumières ».

24. Voir J.-M. Mathonière, « Jean-Paul Douliot... ».

25. Le premier tome de l'architecture de Philibert de L'Orme [...], fol. $51 \mathrm{~V}^{\mathrm{o}}$.

26. Voir J.-M. Mathonière, Le Serpent compatissant...

27. Ibid.

28. Vitruve, De l'architecture, livre I, chap. 1 et 3.

\section{RÉSUMÉS}

Parler de compagnonnage évoque par excellence la transmission des savoirs. Mais la vision contemporaine du sujet est souvent éloignée de la réalité. Au travers de l'exemple bien documenté des compagnons tailleurs de pierre aux XVIII ${ }^{\mathrm{e}}$ et $\mathrm{XIX}^{\mathrm{e}}$ siècles, il est utile de définir quels étaient ces savoirs et comment s'opérait leur transmission. On découvre ainsi que le niveau culturel de ces artisans était souvent bien supérieur à ce qu'une vision ouvriériste des métiers nous a portés à croire : nombre de ces compagnons tailleurs de pierre faisaient en réalité ensuite carrière d'ingénieurs et d'architectes. La transmission des savoirs s'effectuait par des cours du soir et, de manière plus générale, par l'émulation au contact des anciens compagnons lors du tour de France. On peut aussi noter que la tradition compagnonnique des tailleurs de pierre se situait encore dans la droite ligne de l'héritage vitruvien de la Renaissance quant au savoir universel de l'architecte.

\section{INDEX}

Mots-clés : compagnonnage, tailleur de pierre, stéréotomie, architecture, gnomonique, arpentage

Index géographique : Avignon

\section{AUTEUR}

\section{JEAN-MICHEL MATHONIÈRE}

Webmestre du site www.compagnons.info 


\title{
De la conception médiévale à la
} restauration des $\mathrm{XIX}^{\mathrm{e}}$ et $\mathrm{XX}^{\mathrm{e}}$ siècles : réception et traduction du décor sculpté gothique en vallée mosane (Belgique et Pays-Bas)

\author{
Aline Wilmet
}

C'est en 2017 que la première synthèse consacrée à l'ornementation des supports de l'architecture gothique mosane est défendue à l'université de Namur ${ }^{1}$. Cette étude, héritière de l'archéologie du bâtiment, livre un renouvellement de l'approche du décor sculpté architectural demeuré longtemps englué dans un immobilisme scientifique dû à la persistance de considérations régionalistes. Elle offre une lecture novatrice de l'ornement, analysant les interactions entre les contraintes matérielles et techniques, les modèles formels et les enjeux économiques du chantier médiéval, renouvelant ainsi l'approche de ce parent pauvre de l'architecture. Outre l'appréciation de l'ornement comme outil de compréhension et de datation du patrimoine bâti, cette étude réévalue une considération, née dans la première moitié du $\mathrm{xx}^{\mathrm{e}}$ siècle, selon laquelle le chapiteau dit «à feuilles de plantain» donne sa "personnalité mosane» à l'architecture régionale. Cette contribution vise à présenter les facteurs qui ont incité les historiens de l'architecture à considérer cet ornement comme un produit de terroir régional, à savoir, d'une part, le développement au $\mathrm{xv}^{\mathrm{e}}$ siècle de formes et de techniques optimisées pour faciliter la reproduction et la diffusion de cet ornement, et d'autre part l'influence de la perception de cette production par les restaurateurs des $\mathrm{xIX}^{\mathrm{e}}$ et $\mathrm{xx}^{\mathrm{e}}$ siècles. 


\section{Un critère de définition de l'architecture régionale sujet à débat : le chapiteau mosan}

Dans le contexte de la création de la Belgique en 1830, l'histoire de l'architecture se teinte inévitablement de forts accents nationalistes. Le patrimoine bâti, par son caractère immobilier et vénérable, permet de valoriser et légitimer la jeune nation ${ }^{2}$. Dès les années 1890 , ce paysage artistique se teinte progressivement de revendications identitaires flamandes et wallonnes ${ }^{3}$ qui cloisonnent très tôt les recherches. Dès les années 1850, la Meuse apparaît comme un facteur géographique déterminant pour le développement de l'activité économique et socioculturelle du territoire de l'ancien diocèse de Liège et des régions limitrophes, et est ainsi directement liée à la pérennité historique de ceux-ci. Les recherches consacrées à la production artistique de cette région se focalisent essentiellement sur l'orfèvrerie et la sculpture monumentale, et les historiens de l'architecture tentent de déterminer les caractéristiques d'une école d'architecture fondée sur les mêmes principes ${ }^{4}$. La quête des influences stylistiques à l'origine de la production artistique mosane pousse les chercheurs à considérer l'architecture romane et gothique comme deux phénomènes distincts. Ainsi, jugée trop influencée par le style de l'île-de-France et de la Champagne, l'architecture gothique sera longtemps délaissée par les chercheurs au profit de l'étude de l'architecture romane. Il faut attendre 1930 pour que la première synthèse consacrée à l'architecture gothique soit publiée. Paul Rolland y met en évidence les caractéristiques propres aux constructions de la région mosane, à savoir les matériaux locaux et l'usage de chapiteaux ornés de feuilles de plantain $^{5}$. Peu de temps après, Simon Brigode approfondit cette question en distinguant les chapiteaux spécifiques des bassins de l'Escaut et de la Meuse, constituant les axes de diffusion des matériaux pierreux ${ }^{6}$ et des styles. Le chapiteau à feuilles de plantain (fig. 1), façonné dans la pierre bleue locale, devient alors un marqueur stylistique régional de l'architecture ${ }^{7}$. 
Fig. 1. - Le chapiteau mosan à feuilles de plantain.

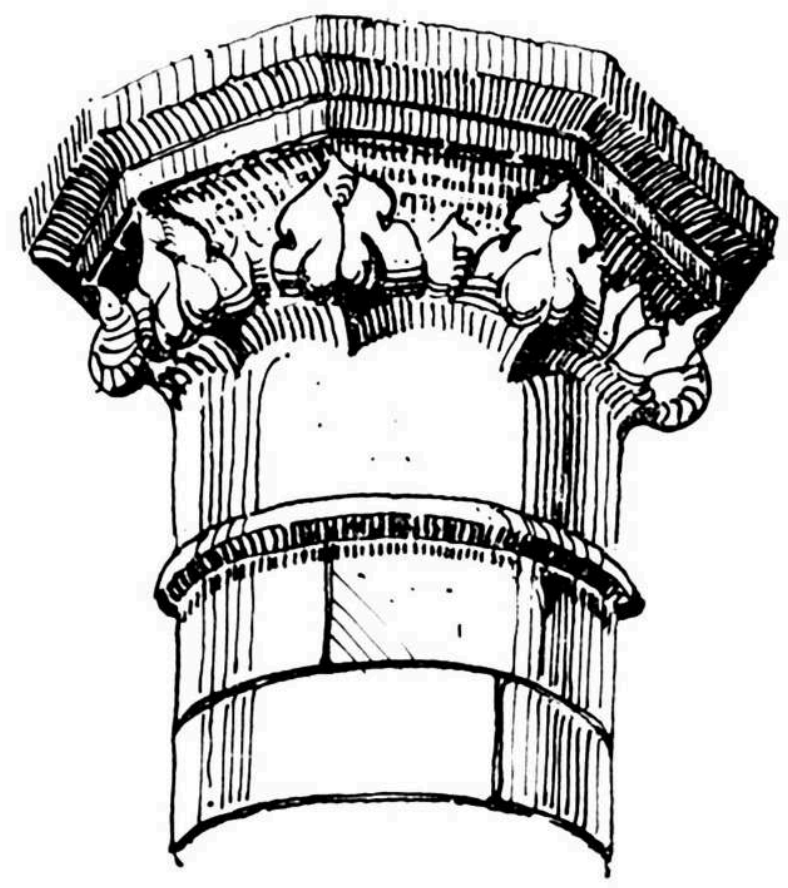

Extrait de S. Brigode, Les églises gothiques de Belgique (D.R.).

3 Depuis cette époque, le décor sculpté fait l'objet de catégorisations régionales qui, bien qu'elles soient fortement remises en question depuis les années 1970 en Europe, demeurent mal accueillies en Belgique. Il faut en effet attendre la fin du $\mathrm{xx}^{\mathrm{e}}$ siècle et le développement des approches iconologiques et de l'archéologie du bâtiment pour qu'apparaissent les premières retenues à ce propos. Malgré la multiplication des recherches concernant le travail de la pierre (approvisionnement, mise en œuvre, analyses tracéologiques telles que l'étude des traces d'outils, des marques lapidaires, des tracés préparatoires, etc.) et permettant d'affiner la compréhension de l'organisation du chantier de construction, le décor sculpté n'est que très rarement intégré à ces travaux ${ }^{8}$. Si l'analyse de l'ornement s'impose aujourd'hui naturellement pour compléter les monographies architecturales des monuments français", elle ne va pas de soi dans un contexte où les études des sites majeurs, quand elles existent, sont souvent dépassées.

4 Aujourd'hui encore envisagé de façon générale, le décor sculpté a été catégorisé en écoles régionales d'architecture qui, bien que cette conception soit passablement dépassée, sont encore évoquées occasionnellement. Peut-être la régionalisation de la gestion du patrimoine architectural et, avec elle, la remise à l'honneur de considérations aux accents régionalistes ont-elles contribué à la persistance du concept de « chapiteau mosan » dans la littérature ${ }^{10}$ ? 


\section{Les matériaux lithiques comme produits de terroir}

5 La région baignée par la Meuse, dans la zone géographique correspondant aux Ardennes belges jusqu'au sud des Pays-Bas, se caractérise par l'usage de pierres calcaires offrant un camaïeu de bleus tout à fait caractéristique de l'architecture. Ces pierres sédimentaires, extraites dans des carrières situées entre Dinant et Engis, près de Liège, et essentiellement autour de Namur, sont dotées d'une structure très fine qui a l'avantage d'offrir une bonne aptitude à la taille et au polissage malgré une grande dureté. Celle-ci induit une robustesse considérable et une excellente résistance à la compression $^{11}$, qui va valoir aux calcaires de Meuse, accessibles en grandes quantités au bord du fleuve éponyme, de s'imposer progressivement sur les chantiers mosans dès le deuxième quart $\mathrm{du} \mathrm{xIII}^{\mathrm{e}}$ siècle. Pourtant le grès houiller, matériau privilégié de l'architecture romane à partir du $\mathrm{x}^{\mathrm{e}}$ siècle, demeure très présent sur les chantiers gothiques, où il cohabite avec les calcaires de Meuse. Citons, par exemple, le bâtiment des moines de l'abbaye du Val-Saint-Lambert de Seraing ${ }^{12}$ (1233-1234), près de Liège, qui atteste de l'usage du grès houiller dans les supports de la salle des moines et de la salle du chapitre, tandis que certains culots ainsi que les supports géminés (chapiteaux à crochets, fûts de colonnettes et bases à scotie) qui encadrent les baies de la salle du chapitre sont façonnés en calcaire de Meuse. On constate donc une cohabitation des deux matériaux sur un même chantier. Grâce à son grain très fin, le grès wesphalien extrait localement en région liégeoise, entre Saint-Gilles et Vivegnis, se prête tant au moellonnage qu'au façonnage de pierres de taille ou à la réalisation d'éléments architectoniques. Bon marché, il est présent sur plusieurs chantiers du XIII ${ }^{\mathrm{e}}$ siècle et du XIV ${ }^{e}$ siècle, comme l'atteste la collégiale Sainte-Croix de Liège, qui en constitue probablement l'occurrence la plus tardive (1283-1284) ${ }^{13}$.

6 Parallèlement à l'usage du grès houiller et des calcaires de Meuse, l'architecture mosane témoigne également de l'emploi de tuffeaux maastrichtiens et de calcaires bajociens, respectivement extraits au nord et au sud de la région envisagée, dans la mise en œuvre des remplages des baies, des nervures de voûtes et plus particulièrement dans la sculpture et l'ornementation architecturale.

7 Le commerce des «pierres de Meuse » connaît un succès considérable au Moyen Âge, particulièrement aux $\mathrm{XV}^{\mathrm{e}}$ et $\mathrm{XVI}^{\mathrm{e}}$ siècles, où elles sont exportées dans toute la vallée mosane, bien au-delà des zones d'extraction. Cette « industrie » touche tant les pierres d'appareillage que l'ornement sculpté des supports. Des chapiteaux «typiquement mosans » dits "à feuilles de plantain », façonnés en calcaires de Meuse, sont en effet employés dans l'architecture de Merbes-le-Château, en Hainaut, jusqu'à Leende, au nord de Roermond, aux Pays-Bas. Les calcaires de Meuse seront employés dans l'architecture jusqu'au XIX ${ }^{\mathrm{e}}$ siècle, où ils seront progressivement remplacés par le " petit granit » dans les travaux de restauration.

\section{Le chapiteau « mosan », un concept « préfabriqué »?}

$\mathrm{Au} \mathrm{Xv}^{\mathrm{e}}$ siècle, l'activité des carrières du Namurois prospère suite à une forte demande de matériaux et de main-d'œuvre, due notamment à la réédification des remparts de Namur à partir de 1464, à l'achèvement des grands chantiers mosans ainsi qu'aux nombreuses reconstructions d'édifices de moindre ampleur entreprises un peu partout 
en région mosane. À cette époque, l'architecture se caractérise à la fois par l'adaptation des églises romanes aux nouvelles exigences du culte - les supports sont parfois repris en sous-œuvre afin de dégager de l'espace pour bénéficier d'une vue optimale sur le maitre autel ${ }^{14}$ - et par de nouvelles constructions. Face à l'importante demande en matériaux sculptés pour ces chantiers parfois situés bien loin des lieux d'extraction des calcaires de Meuse, l'ornement des supports - bases et chapiteaux - fait l'objet d'une optimisation des formes et des techniques visant à faciliter la reproduction et le transfert des formules ornementales, tout en accélérant leur façonnage.

Cette volonté d'optimisation des modes opératoires se développe déjà, dans une certaine mesure, entre le milieu du xiII ${ }^{e}$ siècle et la fin du xIV siècle. Elle concerne alors un perfectionnement des techniques par la sélection d'un outillage au rendement optimisé: le ciseau grain d'orge, dès le milieu du xiII siècle, et même le ciseau boucharde, dans la seconde moitié du XIve siècle, remplacent progressivement la pointe utilisée en taille brochée ${ }^{15}$. Devant l'importante surface murale et la quantité d'ornements à traiter, les tailleurs de pierre auraient opté pour des outils favorisant un meilleur rendement tout en préservant la qualité de finition. Le ciseau bédane, outil à taillant droit de quelques millimètres, renforcé par un élargissement en bec de canard $^{16}$, est également employé pour tailler le feuillage de certains exemplaires.

Les formes sont, quant à elles, héritières des modèles du début du XIII ${ }^{\mathrm{e}}$ siècle. Outre la sélection du chapiteau à crochet, les supports sont couronnés d'un chapiteau à corolle de feuilles se recourbant sur la lèvre et qui affecte à présent un profil anguleux, dit «à crossettes ${ }^{17}$ ». Les feuillages, aux formes soignées et au modelé accentué de gonflements globulaires plus ou moins marqués, sont traités avec souplesse. La sélection du type de feuille (lancéolée, rubanée, panduriforme, hastée ${ }^{18}$ ), le traitement du relief et le modelé $\mathrm{du}$ bord du limbe varient sensiblement d'un exemplaire à l'autre. Les feuilles sont implantées sur toute la hauteur de la corbeille ou le quart inférieur de celle-ci. Parallèlement à ce modèle privilégié, les chapiteaux de la fin du XIII siècle et du XIV ${ }^{e}$ siècle sont parfois décorés de feuillages incisés ou polylobés, motifs transposés des exemplaires en calcaires bajociens sur les calcaires de Meuse (fig. 2).

Fig. 2. - Évolution du chapiteau mosan en calcaires de Meuse entre le $\mathrm{XIII} \mathrm{I}^{\mathrm{e}}$ et le $\mathrm{XVI} \mathrm{I}^{\mathrm{e}}$ siècle.
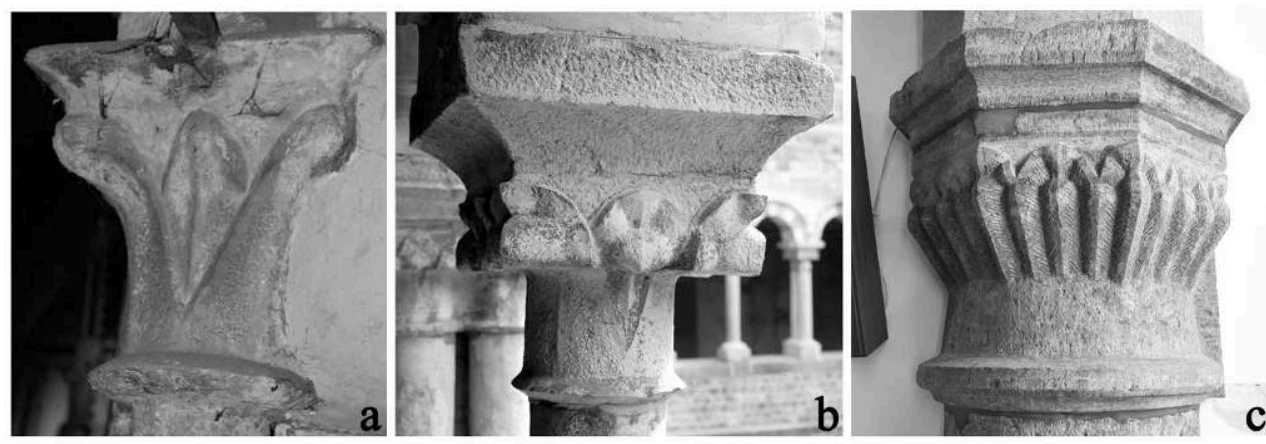

A : Liège (Belgique), ancienne collégiale Saint-Paul, xIII siècle. B : Tongres (Belgique), cloître de la collégiale Notre-Dame, $x_{1}{ }^{e}$ siècle. $\mathbf{c}$ : Warsage (Belgique), église paroissiale Saint-Pierre, $x v^{e}$ siècle. (c) Aline Wilmet.

11 Cette variété formelle disparaît sur les chantiers achevés ou entrepris au $\mathrm{XV}^{\mathrm{e}}$ siècle, au profit de deux modèles, l'un doté d'un décor de feuilles rubanées, lancéolées ou cunéiformes stylisées, au relief très accentué de vésicules globulaires ou allongées, 
inscrites dans la moitié supérieure de la corbeille; l'autre, très simple, constitué d'un corps de moulures (fig. 3) ${ }^{19}$.

Fig. 3. - Carte de diffusion des modèles rationalisés aux $x V^{e}$ et $X V{ }^{e}$ siècles.
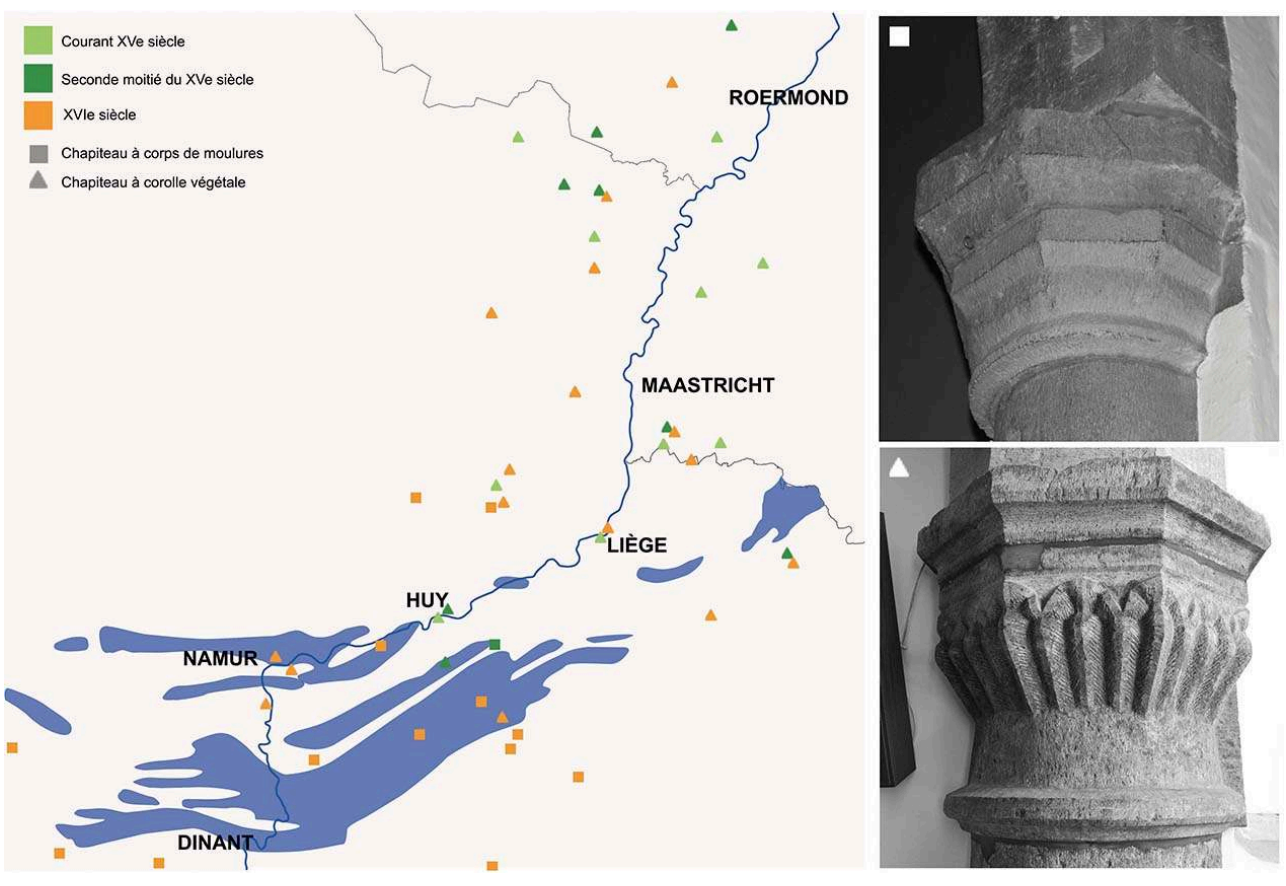

EN BLEU : affleurement des calcaires de Meuse.

(c) Aline Wilmet.

12 Les bases font également l'objet de simplifications : il s'agit de bases buticulaires ${ }^{20}$ à corps de moulures prismatiques souvent dotées de congés (fig. 4). Il arrive que ce type de base soit associé sur un même support à un chapiteau à corps de moulures identique, rendant ainsi les ornements interchangeables, sans distinction de leur fonction initiale. 
Fig. 4. - Exemple de base à congés pyramidaux : Hodeige (Belgique), église paroissiale SaintAndré, $\mathrm{XV}^{\mathrm{e}}$ siècle.

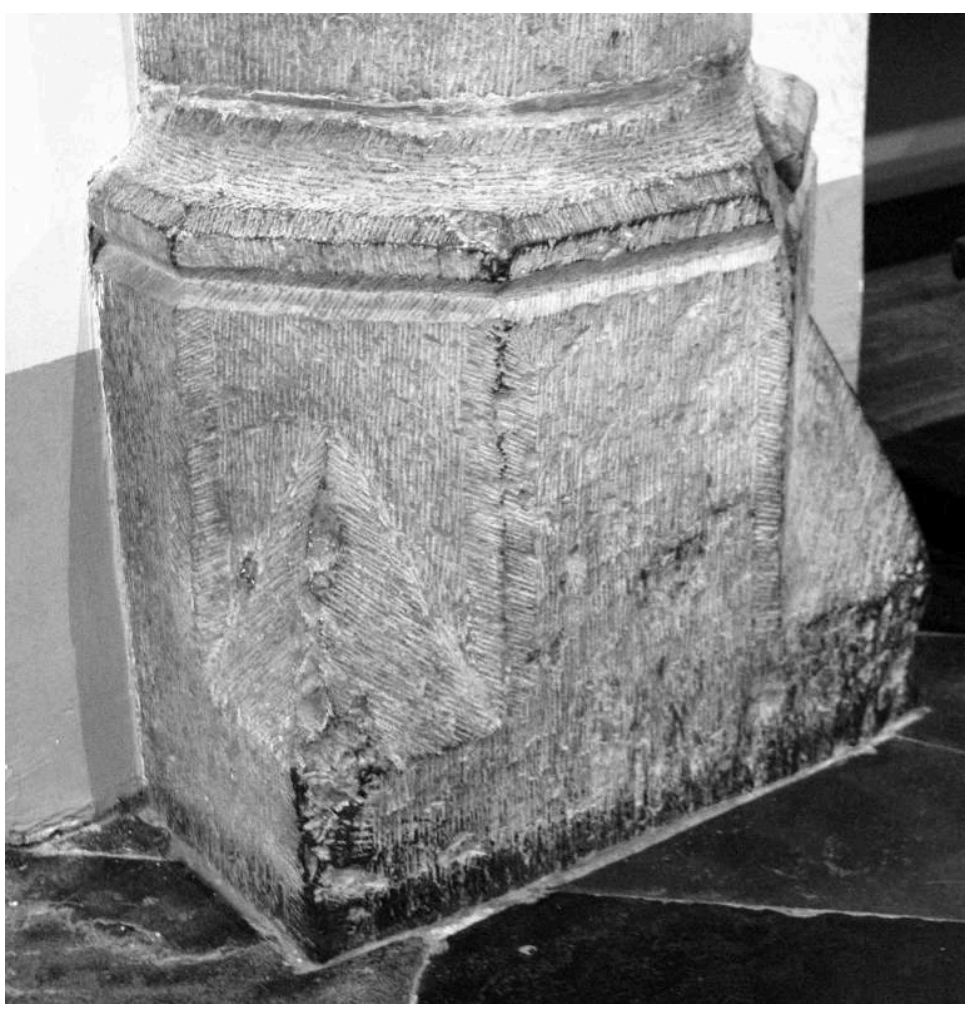

(C) Aline Wilmet.

Quant aux techniques de taille, elles témoignent, elles aussi, d'une volonté de rentabilité dans la conception des ornements. En effet, la taille brochée disparaît dans le traitement du décor sculpté au profit de la taille ciselée. Celle-ci atteint son apogée dans le courant $\mathrm{du} \mathrm{xv}^{\mathrm{e}}$ siècle sur les maçonneries, les meneaux, les tambours de colonne, et les moulures planes. Ainsi l'astragale, la partie inférieure de la corbeille (sous le feuillage), la lèvre et le tailloir sont intégralement taillés à l'aide du ciseau. Le feuillage est taillé de fins sillons parallèles, disposés de part et d'autre de la nervure médiane, réalisés à l'aide d'une broche ou d'un ciseau bédane. Ce phénomène global de simplification permet donc d'économiser de la matière lors de la taille du bloc capable et accélère considérablement la création des ornements, par le biais d'une part de la sélection de modèles aisément reproductibles - voire même interchangeables - et d'autre part par la systématisation de l'usage du ciseau en taille de finition.

Dès lors, il semble que ce soit ce chapiteau à décor végétal rationalisé et fortement diffusé dès le $\mathrm{xv}^{\mathrm{e}}$ siècle qui ait influencé les travaux de restauration. Les restaurations menées sur l'ornement s'inspirant des modèles médiévaux les plus répandus, il est probable qu'elles ont joué un rôle dans la définition d'un critère de caractérisation de l'architecture mosane née dans la première moitié $\mathrm{du} \mathrm{xx}^{\mathrm{e}}$ siècle. 


\section{Perception du décor médiéval par les dessinateurs et architectes restaurateurs au XIX $X^{\mathrm{e}}$ et au $\mathrm{XX}^{\mathrm{e}}$ siècle}

Mettre au jour les archives correspondant aux travaux de restauration menés sur l'ornementation intérieure des édifices gothiques de la région mosane aux $\mathrm{xIX}^{\mathrm{e}}$ et $\mathrm{xx}^{\mathrm{e}}$ siècles relève d'une véritable gageure. Probablement jugées anecdotiques par les restaurateurs, ces interventions ne sont pas précisément consignées dans les registres de restaurations et sont noyées dans les comptabilités générales. L'analyse archéologique de l'ornement permet de suppléer ces lacunes documentaires, grâce à l'observation des traces de retaille, de remplacement ou de polychromie liés aux restaurations. Ainsi, les réparations en plâtre ou parfois en tuffeau de certains éléments sculptés ont pu être mises en évidence sur plusieurs sites. La collégiale Sainte-Croix, à Liège, par exemple, offre un cas d'étude tout à fait exceptionnel de réparation quasiment systématique des chapiteaux en grès houiller : celui-ci dispose de crochets systématiquement refaits en plâtre et d'une surface entièrement recouverte par un repeint grisâtre ponctué de petites taches blanches imitant la couleur de la pierre de Meuse et la taille pointée des outils ${ }^{21}$. Cette pratique a également été observée à l'ancienne collégiale Saint-Paul à Liège, où les chapiteaux à crochets en grès houiller qui couronnent les supports de la croisée du transept sont, eux aussi, restaurés en plâtre et repeints en gris $^{22}$. Ces observations attestent que, déjà au XIX siècle, les restaurateurs considèrent ce matériau comme la marque de fabrique de l'architecture mosane, niant ainsi la diversité des matériaux initialement employés dans le bâti médiéval. Sans une analyse matérielle approfondie de ces ornements, souvent rendue complexe par leur accès limité, ces décors ont été considérés comme d'authentiques modèles caractéristiques du XIII ${ }^{\mathrm{e}}$ siècle, et ce jusque dans des études récentes ${ }^{23}$.

Si les archives textuelles qui nous renseignent sur les restaurations menées sur l'ornement sculpté sont rares, les documents iconographiques, essentiellement composés de relevés, plans d'architectes, gravures et lithographies d'intérieurs d'églises, constituent un témoignage indispensable qui permet d'appréhender la place occupée par l'ornementation sculptée dans la conception de l'architecture à cette époque. Bien que certaines représentations démontrent une observation minutieuse des détails architecturaux, d'autres témoignent d'une tendance à la standardisation des formes, oblitérant la nature exacte de celles-ci.

17 En effet, la majorité des documents iconographiques qui représentent l'intérieur des grands édifices mosans est assez évocatrice des préconceptions qui gravitent autour de l'ornementation médiévale des supports. Ceux-ci font en effet les frais d'une simplification des formes et d'interprétations, faisant fi de l'état original de la décoration médiévale. Bien que le traitement du décor représenté sur ces documents ne fasse pas toujours état de transformations effectives, il trahit une philosophie de la restauration alors très répandue, celle visant à une « unité de décoration ${ }^{24}$ ».

18 La restauration de l'église Saint-Christophe du béguinage de Liège, menée entre 1885 et 1892, est l'un des exemples les plus emblématiques de ce cas de figure. L'architecte Auguste Van Assche, en collaboration avec Jules Helbig, entreprend l'étude préalable du bâtiment, qu'il publie en 1877 sous le titre Monographie de l'église paroissiale de SaintChristophe à Liège ${ }^{25}$. Cette publication, par le biais de relevés, a pour objectif de «mener à la juste connaissance architecturale technique et stylistique du bâtiment, sans 
laquelle tout projet de restauration valable était inconcevable ${ }^{26} »$. Les chapiteaux de l'édifice sont par ailleurs détaillés parmi les quinze planches qui illustrent l'ouvrage (fig. 5). Il ne s'agit pourtant pas de relevés objectifs, témoignant de l'état de l'église avant les restaurations qui avaient agrémenté l'intérieur d'une ornementation rococo au XVIII ${ }^{\mathrm{e}}$ siècle. En effet, les planches " ont été exécutées de manière à faire comprendre le monument, non absolument tel qu'il est [...], mais tel qu'il a été conçu et bâti par le maître d'œuvre primitif, et tel qu'il sera, nous l'espérons du moins, bientôt restitué par une main intelligente ${ }^{27} »$. Si, dans leur état actuel, postérieur à cette importante campagne de restauration, les chapiteaux à crochets en grès houiller de la nef offrent une ornementation proche de celle des années 1230-1250, il demeure difficile de déterminer dans quelle mesure ils reflètent l'état médiéval du décor de l'édifice. En effet, tous les ornements ont été profondément décapés, et nombreux sont les chapiteaux à avoir subi des modifications de leur décor à l'aide de plâtre ou encore à être entièrement renouvelés en pierre de Meuse.

Fig. 5. - Ancienne église du béguinage Saint-Christophe (Liège, Belgique) : croquis des chapiteaux de la nef. Extrait de A. Van Assche et J. Helbig, 1877, pl. 12.

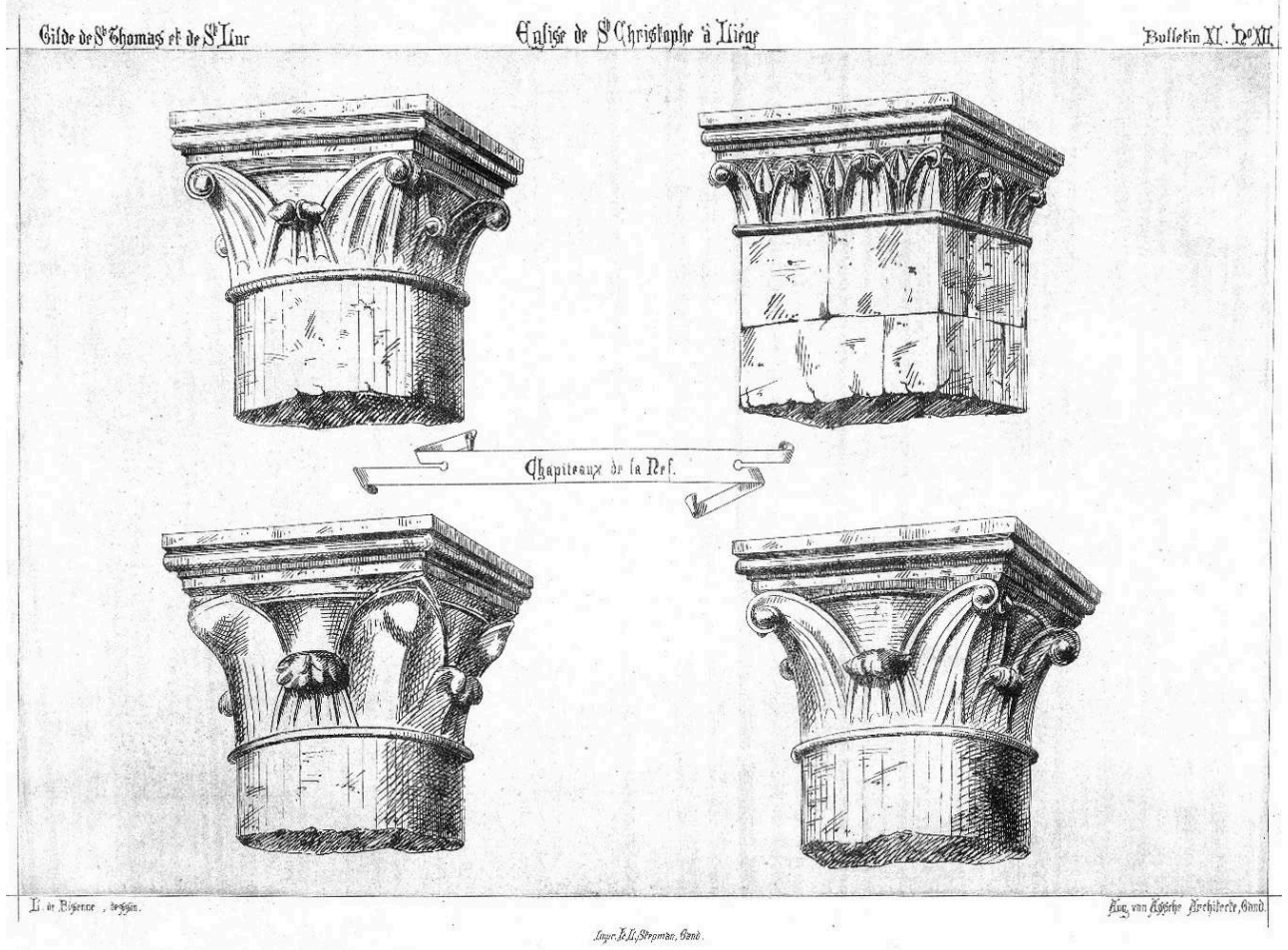

Cliché Aline Wilmet (D.R.).

19 Il arrive également que la réalité architecturale et les représentations iconographiques ne coïncident pas, démontrant une part importante d'interprétation de la part des dessinateurs et restaurateurs. En témoignent plusieurs lithographies et estampes qui représentent la chaire de vérité de l'ancienne collégiale Saint-Paul à Liège, aujourd'hui cathédrale, dans son écrin architectural ${ }^{28}$. Ces gravures ont probablement été réalisées peu après son installation en 1843. Sur ces documents, les chapiteaux peuvent être représentés avec un ou deux rangs de feuillages, constitués soit de simples crochets, soit d'une association de crochets et de feuilles pointues. Les bases sont tantôt circulaires à bases moulurées constituées de tores simples, tantôt polygonales à base 
moulurée en doucine ou en cavet renversé encadré de deux tores. Dans son Essai historique sur l'église de Saint-Paul... publié en 1867, le chanoine Thimister indique que les colonnes sont couronnées de « chapiteaux garnis de crochets, ce qui caractérise le style ogival primaire ${ }^{29} »$. Pourtant les chapiteaux de la nef, authentifiés par l'analyse archéologique, sont ornés de feuilles lancéolées disposées en deux plans, et seuls ceux de la croisée du transept sont dotés de crochets (fig. 6). Les publications et archives contemporaines aux interventions sur le bâti médiéval ne traitant aucunement de la réalisation de nouveaux décors en plâtre, cette variété d'interprétations - ne visant probablement pas l'exactitude à l'origine - reflète le souhait d'enjoliver la réalité architecturale, probablement jugée trop simple.

Fig. 6. - Ancienne collégiale Saint-Paul (Liège, Belgique).
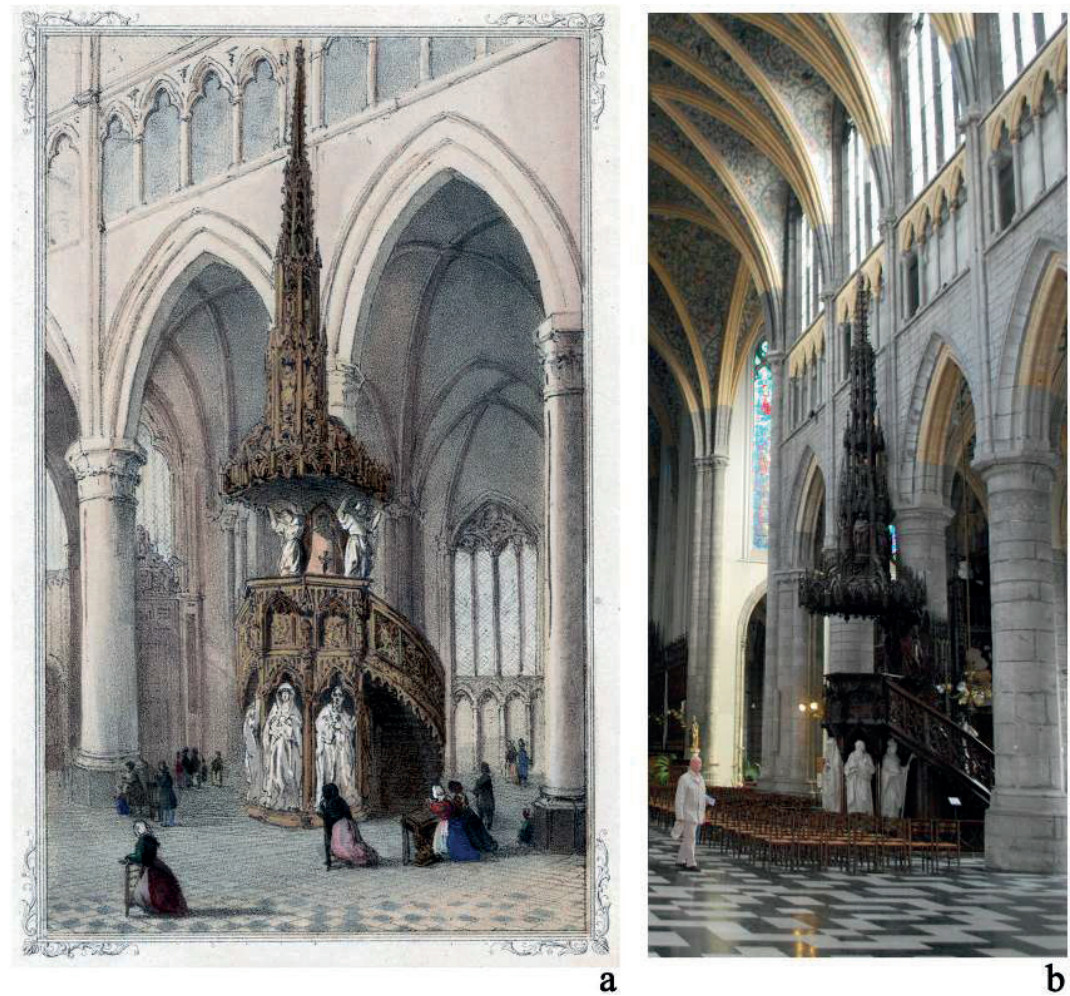

A : la chaire (collections artistiques de l'université de Liège, lithographie $\left.n^{\circ} 28478\right)$. B : les colonnes de la nef.

(c) Université de Liège - musée Wittert (A), Aline Wilmet (B)

Enfin, signalons un relevé d'architecte présentant un projet de réalisation du buffet d'orgue du chœur de la collégiale de Huy, conservé dans les archives de la commission royale des Monuments et sites, qui montre les supports du chœur couronnés de chapiteaux ornés de feuilles lancéolées au relief accentué. Ils diffèrent nettement de ceux qui ornent en réalité des supports du chœur, ornés de bouquets de feuillages polylobés (fig. 7). 
Fig. 7. - Collégiale Notre-Dame (Huy, Belgique).

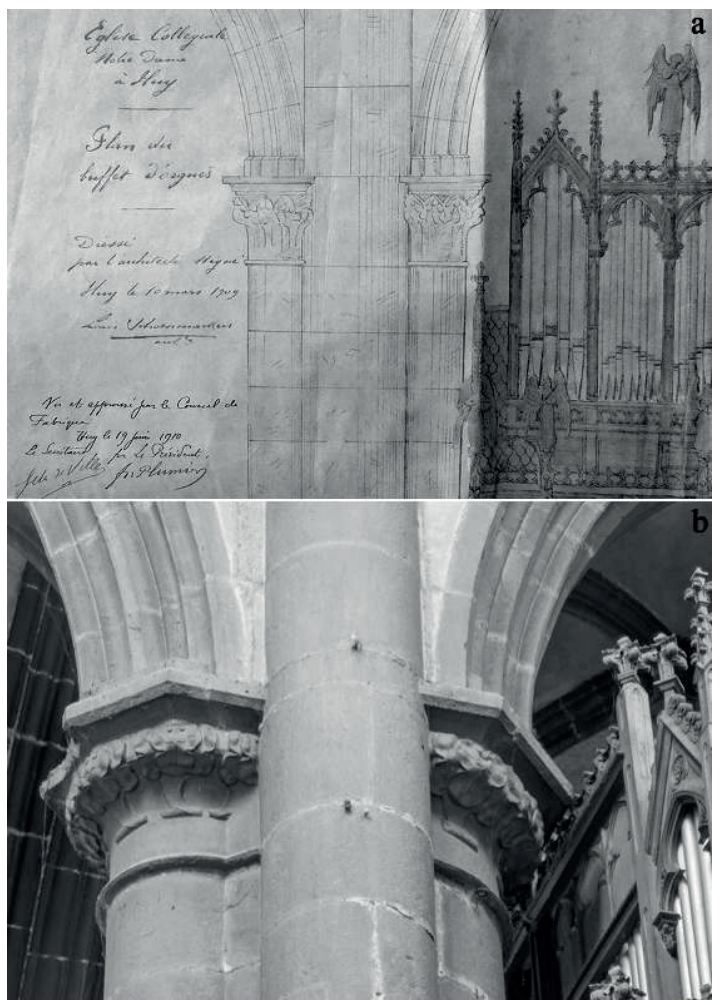

A : Louis Schoenmakers, détail du projet de buffet d'orgues, 1909, Arch. de l'État à Liège, archives des Cures, Huy II Notre-Dame, dossier 104. B : photographie du chapiteau du vaisseau central du chœur. (c) Arch. de l'État à Liège (A), Aline Wilmet (B).

Ce modèle " par défaut » permet, dans ce cas, de « résumer » l'architecture à un cadre reconnaissable permettant d'illustrer le contexte «mosan» du sujet du relevé: la présentation du nouveau buffet d'orgue de la collégiale hutoise. Ce type de dessin atteste que le chapiteau « mosan » est considéré au XIx et au début du xxe siècle comme un « produit de terroir ${ }^{30}$ », une marque de fabrique de l'architecture régionale.

À côté de ces représentations interprétées figurent des gravures plus réalistes, où l'ornementation intérieure a bénéficié d'une observation détaillée visant davantage de fidélité. Citons, par exemple, trois gravures réalisées entre 1850 et 1880, montrant l'intérieur de la collégiale Notre-Dame de Dinant sous différents angles. Ces lithographies réalisées par Hoolans, Boutquin et Stroobant ${ }^{31}$ permettent d'envisager l'architecture et son décor avant les interventions $\mathrm{du}$ xix ${ }^{\mathrm{e}}$ siècle. Elles démontrent une impressionnante exactitude de transcription de l'ornementation de l'édifice. Les nuances dans la reproduction du décor sont conformes aux modèles sélectionnés dans les parties orientales, le transept et la nef ${ }^{32}$.

Pour finir, abordons le cas de la reconstruction de la nef de l'église Saint-Lambert, à Bouvignes. Cette église paroissiale située non loin de la ville de Dinant fait l'objet de profondes restaurations menées entre 1924 et 1927, suite aux bombardements de 1914. La restauration fait l'objet d'une attention particulière de la part de son architecte, Henri Vaes ${ }^{33}$. En effet, les courriers conservés témoignent tous d'une volonté de rétablir les formes primitives et du fait qu'aucune restitution ou restauration ne pourra être menée sans des travaux de recherche préalables. Les archives de la restauration prescrivent l'usage de matériaux de même nature que les maçonneries et décors 
anciens, plutôt que celui de matériaux exogènes, comme la " pierre de France ${ }^{34}$ ». Dans la mesure du possible, les pierres et ornements en bon état sont conservés, numérotés et remis en œuvre. Quant aux ornements nouvellement réalisés, ils sont scrupuleusement copiés sur les modèles médiévaux conservés. Suite aux bombardements de 1914, il ne reste que peu de choses de la nef édifiée vers le milieu du $\mathrm{Xv}^{\mathrm{e}}$ siècle. Les supports en calcaires de Meuse, trop endommagés et fragilisés par le feu, sont dérochés puis reparementés et taillés à l'aide d'une technique de taille distincte de celle employée au Moyen Âge. C'est la taille ciselée qui est préconisée sur le reste des blocs ${ }^{35}$. Quant aux chapiteaux, ils sont façonnés sur le modèle des chapiteaux à corolle de feuilles diffusés entre la fin $\mathrm{du}_{\mathrm{XIV}}{ }^{\mathrm{e}}$ siècle et le $\mathrm{Xv}^{\mathrm{e}}$ siècle et dont l'église SaintLambert conserve un seul exemplaire, situé dans la première travée de la nef (fig. 8a).

Fig. 8. - Influence des modèles médiévaux sur des chapiteaux néogothiques en Belgique.
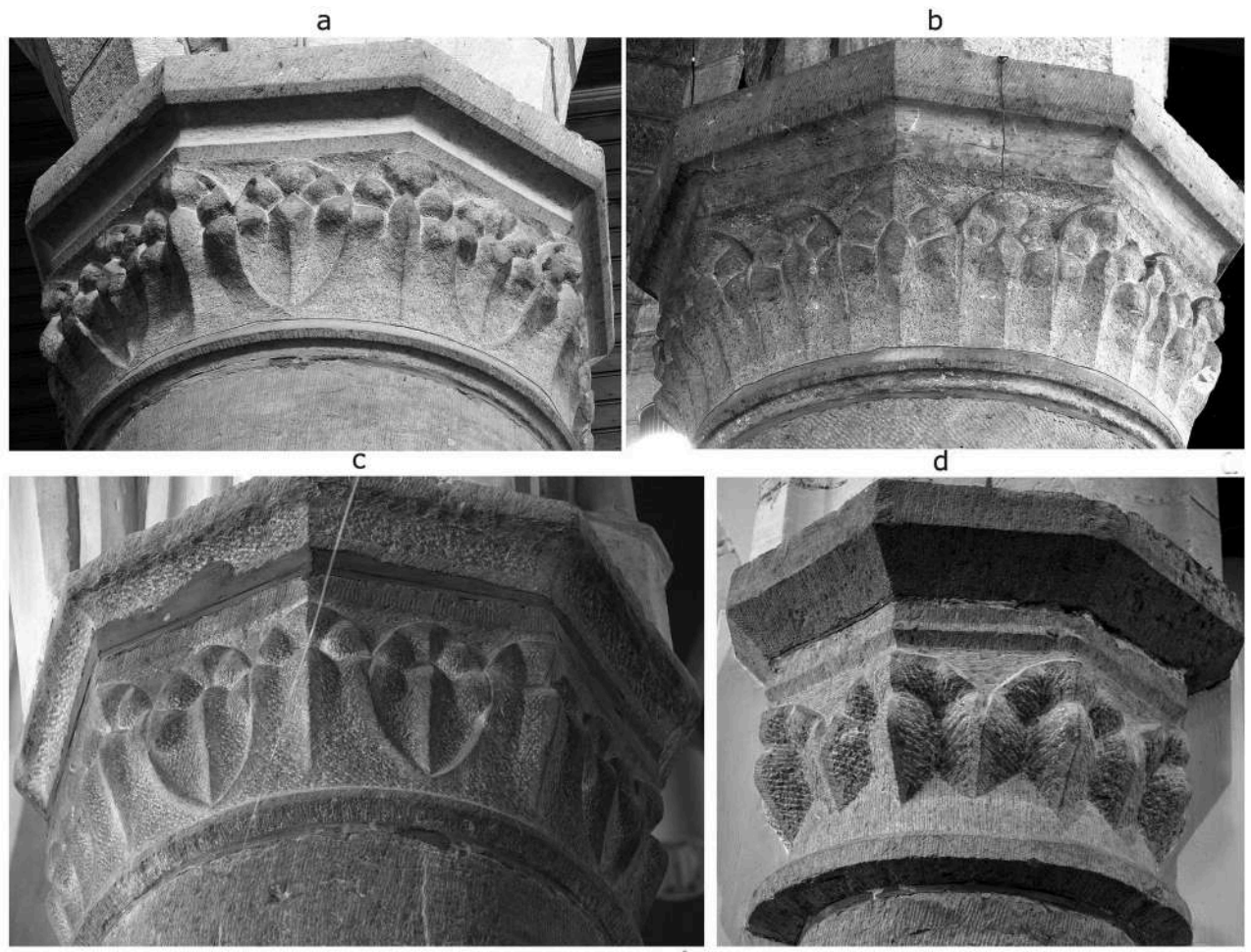

A ET B : église paroissiale Saint-Lambert (Bouvignes-sur-Meuse, Belgique), chapiteaux de la nef. C : église paroissiale Saint-Trudon (Eksel, Belgique), xv siècle. D : église paroissiale Saint-André (Hodeige, Belgique), $x v^{\mathrm{e}}$ siècle.

(C) Aline Wilmet.

Tout comme la plupart des maçonneries, la finition des chapiteaux est entreprise au moyen d'une taille ciselée, ce qui tranche nettement avec les pratiques médiévales. Cette importante campagne de restauration qui touche l'église dans les années 1920 témoigne donc de la volonté des restaurateurs de se conformer à la tradition formelle régionale, tout en identifiant clairement les interventions par l'emploi de techniques de taille distinctes de celles pratiquées au Moyen Âge dans la région. Cette pratique est fréquente sur les chantiers menés au $\mathrm{XIX}^{\mathrm{e}}$ et au $\mathrm{Xx}^{\mathrm{e}}$ siècle, comme en témoignent de nombreux autres sites, tels que l'église Sainte-Gertrude de Gruitrode, l'église SaintLaurent de Bocholt, l'église d'Eksel, celle de Meeuwen, etc., dont les travaux de restauration et d'agrandissement sont menés au début du $\mathrm{xx}^{\mathrm{e}}$ siècle ${ }^{36}$. 


\section{Conclusions et perspectives}

Ce qui précède témoigne $\mathrm{du}$ rôle joué par les restaurateurs et dessinateurs d'architecture des $\mathrm{XIX}^{\mathrm{e}}$ et $\mathrm{xx}^{\mathrm{e}}$ siècles dans la diffusion du chapiteau dit «à feuille de plantain» sur les chantiers de la vallée mosane. L'observation minutieuse de l'ornementation médiévale dont ont fait preuve certains restaurateurs démontre une volonté de pérenniser les modèles médiévaux. Déjà répandu sur les chantiers achevés ou entrepris dans le courant des $\mathrm{xv}^{\mathrm{e}}$ et $\mathrm{xvI}^{\mathrm{e}}$ siècle, ce modèle est favorisé sur les chantiers de restauration, devenant omniprésent dans le paysage mosan. Ainsi, malgré la sélection d'autres modèles comme le chapiteau à crochets sur certains chantiers, le chapiteau dit «à feuilles de plantain » sera considéré comme le modèle caractéristique d'une école régionale, que les historiens de l'architecture définissent au milieu du $\mathrm{xx}^{\mathrm{e}}$ siècle. Cet état de la question doit être approfondi par l'élargissement du cadre de la recherche à l'échelle nationale, afin d'évaluer l'impact des académies et de l'enseignement de l'architecture sur la sélection des modèles ornementaux sur les chantiers de restauration gothiques.

\section{BIBLIOGRAPHIE}

BAUDRY Antoine, « Les chapiteaux des parties orientales de la collégiale Notre-Dame de Dinant », dans Xhayet Geneviève (dir.), Actes du neuvième congrès de l'Association des cercles francophones d'histoire et d'archéologie de Belgique, Liège, Institut archéologique liégeois, 2017, t. II, vol. II, p. 607-615.

BAUDRY Antoine, « La reconstruction de la collégiale Notre-Dame de Dinant après le désastre de 1227 : analyse architecturale des parties orientales (1230-1250) », Bulletin de la commission royale des Monuments, sites et fouilles, 2012, vol. XXIV, p. 7-65.

BRIGODE Simon, Les églises gothiques de Belgique, Bruxelles, Éd. du Cercle d'art, 1944.

DELÉHOUZÉE Laurent, « Essai d'analyse archéologique des églises paroissiales de Tournai dans la première moitié du XIII ${ }^{\mathrm{e}}$ siècle ", mémoire de licence, Louvain-la-Neuve, Université catholique de Louvain-la-Neuve, 1997.

COLLON-GEVAERT Suzanne, LEJEUNE Jean, STIENNON Jacques, Art roman dans la vallée de la Meuse aux XI , $\mathrm{XII}^{e}$ et XIII ${ }^{e}$ siècles, Bruxelles, L'Arcade, 1960.

coomans Thomas, L'abbaye de Villers-en-Brabant : construction, configuration et signification d'une abbaye cistercienne gothique, Bruxelles, Éd. Racine et Brecht (Citeaux studia et documenta, 11), 2000.

coomANS Thomas, «Seraing : le bâtiment des moines de l'ancienne abbaye du Val-SaintLambert », dans Maquet Julien (dir.), Le patrimoine médiéval de Wallonie, Namur, Institut du patrimoine wallon, 2005, p. 123-124. 
COOMANS Thomas, « Saint-Christophe à Liège : la plus ancienne église médiévale du mouvement béguinal », Bulletin monumental, 2006, vol. 164-4, p. 359-376.

coomans Thomas, " "Produits du terroir" et "appellations contrôlées" : le rôle des pierres à bâtir dans la définition des écoles régionales médiévales en Belgique », dans Gallet Yves (dir.), Ex quadris lapidibus : la pierre et sa mise en œuvre dans l'art médiéval. Mélanges d'histoire de l'art offerts à Éliane Vergnolle, Turnhout, Brepols, 2011, p. 221-232.

COURTOY Fernand, «Le travail et le commerce de la pierre à Namur avant 1500 », Namurcum, 1946, vol. XXI, p. 17-29.

DAUSSY Stéphanie, Sculpter à Amiens en 1500, Rennes, Presses universitaires de Rennes, 2013.

DAUSSY Stéphanie et TIMBERT Arnaud (dir.), Architecture et sculpture gothiques : renouvellement des méthodes et des regards, Rennes, Presses universitaires de Rennes, 2012.

DE JONGHE Sabine, GEHOT Hélène, GENICOT Luc Francis, WEBER Philippe, TOURNEUR Francis, Pierres à bâtir traditionnelles de la Wallonie : manuel de terrain, Jambes, ministère de la Région wallonne, direction générale des Ressources naturelles et de l'environnement, 1996.

GENICOT Luc Francis, «La collégiale Notre-Dame de Huy. $2^{\text {e }}$ partie : La collégiale gothique (1311-1536) », Revue des archéologues et historiens d'art de Louvain, 1991, vol. XXIV, p. 21-45. GENICOT Luc Francis et COOMANS Thomas, "La région mosane », dans Buyle Marjan, Coomans Thomas, Ester Jan, Genicot Luc Francis (dir.), Architecture gothique en Belgique, Bruxelles, Racine, 1997, p. 64-81.

GROESSENS Éric et TOURNEUR Francis, «Les “pierres bleues”, fleurons incontestés de l'industrie extractive wallonne, une industrie toujours bien vivante ! ", dans Toussaint Jacques (dir.), Regards sur le bleu, Namur, Société archéologique de Namur (Monographies du TreMa, 51), 2011, p. 49-62. HECKNER Ulrike, « Die gotische Chorhalle des Aachener Doms: Ergebnisse der Bauforschung », dans Knopp Gisbert et Heckner Ulrike (dir.), Die gotische Chorhalle des Aachener Doms. Baugeschichte. Bauforschung. Sanierung, Petersberg, Kempen, 2002, p. 105-135.

HENDRIX Louis, « Comment fut conçue la restauration de la cathédrale de Liège vers 1850 », Leodium, 1929, vol. XXII, p. 7-18.

HOFFSUMMER Patrick, TOURNEUR Francis, DOPERÉ Frans, PIAVAUX Mathieu, « Églises liégeoises en chantier au XIII et au XIV siècle ", dans Van den Bossche Benoît (dir.), La cathédrale gothique SaintLambert : une église et son contexte. Actes du colloque international de Liège, 16-18 avril 2002, Liège, université de Liège (ERAUL, 108), 2005, p. 97-110.

LANOTTE André, «L'adaptation des églises du XVI ${ }^{\mathrm{e}}$ siècle ", dans Volder Jacques de et al., (dir.), Trésors d'art dans l'ancien doyenné de Havelange, Flostoy, Soledi, 1979, p. 45-48.

LAURENT Marcel, L'architecture et la sculpture en Belgique, Paris / Bruxelles, Van Oest, 1928.

NOËL Pierre, Technologie de la pierre de taille: dictionnaire des termes couramment employés dans l'extraction, l'emploi et la conservation de la pierre de taille, $2^{\mathrm{e}}$ éd., Paris, Société d'éditions du bâtiment et des travaux publics, 1965.

PIAVAUX Mathieu, La collégiale Sainte-Croix à Liège : formes et modèles gothiques dans l'architecture religieuse du Saint-Empire, XIII ${ }^{e}-\mathrm{XV}^{e}$ siècle, Namur, Presses universitaires de Namur, 2013.

ROLLAND Paul, « L'architecture et la sculpture gothique », dans Fierens Paul (dir.), L'art en Belgique, Bruxelles, La Renaissance du livre, 1939, p. 45-90. 
ROUSSEAU Félix, L'art mosan : introduction historique, Gembloux, Duculot (Wallonie, art et histoire), 1970.

SCHAYES Antoine Guillaume Bernard, Histoire de l'architecture en Belgique, Bruxelles, Jamar, 1849-1852, 4 vol.

THIMISTER Olivier-Joseph, Essai historique sur l'église de S. Paul ci-devant collégiale, aujourd'hui cathédrale de Liège, Liège, Grandmont-Donders, 1867.

TIMBERT Arnaud, « Précisions sur l'évolution de la base attique durant le XII siècle en île-deFrance et en Picardie », Revue archéologique de Picardie, 2003, vol. 3-4, p. 91-101.

TIMBERT Arnaud, « Documents pour l'histoire de l'architecture médiévale : propos et dessins de Pierre Rousseau sur la modénature de Notre-Dame de Chartres, de Saint-Julien du Mans et de Saint-Germer-de-Fly », Bulletin de la Société des fouilles archéologiques et des monuments historiques de l'Yonne, 2007, vol. XXIV, p. 9-40.

TIMBERT Arnaud et DAUSSY Stéphanie, La cathédrale Notre-Dame de Noyon : cinq années de recherches, Noyon, Société historique de Noyon, 2011.

TOLLENAERE Lisbeth, La sculpture sur pierre de l'ancien diocèse de Liège à l'époque romane, Gembloux, Duculot, 1957.

TOURNEUR Francis, « Les langages des pierres », Les cahiers de l'urbanisme, 2003, n 44 (« Archéologie du bâti »), p. 24-35.

TRICOIT Mathieu, «Remarques sur l'évolution de la base de colonne au XIII siècle en France du nord : maturité et disparition du profil attique », Bulletin de la Société des fouilles archéologiques et des monuments historiques de l'Yonne, 2006, vol. XXIII, p. 17-25.

VAN Assche Auguste et HELBIG Jules, Monographie de l'église paroissiale de Saint-Christophe à Liège, Gand, autographies de H. Stepman / Bruges, Lith. Vve I. Petyt, 1877.

WILMET Aline, « Le décor sculpté de l'église Saint-Lambert à Bouvignes : de la conception médiévale à la restauration de l'entre-deux-guerres », dans Saint-Amand Pascal et Tixhon Axel (dir.), L'église Saint-Lambert de Bouvignes, 1217-2017 : autour du 800 anniversaire de sa dédicace, Bouvignes, Les échos de Crèvecœur ( ${ }^{\circ}$ spécial 47), 2017, p. 37-59.

WILMET Aline, « Le décor sculpté des supports de l'architecture gothique en vallée mosane : analyse des formes et des techniques pour une approche renouvelée du chantier médiéval ", thèse de doctorat en histoire de l'art et archéologie, Namur, université de Namur, 2017, 3 vol. WILMET Aline, « Pour une lecture affinée du chantier gothique en région mosane : étude archéologique de l'ornement sculpté ", Bulletin de la commission royale des Monuments, sites et fouilles, 2015, vol. XXVII, p. 7-58.

WILMET Aline et BAUDRY Antoine, «L'optimisation des procédés de façonnage et de mise en œuvre du calcaire de Meuse aux Xve et XvI ${ }^{\mathrm{e}}$ siècles », dans Bienvenu Gilles, Monteil Martial, RousteauChambon Hélène (dir.), Construire! Entre Antiquité et époque contemporaine. Actes du III Congrès francophone d'histoire de la construction (Nantes, 21-23 juin 2018), Paris, Picard, 2019, p. 569-580.

\section{NOTES}

1. A. Wilmet, «Le décor des supports de l'architecture gothique de la vallée de la Meuse...". 
2. A. G. B. Schayes, Histoire de l'architecture en Belgique.

3. F. Rousseau, «L'art mosan », p. 1-248.

4. S. Collon-Geveart et al., Art roman dans la vallée de la Meuse aux XI ${ }^{e}, \mathrm{XII}^{e}$ et $\mathrm{XIII}^{e}$ siècles;

M. Laurent, L'architecture et la sculpture en Belgique.

5. P. Rolland, «L'architecture et la sculpture gothique ».

6. F. Courtoy, «Le travail et le commerce de la pierre à Namur avant 1500 »; S. Brigode, Les églises gothiques de Belgique; L. Tollenaere, La sculpture sur pierre de l'ancien diocèse de Liège à l'époque romane.

7. S. Brigode, Les églises gothiques de Belgique, p. 19.

8. L. F. Genicot, «La collégiale Notre-Dame de Huy»; L. Deléhouzée, «Essai d'analyse archéologique des églises paroissiales de Tournai... »; T. Coomans, L'abbaye de Villers-enBrabant ; U. Heckner, «Die gotische Chorhalle des Aachener Dom..." ; M. Piavaux, La collégiale Sainte-Croix à Liège...; A. Baudry, «La reconstruction de la collégiale NotreDame de Dinant après le désastre de $1227 . .$. » et « Les chapiteaux de la collégiale NotreDame de Dinant ».

9. A. Timbert, «Précisions sur l'évolution de la base attique durant le XII ${ }^{\mathrm{e}}$ siècle en Îlede-France et en Picardie» et "Documents pour l'histoire de l'architecture médiévale... »; A. Timbert et S. Daussy, La cathédrale Notre-Dame de Noyon...; S. Daussy, Sculpter à Amiens en 1500 ; S. Daussy et A. Timbert, Architecture et sculpture gothiques; M. Tricoit, « Remarques sur l'évolution de la base de colonne au XIII ${ }^{\mathrm{e}}$ siècle en France du nord...».

10. L. F. Genicot et T. Coomans, "La région mosane"; T. Coomans, "Produits du terroir" et "appellations contrôlées"... ».

11. S. De Jonghe et al., Pierres à bâtir traditionnelles de la Wallonie, p. 190 ; F. Tourneur, « Le langage des pierres », p. 28 ; ́́. Groessens et F. Tourneur, « Les "pierres bleues"... ».

12. T. Coomans, «Seraing: le bâtiment des moines de l'ancienne abbaye du Val-SaintLambert ", p. 123-124.

13. P. Hoffsummer et al., "Églises liégeoises en chantier au XIII et au XIV siècle ", p. 97-100 ; M. Piavaux, La collégiale Sainte-Croix à Liège...

14. A. Lanotte, "L'adaptation des églises du $\mathrm{XvI}^{\mathrm{e}}$ siècle», p.46; L. F. Genicot et T. Coomans, « La région mosane », p. 80.

15. A. Wilmet, « Pour une lecture affinée du chantier gothique en région mosane... ».

16. P. Noël, Technologie de la pierre de taille, p. 62.

17. S. Brigode, Les églises gothiques de Belgique, p. 19 ; A. Wilmet, « Le décor des supports de l'architecture gothique de la vallée de la Meuse... ", p. 21.

18. A. Wilmet, «Le décor des supports de l'architecture gothique de la vallée de la Meuse... ", p. 153-154.

19. A. Wilmet et A. Baudry, «L'optimisation des procédés de façonnage et de mise en œuvre du calcaire de Meuse aux Xve et XvI ${ }^{\mathrm{e}}$ siècles ».

20. Base "étagée " caractérisée par un étranglement à mi-hauteur de son élévation, marquant la délimitation entre le socle et la plinthe et souligné par une moulure ou un corps de moulures plus ou moins complexe (A. Wilmet, «Le décor des supports de l'architecture gothique de la vallée de la Meuse... », p. 316).

21. M. Piavaux, La collégiale Sainte-Croix à Liège, p. 95. 
22. A. Wilmet, "Le décor des supports de l'architecture gothique de la vallée de la Meuse... », p. 133.

23. M. Piavaux, La collégiale Sainte-Croix à Liège, p. 237-241; A. Baudry, «La reconstruction de la collégiale Notre-Dame de Dinant après le désastre de 1227... ».

24. L. Hendrix, «Comment fut conçue la restauration de la cathédrale de liège vers $1850 »$, p. 18.

25. A. Van Assche et J. Helbig, Monographie de l'église paroissiale de Saint-Christophe à Liège.

26. T. Coomans, "Saint-Christophe à Liège: la plus ancienne église médiévale du mouvement béguinal », p. 363 .

27. A. Van Assche et J. Helbig, Monographie de l'église paroissiale de Saint-Christophe à Liège, p. 4.

28. Collections artistiques de l'université de Liège, CA 28474, CA 28477, CA 28478, CA 28479, CA 28574, CA 28575, «La chaire de vérité de Saint-Paul à Liège ».

29. O.-J. Thimister, Essai historique sur l'église de S. Paul ci-devant collégiale..., p. 175.

30. T. Coomans, « "Produits du terroir" et "appellations contrôlées" : le rôle des pierres à bâtir dans la définition des écoles régionales médiévales en Belgique ».

31. Les reproductions de ces lithographies ont été rassemblées dans l'article de A. Baudry, «La reconstruction de la collégiale Notre-Dame de Dinant après le désastre de $1227 \ldots »$, p. 13.

32. A. Wilmet, "Le décor des supports de l'architecture gothique de la vallée de la Meuse... », p. 137-138.

33. Liège, Centre d'archives et de documentation de la CRMSF, fonds de la CRMSF, dossier « Dinant 1.6 », lettre de H. Vaes à la CRM, 3 décembre 1917.

34. Liège, Centre d'archives et de documentation de la CRMSF, rapport de S.-E. Mortier, 8 décembre 1923 ; lettre du curé É. Hayot à la CRM, 11 octobre 1923.

35. Liège, Centre d'archives et de documentation de la CRMSF, rapport de S.-E. Mortier, 8 décembre 1923 ; lettre de la CRM à H. Vaes, 27 août 1924.

36. A. Wilmet, "Le décor des supports de l'architecture gothique de la vallée de la Meuse... », p. 121-128.

\section{RÉSUMÉS}

$\mathrm{Au} \mathrm{XIX}{ }^{\mathrm{e}}$ et au Xx $\mathrm{x}^{\mathrm{e}}$ siècle, les travaux de rénovation et d'embellissement de l'architecture gothique de la région mosane, parfois abusifs, parfois raisonnés, sont tantôt influencés par la philosophie de "l'unité de décoration ", tantôt par la volonté de respecter une certaine tradition formelle. Aussi cette contribution propose de s'intéresser à l'impact des catégorisations régionales de l'architecture sur les interventions menées sur l'ornementation sculptée des supports des édifices bâtis dans la région baignée par la Meuse entre Dinant (Belgique) et Roermond (PaysBas). D'importants changements dans les modes opératoires au cours des $\mathrm{XV}^{\mathrm{e}}$ et $\mathrm{XVI}^{\mathrm{e}}$ siècles, reflets d'une volonté d'optimiser les techniques de façonnage de la pierre, ont conditionné la 
création d'un modèle ornemental qui connaîtra un vif succès durant le bas Moyen Âge et qui influencera la perception du décor des historiens de l'architecture et des acteurs de la restauration dès le XIX ${ }^{e}$ siècle.

INDEX

Mots-clés : ornement, chapiteau, architecture, mosan, transmission des savoirs, restauration, interprétation, gothique, $\mathrm{xIX}^{\mathrm{e}}$ siècle, $\mathrm{xx}^{\mathrm{e}}$ siècle

\section{AUTEUR}

\section{ALINE WILMET}

Collaboratrice scientifique à l'université de Liège, département des sciences historiques 